\title{
EVAPORATION, CRACKING, AND SALINITY IN A THICKENED OIL SANDS TAILINGS
}

\author{
A thesis submitted to \\ the Faculty of Graduate and Postdoctoral Affairs \\ in Partial Fulfillment of the requirements for the degree \\ Masters of Applied Science in Environmental Engineering
}

by

Tessa Innocent-Bernard

B.A.Sc., Universidad de Camaguiey, 2007

Department of Civil and Environmental Engineering

Carleton University

Ottawa-Carleton Institute of Civil and Environmental Engineering

May 2013

C2013 Tessa Innocent-Bernard 
Library and Archives

Canada

Published Heritage

Branch

395 Wellington Street

Ottawa ON K1A ON4

Canada
Bibliothèque et

Archives Canada

Direction du

Patrimoine de l'édition

395 , rue Wellington

Ottawa ON K1A ON4

Canada
Your file Votre référence

ISBN: 978-0-494-94668-8

Our file Notre référence

ISBN: $978-0-494-94668-8$
NOTICE:

The author has granted a nonexclusive license allowing Library and Archives Canada to reproduce, publish, archive, preserve, conserve, communicate to the public by telecommunication or on the Internet, loan, distrbute and sell theses worldwide, for commercial or noncommercial purposes, in microform, paper, electronic and/or any other formats.

The author retains copyright ownership and moral rights in this thesis. Neither the thesis nor substantial extracts from it may be printed or otherwise reproduced without the author's permission.
AVIS:

L'auteur a accordé une licence non exclusive permettant à la Bibliothèque et Archives Canada de reproduire, publier, archiver, sauvegarder, conserver, transmettre au public par télécommunication ou par l'Internet, prêter, distribuer et vendre des thèses partout dans le monde, à des fins commerciales ou autres, sur support microforme, papier, électronique et/ou autres formats.

L'auteur conserve la propriété du droit d'auteur et des droits moraux qui protege cette thèse. $\mathrm{Ni}$ la thèse ni des extraits substantiels de celle-ci ne doivent être imprimés ou autrement reproduits sans son autorisation.
In compliance with the Canadian Privacy Act some supporting forms may have been removed from this thesis.

While these forms may be included in the document page count, their removal does not represent any loss of content from the thesis.
Conformément à la loi canadienne sur la protection de la vie privée, quelques formulaires secondaires ont été enlevés de cette thèse.

Bien que ces formulaires aient inclus dans la pagination, il n'y aura aucun contenu manquant. 


\section{ABSTRACT}

This research investigates the evaporative behaviour of oil sands thickened tailings from a Pilot plant at the Total E\&P operations in Alberta. The materials under study are of 50 and 55\% solids concentration and have average sodium concentrations of 527 and 660 $\mathrm{mg} / \mathrm{L}$ respectively.

A series of small scale and medium scale drying tests were conducted in which mass loss through evaporation, crack propagation, total suction and solids concentrations were measured. Multilayer deposition was simulated and tailings were sectioned to analyse uniformity in drying and solute transport.

Results indicate that high salinity shuts down evaporation due to the precipitation of salts on the surface causing an increase in total suction, while cracking facilitates drying through the exposure of underlying material with lower suctions. Additionally, multilayer tests show that the infiltration of water from new layers into desiccated underlying layers contributes to significant volume change and a more uniform drying of the tailings. 


\section{DEDICATION}

For my sister Beverly Innocent,

Though you've never had the chance to hear my voice or express the way you feel, you give me reason to live another day.

My decision to pursue these studies was rooted in my undying love for you.

\section{With my life I will protect you.}

For my Husband,

God gave the best to me. The extent of your love for me cannot be described with words. Love you, El.

"And we know that all things work together for good to them that love God, to them who are the called according to his purpose."

Romans 8:28 


\section{ACKNOWLEDGEMENTS}

The opportunity to execute and complete this study would not have been possible without the guidance, continual support and understanding of my supervisor, Dr. Paul Simms. Thank you for the passion you nurtured in me and your understanding.

I am grateful to Total E\&P for the opportunity to work on this project and all the support provided through its staff

The constant support offered by the technical and administrative staff of the Department of Civil and Environmental Engineering made this journey smoother and I am thankful for it. Marie, Jason, Pierre, Stan and Ken, "la misérable" would like to thank you for your endless support even during the snow storm (wink).

Special thanks to Drs. Sai Vanapalli and Roberto Narbaitz, for the encouragement and steering in choosing a research oriented degree.

Prabodha, my dear friend, I thank you for being there, for a shoulder to cry on, someone to laugh with and have an adventure, thank you so much. You are truly a special friend.

To my family at the Ottawa Seventh Day Adventist Church, Pastors Elizabeth and Orlando Pule, Pastor Spence, Angeline Jn Pierre, Brother Vinroy and family, Dr. Gerald Grant and family: thank you for allowing me to worship with you and share my ministry of song.

The Johnson Family, Kerina, Nigel, Jaylen, Quintan and Peter: Thank you for a wonderful year of adventure. 
To my Mother, Father and brother Francis: Thank you for supporting me through your prayers and love.

My husband, Wendell Bernard, your unconditional love and support has kept me even though we are oceans apart. Thank you, love.

And to Him who is able to keep me from falling, the Almighty God, be praise and honour and glory. I thank you for your steadfast love even when I failed you. 


\section{TABLE OF CONTENTS}

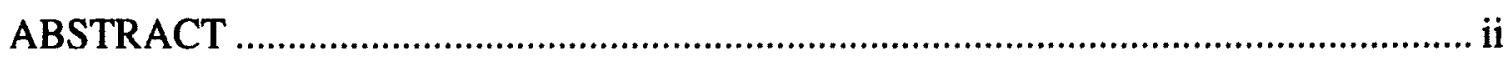

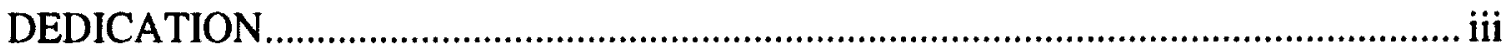

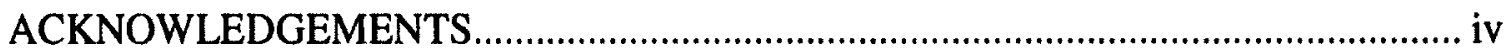

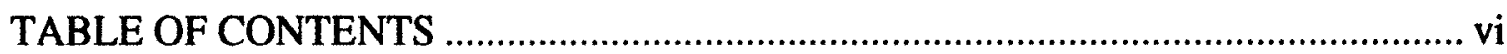

LIST OF TABLES

LIST OF FIGURES

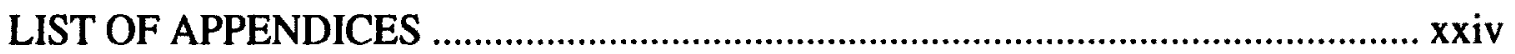

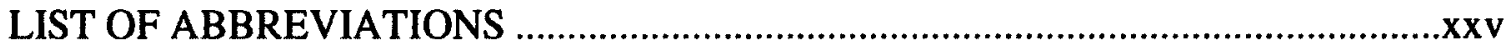

Chapter 1 INTRODUCTION ……............................................................................

1.1 Statement of problem ...............................................................................

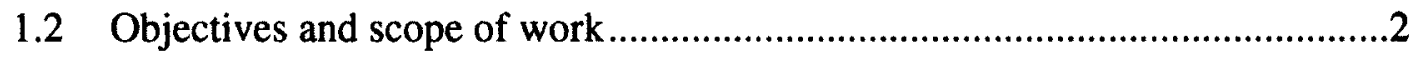

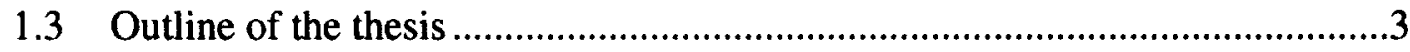

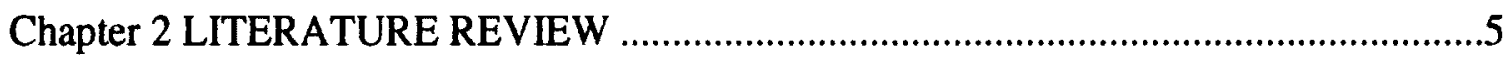

2.1 Oil Sands Tailings. Management. Approaches and Problems..........................5

2.2 Oil Sand Thickened Tailings. Technology. Properties.....................................7

2.3 Consolidation and Evaporation in other amended Oil Sands tailings ..............9

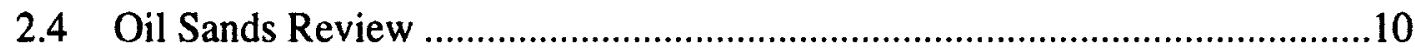

2.5 Flow in Unsaturated soils. Water, vapour and heat.......................................13 


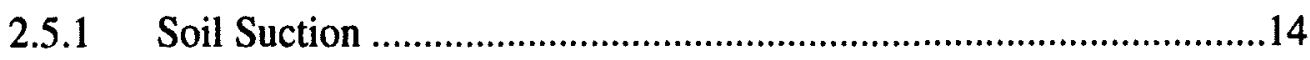

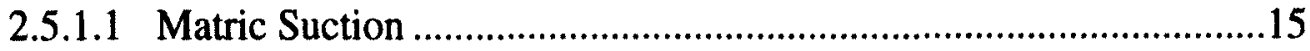

2.5.1.2 Osmotic Suction ..........................................................................

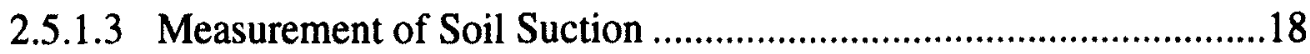

2.5.2 Soil Water Characteristic Curve or Water Retention Curve..............24

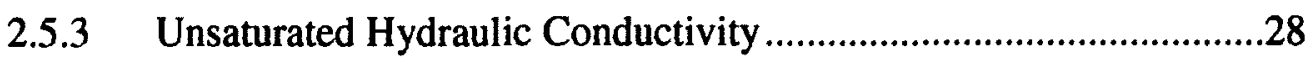

2.5.4 Methods for determination of relative hydraulic conductivity

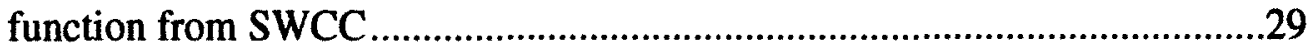

2.5.5 Richards' Equation and Liquid water flow........................................31

2.5.6 Heat and Water vapour flow.........................................................32

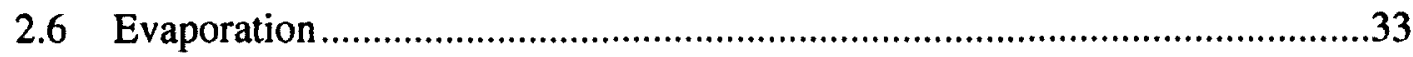

2.6.1 Actual Evaporation ......................................................................33

2.6.2 Determination of Potential Evaporation .............................................36

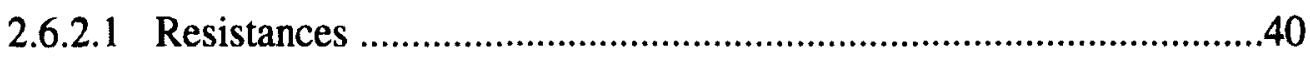

2.6.3 Determination of Relative Evaporation .............................................44

2.6.4 Pore-water Salinity and Evaporation ................................................48

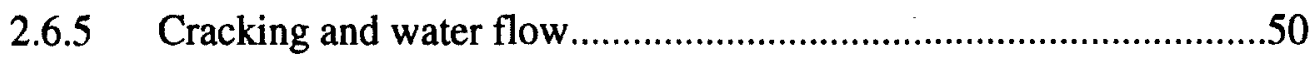

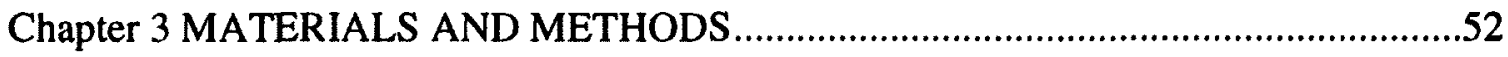

3.1 Material Characterization Overview..........................................................52

3.1.1 Preparation of samples.............................................................54 
3.1.1.1 Atterberg Limits: Liquid Limit and Plastic Limit:..................................54

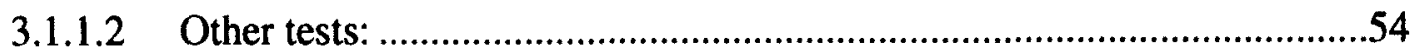

3.2 Properties Test and Soil Characterization....................................................56

3.2.1 Solids Concentration. Bitumen Content. Water Content...................56

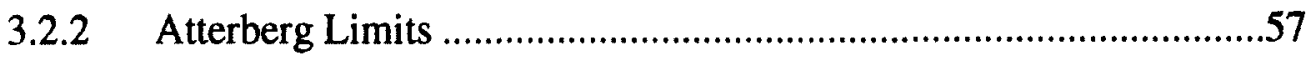

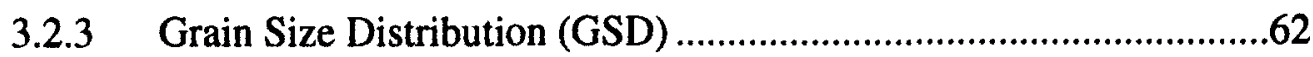

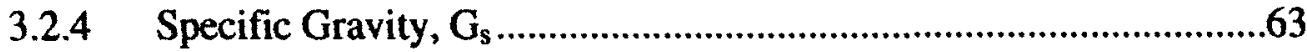

3.2.5 Total (Wet) Density ....................................................................64

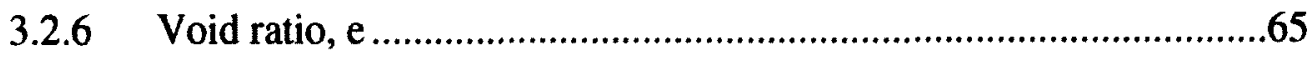

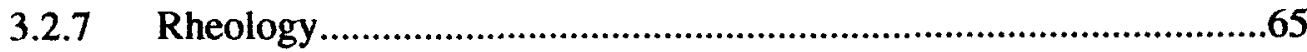

3.2.8 Soil Water Characteristic Curve (SWCC) .......................................67

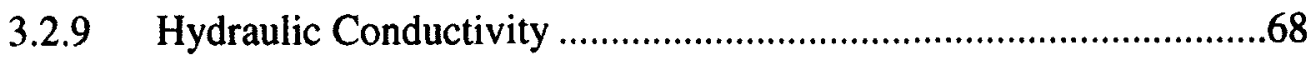

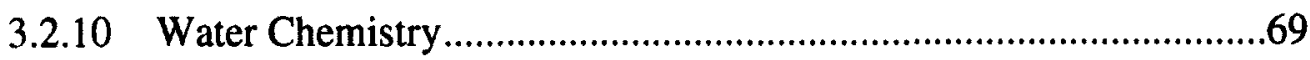

3.2.11 Elemental Composition. XRF Analysis. ..........................................69

3.2.12 Mineralogical Composition. XRD Analysis...................................70

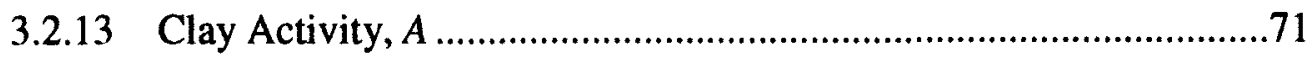

3.3 Drying Tests

3.3.1 Vertical Column Drying Test ..........................................................72

3.3.2 Wax Column Test....................................................................

3.3.3 Small Drying Box Test ....................................................................75 
4.2 Tailings Composition: Solids Concentration, Gravimetric Content and Bitumen Content .83

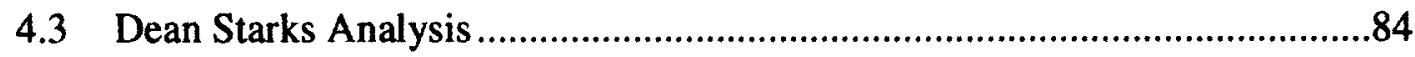

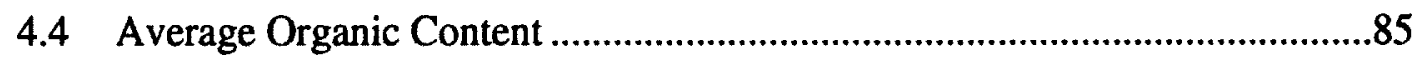

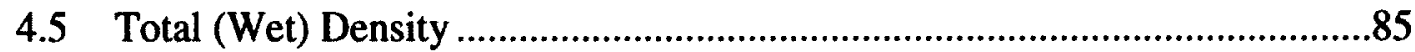

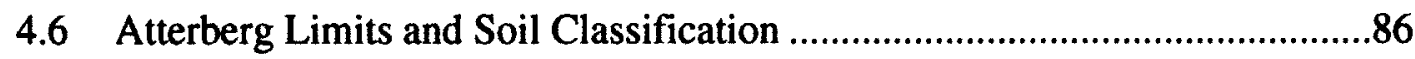

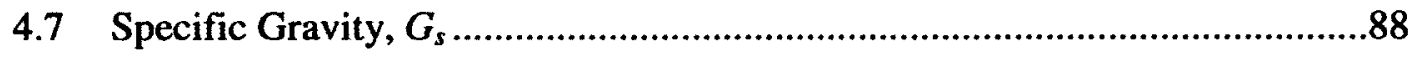

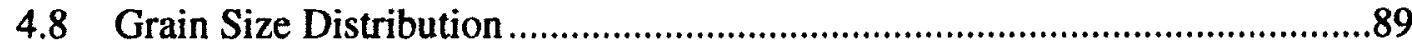

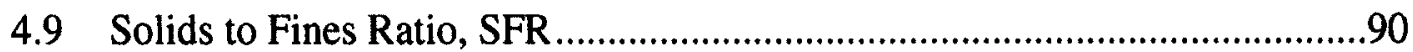

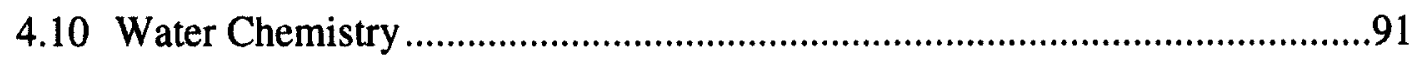

4.11 Methylene Blue Index (MBI) and Clay Fraction.........................................96

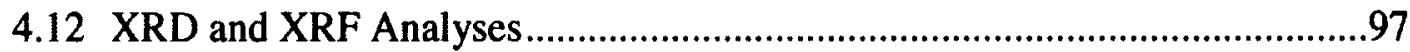

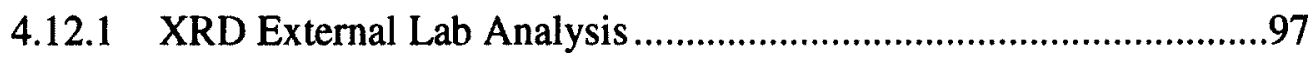

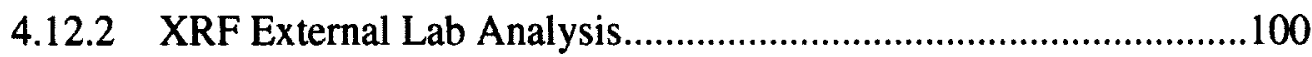

4.13 Rheology

4.13.1 Slump Tests ..................................................................................101

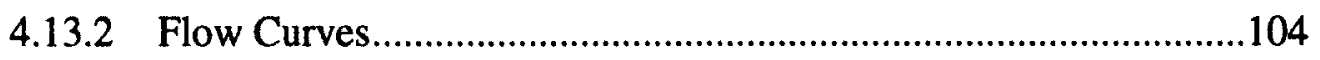


4.13.3 Other measurements of Yield Stress

4.14 Soil Water Characteristic Curve, SWCC.

4.15 Saturated Hydraulic Conductivity

4.16 Drum Sectional Analysis

4.17 Conclusions 120

Chapter 5 DRYING TEST RESULTS 122

5.1 Vertical Column Drying Test 122

5.1.1 Matric Suction 124

5.1.2 Evaporation. 126

5.1.3 Column Sectional Analysis 129

5.1.4 Comparison to previous study

5.2 Wax Column Drying Test 132

$5.35 \mathrm{~cm}$ Thick Drying Box Test 142

$5.4 \quad 10 \mathrm{~cm}$ Thick Drying Box Test .................................................................146

5.5 Drying Box Test

5.5.1 Layer 1 Deposition .151

5.5.1.1 Mass Loss and Evaporation. .151

5.5.1.2 Temperature and Humidity 154

5.5.1.3 Gravimetric Water Content, $w$. 155

5.5.1.4 Volumetric Water Content, $\Theta_{w}$ 
5.5.1.5 Volume change and Settlement

5.5.1.6 Suction .161

5.5.1.7 Sectional Analysis .168

5.5.2 Layer 2 Deposition 173

5.5.2.1 Mass Loss and Evaporation 173

5.5.2.2 Temperature and Humidity....... .176

5.5.2.3 Gravimetric Water Content, w. .176

5.5.2.4 Volumetric Water Content, $\Theta_{w}$ 178

5.5.2.5 Volume change and Settlement .181

5.5.2.6 Suction 184

5.5.2.7 Sectional Analyses .190

5.5.3 Layer 3 Deposition 196

5.5.3.1 Mass Loss and Evaporation. 196

5.5.3.2 Temperature and Humidity 199

5.5.3.3 Gravimetric Water Content, $w$ .200

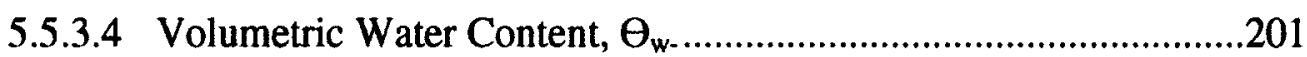

5.5.3.5 Volume change and Settlement .................................................203

5.5.3.6 Suction .205

5.5.3.7 Sectional Analyses. .208

5.5.3.8 Summary of 3 layer tests .215 


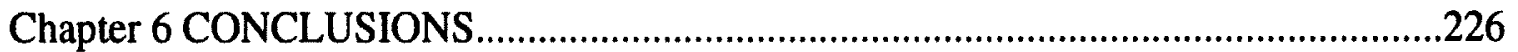

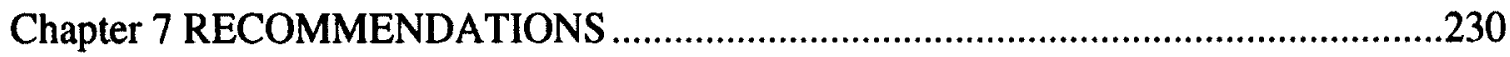

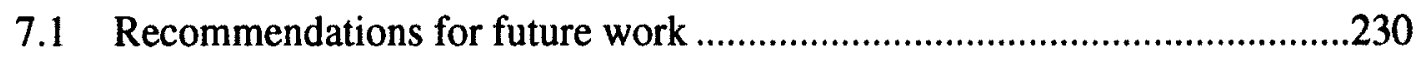

REFERENCES …

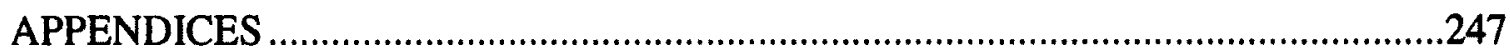




\section{LIST OF TABLES}

Table 2-1: Empirical Equation for the unsaturated coefficient of permeability .29

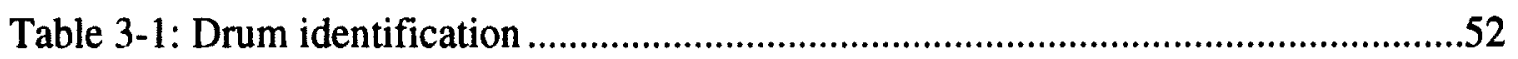

Table 3-2: Tailings Properties - Wax Column Test ............................................................74

Table 3-3: Basic Properties Tailings - Multilayer Drying Box Test..................................77

Table 4-1: Analysis of settled material and supernatant water.........................................82

Table 4-2: Statistical Analysis - Tailings Composition ...................................................83

Table 4-3: Dean Stark Analysis Results .........................................................................84

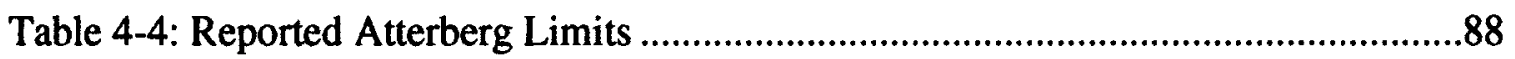

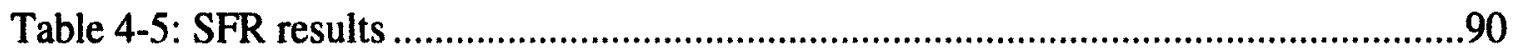

Table 4-6: Composition of Bulyanyulu gold tailings (Fissheha et al., 2010) and Oil sand

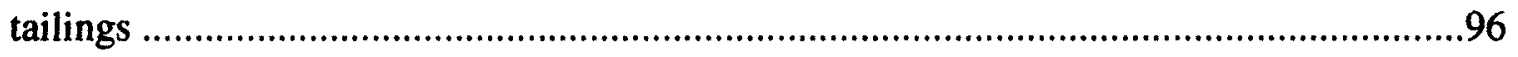

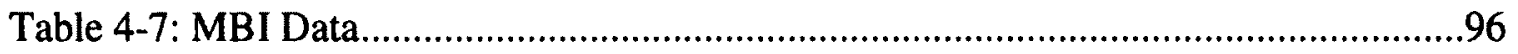

Table 4-8: Minerals identified and their quantitative amounts (bulk sample analysis) wt \%

Table 4-9: Clay minerals identified in the $<2$ micron fraction and their semi-quantitative amounts (wt \%) .

Table 4-10: Elemental composition.........................................................................100

Table 4-11: Slump Test Data for remixed samples at "as-shipped" solids concentrations 102

Table 4-12: Static, Dynamic and Residual Yield stresses at $0.891 / \mathrm{s}$ for samples at "as

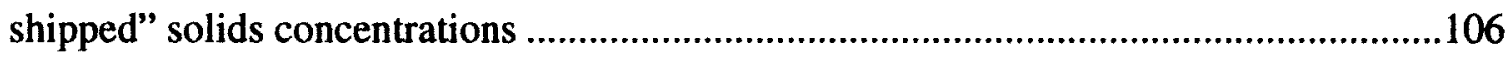

Table 4-13: Measured Hydraulic Conductivity ..............................................................112 
Table 4-14: Void ratio values of remixed tailing samples...............................................112

Table 5-1: Variation in Total Suction with depth..........................................................129

Table 5-2: Suction values (MPa) at the surface - 5-cm thick Drying Box ......................143

Table 5-3: Crack Suctions in MPa........................................................................147

Table 5-4: Measured Total Suction - Crack Surface - Layer 1 .........................................165

Table 5-5: Measured Total Suction - Crack Surface - Layer 2 .......................................188

Table 5-6: Measured Total Suction - Crack Surface - Layer 3 .........................................208

Table 5-7: Undrained shear strength measurements......................................................209

Table 5-8: Undrained shear strength measurements for soil profile ...............................220 


\section{LIST OF FIGURES}

Figure 2-1: Ore Preparation Process (Total E\&P, 2010) ................................................12

Figure 2-2: Froth Production (Total E\&P, 2010) ….....................................................13

Figure 2-3: Capillary rise in a narrow tube and equilibrium at the meniscus (Aghajani, et

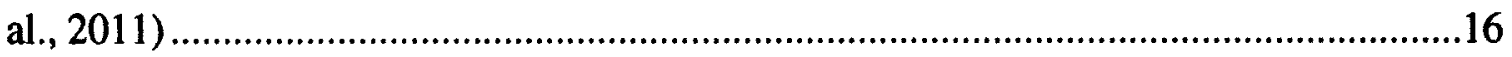

Figure 2-4: View inside chamber of WP4-T Potentiameter (Degacon, 2007) ...................19

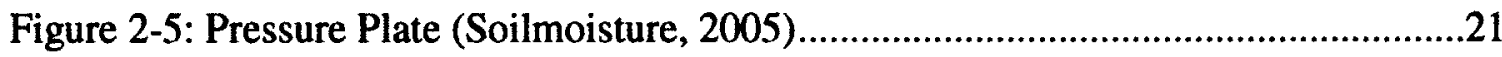

Figure 2-6: Tensiometer (UMS, 2009) .......................................................................23

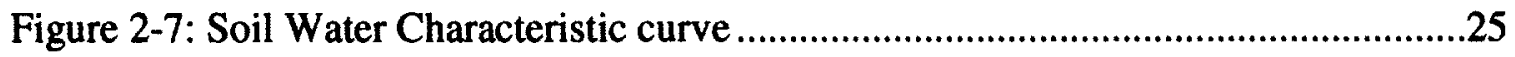

Figure 2-8: Variation of the coefficient of permeability with matric suction (Vanapalli et

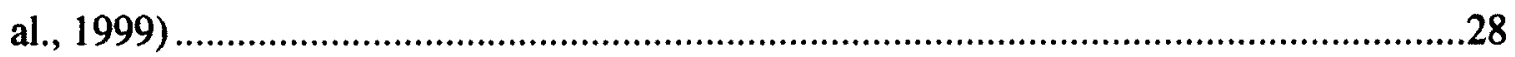

Figure 2-9: Stages of evaporation - AE or RE vs time (After Wilson et al, 1994) ...........35

Figure 2-10: Resistance to vapor diffusion from a wet bare soil surface (After van de Griend and Owe (1994)) 41

Figure 2-11: Relative evaporation measured from desiccating $10 \mathrm{~cm}$ NS soil columns and predictions using equation 2.35 (After Dunmola, 2012) .47

Figure 2-12: Soil resistance $\left(\mathrm{R}_{\mathrm{s}}\right)$ calculated for $10 \mathrm{~cm}$ NS soil columns as a function of volumetric water content (After Dunmola, 2012) ............................................................48

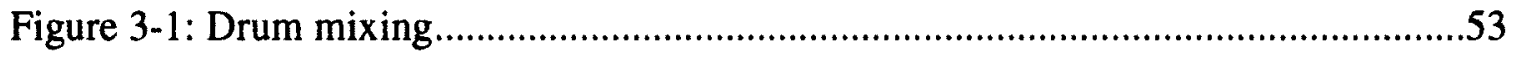

Figure 3-2: Flow Chart - Sample Preparation and Characterization Tests.........................55

Figure 3-3: Relative locations of the Atterberg Limits of a soil. After Bowles (1979).....58

Figure 3-4: Liquid Limit Device (Casagrande Cup) .........................................................59 


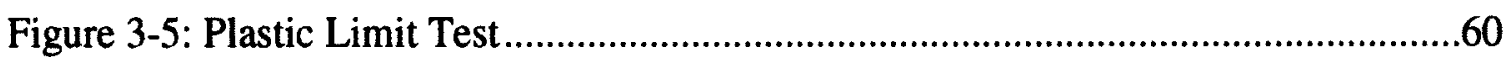

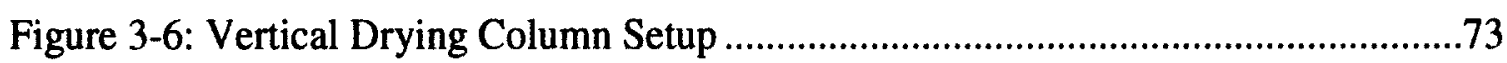

Figure 3-7: Small Box Drying Test Set-up..................................................................75

Figure 3-8: Crack Geometries and measured dimensions .................................................76

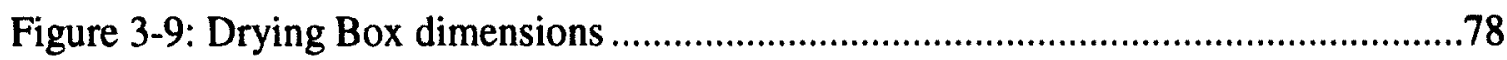

Figure 3-10: Drying Box prior to Layer 1 Deposition.......................................................79

Figure 4-1: Solids Concentration and Gravimetric Water Content ...................................83

Figure 4-2: Average Organic Content (wrt whole sample) ............................................85

Figure 4-3: Tailings Total (Wet) Density …...................................................................86

Figure 4-4: Atterberg Limits - November 2011 ..............................................................86

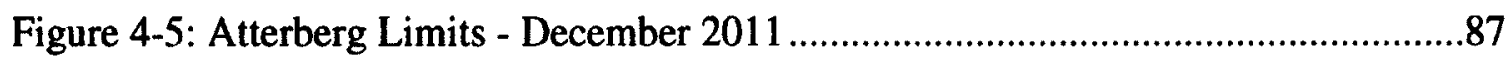

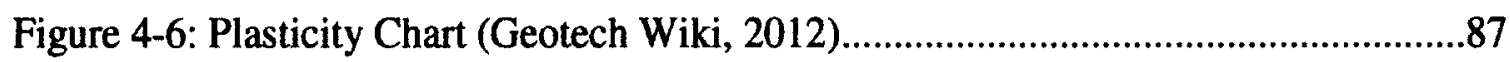

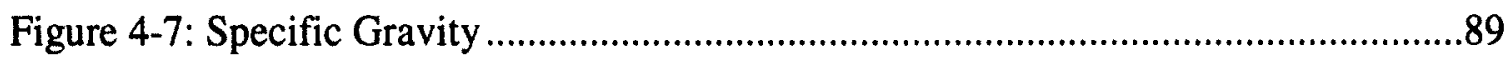

Figure 4-8: General Water Chemistry Data (Conductivity and TDS) .............................91

Figure 4-9: General Water Chemistry Data (Major Cations - Fe, $\mathrm{K}, \mathrm{Ca}, \mathrm{Mg}$ ).................92

Figure 4-10: General Water Chemistry Data (Major Cation - Sodium) ...........................93

Figure 4-11: General Water Chemistry Data (Major Anions - Bicarbonate and Chloride)

Figure 4-12: General Water Chemistry Data (Major Anions - Carbonate and Sulphate) .94

Figure 4-13: General Water Chemistry Data (TSS and Alkalinity) ..................................95

Figure 4-14: General Water Chemistry Data (pH) ...................................................95

Figure 4-15: Variation in Yield Stress with Solids Concentration - Drum 2 (remixed

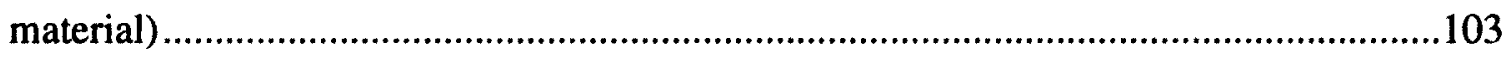


Figure 4-16: Variation in Yield Stress with Solids Concentration - Drum 11 (remixed material) 103

Figure 4-17: Flow Curve - Drum 6 remixed material of 54.4\% solids concentration (November) .104

Figure 4-18: Flow Curve - Drum 13 remixed material of $49.7 \%$ solids concentration (December) .105

Figure 4-19: Stress-time profile of tailings in Drum $1(54.3 \% \mathrm{Cs})$ at $0.891 / \mathrm{s}$ 107

Figure 4-20: Controlled Mode Drum 2 (Nov 2011 Cs - 55\%) ......................................108

Figure 4-21: Controlled Mode Drum 12 (Dec 2011 Cs - 50 \%) .......................................108

Figure 4-22: Pressure plate used in construction of SWCC ............................................110

Figure 4-23: SWCC (Drum 7 - Cs 54.6\% November) ……........................................110

Figure 4-24: Falling Head Test Setup........................................................................111

Figure 4-25: Drum 4 sectional analysis. (a) Initial height of sample. (b) Settled material after removal of water. (c) and (d) Sections of sampler

Figure 4-26: Drum 12 sectional analysis. (a) Initial height of sample; (b) Settled material after removal of water; (c), (d) and (e) Samples from sections of sampler. .114

Figure 4-27: Variation of Gravimetric Water Content with depth (Drum 4 Nov. Batch, Drum 12 Dec. Batch)

Figure 4-28: Variation of Solids Concentration with depth (Drum 4 Nov. Batch, Drum 12 Dec. Batch) 116

Figure 4-29: Variation of Total (Wet) Density with depth (Drum 4 Nov. Batch, Drum 12 Dec. Batch) 
Figure 4-30: Variation of Specific Gravity with depth (Drum 4 Nov. Batch, Drum 12

Dec. Batch)

Figure 4-31: Drum 12 Sectional analysis - GSD non-dispersed 118

Figure 4-32: Drum 4 Sectional analysis - GSD non-dispersed

Figure 4-33: Drum 4 Sectional analysis - GSD dispersed

Figure 4-34: Comparison of average non-dispersed GSDs from the high and low plasticity tailings 120

Figure 5-1: Gap observed in vertical column after Test 1 ...........................................122

Figure 5-2: Surface of TT upon termination of column drying tests.................................123

Figure 5-3: Variation of Matric Suction during Test 1.................................................125

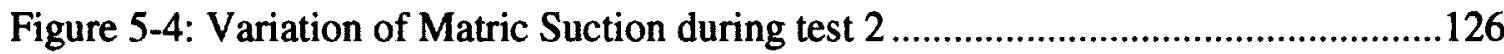

Figure 5-5: Cumulative evaporation results from thickened tailings over time for Test 1 and 2 .127

Figure 5-6: Solids concentration of thickened tailings over time for Test 1 and 2. Test 2 not considering free water. .128

Figure 5-7: Solids concentration of thickened tailings over time for Test 1 and 2. Test 2 considering free water. 128

Figure 5-8: Change in Solids Concentration with depth ............................................130

Figure 5-9: Variation in Volatiles content with depth ....................................................130

Figure 5-10: Matric Suction Measurements unamended tailings ....................................131

Figure 5-11: Sectional Analysis of Column A1 ........................................................132

Figure 5-12: Solids Concentration Profile in Columns A1 ad B1 .................................133

Figure 5-13: Sectional Analysis of Column B1 .........................................................134 
Figure 5-14: Sectional Analysis of Column B4

Figure 5-15: Solids Concentration Profiles: (a) $t=167$ hrs (b) $t=226$ hrs (c) $t=340$ hrs

Figure 5-16: Osmotic and Total Suction development at the surface - Sample B..........136

Figure 5-17: EC profile Column A4 ……………….............................................137

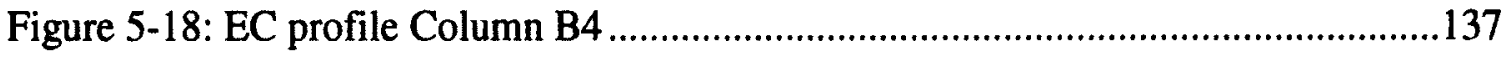

Figure 5-19: Visual of the Soil surfaces in Wax Columns .............................................138

Figure 5-20: Measured RE versus drying time (Sample A) ........................................139

Figure 5-21: Measured RE versus drying time (Sample B) ............................................139

Figure 5-22: Actual and Predicted RE - Sample A.........................................................141

Figure 5-23: Measured AE in $\mathrm{mm} / \mathrm{d}$ - With and without crack contribution to SA .......143

Figure 5-24: Measured Cumulative evaporation in $\mathrm{mm} / \mathrm{d}$..............................................143

Figure 5-25: Evolution of Tailing Crack and Total Surface Area (SA) ..........................144

Figure 5-26: Evolution of Tailing Crack Volume ...........................................................144

Figure 5-27: Suction development within cracks in Sample 1 (a) Day 7 (b) Day $8 \ldots \ldots . .145$

Figure 5-28: Measured RE - With and without crack contribution to SA .......................146

Figure 5-29: Measured and predicted RE - 10cm thick Drying Box test ........................149

Figure 5-30: Temperature, RH and Suction measurement $-10 \mathrm{~cm}$ thick Drying Box test

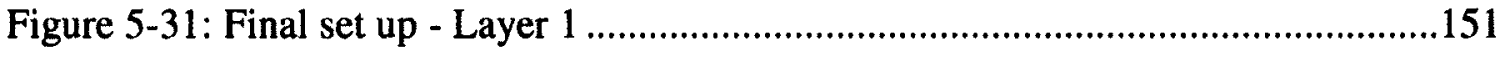

Figure 5-32: Actual Evaporation in kg/d - Layer 1 ...................................................152

Figure 5-33: Actual Evaporation in mm/d - Layer 1 ..................................................153

Figure 5-34: Crust and Crack Formation - Layer 1 ......................................................153 
Figure 5-35: Temperature Profile within soil and at Soil surface - Layer 1 .154

Figure 5-36: RH and Temperature Data above the soil - Layer 1 .155

Figure 5-37: Overall Gravimetric Water Content of Layer 1 155

Figure 5-38: Variation in Gravimetric Water Content at the surface - Layer 1 .156

Figure 5-39: Variation of Solids Concentration at the surface - Layer 1. 157

Figure 5-40: Volumetric water content data - Layer 1 158

Figure 5-41: Settlement and Cumulative Evaporation with time - Layer 1 .159

Figure 5-42: Evolution of Void ratio - Layer 1 160

Figure 5-43: Shrinkage curve - Layer 1 161

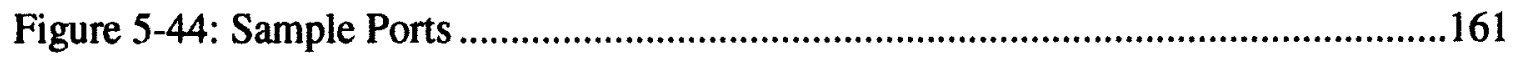

Figure 5-45: Evolution of Matric Suction - Layer 1 .....................................................162

Figure 5-46: Evolution of Total Suction at the surface - Layer 1 ..................................163

Figure 5-47: Predicted and Measured RE - Layer 1 ....................................................164

Figure 5-48: Sample Crack Shutdown - Layer 1 .....................................................166

Figure 5-49: Total Crack and Tailing Surface Area - Layer 1 .........................................167

Figure 5-50: Sampling (end of Layer 1) ................................................................168

Figure 5-51: Solids Concentration profile (Sample 1) ....................................................169

Figure 5-52: Total and Osmotic Suction Profile (Sample 1) ........................................170

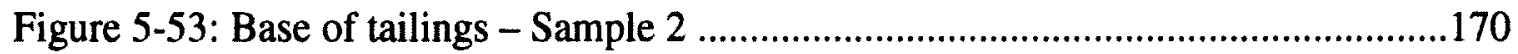

Figure 5-54: Upper Part of Tailings Section - Sample 2 ..............................................171

Figure 5-55: Solids Concentration Profile (Sample 2) ...............................................171

Figure 5-56: Total and Osmotic Suction Profile (Sample 2)..........................................172

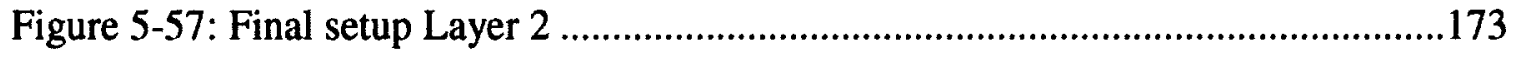


Figure 5-58: Actual Evaporation in $\mathrm{kg} / \mathrm{d}$ - Layer 2 .174

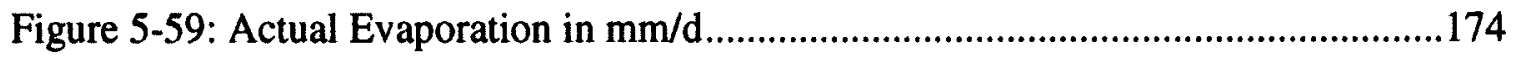

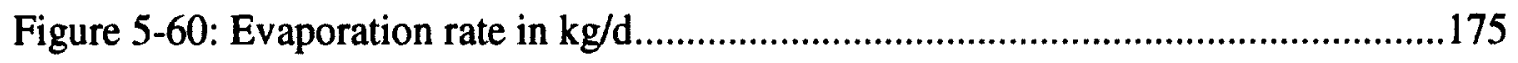

Figure 5-61: Visual of Exposure of underlying material (Day 32) ..............................176

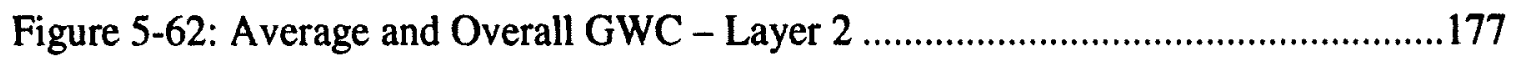

Figure 5-63: Variation in Gravimetric Water Content at the surface - Layer 2............178

Figure 5-64: Volumetric water content data (After Layer 2 deposition).......................179

Figure 5-65: Change in Volumetric water within cracks........................................181

Figure 5-66: Settlement and Cumulative Evaporation with time - Layer 2..................182

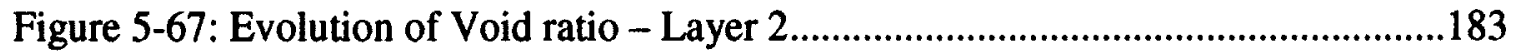

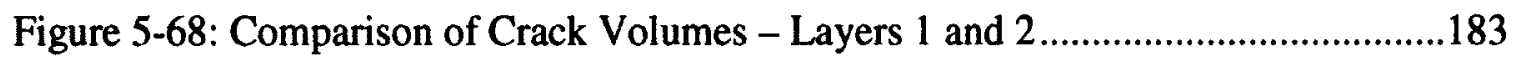

Figure 5-69: Shrinkage Curve showing the variation in the Degree of Saturation (S)...184

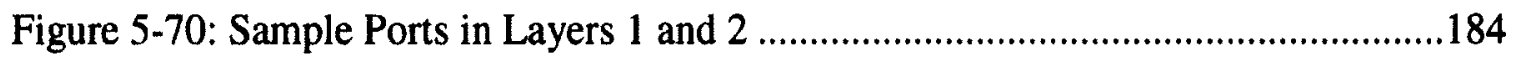

Figure 5-71: Evolution of Matric Suction - New (Layer 2) and Old (Layer 1) Layers ... 185

Figure 5-72: Evolution of Total Suction at the surface - Layer 2 ...............................186

Figure 5-73: Electrical Conductivity measured at the surface ....................................187

Figure 5-74: Osmotic and Total Suction measurements at Surface - Layer 2...............187

Figure 5-75: View of salt deposits along crack edges ........................................... 188

Figure 5-76: Total Crack and Tailing Surface Area - Layer 2............................... 189

Figure 5-77: Difference in Crack formation in first few days of Layer 1 and Layer 2

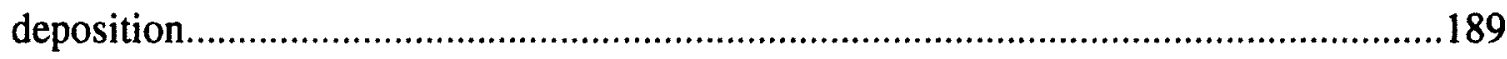

Figure 5-78: Extraction of Sample 1 along depth of Layer 1 and 2 ..........................191

Figure 5-79: Solids Concentration profile (Sample 1 - Layer 2) ...............................192 
Figure 5-80: Total Osmotic Suction Profile (Sample 1 - Layer 2).

Figure 5-81: Base of tailings - Sample 1 - Layer 2

Figure 5-82: Solids Concentration profile (Sample 2 - Layer 2)

Figure 5-83: Total and Osmotic Suction Profile (Sample 2 - Layer 2) .195

Figure 5-84: Layer 3 Deposition .196

Figure 5-85: Actual Evaporation in $\mathrm{kg} / \mathrm{d}$ - Layer 3 197

Figure 5-86: Actual Evaporation in $\mathrm{mm} / \mathrm{d}$ - Layer 3 197

Figure 5-87: Crack formation - Day 1 (63) - Layer 3 198

Figure 5-88: Measured RE - Layer 3 198

Figure 5-89: Snapshots of the Exposure of underlying material 199

Figure 5-90: Average GWC of Layer 3 and Box overall GWC .200

Figure 5-91: Variation in Gravimetric Water Content at the surface - Layer 3.............201

Figure 5-92: Volumetric water content data (After Layer 3 deposition)..........................202

Figure 5-93: Settlement and Cumulative Evaporation with time - Layer 3.....................203

Figure 5-94: Evolution of Void ratio - Layer 3 .............................................................204

Figure 5-95: Shrinkage Curve - Layer 3 ……………...............................................204

Figure 5-96: Sample Ports in Layers 1, 2 and 3 .......................................................205

Figure 5-97: Evolution of Matric Suction - New (Layer 3) and Old (Layer 1 and 2)

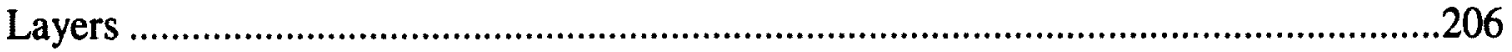

Figure 5-98: Total and Osmotic Suction - Layer 3 .....................................................207

Figure 5-99: Shelby tube Sampling .......................................................................209

Figure 5-100: Sample 1 - Material extracted using from Shelby Tube - End of Layer 3 .210 


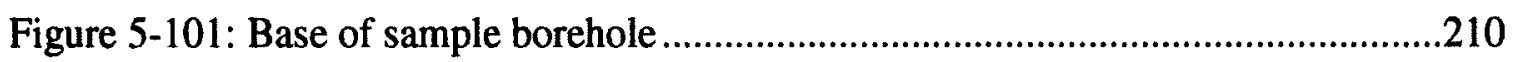

Figure 5-102: Solids Concentration Profile - Sample 1 - Layer 3 ..................................211

Figure 5-103: Total and Osmotic Suction Profile - Sample 1 - Layer 3 .........................212

Figure 5-104: Sample 2 (a) Salt accumulation along crack (b) Void spaces top of sample

Figure 5-105: Sample 2 - Material extracted using from Shelby Tube - End of Layer 3

Figure 5-106: Sample 2 - Solids Concentration Profile - End of Layer 3......................214

Figure 5-107: Total and Osmotic Suction Profile - Sample 2 - Layer 3 ..........................214

Figure 5-108: Average and Surface Gravimetric Water Content Layers 1-3..................216

Figure 5-109: Overall and Average Gravimetric Water Content Layers 1-3 .................217

Figure 5-110: Solids Concentration Profiles at the end of Layers 1-3 ..........................217

Figure 5-111: Gravimetric Water Content Profiles at the end of Layers 1-3 .................218

Figure 5-112: Change in Void Ratio in Layers 1-3 .......................................................219

Figure 5-113: Settlement and Cumulative Evaporation in Layers 1-3 ..........................220

Figure 5-114: AE (with crack SA consideration) in Layers 1-3......................................221

Figure 5-116: Measured and Predicted RE Layer 2 ………………..............................222

Figure 5-117: Measured and Predicted RE Layer 3 .....................................................223

Figure 5-118: Change in Total surface area against RE - Layer 3 - Plot 1 ....................224

Figure 5-118: Change in Total surface area against RE - Layer 3 - Plot 2 ....................225 


\section{LIST OF APPENDICES}

Appendix A: Solids Concentration. Gravimetric Water content. Bitumen Content.

Density

Appendix B: Atterberg Limits .............................................................................250

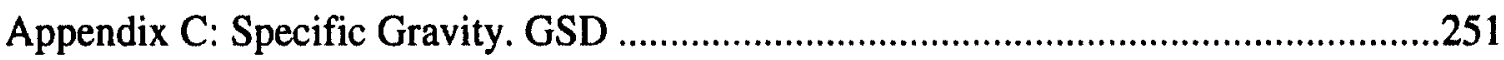

Appendix D: XRD

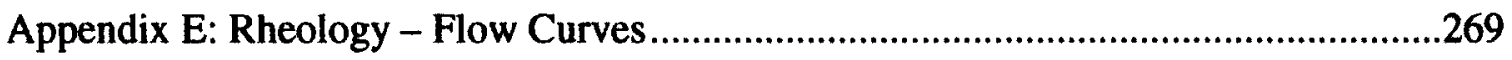

Appendix F: Rheology - Maximum Yield Stress Measurement.......................................274

Appendix G: Rheology - Controlled Mode ……………............................................278

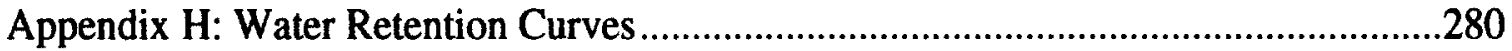

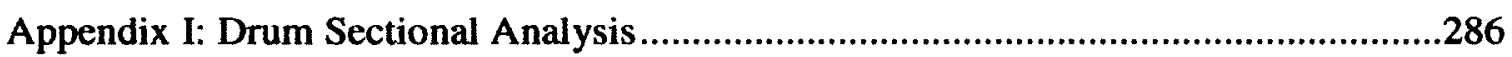

Appendix J: Water Chemistry ..............................................................................290

Appendix C: Wax Column Tests - Solute Transport .....................................................291

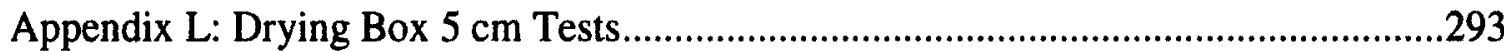

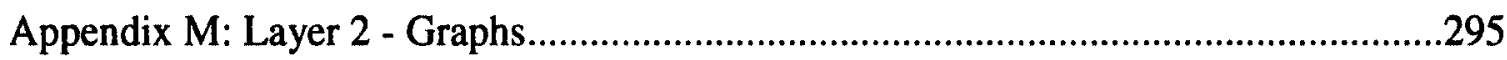

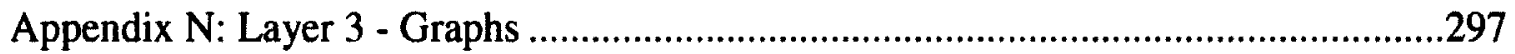




\section{LIST OF ABBREVIATIONS}

AE- Actual Evaporation

ASTM- American Society for Testing and Materials

CanMet - Canada Centre for Metallurgical Society

CAPP - Canada Association of Petroleum Producers

CEC - Cation Exchange Capacity

CSS—Cyclic Steam Simulation

EC-Electrical Conductivity

EF - Empirical Adjustment Factor

ERCB-Energy Resources Conservation Board

FAO_ Food and Agricultural Organization

GSD_ Grain Size Distribution

LL- Liquid Limit

MB-Methylene Blue

MBI-Methylene Blue Index

MFT-Mature Fine tailings 
PE-Potential Evaporation

PI- Plasticity Index

PL_Plastic Limit

PSC_-Primary Separation Cell

RE-Relative Evaporation

RH-Relative Humidity

SA-Surface Area

SAGD—Steam Assisted Gravity Drainage

SEM-Standard Error Mean

SFR - Sands to Fines Ratio

SL_ Shrinkage Limit

SWCC-Soil Water Characteristic Curve

TDS—Total Dissolved Solids

TG-Thermogravimetric

TSS - Total Suspended Solids IV

TT-Thickened Tailings

USDA-United States Department of Agriculture 
WRC - Water Retention Curve

XRD-X-Ray Diffraction

XRF- X-Ray Fluorescence 


\section{Chapter 1 introduction}

\subsection{Statement of problem}

The oil sands in Alberta are a key component of the nation's energy mix, offering a secure energy supply to the United States and other potential markets such as the AsiaPacific region. Although the National Energy Board cites Canada to be a world leader in oil production in the foreseeable future (National Energy Board, 2006), new market options translate into increased bitumen extraction from the oil sands and one of the main issues facing the industry, environmental concerns, surfaces bringing about major discussions by environmental lobbyists and government entities.

With water consumption at unfavourable rates to water restoration, reuse, and recycling, concerns are elevated regarding oil sands mining and the sustenance of flows in the Athabasca River. In addition, the waste stream from the process, a low solid content slurry called tailings, containing sand, clay, water and residual bitumen, requires increased land use for storage in huge ponds. When deposited, the fines present in this waste stream do not allow for settling, water removal or consolidation to be achieved even over a period of 30 to 50 years (Wells, 2011), making land reclamation difficult. As a result, companies are adopting technologies aimed at reducing the volume of existing and future inventories of these fine tailings.

Total E\&P, in its Pilot Project, employs thickened tailings technology, a technology already utilized in other mining industries. The product is thickened tailings, a material with increased solids content, improved settling and strength properties, 
formed from the introduction of chemical additives called flocculants to fine tailings. The thickened tailings will be deposited in dedicated disposal areas in thin lifts, where through evaporation, freeze-thaw, and consolidation they are expected to dewater and gain strength sufficient to allow for reclamation within a reasonable time. Current regulations mandate that an increasing inventory of oil sand tailings must achieve given undrained shear strengths within prescribed times post-deposition.

Affecting the evaporation of thickened tailings are a number of factors which include lift thickness, salinity, cracking, climatic conditions among others as have been shown from studies carried out on gold tailings and other soils ( (Chen, 1992); (Fujiyasu et al., 2000); (Simms et al., 2007); (Fissheha et al, 2010); (Junqueria et al., 2011)).

\subsection{Objectives and scope of work}

The reduction in volume and increase in strength of the Oil sand thickened tailings is a function of the evaporation that occurs in the field. Understanding the evaporative behaviour and the factors affecting it can contribute to the achievement of the overall goal of the technology, that of reducing the quantities of wet tailings material and preparing the land for reclamation. With this is mind, the main objectives of this research are:

1. To gain a basic understanding of the evaporative behaviour of oil sand thickened tailings

2. To investigate the effect of salinity and cracking on the drying of oil sand thickened tailings. 
3. To obtain sufficient data that could be used to model dewatering of the tailings, using a coupled desiccation-consolidation.

To achieve the above-mentioned goals the following experimental work was conducted:

1. Characterization of the tailings to determine baseline characteristics such as water retention curve, water chemistry, particle size distribution, bitumen, solids and water content, Atterberg limits, mineralogy among others.

2. Wax column drying tests to study solute transport.

3. Small scale drying tests on materials of different salinity to determine the effect of salinity on drying and to understand the cracking behaviour of tailings and its influence on evaporation rates.

4. Multilayer deposition tests with a $1 \mathrm{~m}$ by $0.7 \mathrm{~m}$ plan area, to study how dewatering evolves as layers are built, and to assess the influence of cracking on evaporation.

\subsection{Outline of the thesis}

The outline of the thesis is presented below:

Chapter 2: Literature review - a review of oil sands processing and tailings management as proposed and practiced by Total E\&P, unsaturated soil mechanics: liquid, vapour and heat flow, evaporation: theory, measurement and factors affecting it.

Chapter 3: Materials and Methodology - a description of the methods employed throughout the course of this study and the materials utilized for both characterization tests and drying tests. 
Chapter 4: Results of the characterization tests for the material under study.

Chapter 5: Results from all drying tests conducted.

Chapter 6: Summary and conclusions drawn from results.

Chapter 7: Recommendations for future work. 


\section{Chapter 2 LITERATURE REviEw}

\subsection{Oil Sands Tailings. Management. Approaches and Problems}

An inevitable waste stream of the oil sand mining process is the tailings stream; noting as previously discussed that bitumen forms only $10-12 \%$ of the ore and the volume of water utilized to extract it. It is a "headache" obtained during the recovery of such a valuable product, bitumen. Tailings, composed of water, sands, silt, clay and residual bitumen, require long term containment and management, which can be very costly due to the large volumes generated.

Traditionally, whole tailings, are deposited in the confines of the dammed impoundments where they naturally undergo particle size separation in which the sands, the coarser fraction, settle out to form beaches leaving the fines (particles less than 44 $\mu \mathrm{m})$ in suspension. After a few years, settling increases the solids concentration of the fines to about $30 \%$ but consolidation is thereafter very slow. Wells, presented data which showed that after nearly 35 years, there was no significant difference in the initial profile of the fine tailings in Suncor's Pond 1A (Wells, 2011). These fine tailings are referred to as mature fine tailings (MFT) and require increasing containment volumes as processing continues. As a result, safety concerns in case of a facility breach or failure surfaced and environmental concerns by surrounding communities have been expressed with regard to the pollution of nearby sources of surface water and the disappearance of natural flaura and fauna. 
The regulatory body for this resource, the Energy Resources Conservation Board (ERCB), in a bid to reduce environmental liabilities associated with unconsolidated fine tailings, instituted a new regulation (Directive 074) in 2009. This directive required the reduction of fluid tailings and their conversion into trafficable deposits (minimum undrained shear strength of $10 \mathrm{kPa}$ ) by entities engaged in open pit mining (Energy Resources Conservation Board , 2009). To achieve this, a minimum of 5 kilopascals (kPa) undrained shear strength must be achieved within a year of deposition of the tailings and each consecutive year thereafter. If the material does not meet the $5 \mathrm{kPa}$ requirement it must be removed or remediated; all this to ensure that the deposit is ready for reclamation within five years after active deposition (Energy Resources Conservation Board, 2009). In 2011, Alberta's inventory of tailings ponds was at 720 million cubic metres and covered an area of about 130 square kilometres (Energy Resource Conservation Board, 2011).

To comply with the requirements stated by the ERCB, many companies have applied a wide range of technologies, from the use of flocculants and coagulants to the use of giant centrifuges, composite tailings disposal, altering of water chemistry, desiccation in thin lifts to name a few. In the present research, thickened tailings (TT) technology is investigated.

In an effort to tackle the poor consolidation of the fine tailings, whole tailings are not produced at the Total plant. Instead, coarse sand tailings are separated in the hydrocyclone and deposited in a sand beach area where runoff is collected and later centrifuged to accommodate water recovery (Total E\&P, 2010). The underflow of the 
secondary flotation vessel is sent to the thickener and deposited as thickened tailings. The froth treatment tailings are also deposited in a separate pond where solvent is recycled.

\subsection{Oil Sand Thickened Tailings. Technology. Properties.}

As shown in Figure 2-2 above, the separation by particle size and density in the hydrocyclone of the majority of the coarse sand fraction of the tailings leaves behind a fines filled dilute suspension as overflow which is sent to the secondary flotation vessel for further recovery of bitumen trapped in the fines. As a result, the tailings produced are very fine and are not mixed with the coarser tailings as was done traditionally but are sent to a thickener. The thickening stage facilitates an increase in solids concentration of the tailings and allows for warm water recovery, a huge energy saving operation (Devenny, 2010).

Thickened tailings technology, has been used in metal and aluminum operations for several decades. It was originally conceptualized (in 1965) and implemented by Robinsky in 1973 at the Kid Creek Mine, Timmins Ontario and has been implemented at 20 or so mines worldwide since that time, and is considered as an alternative in nearly all new projects (Fourie, 2012). Due to the topography and the threat of acid generation at Kid Creek, copper/zinc tailings were thickened to a higher solids concentrations ranging from 60 to $65 \%$ and then deposited from a central discharge point to dry in thin lifts, thus avoiding the need for embankments (Engels, 2006). Further applications include other metal mines and several red mud operations (Williams, et al., 2008). With the major improvements on thickener technology and the closing of knowledge gaps on TT production and transport, TT has seen increased applications including use of thickened 
or "paste" tailings in the cemented backfill operations and recently in Oil sand tailings management.

In the thickening process used by Total, the Hychem polymeric flocculant, AF246 (high molecular weight polymer) is used to bridge the fine particles, forming larger ones called flocs. The flocs settle quickly releasing water of low turbidity (less than 6.5 clarity corresponding to less than $0.5 \%$ solids concentration) and producing an underflow of increased solids concentration of up to about $50-55 \%$.

The tailings can still be pumped at this solids concentration to an open area where they are deposited in thin lifts for natural drying. As the polymer remains in the flocculated solid particles it does not affect the water chemistry and so the water is recycled quickly to the extraction plant to preserve the energy contained therein (Gosselin, et al., 2010).

The main factors affecting the thickening process include: shear rate, flocculant molecular weight, water chemistry and initial solids concentration. Optimal operations have been successful in producing TT product with significant yield stress. At Total operations, final solids concentration of the TT and the polymer dosage influence final yield stresses achieved in underflow. A $46 \%$ material exhibits a $120 \mathrm{~Pa}$ yield stress while a 50\% exhibits one of $170 \mathrm{~Pa}$. The TT shears extremely quickly, with little amount of energy to a yield stress of $15-20 \mathrm{~Pa}$. 


\subsection{Consolidation and Evaporation in other amended Oil Sands tailings}

Consolidation is a process by which a soil's volume is decreased due to applied stresses where the soil simultaneously gains effective stress through the dissipation of excess pore pressure (Terzaghi, 1943). The applied stress causes the soil particles to pack more tightly together reducing its volume. Because of the large settlements and highly nonlinear hydraulic conductivity, finite (large) strain theory is generally applied. One commonly used method in literature is proposed by Krizek and Somogyi (1984).

The experience with other treatments of fine oil sand tailings, is that even in relatively thin lifts $(\sim 0.5 \mathrm{~m})$, significant self-weight consolidation occurs during the summer in Fort McMurray. Matthews et al. (2011) showed that the bottom of lifts at Shell's in-line polymer amended tailings demonstration achieved higher densities and with relative rapidity. Thus, consolidation is an important mechanism for dewatering in even thin-lift deposition, for oil sand tailings, and may be important for the dewatering behaviour of the thickened tailings investigated in this thesis.

The state of practice with respect to the contribution of evaporation to dewatering of tailings, both metal mines and in the oil sands, is usually to apply a factor to the potential evaporation rate. However, this is too simple and a number of problems can arise. Evaporation rate decreases with time as tailings dewater, and the overall evaporation rate is known to be influenced by both salinity and crack dynamics (Fujiyasu

et al., 2000; Simms et al., 2007; Fisseha et al., 2010), as well as a change in albedo 
(Simms et al. 2007). The correlation between evaporation and soil physics will be briefly reviewed in the following sections.

\subsection{Oil Sands Review}

Oils sands, also referred to as tar sands or bituminous sands, are unconsolidated sand deposits filled with bitumen (Masliyah et al., 2004). The average composition of the ore is $83 \%$ sand, $10-12 \%$ bitumen, $3 \%$ clay and $4 \%$ water. The viscous bitumen coats the water-wet sand grains and therefore requires further processing to efficiently remove and transport it. Alberta is home to the largest known deposit of Oil Sands in the world covering an area of approximately 140,800 square kilometers in the regions of Athabasca, Peace River and Cold Lake combined with proven oil reserves of 169.3 billion barrels of bitumen (Energy Resource Conservation Board, 2011). Through the many variations and adaptations to the Clark Hot Water Extraction Process in an effort to reduce operating costs and reduce greenhouse gas emissions, Alberta's oil sands produce approximately 1.6 million barrels of oil daily accounting for a little over one half of the Canada's crude oil production, 3.0 million barrels per day (CAPP, 2012).

Approximately 20 percent of the bitumen available at these sites is attainable through open pit mining while the rest could be recovered through in situ methods due to the variation in depth of the deposits (CAPP, 2012). As of April 2012, the Government of Alberta reports a total of 101 active oil sands projects of which five are mining with three more under construction (Government of Alberta, 2012). 
Open pit mining is employed when dealing with deposits located near the surface; where overburden is less than 75 metres (National Energy Board, 2004). At lower depths, in situ methods based on steam assisted gravity drainage (SAGD) and cyclic steam simulation (CSS) are applied.

In SAGD bitumen is heated by steam injection into an horizontal wellbore and allowed to drain into a second wellbore below, where it is then produced to the surface. However in CSS, the injection of heat, thinning and production to the surface of bitumen is done in one wellbore.

In the present research, open pit mining is investigated and is presented based on the operations undertaken at the Total E\&P, Canada. This process entails the removal of overburden, a mixture of muskeg, sandstone and shale, to access the crude bitumen which occurs near the surface. The overburden is stockpiled for future reclamation and landscape reconstruction of the mine site. The oil rich sands are mined using large excavators and loaded into huge 400 tonne trucks for transportation to the crushing station, the first unit operation of the extraction process.

Giant lumps of oil sands are crushed to about 400 to $600 \mathrm{~mm}$ with the resulting crushed ore stored in surge bins and then transferred by conveyor to the slurry preparation unit (Total E\&P, 2010). The material from the surge bin is then mixed with hot process water filtered to form slurry in a conditioning drum which also serves as a mechanical separator; facilitating the rejection of oversized particles (See Figure 2-1). Traditionally, temperatures of $85{ }^{\circ} \mathrm{C}$ were used in accordance to Karl Clark's hot water extraction method (Clark, 1939). However, due to stiffer regulations for energy 
conservation, the temperature is now reduced to $45-55{ }^{\circ} \mathrm{C}$ (Omotoso, Mikula, \& Stephens, 2002). Total E\&P employs an extraction temperature of $50^{\circ} \mathrm{C}$. The slurry is then transported to the froth production plant in pipelines of about 1600 metres long where additional chemical reagents and air are introduced to aid in the extraction process.

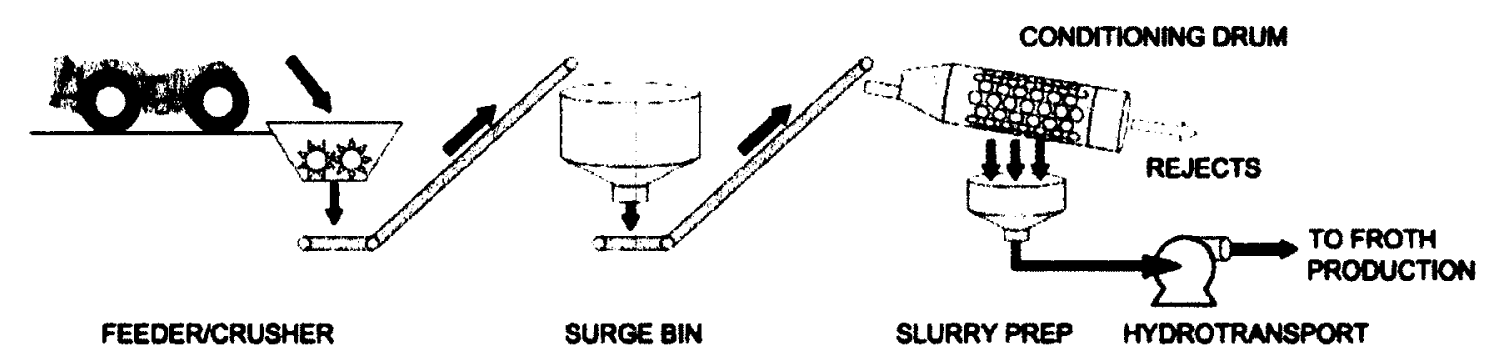

Figure 2-1: Ore Preparation Process (Total E\&P, 2010)

At the froth production plant, the prepared slurry is sent to a large separation vessel (Primary Separation Cell, PSC). Sedimentation of sands, clay and rocks at the bottom of the vessel facilitates the removal of the lighter material bitumen and in some cases finer clay particles in the form of a froth. The middle layer of finer particles, middlings, is sent to a subsequent bitumen recovery stage (middlings flotation) and the underflows from both this vessel and the PSC are sent to a hydrocyclone for further separation.

The over flow of the hydrocycloning step is also sent to a secondary flotation vessel for subsequent bitumen recovery. The underflow of the hydrocyclone is a waste product referred to as "coarse sand tailings" while the underflow of the secondary 
flotation vessel is referred to as "fine tailings". These fine tailings are sent to a thickener to produce thickened tailings (See Figure 2-2) (Total E\&P, 2010).

Bitumen froth from the PSC is skimmed and treated to remove trapped water, clay and any other solids before upgrading. This involves the addition of diluents such as naphtha or paraffin to reduce the viscosity of the bitumen and the increase in froth temperature (CANMET, 2008). The recovered bitumen from this stage is sent to the upgrader while the waste products, coarse sand tailings, thickened tailings and froth treatment tailings are sent to their respective disposal sites.

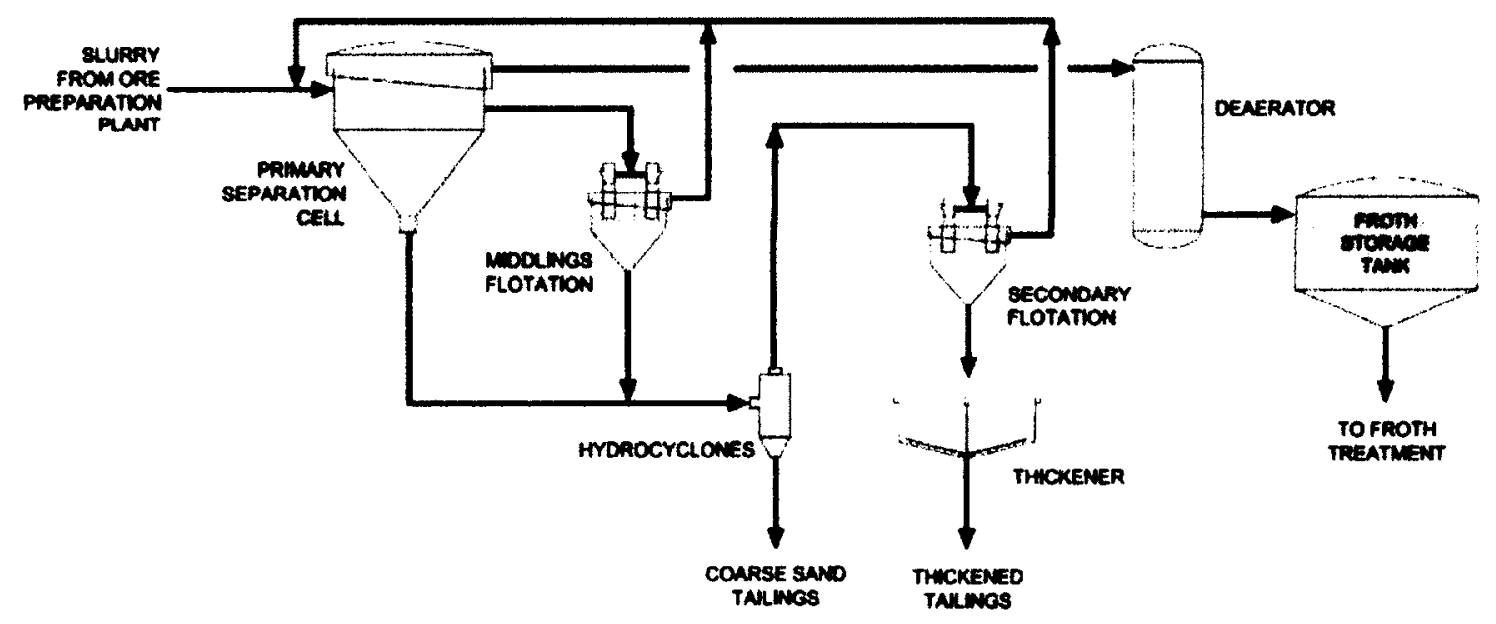

Figure 2-2: Froth Production (Total E\&P, 2010)

\subsection{Flow in Unsaturated soils. Water, vapour and heat.}

The pores in a soil specimen can either be filled with water in which are found dissolved salts or dissociated ions or a combination of water and air. When all the pores are filled with only water, the soil is said to be saturated and has a degree of saturation, $\mathrm{S}$, of $100 \%$. 
However, natural surface deposits generally have low water contents (Fredlund \& Rahardjo, 1993) and physical processes such as excavation can decrease the water content of soils. Soils containing the three main phases of soil particles, water and air are referred to as unsaturated soils. Climatic conditions also play a pivotal role in whether a soil remains saturated, through net infiltration or unsaturated, through net evaporation or evapotranspiration with time. Since the process of evaporation of oil sand thickened tailings deals with an unsaturated material, the following subsections provides information on the main properties of unsaturated soils, their measurements and methods of estimation.

\subsubsection{Soil Suction}

Water in the soil undergoes a variety of processes. Whether it is retention, movement, uptake by plants or loss to the atmosphere, energy is required. The energy required to remove a unit weight of water from the soil is equivalent to the "free energy" of the soil water also known as Suction, which is a measure of how strongly water is held in the soil. The stronger the water is held, the more energy or work is required to remove it from the soil. This suction also known as total suction comprises of two main components: matric suction and osmotic suction.

The total suction of a soil can be expressed through the laws of thermodynamic as a function of the relative humidity $(\mathrm{RH})$ of the air in the soil pores. The RH is expressed by:

$R H=\frac{\bar{u}_{v}}{\bar{u}_{v o}}$ 
Where:

$\bar{u}_{v}$ - partial pore water vapour pressure

$\bar{u}_{v o}$ - partial pure water vapour pressure

Richards (1965) expressed the free energy of the soil (total suction, $\psi$ ) in terms of the partial pressure of the pore water vapour using the following expression:

Total suction, $\psi=-\frac{R T}{W} \ln \left(\frac{\bar{u}_{v}}{\bar{u}_{v 0}}\right)$

Where:

$\psi-$ Soil suction or total suction, [kPa]

$R$ - Universal (molar) gas constant, $[8.314 \mathrm{~J} / \mathrm{mol} \mathrm{K}]$

$T$ - Absolute temperature, $[\mathrm{K}]$

$W$ - Molar volume of water $\left[\mathrm{m}^{3} / \mathrm{kmol}\right]$

\subsubsection{Matric Suction}

The component of total suction which results from the decrease in vapour pressure of the pore water due to capillary action, a decrease in the radius of curvature, is called matric suction. It is best described in terms of capillary forces. Above the ground water table, the soil is unsaturated and water moves upward in the soil through adhesion to the sides of the pores also referred to as capillars and is held there by surface tension forces. This process is called capillary rise (Figure 2-3).

At the interface between the water and air, the contractile skin (Fredlund \& Rahardjo, 1993), imbalanced intermolecular forces result in a pressure difference of $u_{a}$ - 
$u_{w}$ where $u_{a}$ and $u_{w}$ refer to pore air and pore water pressure respectively. To achieve mechanical equilibrium, surface tension is mobilized at the air-water boundary forcing the contractile skin to behave as an elastic sheet or membrane in forming a meniscus with radius of curvature, $R_{s}$ (Taylor, 1948).

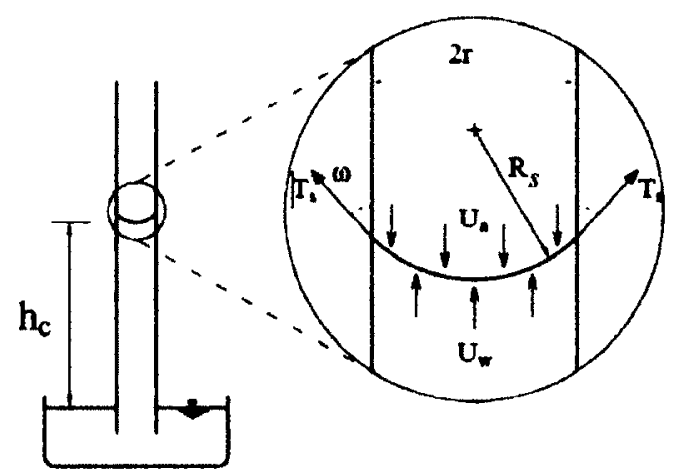

Figure 2-3: Capillary rise in a narrow tube and equilibrium at the meniscus (Aghajani, et al., 2011)

The surface tension gives rise to large negative pore water pressures in the liquid and the Young- Laplace equation provides the following condition for the pressure difference at the interface:

$$
\left(u_{a}-u_{w}\right)=\frac{2 T_{s} \cos \alpha}{r}=\frac{2 T_{s}}{R_{s}}
$$

And accordingly water is driven up the pores via the pressure difference at the meniscus to a height, $h_{c}$.

$$
h_{c}=\frac{2 T_{s} \cos \alpha}{r \rho_{w} g}=\frac{2 T_{s}}{R_{s} \rho_{w} g}
$$

Where:

$T_{\mathrm{s}}$ - Surface tension of water 
$\cos \alpha-$ the contact angle of water and capillary wall (soil particle), assumed to be 1 for water

$r$-Radius of the capillary

$R_{s}=\cos \alpha / r-$ radius of curvature of the capillary

$h_{c}$ - the height of rise $(\mathrm{cm})$

$\rho_{w}$ - Density of liquid, assumed to be water at $1 \mathrm{~g} \mathrm{~cm}^{-3}$

$\mathrm{g}$ - Force of gravity, a constant of $981 \mathrm{~cm} \mathrm{sec}^{-2}$

The pressure difference at a point in the contractile skin is $\left(\mathrm{u}_{\mathrm{a}}-\mathrm{u}_{\mathrm{w}}\right)$ and is known as matric suction. The matric suction associated with the desaturation of a given pore depends on the radius of the soil pore. The smaller the pores, the higher water rises in the soil and the greater the matric suction. Since the pore air pressure is considered to be atmospheric, and takes a value of 0 , the matric suction is a negative pressure.

As a result, when a soil begins to desaturate, the larger pores are the first to empty as they are not held under as high tensile forces as the water held in smaller pores. This means that at lower suction values, large pores are emptied and at higher matric suctions, smaller pores are emptied.

This decrease in the radius of curvature is what causes a decrease in the vapour pressure when compared to a flat water surface and this is called the matric suction.

\subsubsection{Osmotic Suction}

The further decrease in $\mathrm{RH}$ is due to the presence of impurities as water content decreases. This is referred to as the osmotic suction $(\pi)$ component of the total suction in 
soils. The pore water normally contains dissolved salts and as a result these lower the vapour pressure when compared to pure water (Fredlund \& Rahardjo, 1993). Impure water in a capillary when compared to pure water in a similar capillary has a lower vapour pressure due to the presence of the impurity. Kevin's equation for vapour pressures reveals that a further reduction in the vapour pressure is due to introduction of a partial pressure for water as a result of the solutes present in the soil.

This decrease in vapour pressure due to presence of salts results in the further decrease in the relative humidity and is termed osmotic suction. It increases the total suction of the soil.

\subsubsection{Measurement of Soil Suction}

Total Suction in a soil can be measured directly or indirectly. The direct method measures the relative humidity of the air phase in the soil or in the region near the soil (Fredlund \& Rahardjo, 1993) and total suction is computed via equation 2.02.

Two devices which measure total suction directly are psychrometers and potentiometers. The pyschrometer measures the temperature difference between the evaporating (wet bulb) and non-evaporating (dry bulb) surfaces through thermocouples and relates it to the relative humidity (Vanapalli et al., 2004). They measure high suctions of 100 to $8000 \mathrm{kPa}$ but are very sensitive at fluctuating temperatures and so are not generally recommended for in situ measurements. They are calibrated though the determination of a relationship between microvolts output from the thermocouples and known total suctions. 
Another direct method of measuring total suction, which was employed in this present research, is the use of the water potentiameter, WP4- T. This equipment employs the chilled mirror dewpoint technique and has a wide range of suction from 0 to 300 MPa. In this method, a soil sample is equilibrated in a sealed chamber which contains a tiny mirror on which condensation is detected. At equilibrium, the relative humidity of the air in the chamber is the same as that in the soil sample (Degacon, 2007). The temperature on the mirror is controlled by a thermoelectric cooler and the detection of condensation is observed by a photoelectric cell which senses the change in reflectance of a beam of light directed at the mirror (Figure 2-4). The temperature at which condensation occurs is recorded by a thermocouple and the potentiometer signals the end of the test, displaying water potential results in $\mathrm{pF}$ and $\mathrm{MPa}$ with sample temperature (Degacon, 2007).

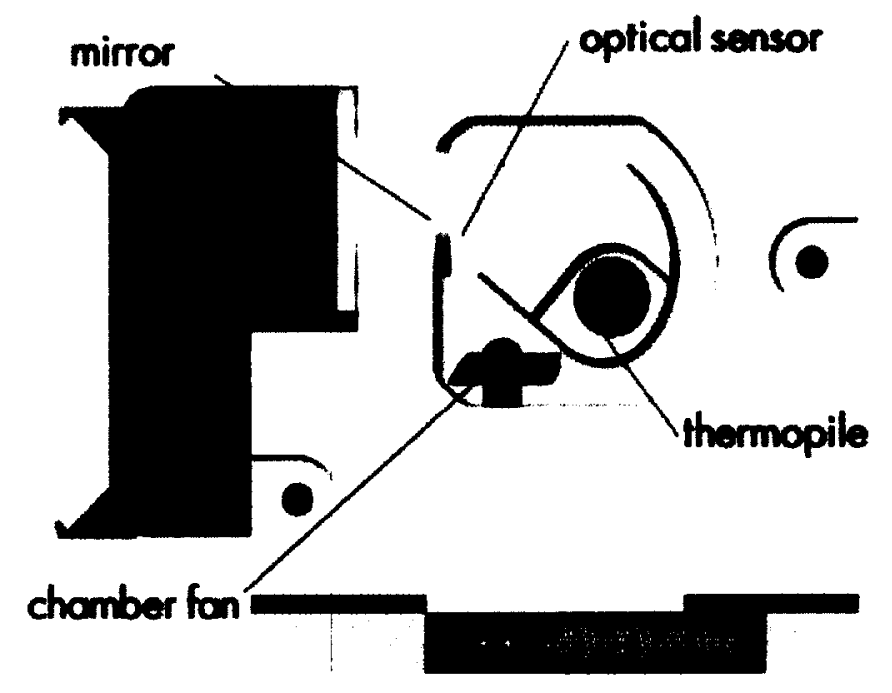

Figure 2-4: View inside chamber of WP4-T Potentiameter (Degacon, 2007) 
An indirect method of total suction measurement is the filter paper method in which a filter paper is set to equilibrium with respect to moisture flow (vapour or liquid) with a soil having a specific suction. Direct and non-contact procedures measure the matric and osmotic suction components of total suction respectively. Calibrated curves are used to estimate total suction. The method was not applied in this research.

\section{Matric Suction}

Matric Suction is also measured using direct and indirect methods. Direct methods applied in this research include the axis translation technique and tensiometers.

\section{The axis translation technique}

When attempting to measure the negative pore-water pressure, $u_{w}$, of an unsaturated soil directly, a normal measuring system will face difficulty in that the water in the system may start to cavitate as zero absolute pressure is approached. Air enters the solution and water from the measuring system is forced into the soil. In order to avoid this, the axis translation technique is used. It involves a translation of the reference pressure (pore air pressure).

In a normal system the pore-water pressure is referenced to the pore-air pressure, $u_{a}$, at atmospheric conditions but with the translation, the pressure in the chamber is increased and used as the reference pressure. Therefore the pore-water pressure, being negative can be measured without cavitation problems.

This method is made practical by the use of a pressure plate apparatus which has its main component a high air-entry disk which allows the pore-water pressure of the soil 
to be measured as equilibrium is reached. The high air-entry disk acts as a semipermeable membrane that separates the air and water phases (Vanapalli et al., 2004). The air-entry value refers to the maximum matric suction to which the high air-entry disk can be subjected before free air passes through the disk and so matric suction can be measured up to the air-entry value. Suction of up to $1500 \mathrm{kPa}$ can be measured.

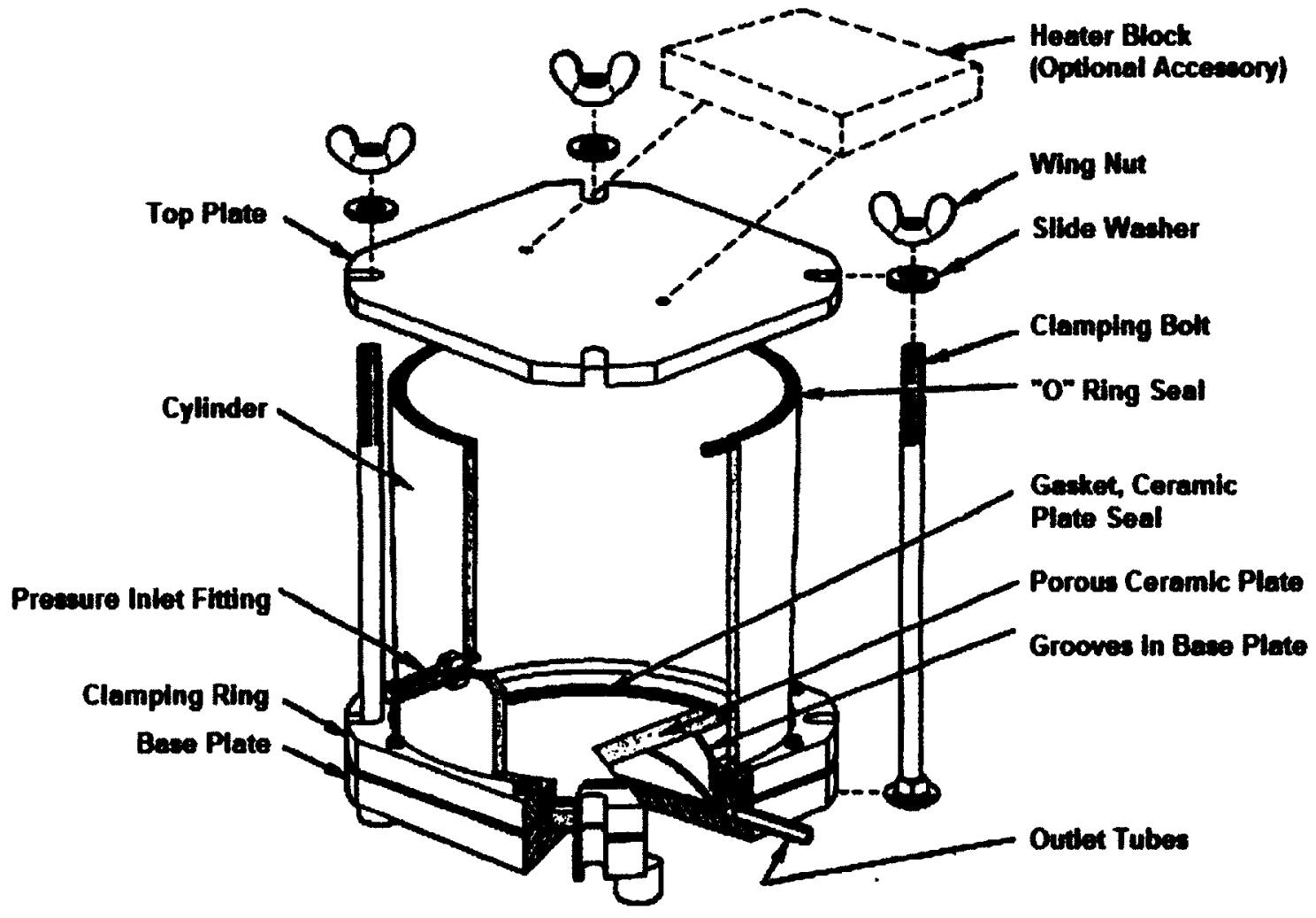

Figure 2-5: Pressure Plate (Soilmoisture, 2005)

The soil specimen is placed in the stainless steel pressure chamber on top of the previously saturated high air entry disk (Figure 2-5). An air pressure is applied by manipulating the pressure gauge. The high pore air pressure forces the water to flow out of the soil through the ceramic disk until the soil pore water pressure attains equilibrium with the soil air pressure, at which point no more water flows out of the soil. The soil 
matric suction is the applied pressure since the pore water pressure is zero because it is open to atmospheric conditions (Vanapalli, 2004). The process is repeated at varied pressures. The soil moisture is determined by measuring the volume of water flowing out of the volumetric plate or by measuring the difference in weight at each equilibrium point.

\section{Tensiometers}

The tensiometer is commonly used to measure the in situ matric suction of an unsaturated soil. The standard tensiometer is able to measure negative pore water pressure in the range of 0 to $101.3 \mathrm{kPa}$. However, some tensiometers like the T5x measure up to 250 $\mathrm{kPa}$. The tensiometer consists of a porous ceramic cup of high air-entry value of 200 (standard) or $500 \mathrm{kPa}$ (T5x) connected to a vacuum gauge through a small plastic bore tube (Vanapalli et al., 2004) depicted in Figure 2.6. The ceramic cup and the tube are filled with deaired water through vacuum before they are placed in the soil. Once in the soil, the soil, based on its water content, exerts a suction or causes tension in the tensiometer which is in turn measured by the gauge once equilibrium is attained between the soil and the measuring system as a negative pressure. This negative pressure is the matric suction as the pore air pressure is atmospheric. 


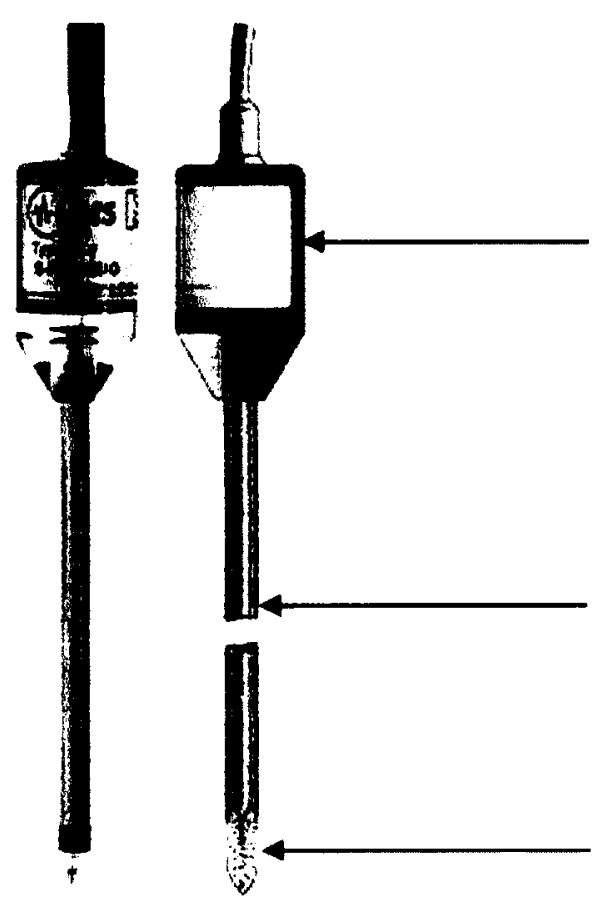

Sensor body: contains piezoelectric pressure sensor which measures soil water tension against atmospheric pressure.

Acrylic, non-corrosive glass shaft with varied lengths of 2 to $20 \mathrm{~cm}$.

Figure 2-6: Tensiometer (UMS, 2009)

High grade porous ceramic tip of 200 or $500 \mathrm{kPa}$ air-entry value

Cavitation will occur at the saturated vapour pressure but this is temporarily avoided in the tensiometer by removing cavitation nuclei from the water in the reservoir. The air entry value (AEV) of the ceramic tip is an upper limit to measurable suction, but it is a matter of time until sufficient air diffuses into the reservoir to nucleate cavitation.

\section{Osmotic suction}

Since osmotic suction is induced by the presence of salts in the pore water, the measurement of concentrations of these salts can be utilized to estimate indirectly the osmotic suction. A property of the soil pore water which gives us an idea of the amount of solutes present is its conductance capacity commonly referred to as the Electrical Conductivity. By attaining this value, the USDA (1954), derived an equation to calculate the Osmotic suction. 
Osmotic Suction, $\pi=0.36 \times E C \times 101.35$

Where EC is the Electrical Conductivity in $\mathrm{mS} / \mathrm{cm}$ and Osmotic Suction is given in $\mathrm{kPa}$.

To measure the EC, two methods are employed. The first, called the saturation technique, involves the addition of deionized or distilled water to the soil, mixing and then draining or centrifuging to attain the pore water. The conductivity of the effluent or supernatant is measured and extrapolated to the osmotic suction corresponding to that of the natural water content (USDA, 1954; Krahn \& Fredlund, 1973; Fredlund \& Rahardjo, 1993). Although the method is simple, there is a small degree of uncertainty in the resulting osmotic suction as it is assumed that there is a linear relationship between dilution and EC (Krahn \& Fredlund, 1973).

The second method, the squeezing technique, sees the use of a device called the pore squeezer which allows the removal of the pore water from wetter samples. The pore fluid squeezed out is then measured for EC and then osmotic suction is determined using calibrated curves of osmotic suction versus concentration or through the application of equation 2.05. One limitation of this method is the application for drier soils.

\subsubsection{Soil Water Characteristic Curve or Water Retention Curve}

The variation in water content of a soil from fully saturated to dry conditions and the development of suction as this occurs is defined by the water retention curve (WRC) or the Soil water characteristic curve (SWCC). It gives an idea of the storage capacity of the soil in that it describes how water content changes when the soil is subjected to 
various suction values. The water content can be expressed as gravimetric water content, $w$, volumetric water content, $\theta_{w}$, or degree of saturation, $S$.

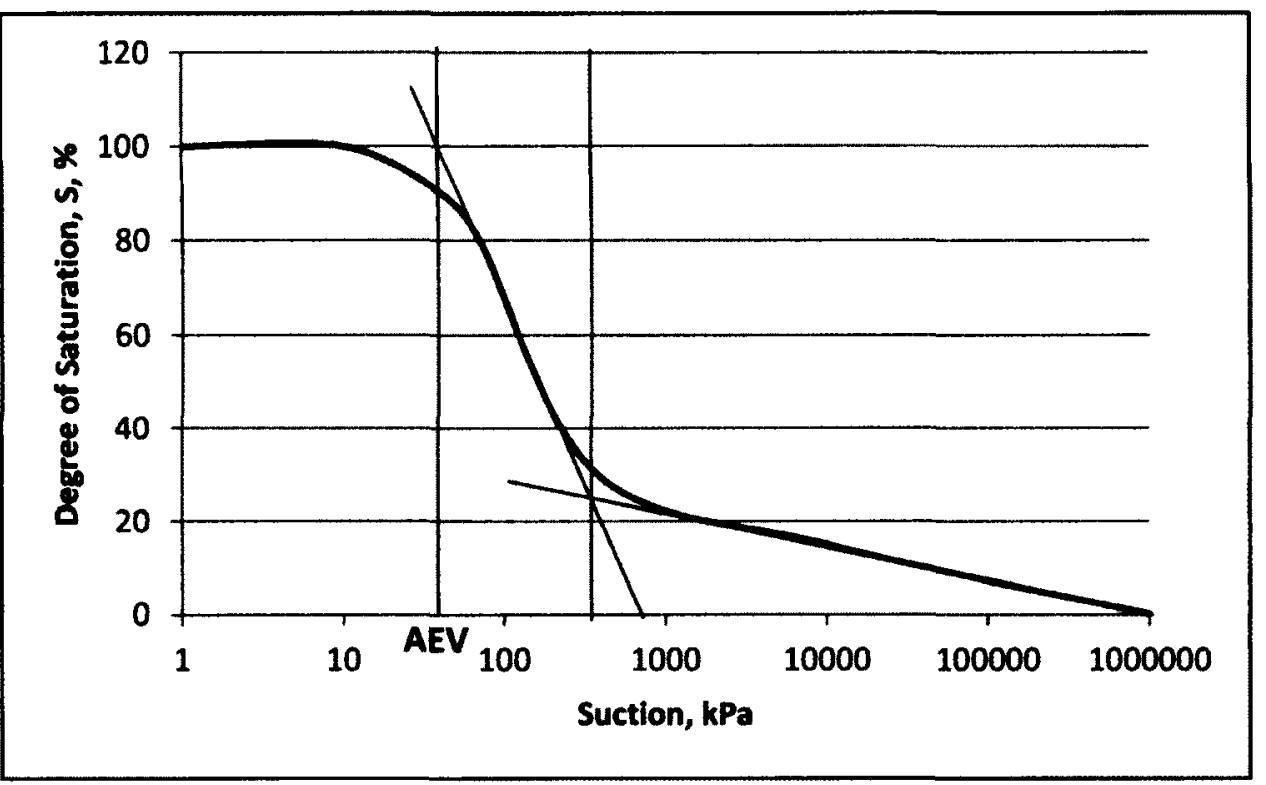

Figure 2-7: Soil Water Characteristic curve

The SWCC plotted above can be divided into three stages: the boundary effect stage (stage 1), the transition stage (stage 2) and the residual zone of desaturation (stage $3)$.

\section{Boundary effect stage:}

At degree of saturation, $\mathrm{S}$, equal to $100 \%$ and suction equal to $0 \mathrm{kPa}$, the soil is in state of saturation. All of the pores are filled with water. The two phases present are soil particles and water. The contact between water menisci and soil particles is continuous. However, due to the action of capillary forces, the pore water is in tension and suction is present (Vanapalli, et al., 2004).

\section{Transition Stage}


As suction increases, the resistance offered by the capillary tension prevents the flow of water out of the soil up to a point where it is big enough to overcome the capillary forces, the air entry value, where air enters the largest pores in the soil and the soils begins to desaturate. Water content decreases with increasing suction as water leaves the soil in liquid state and soil particle -water contact reduces. Therefore, water menisci area in contact with soil particles is not continuous and reduces as air phase becomes more continuous.

\section{Residual zone of desaturation}

The stage at which large changes in the suction leads to very small changes in the water content is the residual zone of desaturation. The water phase is discontinuous and the air phase is very continuous. There is very little water-soil particle contact and water leaving the soil occurs in vapour phase (Fredlund \& Rahardjo, 1993). A completely dry soil attains a suction of $10^{6} \mathrm{kPa}$.

\section{Determination of SWCC}

The SWCC can be measured using the axis translation technique up to $1500 \mathrm{kPa}$ after which alternative methods can be used to complete the rest of the curve. These include but are not limited to: osmotic desiccators (Vanapalli et al., 1999) or the filter paper methods as was applied by (Melgarejo et al., 2002).

In addition, several models have been developed that allow the user to fit the SWCC. Two very commonly used ones are the van Ganutchen (1980) and the Fredlund and Xing (1994) models given by Equations 2.06 and 2.08 respectively. 
$\Theta=\left[\frac{1}{1+(a \psi)^{n}}\right]^{m}$

Where, $\Theta$ is the normalized water content, $\psi$ is the soil suction and $a, m$ and $n$ are fitting parameters.

$\theta=\frac{\theta-\theta_{r}}{\theta_{r}-\theta_{s}}$

Where $\theta$ is the volumetric water content and sub-indices $r$ and $s$ refer to residual and saturated volumetric water contents respectively.

Parameter " $a$ " is related inversely to the air entry value, while " $n$ " is related with the pore size distribution and " $m$ " is related with the asymmetry of the model.

Fredlund and Xing (1994) proposed equation 2.08 that can be used to fit the entire SWCC, from 0 to $10^{6} \mathrm{kPa}$.

$$
\theta=C(\psi) \frac{\theta_{s}}{\left\{\ln \left[e+\left(\frac{\psi}{a}\right)^{n}\right]\right\}^{m}}
$$

Where $\mathrm{a}, \mathrm{m}$ and $\mathrm{n}$ are three different fitting parameters and $C(\psi)$ is a correction factor determined through the following equation:

$C(\psi)=1-\frac{\ln \left(1+\frac{\psi}{\psi_{r}}\right)}{\ln \left(1+\frac{100000}{\psi_{r}}\right)}$

Where $\psi_{r}$ is the residual suction. 


\subsubsection{Unsaturated Hydraulic Conductivity}

Water flow in saturated soils and unsaturated soils can be characterized by Darcy's law (Darcy, 1856). However, unlike the case of the saturated soil, the unsaturated permeability function is not considered constant (Figure 2-8) and depends on both the

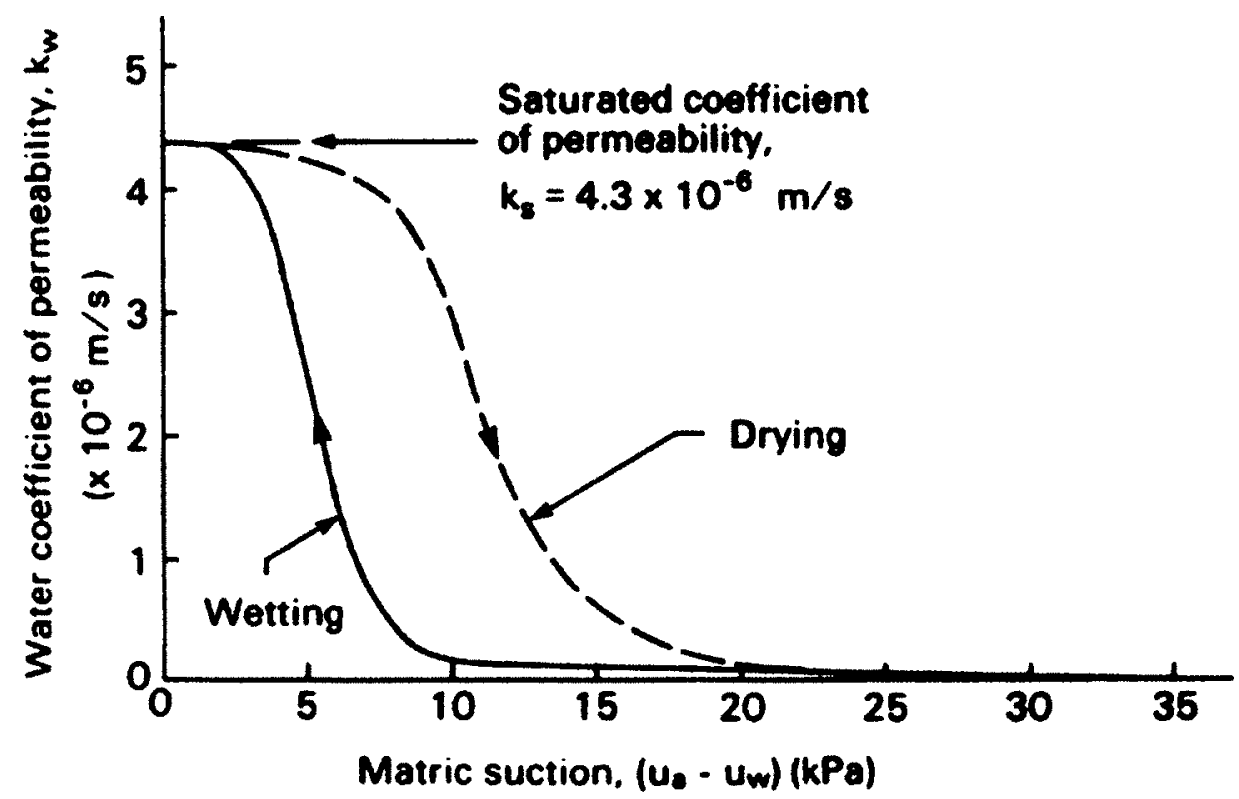

Figure 2-8: Variation of the coefficient of permeability with matric suction (Vanapalli et al., 1999)

water content and the void ratio of the soil, and consequently the suction of the soil (Fredlund, et al., 1994). The soil suction referred to above is either the matric or total suction. Therefore, the coefficient of permeability of an unsaturated soil is represented as: $k(\psi)$ and when referenced to the saturated coefficient of permeability, $k_{s}$, produces the relative coefficient of permeability $k_{r}(\psi)$ or $k(\theta)$, given by equation 2.10 (Fredlund, et al., 1994).

$k_{r}(\psi)=\frac{k(\psi)}{k_{s}}$ 


\subsubsection{Methods for determination of relative hydraulic conductivity function from SWCC}

$k(\psi)$, referred to as the permeability function for unsaturated soils (Xing et al., 1994), can be determined through empirical equations, macroscopic or statistical models.

Empirical equations include Richards (1931), Gardner (1958) and Brooks \& Corey (1964) among others and are presented in Table 2-. They combine the saturated hydraulic conductivity and a sufficient set of experimental data of unsaturated hydraulic conductivity measurements that are best fitted. The equations are either related to the suction or to the volumetric water content. Therefore, well-established soil-water characteristic curve parameters of a soil can be used to determine unsaturated hydraulic conductivity function (Leong \& Rahardjo, 1997).

Table 2-1: Empirical Equation for the unsaturated coefficient of permeability

\begin{tabular}{|c|c|}
\hline Equation & Reference \\
\hline$k=a \psi+b$ & (Richards, 1931) \\
\hline$k_{r}=\exp (-\alpha \psi)$ & (Gardner, 1958) \\
$k=k_{s} / a \psi^{n}+1$ & \\
\hline$k=k_{s}$ for $\psi \leq \psi_{A E V}$ & (Brooks \& Corey, 1964) \\
$k_{r}=\left(\psi / \psi_{A E V}\right)^{-n}$ for $\psi>\psi_{A E V}$ & \\
\hline
\end{tabular}


Macroscopic models were developed on the assumption that laminar flow occurs on a microscopic scale that obeys Darcy's law at the macroscopic level. Generally macroscopic models are based on the following general form:

$k_{r}=\left(S_{e}{ }^{\delta}\right)$

Where Se, the effective degree of saturation is given by, $S_{e}=\frac{S-S_{r}}{1-S_{r}}$ where $S_{r}$ is the residual degree of saturation and $\delta=\frac{2+3 \lambda}{\lambda}$, is a fitting parameter with $\lambda$ being the pore size distribution index . Mualem (1976) based on data from 50 soil types suggested that $\delta$ be equal to $3-2 m$ where $m$ is a soil parameter and that $\delta$ varies from 2.5 to 24.5 .

\section{Statistical Models}

Statistical models use the best fitted suction-water content relation in connection with the saturated hydraulic conductivity to derive the relative hydraulic conductivity function as they embrace the dependence of both the SWCC and the permeability on the pore size distribution of the soil. The unsaturated hydraulic conductivity function $\mathrm{k}(\psi)$ can be calculated from the following relationship:

$k_{r}(\psi)=k(\psi) / k_{s} ;$ with $k_{r}(\psi)=1$ for $\psi<\psi_{\mathrm{AEV}}$

Using the Hagen-Poiseuille equation, several models have been developed but the one focused on in this research is that of Fredlund et al. (1994). Their method employs the substitution of equation 2.06 into the integral form of the Childs and Collis-George (1950) model to predict the relative permeability function using the water retention curve. The model divides the SWCC into equal intervals along volumetric water content and integrates over the suction range to attain the permeability. The resulting equation is: 
$k_{r}(\psi)=\frac{\int_{\ln (\psi)}^{b} \frac{\theta\left(e^{y}\right)-\theta(\psi)}{e^{y}} \theta^{\prime}\left(e^{y}\right) d y}{\int_{\ln \left(\psi_{A E V}\right) \frac{\left(e^{y}\right)-\theta_{S}}{e^{y}} \theta^{\prime}\left(e^{y}\right) d y}^{b}}$

Where:

$b-\ln (1000000)$

$y$ - dummy variable of integration representing suction

$\theta^{\prime}$ - derivative of equation 2.06

\subsubsection{Richards' Equation and Liquid water flow}

Water flow to the ground surface in an unsaturated soil may occur in liquid form or in the form of water vapour. Therefore liquid water, vapour and heat flow must be coupled and investigated to acquire a system of equations which represents the system.

Liquid water flow may be described by the Richard's equation, a generalized form of Darcy's law to unsaturated flow:

$S(\psi) \frac{\partial h}{\partial t}=k_{r x} \frac{\partial^{2} h}{\partial x^{2}}+k_{r y} \frac{\partial^{2} h}{\partial y^{2}}$

Where $S$ is the storage term, at suction $\psi, x$ and $y$ are directions; $\mathrm{h}$ is total hydraulic head, and $k_{r x}$ and $k_{r y}$ are the hydraulic conductivities $(\mathrm{m} / \mathrm{s})$ in the $x$ and $y$ directions. Both the storage parameter (the slope of the SWCC or the stiffness coefficient in saturated conditions) and the hydraulic conductivity vary with degree of saturation or matric suction. Coded solutions to Richards' equation use measured SWCC data to solve for the relative conductivity as described previously. 


\subsubsection{Heat and Water vapour flow}

The flow of water vapour during evaporation occurs due to a vapour pressure gradient and follows Fick's law. Through a modified version of Fick's law which couples mass flux and advection (Philip \& de Vries, 1957), vapour flow is represented by:

$q_{v}=-D_{z} \frac{\partial P_{v}}{\partial z}$

Where:

$q_{v}$ - water vapour flux $\left[\mathrm{kg} / \mathrm{m}^{2} \cdot \mathrm{s}\right]$

$P_{v}$ - Partial pressure due to water vapour, $[\mathrm{kPa}]$

$D_{v}$ - Diffusion coefficient of the water vapour through the soil, $[\mathrm{kg} \cdot \mathrm{m} / \mathrm{kN} \cdot \mathrm{s}]$

The calculation of the vapour pressure requires the temperature of the soil. Therefore a soil temperature profile must be determined (Wilson et al., 1994). Heat flow due to convective and latent heat transfer is expressed by an extended equation of Fourier's Law and is given by the expression:

$C_{h} \frac{\partial T}{\partial t}=\frac{\partial}{\partial z}\left(\lambda \frac{\partial T}{\partial t}\right)-L_{v}\left(\frac{P+P_{v}}{P}\right) \frac{\partial}{\partial z}\left(D_{v} \frac{\partial P_{v}}{\partial z}\right)$

Where:

$C_{h}$-volumetric specific heat, $\left[\mathrm{J} / \mathrm{m}^{3}{ }^{\circ} \mathrm{C}\right]$

$\lambda$ - Thermal conductivity, $\left[\mathrm{W} / \mathrm{m}{ }^{\circ} \mathrm{C}\right]$

$L_{v}$ - Latent heat of vaporization for water, [J/kg]

The partial pressure of water vapour, $p_{v}$, is related to the soil water potential through the fractional relative humidity (Edlefsen \& Anderson, 1943). As a result, liquid and vapour 
flow are coupled using the equation for relative humidity in terms of suction and temperature, both responsible for the change in vapour pressure.as will be described below.

\subsection{Evaporation}

The exfiltration of water from a soil surface in the form of vapour is called evaporation. According to Lal and Shukha (2004), evaporation of water from bare soil (i.e., in the absence of vegetation) is the process by which water is lost from the soil to the atmosphere through a change of the state of water from a liquid to gaseous phase.

The evaporation process can be summarized through the following processes in three stages in which water is transported to the soil surface and through an uninterrupted supply of heat (solar energy, exothermic reactions, microbial activity, etc.), the water is changed from a liquid to vapour state. Due the difference in vapour pressure between the air above the surface and within the soil, water vapour escapes from the soil to the atmosphere through the process of convection and diffusion.

\subsubsection{Actual Evaporation}

In soil, the actual evaporation (AE) rate at which the soil loses water is a fraction of the potential evaporation (PE), the maximum rate of evaporation from a pure water surface under the given climatic conditions (Wilson et al., 1994). A saturated soil has much available water and thus when evaporation begins; it is almost equivalent to the PE rate 
provided that the relative humidity of the air above the soil surface remains at $100 \%$ (Monteith, 1981). This is referred to as Stage 1 evaporation.

As evaporation proceeds at the soil surface, a suction gradient is established between the soil surface and the layer beneath. Lal and Shukla (2004) and Smits et al. (2012) comment that this gradient forces liquid water to be supplied from underlying soil layers to the surface by capillary action (capillary rise) and this is characterized by high and constant evaporation rates and the formation of a drying front that recedes vertically into the soil profile. As the soil desaturates, the larger pores are emptied out and then the smaller ones which are held under high suctions. Due to the decrease in the radius of the pore and the high suctions present, the relative humidity of the soil decreases and this translates into a decline of the vapour pressure gradient, the driving force for evaporation. As a result, the evaporation rate decreases substantially characteristic of Stage 2 evaporation.

It is not clear as to when Stage 3 evaporation begins but it is noted by the very gradual decrease in the evaporation rate shown in Figure 2-9. It is described by Hillel (1980) as the stage of evaporation in which the soil surface is significantly desiccated and there is no longer any flow of water to the surface in the form of liquid but vapour which migrates through vapour diffusion to the surface. Water is discontinuous and water left in the soil is held under very high suctions, decreasing the $\mathrm{RH}$ of the soil and the evaporation rate. Wilson et al. (1994) describe the development of a drying front which in Stage 3 evaporation is the zone of vapour diffusion. Results from their evaporation study revealed that a $1 \mathrm{~cm}$ thick drying front which developed after 21 days of drying had 
increased in thickness to $6-8 \mathrm{~cm}$ decreasing significantly the evaporation rate from 2 $\mathrm{mm} / \mathrm{d}$ to $0.4 \mathrm{~mm} / \mathrm{d}$.

Due to the effects of the change in suction in the soil on the evaporation rate, if plotted, the curve would take similar shape as that of the SWCC and also shows the dependence of the soil water content on soil suction (Figure 2-9).

Allen, et al. (2005) introduced a third stage to evaporation in their models (an addition to the previously existing model for FAO in 1995) based on cracking soils. The authors concluded that for soils which show substantial cracking upon drying, a third stage of evaporation represented the progressive drying by evaporation of the newly exposed depths of the soil. At this stage evaporation continues at a very low rate for an extended period of time (Allen, et al., 2005).

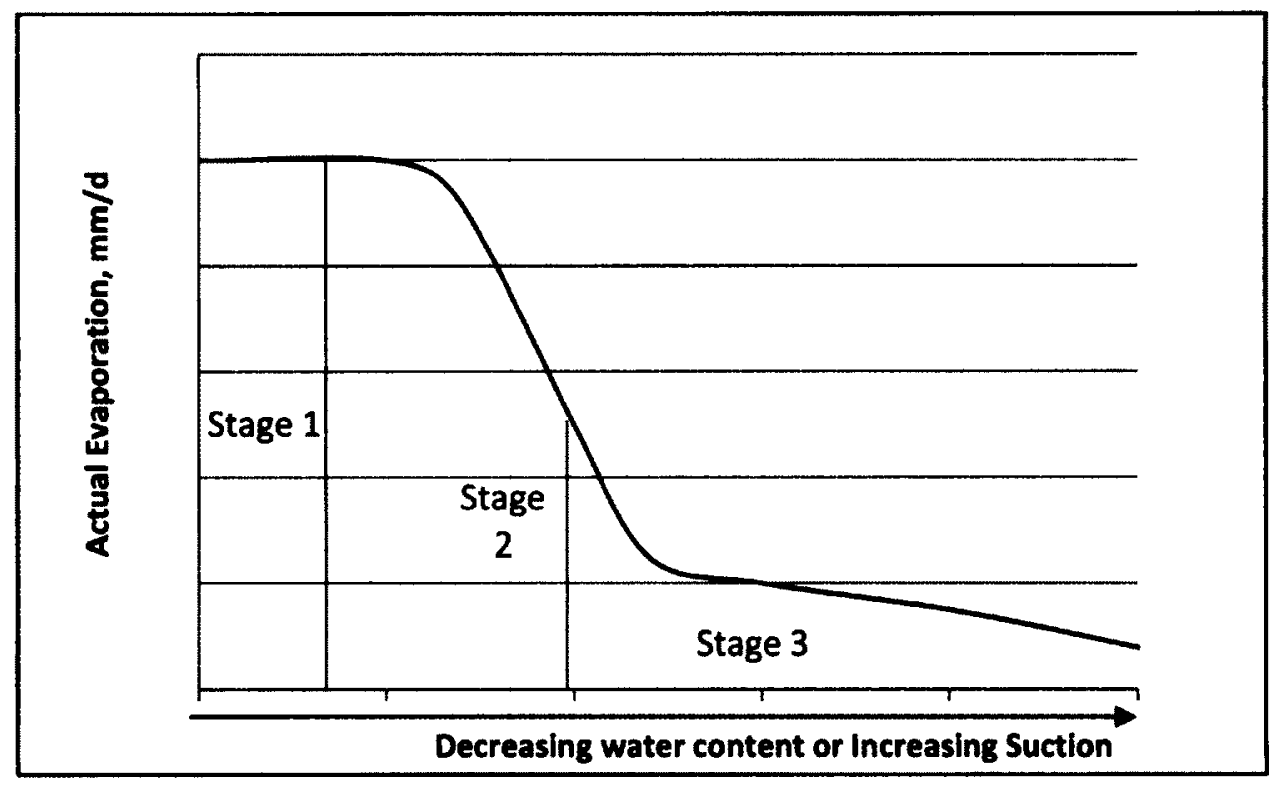

Figure 2-9: Stages of evaporation - AE or RE vs time (After Wilson et al, 1994)

Actual evaporation is measured in a laboratory setting or pilot scale setup from weight measurements in time intervals in the absence of drainage or accounting for the 
moisture loss due to drainage. Lysimeters can also be used at a lab scale and small field scale. The Penman-Monteith equation can be used to predict AE:

$A E=\frac{\Delta\left(R_{n}-G\right)+\rho_{a} C_{p}\left(e_{s}^{o}-e_{a}\right) / r_{a}}{\lambda\left[\Delta+\gamma\left(1+r_{s} / r_{a}\right)\right]}$

Where $\lambda$ - latent heat of vaporization, [2.45 MJ/kg at a temperature of $20^{\circ} \mathrm{C}$ ]

$\mathrm{AE}$ is usually reported as relative evaporation (RE), a ratio between the $\mathrm{AE}$ and PE. The derivations of the expressions for RE are presented in Section 2.6.3.

\subsubsection{Determination of Potential Evaporation}

As mentioned before, PE is the maximum evaporation rate that can be achieved based on climatic conditions and can be quantified in the laboratory or in the field through the use of the pan evaporation method. In the laboratory, a container of similar dimensions is installed in the same conditions as the material under study where weight is monitored in a specific time interval. This method was employed by Wilson et al. (1991) in their column study of evaporation in sands.

In the field, one very common method employed by agricultural scientists, is the use of the irrigated lysimeter. This apparatus measures the evaporation from an installed tank of soil which is maintained with unlimited supply of water through irrigation during dry spells (Brouwer \& Heibloem, 1986). A micro-lysimeter was employed by Newson and Fahey (2003) where a body of soil was hydrologically isolated from the soil surrounding the facility and samples were removed and weighed on a daily basis to determine the water loss due to evaporation. 
Other methods used involve the application of an atmometer or the standardized US Class A pan. Newson and Fahey (2003) used a Class A pan located next to a tailings storage facility to estimate potential evaporation. Many standardized pans exist but the US Class A pan is the most used. It is circular with a diameter of $1.21 \mathrm{~m}$ and a depth of $0.255 \mathrm{~m}$. The pan is placed on a $1.5 \mathrm{~m}$ high wooden frame and surrounded by a bird cage. The water level is kept at $50 \mathrm{~mm}$ below the rim. The loss of water is measured from the difference in water levels measured every day or from the amount of water introduced to re-establish the initial water level.

Potential evaporation can be calculated through the Penman-Monteith equation (Equation 2.15) with the use of meteorological data such as temperature, relative humidity, wind speed and radiation and considering that there is a constant supply of water to the soil (Howell \& Evett, 2013). The equation is based on the simple mass transfer equation which describes vapour flow from the soil surface as a function of the gradient in vapour pressure between the soil surface and the overlying air (Wilson et al., 1991).

$E=f(u)\left(p_{s v}-p_{a}\right)$

Where:

E - Vertical evaporative flux, $[\mathrm{mm} / \mathrm{d}]$

f (u) - Function dependent on wind speed, surface roughness and eddy diffusion

$p_{s v}-$ Vapour pressure of saturated evaporating surface

$\mathrm{p}_{\mathrm{a}}$ - Vapour pressure in the air above the evaporating surface 
From this simple mass transfer equation and Penman's (1948) coupling with the heat budget at the surface, a series of expressions emerged to quantify potential evaporation needing only weather measurements like $\mathrm{RH}$, wind speed and Temperature and information on solar radiation, one being the Penman- Monteith equation (1981):

$P E=\frac{\Delta\left(R_{n}-G\right)+\rho_{a} C_{p}\left(e_{s}^{o}-e_{a}\right) / r_{a}}{\Delta+\gamma\left(1+r_{s} / r_{a}\right)}$

Where:

PE - Potential evaporation, [mm/day]

$\mathrm{Rn}$ - Net radiation, [MJ $\mathrm{m}^{2} /$ day]

$\mathrm{G}$ - Soil heat flux, [MJ $\mathrm{m}^{2} /$ day]

$y$ - Psychometric constant, $\left[\mathrm{kPa} /{ }^{\circ} \mathrm{C}\right]$

$\Delta$ - Slope of saturation vapour curve, $\left[\mathrm{kPa} /{ }^{\circ} \mathrm{C}\right]$

$u$ - Wind speed, $\mathrm{m} / \mathrm{s}$

$e_{s}$ - Mean saturation pressure, $[\mathrm{kPa}]$

$e_{a}-$ Actual vapour pressure derived from Relative humidity $(\mathrm{RH}),[\mathrm{kPa}]$

$e_{s}-e_{a}-$ saturation vapour pressure deficit $[\mathrm{kPa}]$

$\mathrm{T}$ - Temperature $\left[{ }^{\circ} \mathrm{C}\right]$

$r_{s}-$ Soil surface resistance, $[\mathrm{s} / \mathrm{m}]$

$r_{a}$ - Bulk surface aerodynamic resistance do water vapour $[\mathrm{s} / \mathrm{m}]$

$\rho_{a}$ - Density of air, $\left[\mathrm{kg} / \mathrm{m}^{3}\right]$

$C_{p}$ - Specific heat of air, $\left[1.013 \times 10^{-3} \mathrm{MJ} / \mathrm{kg}^{0} \mathrm{C}\right]$

Equation 2.18 includes the resistance to diffusion presented by the air and also soil surfaces in the case of evaporation from a bare surface and/or stomatal resistance in 
the case of evapotranspiration. In this study the Radiation component was omitted as the experimental work was carried out indoors, away from sources of radiation.

Equation 2.19, used for short crop calculations can be used to estimate PE also on bare soil with very good accuracy.

$P E=\frac{0.408 \Delta\left(R_{n}-G\right)+\gamma \frac{900}{T+273} u_{2}\left(e_{s}-e_{a}\right)}{\Delta+\gamma\left(1+0.34 u_{2}\right)}$

From the above equations $\Delta, \gamma$ and $G$ are calculated through the following equations:

$\Delta=\frac{4098\left[0.6108 e^{\left(\frac{17.27 T}{T+273.3}\right)}\right]}{(T+273.3)^{2}}$

Where: $\mathrm{T}$ - Mean air temperature in ${ }^{\circ} \mathrm{C}$

$\gamma=0.665 \times 10^{-3} P$

Where: $\mathrm{P}$ - Atmospheric pressure in $\mathrm{kPa}$

$e_{s}=\frac{e^{o}\left(T_{\max }\right)+e^{o}\left(T_{\min }\right)}{2}$

Where $e^{o}\left(T_{i}\right)=0.6108 e^{\left(\frac{17.27 T}{T+273.3}\right)}$

$e_{a}=\frac{e^{o}\left(T_{\max }\right) R H_{\max } / 100+e^{o}\left(T_{\min }\right) R H_{\min } / 100}{2}$

$G=c_{s} \frac{T_{l}-T_{l-1}}{\Delta t} \Delta z$

Where:

$\mathrm{c}_{\mathrm{s}}-$ Soil heat capacity, $\left[\mathrm{MJ} / \mathrm{m}^{3} \mathrm{~d}\right]$

$\mathrm{T}_{\mathrm{i}}$ - Mean air temperature at time $\mathrm{i},\left[{ }^{\circ} \mathrm{C}\right]$ 
$\mathrm{T}_{\mathrm{i}-1}$ - Mean air temperature at time $\mathrm{i}-1,\left[{ }^{\circ} \mathrm{C}\right]$

$\Delta t$ - length of time interval, [d]

$\Delta \mathrm{z}-$ effective soil depth, [m]

\subsubsection{Resistances}

Vapour flow from the soil surface and from within the soil faces two types of resistance presented in Figure 2-10. Vapour flow $\left(J_{a}\right)$ from the soil surface into the atmosphere faces the aerodynamic resistance, $r_{a}$.

$J_{a}=\rho_{a}\left(q_{s}-q_{a}\right) / r_{a}$

Where:

$J_{a}-$ Vapour flow

$\rho_{a}$ - Density of air

$q_{a}$ - Specific humidity of the air at the distance $\mathrm{z}$

$q_{s}-$ Specific humidity of the air at the soil surface

$r_{a}$ - Bulk aerodynamic resistance, $[\mathrm{s} / \mathrm{m}]$ 


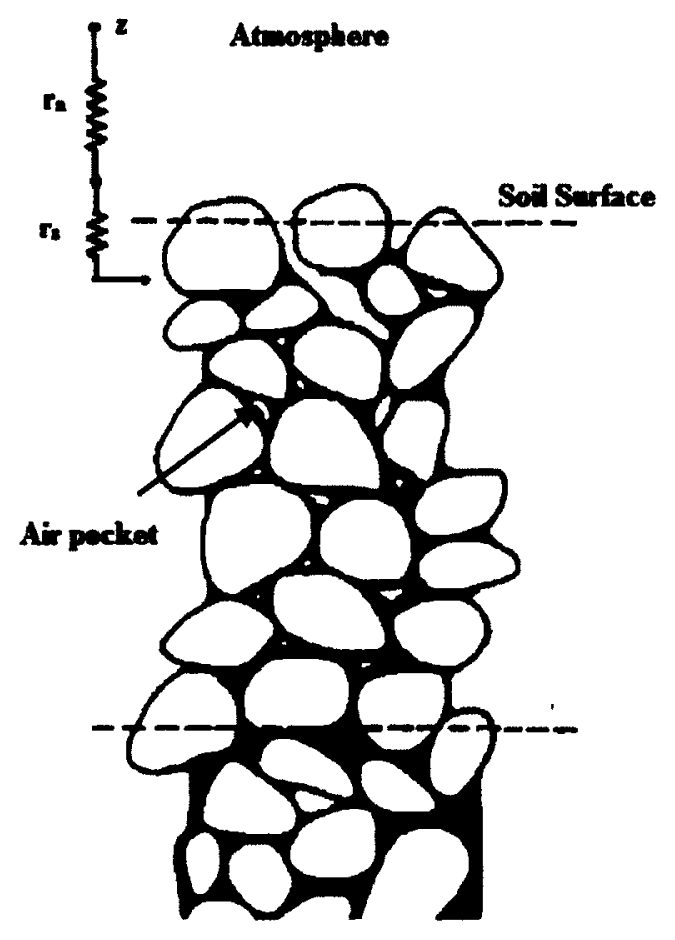

Figure 2-10: Resistance to vapor diffusion from a wet bare soil surface (After van de Griend and Owe (1994))

It is the aerodynamic boundary layer resistance to heat transfer between the soil surface and air at a reference height at which temperature and humidity are assumed to be independent of the state of the soil surface ((van de Griend \& Owe, 1994); (Howell \& Evett, 2013))

The resistance is a function of wind speed and surface roughness properties (Bitelli, et al., 2008) and is given by the following expression:

$r_{a}=\frac{\left[\ln \left(\frac{z-d}{z_{0}}\right)\right]^{2}}{K^{2} U_{z}}$

Where:

$z$ - Wind speed measurement height above ground, [m] 
$\mathrm{d}$ - Zero-plane displacement height, [m] in $\mathrm{m}(\sim 2 / 3$ of the reference crop height and 0 for bare soils)

$\mathrm{z}_{\mathrm{o}}$ - Reference crop momentum aerodynamic surface roughness length, [m] $(0.01$ according to (Bitelli, et al., 2008))

As evaporation continues, the top surface of the soil is no longer fully saturated as explained previously; the development of a drying front, due to the drying of the top layer of soil, introduces a very important component of evaporation in soil. It is the resistance to vapour flow at the interface between the soil and the atmosphere and is represented by $r_{s}$.

$J_{s}=\rho_{a}\left(q_{e}-q_{s}\right) / r_{s}$

Where:

$J_{d}-$ Vapour flow

$\rho_{a}$ - Density of air

$q_{e}-$ Specific humidity of the air at the depth of the evaporating front

$q_{s}$ - Specific humidity of the air at the soil surface

$r_{s}-$ Resistance to vapour flow in the dry layer of soil, $[\mathrm{s} / \mathrm{m}]$

Monteith (1981), through the assumption that Stage 2 evaporation of water takes place from a wet soil below a dry soil layer of increasing thickness, treated as isothermal, expressed the resistance of said layer to the diffusion of water vapour through the term, $r_{s} . \quad r_{s}$ has a value of 0 initially but increases as drying proceeds. It is highly dependent on the depth of the dry layer above the wet soil which in turn depends on the total amount of water lost from the soil. For this reason, a comprehensive understanding of what 
happens at the surface in terms of water content and increase in thickness is of vital importance to properly quantify actual evaporation rates.

Some researchers have expressed $r_{s}$ in terms of the volumetric water content at the surface, measured within the top $1 \mathrm{~cm}$ of soil and are given by the following expressions:
a. $r_{s}=3.5\left(\frac{\theta_{s}}{\theta_{t}}\right)^{2.3}+33.5$
b. $r_{s}=-805+4140\left(\theta_{s}-\theta_{\text {top }}\right)$
c. $r_{s}=10 e^{\left(\theta_{\min }-\theta_{\text {top }}\right)}$

(Shu Fen Sun, 1982)

(Camilo and Gurney, 1986)

(van de Griend and Owe, 1994)

$\theta_{s}$ and $\theta_{t}$ or $\theta_{\text {top }}$ are the saturated volumetric water content at the volumetric content of the top layer.

$\theta_{\text {min }}$ - empirical minimum above which the soil is able to deliver vapour at a potential rate; in their case this value was $15 \%$

However problems have arose from the expressions above as assumptions were made that the thickness of the dry layer are only a few centimetres and that the water content measured at the surface is representative for the entire layer. In the case of van de Griend and Owe (1994), it was pointed out that to get a more accurate computation of the soil resistance, the deepening of the evaporative front must be accounted for and can be found by adding additional resistances in series corresponding to the resistances of the drying soil layers.

As a result Yamanaka et al. (1997) conducted a study in which the relationship between the soil surface resistance, $r_{s}$, and the depth of the evaporating front was investigated. The experiment was set up in a wind tunnel in which radiation and wind 
speed was controlled. It was observed that an increase in the depth of the evaporating front resulted in an increase in the soil resistance. However, also observed was that the difference in temperature between the evaporating front and the soil surface was pivotal in not overestimating the value of the soil resistance which in turn could result in underprediction of actual evaporation rates.

Another limitation which the author has identified through the course of literature review is that cracking is not considered. When cracking occurs, what fraction of this resistance can be applied to actual evaporation rates as preferential flow paths are created by the cracks? The new surface area created now presents a new resistance value.

\subsubsection{Determination of Relative Evaporation}

Relative evaporation (RE) is the ratio between potential and actual evaporation. Having stated previously that the actual evaporation rate declines as the evaporation proceeds, a ratio between $\mathrm{AE}$ and $\mathrm{PE}$ should oscillate between 0 and 1. RE can be calculated from measured values of $\mathrm{AE}$ and $\mathrm{PE}$ or predicted. Wilson et al. (1997) predicted RE considering that $f(u)$ from equation 2.17 was the same for both the soil surface and the water surface and came up with the relationship represented in equation 2.28 below.

$R E V=\frac{A E}{P E}=\frac{\left(e_{0}-e_{a}\right)}{\left(e_{s}-e_{a}\right)}$

Where:

$e_{0}-$ Actual vapour pressure of the soil surface $=\mathrm{RH}_{\mathrm{s}} \times \mathrm{e}_{\mathrm{s}},[\mathrm{kPa}]$

$e_{s}-$ Saturation vapour pressure at the $\mathrm{T}$ of the soil, water and air, [kPa]

$e_{a}-$ Vapour pressure of the air $=\mathrm{RH}_{\mathrm{a}} \times \mathrm{e}_{\mathrm{s}}[\mathrm{kPa}]$ 
Assuming that the temperatures are the same for soil, water and air equation 2.28 becomes:

$R E V=\frac{A E}{P E}=\frac{R H_{s}-R H_{a}}{1-R H_{a}}$

Where the subindices $s$ and $a$ refer to the soil and the air respectively. The RH of the air is measured.

Substituting equation 2.01 into equation 2.02 , the $\mathrm{RH}$ in the soil can be expressed in terms of total suction as:

$R H=e^{-\frac{\psi W}{R T}}$

From this relationship, equation 2.29 becomes:

$\frac{A E}{P E}=\frac{e^{\frac{\psi W}{R T}}-R H_{\text {air }}}{1-R H_{\text {air }}}$

It means that an increase in total suction in the soil translates into a decrease in relative humidity of the pore air and consequently a decrease in actual evaporation since the vapour pressure will also be reduced.

Equation 2.31 lacks consideration for the resistances $\left(r_{s}\right.$ and $r_{a}$ presented earlier, due to the fact that Wilson et al. (1997) used thin samples of soil and considered $f(u)$ the same for the soil and the air. However, if PE is to be written with consideration of the bulk aerodynamic resistance, $r_{a}$, the equation 2.17 is written as:

$P E=\frac{\left(e_{s}-e_{a}\right)}{r_{a}}$

considering $r_{s}=0$ (Mahfouf \& Noilhan, 1991) 
Considering both resistances for the calculation of $\mathrm{AE}$ gives the following equation:

$$
A E=\frac{\left(e_{0}-e_{a}\right)}{r_{a}+r_{s}}
$$

Therefore, the expression for relative evaporation becomes:

$$
R E V=\frac{A E}{P E}=\frac{R H_{s}-R H_{a}}{1-R H_{a}} \times \frac{1}{\left(1+r_{a} / r_{s}\right)}
$$

Dunmola (2012), from a study of evaporation in non-saline, $10 \mathrm{~cm}$ thick soil columns, obtained a best fit for experimental and predicted data using a modified version of equation 2.34 .

$R E V=\frac{A E}{P E}=\frac{R H_{s}-R H_{a}}{1-R H_{a}} \times \frac{1}{\left(1+r_{a}+r_{s}\right)^{a}}$

Where " $a$ " is a fitting parameter that is a function of the stage of evaporation, i.e. the phase in which water transport occurs and the location of the evaporation front. Figure 211 shows results from one of the column tests carried out.

The experiment was repeated and Dunmola (2012), achieving good agreement between measured and predicted data, also attained an expression which represented the relationship between the soil resistance, $r_{s}$ and the water content at the surface (equation 2.36).

$$
r_{s}=4.0253 e^{-0.106 \theta_{\text {top }}}
$$

To attain values of Relative evaporation (RE), Dunmola (2012) determined PE from the columns of water of equal dimensions under the same conditions. Using the 
measured values of $\mathrm{PE}, \mathrm{RH}$ and temperature, $r_{a}$ was determined through substitution in equation 2.32 .

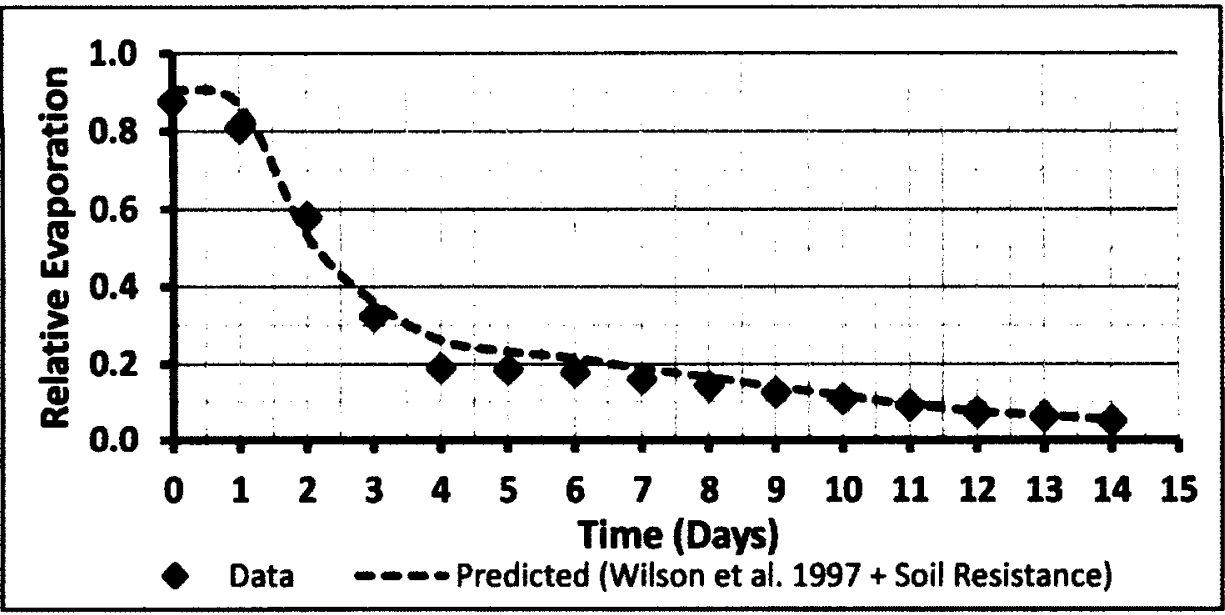

Figure 2-11: Relative evaporation measured from desiccating $10 \mathrm{~cm}$ NS soil columns and predictions using equation 2.35 (After Dunmola, 2012)

Measured values of AE were also used to determine $r_{\mathrm{s}}$ by way of equation 2.33 , inputting previously calculated values of $r_{a}$ and $\mathrm{T}$ and RH data. Best fit curves produced values of " $a$ " of 0.6 for total suctions at the top $1 \mathrm{~cm}<3000 \mathrm{kPa}$ (Stage I evaporation) and 2.1 for total suctions $>3000 \mathrm{kPa}$ (beyond stage I evaporation) (Dunmola, 2012).

From the plot of soil resistance, $r_{s}$, against volumetric water content $\left(\theta_{\text {top }}\right)$ of the top $1 \mathrm{~cm}$ of the soil columns (Figure 2-12), Dunmola (2012) observed an increasing in soil resistance with decreasing volumetric water content as the soil dried. The expression is similar to that obtained by van de Griend and Owe (1994). 


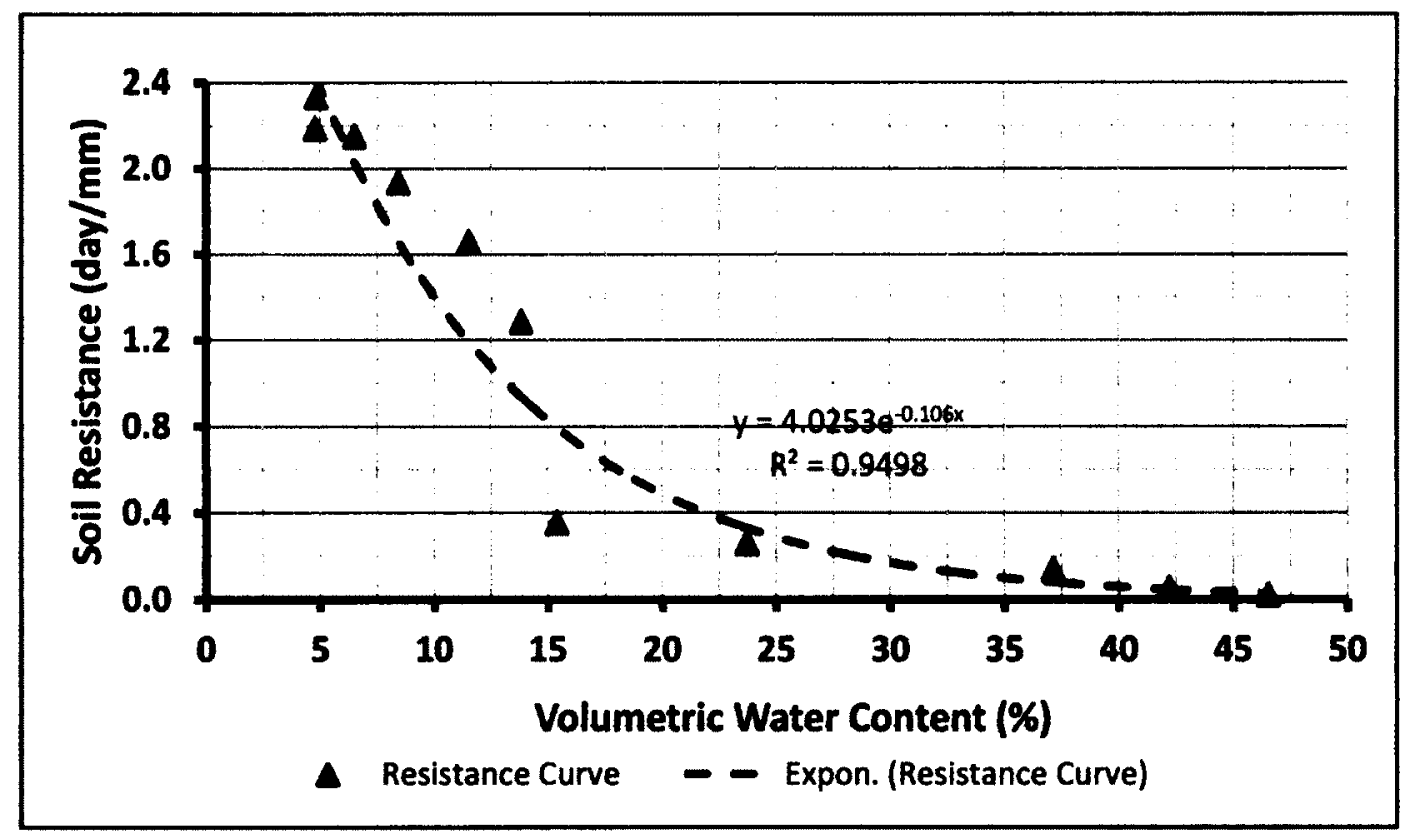

Figure 2-12: Soil resistance $\left(R_{s}\right)$ calculated for $10 \mathrm{~cm}$ NS soil columns as a function of volumetric water content (After Dunmola, 2012)

\subsubsection{Pore-water Salinity and Evaporation}

Agriculturists have faced the challenge posed by salts in the soil such as toxicity to crops and the reduction of the availability of water to crops by reduction in the osmotic potential of the soil solution (Hillel, 1980). The latter phenomenon is not unique to crop fields but is also a problem where evaporation occurs in bare soils with salinity. Lower evaporation rates mean lower consolidation rates and a decreasing rate of strength gain, the opposite of that desired in the case of oil sand thickened tailing.

Water driven up to the soil surface, leaves behind the salts contained in it as evaporation occurs. As saturation nears, for the top layer, the salts precipitate resulting in the formation of a salt crust. The salt crust may have low hydraulic conductivity due to the lower water content as a result of water removal and the presence of salt crystals in the soil pores. This decreased conductivity makes it difficult for further removal of water 
in both water and vapour form. This becomes a component of the soil resistance. Several authors ( (Chen, 1992); (Fujiyasu \& Fahey, Experimental study of evaporation from saline tailings, 2000a); (Fujimaki et al., 2006) and (Shimojima et al., 1996)) have shown that this phenomenon can significantly lower the evaporation rate even up to $90 \%$. The three mechanisms by which this occurs have been investigated, ( (Fujiyasu \& Fahey, Experimental study of evaporation from saline tailings, 2000a), (Simms et al, 2007), (Fissheha et al., 2010); (Dunmola \& Simms, 2010)) and may include:

1. Shortwave radiation reaching the soil is highly reflected by the salts deposited on the surface as they possess higher albedo than the original salt surface. This is particularly important for the case of high salinity in darker tailings. Simms et al. (2007) reported an increase in albedo in the laboratory and field from 0.1 to 0.25 .

2. The increase in osmotic suction and thus total suction due to high salt concentrations result in the decrease in vapour pressure at the soil surface, therefore decreasing evaporation.

3. Salt resistance to moisture flow. This refers to the physical obstruction to moisture flow due the presence of salt precipitates in the pore space.

The effects of the salinity are seen in reduced volume change in drying tailings and the surface sealing effects of salt precipitates greatly reduce infiltration and runoff is high on such soil surfaces.

Ion transport in the soil can be represented via the transient advection-dispersion equation:

$D_{e} \frac{\partial^{2} C}{\partial z^{2}}-v_{z} \frac{\partial C}{\partial z}-C \frac{\partial v_{z}}{\partial z}=\frac{\partial C}{\partial t}$ 
Where $D_{e}$ is the hydrodynamic dispersion, $v_{z}$ is the linear groundwater velocity and $\mathrm{C}$ is the ionic concentration.

Fujiyasu and Fahey (2000a) observed a rapid accumulation of salts at the surface irrespective of the initial salt concentrations of the tailings under study. RE decreased significantly with the salted crust formation but a spike in the RE was reported with the removal of the salt crust at the surface of the desiccated tailings.

Simms et al. (2007), in a single layer deposition field trial at the Bulyanyulu mine in Tanzania found that salts shut down evaporation three (3) weeks after deposition. The authors concluded that while a decrease in albedo was responsible, it was not the sole contributor. Similar results were obtained in the studies aforementioned and understanding the transport of ions and contribution of salinity to the reduction in evaporation rates in Oil sands TT is imperative.

\subsubsection{Cracking and water flow}

Results from both lab and field tests conducted by Adams \& Hanks (1964) and Hatano et al. (1988) suggest that cracks intensify water loss from the soil. Cracking in soils evolves with decreasing water content and depends on the clay content, mineralogy and the physical boundary conditions that exist (Vogel et al., 2005). Once formed the cracks present a new network of macropores which play a major role in the infiltration of water into the soil during a rainfall event and also act as channels for water flow during evaporation (Vogel et al., 2005). They provide a preferential flow path for water when surfaces are impermeable and consequently the solutes contained in the pore water and 
therefore their addition to the surface area through which evaporation takes place has to be accounted for.

Fujiyasu et al (2000b)reported increases in evaporation rates with the appearance of cracks. The authors noted from their field investigation of evaporation from fresh water tailings that when the top of the tailings became dry or of decreasing water content, evaporation from cracks contributed significantly to total water loss while Simms et al (2010) reported no significant increases in evaporation rates due to cracking in a saline gold thickened tailings. In this research, crack contribution to surface area, suction development within cracks and water content change is investigated. 


\section{Chapter 3 materials AND METHODS}

\subsection{Material Characterization Overview}

A total of Fifteen (15) $200 \mathrm{~L}$ drums of oil sands thickened tailings (TT) were received from Total E\&P's Pilot Plant. Of the 15, 10 were from the November 2011 batch and the remaining five (5) from December 2011. Each drum was assigned a number and its corresponding batch date can be found in Table 3-1.

Table 3-1: Drum identification

\begin{tabular}{|l|ll|l|}
\hline Batch Date & \multicolumn{2}{|c|}{ November 2011 } & December 2011 \\
\hline \multirow{4}{*}{ Drum } & Drum 1 & Drum 6 & Drum 11 \\
& Drum 2 & Drum 7 & Drum 12 \\
& Drum 3 & Drum 8 & Drum 13 \\
& Drum 4 & Drum 9 & Drum 14 \\
& Drum 5 & Drum 10 & Drum 15 \\
\hline
\end{tabular}

Characterization tests on the oil sand thickened tailings were performed with the following objectives:

1. Determine baseline characteristics of tailings.

2. Classify tailing samples based on Atterberg Limits and Grain size distribution.

3. Compare two batches of samples received to determine whether they are significantly different and identify the properties that present significant variation.

The initial height of the sample in each drum was recorded along with the height of supernatant water since the contents of the drum settled during transportation. The supernatant was collected and analyzed for $\mathrm{pH}$, alkalinity, electrical conductivity (EC), 
total dissolved solids (TDS), total suspended solids (TSS), and major cations and anions. Using a sample column, attempts to withdraw samples of the settled material were made but were unsuccessful for full drums due to the consistency of the material. However, for the smaller quantities of tailings, samples were collected and were analyzed for variation in solids concentration, specific gravity and Grain Size Distribution (GSD) with depth. The drums were re-mixed to attain initial solids concentrations using a drum mixer with the following details (see Figure 3-1):

Model No.: DLM150VGD

Description: Drum Lid Mount, 1.5 HP, VS Electric Gear Drive

Manufacturer: Mixer Direct

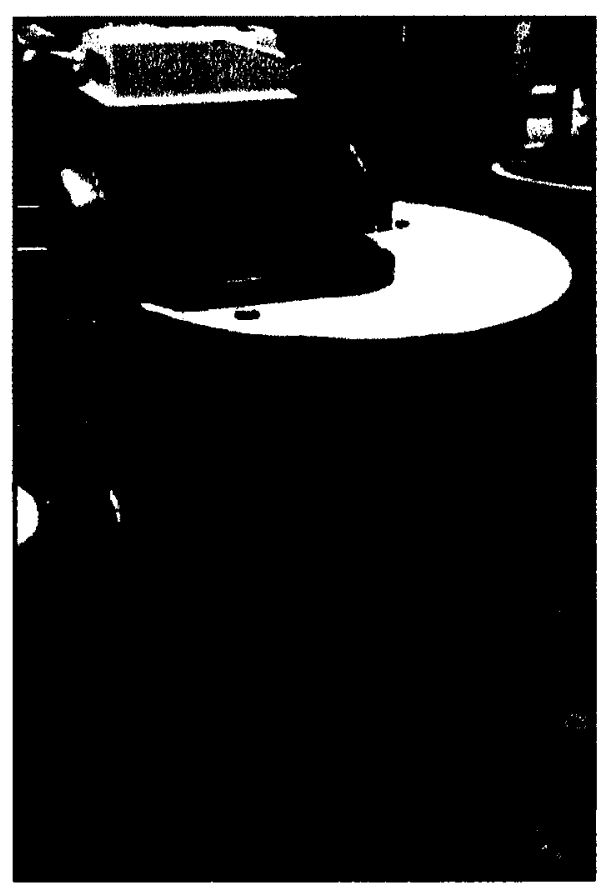

Figure 3-1: Drum mixing

Barrels containing the TT were mixed at an average speed of $190-200 \mathrm{rpm}$ for 30 minutes to 1 hour alternating every 30 minutes between forward and reverse modes to 
ensure complete homogenization whilst bringing them back to upon shipping conditions. The mixed samples were then transferred to 20-gallon buckets and were characterized using the following properties: Solids concentration $\left(C_{s}\right)$, Water content, Bitumen content, bulk density, Atterberg Limits, Water retention curve, Hydraulic Conductivity, specific gravity $\left(\mathrm{G}_{\mathrm{s}}\right)$, GSD, rheology, X-Ray Diffraction (XRD), X-Ray Fluorescent (XRF) and Methylene blue Index (MBI). See Figure 3-2 for Flow Sheet.

\subsubsection{Preparation of samples}

\subsubsection{Atterberg Limits: Liquid Limit and Plastic Limit:}

The samples were air-dried to a lower water content (that which corresponds to a value lower than the liquid limit). A sample was removed to test for the plastic limit. Samples were then remixed to various water contents and tested using distilled water.

For the GSD, samples were air-dried in thin layers, ground with a mortar, weighed and used in the test procedure.

\subsubsection{Other tests:}

For all other tests, the samples were utilized in their remixed state. 


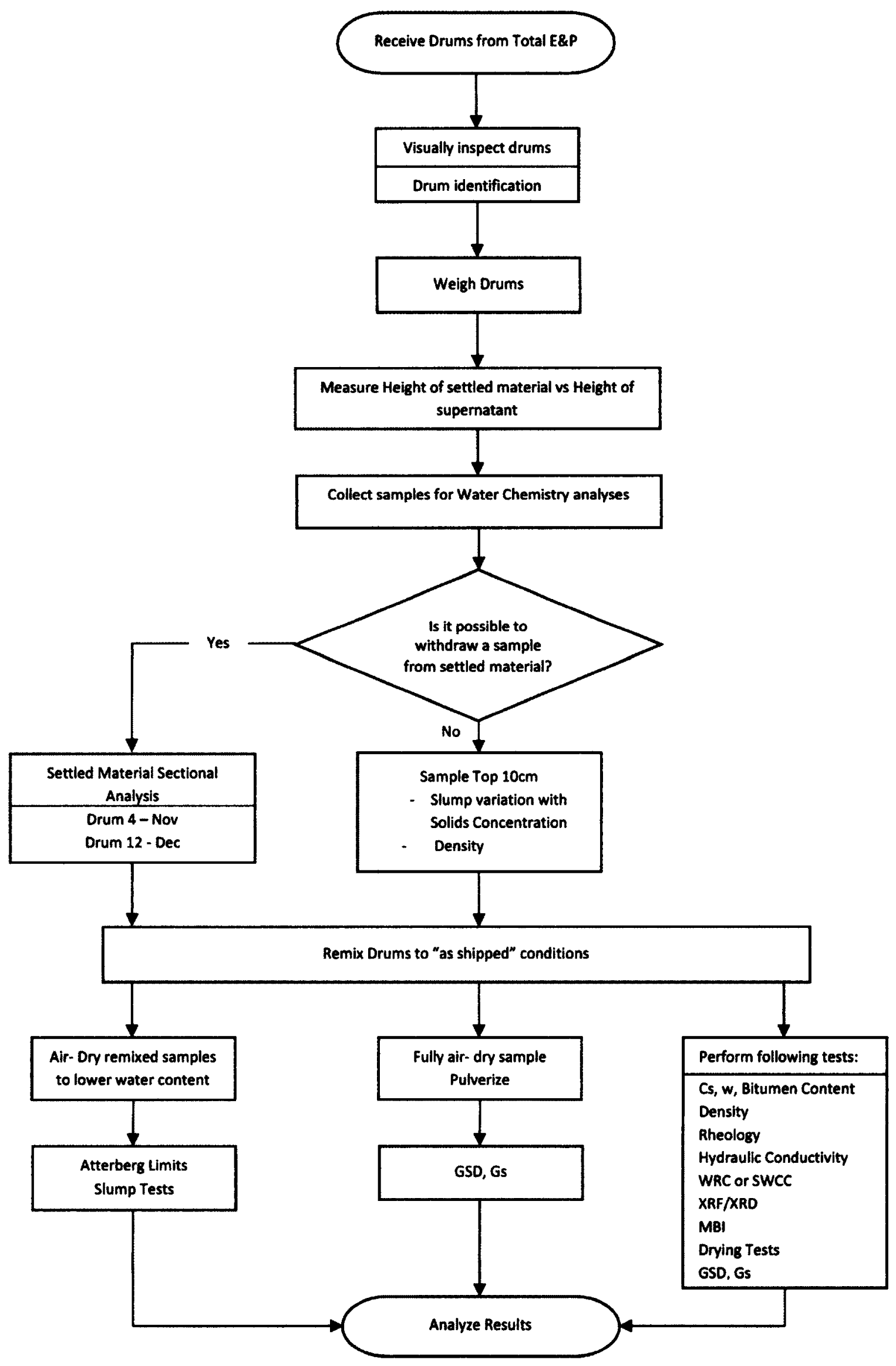

Figure 3-2: Flow Chart - Sample Preparation and Characterization Tests 


\subsection{Properties Test and Soil Characterization}

\subsubsection{Solids Concentration. Bitumen Content. Water Content.}

Solids Concentration in the oil sands industry refers to the mass of tailings solids (consisting of bitumen and other mineral solids) over the total mass.

$C_{s}=\frac{M_{s}}{M_{T}} \times 100$

where $M_{s}$ and $M_{T}$ represent the mass of soil and the total mass of the sample respectively. Tailings samples were dried in an oven at $105^{\circ} \mathrm{C}$ for a period of 24 hours to obtain the total mass of solids present in the sample.

The water content (water contained in the sample - evaporated upon drying) is therefore expressed as a percentage of the total mass $\left(\mathrm{C}_{w}\right)$ or with reference to the mass of solids in the sample (gravimetric water content, $w$ ). They are computed with the use of equations 3.02 and 3.03 respectively.

$$
\begin{aligned}
& C_{w}=\frac{M_{w}}{M_{T}} \times 100 \\
& w=\frac{M_{w}}{M_{s}} \times 100
\end{aligned}
$$

Bitumen Content was determined by the Dean Stark Analysis at an external laboratory. The Dean stark analysis involves the use of a solvent, toluene, to separate water and bitumen from the soil solids in a tailings sample. The toluene is heated so that the vapours wash over the sample contained in the thimble of a modified soxhlet extractor, thereby separating the water and bitumen from the solids (Kaminsky, 2008). A graduated water trap collects water during the extraction (Yeung et al., 1993). The process is complete when the solvent dripping from the bottom of the thimble is 
colourless and the sample is dry. The solvent is allowed to evaporate at room temperature in a fume hood allowing for the calculation of water and oil content.

Total Organic Content. According to Schumacher (2002) and Majid \& Sparks (1983), the total organic carbon content can be estimated by the indiscriminate removal of organic matter from the soil by heated destruction at high temperatures. Based on research performed by Kaminsky (2008) on the thermogravimetric (TG) analysis on oil sand tailing samples, inorganic carbon was not destroyed up to $500^{\circ} \mathrm{C}$. Kaminsky also reports that for tailings, most of the mass loss $(2 \%)$ which occurred up to $500{ }^{\circ} \mathrm{C}$ was that of organics based on gas analyses. Therefore, samples were dried at $105^{\circ} \mathrm{C}$ for 24 hours in porcelain crucibles to remove the moisture and subsequently burned at $500^{\circ} \mathrm{C}$ for four (4) hours at the local laboratory to give an estimated \% of Total Organic Carbon present.

$\%$ Organic Content $=\frac{(\text { Dried weight }- \text { Ash weight })}{\text { Total weight of sample }} \times 100$

\subsubsection{Atterberg Limits}

The Atterberg Limits are used to describe the consistency of fine-grained soils, a property which manifests the ease with which a soil maybe deformed; a measure of firmness and is related to its strength (Venkatramaiah, 2006). Since a fine-grained soil has water surrounding the soil particles, the amount of water determines its consistency or state. The states used to describe a soil's consistency are solid, semi-solid, plastic and liquid and are separated by specific water contents namely; the plastic limit (PL) and liquid limit (LL) which are shown in Figure 3-3. These limits provide information which can 
be used for soil identification, classification and estimation of strength and settlement characteristics.

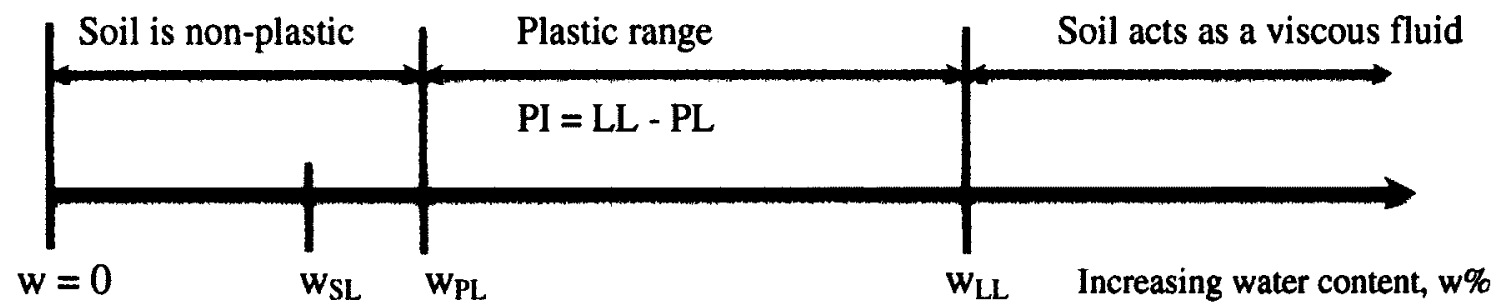

Figure 3-3: Relative locations of the Atterberg Limits of a soil. After Bowles (1979)

A completely air dried, pulverized sample is commonly used for the LL and PL tests but Bowles (1979) noted that this can lower the LL from 2-6\%, not affecting the PL as rewetting may not adequately return the soil to its natural redistribution. He suggests that once the material is predominantly (-) 40 material, that is. material which passes through the no. 40 sieve, wet or damp soil could be used.

\subsubsection{Liquid Limit}

The liquid limit is the margin between the plastic and fluid state. It is determined through the use of the "Liquid Limit Device" known as the Casagrande Cup or Standard Cone Penetrometer (Bowles J. E., 1992).

\section{Determination through use of the Casagrande Cup}

According to the procedure outlined in ASTM D4318, the liquid limit is the moisture content (\%) required to close a $2 \mathrm{~mm}$ groove in a soil pat to 0.5 inches $(12 \mathrm{~mm})$ after 25 
blows of the cup (ASTM D4318, 2000). The soil sample used was that passing the no. 40 sieve. See figure 3-4.

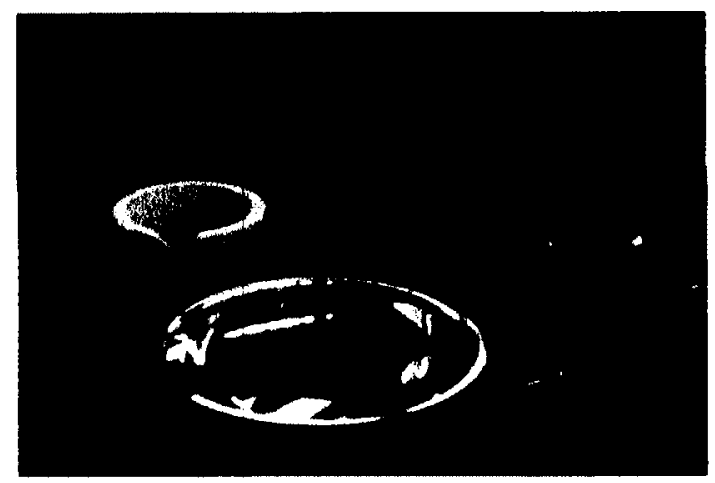

Figure 3-4: Liquid Limit Device (Casagrande Cup)

\section{Procedure}

After air dying the (-) 40 tailings sample, it was mixed carefully to a uniform texture. A small amount of soil was placed in the clean brass cup to the depth indicated by the grooving tool and smoothed with a spatula. A groove was cut with one of the tools and the crank was rotated at approximately $120 \mathrm{rpm}$ until the grove closed up to $12.7 \mathrm{~mm}$. The number of blows was recorded and a sample was collected for water content at the closing. Increasing the water content of the sample in steps by addition of a small quantity of distilled water, the procedure was repeated to obtain a minimum of three (3) blows and corresponding water contents. A semi- log plot of number of blows versus moisture content was constructed and the LL was determined as the water content corresponding to 25 blows.

Determination through the use of the Cone Penetrometer 
With the standard cone penetrometer test, the water content at which there is $20 \mathrm{~mm}$ penetration by a standard $80 \mathrm{~g}$ cone is known as the liquid limit.

\section{Procedure}

A thoroughly mixed soil sample was placed in the sampling dish $(55 \mathrm{~mm}$ diameter $\mathrm{x} 40$ $\mathrm{mm}$ depth) and the cone was lowered to the surface of the sample. The cone was then released into the sample and the penetration in $\mathrm{mm}$ was recorded after 5 seconds. As with the previous procedure, it was repeated a minimum of three (3) times to obtain a semi-log plot of penetration versus water content.

\subsubsection{Plastic Limit}

The plastic limit of a soil defines the margin between the non-plastic and plastic states. It is determined by the rolling of the soil into a thread adjusting the moisture content until the thread crumbles at a diameter of $3 \mathrm{~mm}(1 / 8 \mathrm{in})$ as shown in Figure 3-5. The soil, also passing the no. 40 sieve, was rolled into small balls. It was rolled with the finger tips at a rate of 90 strokes $/ \mathrm{min}$. The backward and forward rolling was continued until a $3 \mathrm{~mm}$ thread was attained. This was repeated until the failure occurred. The failed threads were placed in a moisture can, covered, weighed, and dried.
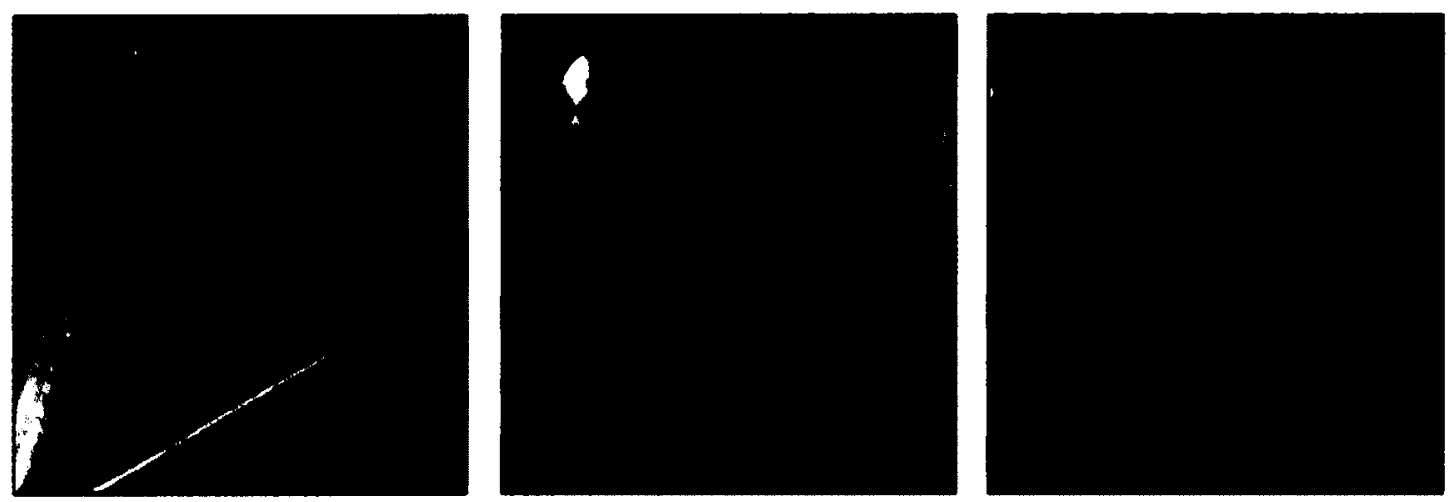

Figure 3-5: Plastic Limit Test 


\subsubsection{Plasticity Index}

The plasticity index (PI) defines the complete range of the plastic state and is the difference between the liquid and plastic limits, Equation 3.05.

$P I(\%)=L L(\%)-P L(\%)$

\subsubsection{Shrinkage Limit}

The shrinkage limit is defined as the maximum water content expressed as a percentage of the oven dried weight at which any further reduction in water content will not cause a decrease in the volume of the soil mass. This is determined through the use of the Mercury or Wax method. In this characterization exercise, the Wax Method was used.

\section{Procedure for Wax Method}

1. Shrinkage dishes were greased with petroleum jelly.

2. The volume $\left(V_{f}\right)$ and the empty weight $\left(M_{d}\right)$ were determined.

3. The shrinkage dish was then filled with a soil sample, weighed (Mass of wet sample $\left.M_{w s}\right)$ and left to air dry till the surface of the soil sample paled.

4. The dish was then placed in the oven at $105^{\circ} \mathrm{C}$ for $24 \mathrm{hrs}$. After drying, the dish was removed and weighed (Mass of dry sample $\left.-\mathbf{M}_{\mathrm{ds}}\right)$. The mass of dry soil $\left(\mathbf{M}_{\mathbf{s}}\right)$ was calculated $\left(M_{\mathrm{ws}}-M_{d s}\right) . W_{0}$ was determined through equation no. 3.

5. The dried soil pat was removed from the shrinkage dish, coated with wax and weighed (Mass of soil + wax coat $-\mathrm{M}_{\mathrm{scw}}$ ). 
6. The volume of the wax coated soil was estimated through the water displacement technique.

Mass of beaker + known volume of water $-M_{b w}$

Mass of beaker + wax coated soil + water $-\mathrm{M}_{\mathrm{bws}}$

Volume of wax coated soil $\left(V_{t}\right)=M_{b w}+M_{s c w}-M_{b w s}$

Volume of soil cake $\left(V_{f}\right)=V_{t}-V_{\text {wax }}$

Where, $V_{\text {wax }}=\left(M_{\text {scw }}-M_{s}\right) / \rho_{\text {wax }}$

7. The shrinkage Limit $\left(w_{\mathrm{s}}\right)$ was calculated using the following equation:

$$
w_{s}=w_{0}-100 *\left(V_{d}-V_{f}\right) / M_{s}
$$

\subsubsection{Grain Size Distribution (GSD)}

Many material properties of soils are a function of the grain size distribution. This distribution can be determined by mechanical separation using a sieve analysis or by the use of the settling rates (based on the principles of sedimentation) as described by Stokes Law in the Hydrometer method (Miller et al., 1988) or even the laser light scattering technique (LD) (Cooper et al., 1984).

Due to the small particle size of the fines tailings, the hydrometer method was used to analyze the grain size distribution followed by a wet sieve analysis. Both dispersed and non-dispersed methods were used to analyze particle size and settling characteristics respectively.

Approximately $40 \mathrm{~g}$ of air dried soil samples were used for both tests. 


\subsubsection{Dispersed Test}

$125 \mathrm{ml}$ of dispersant (sodium hexametaphosphate, $4 \%$ (wt.) solution) was added to air dried soil sample, covered and allowed to stand for 24 hrs. The dispersed sample was then mixed in a malt mixer for five (5) minutes. The mixed sample was then added to a $1000 \mathrm{ml}$ measuring cylinder and topped off with water to the volumetric mark. The cylinder was shaken for a total of 60 seconds by inversion. Hydrometer and thermometer readings were taken in the following times: $2,8,16,30,60,120,240,480,960,1920$ minutes. These readings were then used to calculate the \% passing and the diameter of particles still in suspension at the time measured.

\subsubsection{Non-Dispersed Test}

The soil sample was placed in the cylinder and topped off with water to the volumetric mark. The cylinder was mixed thoroughly. Hydrometer and thermometer readings were taken in the following times: $2,8,16,30,60,120,180.240,300,360,420,480,540$, 600.

\subsubsection{Specific Gravity, Gs}

The specific gravity of a soil is defined as the ratio of the mass of a volume of soil particles to the mass of equal volume of water at a specific temperature. It is used to calculate other engineering properties like the volume of solids in a sample, void ratio, PSD among others. 


\section{Procedure}

The specific gravity was determined by the flask method described in (ASTM International, 2003). A $10 \mathrm{~g}$ sample of soil was placed in the empty flask and filled to two thirds with deaired distilled water. The entrapped air was removed via vacuum. The flask was filled to the volumetric mark and weighed. The weight of the flask containing only deaired distilled water was also measured. The specific gravity of the soil was therefore calculated via the following equation:

$G_{s}=\frac{m_{d s}}{m_{f w}+m_{d s}-m_{f w s}}$

Where:

$m_{d s}:$ mass of dry soil $(\mathrm{g})$

$m_{f w}:$ mass of full flask of water $(\mathrm{g})$

$m_{\text {fws }}:$ mass of flask of water and soil $(\mathrm{g})$

\subsubsection{Total (Wet) Density}

The total or wet density of a soil, $\rho_{t}$, is the ratio of the total mass of soil to its total volume and can be defined as follows:

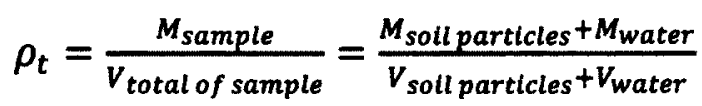

Due to the high water contents of the soil samples, direct measurement by weight in a container of known volume and weight was used to estimate the density of each soil sample. 


\subsubsection{Void ratio, e}

The ratio between the volume of voids and the volume of soil particles defines the void ratio of a soil. It may be computed via Equation 3.09. The voids are made up of water mainly in the case of a saturated; soil and water and air in the case of an unsaturated soil.

$e=\frac{V_{v}}{V_{s}}=\frac{V_{w}}{V_{s}}=\frac{M_{w} \times G_{s}}{M_{s}}$

\subsubsection{Rheology}

Rheology is the study of deformation and flow of matter (Boger, 2006). Oil sand thickened tailings is a high concentrated slurry and so requires a high shear stress to initiate flow. This stress is termed yield stress and is referred to as the critical shear stress that must be exceeded before irreversible deformation and flow can occur (Boger, 2006). The yield stress was estimated through the use of the slump test and measured through the use of a Rheometer. The flow curves were also constructed.

\subsubsection{Slump Test}

In order to simplify the measurement of the yield stress, a modified slump test was used. It involved the use of an ASTM standard slump cone or a cylinder and a ruler. The material was poured into the cylinder up to the fill height. The cylinder was then pulled away using the sides. Using a ruler, the height of the material was measured from the centre. The slump is the difference between the initial height of the sample and the measured height. 
The yield stress was calculated through the following equation using the slump height measured:

$\tau_{y}=0.5 \rho g h\left(1-\sqrt{S^{\prime}}\right)$

Where

$\tau_{y}$-yield stress $(k P a)$

$\rho$ - bulk density of sample $\left(\mathrm{kg} / \mathrm{m}^{3}\right)$

$g$ - acceleration due to gravity $\left(\mathrm{m} / \mathrm{s}^{2}\right)$

$h$ - height of the slump cylinder (m)

$S^{\prime}$ - dimensionless slump $\left(\left(h-h_{f}\right) / h\right)$

\subsubsection{Rheometer - Vane shear Fixture}

Using a rheometer, a wide range of steady and dynamic tests e.g. flow curves, timedependent tests, creep tests, and relaxation tests can be performed with minimization of errors due to limited sample disturbance and those associated with the wall-slip phenomena. (Lideell \& Boger, 1996). Through the use of the various mechanisms, direct and accurate measurement of the yield stress can be attained. The Rheometer used to study the rheology of the material was an Anton Paar MCR 301 with the use of the Vane geometry (ST 224V-4L) and the cup CC 27 . The diameter of the vane fixture was $22 \mathrm{~mm}$.

A thoroughly mixed tailings sample was poured into the available cup (CC 27) and placed into the holder at the base of the rheometer. The four-bladed vane (ST 224V$4 \mathrm{~L}$ ) attached to the torsion measuring head was lowered until its complete submersion 
into the sample. The fixture was rotated at a low speed where the torque was measured as a function of time.

Three mechanisms were used. They include the stress growth made up of a maximum yield stress measurement and the constant stress rate test which are similar and the controlled mode test which includes a constant increasing stress rate. Further discussion on the mechanisms is provided in the presentation of results.

\subsubsection{Soil Water Characteristic Curve (SWCC)}

As was discussed in the previous chapter, the characterization of the hydraulic properties of a soil, important in soil desiccation and seepage, depends heavily on the relationship between the soil water content and the matric suction/total suction referred to as the soil water characteristic curve.

The water retention curve was analysed through the use of the volumetric pressure plate and extended in some cases with the use of the WP4-T Potentiameter which measures total suction. Two set-ups were used: the Fredlund device and a custom built set up.

The samples were placed in sample rings and set at pressure increments of 40 and $50 \mathrm{kPa}$ with weights and sample heights recorded upon the attainment of equilibrium. Diffused air was removed every day to prevent false readings. Additional samples were air dried in thin layers accompanied by total suction measurements and water content determination at various time intervals. 


\subsubsection{Hydraulic Conductivity}

The saturated hydraulic conductivity of the thickened tailings was estimated through the use of the falling head test as it is more suitable for fine-grain soils. This test uses Darcy's Law to back calculate the coefficient of permeability.

$$
k=\frac{a l}{A t_{1}} \ln \frac{h_{0}}{h_{1}}
$$

Where,

$a-$ cross sectional area of the stand pipe above the soil column

$l$ - length of the soil column

$A$ - cross sectional area of the soil column

$t_{I}$ - time taken for the total head to reduce from $h_{0}$ to $h_{1}$

$h_{0}$ - total head loss over the length of the soil column at $t=0$

$h_{1}-$ total head loss over the length of the column at $t=t_{1}$

\section{Procedure}

Soil samples were placed between saturated porous stones in falling head device using filter paper to avoid direct contact between the porous stone and the sample. Before flow measurements were started, the pipes were filled with deaired water to a given level. Water was then allowed to flow through the sample until a certain value. The time required for the water in the standpipe to drop from the upper to the lower level was recorded. The standpipe was refilled and the test was repeated until the calculated values were within $5 \%$ difference of each other 


\subsubsection{Water Chemistry}

The water chemistry is a reflection of the chemical nature of the extraction process as well as post treatment schemes. It is very important as it plays a major role in the behaviour of the tailings post deposition which includes consolidation and desiccation. The water chemistry of the thickened tailings was analysed for major cations and anions concentrations, conductivity, pH, Total solids and alkalinity by an External Laboratory. Supernatant water from the already settled tailings was collected and placed into sample bottles for analysis and in some cases the tailings samples were centrifuged to obtain the pore water.

\subsubsection{Elemental Composition. XRF Analysis.}

The elemental composition of the tailings solids is determined through the use of X-Ray fluorescence spectroscopy (XRF) in which major and trace elements are analysed. The XRF analysis is a non-destructive way to study the chemistry of rocks, fluids etc. The method is based on the behaviour of atoms upon interaction with short wave radiation (High energy x-rays) which, if sufficient, can cause the dislodging of tightly held inner electrons producing an unstable atom. An outer electron replaces the missing inner electron releasing energy due to the decreased binding energy of an inner electron orbital to an outer one.

The emitted radiation is lower than the incident $\mathrm{x}$-rays and is called fluorescent radiation. The abundance of each element in the sample can thus be detected using the 
resulting fluorescent $\mathrm{x}$-rays since the energy of each photon is characteristic of a transition between specific electron orbitals in a particular element (Barth \& Wirth).

Limitations include but are not restricted to: 1) XRF analyses cannot distinguish variations among isotopes of an element, so these analyses are routinely done with other instruments and 2) They also cannot distinguish ions of the same element in different valence states (Barth \& Wirth).

Samples were sent to an external Laboratory for analysis.

\subsubsection{Mineralogical Composition. XRD Analysis.}

Solid matter can be described as either amorphous or crystalline. In the latter, the atoms are arranged in a regular pattern where small volume elements by repetition in the three dimensions describe the crystal. About $95 \%$ of all solids can be described as crystalline (Scintag, 1999).

When certain geometric requirements are met, $\mathrm{X}$-rays scattered from a crystalline solid can constructively interfere, producing a diffracted beam. The diffraction can only take place if the wavelength of the diffracted beam and the magnitude interplanar distance are of equal order of magnitude (Kaminsky, 2008). This interference occurs at a particular plane at a particular angle giving rise to a series of peaks characterized by the angle of incidence for crystalline solids.

Changing the angle between the source and the sample results in an excitement of different planes which can later be used as a guide to identifying different crystals. 


\section{The Rietveld Method}

The method is based on the calculation of the full diffraction pattern from crystal structure formation. The major drawback of the XRD is the gross overlapping of diffraction peaks preventing proper determination of the structure due to the polycrystalline nature of most materials. The Rietveld method permits a more accurate determination through the creation of a virtual separation of these overlapping peaks. It employs a non-linear least squares algorithm to model the XRD pattern until the experimental and measured patterns fit (Kaminsky, 2008).

\subsubsection{Clay Activity, $A$}

Clay activity, as defined in most geotechnical literature, is the plasticity index (PI) of a soil sample divided by the percentage of clay contained in it (Skempton, 1953).

Clay Activity, $A=\frac{P I}{\% \text { clay }}$

The percentage of clay is weight based and is the soil fraction less than $(<) 2 \mu \mathrm{m}$.

The cation exchange capacity (CEC) is also an indication of the clay activity (Bowles J. E., 1979). To get an idea of the CEC, methylene blue analysis was conducted to estimate the surface area of the clay. Methylene blue (MB) is a cationic dye that has been used to identify redox reactions for a wide range of applications in the fields of chemistry and biology (Boxill, 2011). The adsorption of MB to the edges, external surfaces, and accessible interlayer regions of clay minerals dispersed in an aqueous 
solution is to measure CEC and specific surface area of clay minerals (Omotoso D. , 2011).

The methylene blue adsorption index (MBI) is determined in the laboratory though a procedure in which a MB aqueous solution (about $0.006 \mathrm{M}$ ) is prepared with deionized water and titrated in $1 \mathrm{ml}$ increments into an already dispersed sample which is being assessed. A permanent blue halo marks the end of titration and indicates the presence of the methylene blue cation. The $\mathrm{MB}$ cation displaces $\mathrm{Na}^{+}, \mathrm{Ca}^{2+}, \mathrm{K}^{+}$, and $\mathrm{Mg}^{2+}$ cations located on the surfaces of clay particles allowing estimation of the specific surface area of clay minerals present. A thorough description of the test can be found in (Kaminsky, 2008) and (Boxill, 2011). The results are expressed in meq/100g.

\subsection{Drying Tests}

\subsubsection{Vertical Column Drying Test}

A vertical column was setup for the first drying test. The setup entailed a cylindrical plastic settling column placed on a scale with a drainage port through the bottom. See figure 3-6 for setup. The column was lined with geotextile and two conditioned T5 tensiometers were placed in the upper and lower ports of the column, blocked with rubber stoppers and connected to a data logging device. The empty weight of the column was recorded and it was subsequently filled with oil sands TT from Drum 1 at an initial solids concentration of $51.3 \%$ to a height of $30 \mathrm{~cm}$. Attached to the drainage port was a tube leading to a sealed graduated cylinder placed on a scale to monitor drainage from the tailings sample. 


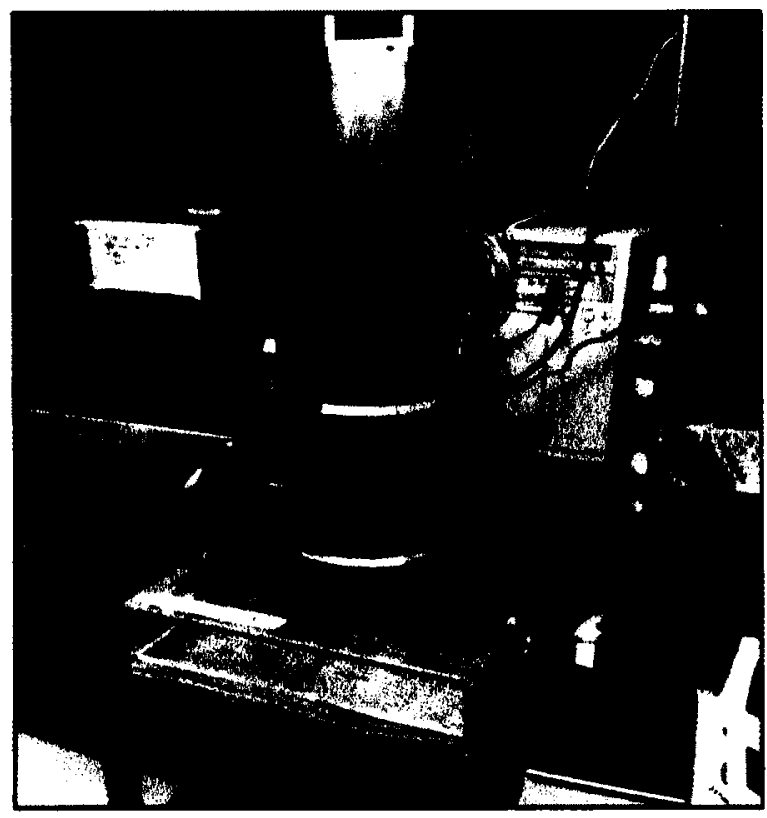

Figure 3-6: Vertical Drying Column Setup

A webcam was positioned at the front of the setup and was scheduled to capture and save a photo of the scale every 30 minutes. The data logger was set to collect measurements from both tensiometers every minute. Due to little change in the column after a week, an electric fan was set up and remained for the duration of the test. Matric Suction and Evaporation data was collected for a period of 26 days (Test 1).

At the end of Test 1, a volume of distilled water equivalent to what had been lost through evaporation was added to the column and monitoring ensued for 15 more days (Test 2).

\subsubsection{Column Sectional Analysis}

Upon completion of Test 2 , the column was divided into six (6) sections. Duplicate samples from each section were analyzed for solids concentration, volatiles content, conductivity, TDS and total suction. The WP4 Dewpoint Potentiometer was used to 
measure total suction after having been calibrated. For measurement of the conductivity and TDS of pore water, samples (approximately $3 \mathrm{~g}$ ) were diluted with distilled water in the ratio of tailings to distilled water of 1:4 (by weight). Samples were then centrifuged for 2.5 minutes at $3000 \mathrm{rpm}$. A calibrated Traceable electrical conductivity meter (VWR International, Friendswood, TX) was utilized to measure conductivity and TDS concentrations of the centrifuged supernatant. Appropriate calculations were performed to account for dilution and determine actual TDS concentrations.

\subsubsection{Wax Column Test}

To gain an understanding of solute transport during evaporation, the $12 \mathrm{~cm}$ high sample columns were constructed from a molten petroleum jelly and paraffin wax mixture of composition 1:2.5 parts by mass. The two components were melted and the mixture poured in intervals into the mould constructed from empty juice cartons with a cavity created by the placement of a $7 \mathrm{~cm}$-diameter aluminium can.

Two sets of five (5) wax columns were filled with soil samples with the following characteristics:

Table 3-2: Tailings Properties - Wax Column Test

\begin{tabular}{|l|l|l|l|l|l|}
\hline Sample ID & Drum ID & Cs (\%) & TDS (mg/L) & EC $(\mu \mathrm{S} / \mathrm{cm})$ & $\mathbf{N a}(\mathbf{m g} / \mathbf{L})$ \\
\hline A & 10 & 54.7 & 1570 & 2420 & 532 \\
\hline B & 15 & 50 & 1980 & 3050 & 673 \\
\hline
\end{tabular}

The columns were placed on an obstacle free surface in the laboratory and left to the atmosphere for drying. 
The weight of each column was monitored daily along with the $\mathrm{RH}$ and the temperature. At the end of a select time period, one column from each set was destroyed and sectioned to analyze water content, solids concentration, EC and Total Suction. A column of similar dimensions was filled with distilled water and labelled "blank". The aforementioned allowed the estimation of potential evaporation under the same conditions.

\subsubsection{Small Drying Box Test}

Three rectangular boxes of dimension: $67.3(\mathrm{~L}) \times 40.6(\mathrm{~W})$ were utilized to simulate $5 \mathrm{~cm}$ lift deposition of the following two materials (See Figure 3-7):

- $50 \%$ solids concentration with sodium (Na) concentration of $652 \mathrm{mg} / \mathrm{L}$ and an $\mathrm{EC}$ of $3070 \mu \mathrm{S} / \mathrm{cm}$.

- $55 \%$ broken to $50 \%$ solids concentration with a final sodium concentration of $464.4 \mathrm{mg} / \mathrm{l}$ and $\mathrm{EC}$ of $2187 \mu \mathrm{S} / \mathrm{cm}$.

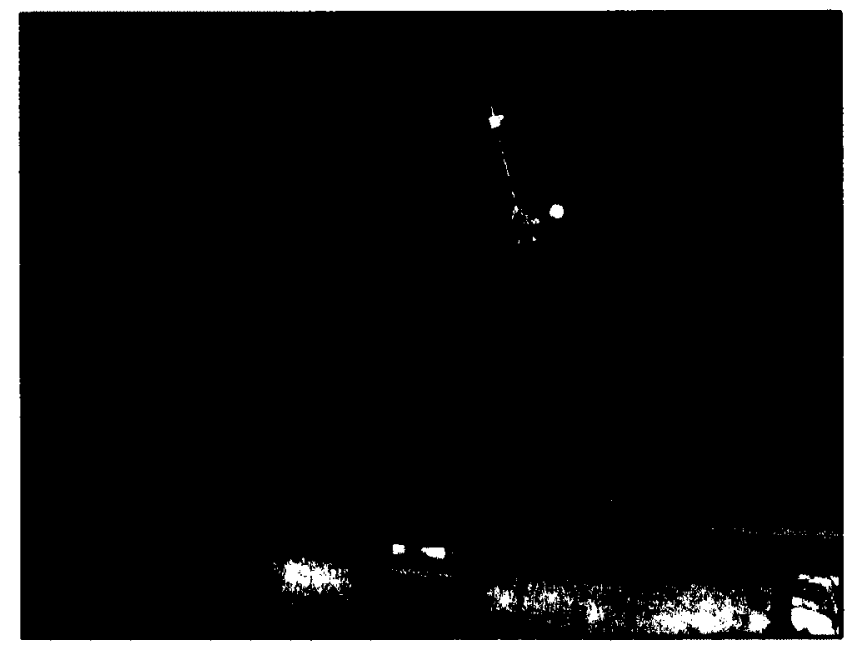

Figure 3-7: Small Box Drying Test Set-up 
The third box was the blank to estimate potential evaporation. The weight of each box was recorded and the following measured at the surface on a periodic basis:

- Total suction

- $\mathrm{RH}$

- Temperature

- Crack dimensions and suctions

At the end of the drying test, the experiment was repeated with the $50 \%$ solids concentration material at a lift thickness of $10 \mathrm{~cm}$.

\subsubsection{Crack Surface Area and Volume Measurements}

To estimate Crack surface area, the cracks were measured along the entire perimeter using a bendable stainless steel ruler. The length of each crack was also recorded. For volume measurements, the crack depth, length, and widths were measured and based on the geometry, volume was calculated. See Figure 3-8.

Width

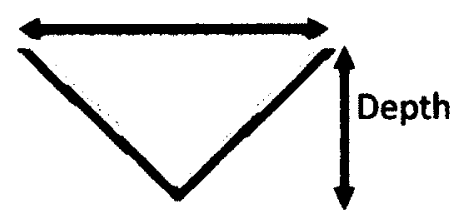

Perimeters are indicated in grey

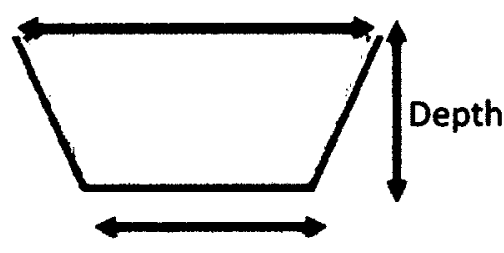

Width

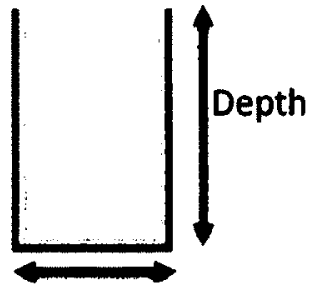

Depth

Figure 3-8: Crack Geometries and measured dimensions 


\subsubsection{Medium Scale Drying Box Test}

The medium scale drying box test consists of multilayer deposition of approximately $0.20 \mathrm{~m}$ of oil sand thickened tailings of $50 \%$ solids concentration. The basic material properties of the tailings for layers one (1) through three (3), are given in Table 3-3 below. For information not provided below, please refer to Characterization results in Chapter 4.

Table 3-3: Basic Properties Tailings - Multilayer Drying Box Test

\begin{tabular}{|c|c|c|c|c|}
\hline Property & Layer 1 & Layer 2 & \multicolumn{2}{|l|}{ Layer 3} \\
\hline Solids Concentration, $\mathrm{Cs}$ & 49.66 & 50.23 & 51.47 & $\%$ \\
\hline Gravimetric water content, $w$ & 101.37 & 99.34 & 94.37 & $\%$ \\
\hline Volumetric water content & 0.72 & 0.71 & 0.72 & $\%$ \\
\hline Specific Gravity & 2.5 & 2.563 & 2.7 & \\
\hline \multicolumn{5}{|l|}{ Atterberg Limits } \\
\hline Liquid Limit, LL & 27 & 35 & 25 & $\%$ \\
\hline Plastic Limit, PL & 19.51 & 20 & 19.82 & $\%$ \\
\hline Shrinkage Limit, SL & 17.5 & 18 & 17.13 & $\%$ \\
\hline Plasticity Index, PI & 7.49 & 15 & 5.18 & $\%$ \\
\hline \multicolumn{5}{|l|}{ Grain Size } \\
\hline $\mathrm{D}_{90}, \mathrm{D}_{60}, \mathrm{D}_{50}, \mathrm{D}_{10}$, in $\mathrm{mm}$ & $\begin{array}{r}0.11,0.0045 \\
0.034,0.001\end{array}$ & $\begin{array}{l}0.13,0.058 \\
0.043,0.001\end{array}$ & $\begin{array}{r}0.13,0.057 \\
0.046,0.0013\end{array}$ & \\
\hline Sands to Fines Ratio, SFR & 0.72 & 0.79 & 0.66 & \\
\hline \multicolumn{5}{|l|}{ Water Chemistry } \\
\hline Conductivity & 3050 & 3050 & 3025 & $\mu \mathrm{S} / \mathrm{cm}$ \\
\hline TDS & 1980 & 1980 & 1965 & $\mathrm{mg} / \mathrm{L}$ \\
\hline $\mathrm{HCO}_{3}$ & 810 & 791 & 774.5 & $\mathrm{mg} / \mathrm{L}$ \\
\hline $\mathrm{SO}_{4}$ & 68 & 74 & 72 & $\mathrm{mg} / \mathrm{L}$ \\
\hline $\mathrm{Cl}$ & 454 & 449 & 463 & $\mathrm{mg} / \mathrm{L}$ \\
\hline $\mathrm{Fe}$ & 17.3 & 12.5 & 16.05 & $\mathrm{mg} / \mathrm{L}$ \\
\hline K & 12 & 12 & 15 & $\mathrm{mg} / \mathrm{L}$ \\
\hline $\mathrm{Na}$ & 650 & 673 & 689 & $\mathrm{mg} / \mathrm{L}$ \\
\hline $\mathrm{Ca}$ & 6 & 6 & 7 & $\mathrm{mg} / \mathrm{L}$ \\
\hline $\mathrm{Mg}$ & 7 & 6 & 7.5 & $\mathrm{mg} / \mathrm{L}$ \\
\hline
\end{tabular}




\subsubsection{Set-up}

The box used in the experiment was constructed from Plexiglas and steel frames with dimensions of $0.697 \mathrm{~m}$ Width $\times 0.987$ Length $\mathrm{x}$ an adjustable height of up to $1 \mathrm{~m}$ (Figure 3-8). It is an easily detachable box allowing assembly by layer. The box was mounted to loading cells and has a tipping bucket in the base for measurement of drainage. Geotextile material was placed at the base of the box to prevent soil particle loss with drainage.

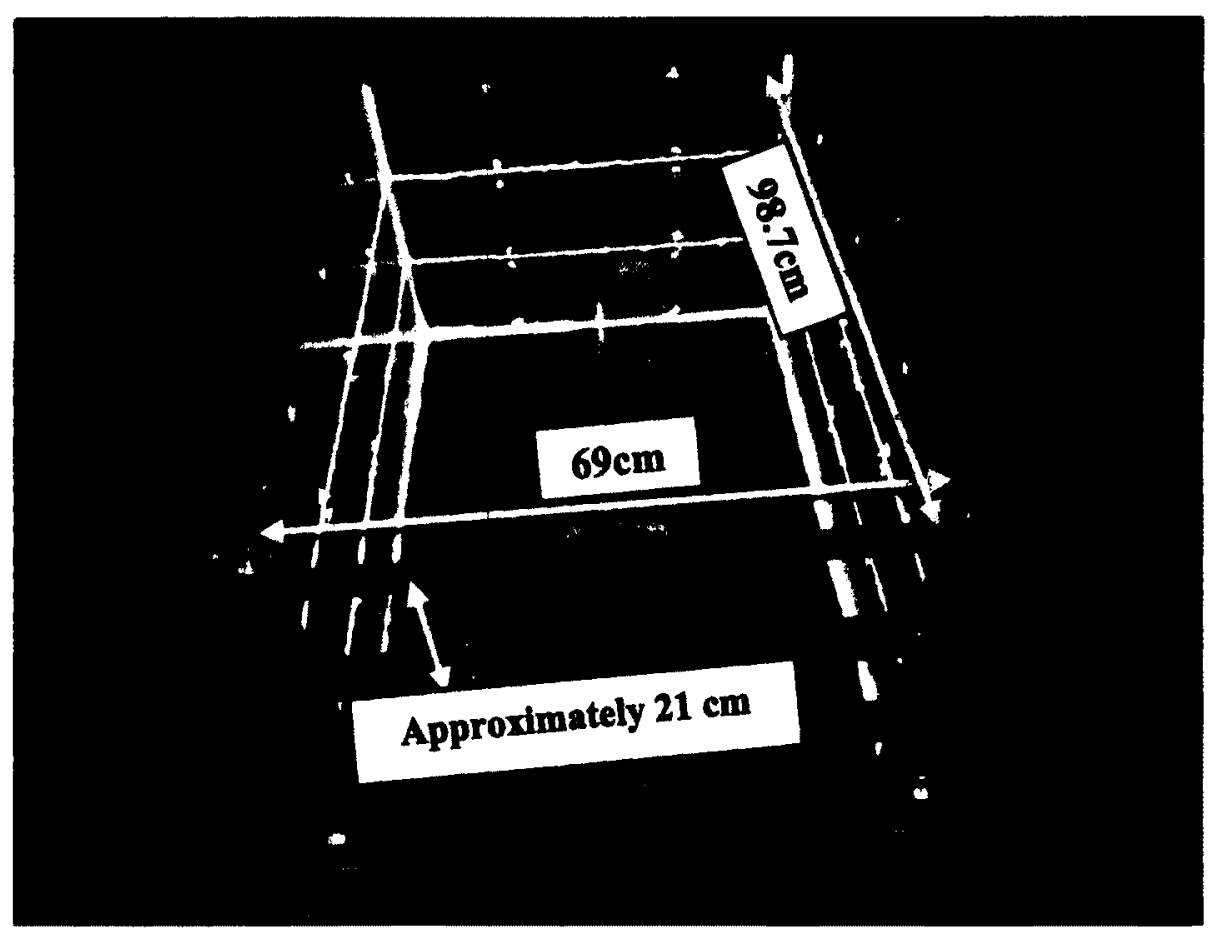

Figure 3-9: Drying Box dimensions

The loading cells are connected to a data acquisition system where the variation in mass is monitored to compute water loss due to evaporation. 
Above the box, four (4) Senix distance sensors were placed to monitor the variation in height of the sample for estimation of the volume change (Figure 3-9). These were also connected to the data acquisition system after having been calibrated with samples of known heights.

T5 Tensiometers (UMS) were placed horizontally within $5 \mathrm{~cm}$ of the top layer and at the centre, $10 \mathrm{~cm}$ from the surface of the tailings to observe Matric Suction. Volumetric water content sensors (Decagon) were also placed at the same heights where volumetric water content and temperature of the sample were monitored hourly.

\section{Distance Sensors}

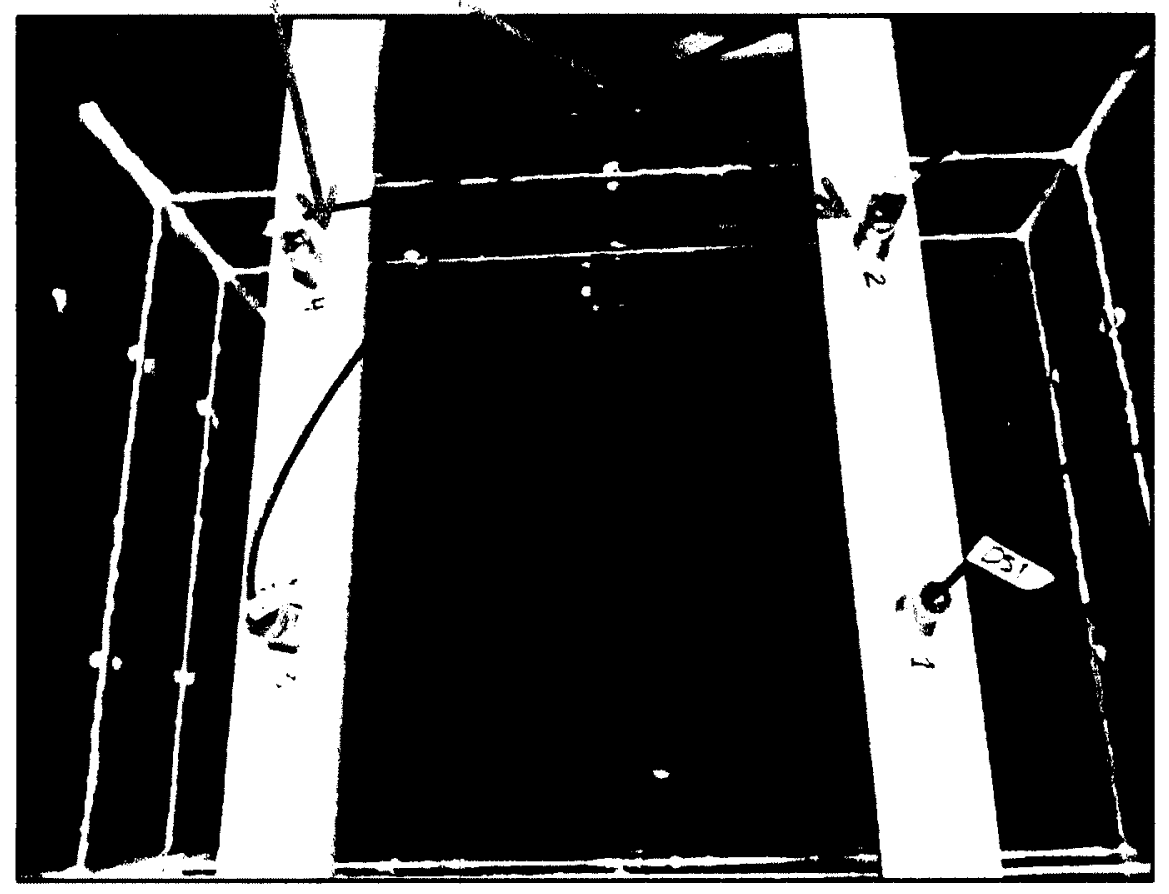

Figure 3-10: Drying Box prior to Layer 1 Deposition

Above the soil surface, a Relative Humidity (RH) Easy Log USB sensor was placed to observe RH and temperature change. Two electrical standing fans, set at the 
lowest speed, were used to simulate wind to aid in running the test during a reasonable time period.

The box was placed in an area of the laboratory bound by tarpaulins and with no sunlight reaching the setup thus nulling the effect of radiation.

\subsubsection{Sampling and other monitoring}

On a daily basis with a few exceptions due to inclement weather, a sample from the first $1 \mathrm{~cm}$ of the tailings surface was collected to measure total suction using a WP4 Dewpoint Potentiameter, and gravimetric water content. Additionally, crack development was monitored by the measurement of crack dimensions to estimate surface area and volume.

At the end of each layer, correspondent with a void ratio of approximately $17.5 \%$ gravimetric water content (decided by the author from average of three samples), a section of the tailings was removed to analyse, water content, total suction, and electrical conductivity to gain an understanding of what transpired throughout the soil profile during drying.

\section{Vane shear tests}

Vane shear tests were conducted occasionally to avoid sample disturbance. A vane of varied diameters was inserted into the soil to a depth at least twice the length of the blade. Ensuring that the vane pointer was at zero, the vane head was rotated slowly at a uniform rate. The maximum deflection recorded is a direct measurement of undrained shear strength of the material in $\mathrm{kPa}$. The use of specific vane sizes required the correction of measurement using a multiplication factor of 0.5-2. 


\section{Chapter 4 COMPRehEnSIVE TAILINGS ANALYSIS}

\subsection{Settled Height vs. Total Height}

For each batch of material 4 drums were analysed for settled material vs. total material. Each drum was opened and the total weight and initial heights of the material were measured. The supernatant water, resultant of settling, was removed, weighed and the height of the settled material was recorded. The results are presented below in Table 4-1.

For the full drums, $6,7,11,13$ and 14 , the ratio of supernatant water to settled material varied with the initial height of the material with the highest initial height showing the higher ratio of decant water possibly due to the effect of weight on settling. However, for the partially-filled drums, 4 and 12, the ratio of height of decant water to settled material is much higher with Drum 12 having the least material but the highest ratio. A shorter drainage path in partially filled drums may account for higher ratios. Further analysis of the material consistency and composition in the two drums aforementioned is presented in Section 4.15 . 
Table 4-1: Analysis of settled material and supernatant water

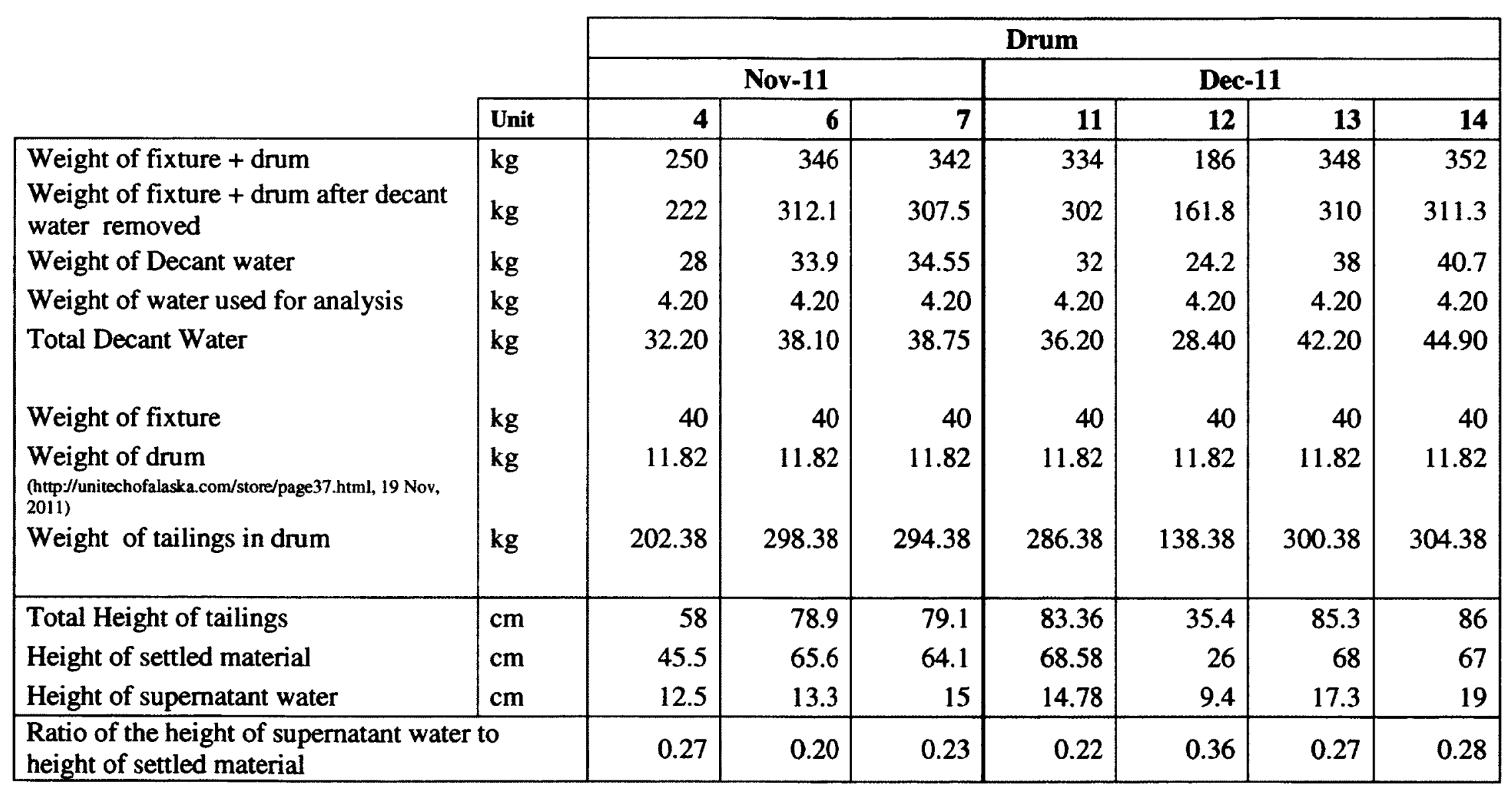




\subsection{Tailings Composition: Solids Concentration, Gravimetric Content and Bitumen Content}

The oil sands TT analysed presented an average solids concentration of $54.3 \%$ and $49.9 \%$ and gravimetric water content of $84.2 \%$ and $100.4 \%$ for the November and December batches respectively. Figure 4.1 shows results for both batches with a statistical analysis presented in Table 4-2. Exact values for each drum can be found in Table A-1.

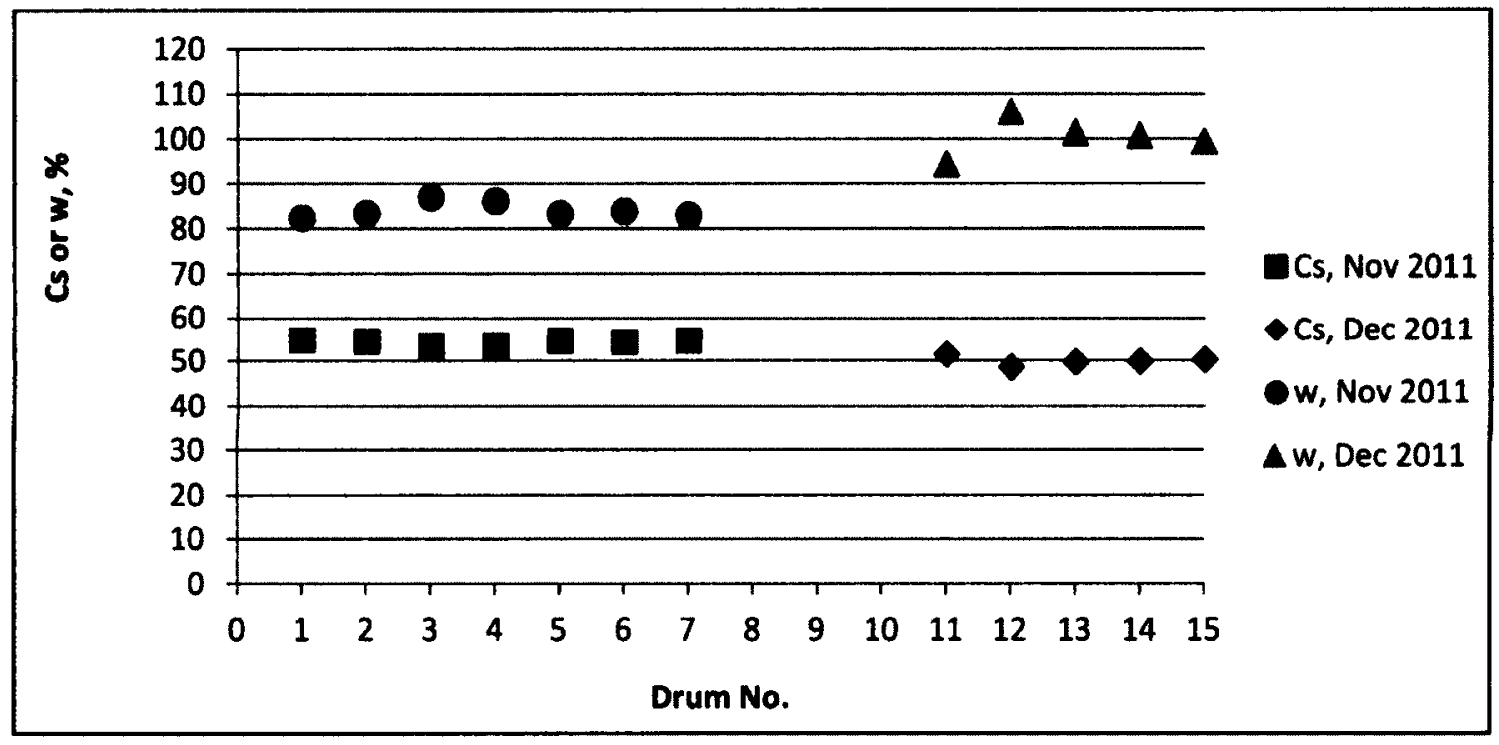

Figure 4-1: Solids Concentration and Gravimetric Water Content

Table 4-2: Statistical Analysis - Tailings Composition

\begin{tabular}{|l|c|c|c|c|}
\cline { 2 - 5 } \multicolumn{1}{c|}{} & \multicolumn{2}{c|}{ Cs (\%) } & \multicolumn{2}{c|}{ w (\%) } \\
\hline Run & Nov-11 & Dec-11 & Nov-11 & Dec-11 \\
\hline Mean & 54.2824 & 49.9454 & 84.1511 & 100.3527 \\
\hline Standard Deviation & 0.5212 & 1.0543 & 1.7066 & 4.1660 \\
\hline SEM & 0.1970 & 0.4715 & 0.6450 & 1.8631 \\
\hline $\mathrm{N}$ & 7 & 5.00 & 7.00 & 5.00 \\
\hline $\mathrm{t}$ - test & $\mathrm{P}$ & 0.00025185 & $\mathrm{P}$ & 0.000447742 \\
\hline
\end{tabular}


With $p$ values less than 0.05 , it is evident that samples are from two separate batches with significantly different solids concentrations and gravimetric water contents.

\subsection{Dean Starks Analysis}

Oil Sands TT samples were sent to an external laboratory for Dean Stark Analysis. The results show that bitumen content ranged from 0.23 to $0.44 \%$ with respect to total weight of sample. The recovery of material during the analysis ranged from 99.91 to $99.96 \%$. See Table 4-3 for results.

Table 4-3: Dean Stark Analysis Results

\begin{tabular}{|c|c|c|c|c|c|c|c|c|}
\hline & \multicolumn{4}{|c|}{ Nov-11 } & \multicolumn{4}{|c|}{ Dec-11 } \\
\hline & \multicolumn{2}{|c|}{ Drum 5} & \multicolumn{2}{|c|}{ Drum 7} & \multicolumn{2}{|c|}{ Drum 13} & \multicolumn{2}{|c|}{ Drum 14} \\
\hline & Mass (8) & $\%$ & Mass (B) & $\%$ & Mass (8) & $\%$ & Mass (8) & $\%$ \\
\hline Bitumen & 5.78 & 0.44 & 4.97 & 0.38 & 5.5 & 0.44 & 3.53 & 0.28 \\
\hline Solids & 704.17 & 54.18 & 709.87 & 54.20 & 619.73 & 49.52 & 627.9 & 49.56 \\
\hline Water & 589.78 & 45.38 & 594.86 & 45.42 & 626.24 & 50.04 & 635.52 & 50.16 \\
\hline $\begin{array}{l}\text { Total Mass } \\
\text { recovered }\end{array}$ & 1299.73 & 100 & 1309.7 & 100 & 1251.47 & 100 & 1266.95 & 100 \\
\hline $\begin{array}{l}\text { Total sample } \\
\text { mass }\end{array}$ & \multicolumn{2}{|c|}{1300.2} & \multicolumn{2}{|c|}{1310.9} & \multicolumn{2}{|c|}{1258.4} & \multicolumn{2}{|c|}{1267.6} \\
\hline \% recovery & \multicolumn{2}{|c|}{0.9996} & \multicolumn{2}{|c|}{0.9991} & \multicolumn{2}{|c|}{0.9945} & \multicolumn{2}{|c|}{0.9995} \\
\hline
\end{tabular}

Junqueira et al, (2011) presented results for bitumen on oil sand TT from the Total E\&P Pilot Plant, with respect to total sample as less than 5\% residual bitumen. It must be noted that during transportation, storage and handling, significant amounts of Bitumen were lost to the walls and covers of drums evidenced from visual inspection of the drums. 


\subsection{Average Organic Content}

Average organic content with respect to the total sample was measured and the results can be found in Figure 4-2 below. The averages were $1.86 \%$ (Nov) and $1.76 \%$ (Dec). A summary of the results including average $g$ of volatiles per gram of solid can be found in Table A-4. These values are much higher when compared to the results of the Dean Stark analysis although they match results from Yao et al. (2010) and Kaminsky (2008).

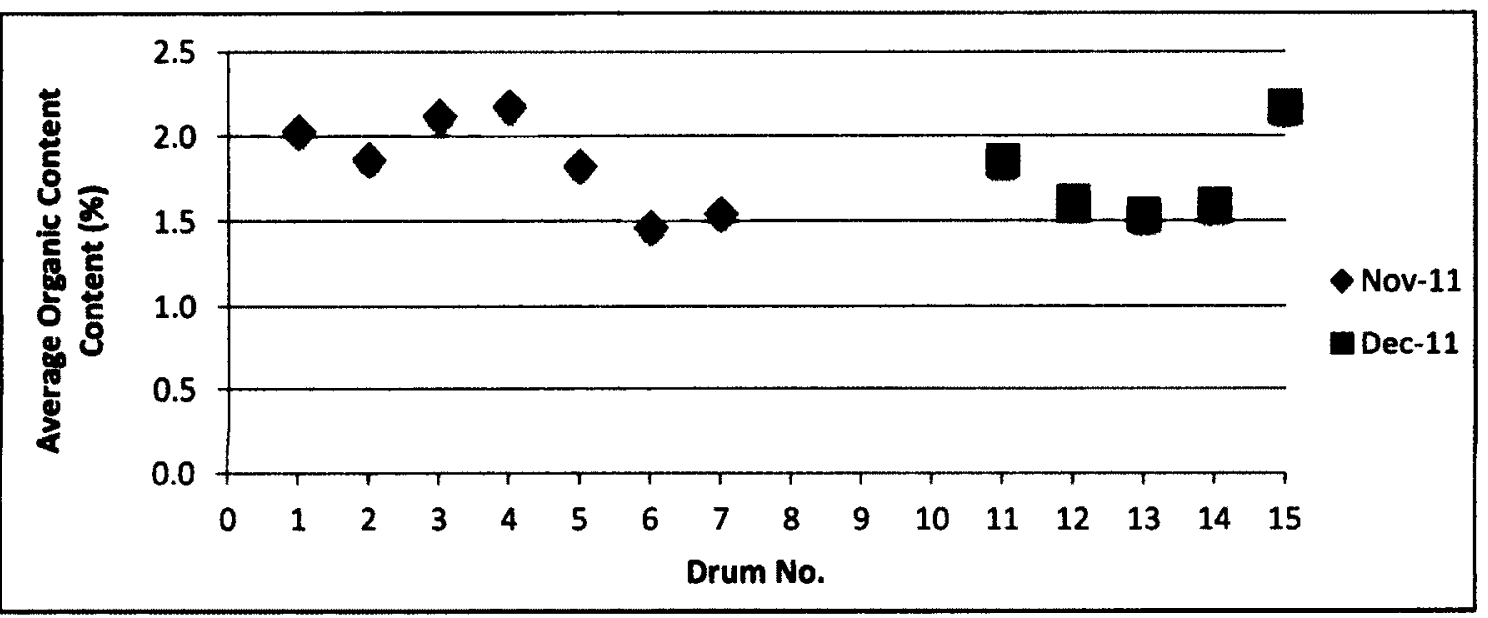

Figure 4-2: Average Organic Content (wrt whole sample)

\subsection{Total (Wet) Density}

Estimated average wet density values are 1562 and $1549 \mathrm{~kg} / \mathrm{m}^{3}$ for November and December respectively. Figure 4-3 shows the results of density tests. Exact values and statistical analysis are presented in Appendix A, Tables A-2 and A-3. 


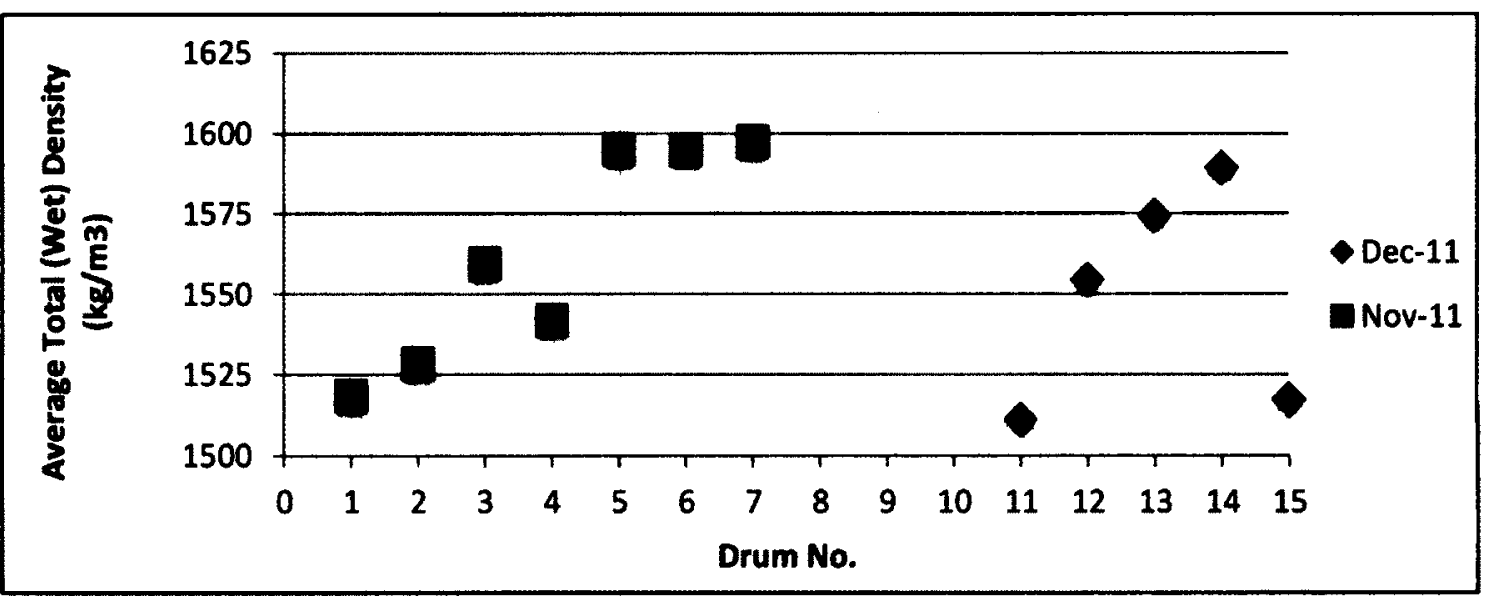

Figure 4-3: Tailings Total (Wet) Density

From the data presented, it shows that there is some variation in the densities for each batch and between batches. This could be due to the accuracy of the method applied for density measurement.

\subsection{Atterberg Limits and Soil Classification}

Results for Atterberg Limits are shown in Figures 4-4 and 4-5. Full results are reported in Appendix B.

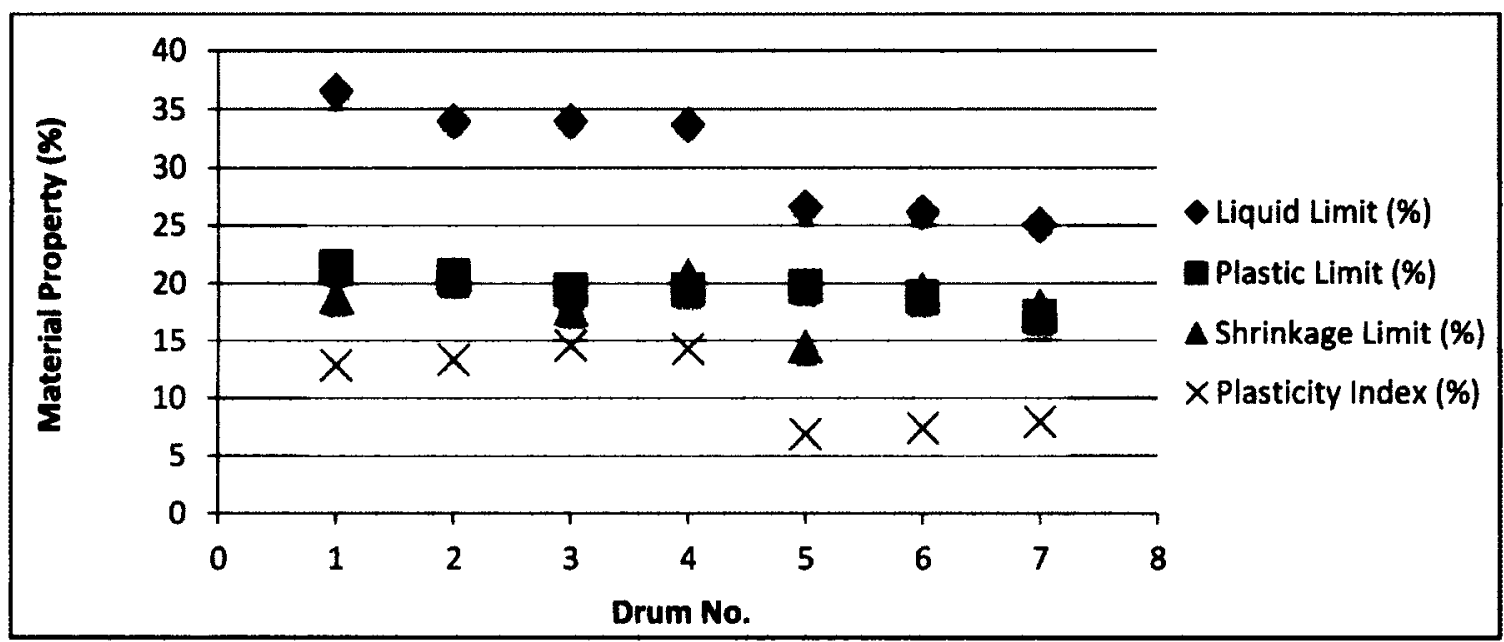

Figure 4-4: Atterberg Limits - November 2011 


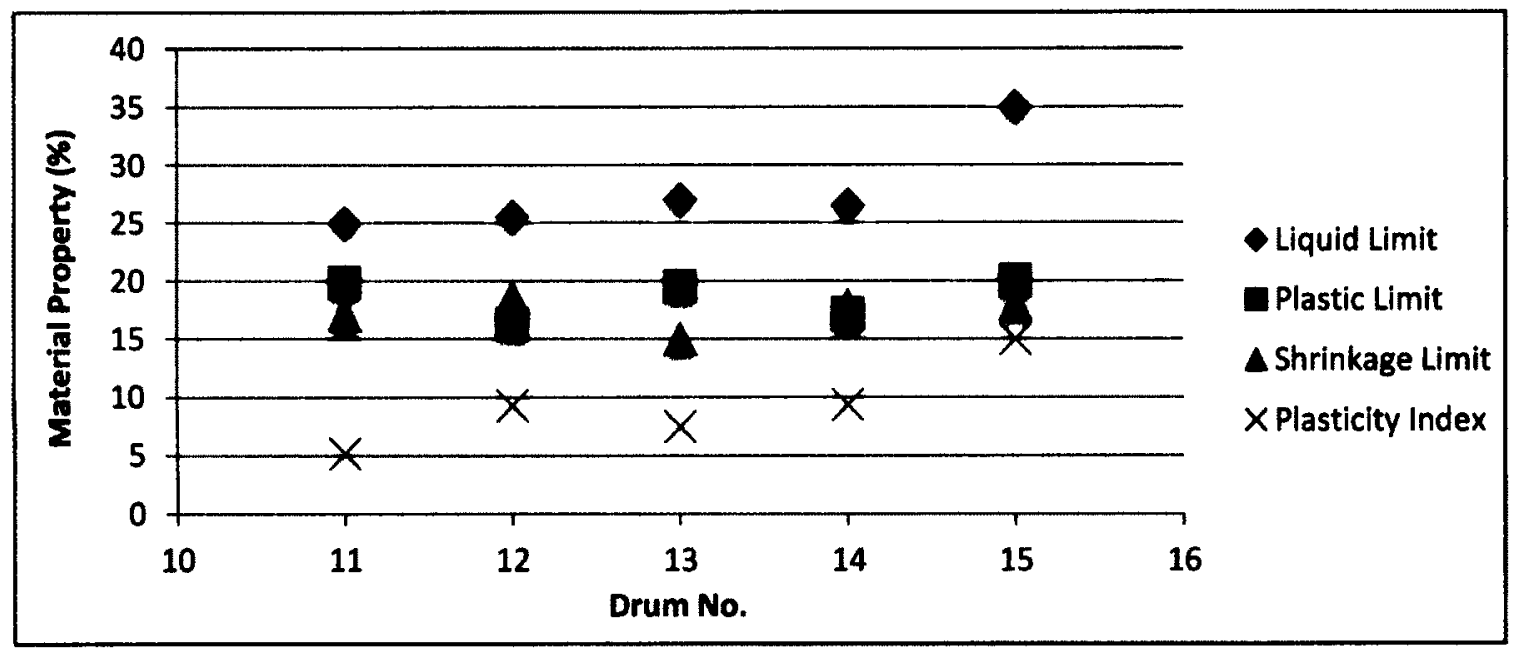

Figure 4-5: Atterberg Limits - December 2011

Average values of liquid limits and plasticity indices of $30.88 \%$ and $11 \%$ respectively for the month of November (red dot) and $27.8 \%$ and $9.25 \%$ for the month of December (pink dot) classify the materials as clay with November showing immediate plasticity and December low plasticity shown in Figure 4-6. The first four drums of the November batch and one drum from the December batch show an average liquid limit of 35 and an average plasticity index of 14 (green dot). These classify with higher plasticity.

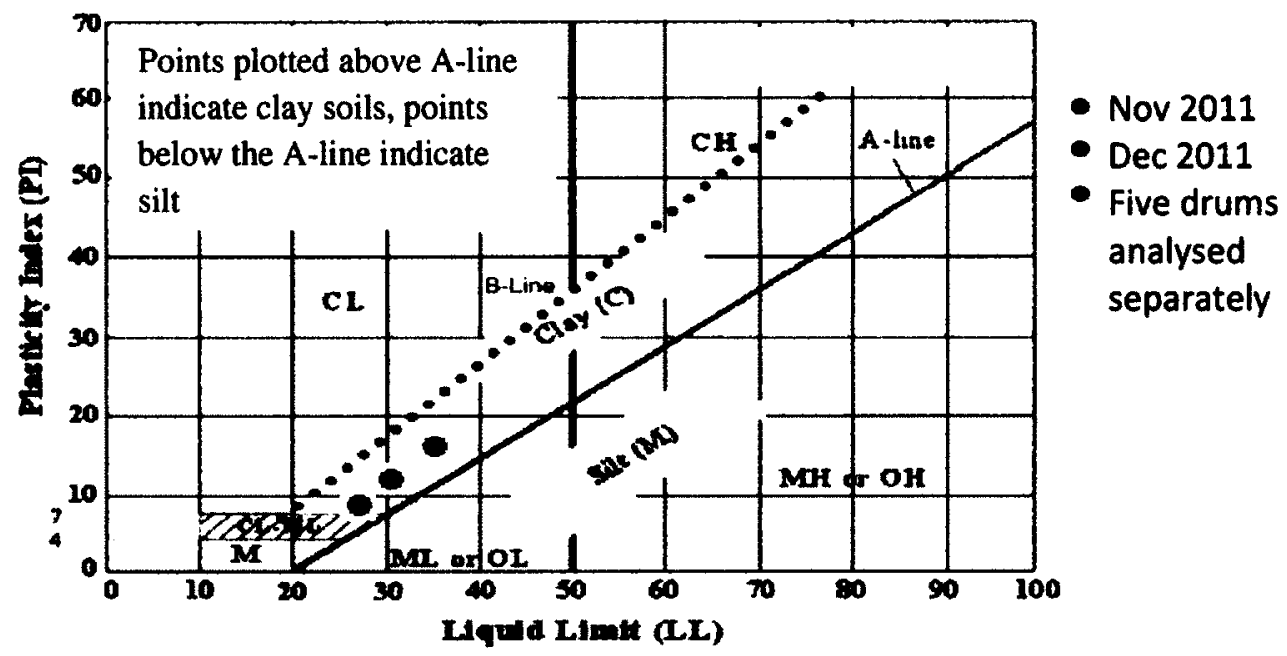

Figure 4-6: Plasticity Chart (Geotech Wiki, 2012) 
The liquid limit is affected by the chemistry of the pore water. The water chemistry results presented in Section 3.9 show variation in water chemistry in particular concentration of sodium ions, sulphate and chlorine.

Results were compared to those of two thickened tailings reported in literature from Fort Mc Murray to assess variability in TT production and characteristics. From literature review, Wijermars (2011) reported Atterberg limits in Table 4-4 from tests performed on oil sand TT from the Albian Sands Muskeg River Mine at Fort McMurray which had a solids concentration of $40-50 \%$. Both his results and that of Yao et al. (2010) show higher $\mathrm{LL}$ and PI. In the case of PL, values fell within the range stated by Yao et al.

Table 4-4: Reported Atterberg Limits

\begin{tabular}{|l|c|c|c|c|}
\cline { 2 - 5 } \multicolumn{1}{c|}{} & \multicolumn{2}{c|}{ Author } & \multicolumn{2}{c|}{ Current Study (Average) } \\
\hline Property & (Wijermars, 2011) & (Yao et al., 2010) & Nov & Dec \\
\hline Liquid Limit (\%) & 38.1 & $40-70$ & 30.88 & 27.8 \\
\hline Plastic Limit (\%) & 21 & $16-27$ & 19.5 & 18.5 \\
\hline PI (\%) & 17 & $20-30$ & 11 & 9.25 \\
\hline
\end{tabular}

\subsection{Specific Gravity, $G_{s}$}

The average specific gravity of both batches of tailings determined in the laboratory was 2.55. One of the challenges encountered on using the Flask method was a small degree of foaming in some cases. The foaming hindered accurate levelling of the volume inside the flask after vacuuming. Figure 4-7 shows the results with a summary in Appendix C, Tables C-1 and C-2. 


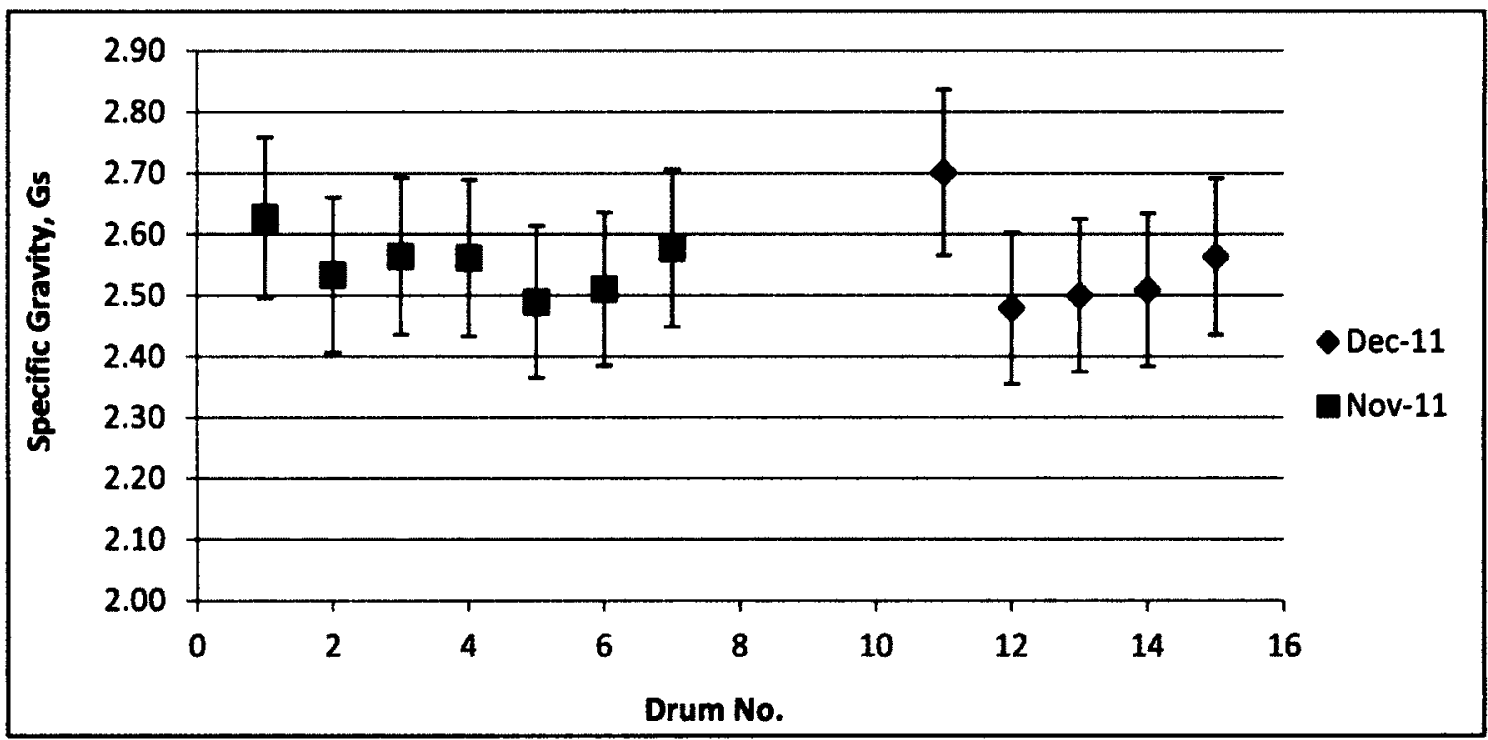

Figure 4-7: Specific Gravity

Within a $95 \%$ confidence interval, one drum was very different from the rest, having a value of 2.7. Values of $\mathrm{G}_{\mathrm{s}}$ appear to be a little low in some cases (esp. sectional analysis). This may be due in some part to the bitumen attachment to the fine mineral particles. Bitumen has a low specific gravity.

\subsection{Grain Size Distribution}

Results from the dispersed and non-dispersed tests are presented in Appendix C, Figures C-1 to C-12 and with a summary and statistical analysis of key parameters found in Tables C-3 and C-4. Clay fraction from the GSD data varies from 14 to $25 \%$ in the samples analysed whereas MBI tests reveal higher percentages of clay, between 31 and $38 \%$. Thickened tailings from previous studies of $40-50 \%$ solids concentration show a clay content range of 5 to $20 \%$ and for MFT 30 to $50 \%$ Yao et al. (2010). The tailings utilized by Junqueira et al. (2012) had a clay fraction of $17 \%$. 


\subsection{Solids to Fines Ratio, SFR}

In Oil Sand Tailings terminology, the Sands to Fines Ratio (SFR) is referred to as the ratio between sands content (larger than 44 microns) to fines content (smaller than 44 microns). Using GSD data, the average SFRs were 1.05 and 0.8 for the November $(\mathrm{Cs}=$ $54 \%)$ and December $(\mathrm{Cs}=49 \%)$ batches respectively. See Table 4-5. Fredlund et al. (2011) report values of 0.8 for thickened tailings sample with the following Atterberg limits:

- Plastic limit: $15 \%$

- Liquid Limit: $38 \%$

Values of SFR range from 0.7 to 1.4 at the bottom of the thickener based on ore grade and season (Total E\&P, 2010).

Table 4-5: SFR results

\begin{tabular}{|c|c|c|}
\hline Date of Run & $\begin{array}{c}\text { Drum } \\
\text { No }\end{array}$ & \multicolumn{1}{c|}{ SFR } \\
\hline \multirow{5}{*}{ Nov-11 } & 1 & 1.08 \\
\cline { 2 - 3 } & 2 & 1.17 \\
\cline { 2 - 3 } & 3 & 1.08 \\
\cline { 2 - 3 } & 4 & 0.92 \\
\cline { 2 - 3 } & 5 & 1.00 \\
\cline { 2 - 3 } & 6 & 1.04 \\
\cline { 2 - 3 } & 7 & 0.98 \\
\hline \multirow{5}{*}{ Dec-11 } & 11 & 0.67 \\
\cline { 2 - 3 } & 12 & 0.92 \\
\cline { 2 - 3 } & 13 & 0.72 \\
\cline { 2 - 3 } & 14 & 0.69 \\
\cline { 2 - 3 } & 15 & 0.79 \\
\hline
\end{tabular}

\begin{tabular}{|l|c|c|}
\hline Run & Nov-11 & Dec-11 \\
\hline Mean & 1.0507 & 0.7978 \\
\hline $\begin{array}{l}\text { Standard } \\
\text { Deviation }\end{array}$ & 0.0852 & 0.1433 \\
\hline SEM & 0.0348 & 0.0641 \\
\hline $\mathrm{N}$ & 6 & 5.00 \\
\hline Ttest & $\mathrm{P}$ & 0.012429 \\
\hline
\end{tabular}




\subsection{Water Chemistry}

Since the drums were shipped and left to rest for a few months, a supernatant was observed for all the drums due to the settling which occurred. The supernatant was analyzed by Exova Accutest Ottawa and results for major cations, anions, conductivity and other parameters are presented below in Figures 4-8 to 4-14. The information listed below is important for analyzing the graphs in the following subsections:

1. November batch: Average $\mathrm{Cs}=54 \%-$ Drums $1-10$

2. December Batch: Average Cs $=50 \%$ Drums $11-15$

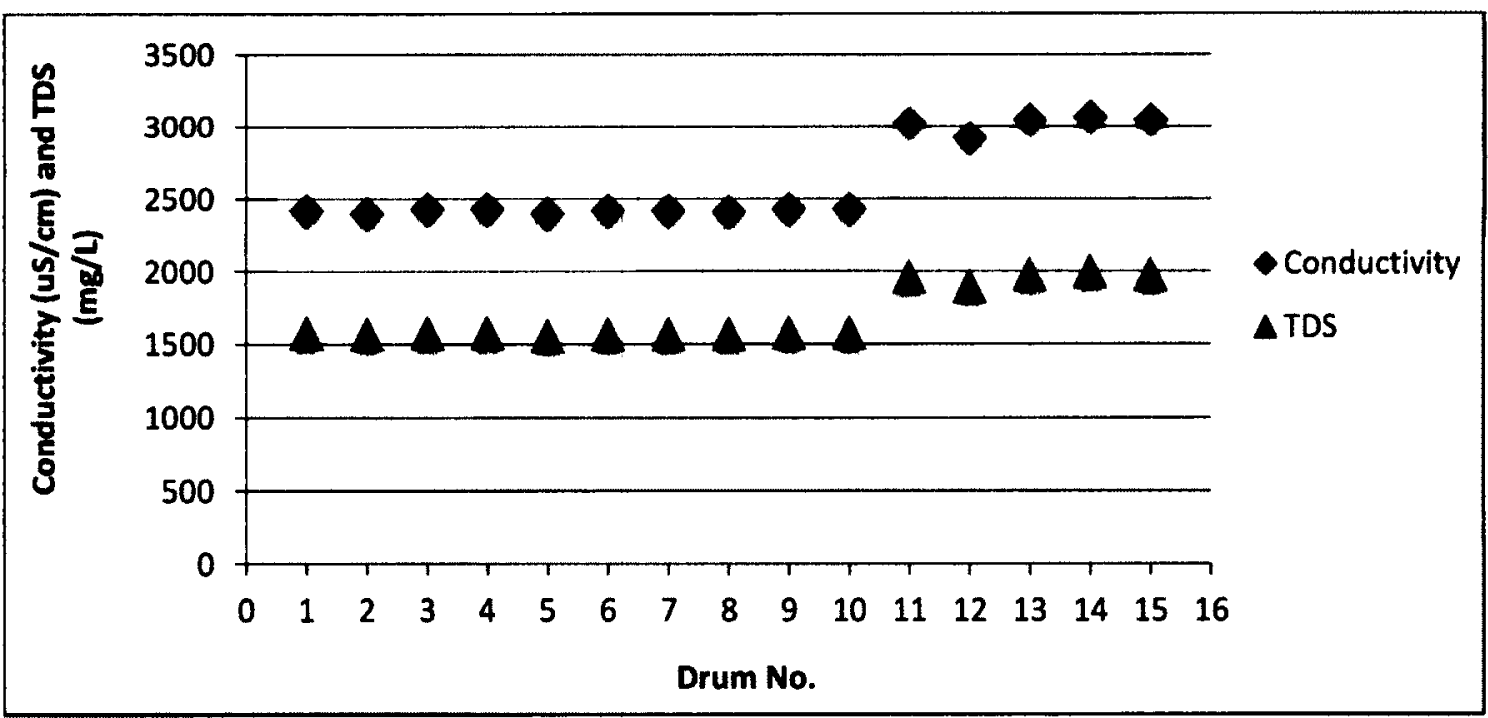

Figure 4-8: General Water Chemistry Data (Conductivity and TDS)

Dissolved solids contained in the pore-water sampled are generally soluble salts that yield ions and they include cations such as sodium $\left(\mathrm{Na}^{+}\right)$, magnesium $\left(\mathrm{Mg}^{2+}\right)$ and calcium $\left(\mathrm{Ca}^{2+}\right)$, and anions such as bicarbonate $\left(\mathrm{HCO}^{3-}\right)$, sulphate $\left(\mathrm{SO}_{4}{ }^{2-}\right)$, and chloride $\left(\mathrm{Cl}^{-}\right)$. Higher TDS values shown in Figure 4-8 for the December batch correspond with 
the major cations and anions analyses conducted on the same material which will be discussed later. Through the use of a conductivity probe the ions' ability to conduct an electrical current was analysed and results match the TDS values which imply that higher concentration of dissolved ions, especially monovalent one, correspond to higher electrical conductivity. See Figure 4-8 for results. More detailed results are presented in Appendix $\mathrm{H}$.

Cationic and Anionic concentrations give a clearer picture of the pore-water makeup. Figure 4-9 show that for cations such as $\mathrm{Ca}, \mathrm{Mg}$ and $\mathrm{K}$, there was no significant difference in concentrations while Fe concentrations were non-uniform but not in very high concentrations.

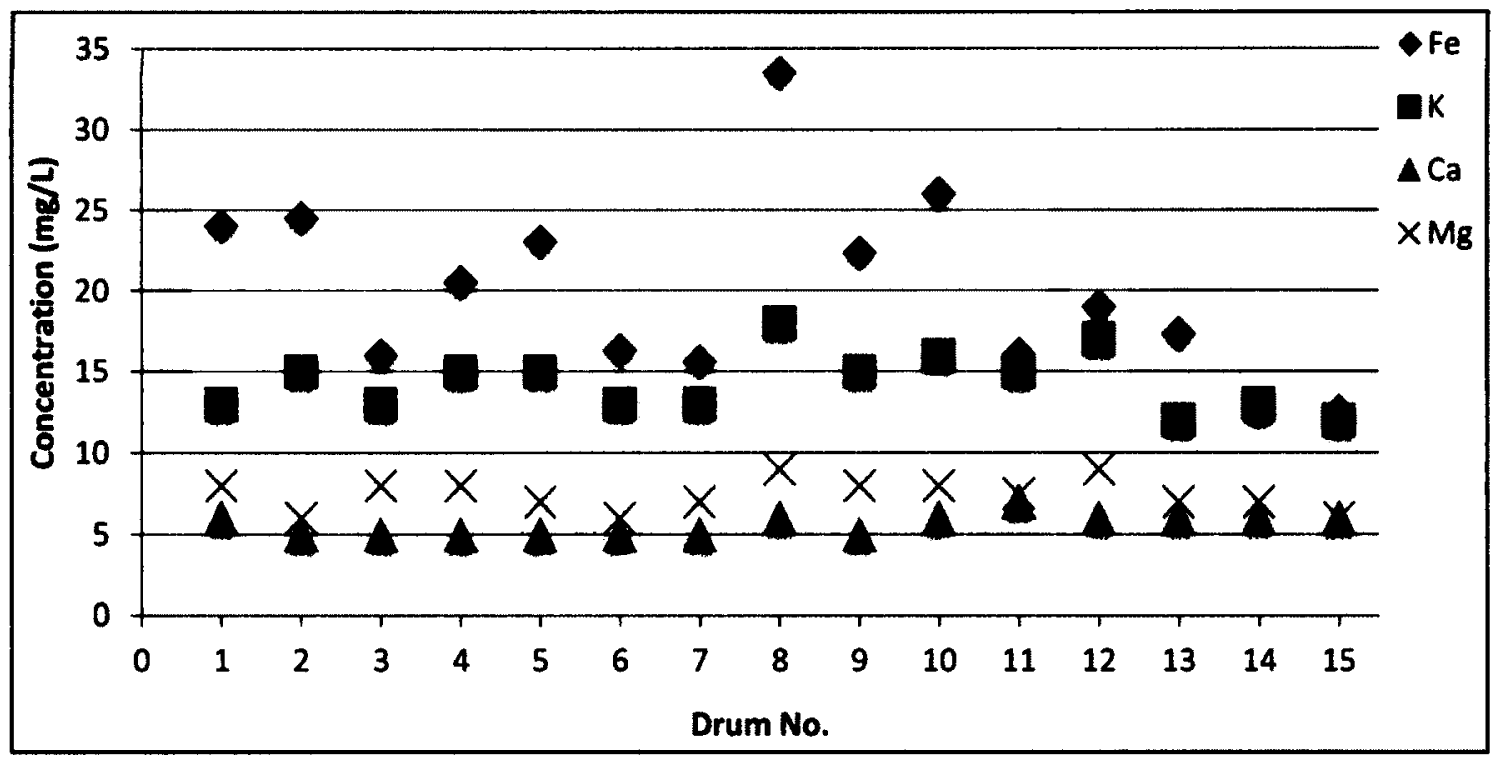

Figure 4-9: General Water Chemistry Data (Major Cations - Fe, K, Ca, Mg)

In contrast, $\mathrm{Na}$ concentrations (Figure 4-10) were significantly higher for the December batch with an average of $527 \mathrm{mg} / \mathrm{L}$ for November and $660 \mathrm{mg} / \mathrm{L}$ for December. 


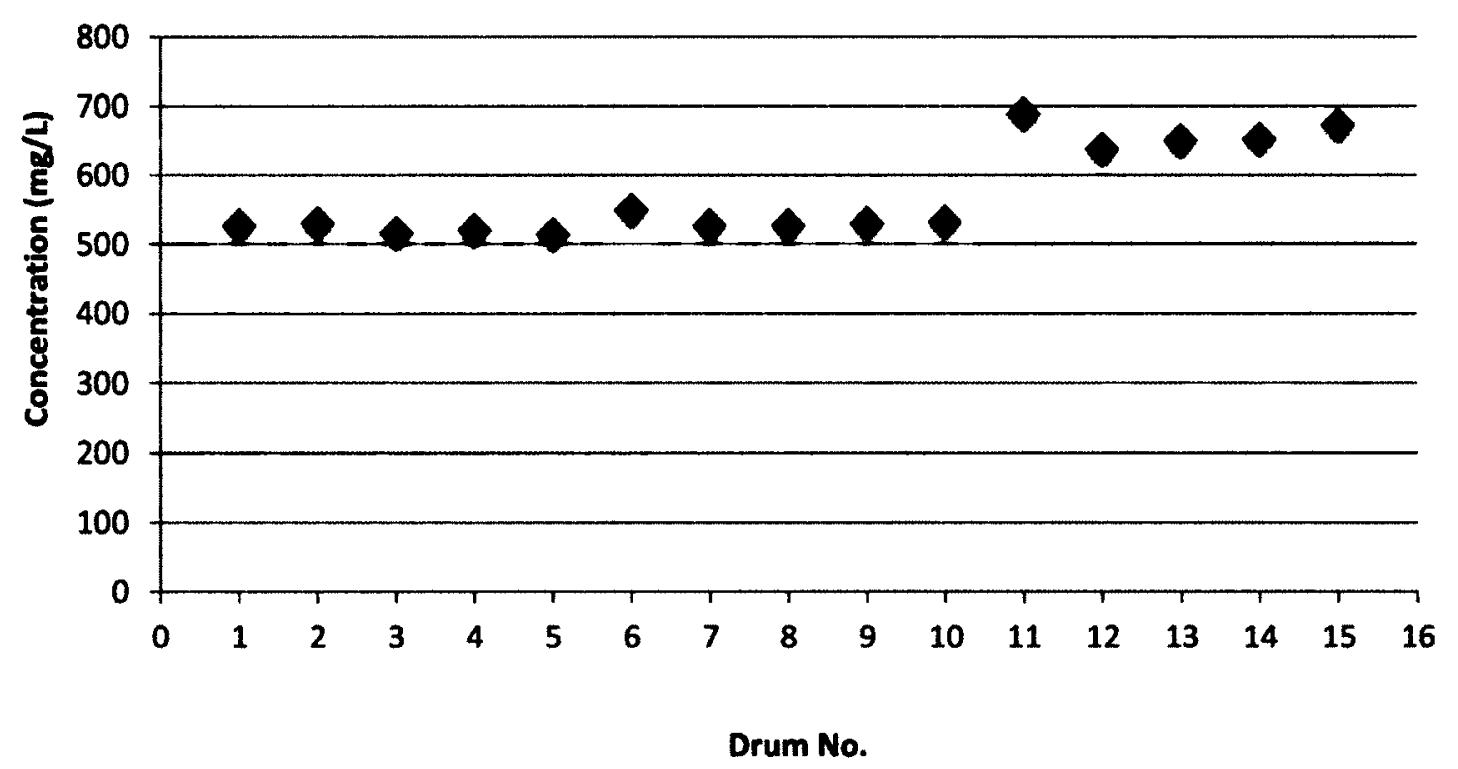

Figure 4-10: General Water Chemistry Data (Major Cation - Sodium)

Anionic Concentrations of bicarbonate $\left(\mathrm{HCO}_{3}\right)$ and carbonate $\left(\mathrm{CO}_{3}\right)$ are comparable for both batches however concentrations of sulphate $\left(\mathrm{SO}_{4}\right)$ and chloride $(\mathrm{Cl})$ are greater for samples from the December batch. Concentrations are presented in Figures 4-11 and 412. With average sulphate concentrations of 12 versus $74 \mathrm{mg} / \mathrm{L}$ and chloride concentrations of 322 versus $449 \mathrm{mg} / \mathrm{L}$ for November and December batches respectively, the December batch of thickened tailings presents a greater ionic concentrations and this explains higher TDS and EC values. 


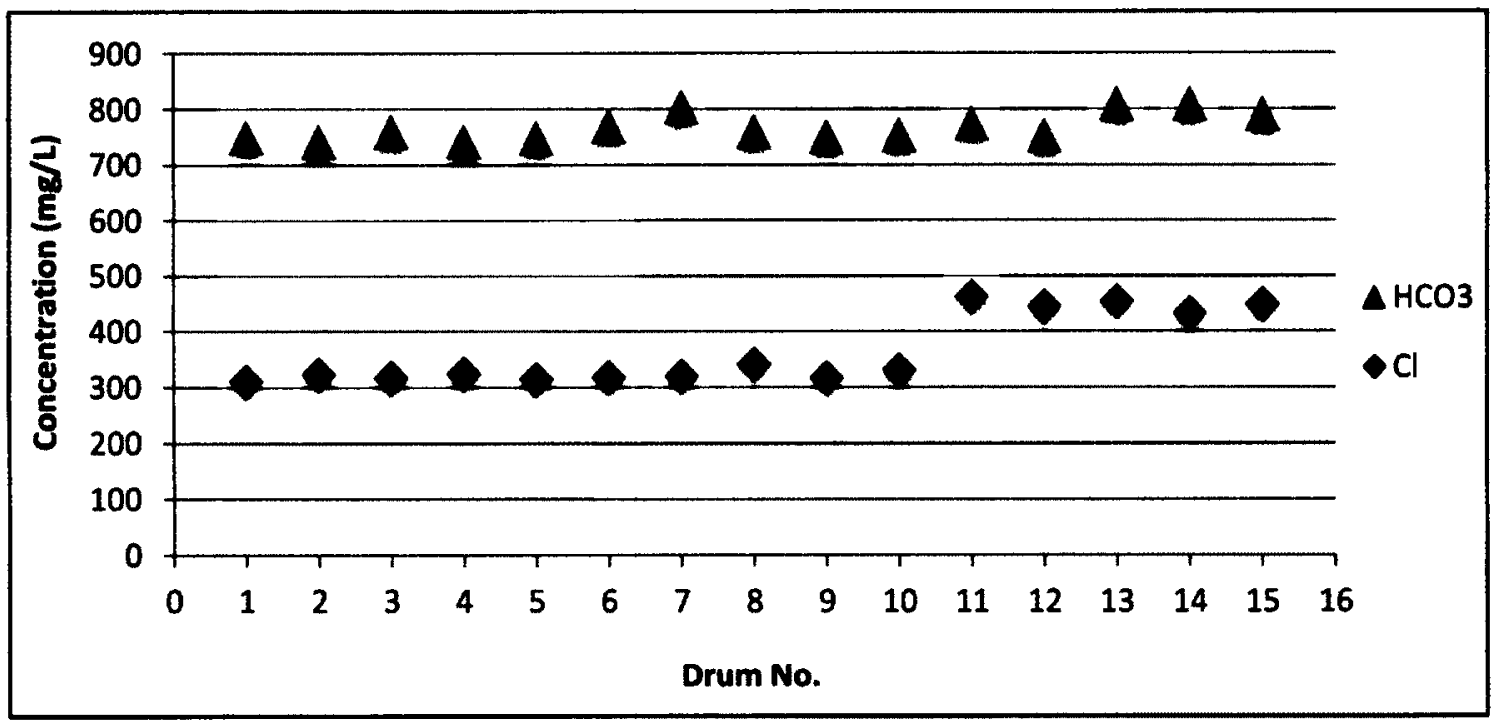

Figure 4-11: General Water Chemistry Data (Major Anions - Bicarbonate and Chloride)

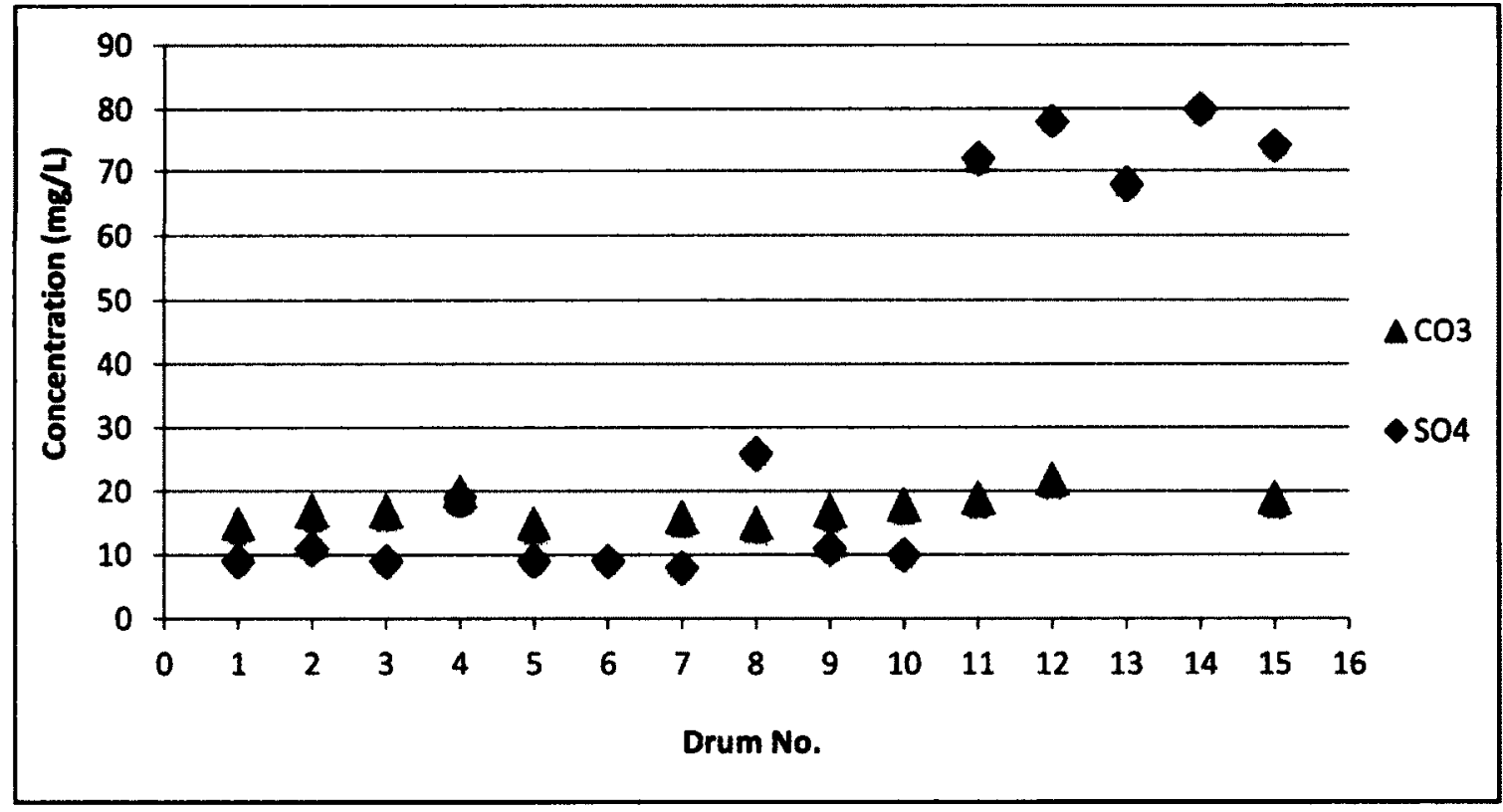

Figure 4-12: General Water Chemistry Data (Major Anions - Carbonate and Sulphate)

Suspended solids in the pore-water include stirred up sediment or fines left in suspension. Measured as total suspended solids (TSS), Figure 4-13 shows that values 
vary much across the samples and this is due mainly to the degree of settlement which occurred in each drum and also the method of collection of samples.

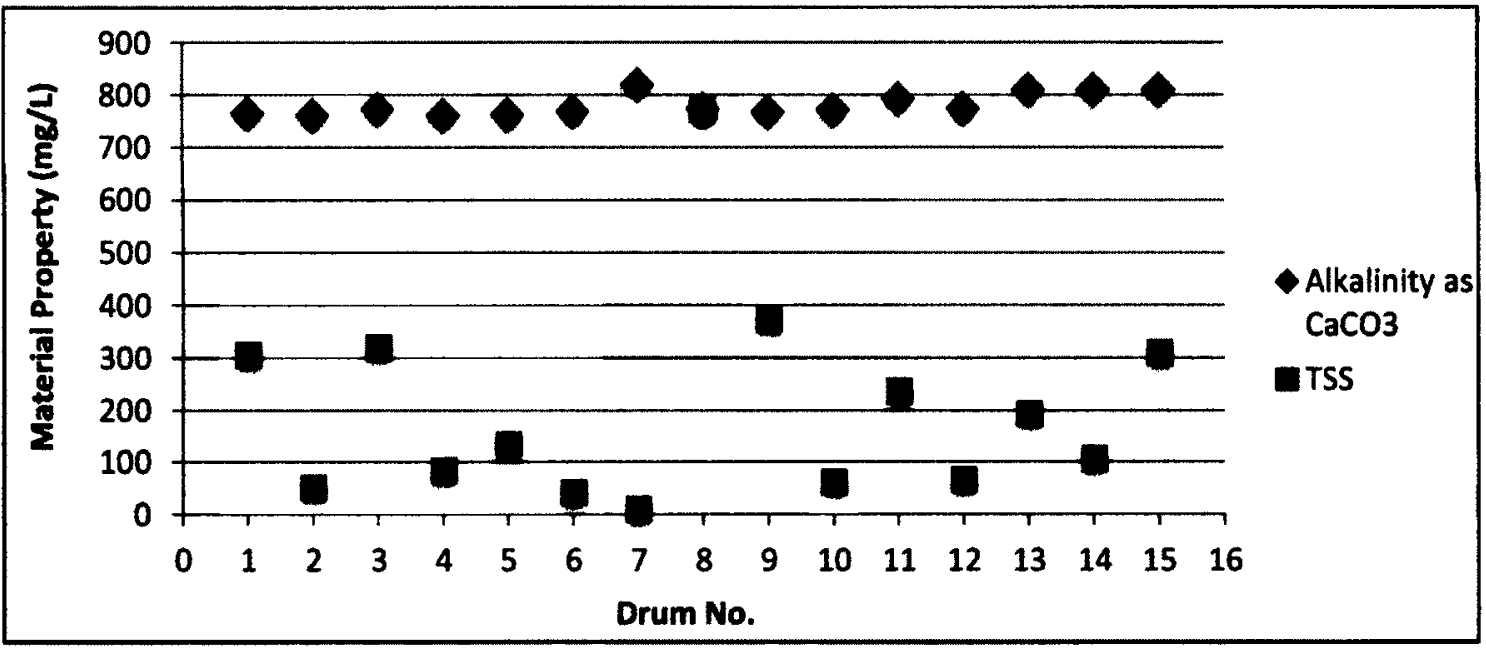

Figure 4-13: General Water Chemistry Data (TSS and Alkalinity)

In the same graph, the alkalinity in terms of $\mathrm{CaCO}_{3}$ reveals that generally pore water samples from both batches had high acid neutralizing capacity, accounting for the general high $\mathrm{pH}$ values of the samples presented in Figure 4-14. Although $\mathrm{pH}$ results appear very scattered, the range of the data is very small, $8.23-8.46$.

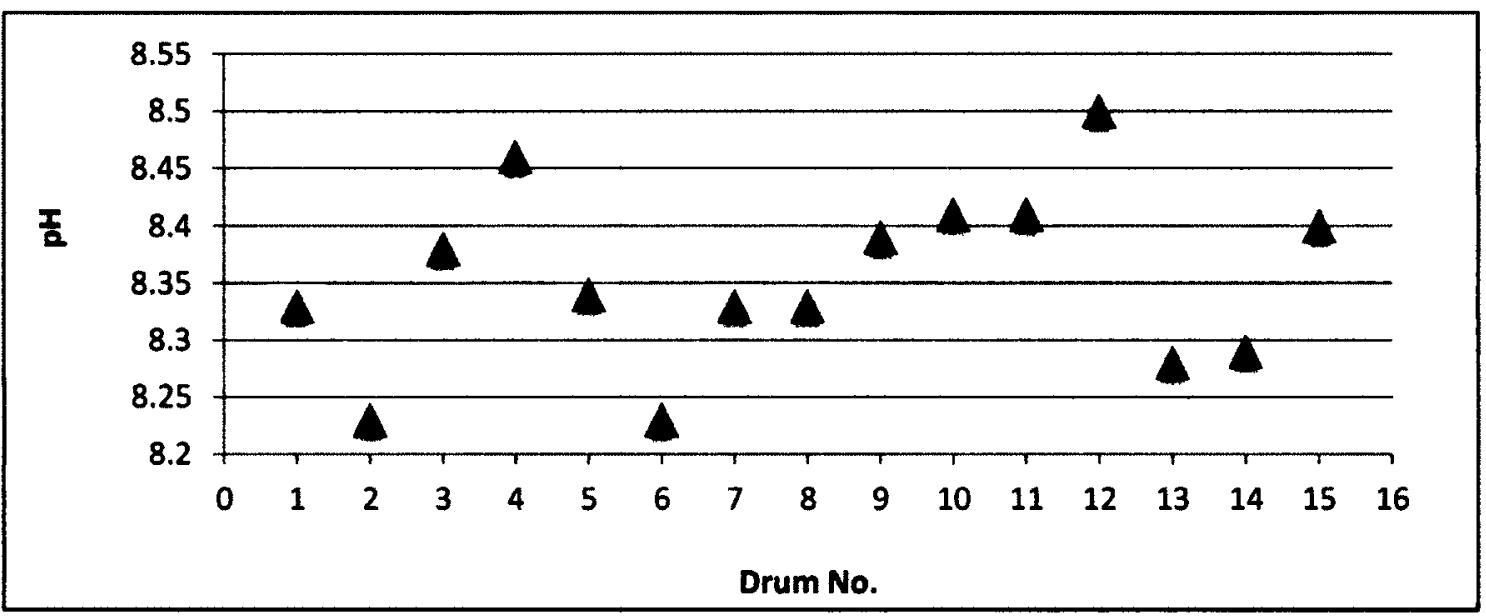

Figure 4-14: General Water Chemistry Data $(\mathrm{pH})$ 
When compared to thickened gold tailings from the Bulyanyulu site, concentrations of magnesium and sulphate are lower than those found in gold tailings while average sodium concentrations are higher in oil sands TT. Electrical Conductivities are also smaller. Results from gold tailings used by Fissheha et al. (2010) used in an evaporation study of thickened tailings are presented in Table 4-6 along with the average values for the oil sand thickened tailings samples analyzed for this research.

Table 4-6: Composition of Bulyanyulu gold tailings (Fissheha et al., 2010) and Oil sand tailings

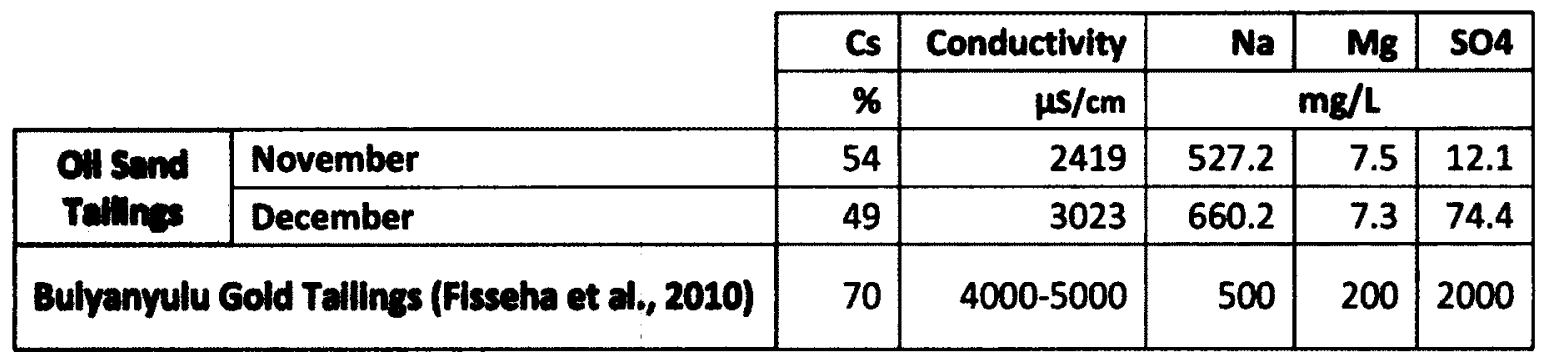

\subsection{Methylene Blue Index (MBI) and Clay Fraction}

Table 4-7 shows results from external analysis of $\mathrm{MBI}$ and calculated clay percentages. Average values are presented for each run. Average clay fractions are higher than those from dispersed tests (Appendix C, table C-3) which may mean that clay minerals may be present in the silt size portion of the tailings sample.

Table 4-7: MBI Data

\begin{tabular}{|c|c|c|c|c|c|c|c|c|}
\hline & \multicolumn{3}{|c|}{ Nov-11 } & \multirow[b]{2}{*}{ Average } & \multicolumn{3}{|c|}{ Dec-11 } & \multirow[b]{2}{*}{ Average } \\
\hline & $\begin{array}{c}\text { Drum } \\
4\end{array}$ & $\begin{array}{c}\text { Drum } \\
5\end{array}$ & $\begin{array}{c}\text { Drum } \\
7\end{array}$ & & $\begin{array}{c}\text { Drum } \\
12\end{array}$ & $\begin{array}{c}\text { Drum } \\
13\end{array}$ & $\begin{array}{c}\text { Drum } \\
14\end{array}$ & \\
\hline $\begin{array}{l}\text { Methylene Blue } \\
\text { Index (meq/100 g) }\end{array}$ & 4.6 & 4.3 & 4.8 & 4.57 & 5.4 & 5.2 & 5 & 5.2 \\
\hline $\begin{array}{l}\text { Calculated Clay } \\
\text { percentage (\%) }\end{array}$ & 33 & 31 & 35 & 33 & 39 & 38 & 36 & 37.67 \\
\hline
\end{tabular}


The average methylene blue surface area is that of $38 \mathrm{~m}^{2} / \mathrm{g}$. In the characterization exercise carried out Kaminisky (2008) on tailings fractions a MBI of 9 meq/100g was obtained with a surface area of $69 \mathrm{~m}^{2} / \mathrm{g}$ representative of the 0.2 to 2 micron fraction. This shows lower activity for the TT. The equation used it the calculation of the surface area is:

$S A\left(\mathrm{~m}^{2} / g\right)=M B I \times S A_{M B} \times 0.0602 \mathrm{~m}^{2} / g$

where $S A_{M B}$ is the surface area of a molecule of methylene blue $\left(1.30 \mathrm{~nm}^{2} /\right.$ molecule).

\subsection{XRD and XRF Analyses}

\subsubsection{XRD External Lab Analysis}

The samples received by the external laboratory were pulverized with one portion being mixed with $10 \%$ wt corundum and loaded into a standard holder. The Rietveld method was used in the determination of the quantities of crystalline mineral phases. Clay speciation was not performed by the company as absence of expandable clay was first reported but a new request was made on the sample to identify mixed layer clay patterns. The $<2$ micron fraction was separated from each sample through gravity settling after dispersion in distilled water. Oriented slides of the $<2$ micron were prepared by placing suspension on glass slide. Expandable clay minerals were identified through the air dry analysis of these oriented slides having been saturated with ethylene glycol and heated for one hour at $375^{\circ} \mathrm{C}$. 
The equipment used was a Panalytical X'Pert Pro diffractometer equipped with $\mathrm{Cu}$ $\mathrm{X}$-ray source and an $\mathrm{X}$ 'cCelerator detector operating at the following conditions:
a. $40 \mathrm{kV}$ and $40 \mathrm{~mA}$
b. Range $4-80 \operatorname{deg} 2 \theta$
c. Step size: $0.017 \mathrm{deg} 2 \theta$
d. Time step: 50.165
e. Fixed divergence stit
f. Angle: $0.5^{\circ}$
g. Sample rotation: $1 \mathrm{rev} / \mathrm{s}$

Results from the XRD performed on the bulk samples are given in Table 4-8 where it can be noted that the main minerals identified were quartz, kaolinite, muscovite (includes illite) and k-feldspar. Diffraction Patterns are shown in Appendix D, figures D-1 and D-2. The sample also contains amorphous material.

Table 4-8: Minerals identified and their quantitative amounts (bulk sample analysis) wt $\%$

\begin{tabular}{|l|l|l|l|l|}
\hline Quartz & Kaolinite & Muscovite & K-Feldspar & Amorphous \\
\hline 50.1 & 15.9 & 8.7 & trace & 25.3 \\
\hline 51.1 & 18.8 & 8.4 & trace & 21.7 \\
\hline
\end{tabular}

Clay speciation was later performed and results show that in the $<2$ micron fraction of the samples, the illite may contain about $10 \%$ smectite component. This is indicated by the illite peak at $9.9 \AA$ being asymmetric in the low angle direction and 
sharper after the saturation with ethylene glycol and heating (See Appendix D, Figures D-3 to D-10 for diffraction patterns of $<2$ micron fraction).

The shift in peak from $14.1 \AA$ to $14.6 \AA$ after saturation with ethylene glycol, points to the presence of trace amounts of mixed layered chlorite smectite. Summary of results from the $<2$ micron fraction are presented below in Table 4-9.

Table 4-9: Clay minerals identified in the $<2$ micron fraction and their semi-quantitative amounts (wt \%)

\begin{tabular}{|l|l|}
\hline Kaolinite & Illite \\
\hline 40 & 60 \\
\hline 39 & 61 \\
\hline
\end{tabular}

Illite and Kaolinite are not the sole contributors to the large surface area of the fine tailings (Omotoso et al., 2002). Other suggested contributors were discrete montmorillonite and mixed layered clays like smectite- kaoline and smectite-illite. Omotoso et al., following up on previously conducted studies, investigated the clay mineralogy of mature fine tailings from two different sites in Fort McMurray. Results show that the mixed layered clays indeed constitute the clay fraction of these tailing sand may be responsible for the high surface area.

Omotoso et al. (2002) measured X- Ray powder patterns on a high resolution beamline X3B1 using a wavelength of $0.7 \AA$. Using 1-D patterns generated from NEWMOD $^{\mathrm{TM}},<2 \mu \mathrm{m}$ and $<0.2 \mu \mathrm{m}$ rendered unidentical patterns for $\mathrm{K}$-saturated and Casaturated. For illite, the layers collapse to $10 \AA$ after K- saturation and dehydration while for kaoline dehydration causes low angle broadening of $7.2 \AA$, a result of the collapse of 
smectite layers in the kaolinite and the higher d-spaced mixed layer reflection in the glycolated kaolinite.. Chlorite was also observed in the drawdown at $14 \AA$ but only in minute quantities. Higher order reflections reveal the mixed layer effects. As mentioned earlier, similar but less pronounced results were obtained for the samples analysed. Interstratification was observed both at the $10 \AA$ illite and the $7.2 \AA$ kaolin peaks.

\subsubsection{XRF External Lab Analysis}

Elemental composition of tailings bulk samples are presented in Table 4-10.

Table 4-10: Elemental composition

\begin{tabular}{|l|l|l|l|l|l|}
\hline Analyte symbol & \multicolumn{2}{|l|}{ Value } & Unit & Detection Limit & Analysis Method \\
\hline Al2O3 & 9.72 & 9.72 & $\%$ & 0.01 & FUS-XRF \\
\hline CaO & 0.15 & 0.12 & $\%$ & 0.01 & FUS-XRF \\
\hline Cr2O3 & 0.01 & 0.01 & $\%$ & 0.01 & FUS-XRF \\
\hline Co304 & $<0.005$ & $<0.005$ & $\%$ & 0.005 & FUS-XRF \\
\hline CuO & $<0.005$ & $<0.005$ & $\%$ & 0.01 & FUS-XRF \\
\hline Fe2O3(T) & 1.47 & 1.49 & $\%$ & 0.01 & FUS-XRF \\
\hline K2O & 1.5 & 1.5 & $\%$ & 0.01 & FUS-XRF \\
\hline LO1 & 5.18 & 5.2 & $\%$ & & FUS-XRF \\
\hline MgO & 0.38 & 0.37 & $\%$ & 0.01 & FUS-XRF \\
\hline MnO & 0.027 & 0.03 & $\%$ & 0.001 & FUS-XRF \\
\hline Na2O & 0.25 & 0.23 & $\%$ & 0.01 & FUS-XRF \\
\hline NiO & $<0.003$ & $<0.003$ & $\%$ & 0.003 & FUS-XRF \\
\hline P2O5 & 0.04 & 0.04 & $\%$ & 0.01 & FUS-XRF \\
\hline SiO2 & 79.45 & 79.94 & $\%$ & 0.01 & FUS-XRF \\
\hline TiO2 & 0.4 & 0.42 & $\%$ & 0.01 & FUS-XRF \\
\hline V205 & 0.01 & 0.011 & $\%$ & 0.003 & FUS-XRF \\
\hline Total & 98.59 & 99.08 & $\%$ & 0.01 & FUS-XRF \\
\hline Th & 6 & $<2$ & ppm & 1 & INAA \\
\hline U & 5 & $<2$ & ppm & 2 & INAA \\
\hline Mass & 1.805 & 1.711 & $\mathrm{~g}$ & & INAA \\
\hline
\end{tabular}


The main contributors to the elemental composition of the tailings under study are silicon ( $\mathrm{Si})$ followed by aluminium $(\mathrm{Al})$. Iron $(\mathrm{Fe})$ and potassium $(\mathrm{K})$ are found in small quantities. Loss on ignition accounts for approximately $5 \%$ of the total mass of the tailings.

\subsection{Rheology}

\subsubsection{Slump Tests}

The slump test was used to determine the yield stress of the settled and the remixed material. The material was air dried and rewetted using the supernatant liquid in the case of the settled material and distilled water in the case of the remixed material to various solids concentrations for which the yield stress was determined. Several slump tests were conducted and results are presented in Table 4-11. The tailings of 54\% solids concentration (Nov) exhibited an average 11.23 inch slump while the $49 \%$ material (Dec) had an average of 11.44. The corresponding average yield stresses are 37.3 and $26.9 \mathrm{~Pa}$ respectively. 
Table 4-11: Slump Test Data for remixed samples at "as-shipped" solids concentrations

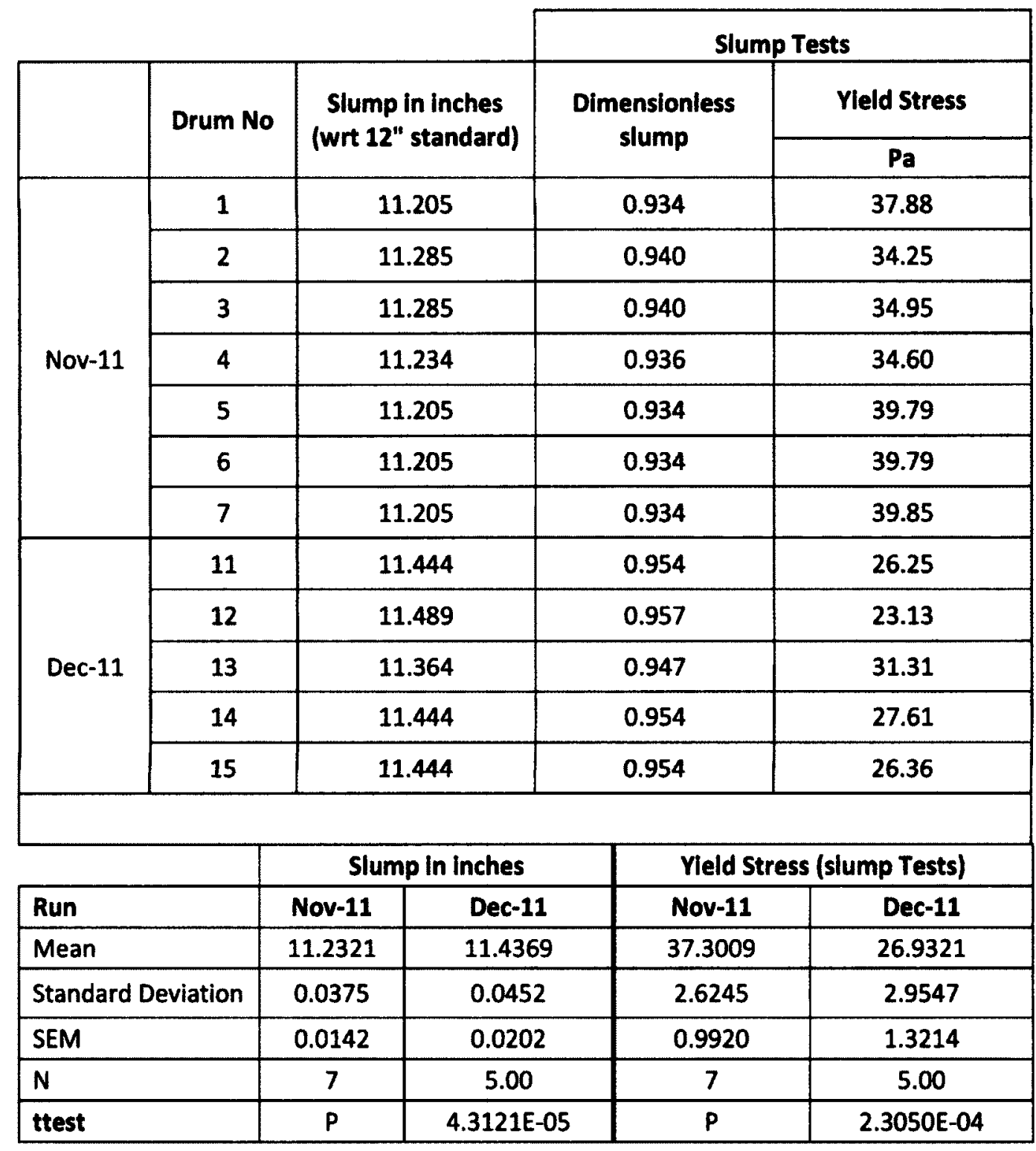

The variation of slump with solids concentration was also analysed for select samples. Figures 4-15 and 4-16 show the variation of yield stress with solids concentration for Drum 2 (Nov) and Drum 11 (Dec). 


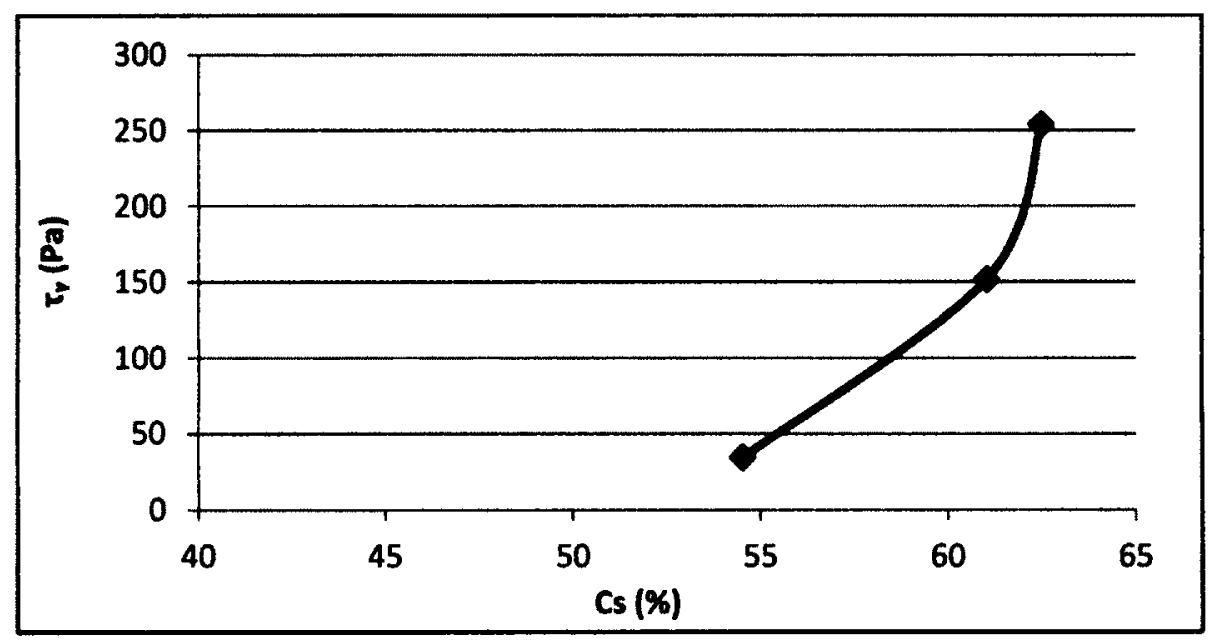

Figure 4-15: Variation in Yield Stress with Solids Concentration - Drum 2 (remixed material)

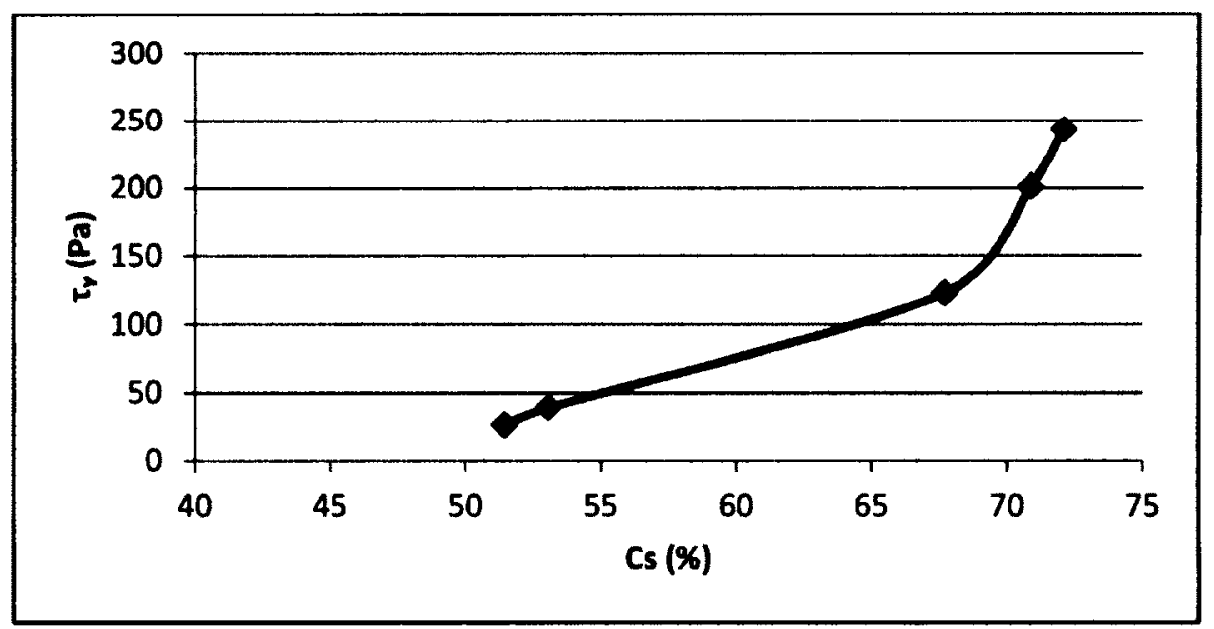

Figure 4-16: Variation in Yield Stress with Solids Concentration - Drum 11 (remixed material)

The results obtained from the slump test are synonymous with previous tests performed where higher yield stresses are obtained with higher solids concentration. Other cylinder sizes could be used to check the sensitivity of the results. 


\subsubsection{Flow Curves}

With the use of the Rheometer, flow curves over a wide range of shear rates (up to 400 $1 / s$ ) were constructed. The relation between the shear stress and the shear rate is nonlinear not allowing for the direct interpolation of the yield stress and so the low shear region of the data must be studied. Resulting flow curves for Drums 6 (Cs of 54.4\% November) and 13 (Cs of 49.7\% - December) are presented below in Figures 4-17 and 418 respectively. Flow curves are presented in Appendix E.

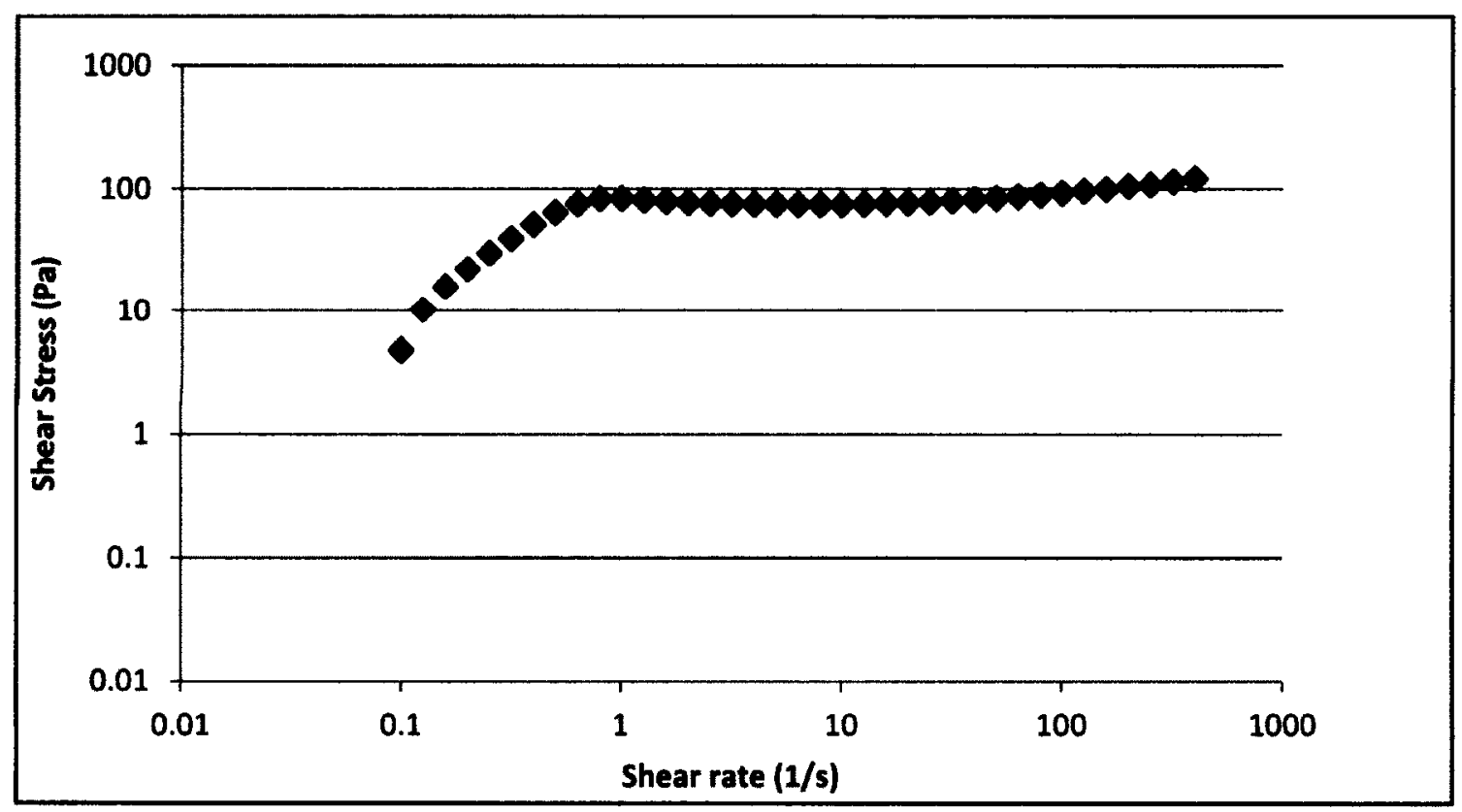

Figure 4-17: Flow Curve - Drum 6 remixed material of 54.4\% solids concentration (November) 


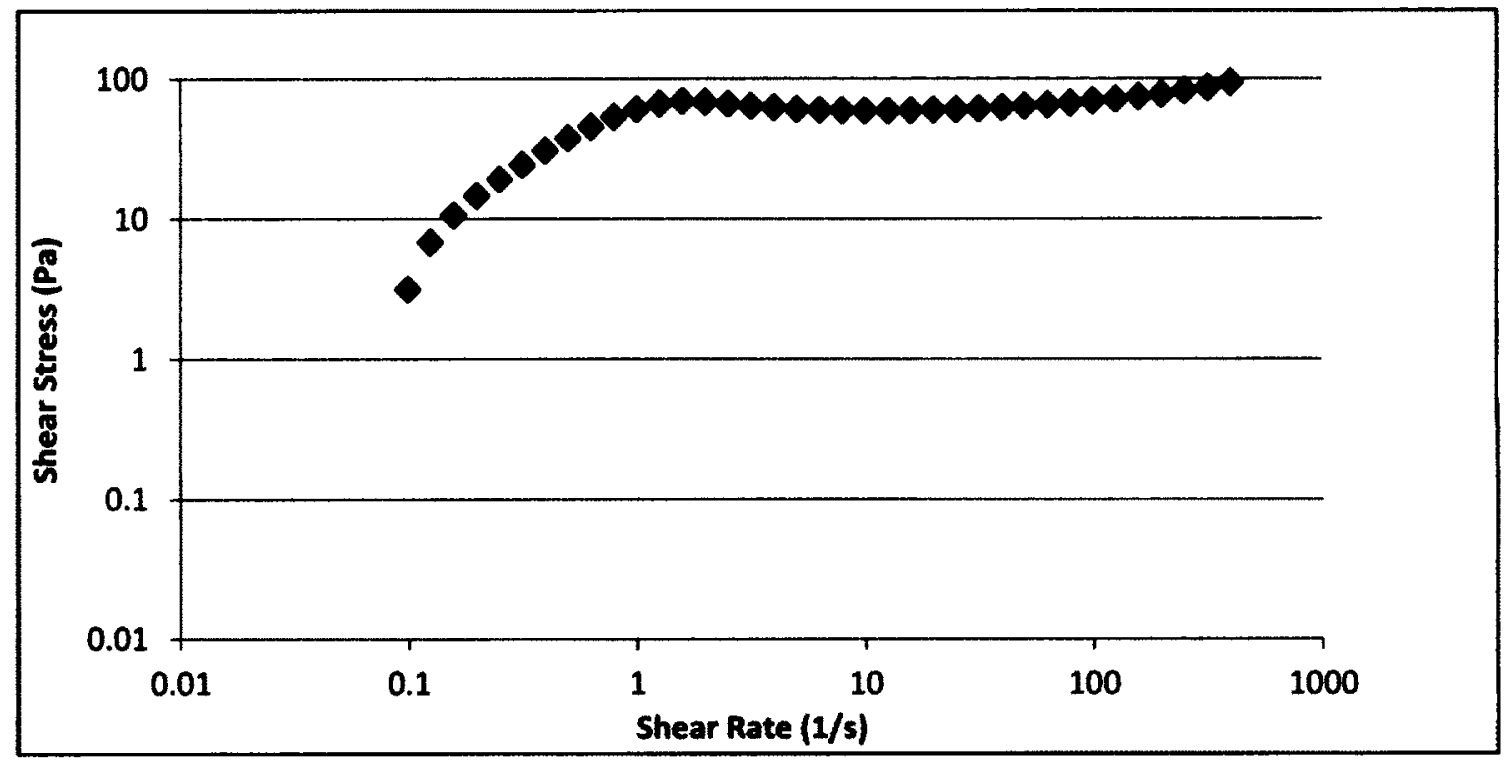

Figure 4-18: Flow Curve - Drum 13 remixed material of $49.7 \%$ solids concentration (December)

\subsubsection{Other measurements of Yield Stress}

\section{Stress Growth}

In this method the yield stress is presented as a function of applied rotational speed (constant shear rate). The yield stress corresponds to the maximum yield stress measured in the stress-time profile. The following rates were applied: $0.89,5$ and $101 / \mathrm{s}$. The maximum yield stresses (Dynamic) obtained from the applied constant stress rate of 0.89 1/s are shown in Table 4-12. 
Table 4-12: Static, Dynamic and Residual Yield stresses at 0.89 1/s for samples at "as shipped" solids concentrations

\begin{tabular}{|c|c|c|c|c|}
\cline { 2 - 5 } \multicolumn{1}{c|}{} & \multicolumn{4}{|c|}{ Yield Stress (Pa) } \\
\cline { 2 - 5 } \multicolumn{1}{c|}{} & Drum & Static & Dynamic & Residual \\
\hline Nov-11 & 1 & 75 & 90.66 & 74 \\
\cline { 2 - 5 } & 2 & 62 & 76.95 & 65 \\
\cline { 2 - 5 } & 4 & 62 & 74.87 & 60 \\
\cline { 2 - 5 } & 5 & 70 & 78.7 & 55 \\
\cline { 2 - 5 } Dec-11 & 7 & 58 & 77.73 & 56 \\
\hline & 12 & & 43.56 & \\
\cline { 2 - 5 } & 13 & 50 & 56.71 & 51 \\
\cline { 2 - 5 } & 14 & 53 & 61.55 & 49 \\
\cline { 2 - 5 } & 14 & 53 & 61.55 & 49 \\
\hline
\end{tabular}

\begin{tabular}{|l|c|c|}
\hline \multicolumn{3}{|c|}{ Dynamic Yield Stress } \\
\hline Run & Nov-11 & Dec-11 \\
\hline Mean & 79.7820 & 53.9400 \\
\hline STDV & 6.2422 & 9.3094 \\
\hline SEM & 2.7916 & 5.3748 \\
\hline N & 5 & 3.00 \\
\hline Ttest & P & 0.02195 \\
\hline
\end{tabular}

Four main regions can be identified from the graphs obtained (See Graph for Drum 1- Figure 4-19). The linear increase signalling the elastic deformation, a non-linear increase followed by a peak stress after which there is a region of stress decay. Three yield stresses can be identified: the static yield stress which is the transition from elastic fluid to viscoelastic, the dynamic yield stress which is required for the material to start flow from a viscoelastic to viscous fluid and the residual yield stress which indicates a state of equilibrium. The graphs obtained can be found in Appendix F. 


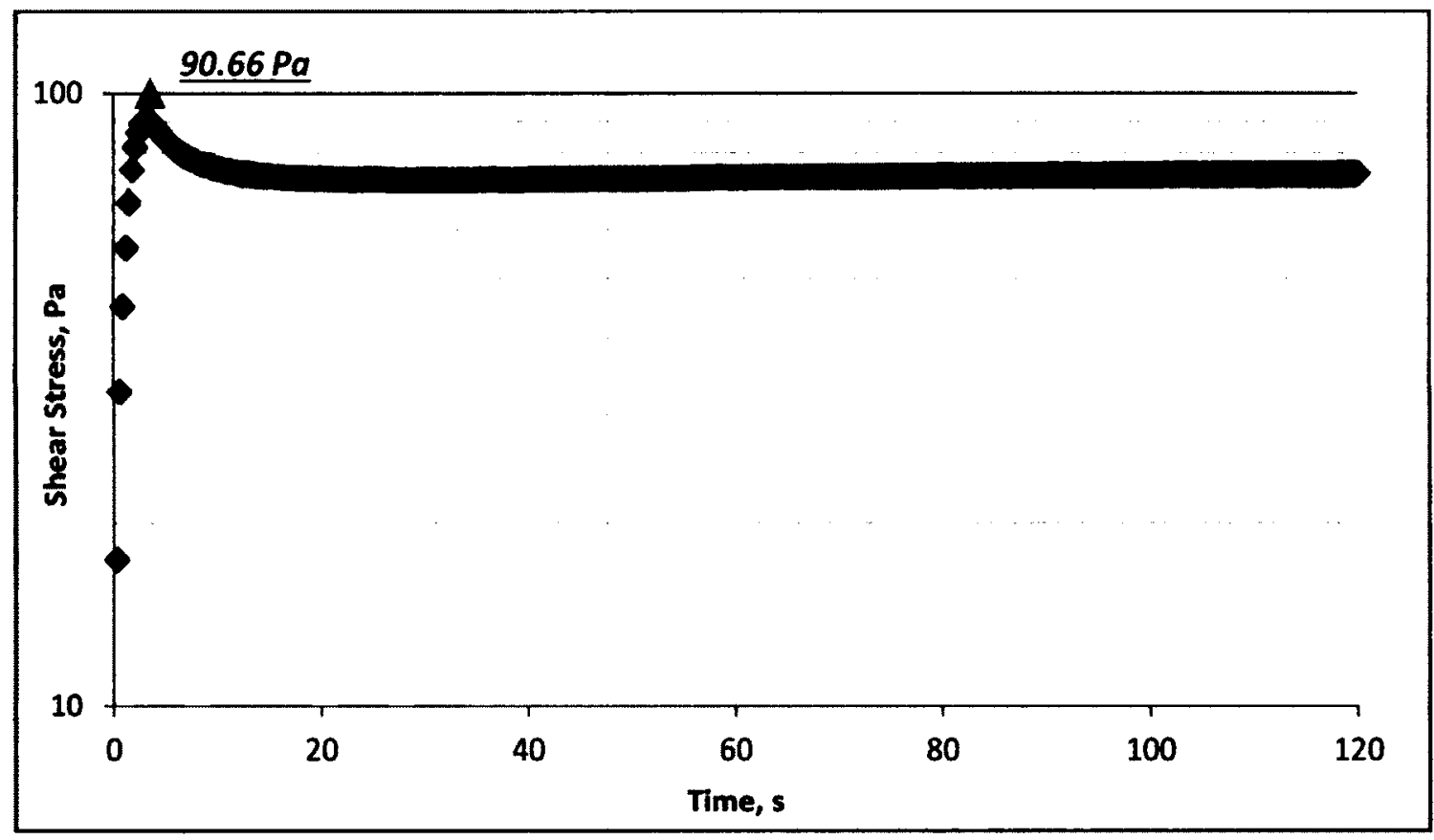

Figure 4-19: Stress-time profile of tailings in Drum 1 (54.3\% Cs) at 0.891/s

From the graphs values of static yield stress range from $40-50 \mathrm{~Pa}$ for the $49 \%$ solids concentration material and from $60-70$ with one drum hitting the region of $70-90$ $\mathrm{Pa}$ for the $54 \%$ material.

\section{Controlled Mode}

A constant stress is exerted in steps. The material exhibits elastic behaviour below the yield stress and the strain increase to a constant value. But as the yield stress is passed it increases indefinitely. Figures $4-20$ and 4-21 show the graphs for drums 2 and 12 respectively. The yield stress for drum 2 like the other drums in the $54 \%$ Cs run, oscillated between 70 and $90 \mathrm{~Pa}$ while drum 12 of $\mathrm{Cs} 49 \%$ oscillates between 40 and 50 Pa. Other graphs can be reviewed in Appendix G. 


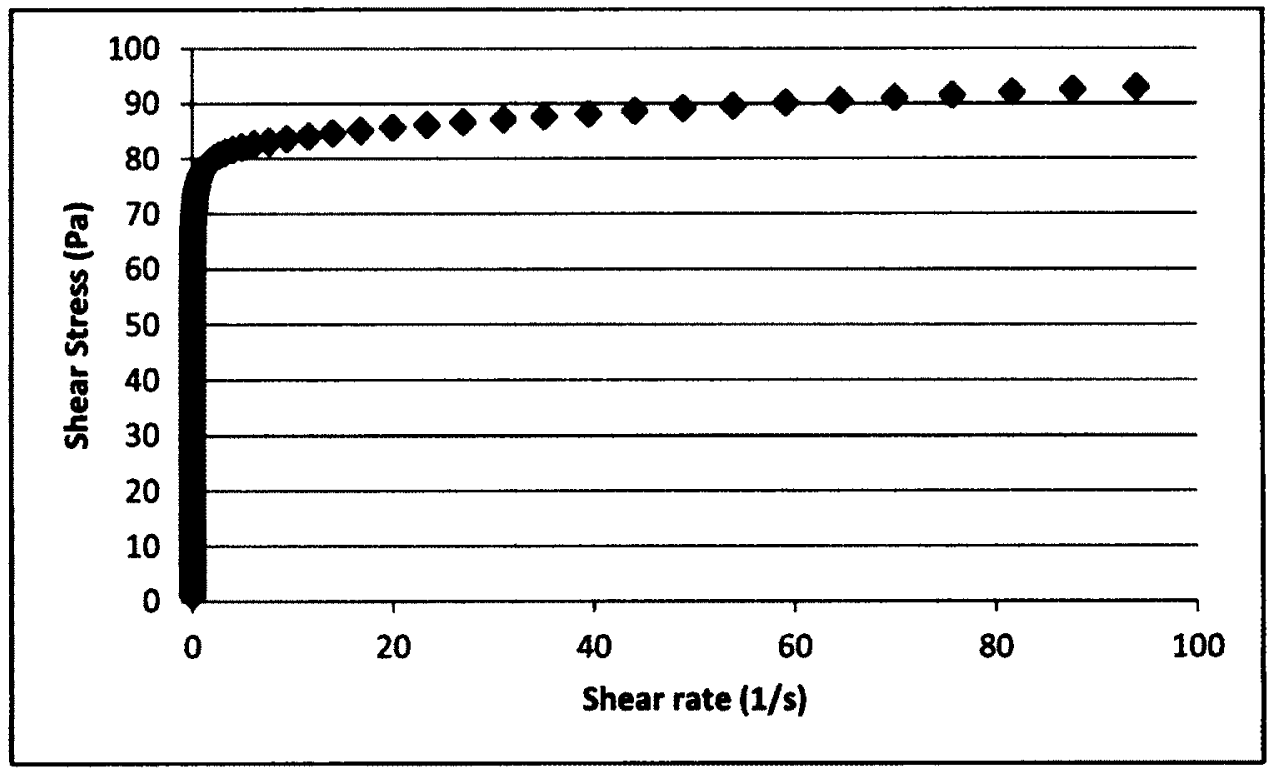

Figure 4-20: Controlled Mode Drum 2 (Nov 2011 Cs - 55\%)

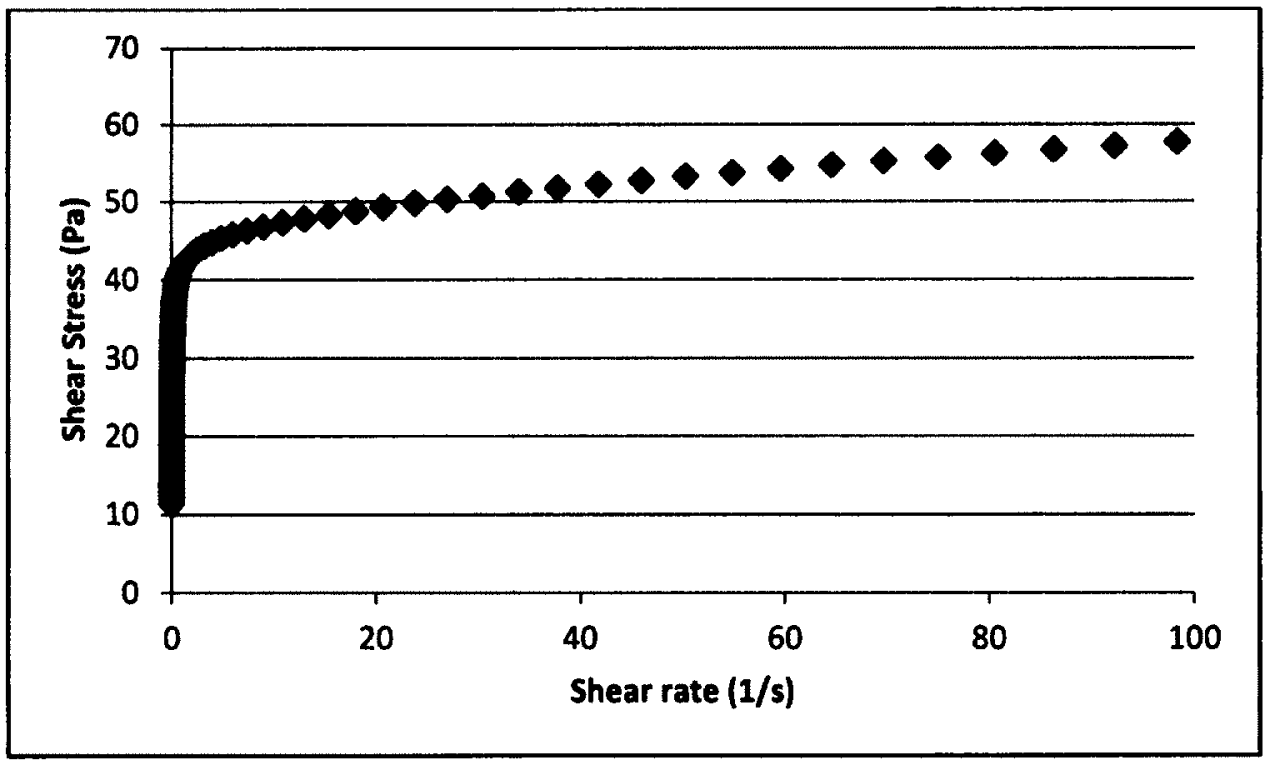

Figure 4-21: Controlled Mode Drum 12 (Dec 2011 Cs - 50 \%)

Tests conducted on fresh thickened tailings from Total E\&P Pilot plant by Gillies et al.(2012) revealed yield stresses of 270 and $140 \mathrm{~Pa}$ for 54 and $51 \%$ solids concentration respectively. Both materials, upon shearing, had their yield stresses 
reduced to 15 and $16 \mathrm{~Pa}$ respectively. The yield stresses measured for the material received were slightly higher after shearing with yield stresses measured through the slump tests being lower than those measured by the rheometer. This has also been seen in Gold tailings and may be a function of thixotropic effects (Mizani et al., 2013). 


\subsection{Soil Water Characteristic Curve, SWCC}

The SWCCs were constructed for the sample material in the range of 0 to $300 \mathrm{kPa}$. The water retention curves show the equilibrium water content of the materials at set suction values in the pressure plate (Figure 4-22).

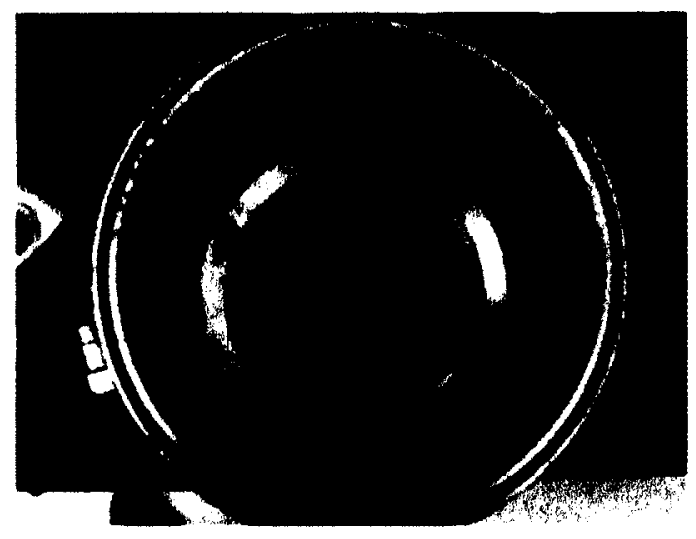

Figure 4-22: Pressure plate used in construction of SWCC

Additional suction and water content values were obtained for select samples by uniform thin surface drying and total suction measurements (WP4 potentiometer). The SWCC for Drum 7 is represented below in Figure 4-23.

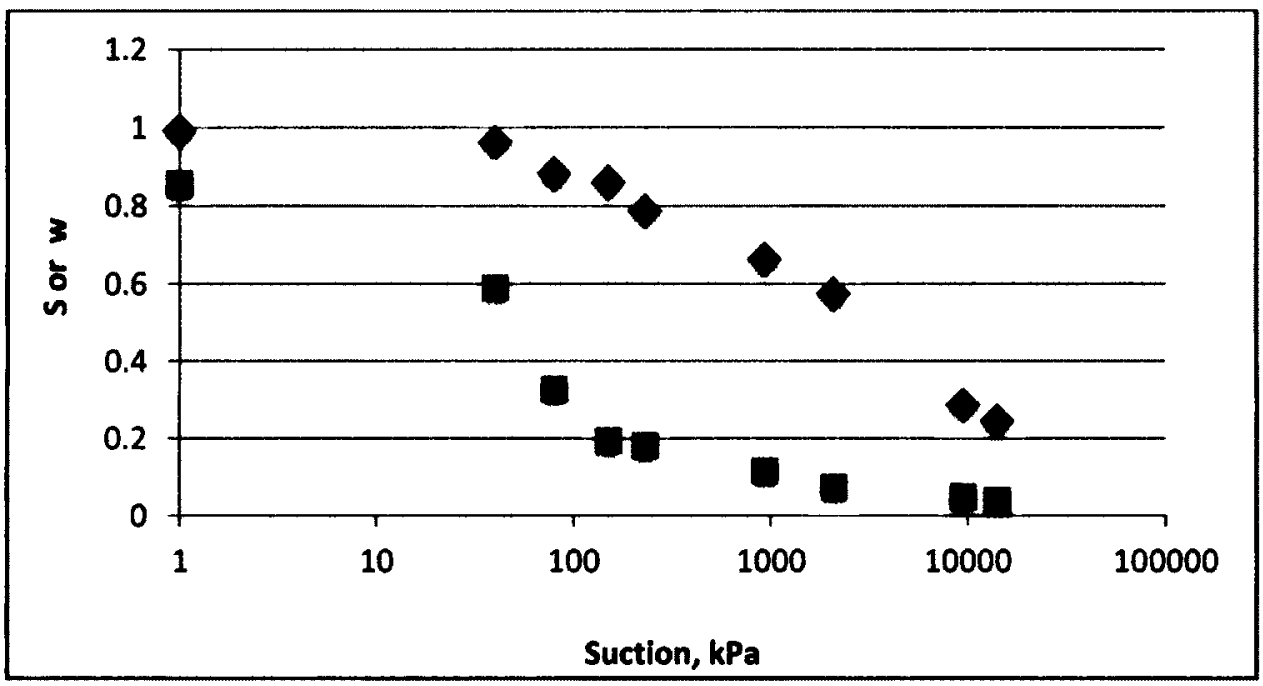

Figure 4-23: SWCC (Drum 7 - Cs 54.6\% November) 
SWCCs are presented in Appendix $\mathrm{H}$ for the remaining drums.

\subsection{Saturated Hydraulic Conductivity}

Figure 27 below shows the setup utilized in the estimation of the hydraulic conductivity of TT samples. Equation 4.02 simplified with the diameter of stand pipe (d) and soil column (D) is:

$k=\frac{d^{2} l}{D^{2} t_{1}} \ln \frac{h_{0}}{h_{1}}$

Where $d=0.35 \mathrm{~cm}, D=6 \mathrm{~cm}$ and $l=15.2 \mathrm{~cm}$.

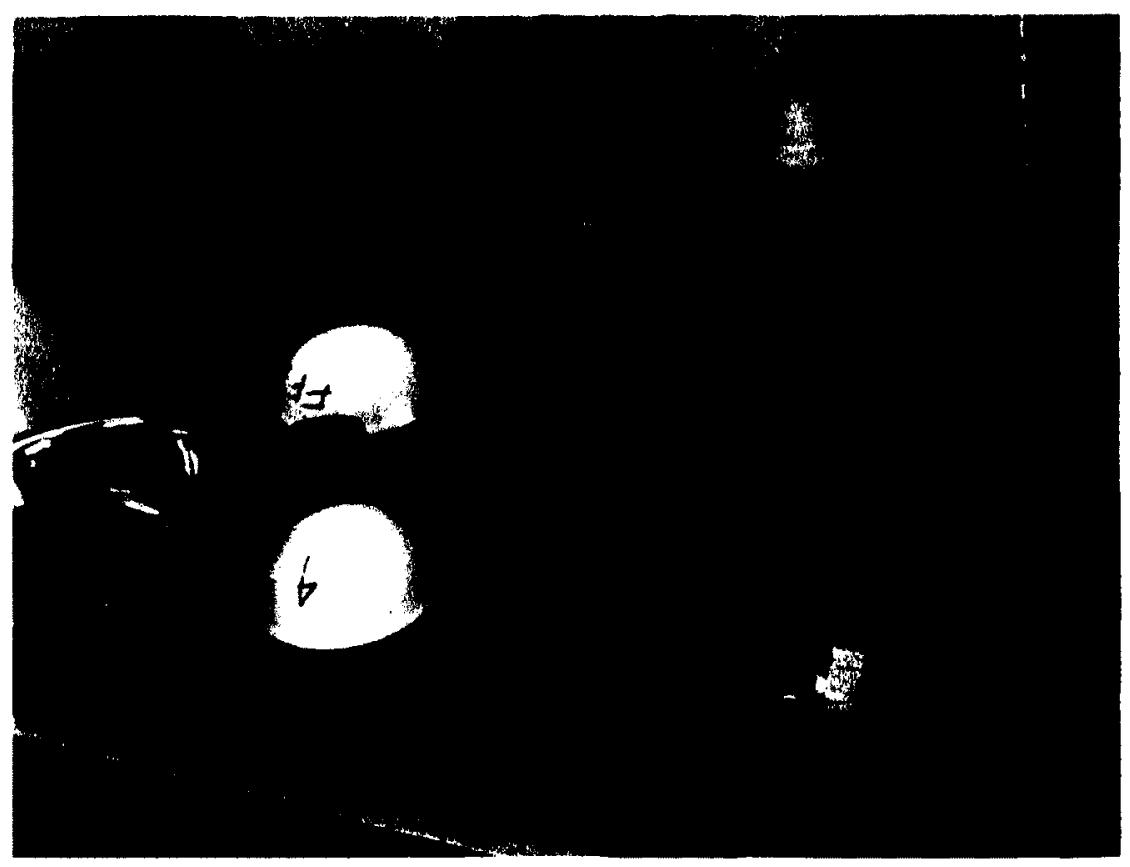

Figure 4-24: Falling Head Test Setup

The soil samples were placed between porous stones with filter paper placed between the samples and the stones. Results from the falling head tests are shown in Table 4-13. 
Table 4-13: Measured Hydraulic Conductivity

\begin{tabular}{|c|c|c|}
\hline $\begin{array}{c}\text { Date of } \\
\text { Run }\end{array}$ & Drum No & Ksat (cm/s) \\
\hline \multirow{4}{*}{ Nov-11 } & 1 & $1.514 \mathrm{E}-05$ \\
\cline { 2 - 3 } & 2 & $6.725 \mathrm{E}-06$ \\
\cline { 2 - 3 } & 4 & $4.190 \mathrm{E}-05$ \\
\cline { 2 - 3 } & 5 & $7.651 \mathrm{E}-05$ \\
\cline { 2 - 3 } & 7 & $1.662 \mathrm{E}-05$ \\
\hline \multirow{4}{*}{ Dec-11 } & 11 & $7.579 \mathrm{E}-06$ \\
\cline { 2 - 3 } & 12 & $7.163 \mathrm{E}-06$ \\
\cline { 2 - 3 } & 13 & $3.098 \mathrm{E}-05$ \\
\cline { 2 - 3 } & 14 & $8.168 \mathrm{E}-06$ \\
\cline { 2 - 3 } & 15 & $4.971 \mathrm{E}-06$ \\
\hline
\end{tabular}

Hydraulic conductivity reported by (Masala \& Matthews) for oil sand thickened tailings (Shell and Syncrude) with a void ratio between 2 and 2.6 (Table 4-14) is approximately $1-3 \times 10^{-5} \mathrm{~cm} / \mathrm{s}$. These results are similar to that obtained for the November batch which has a range of void ratio of 2.07 to 2.23 and an average hydraulic conductivity of $3.134 \times 10^{-5} \mathrm{~cm} / \mathrm{s}$.

Table 4-14: Void ratio values of remixed tailing samples.

\begin{tabular}{|c|c|c|}
\hline $\begin{array}{c}\text { Date of } \\
\text { Run }\end{array}$ & Drum No & Vold Ratio \\
\hline \multirow{4}{*}{ Nov-11 } & 1 & 2.16 \\
\cline { 2 - 3 } & 2 & 2.11 \\
\cline { 2 - 3 } & 3 & 2.23 \\
\cline { 2 - 3 } & 4 & 2.21 \\
\cline { 2 - 3 } & 5 & 2.07 \\
\cline { 2 - 3 } & 6 & 2.10 \\
\cline { 2 - 3 } & 7 & 2.14 \\
\hline \multirow{4}{*}{ Dec-11 } & 11 & 2.55 \\
\cline { 2 - 3 } & 12 & 2.63 \\
\cline { 2 - 3 } & 13 & 2.53 \\
\cline { 2 - 3 } & 14 & 2.53 \\
\cline { 2 - 3 } & 15 & 2.55 \\
\hline
\end{tabular}




\subsection{Drum Sectional Analysis}

Due to the consistency of the material, it was difficult to get the material to remain in the sectioning column. Drums 4 (November, $\mathrm{Cs}=53.6 \%)$ and $12($ December, $\mathrm{Cs}=48.6 \%)$ contained the least amount of material for each batch of tailings production. Therefore, a sample was collected from the entire depth of the settled material and the following properties: gravimetric water content, solids concentration, density, specific gravity and GSD (dispersed) were analyzed with depth. Figures 4-25 and 4-26 show the contents of the drum with and without supernatant water and the sectioning column.

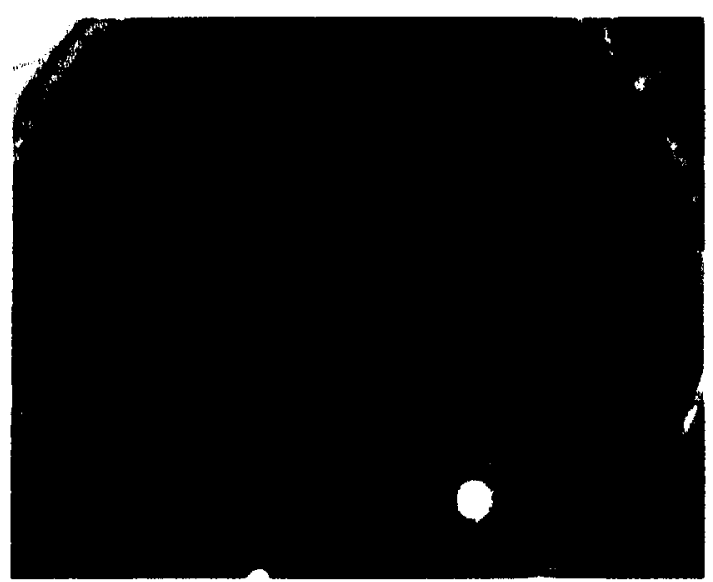

(a)

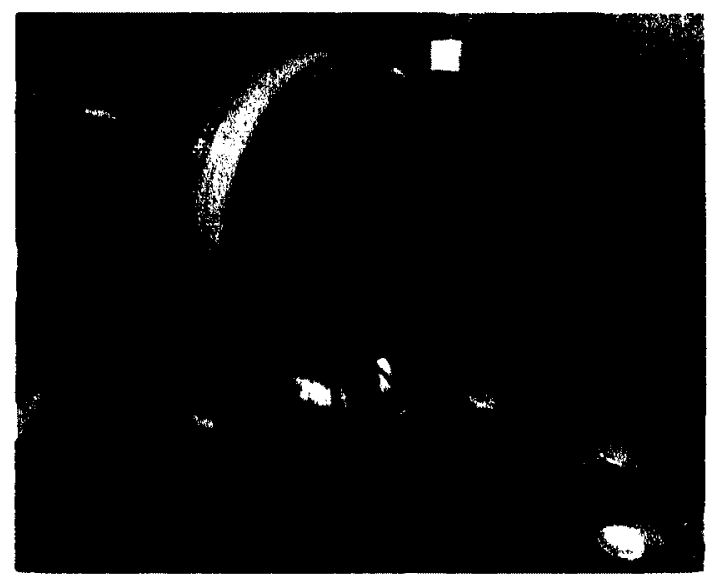

(c)

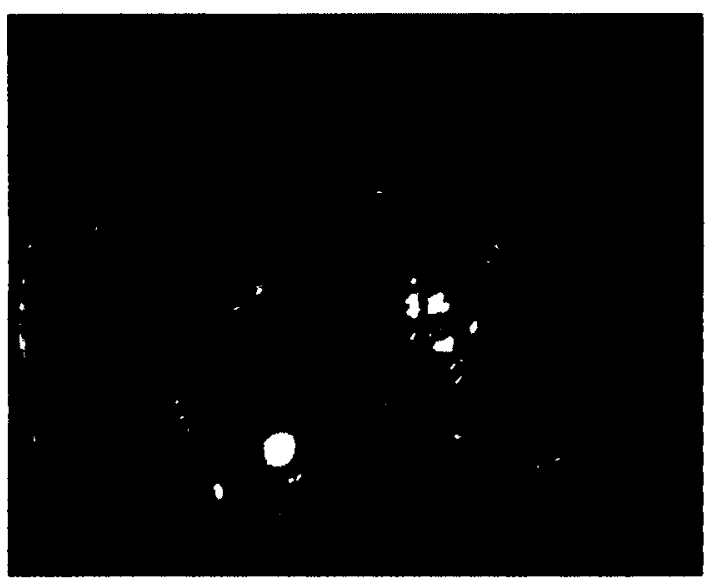

(b)

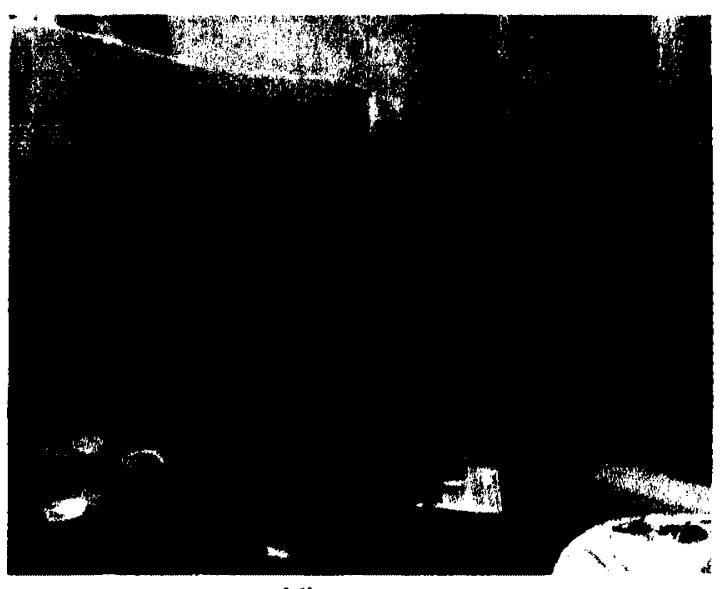

(d)

Figure 4-25: Drum 4 sectional analysis. (a) Initial height of sample. (b) Settled material after removal of water. (c) and (d) Sections of sampler. 


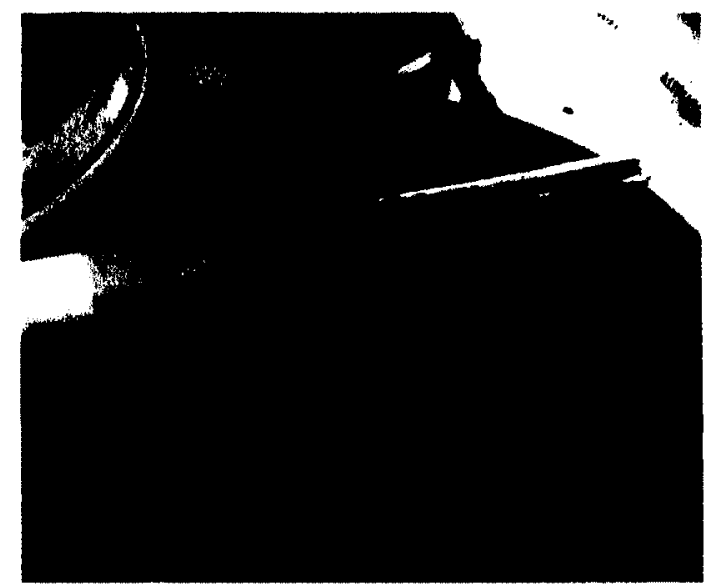

(a)

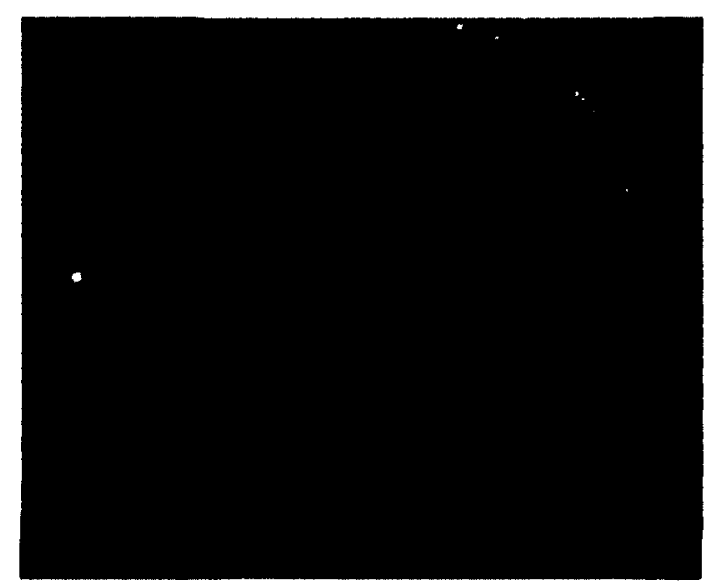

(c)

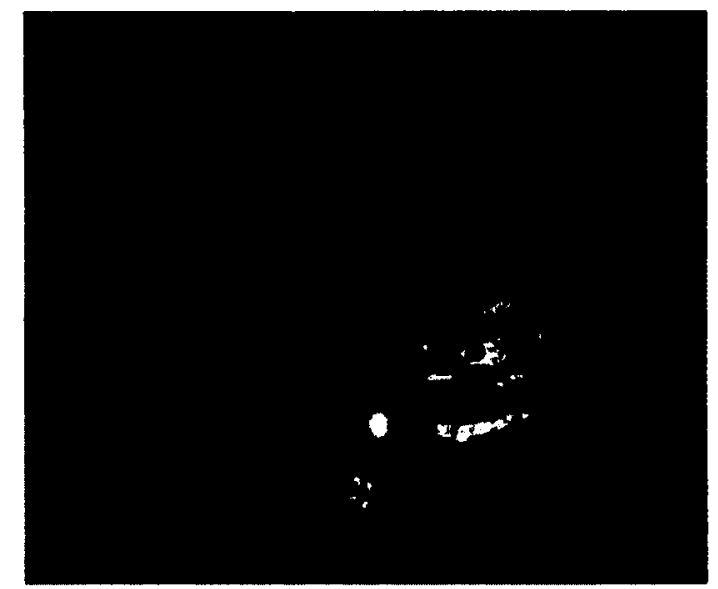

(b)

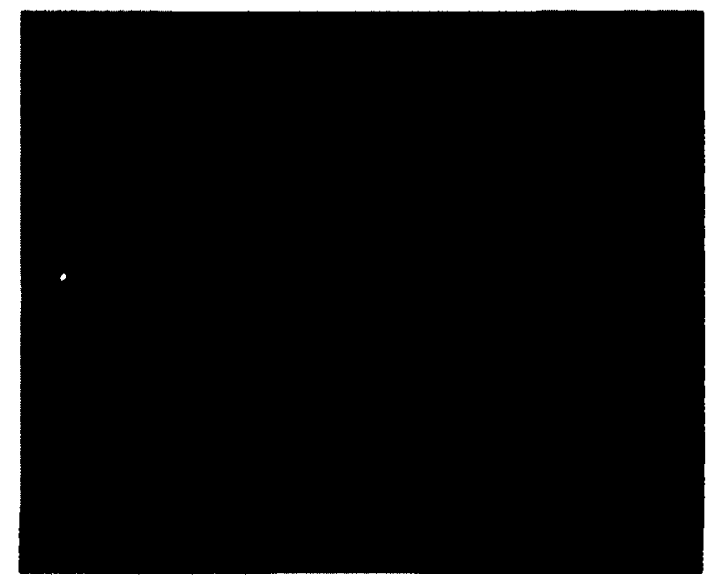

(d)

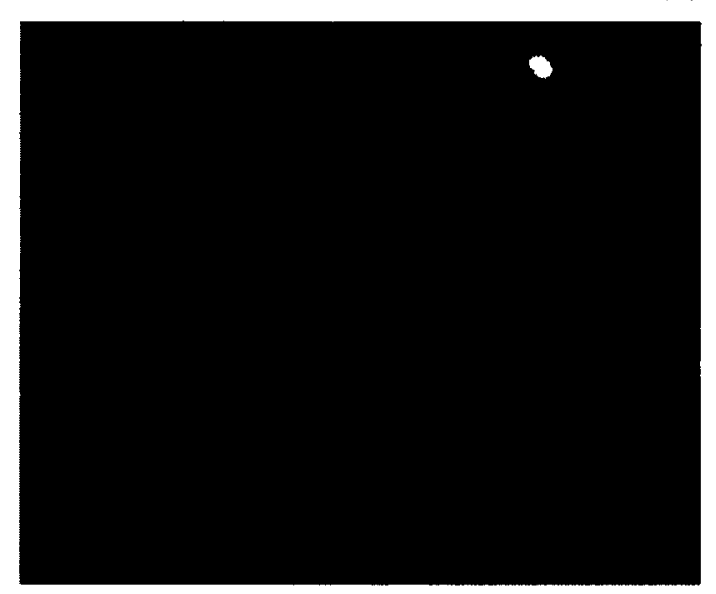

(e)

Figure 4-26: Drum 12 sectional analysis. (a) Initial height of sample; (b) Settled material after removal of water; (c), (d) and (e) Samples from sections of sampler. 
From the tests performed, solids concentration, gravimetric water content and density show steady changes (increments or decreases) in values for drum 4 when compared to drum 12. Drum 12 results show a sharp change in properties with depth. See Figures 4-27 to 33. Values of Specific gravity are very small specifically at the surface. From simple inspection, the material was very fluffy at the top with a decrease in fluffiness with depth.

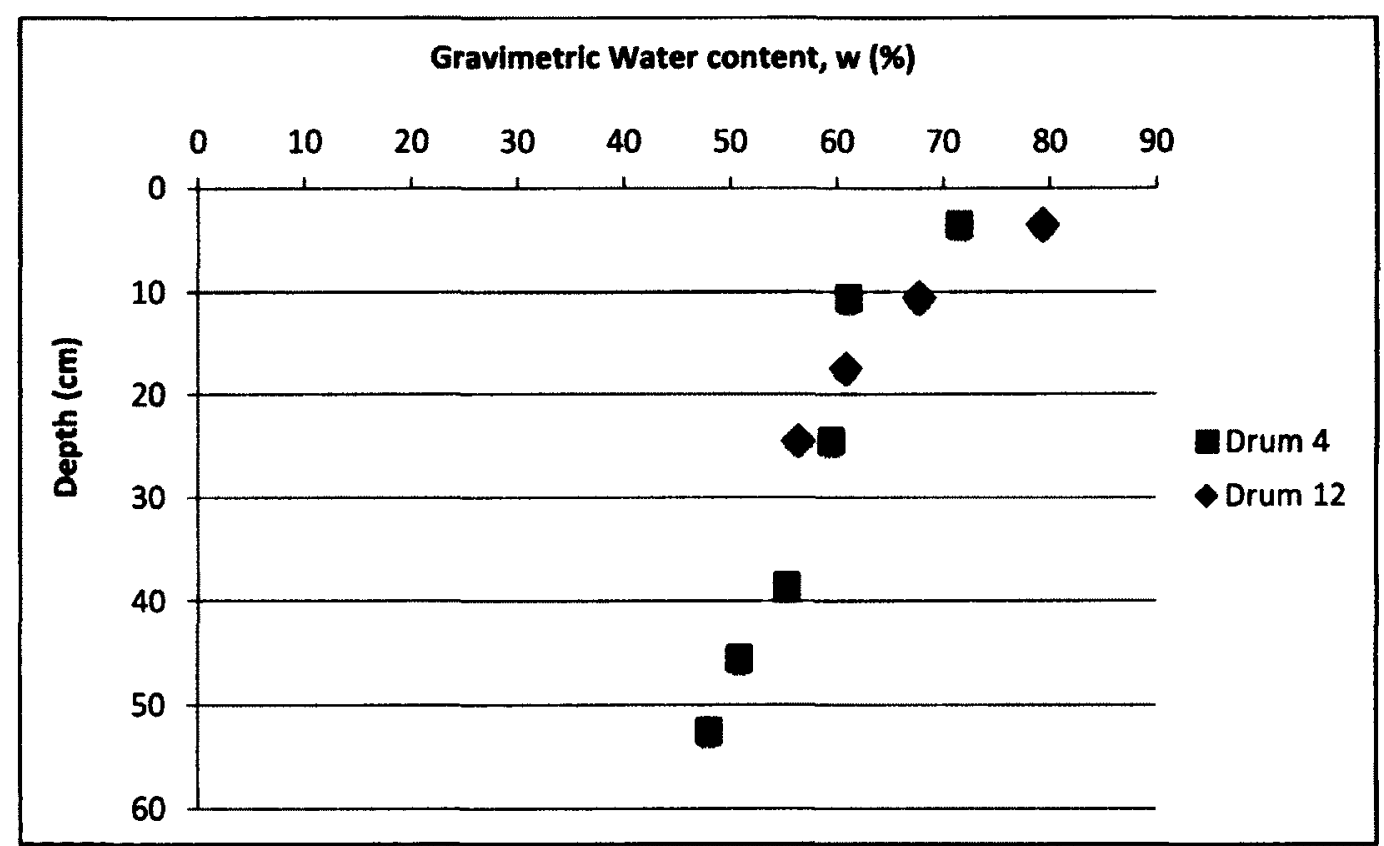

Figure 4-27: Variation of Gravimetric Water Content with depth (Drum 4 Nov. Batch, Drum 12 Dec. Batch) 


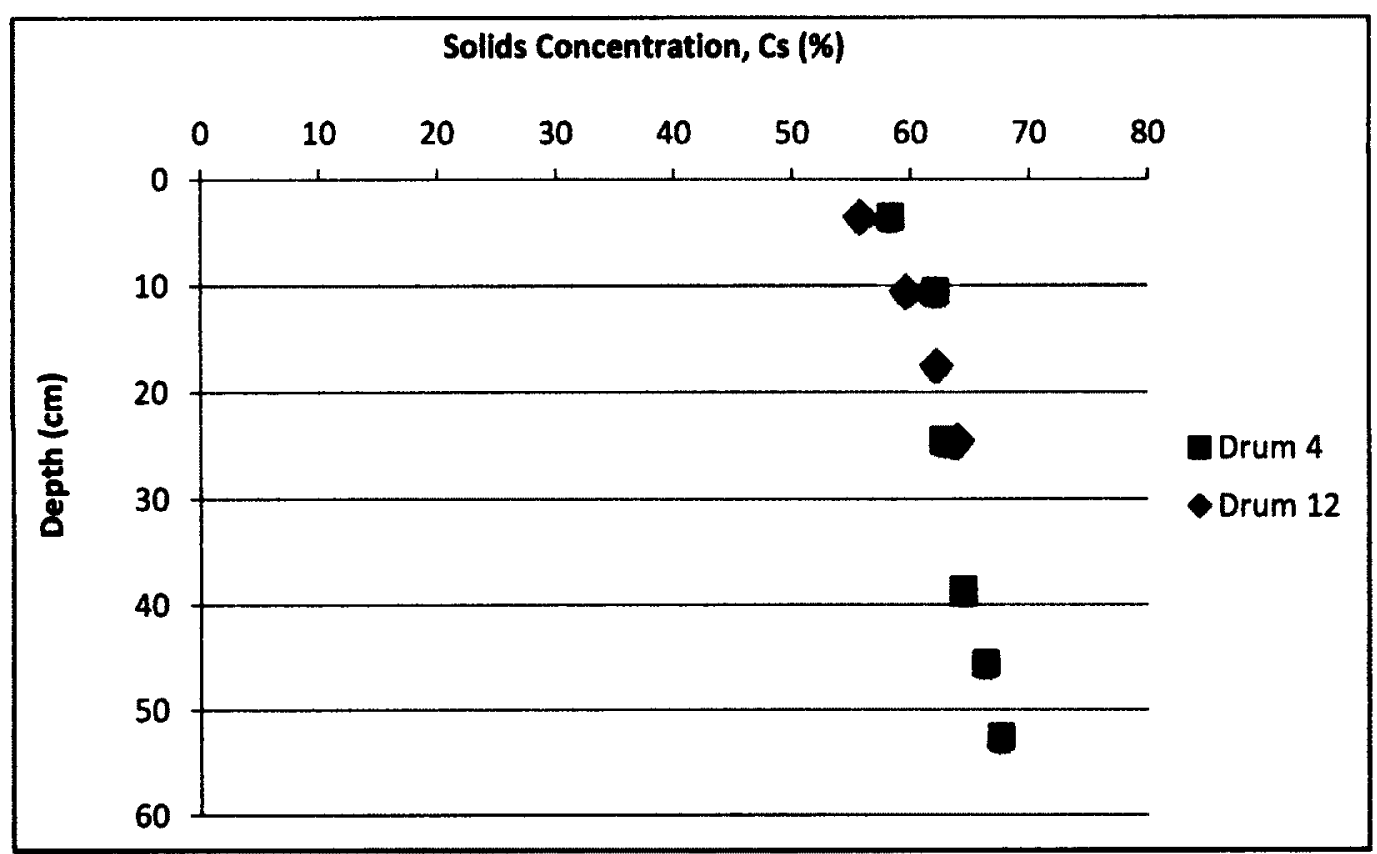

Figure 4-28: Variation of Solids Concentration with depth (Drum 4 Nov. Batch, Drum 12 Dec. Batch)

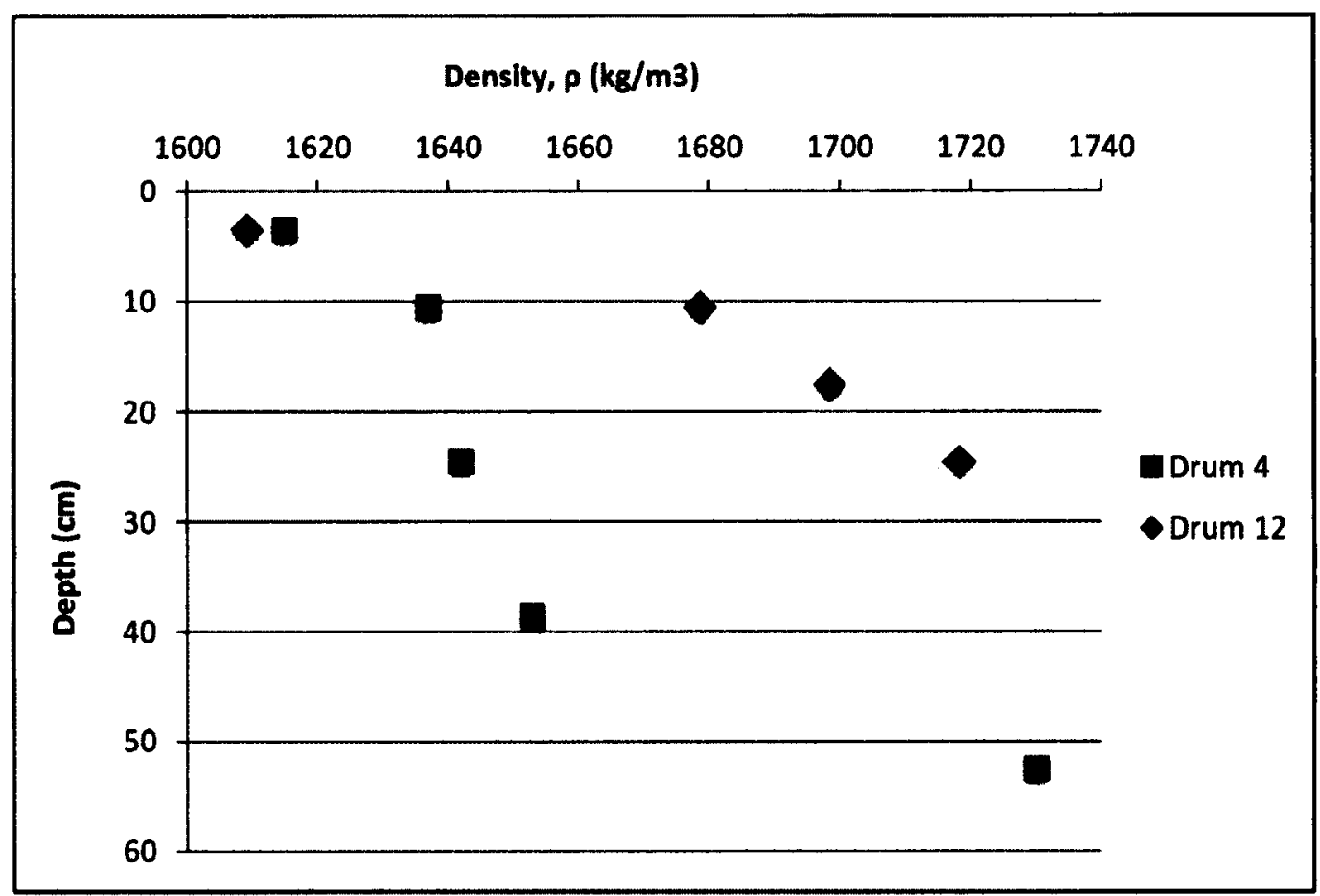

Figure 4-29: Variation of Total (Wet) Density with depth (Drum 4 Nov. Batch, Drum 12 Dec. Batch) 


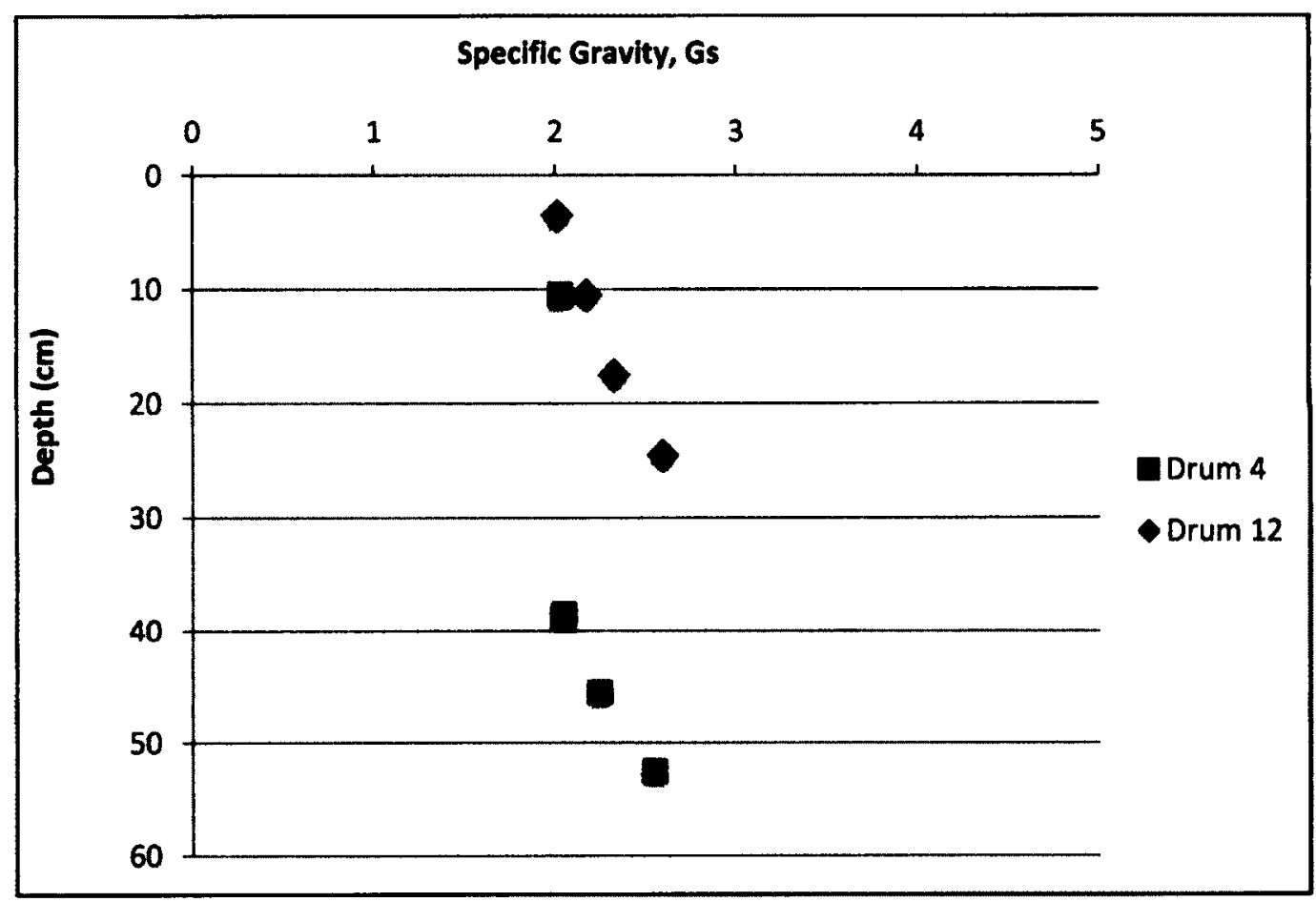

Figure 4-30: Variation of Specific Gravity with depth (Drum 4 Nov. Batch, Drum 12

Dec. Batch)

The density of the material in each drum, regardless of the initial solids concentration, increases with depth (Figure 4-29). In the case of Drum 12, the height of settled material was $26 \mathrm{~cm}$ and so the change in density with depth is not as gradual as that of Drum 4 which despite having the higher solids concentration showed a gradual increase in density with depth. This is supported by $73.4 \%$ of the material in drum 12 being settled material while in drum 4 , settled material is $76.2 \%$

In the case of specific gravity, values are quite low at the top of the material consistent with the idea of heavy materials settling to the bottom. From simple visual inspection, the material was very fluffy and light at the top $10 \mathrm{~cm}$. 
Figures 4-31 and 4-32 show the non-dispersed GSD of drums 4 and 12. Drum 4 shows more variation with the GSD with depth. In the dispersed analysis of Drum 4, the variation is also present. See Figure 4-33.

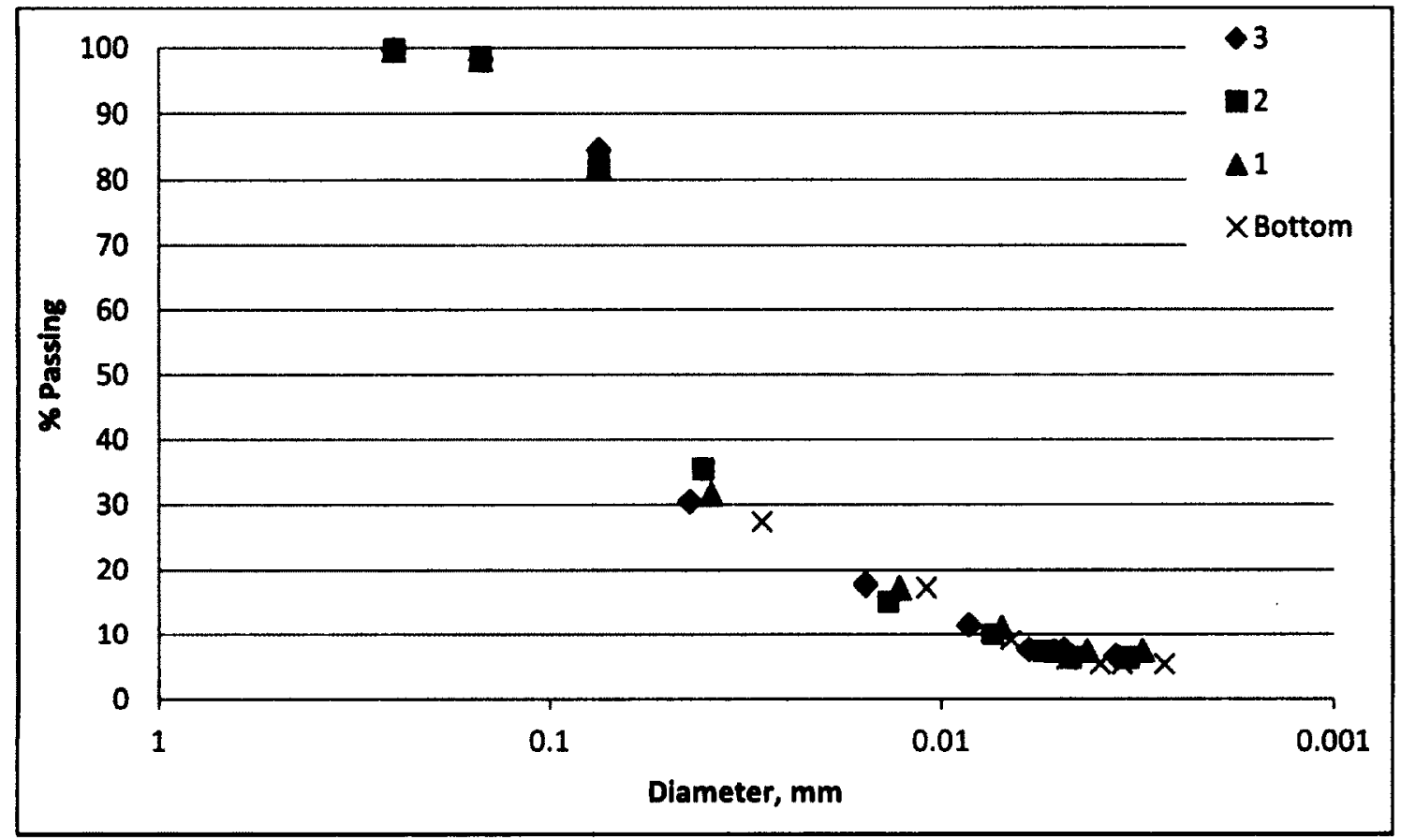

Figure 4-31: Drum 12 Sectional analysis - GSD non-dispersed 


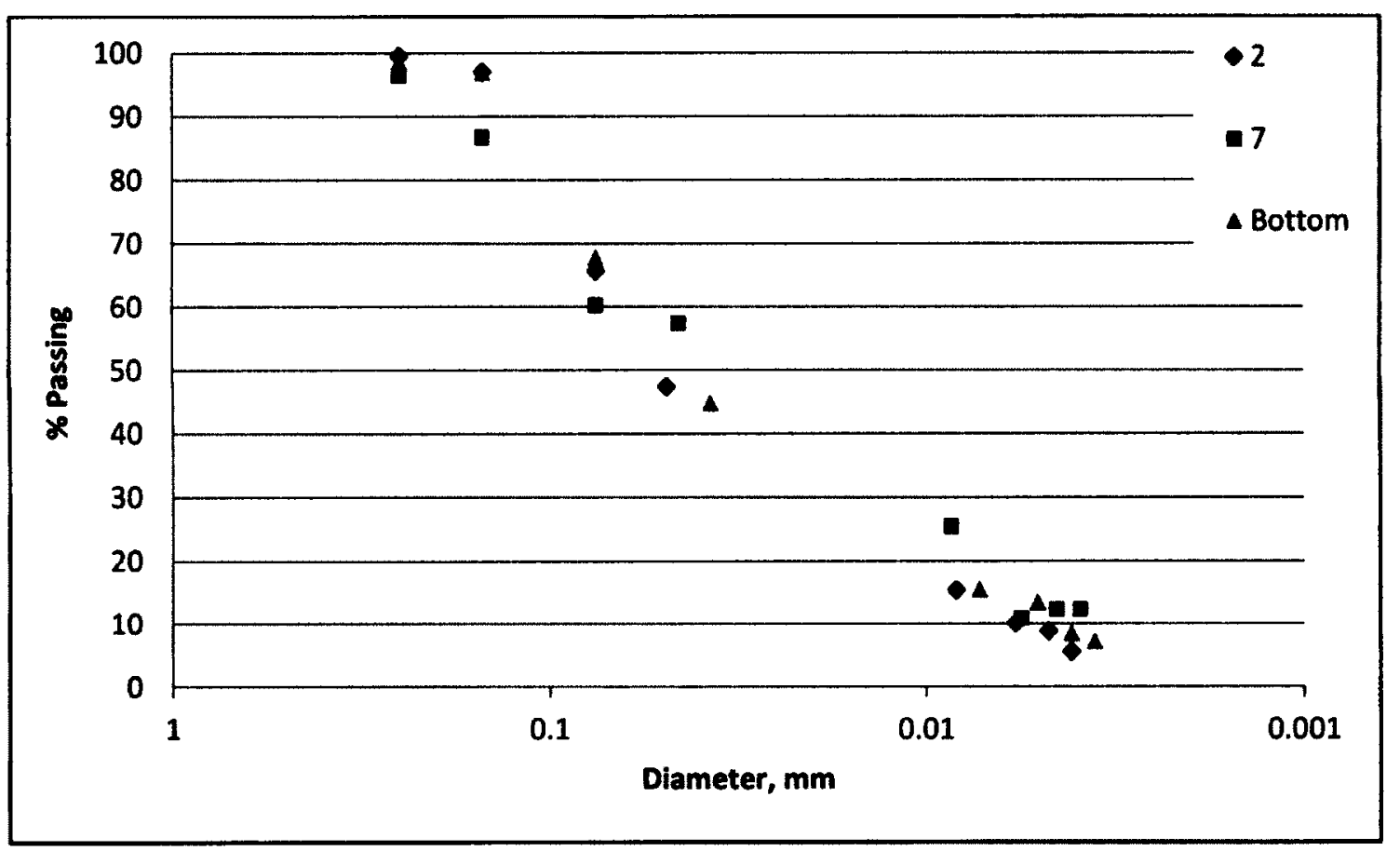

Figure 4-32: Drum 4 Sectional analysis - GSD non-dispersed

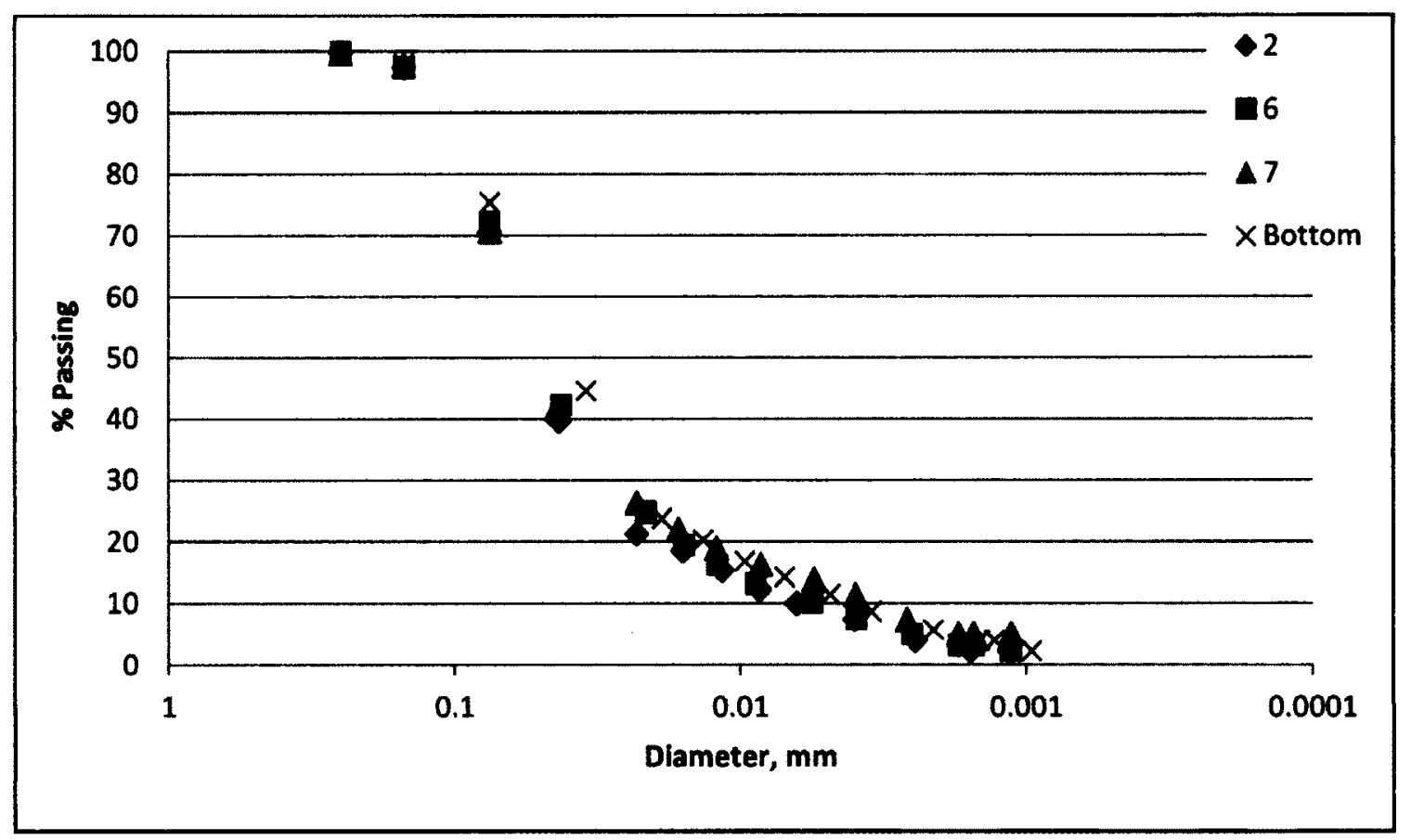

Figure 4-33: Drum 4 Sectional analysis - GSD dispersed 


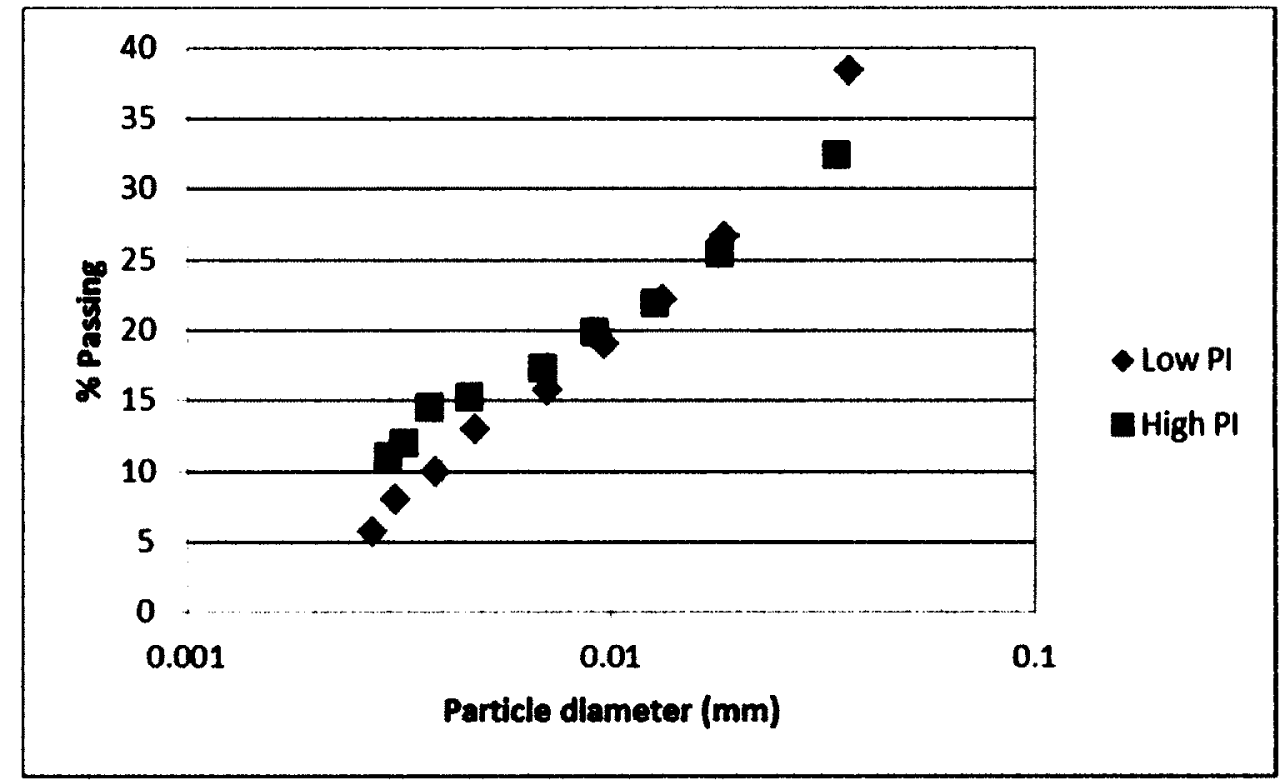

Figure 4-34: Comparison of average non-dispersed GSDs from the high and low plasticity tailings

\subsection{Conclusions}

Characterization tests reveal that the drums proceed from two distinct batches of solids concentration being 54\% (November 2011) and 50\% (December 2011). The main differences between the batches exist in water chemistry (ionic concentrations of sulphate, chloride, sodium and iron and conductivity), and liquid limits. The other properties like GSD, SWCC, and clay mineralogy were quite similar. The rheology of the remixed tailings also differed but only to the difference in density. Tailings brought to the same water content exhibited similar slump.

Considering all tailings together (both November and December), tailings could be classified into high and low plasticity groups. Samples for high plasticity tailings came from both November and December sets. The only difference detected between 
two groups was in the non-dispersed grain-size distributions (shown in Figure 4-34), where the low PI tailings were coarser. This suggests that the difference between the low and high PI tailings might be due to degree of flocculation. In any event, there were no correlations detected between this difference in PI and the hydro-geotechnical or rheological parameters.

While the dependence on physical parameters on the difference in pore-water chemistry between the November and December tailings appears not to be significant, the difference in electrical conductivity may still be important for the evaporative behaviour. Even though the electrical conductivity of the bleed water is slightly lower than for gold tailings, the greater amount of water in the oil sand tailings means that the potential for concentration of mass at the surface, and hence greater osmotic suction, is potentially greater for the oil sand thickened tailings. 


\section{Chapter 5 DRYing TEST RESULTS}

\subsection{Vertical Column Drying Test}

\section{Test 1}

A vertical column test was conducted to obtain an initial idea of the drying behaviour of the tailings with regards to suction development, uniformity in drying and change in solids concentration with depth. Results from the column tests show that no pore water was collected from the drainage port. Some amount of drainage was expected as the addition of flocculant would cause an increase in the hydraulic conductivity of the tailings through the increase in pore size due to the formation of flocs.

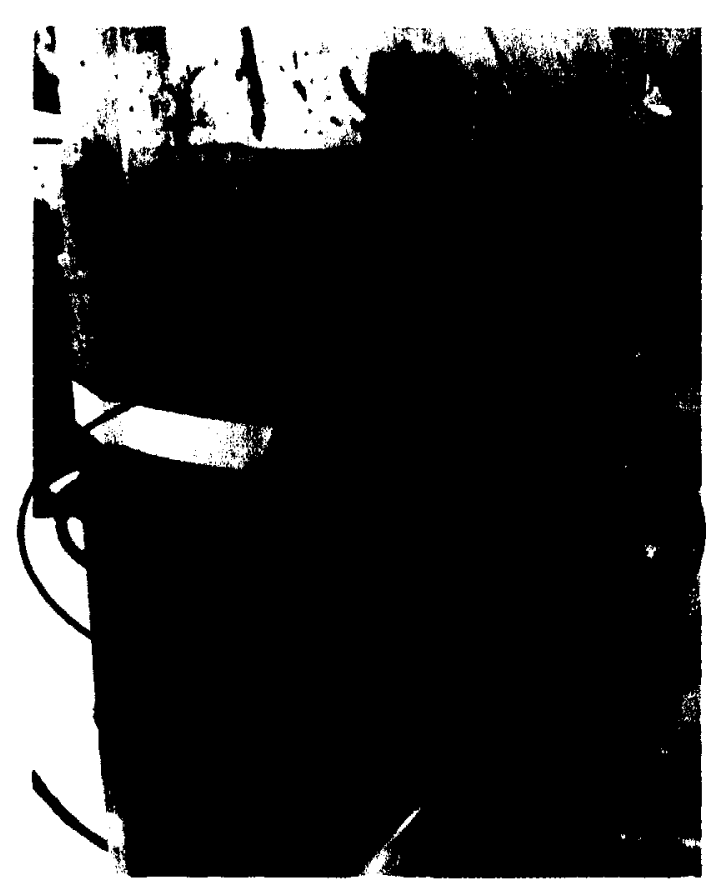

Figure 5-1: Gap observed in vertical column after Test 1 
Instead, very non-uniform drying was observed. A gap of approximately $9 \mathrm{~cm}$ formed near the centre of the column dividing the tailings into a very wet phase (bottom) of approximately $77 \%$ solids concentration and a drier phase (top) of approximately initial solids concentration (52\%). See Figure 5-1. This was due to the adhesion of the tailings to the walls of the column causing the drier material to separate from the rest of tailings.

\section{Test 2}

In the second test, the volume of water that had evaporated in the first test was reintroduced to the column as distilled water (approximately $2 \mathrm{~L}$ ). The gap formed during test 1 was closed and about $927 \mathrm{ml}$ of free water was observed at the surface after flushing. Drying was still non-uniform. At the end of test 2 the column of soil was at a final height of $21 \mathrm{~cm}$ and there was significant cracking through the top with a visible layer of dried bitumen on the top and salt incrustations along the cracks. These can be seen in figure 5-2.

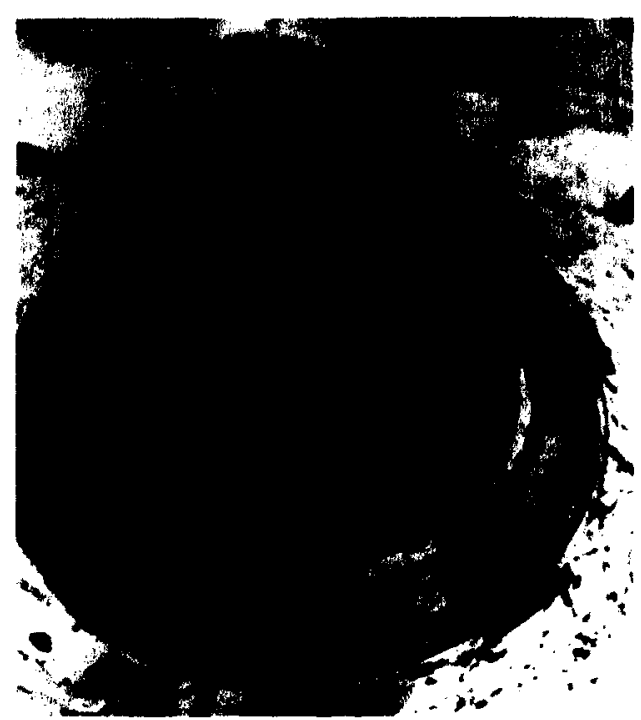

Figure 5-2: Surface of TT upon termination of column drying tests. 
This second test was performed to simulate and observeof what may transpire during a rainfall event or the infiltration of water from freshly deposited layers With the initial surface crust formation, water flow was impeded from the surface and the material below remained very wet. Upon the introduction of the volume of water to the column, the surface was rewetted allowing an increase in water content, the dissolution of salts at the surface and the collapse of the crust. The effects of the former were present in a more improved drying which can be seen in the solids concentration distribution in a later section.

\subsubsection{Matric Suction}

\section{Test 1}

Matric suction measurements reveal a slow rise in both tensiometers for the first 15 days followed by a rapid linear increase in the top tensiometer from day 15 to 26 . The rate of increase of the matric suction of the top tensiometer decreased towards the end of the test as the rate of evaporation decreased. The highest attained matric suction was $60 \mathrm{kPa}$. The lower tensiometer showed a steady increase in matric suction but never passed zero as there was no significant drying in the bottom section of the column. Figure 5-3 shows the variation of matric suction with time for test one measured by the upper and lower tensiometers. 


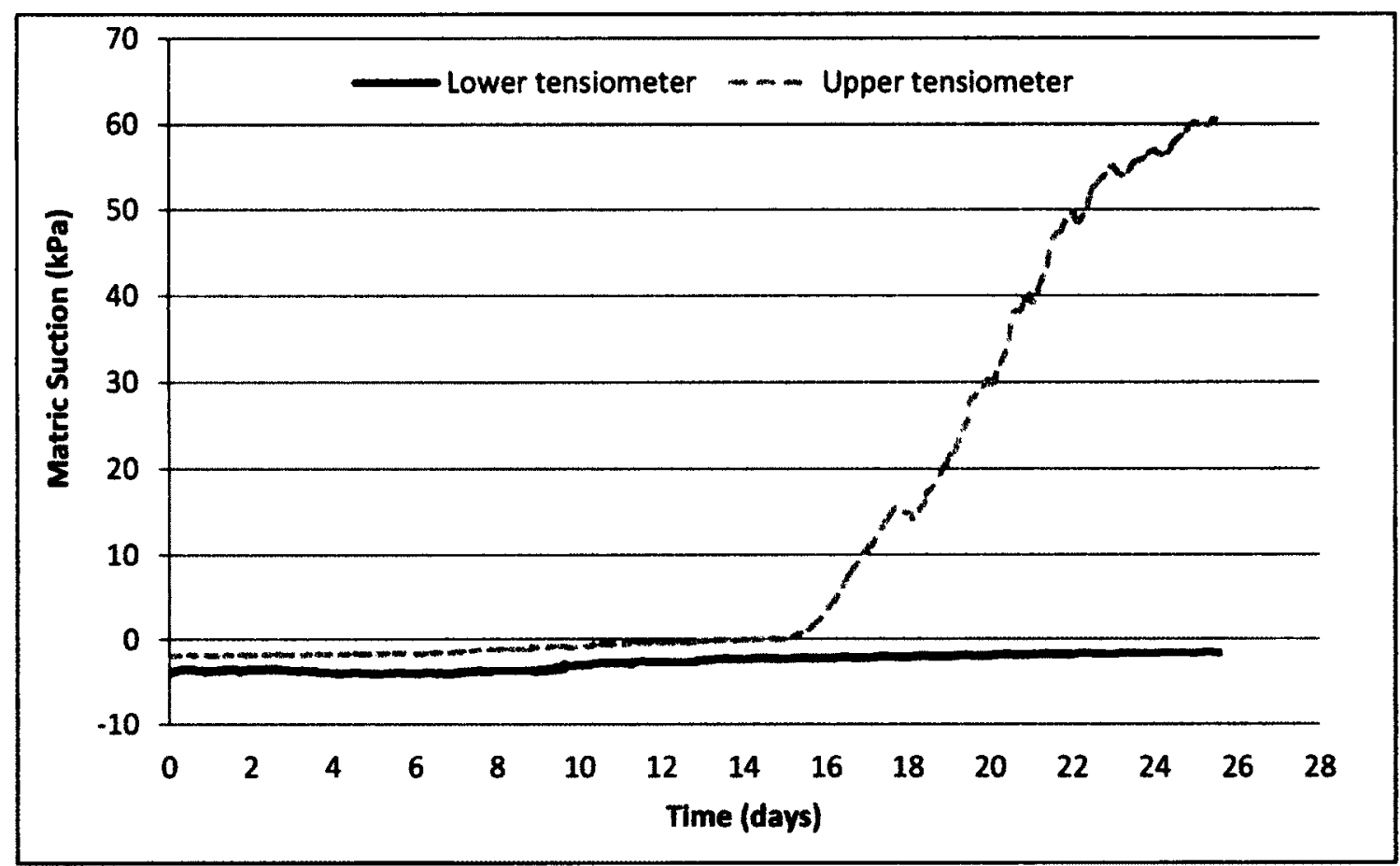

Figure 5-3: Variation of Matric Suction during Test 1

\section{Test 2}

The variation of matric suction during Test 2 is captured in Figure 5-4. A gradual increase in matric suction was observed. By day 12, the upper tensiometer shows recorded values above zero $(0)$ and the matric suction increases steadily thereafter to 15 $\mathrm{kPa}$ at termination of the test. Matric suction values for the lower tensiometer, like in Test 1 , increased slowly and never went pass zero. There is a slight drop on day 7 and this could be due to movement of the measuring instrument or some other malfunction but the instrument quickly returns to the value previously registered. 


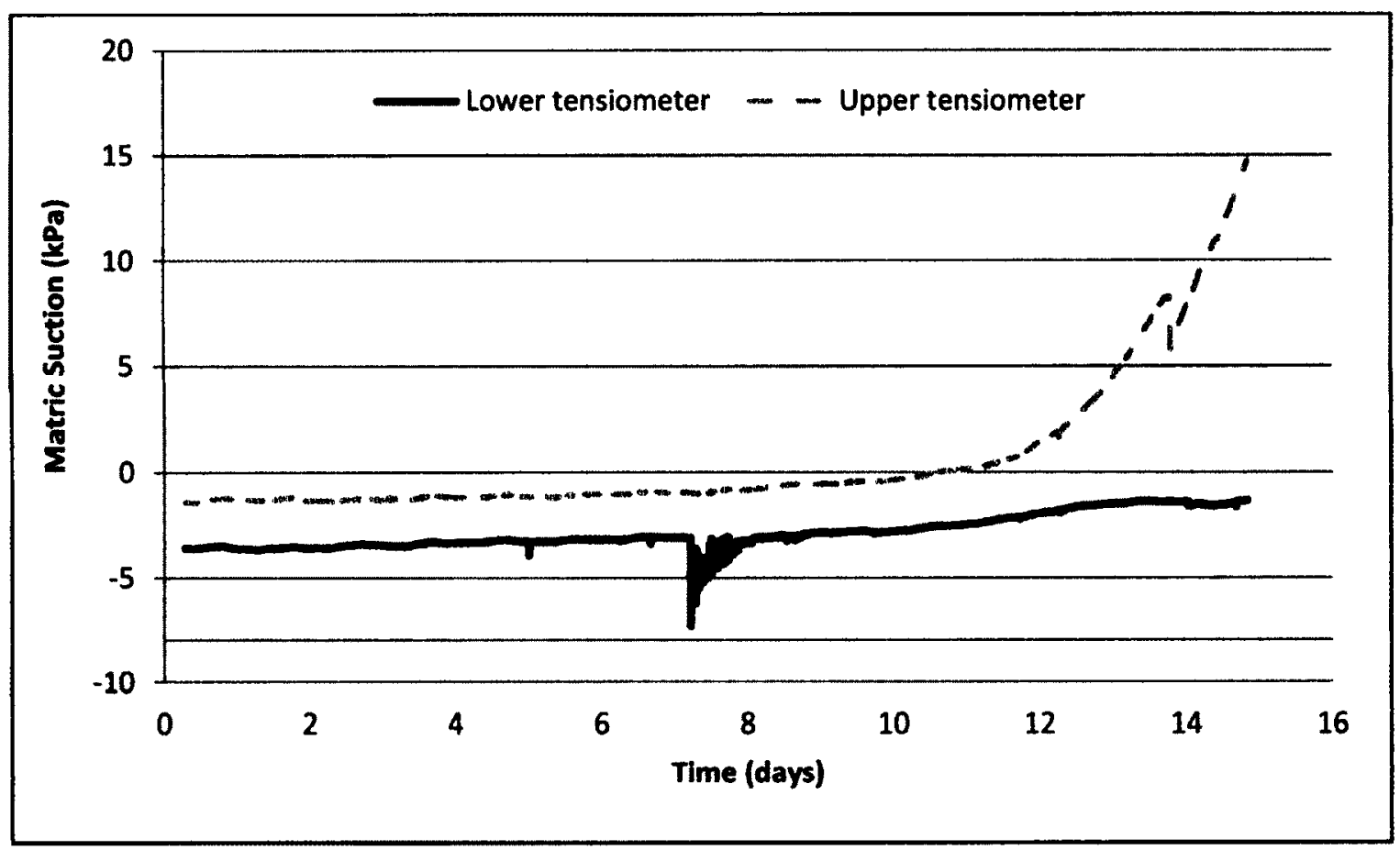

Figure 5-4: Variation of Matric Suction during test 2

\subsubsection{Evaporation}

Since no drainage was collected from the either column, the loss of water is attributed solely to evaporation. In Test 1 , the evaporation increased slowly within the first six (6) days but after the installation of the electric fan a more rapid increase was noted. Evaporation results are presented in Figure 5-5. 


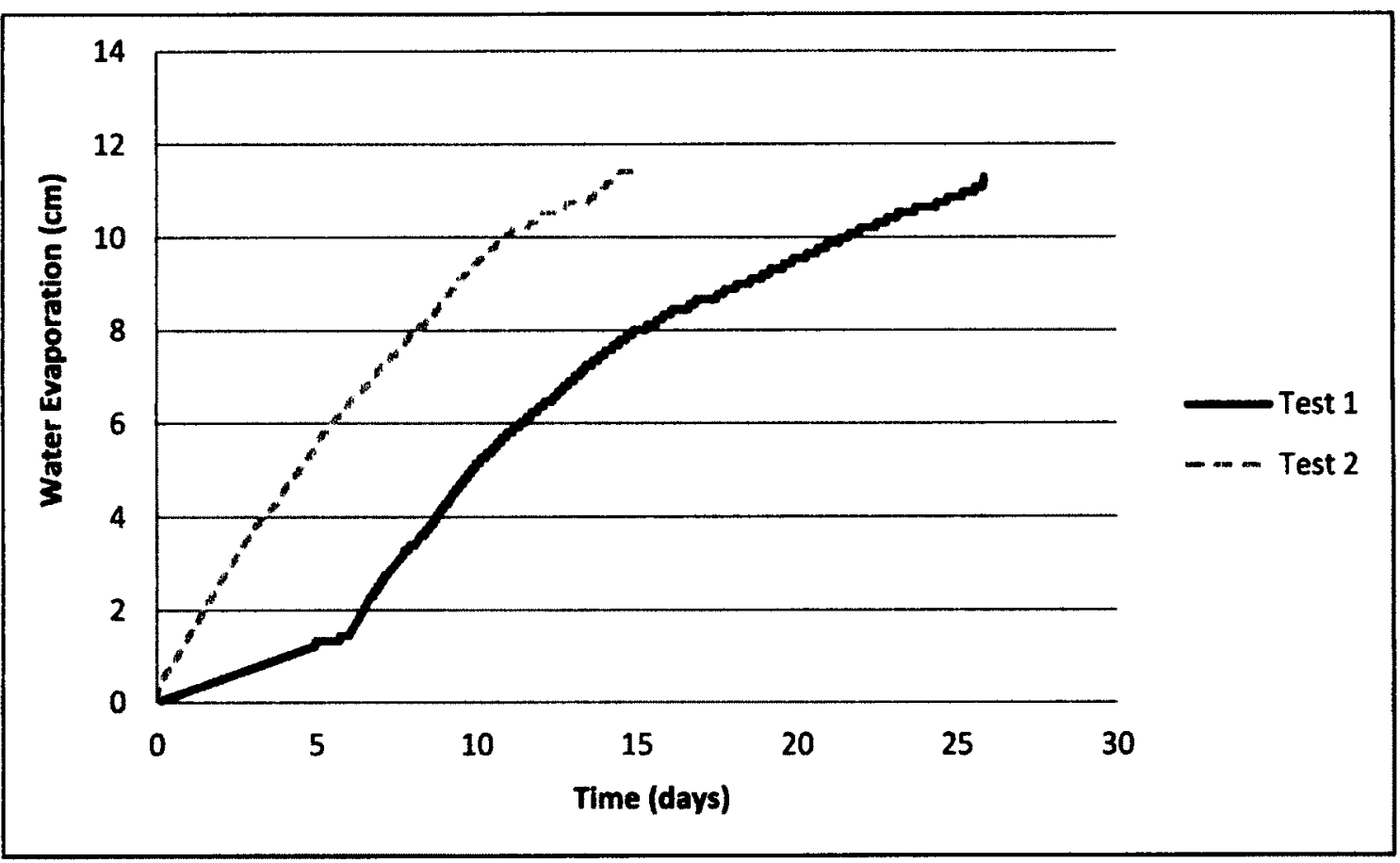

Figure 5-5: Cumulative evaporation results from thickened tailings over time for Test 1 and 2

In Test 2 , due to the volume of free water at the surface, the evaporation rate is noticeably higher and so even though similar evaporation amounts were achieved, Test 2 did at a faster rate. Towards the end of each Test, a decrease in evaporation is noted as the water content near the surface decreases with an increase in matric suction requiring more energy to drive evaporation and the formation of a crust of bitumen at the surface impeding water flow. An overall change in solids concentration of the column based on water loss is presented in Figures 5-6 (not considering free water in calculations) and 5-7 (considering free water in overall calculations) for both tests. 


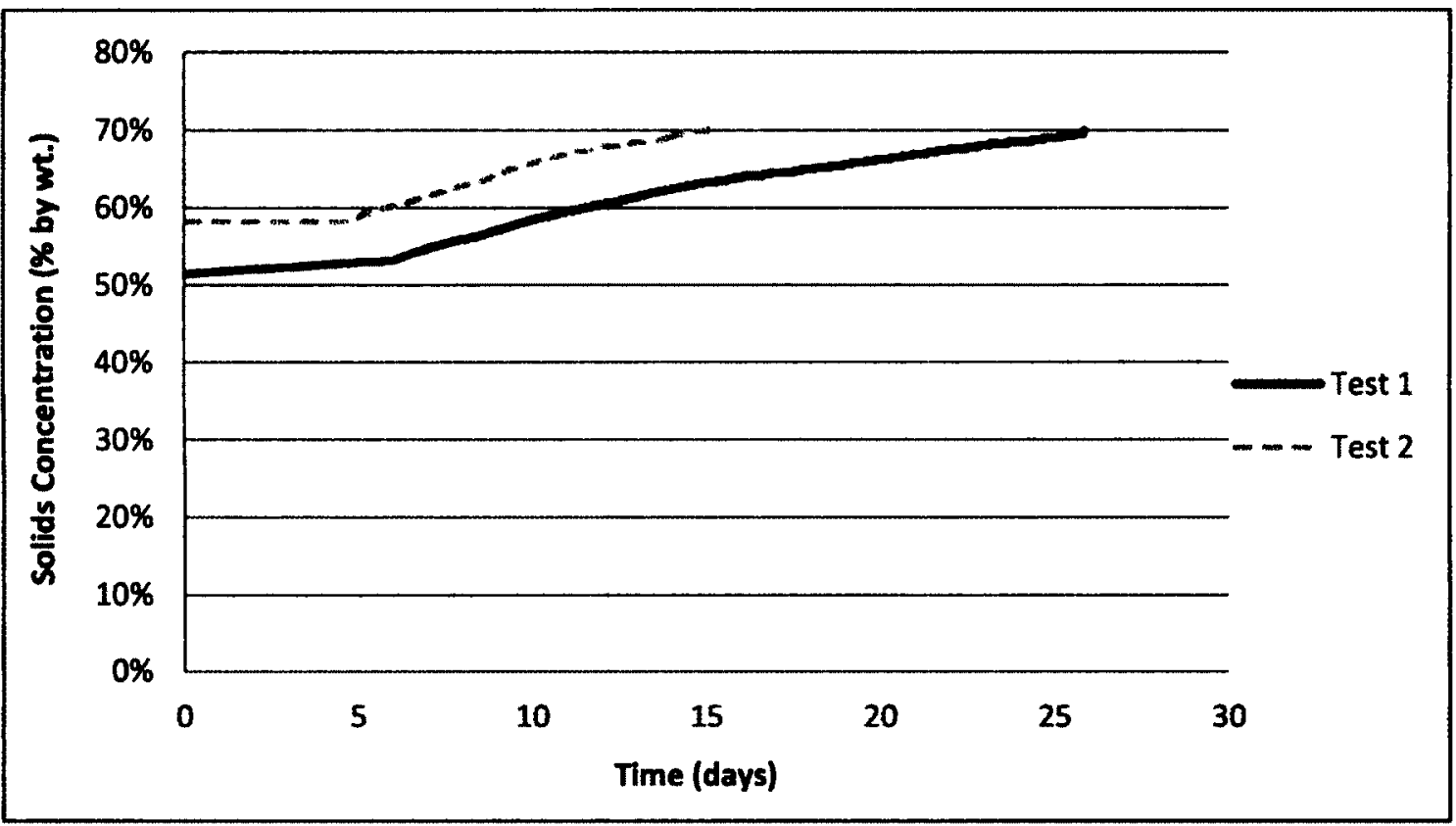

Figure 5-6: Solids concentration of thickened tailings over time for Test 1 and 2. Test 2 not considering free water.

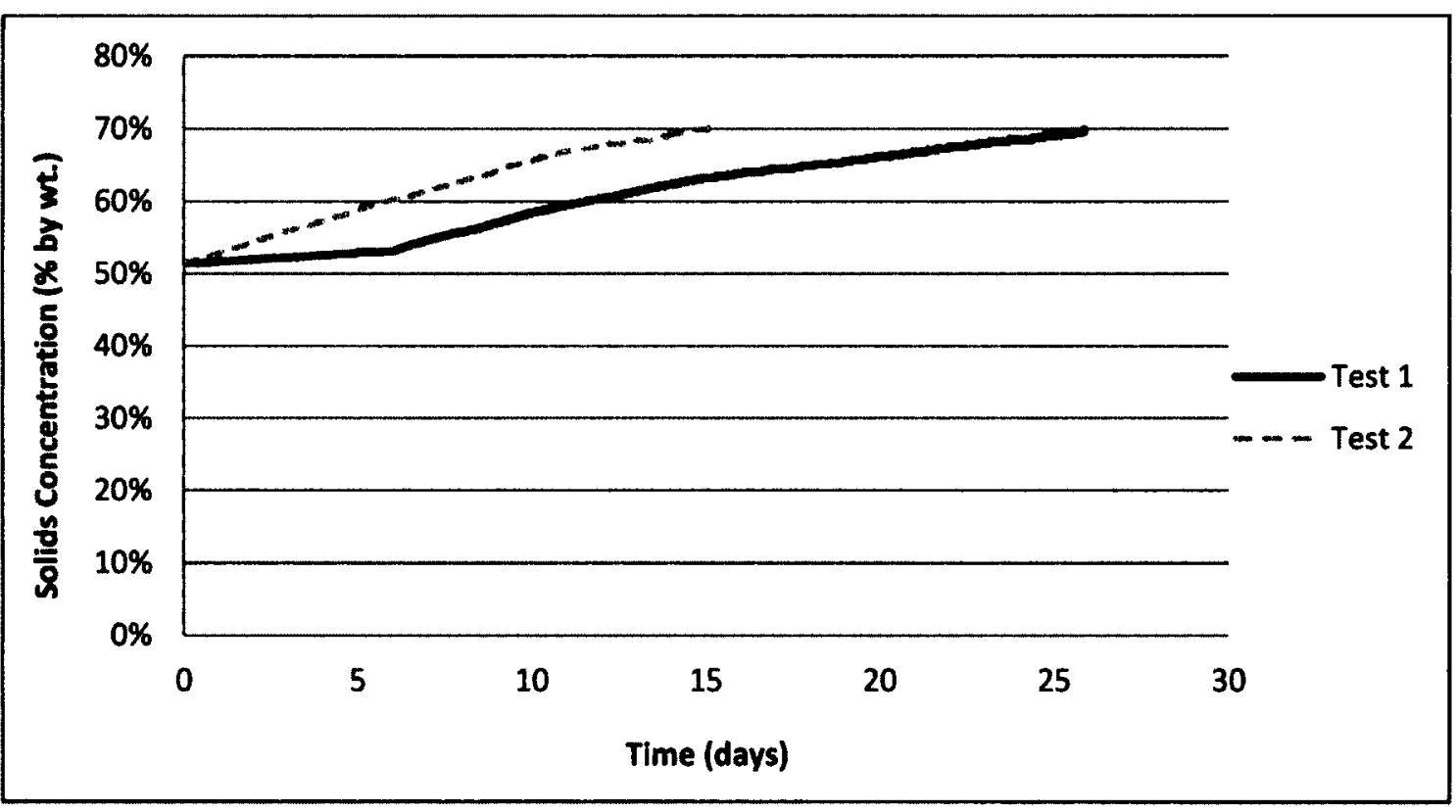

Figure 5-7: Solids concentration of thickened tailings over time for Test 1 and 2. Test 2 considering free water. 


\subsubsection{Column Sectional Analysis}

With a final height of $21 \mathrm{~cm}$, the tailings sample sectioned into six parts of roughly 3.5 $\mathrm{cm}$ in height. The sections varied in consistency with the upper two (1 and 2) being solid, the middle two ( 3 and 4 ) of paste the bottom two ( 5 and 6 ), liquid. Total Suction, solids concentration and volatiles content were analyzed. As shown in Figures 5-8 and 59 and Table 5-1, all properties decreased with depth with the highest suction value of 42 MPa at the surface. With regards to the volatiles content, a higher value at the surface maybe accounted for by the movement of bitumen to the surface during evaporation (crust formation). Its effect on interlayer flow is important. Junqueria et al (2012) observed the migration of residual bitumen into the underlying drainage layer and considered this partly responsible for the low drainage observed in their column tests.

Table 5-1: Variation in Total Suction with depth

\begin{tabular}{cc}
\hline Depth $(\mathrm{cm})$ & Total Suction (MPa) \\
& \\
\hline $0-3.5$ & 42 \\
$3.5-7$ & 0.08 \\
$7-10.5$ & 0 \\
$10.5-14$ & 0 \\
$4-17.5$ & 0 \\
$17.5-21$ & 0 \\
\hline
\end{tabular}

Solids Concentrations increased to $86.2 \%$ from $51.4 \%$ at the surface. At a depth of $14-17.5 \mathrm{~cm}$ there was only a 4.5 percent increase in the solids concentration to 55.9 \%. However at the base of the column, just below the aforementioned material, results 
show a $6.1 \%$ increase in solids concentration. Consolidation of the material due to the weight of the material above may be responsible for this increase in solids concentration.

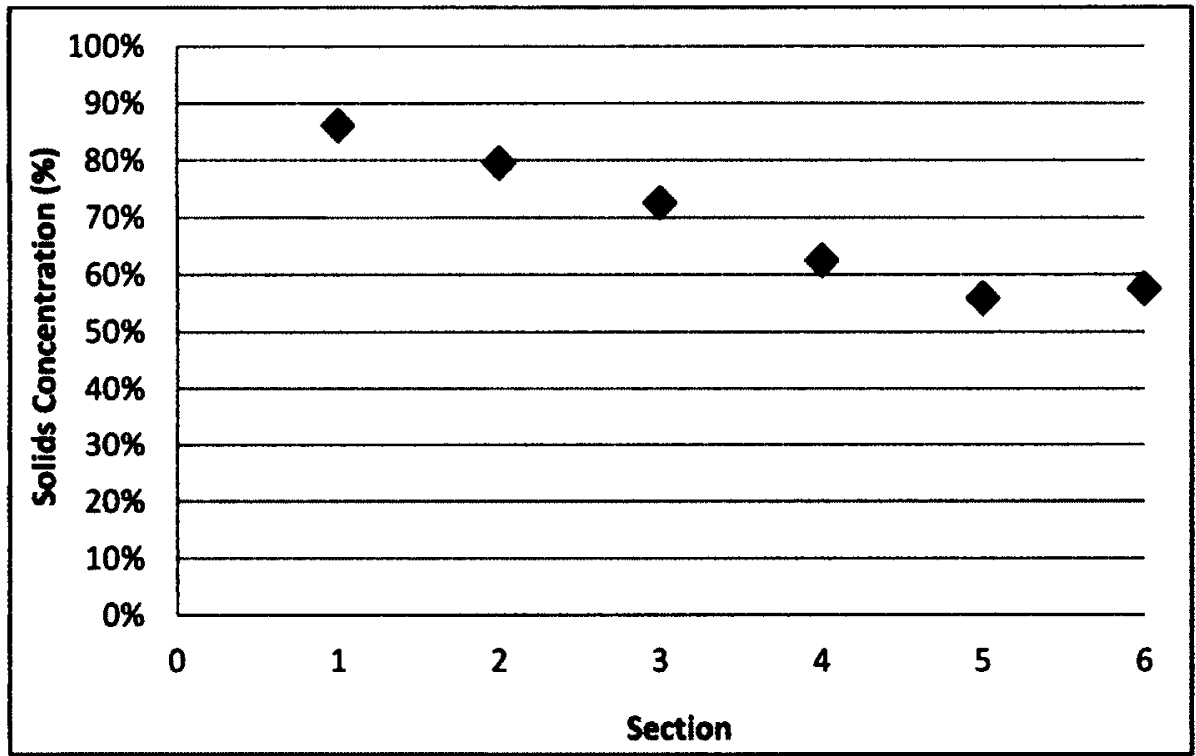

\begin{tabular}{|c|c|}
\hline Section & $\begin{array}{c}\text { Depth } \\
\text { (cm) }\end{array}$ \\
\hline 1 & $0-3.5$ \\
\hline 2 & $3.5-7$ \\
\hline 3 & $7-10.5$ \\
\hline 4 & $10.5-14$ \\
\hline 5 & $14-17.5$ \\
\hline 6 & $17.5-21$ \\
\hline &
\end{tabular}

Figure 5-8: Change in Solids Concentration with depth

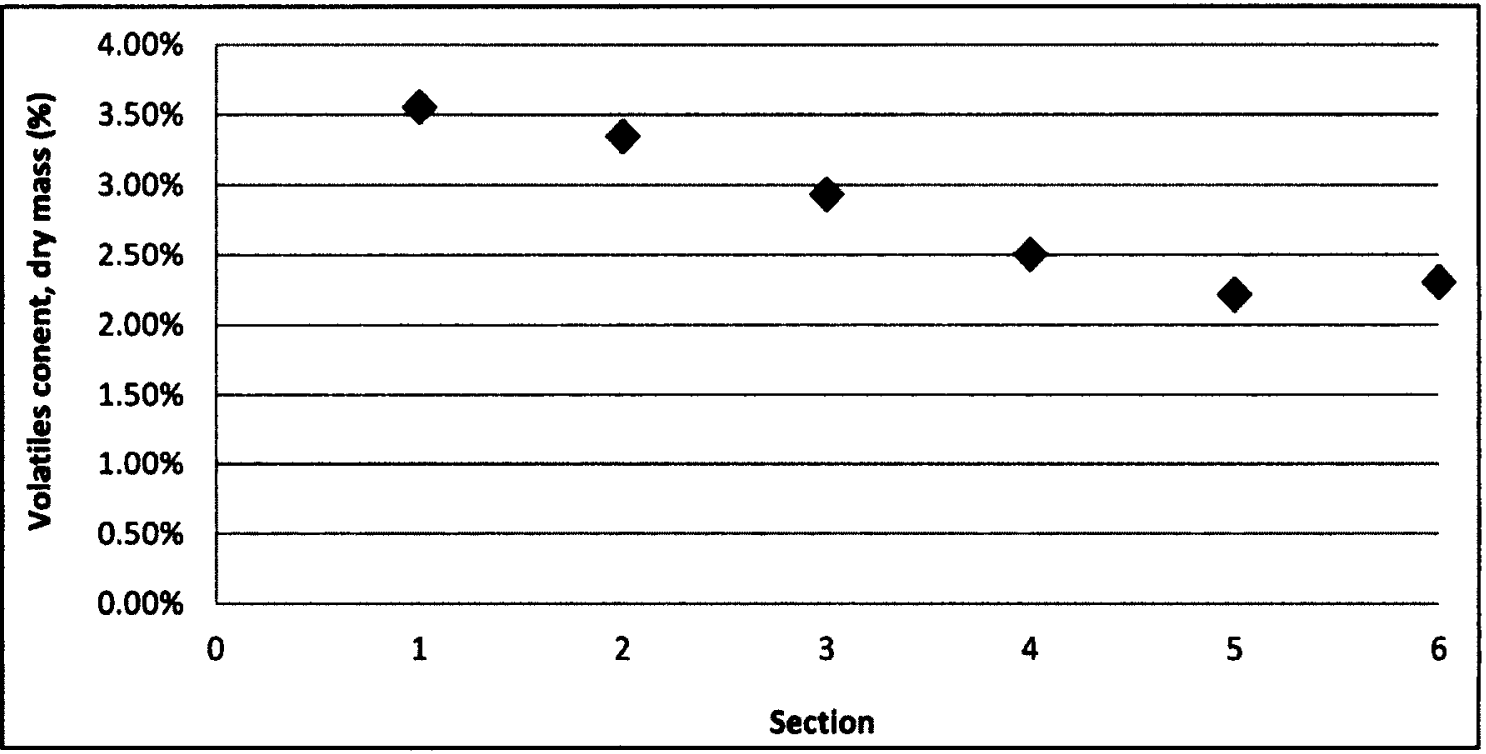

Figure 5-9: Variation in Volatiles content with depth 


\subsubsection{Comparison to previous study}

The results obtained in this study were similar to those obtained in a previous study conducted on unamended mature fine tailings by an undergraduate student. In this previous study, a similar vertical column drying tests was performed on MFT with an initial solids concentration of $35 \%$. The non-uniform drying reported in the unamended MFT, as evidenced by measurements of matric suction with depth shown in Figure 5-10.

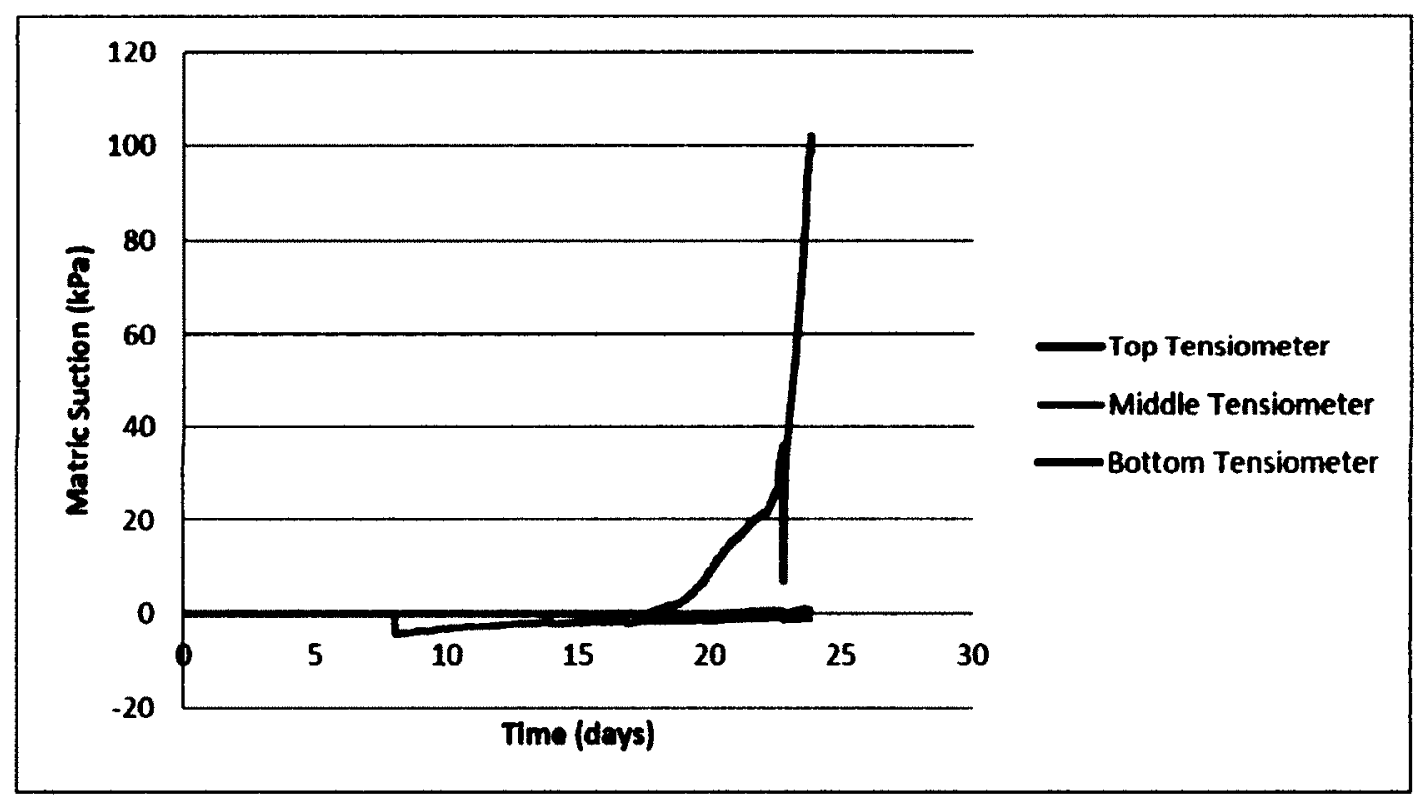

Figure 5-10: Matric Suction Measurements unamended tailings

This non-uniformity is not desirable in the field rather a more uniform drying to allow for shear strength development in the entire lift. 


\subsection{Wax Column Drying Test}

24 hours into the wax column test, it was observed that the top layer of each column was much drier and one side had sunk in. The material in the top layer was also pulling away from the walls of the column.

Sectioning of the first column (A1) from Sample A at 48 hours revealed very dry upper surfaced with no significant difference in solids concentration noted for the bottom layer. Figure 5-11 shows the results for the sectional analysis performed on this column.

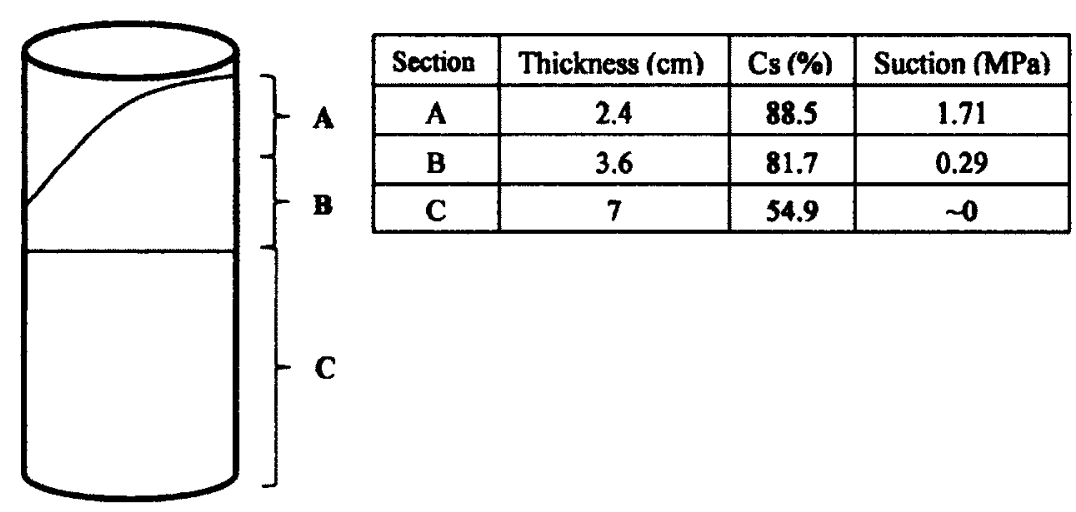

Figure 5-11: Sectional Analysis of Column A1

What this revealed was that the formation of the very low water content crust was impeding further removal of water from the underlying layers and that the evaporative front was now located below this thick crust. For water to be removed, an alternative path had to be created. As a result, the first column of Sample B was not sectioned. As the test proceeded, with the caving in of this crust and the pulling away of the material from the walls of the wax columns, the wet underlying material was exposed and the 
evaporation rate increased again. Sectioning of the other columns along the entire profile was now possible. Figure 5-12 shows the results for sectioning of Columns A1 and B1.

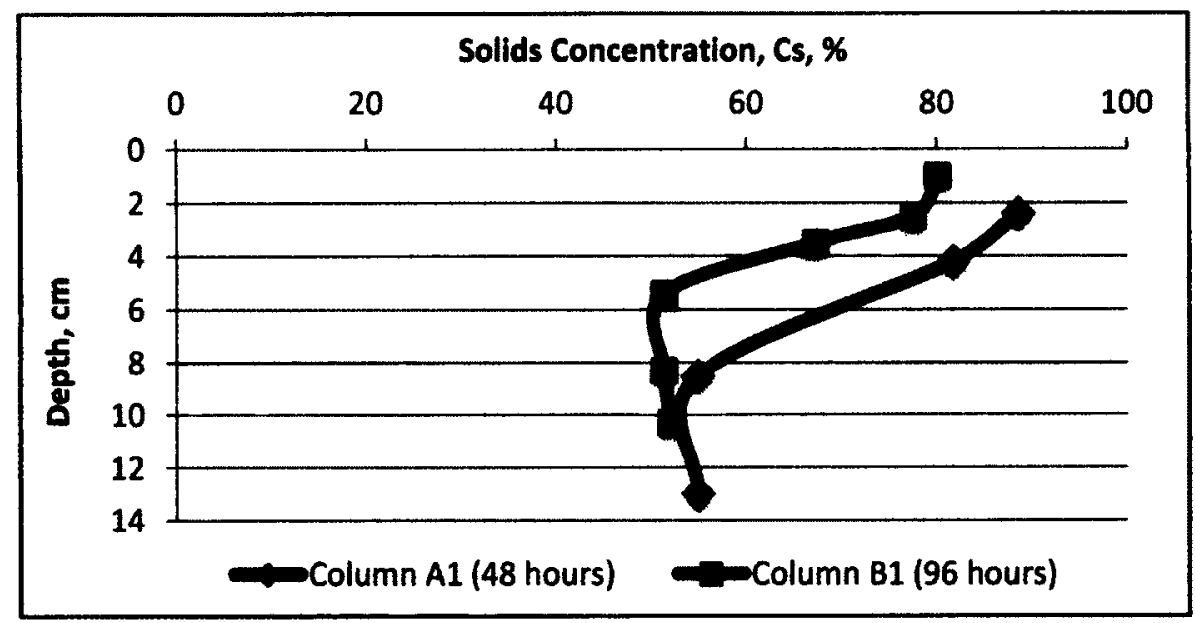

Figure 5-12: Solids Concentration Profile in Columns A1 ad B1

Although there was drying along the profile of the soil in Column B1, there was still a significant amount of wet material in the column. It is of the belief that some consolidation or densification occurred at the base of the column, as the bottom $1 \mathrm{~cm}$ had a higher solids concentration.

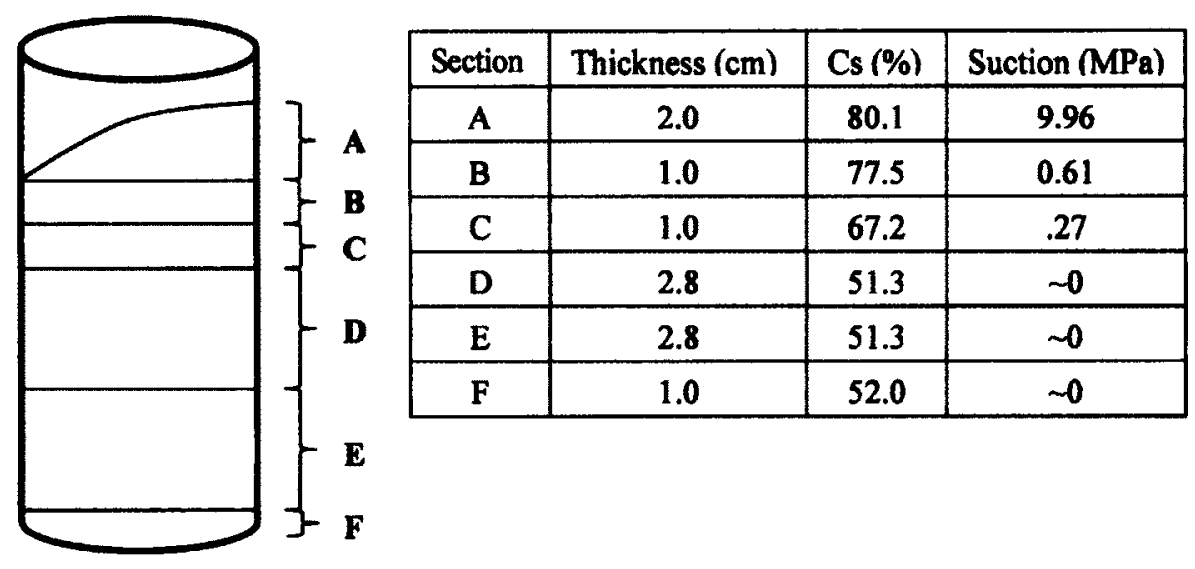


In Column B1, although lower solids concentrations are observed, due to the lower initial solids concentration of $50 \%$, the suction values were much higher at the surface and even along the profile (Figure 5-13). This is due mainly to the initial high EC of the sample, meaning more accumulation of salts at the surface and thus an increase in the osmotic component of the total suction, translating into an increase in the total suction at the surface and the fact that the column had remained for 96 hours. This will be later illustrated with the remaining columns in their sectional analysis.

Three other columns were sectioned at times 167,226 , and 340 hours. Salt deposits can be seen at the surface and around the dry surfaces which pulled away from the column wall; see Figure 5-14. There was significant reduction in volume as the tailings were dryer but the base of the material and a few centimetres above the base had higher moisture contents. The graphs of solids concentration with depth for each of the pair of columns sectioned at the aforementioned times are presented in Figure 5-15.

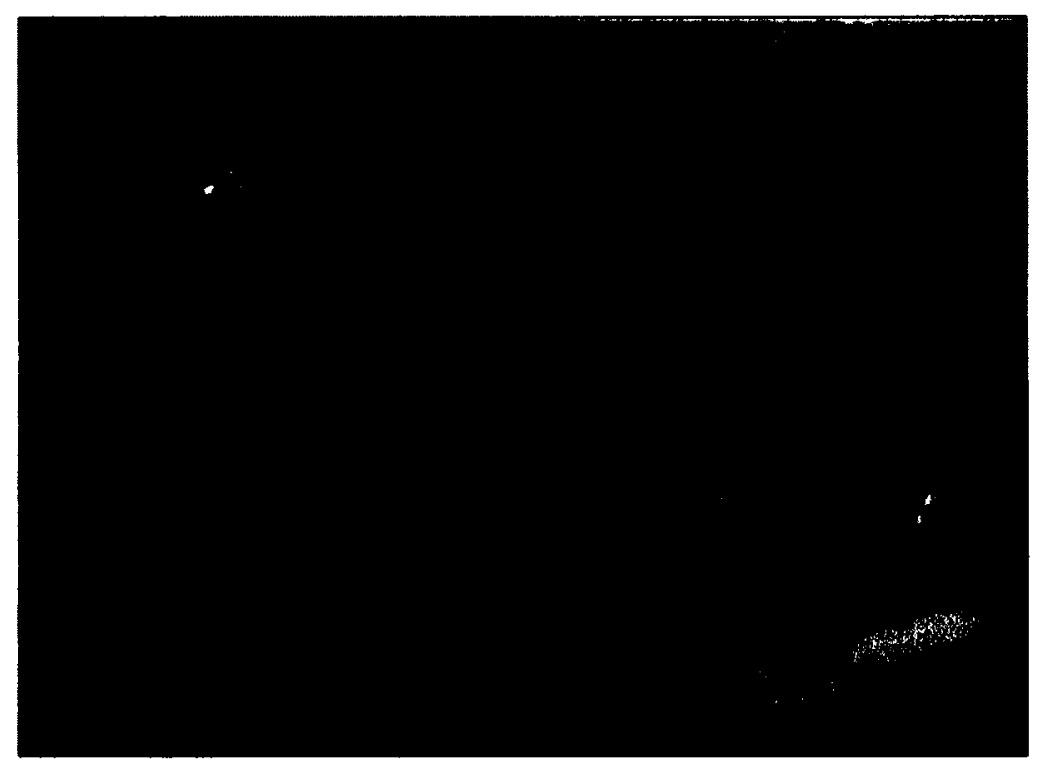


Figure 5-14: Sectional Analysis of Column B4

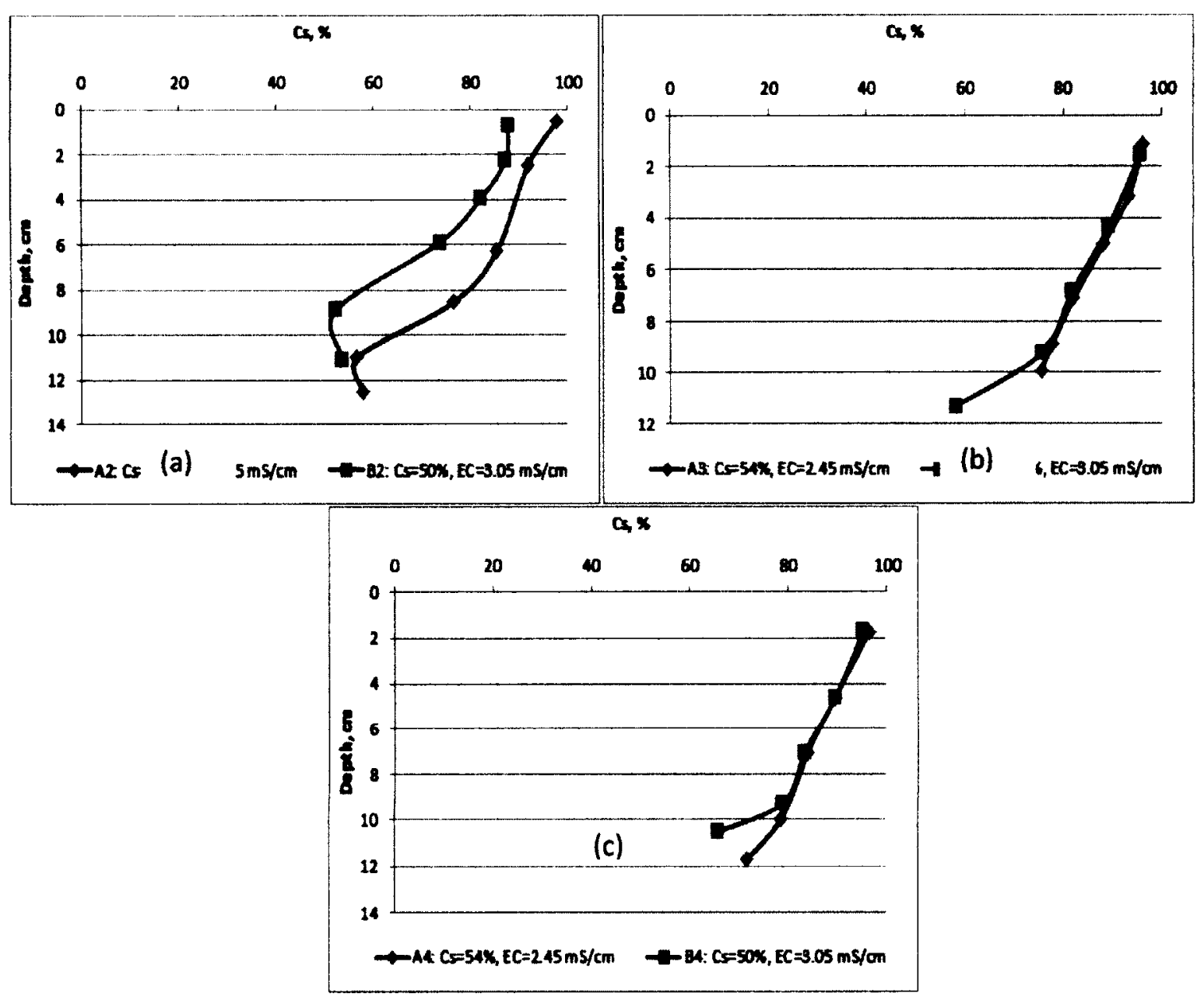

Figure 5-15: Solids Concentration Profiles: (a) $t=167 \mathrm{hrs}$ (b) $t=226 \mathrm{hrs} \mathrm{(c)} t=340 \mathrm{hrs}$

A decrease in solids concentration with depth is observed with both samples. Although they have fairly close solids concentration profile at the top part of the column, there is significant amount of wet material in columns from Sample B.

Solute transport within the columns was further investigated through the measurement of the electrical conductivity after sectioning. For example, the development of suction in the soil at the surface is shown in Figure 5-16 for Sample B. 


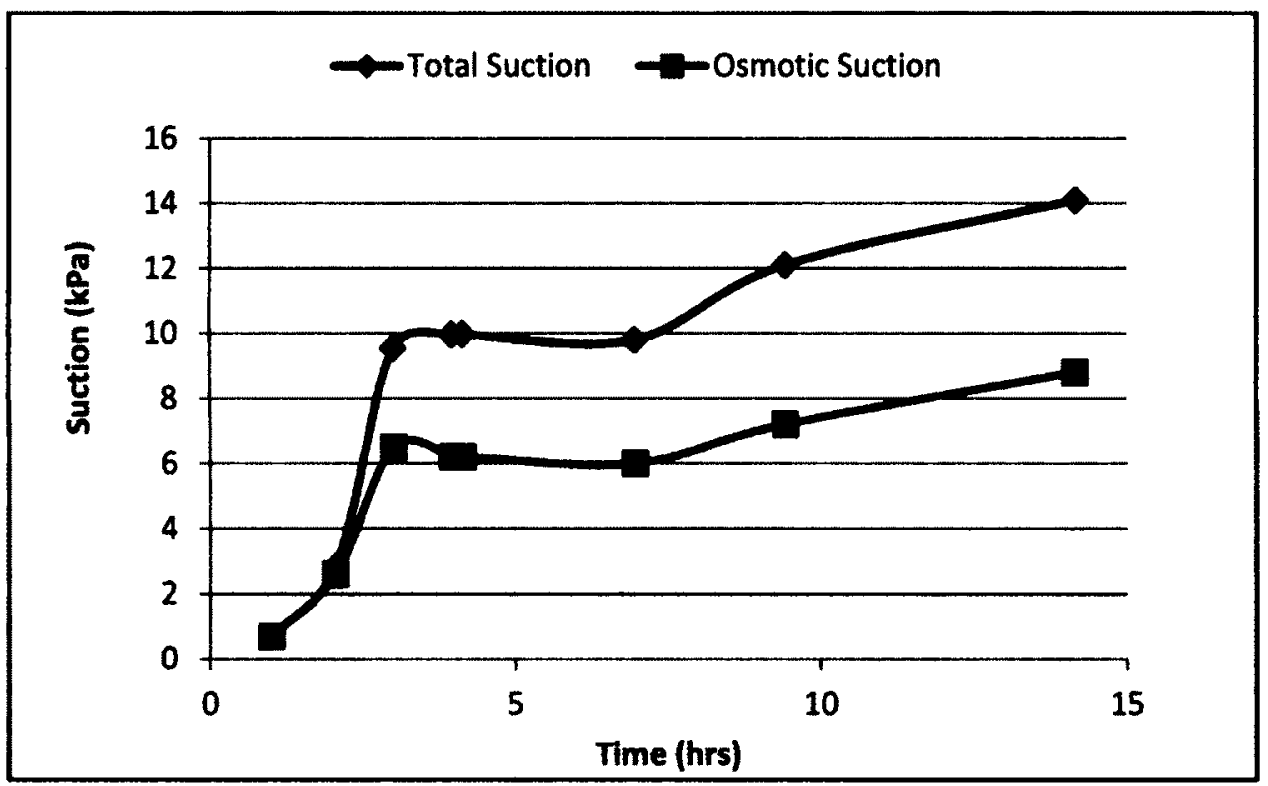

Figure 5-16: Osmotic and Total Suction development at the surface - Sample B

Values of EC were used to calculate the osmotic suction of the soil at each time step and it is appreciated that osmotic suction increases with time and is responsible for up to $60 \%$ of the total suction. To further investigate this behaviour, EC tests were conducted in the sectional analysis.

Electrical Conductivity tests measured from soil samples show decreasing EC with depth. With decreasing water content along the soil profile, EC is expected to be greater than the initial EC and also decreasing with depth. However, when EC was calculated based on water content values, assuming no transport and using volumetric laws, these values differed significantly from the values measured. For example, the bottom 3 sections of column A4 (Figure 5-17) show a decrease of 1.2 to 2.5 whereas the top two show a significant increase in EC. This attests to the movement of solutes to the surface of the soil. 


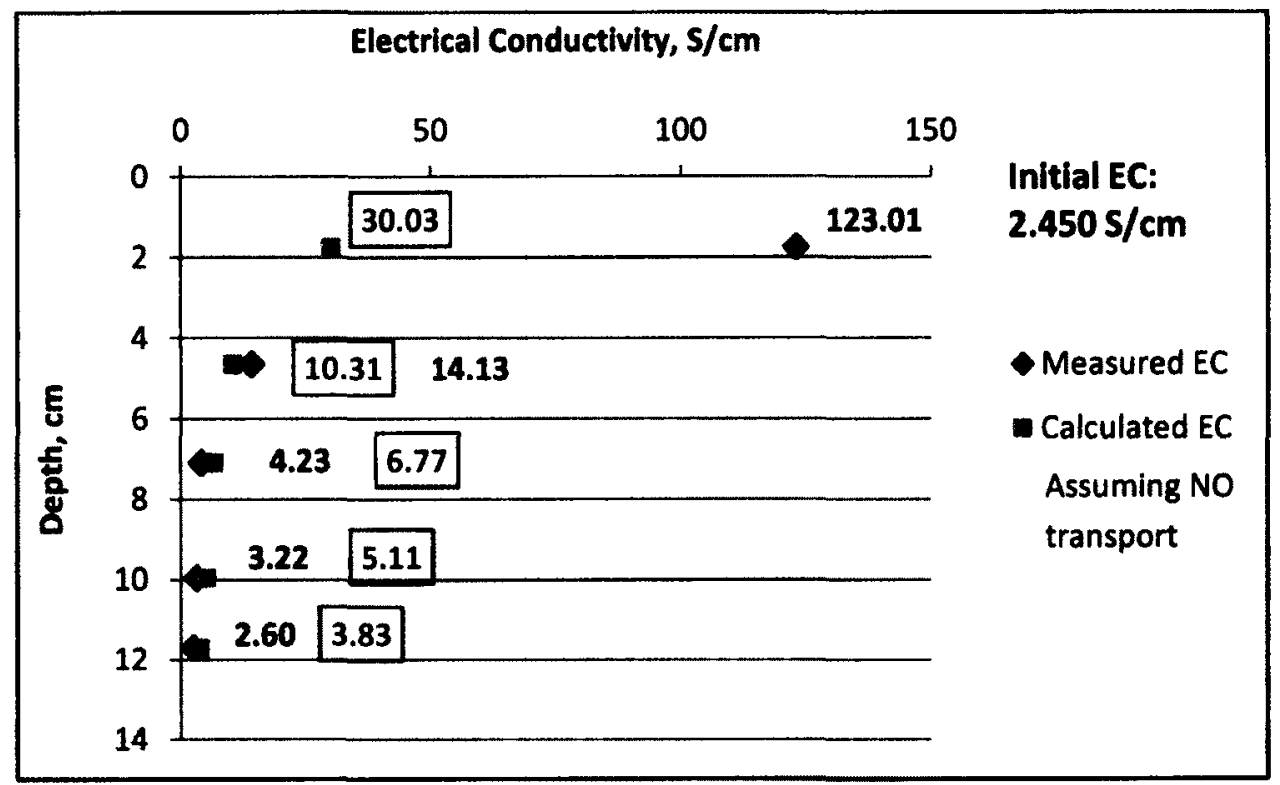

Figure 5-17: EC profile Column A4

Similarly, in Column B4 the same trend was observed, but with way higher EC and suction at the surface due to initially high EC value of $3.050 \mathrm{mS} / \mathrm{cm}$ (Figure 5-18).

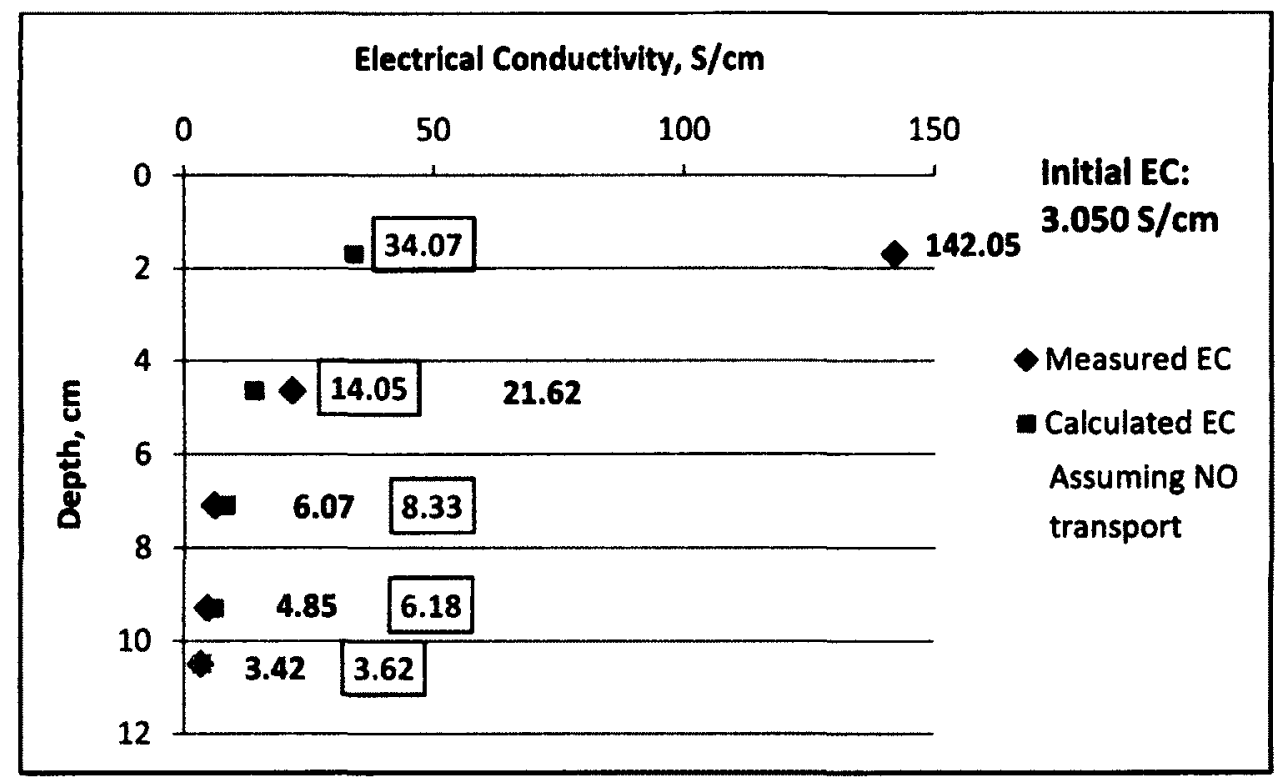

Figure 5-18: EC profile Column B4 
This high value in EC at the top of column B4 also gives an idea as to why evaporation was shut down even though there was much water available from wet underlying layers. The accumulation of salt at the surface made it difficult for water to leave the tailings column. Figures for the other columns can be found in Appendix K.

Relative evaporation calculated from measured values of actual and potential evaporation is presented in Figures 5-20 and 5-21 for Samples A and B respectively. RE at the start of the test for all columns were above unity. A similar trend was observed by Wilson (1997) and the behaviour was attributed to the small differences in aerodynamic resistance and surface temperatures right at the start of the test. It was observed that RE decreases for the first 5 days to 0.6 for all the samples. Then the RE increases to a value very close to 1 immediately after. Observed in the soil both samples on this day was the exposure of wet tailings as the surface caved in and the material drew away from the sides of the column (Figure 5-19). This signified an increase in the total surface area from which evaporation was taking place. Once the salt had been deposited at the surface, it became pale in colour and the evaporation rate declined significantly with little evaporation recorded on some days.

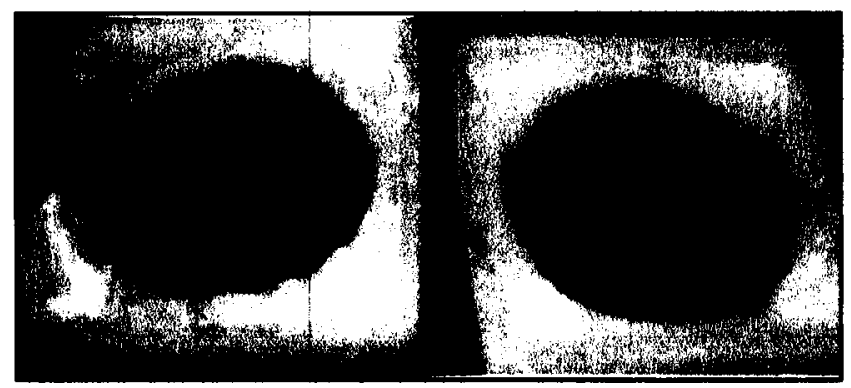

Figure 5-19: Visual of the Soil surfaces in Wax Columns 


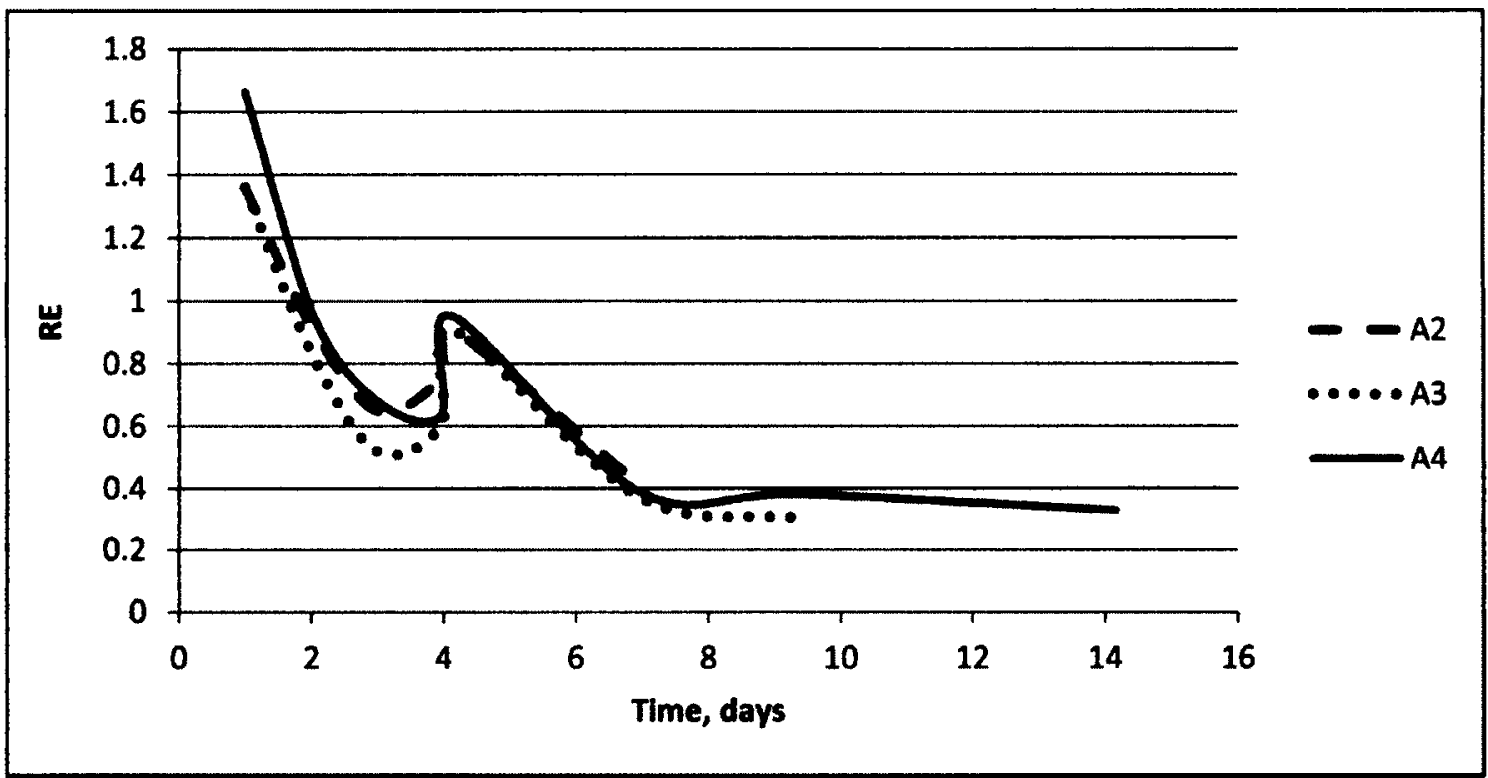

Figure 5-20: Measured RE versus drying time (Sample A)

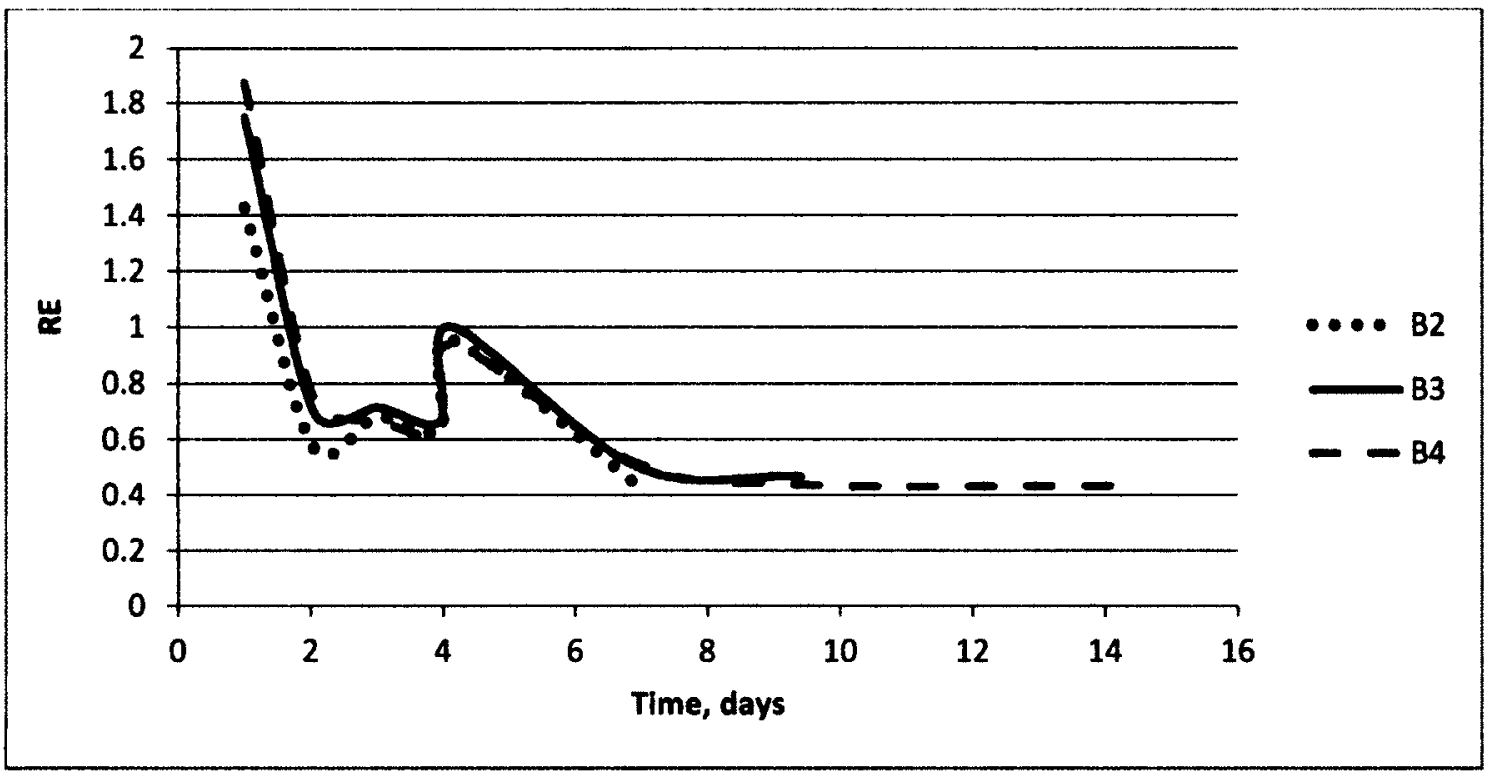

Figure 5-21: Measured RE versus drying time (Sample B) 
In order to predict the RE, two methods were evaluated. The two methods were chosen on the need to account for increasing suctions at the surface and the resistance offered by the soil as water content decreased. The first method is a modified version of Wilson's equation (Equation 5.01) which includes an empirical adjustment factor (EF), $\delta$ (Fredlund et al., 2011). To account for the effect of an increase in total suction brought on by the osmotic suction increase (increased salt concentration at the surface), the authors applied EF to the total suction through equation 5.01.

$\psi_{\text {adjusted }}=\psi_{\text {original }} \times 10^{-\delta}$

The values for the empirical factor $(\delta)$ used ranged from -0.5 to -2 as has been previously applied to gold thickened tailings (Dunmola A. , 2012). The defaultvalue in SV Flus is 1.2

The second method employs Wilson's original equation (equation 2.34) with the inclusion of soil resistances in series. A fitting exercise was performed with Dunmola's modified form of Wilson's equation (Equation 2.35). In the latter exercise, the resistances employed were: a value of bulk aerodynamic resistance $\left(r_{\mathrm{z}}\right)$ of 0.9 day/mm and this was calculated from potential evaporation and temperature values using equation 2.32. The values of soil resistance $\left(r_{s}\right)$ were first estimated through equation 2.33 and through an established relationship between overall gravimetric water content and soil resistance was calculated through equation 5.02 .

$r_{s}=-2.732 \ln (w)+0.1321$

Soil resistance values ranged from 0.16 to $4 \mathrm{day} / \mathrm{mm}$. The overall gravimetric content was chosen due the non-uniformity observed in the drying of the tailings. The overall 
decrease in water content, to the author, was more representative of an overall soil resistance.

The results of the exercise are represented in Figure 5-22. For the first method, EF values of 0.5 and 0.65 produced a few values similar to the data set. As this factor was increased or decreased, the values were under-predicted or over-predicted respectively. Dunmola's method produced best fit data for values of " $a$ ", the fitting parameter, of 0.1 and 0.4 for values less and greater than $3000 \mathrm{kPa}$ respectively. However, no method captured the spike to 1 on day 6 and as will be later shown in subsequent experiments, if the surface area is considered, the spike is lowered considerably.

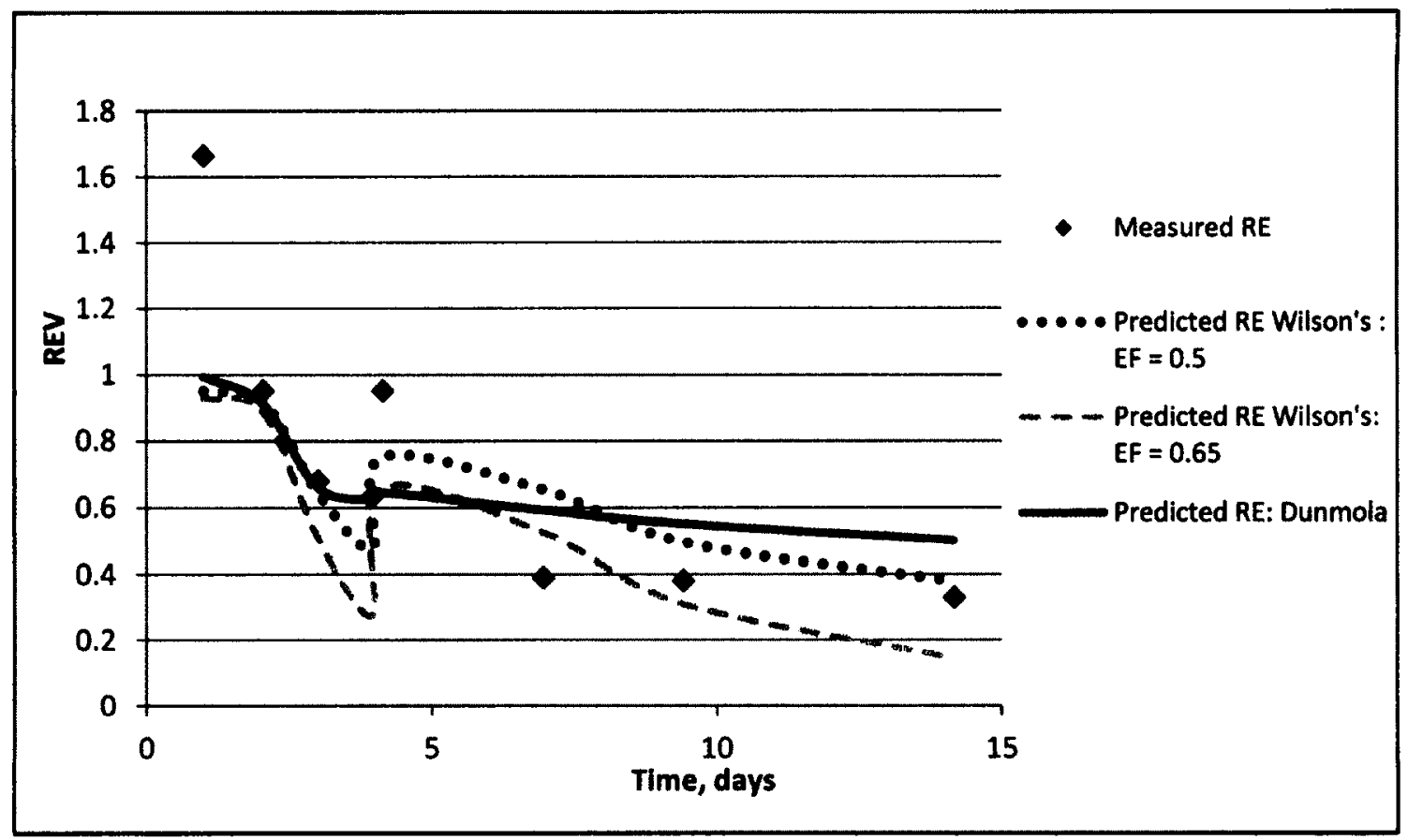

Figure 5-22: Actual and Predicted RE - Sample A 


\section{$5.3 \quad 5 \mathrm{~cm}$ Thick Drying Box Test}

The behaviour of the tailings was further investigated with an increase in the plan area. Bearing in mind that both materials are of the same solids concentration and gravimetric water content of $50 \%$ and $100 \%$ respectively, Actual Evaporation and Cumulative evaporation, presented in Figures 2-23 and 2-24 respectively depict lower evaporation rates and total evaporation for the more sodic material except at the end where the salt formation in both cracks and surface shut down evaporation. Additionally, more oscillations were present in the curve compared to previous tests. To calculate AE, two methods were employed. One method considered the crack surface contribution to total surface area and the other did not, assuming total surface area constant.

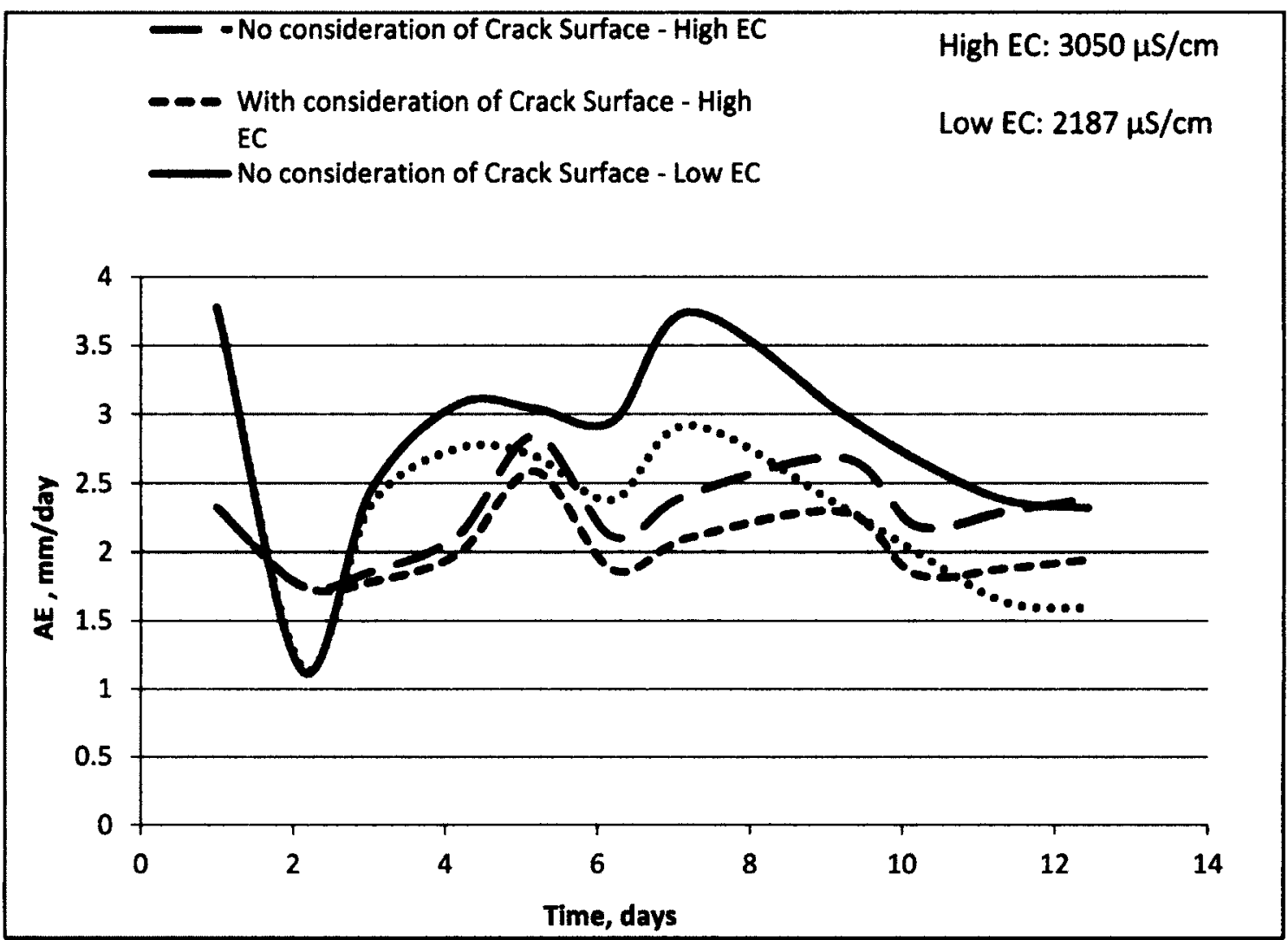


Figure 5-23: Measured AE in $\mathrm{mm} / \mathrm{d}$ - With and without crack contribution to $\mathrm{SA}$

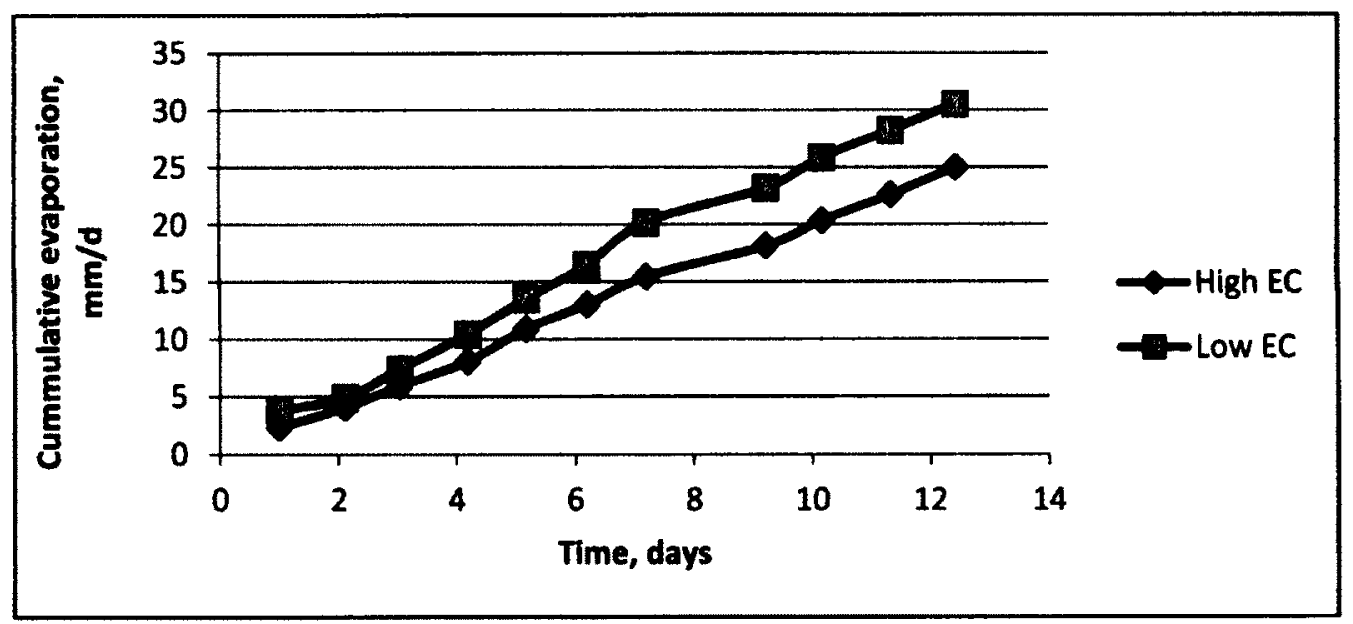

Figure 5-24: Measured Cumulative evaporation in $\mathrm{mm} / \mathrm{d}$

Suction values at the surface (Table 5-2) show the rapid increase in suction for the more sodic material.

Table 5-2: Suction values (MPa) at the surface - 5-cm thick Drying Box

\begin{tabular}{|c|c|c|}
\cline { 2 - 3 } \multicolumn{1}{c|}{} & \multicolumn{2}{c|}{ Sample } \\
\hline Time (days) & $\underline{\text { 1: High EC }}$ & $\underline{\text { 2: Low EC }}$ \\
\hline 1 & 0 & 0 \\
\hline 2 & 0.46 & 0.03 \\
\hline 3 & 0.8 & 0.42 \\
\hline 4 & 1.06 & 0.75 \\
\hline 5 & 1.22 & 0.8 \\
\hline 6 & 1.72 & 0.83 \\
\hline 7 & 2.56 & 1.73 \\
\hline 8 & 5.31 & 2.55 \\
\hline
\end{tabular}

Although higher evaporation rates were obtained for the Sample 2, the increase in crack surface area accounted for it. This increase in crack surface area with growing 
depth of the cracks, exposed underlying material with lower suction values and lower water content, less resistant to water flow. In sample 1, the development of cracks was slowed by the high suction values at the surface (Figure 5-27).

Crack Surface area and volume are presented in Figures 5-24 and 5-25 respectively.

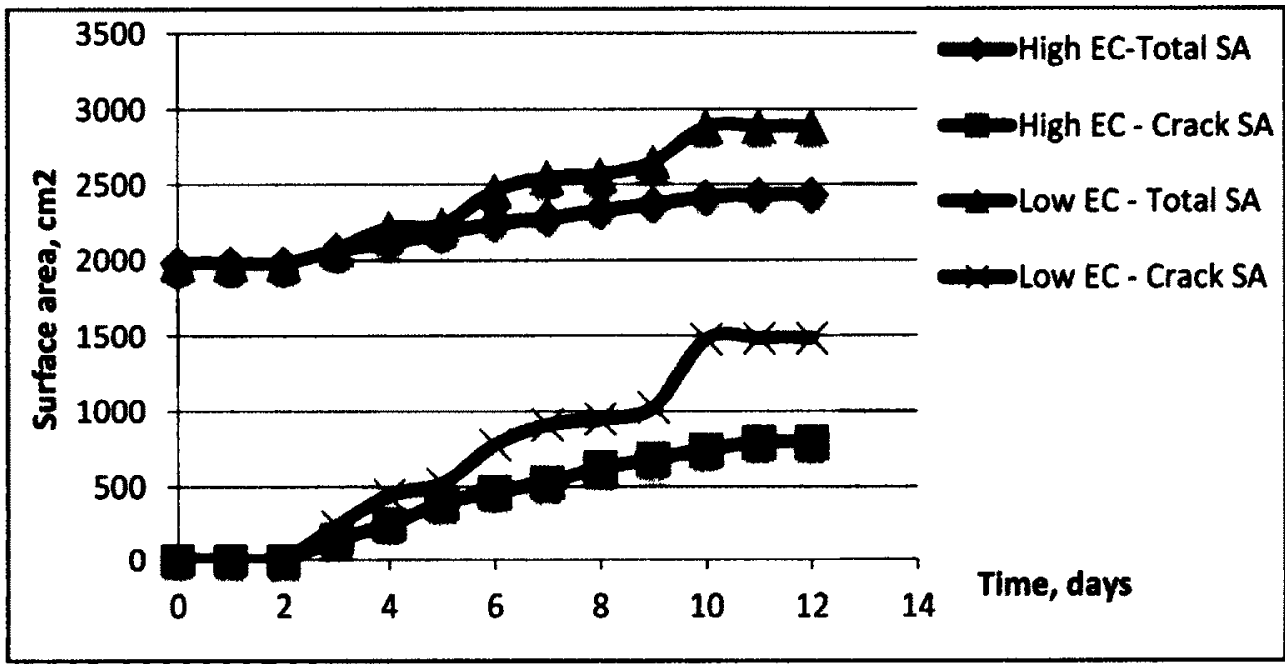

Figure 5-25: Evolution of Tailing Crack and Total Surface Area (SA)

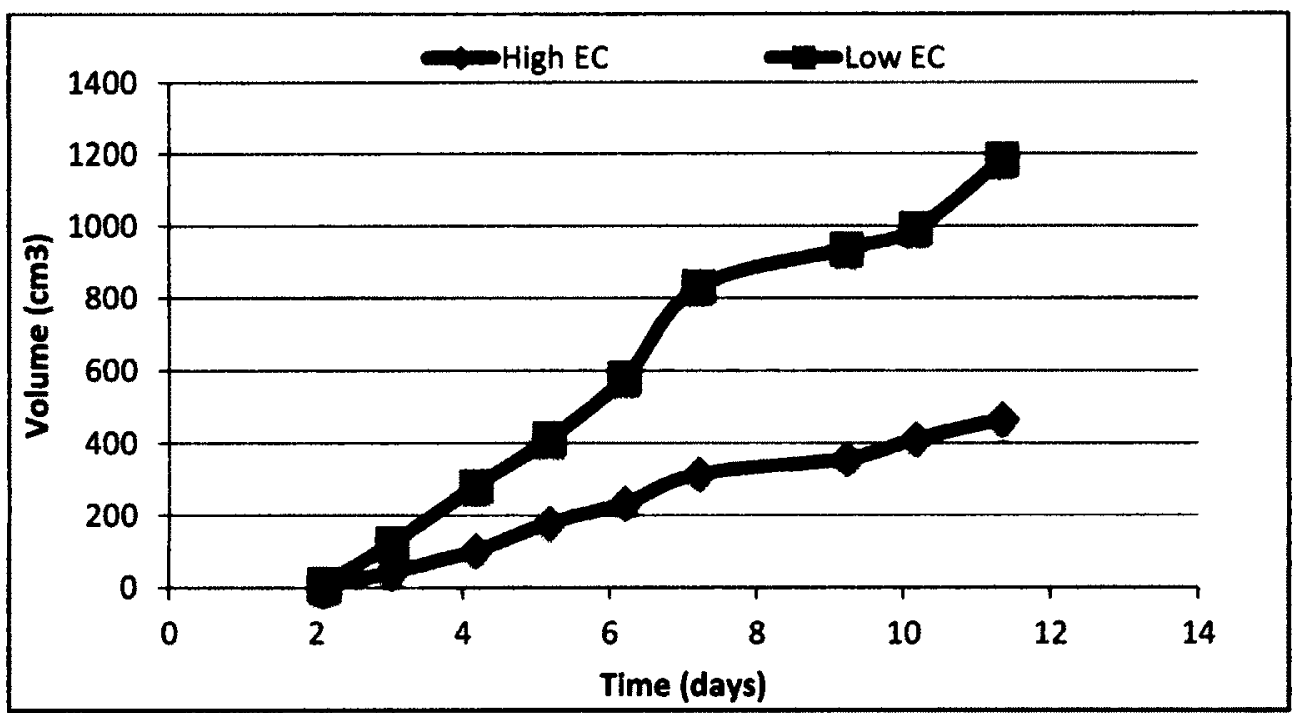

Figure 5-26: Evolution of Tailing Crack Volume 
At first cracks show very low total suctions along their profiles but with time the total suction increases especially at the top edges very close to the surface (Figure 5-27). However, new cracks are formed and the process repeats. This may provide an explanation for the oscillations observed in the AE.

Top: 2.54
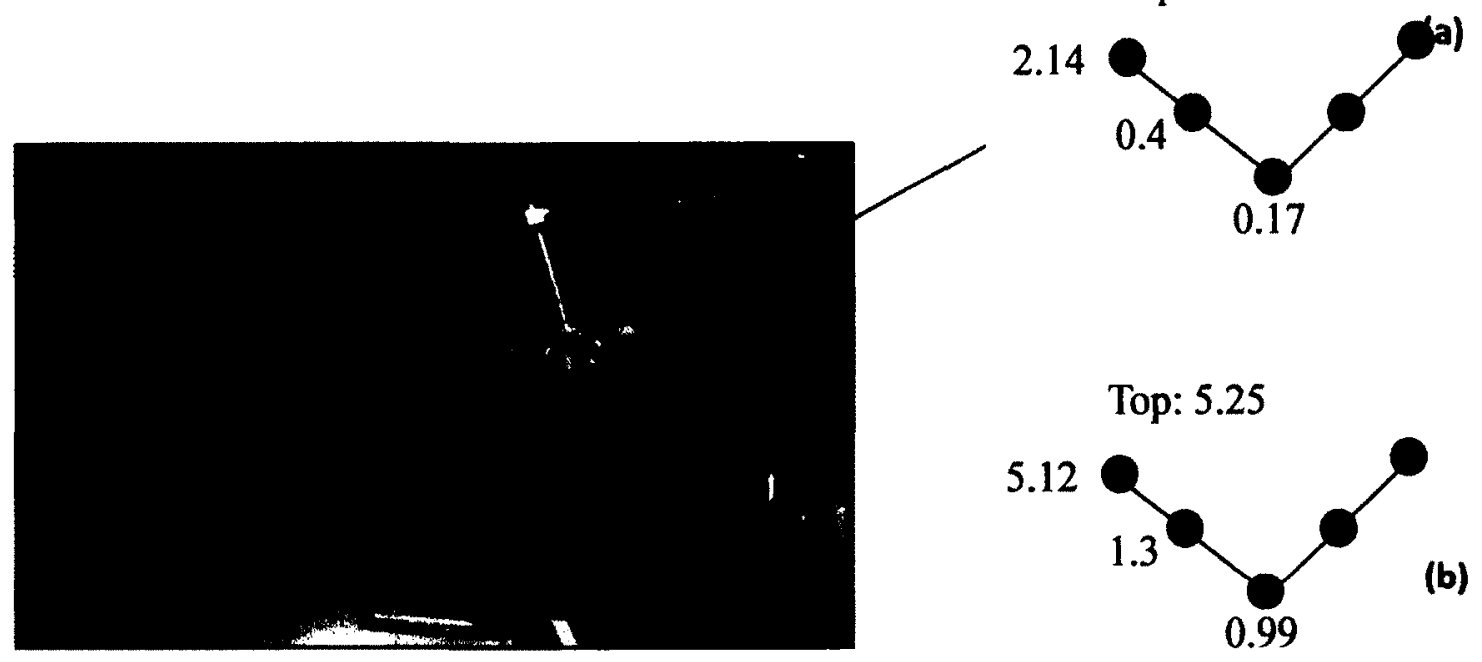

Figure 5-27: Suction development within cracks in Sample 1 (a) Day 7 (b) Day 8

Photos of the setup and the progress of the experiment are presented in Appendix L. The height was monitored periodically during the test but no settlement data is presented here. The less sodic material had experienced greater settlement. This behaviour will be studied more in depth with the medium scale dying box. 


\section{$5.4 \quad 10 \mathrm{~cm}$ Thick Drying Box Test}

The layer thickness in the drying box was increased to $10 \mathrm{~cm}$ and the drying behaviour of $50 \%$ material of EC $3050 \mu \mathrm{S} / \mathrm{cm}$ was investigated to attain a better understanding of the development of suction and crack propagation in the sample. Suction samples of the top 1 $\mathrm{cm}$ of the surface and along the cracks were collected.

With increasing thickness of the layer, the expulsion of underlying material through cracks was observed as the thickness and weight of the top surface of the tailings increased. This was predominantly responsible for the spikes in the measured evaporation rates (Figure 5-28) and also responsible for the change in geometry of the cracks.

Calculated RE with and without consideration of Crack Surface area, are presented in Figure 5-28. A similar trend is observed with a marked increase followed by a decrease in RE and then spontaneous peaks in its values.

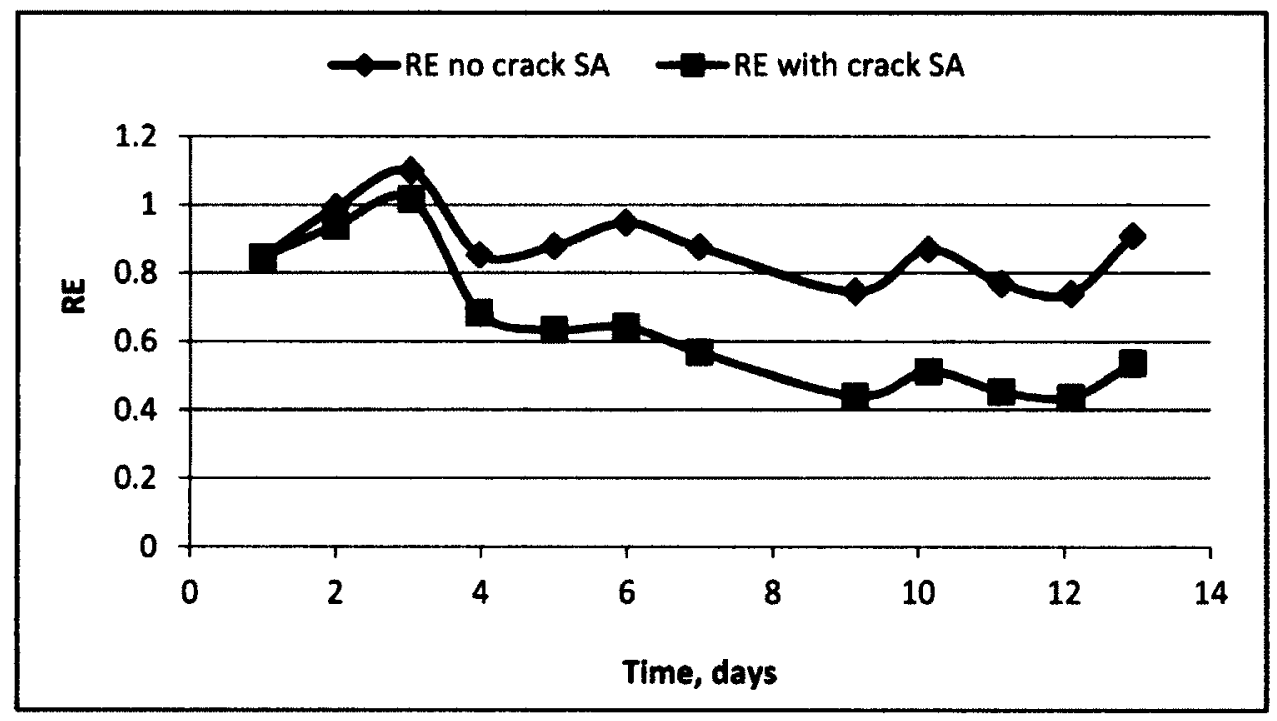

Figure 5-28: Measured RE - With and without crack contribution to SA 
As evaporation proceeded, the suction measurements reveal that the base of the cracks and the sides had much lower suctions than the tailings surfaces. Crack surface area increased the total surface area from 1983 to 3366 cubic centimetres. However, the edges had much higher suction than the surfaces. Refer to Table 5-3.

Table 5-3: Crack Suctions in MPa

\begin{tabular}{|c|c|c|c|c|}
\hline Date & Crack No. & Base & Side & Edge \\
\hline \multirow{2}{*}{15} & 1 & 0 & 0.57 & 6.78 \\
\hline & 5 & 0 & 0.86 & 1.07 \\
\hline \multirow{3}{*}{16} & 1 & 0.07 & 0.6 & 3.72 \\
\hline & 3 & 0 & 1.66 & 4.18 \\
\hline & 5 & 0.03 & 0.23 & 2.55 \\
\hline \multirow{5}{*}{17} & 1 & 0.58 & 0.79 & \\
\hline & 2 & 0.05 & 0.66 & 3.48 \\
\hline & 4 & 0.06 & 0.65 & \\
\hline & 6 & 0.32 & 0.35 & 10.86 \\
\hline & shutdown & 4.57 & & \\
\hline \multirow{3}{*}{18} & 3 & 0.39 & 0.8 & 12.42 \\
\hline & 4 & 0.92 & 0.23 & 4.62 \\
\hline & 6 & 1.53 & 0.53 & 14.81 \\
\hline \multirow{3}{*}{19} & 1 & 0.26 & 0.55 & 3.75 \\
\hline & 3 & 0.24 & 0.56 & 14.17 \\
\hline & 4 & 1.24 & 0.25 & 3.25 \\
\hline \multirow{5}{*}{20} & 1 & 0.16 & 0.29 & 1.42 \\
\hline & 2 & 1.3 & 0.14 & 1.31 \\
\hline & 3 & 2.01 & 0.75 & \\
\hline & 4 & 0.74 & 0.15 & 4.48 \\
\hline & new (within old) & 0 & 0.41 & 6.3 \\
\hline \multirow{3}{*}{21} & 1 & 1.03 & 0.3 & 9.57 \\
\hline & 3 & 0.36 & 0.42 & \\
\hline & 4 & 1.78 & 0.31 & 3.82 \\
\hline \multirow{2}{*}{23} & 1 & 0.24 & 0.89 & 8.24 \\
\hline & 5 & 2.39 & 5.64 & 28.53 \\
\hline \multirow{2}{*}{30} & 1 & 0.45 & 0.81 & 15.07 \\
\hline & 4 & 4.04 & & 14.81 \\
\hline
\end{tabular}


The latter was observed up to the termination of the test. Although some crack bases eventually attained some high suctions the sides remained at very low suctions and precipitated salts were visible at those sites. What flow pattern or solute transport is responsible for this pattern should be investigated. Fuyiyasu et al (2000b) observed increases of up to 4 times the initial surface area due to crack development and that evaporation from cracks at one point were responsible for 80 to $90 \%$ of the total evaporation from the tailings.

In addition, suction measurements within the top $2 \mathrm{~cm}$ of the soil surface revealed that the suction just below the surface was higher. For example 2 readings revealed the following measurements:

1. Depth: 0-1 cm; Suction: $2.98 \mathrm{MPa}$ Depth: 1-2 cm; Suction: $4.29 \mathrm{MPa}$

2. Depth: 0-1cm; Suction: $4.57 \mathrm{MPa}$ Depth: $1-2 \mathrm{~cm}$; Suction: $6.25 \mathrm{MPa}$

Using the same methods employed in the wax column test, the RE was predicted. For Dunmola's method, free parameters attained in the wax column tests were used. Bulk aerodynamic resistance, $r_{a}$, calculated from the potential evaporation was 0.2571 $\mathrm{d} / \mathrm{m}$ whereas soil resistance was calculated with overall gravimetric water content values. The plots of measured and predicted are presented in Figure 5-29.

Wilson's method with empirical adjustment factors of 1 and 1.3 captured the first part of the graph fairly well. However, once suction decreased and RH of the overlying air increased (Figure 30), RE is over predicted. Dunmola's method captured reasonably 
well the change in RE with time even with the change in suction. This is possibly due to the representation of soil resistance factors.

The decrease in the suction of the soil after 7 days has been observed previously by Elrick et al., 1994; Fujimaki et al., 2006 and Fissheha et al., 2010 and has been attributed to a transport process called "back difusion" due to the sharp concentration gradients within the soil profile. This gradient causes diffusive solute transport in the direction opposite to water flow.

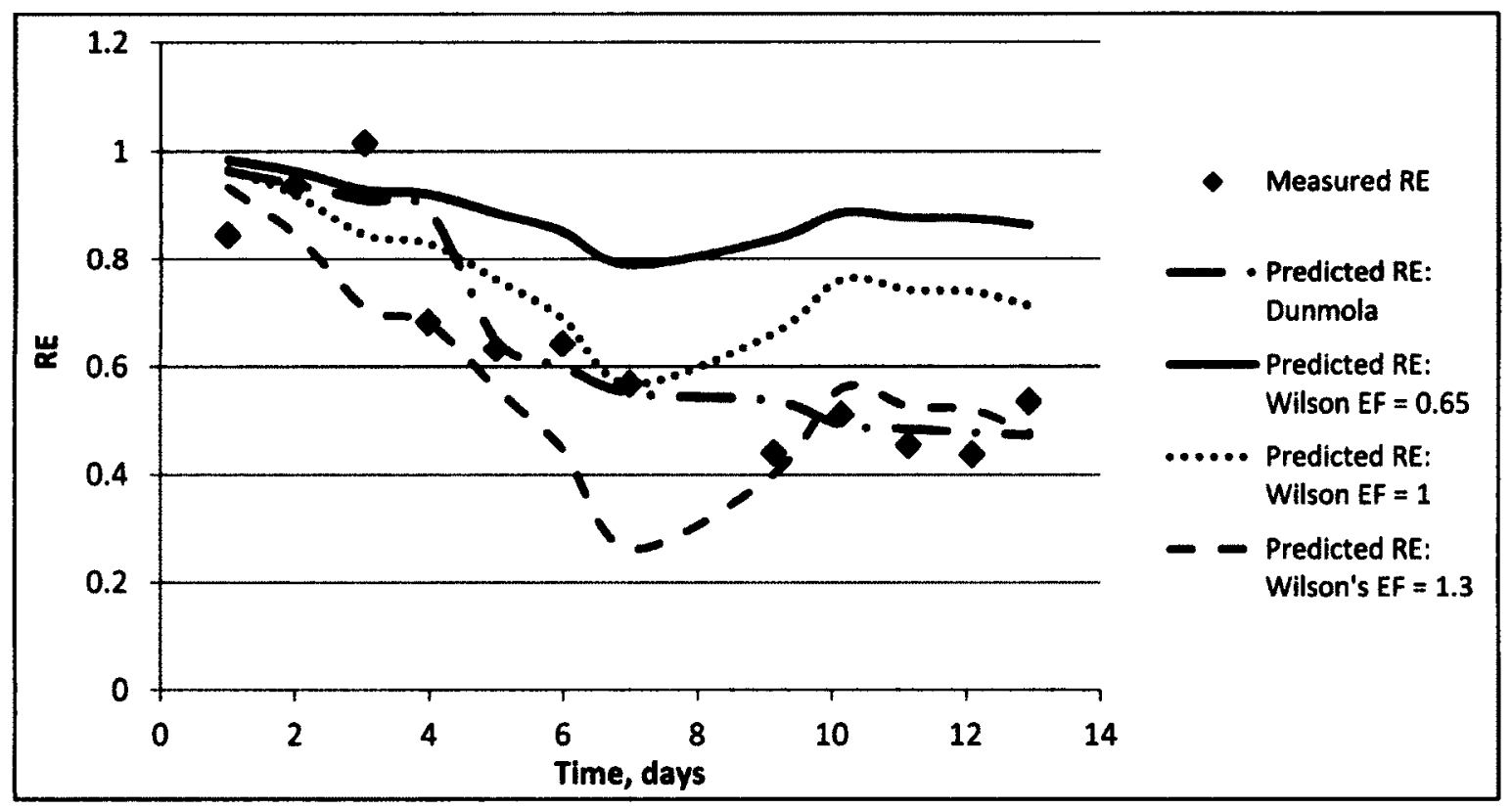

Figure 5-29: Measured and predicted RE - 10cm thick Drying Box test

Establishing a function between gravimetric water content and time with consideration for climatic conditions may provide an option in estimating RE for the TT. The equation's application in multilayer deposition will be examined. 


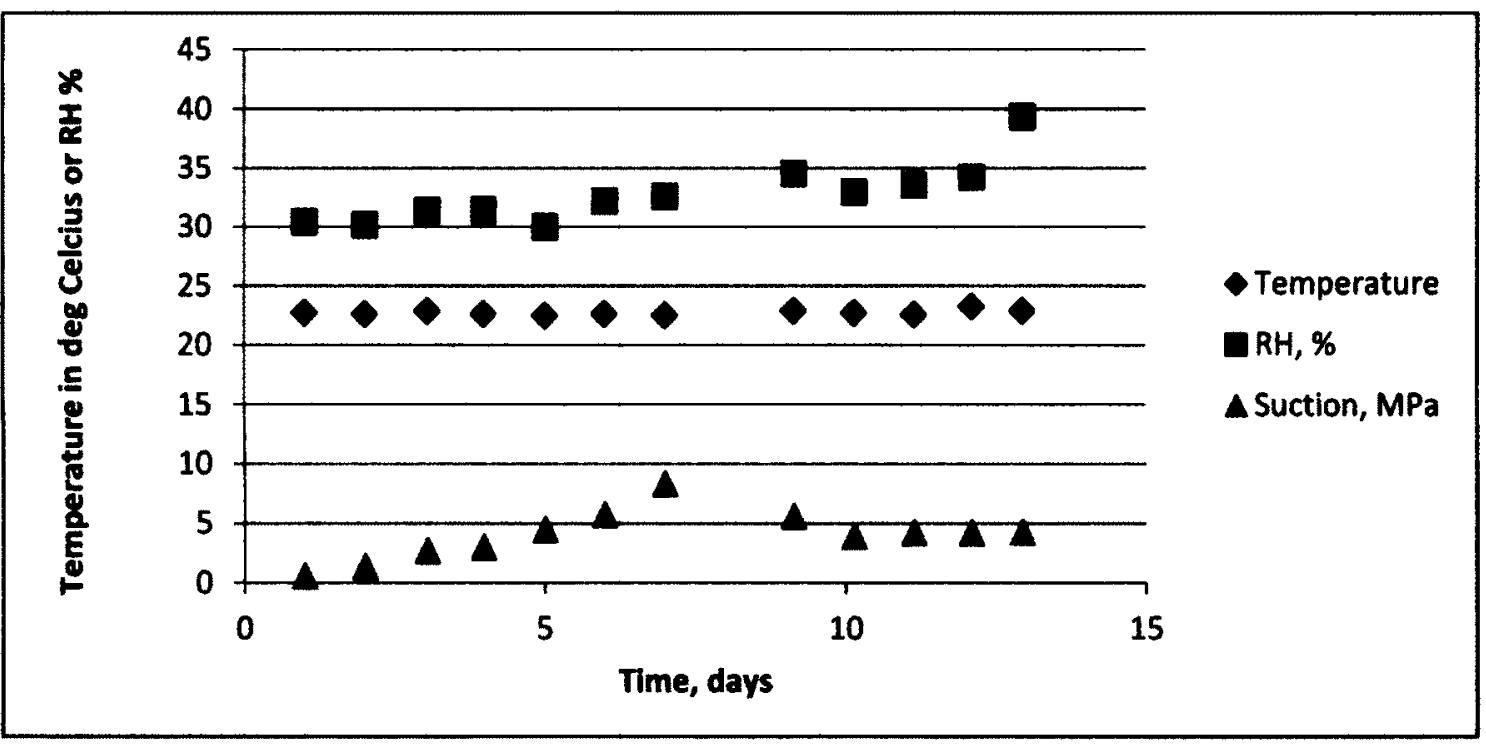

Figure 5-30: Temperature, RH and Suction measurement $-10 \mathrm{~cm}$ thick Drying Box test 


\subsection{Drying Box Test}

\subsubsection{Layer 1 Deposition}

Tailings were remixed using a drum mixer at a speed of $180 \mathrm{rpm}$ for approximately $1 \mathrm{hr}$ in reverse and forward modes. The material was then deposited into the drying box (Figure 5-31) and allowed to dry to overall gravimetric water content close to that of its shrinkage limit, $17.5 \%$, hopefully allowing for maximum volume reduction. When very little or no change was observed in the layer, two samples were collected for analysis. The data acquired and processed during this period is presented in the following sections.

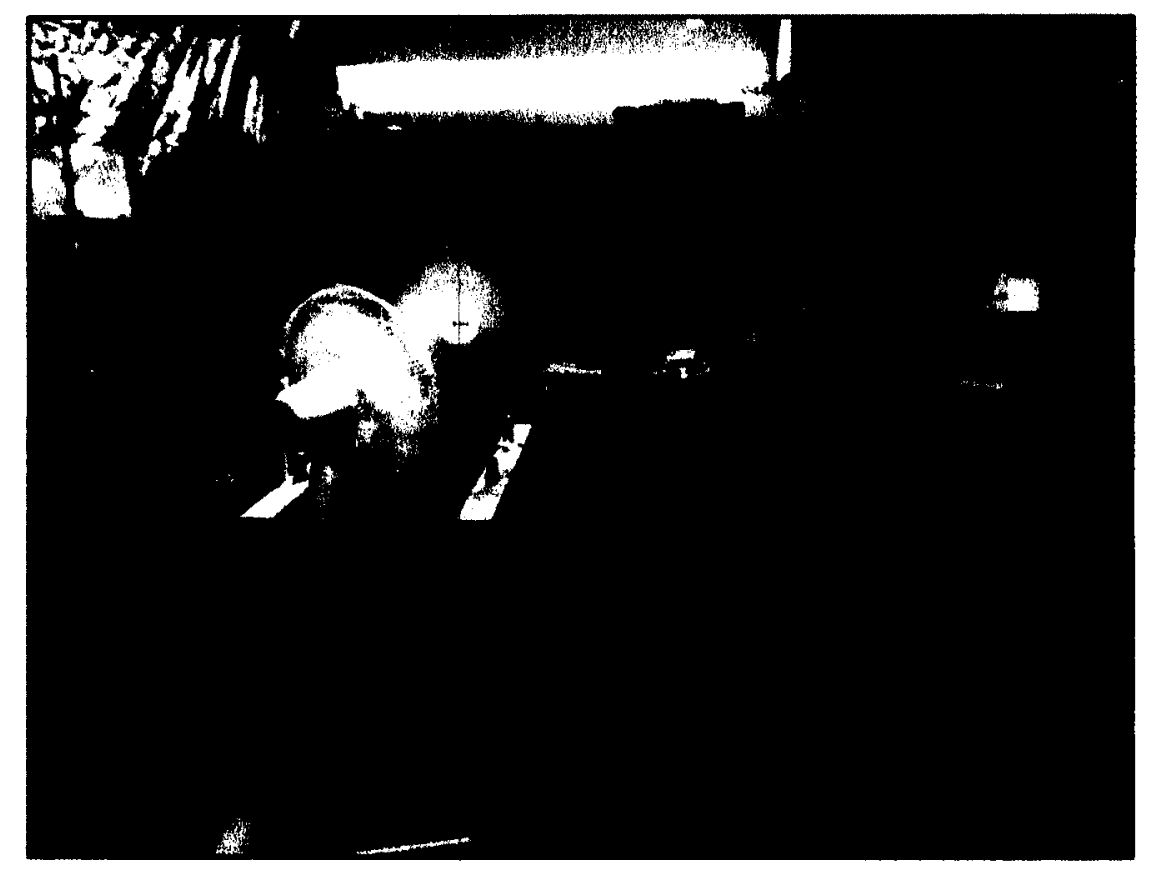

Figure 5-31: Final set up - Layer 1

\subsubsection{Mass Loss and Evaporation}

Since no drainage was measured from the drying box, the mass loss is assumed to be water lost through evaporation. For the period under study, the evaporation rate varied 
from 1.3 to $4.27 \mathrm{~kg} /$ day (See Figure 5-32). Two plots of actual evaporation in $\mathrm{mm} / \mathrm{day}$ were generated showing a variation of $\mathrm{AE}$ from 1.9 to $7 \mathrm{~mm} /$ day (See Figure 5-33). The graph shows the evaporation rate considering the surface area of the box using its dimensions and also considers the crack surface area. In the latter, the width of each crack by its length was subtracted from the total crust area and the total surface area of all the cracks (estimated from measured crack geometries) was added to the remainder. This gave rise to increased surface area and thus we see that evaporation rates for this method fall well below the potential evaporation rate.

Based on the conditions present, the potential rate of evaporation was calculated to oscillate between 4.27 and $5.98 \mathrm{~mm} /$ day (Figure 5-33) using the Penman-Monteith Equation.

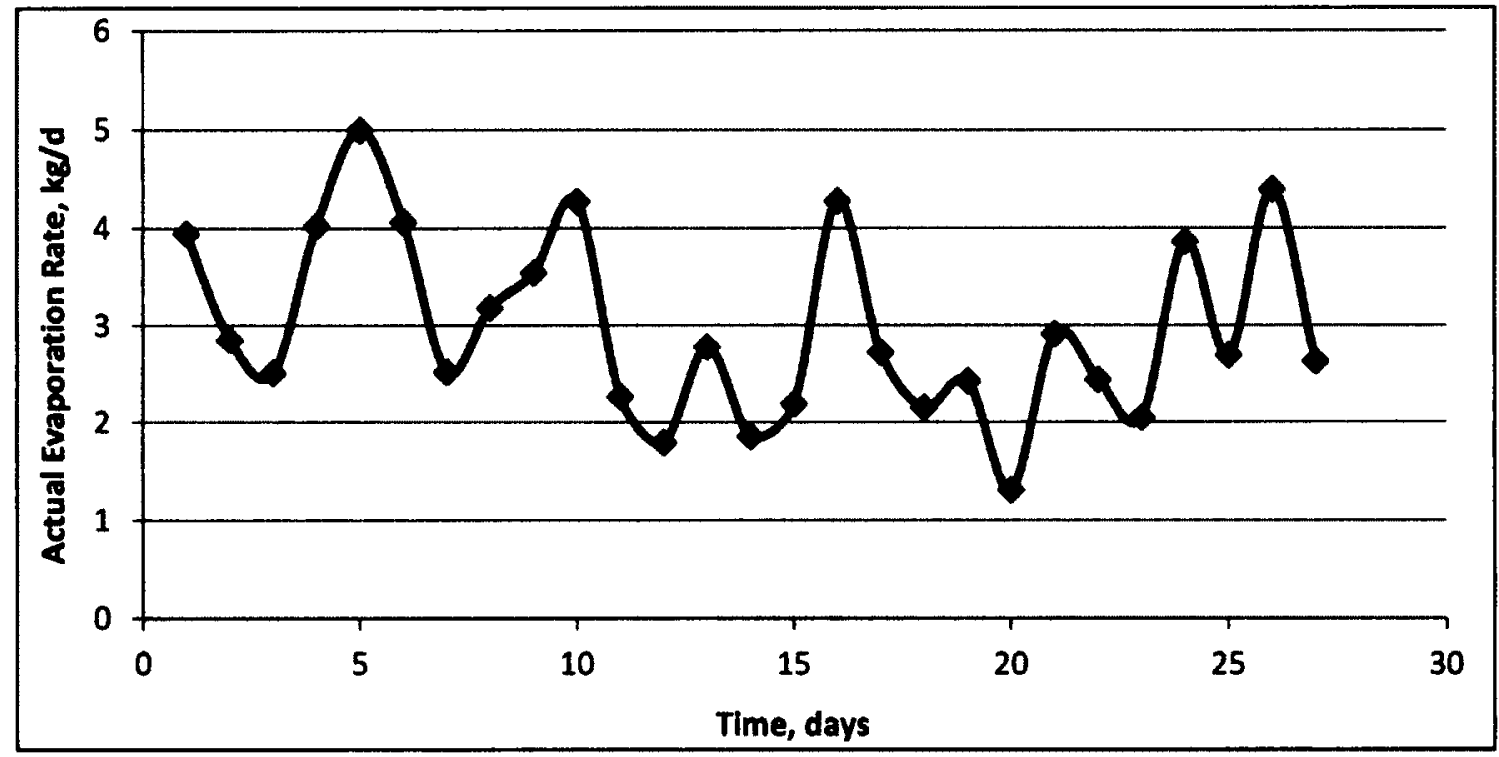

Figure 5-32: Actual Evaporation in $\mathrm{kg} / \mathrm{d}$ - Layer 1

Although the rate of evaporation should be decreasing as time goes on with the decrease in permeability and increase in matric suction of the crust shown in Figure 5-33, 
it was observed that the rate had varied highs and lows, a pronounced oscillatory behaviour. However, if the peaks were removed, a decreasing trend is observed. This will be discussed further on.

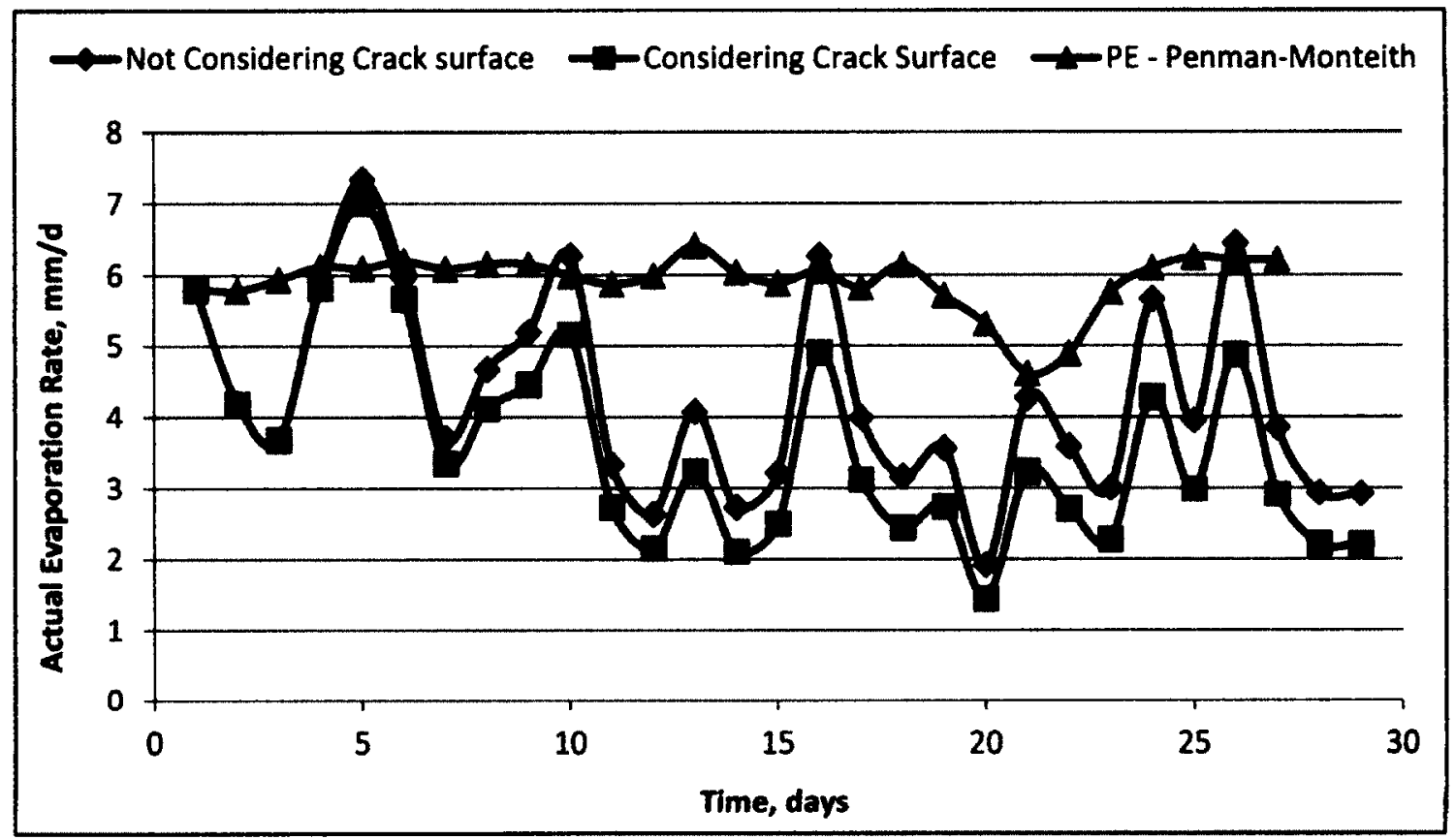

Figure 5-33: Actual Evaporation in $\mathrm{mm} / \mathrm{d}$ - Layer 1

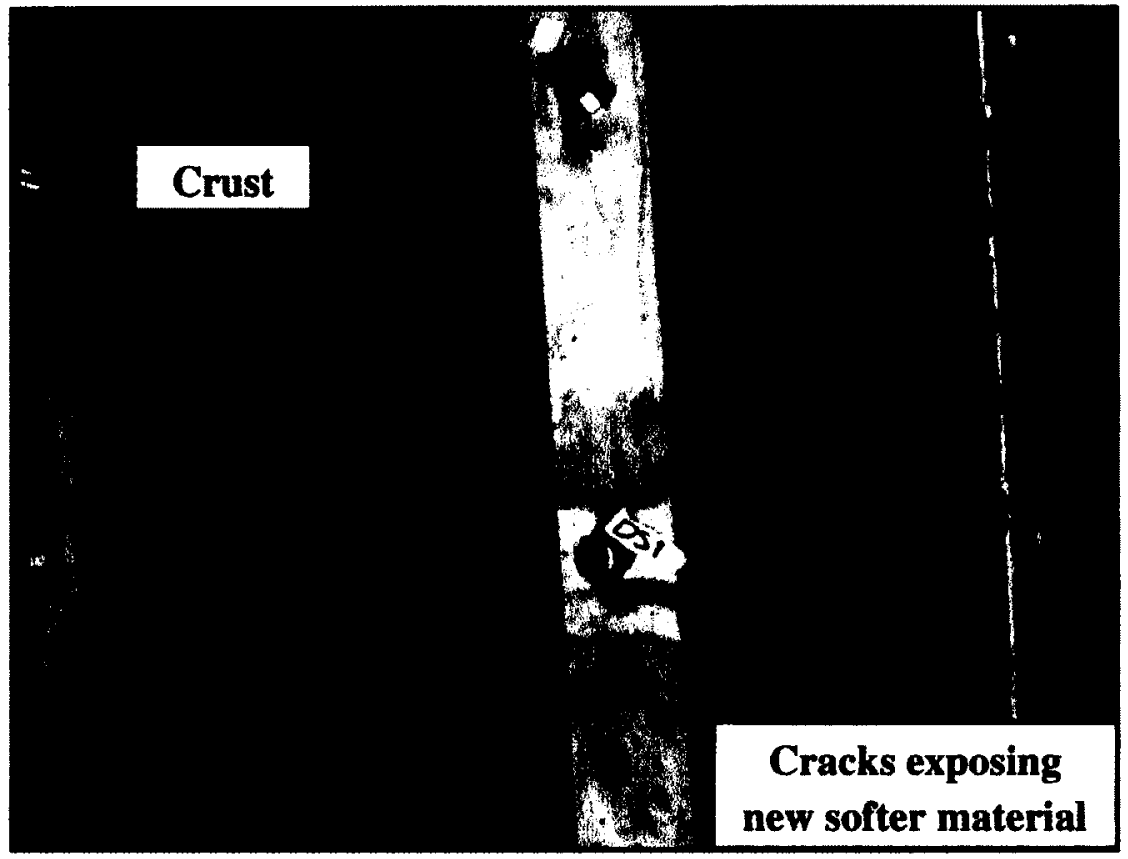

Figure 5-34: Crust and Crack Formation - Layer 1 
From day 10 , the rate of evaporation is approaching a new low value of $2 \mathrm{~mm} /$ day but because of the weight of the crust and the new cracks formed, the rate spirals after a few days, an indication of the possible contribution of cracks to the increase in AE.

\subsubsection{Temperature and Humidity}

The temperature profile above the soil and at the sample points within the soil mass are shown below in Figure 5-35. Temperatures at the soil surface oscillated between 15 and $19{ }^{\circ} \mathrm{C}$. Temperatures within the layer were much lower with the highest being $15.5^{\circ} \mathrm{C}$ and the lowest, $10^{\circ} \mathrm{C}$. The results show slightly warmer temperatures on the inside of the soil sample compared to the top $5 \mathrm{~cm}$. The Relative Humidity of the air above the soil mass is shown in Figure 5-36.

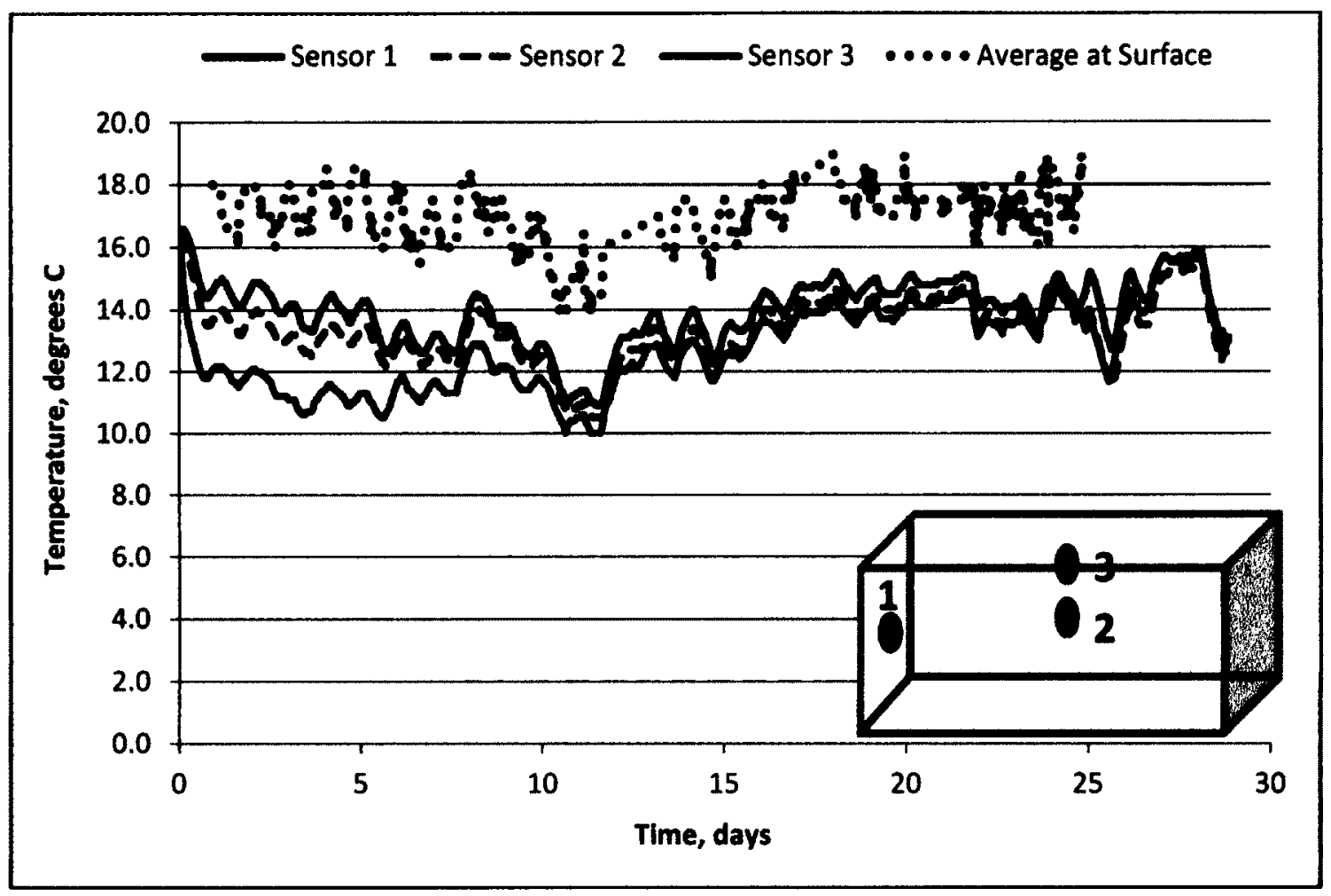

Figure 5-35: Temperature Profile within soil and at Soil surface - Layer 1 


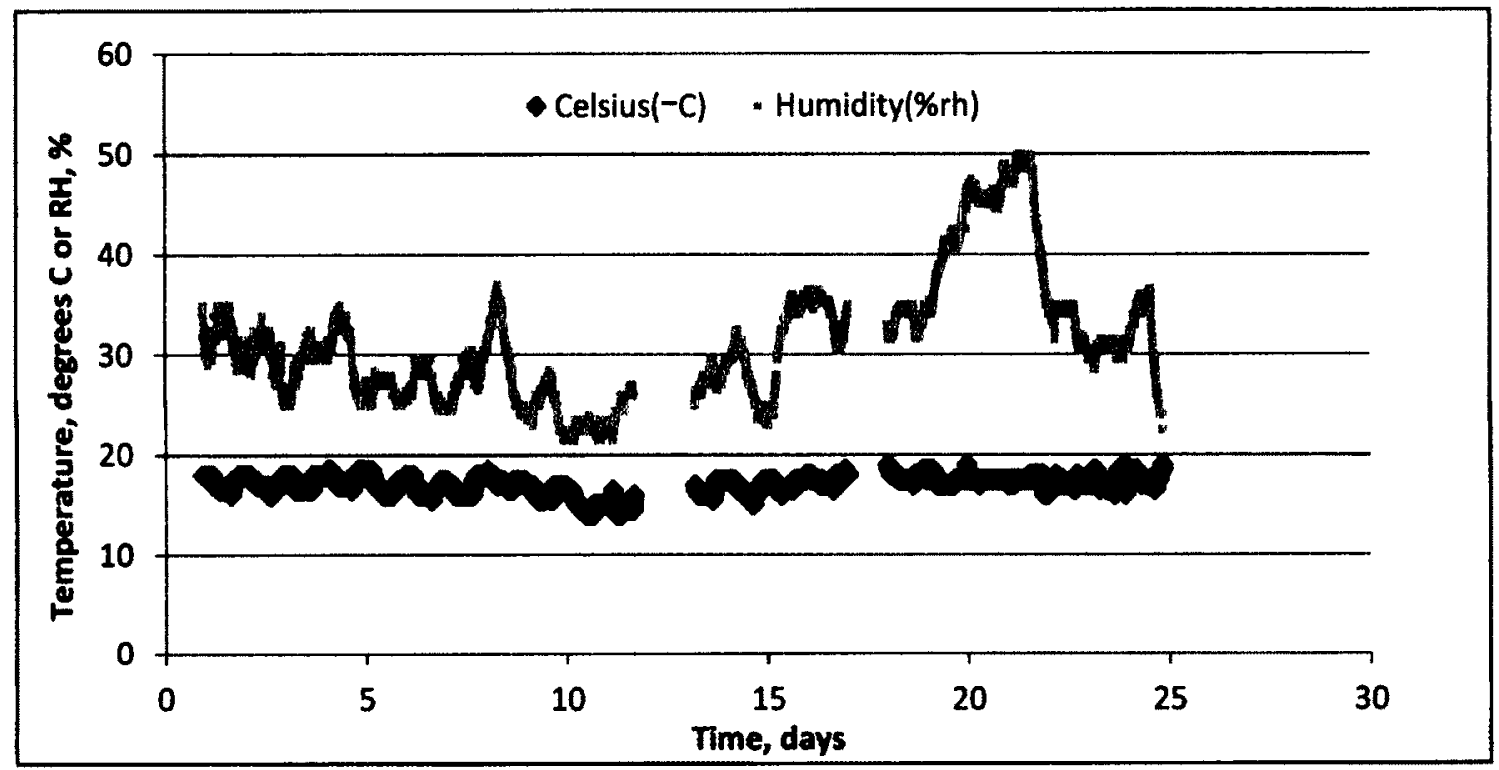

Figure 5-36: RH and Temperature Data above the soil - Layer 1

\subsubsection{Gravimetric Water Content, $w$}

The overall gravimetric water content, $w$, was calculated for the layer considering the loss of water due to evaporation. Figure 5-37 shows the steady decrease in overall gravimetric water content from a value of 101 to $17.6 \%$.

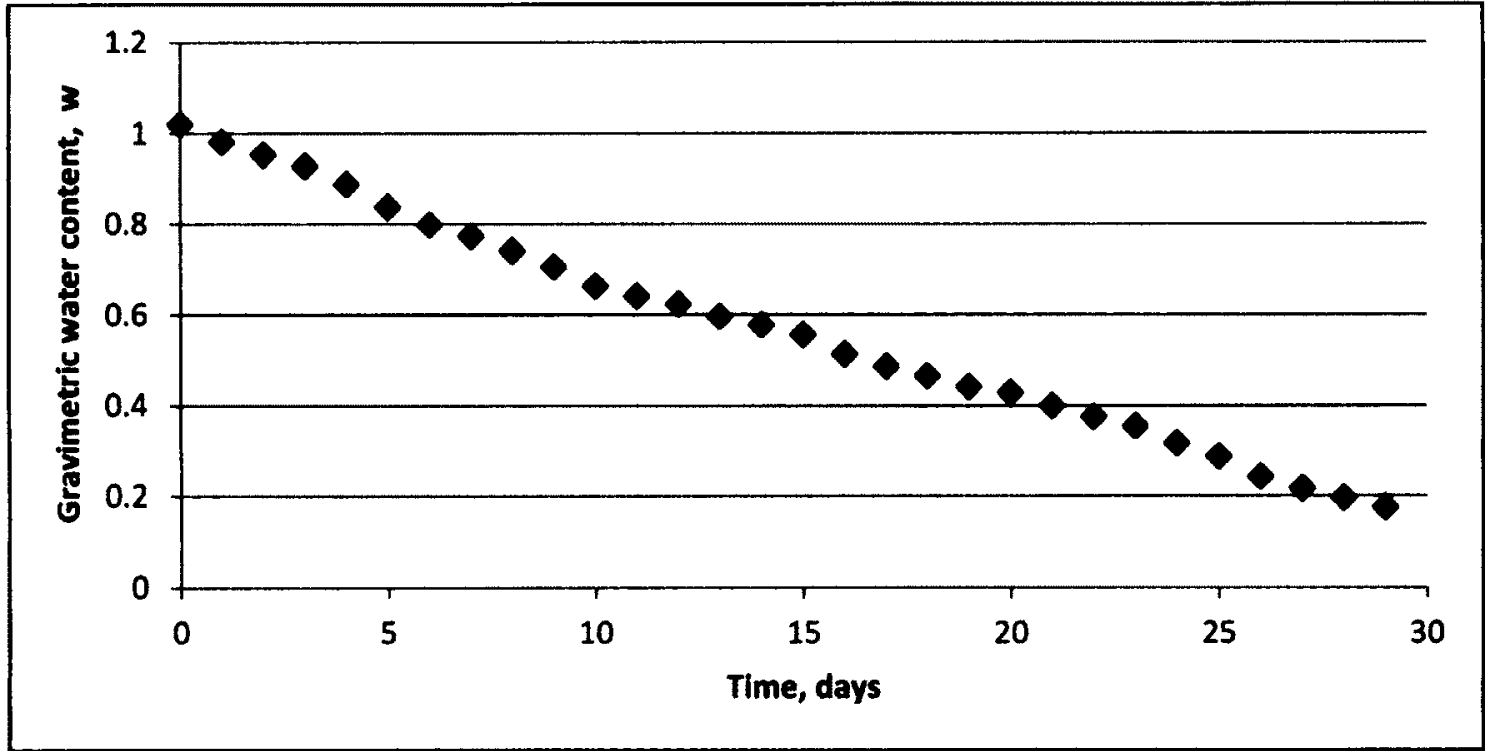

Figure 5-37: Overall Gravimetric Water Content of Layer 1 
Measured gravimetric water content at the surface showed that within one day the tailings had gone from 101 to about $36 \%$ and may be responsible for the decrease in $\mathrm{AE}$ in the first few days as the tailings appeared to be sealed by this low water content surface. The attained low water content fostered the development of the crust seen later on in the test. As observed by Fujiyasu et al. $(2000 \mathrm{~b})$, and by the author in previous drying tests, this low water content material caused a significant decrease in AE. As time progressed, much of the crust reached values lower than the shrinkage limit and this can be seen from Figure 5-38. Once the crust formed, the material began to pull away from

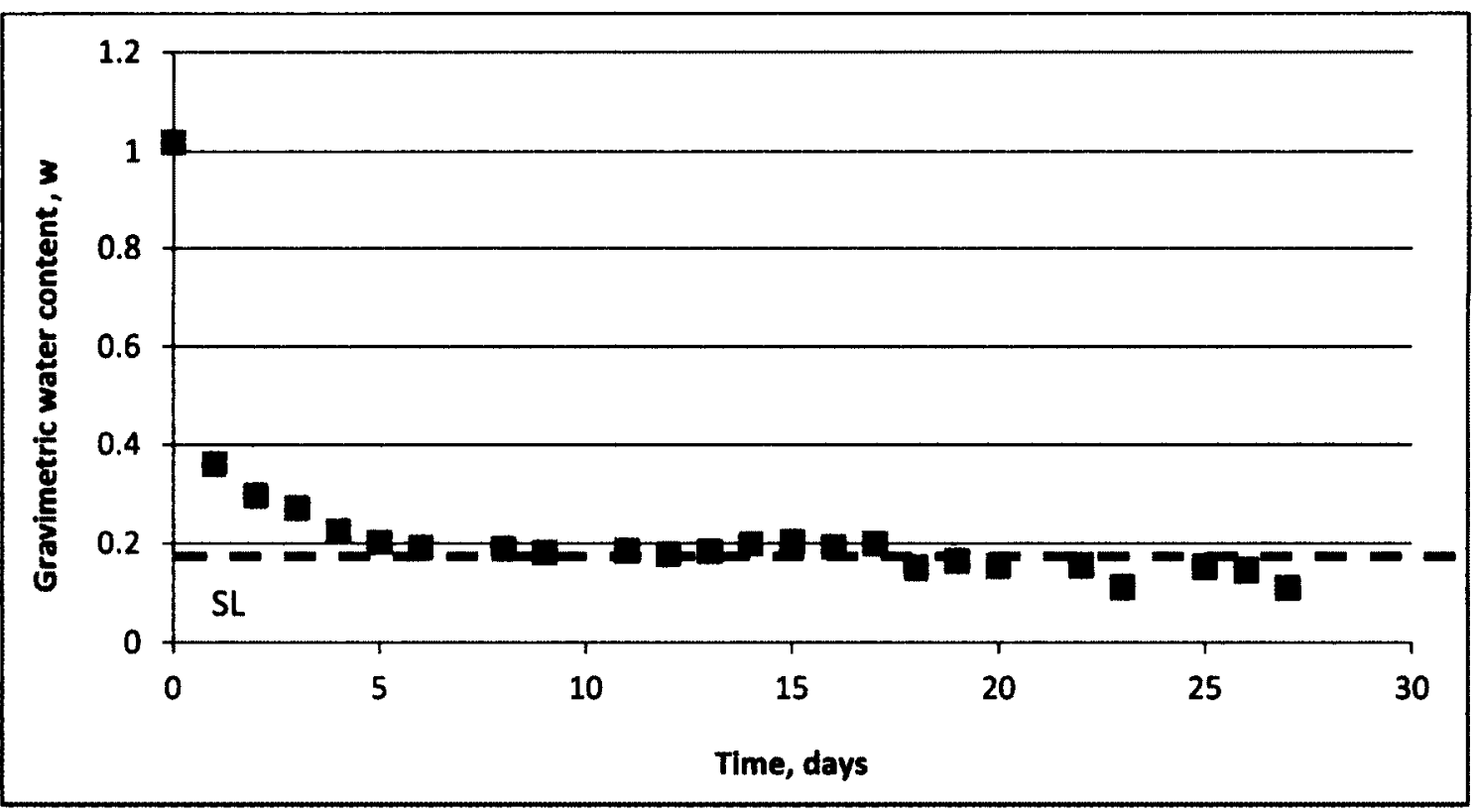

Figure 5-38: Variation in Gravimetric Water Content at the surface - Layer 1

the side of the box. Only cracking exposed new material and this may have aided with evaporation as we will see from the suction values measured along the cracks. Looking at Figure 5-38, slight increases in in water content are noted and this could be due to movement of water to the surface from the underlying wetter tailings. 
Solids concentration, Cs measurements are also presented in Figure 5-39. The surface increased solids concentration form 49.5 to $90 \%$ with an undrained shear strength of $24 \mathrm{kPa}$ at solids content of $83.5 \%$ and $18 \mathrm{kPa}$ at $79.5 \%$ solids concentration. The test was conducted using a vane shear fixture.

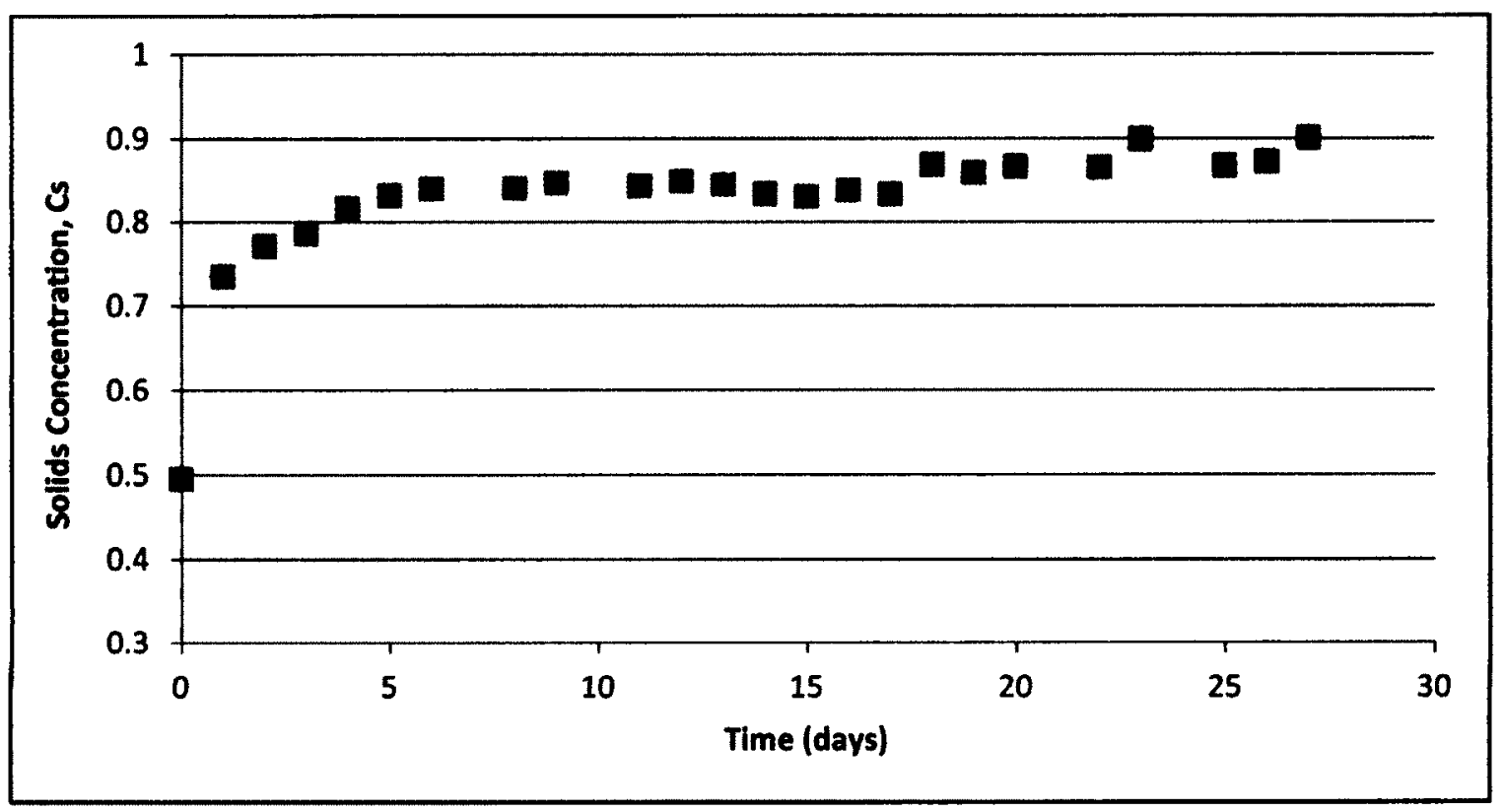

Figure 5-39: Variation of Solids Concentration at the surface - Layer 1

\subsubsection{Volumetric Water Content, $\theta_{w}$}

Volumetric water content data from the data logger was processed using calibration curves for each sensor and the data is presented in Figure 5-40. A gradual change in volumetric water content was observed at the centre of the layer until about day 17, where the decrease was quite significant, falling from about 72 to $55 \%$. However, in the top $5 \mathrm{~cm}$, it can be noted that after a rapid decrease in volumetric water content in the first six days, the volumetric water content then levelled off to $48 \%$ until there was 
another sharp decrease in the days following. The latter behaviour in both the top 5 and $10 \mathrm{~cm}$ could be due to more cracking at the top surface (osmotic crust) which facilitated further dewatering.

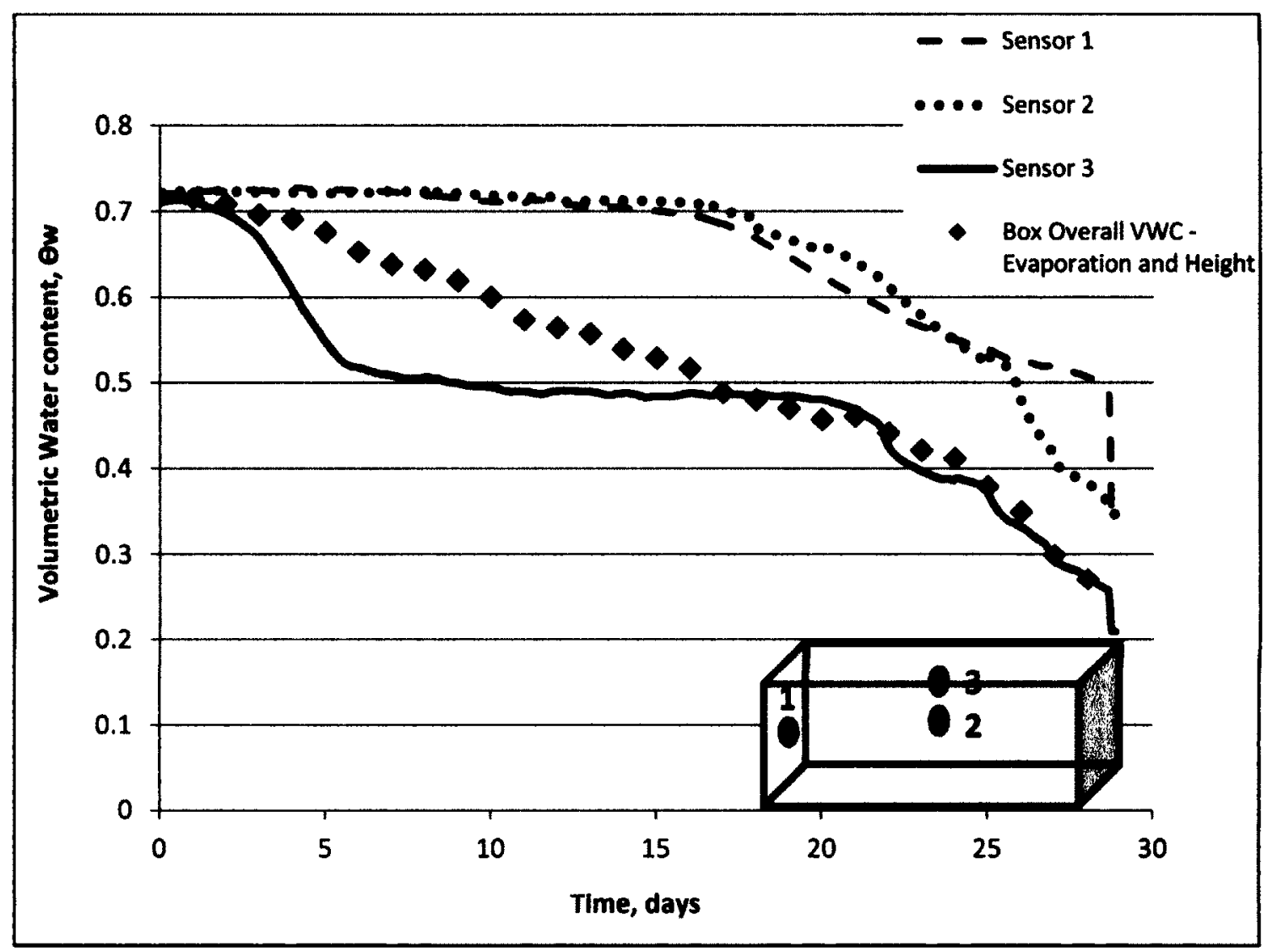

Figure 5-40: Volumetric water content data - Layer 1

The results indicate very non-uniform drying along the tailings profile also observed in previous tests and despite the availability of water in the bottom half of the layer, the surface sealing effect of the top surface did not allow for this water to leave the soil. However, cracking provided that alternative path and dewatering began in the bottom half of the tailings profile. 


\subsubsection{Volume change and Settlement}

Figure 5-41 shows the settlement pattern of the tailings. Matched against water removal, there is almost a one on one relationship at the start. However, as time progressed and the surface crust thickened, water was removed but because of the underlying wet tailings, the settlement of the tailings appeared to be less than the corresponding water removal.

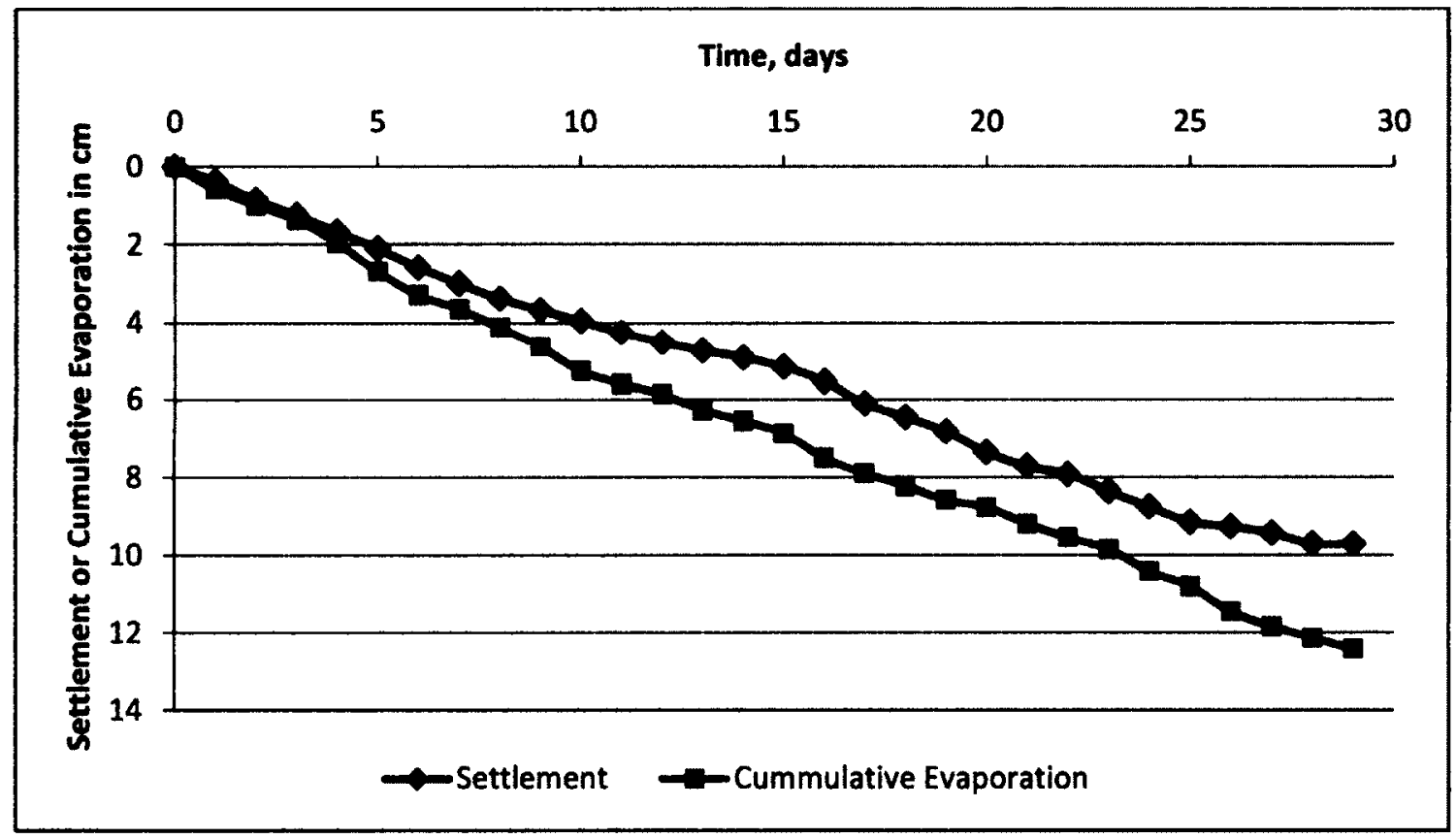

Figure 5-41: Settlement and Cumulative Evaporation with time - Layer 1

The overall void ratio is later plotted based on the calculations overall water loss and measured settlement. Figure 5-42 shows the evolution of void ratio with and without the consideration of crack volume and Figure 5-43 shows the shrinkage curve in a plot of wGs vs e. As evidenced in Figure 5-42, void ratio with and without crack consideration 
are relatively similar for the first few days. However, as cracks developed and their volumes increased, a noted difference of about $0.2-0.3$ exists between the two values.

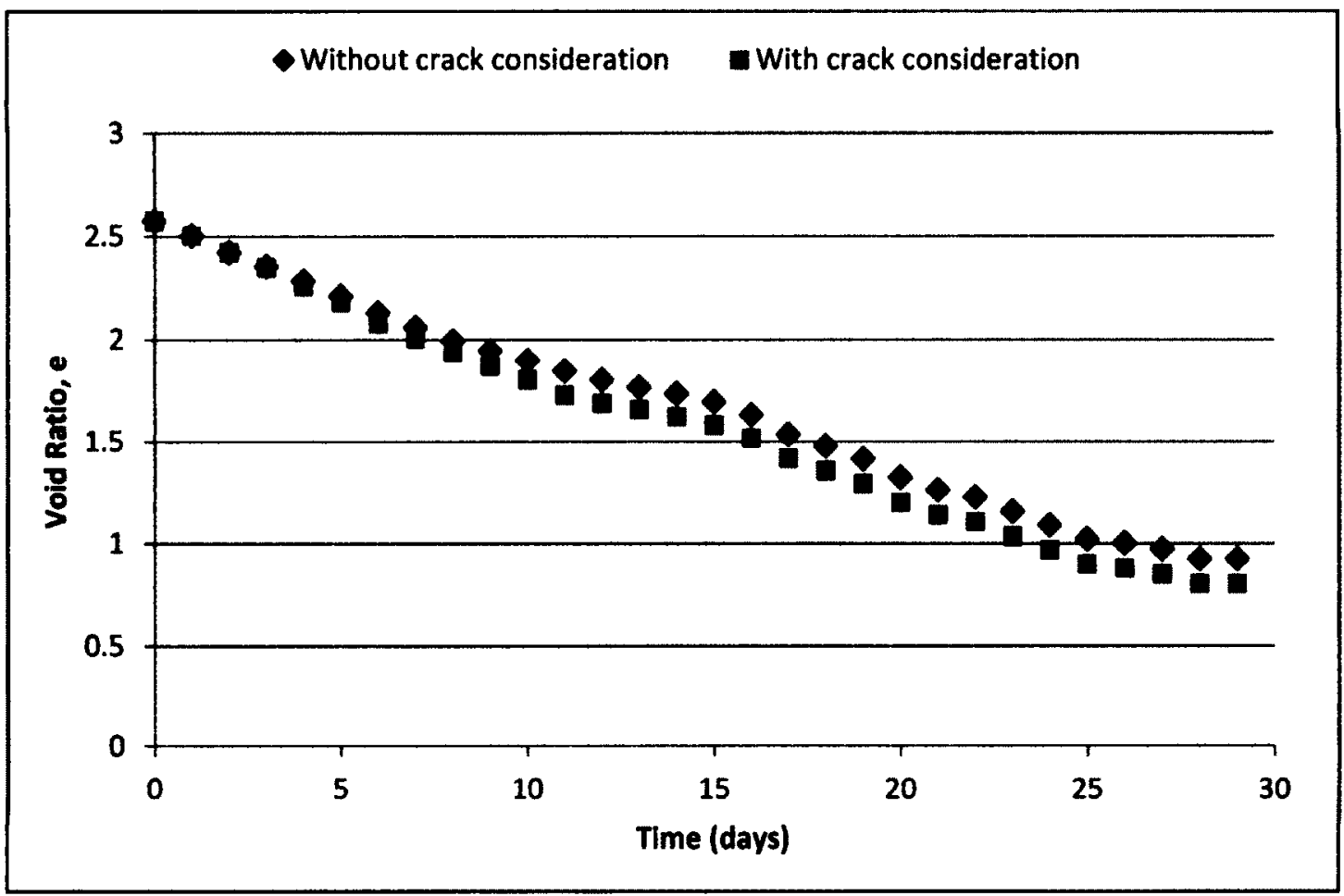

Figure 5-42: Evolution of Void ratio - Layer 1

Void ratio varies from a maximum of about 2.57 to a minimum of about 0.8 . Some levelling off was observed as of day 25 .

In the shrinkage curve constructed below (Figure 5-43) from the data obtained, it is seen that the void ratio at which levelling is occurring is almost corresponding to that of the shrinkage limit which is between 0.7-0.8. 


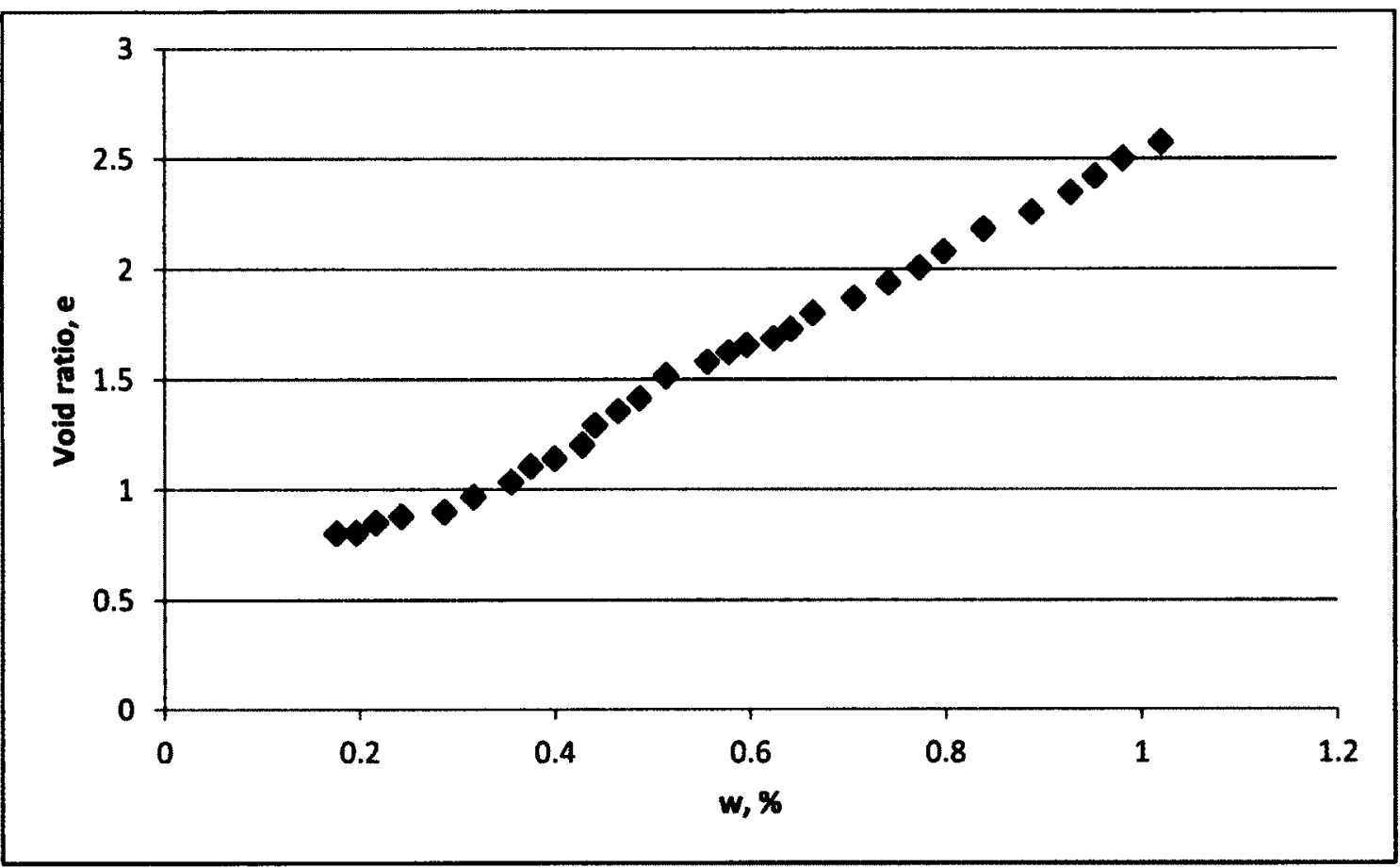

Figure 5-43: Shrinkage curve - Layer 1

\subsubsection{Suction}

\section{Matric Suction}

Matric suction was measured at 3 sample points in the tailings (Figure 5-44). The results are shown in Figures 5-45. Suction development is important to understand tailing strength behaviour and permeability changes, important to the modelling process.

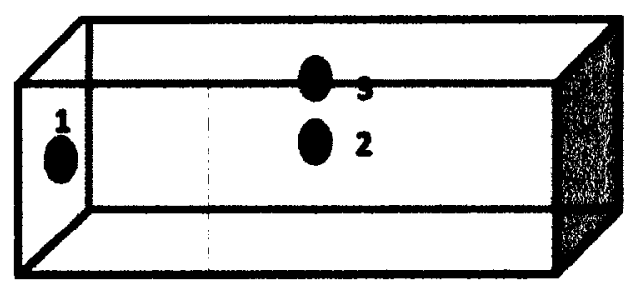

Figure 5-44: Sample Ports 
The tensiometer in sample port 1 malfunctioned. However, the tensiometer in sample port No 2, measured suctions up to $90 \mathrm{kPa}$ and stayed there as this was in the softer material below the crust. The tensiometer was removed for refilling and was found in that soft material.

The tensiometer at sample port 3 measured well for a few days up to high suctions of $85 \mathrm{kPa}$ until cavitation occurred a few days later. This was followed by to the weight of the crust breaking the shaft from the sensor body. The measured suction values correspond with the rapid dewatering pattern of the top surface within the first few days and the high measured strength in the final profile.

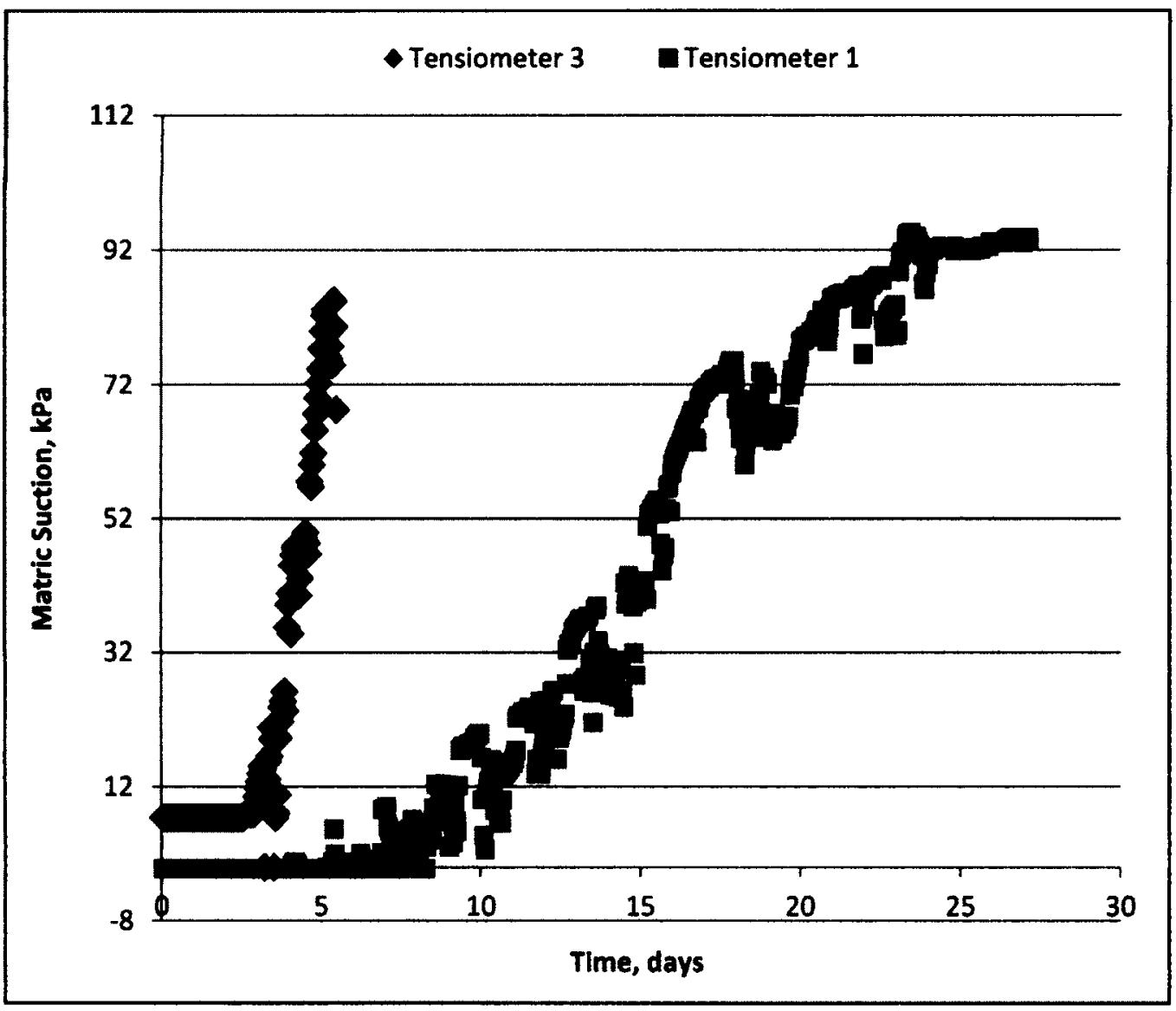

Figure 5-45: Evolution of Matric Suction - Layer 1 
All tensiometers were replaced with newly conditioned tensiometers before deposition of layer 2 .

\section{Total Suction}

Samples within the top $1 \mathrm{~cm}$ of the tailings surface and along cracks were measured for total suction using the WP4 Potentiameter. The total suction results for the surface are presented in Figure 5-46.

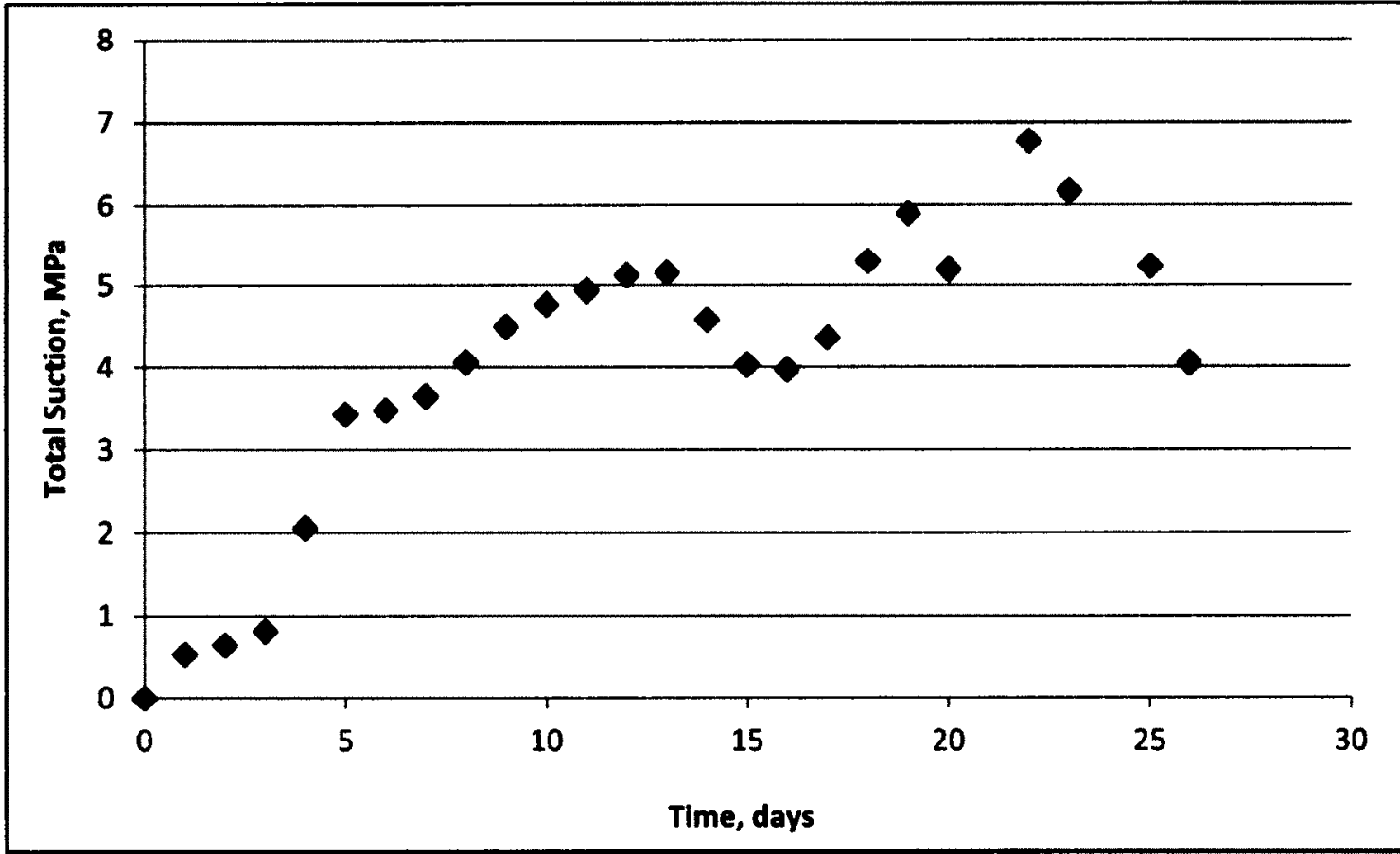

Figure 5-46: Evolution of Total Suction at the surface - Layer 1

At the surface, suction increased as water was being driven out of the surface and salt concentration increased. However, as the evaporation from the crust slowed down (possibly due to low permeability), the suction decreased steadily and in some instances 
increased again. This could be due to the downward movement of salts (discussed previously) causing a decrease in the osmotic suction, thus decreasing the total suction. Electrical conductivity measurements will be undertaken to monitor the development of osmotic suction at the surface.

The total suction measurements were used in the prediction of the RE using the methods employed in previous drying tests (See Figure 5-47). Best fit predicted values of RE were obtained using Wilson's method with an EF of 1.3, while little agreement was obtained with Dunmola's method using parameters from small test. However, no method predicted the peak values or the oscillations presented in the data.

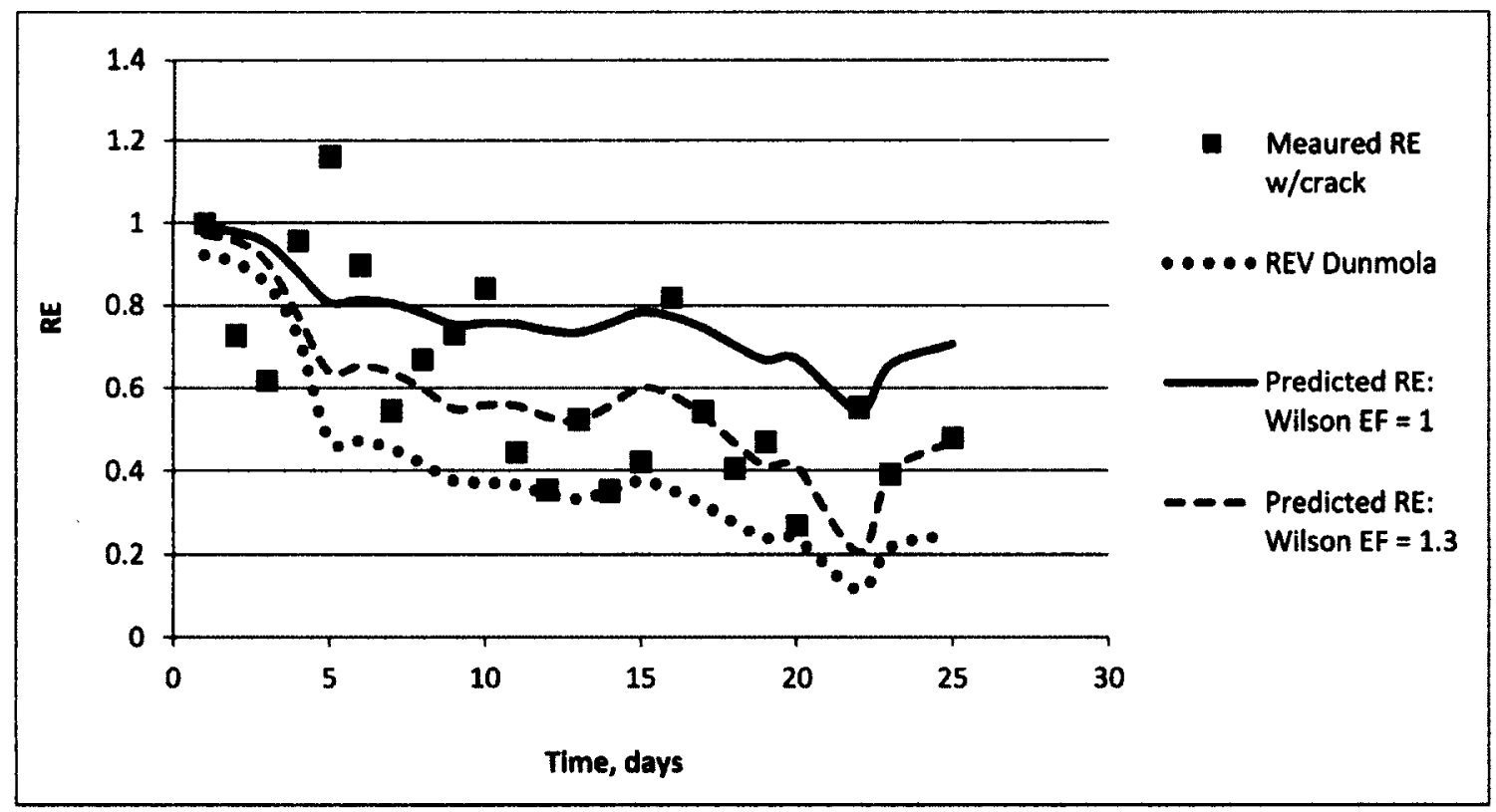

Figure 5-47: Predicted and Measured RE - Layer 1

Of interest, was the development of total suction along cracks. Once formed the cracks exposed very fresh material with very low suctions which later increase as materials get dry. In addition, the crust formed weighed in on the softer material below, 
causing an expulsion of this material which surfaced through the cracks, exposing fresh surface area and providing a preferential path for water flow. Values for some measurements taken are presented in Table 5-4. If the suctions increase too rapidly within the crack, a shutdown may occur and crack development is hampered (see Figure $5-48)$.

Crack development played a pivotal role in tailings drying. With the development of the osmotic crust commencing from day 2 of the experiment and its further increase in solids concentration and impermeability, water had to find an alternative water to leave the materials and thus cracks observed from day 2 , were to be that preferential flow path.

Table 5-4: Measured Total Suction - Crack Surface - Layer 1

\begin{tabular}{|c|c|c|c|c|}
\hline & \multicolumn{4}{|c|}{ Total Suction, $\mathrm{MPa}$} \\
\hline & & & & $\begin{array}{l}\text { shutdown } \\
\text { crack }\end{array}$ \\
\hline Time (Days) & N/A & & & \\
\hline 0 & 0.25 & & & \\
\hline 1 & 0.41 & & & \\
\hline 2 & 0.36 & 0.68 & & \\
\hline 3 & 0.29 & 0.65 & & \\
\hline 4 & 0.01 & 2.03 & & \\
\hline 5 & 0.37 & 1.2 & 2.56 & \\
\hline 7 & 0.22 & & & 6.64 \\
\hline 8 & 0.4 & 2.28 & 4.39 & \\
\hline 10 & 0.33 & 4.75 & 7.27 & \\
\hline 11 & & & & 4.36 \\
\hline 12 & 0.22 & & & 5.97 \\
\hline 14 & 0.25 & 2.33 & & 6.25 \\
\hline 15 & 0.44 & 0.65 & & \\
\hline 17 & 0.14 & 0.34 & & \\
\hline 21 & & 0.36 & 21.55 & \\
\hline
\end{tabular}


Variation in crack surface area and total surface area is also presented in Figure 549. It must be noted that the total surface area of the box based on geometry is $6810.3 \mathrm{~cm}^{2}$. Therefore cracks do cause an increase in the total surface area in this case of approximately $2000 \mathrm{~cm}^{2}$. Fredlund et.al (2011), in their study of water storage and hydraulic properties of thickened tailings observed that the as the specimen under study pulled away from the side of the brass ring in which it was contained, the rate of evaporation increased significantly (about two times) as a direct result of the increase in surface area from which the evaporation was occurring. Fujiyasu et al. (2000a) also observed a significant increase in stage 2 evaporation due to cracking.

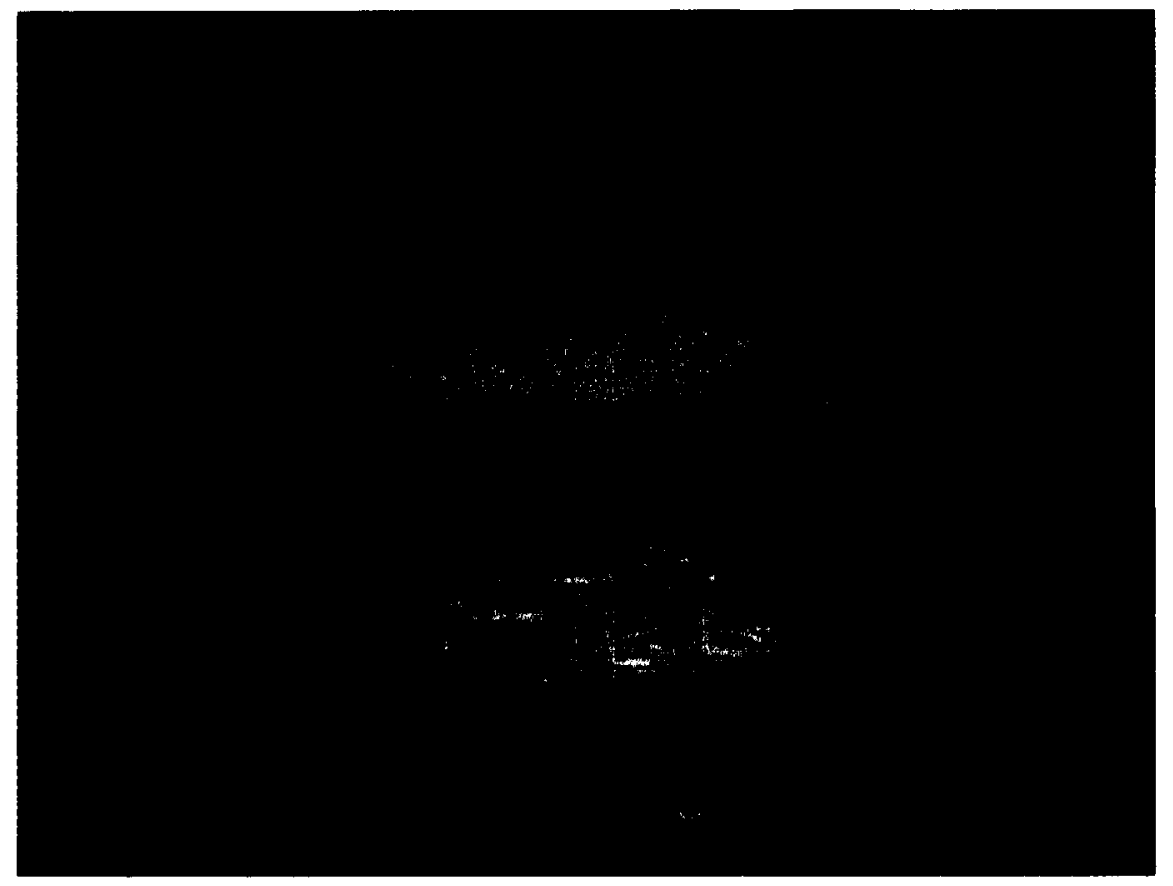

Figure 5-48: Sample Crack Shutdown - Layer 1 


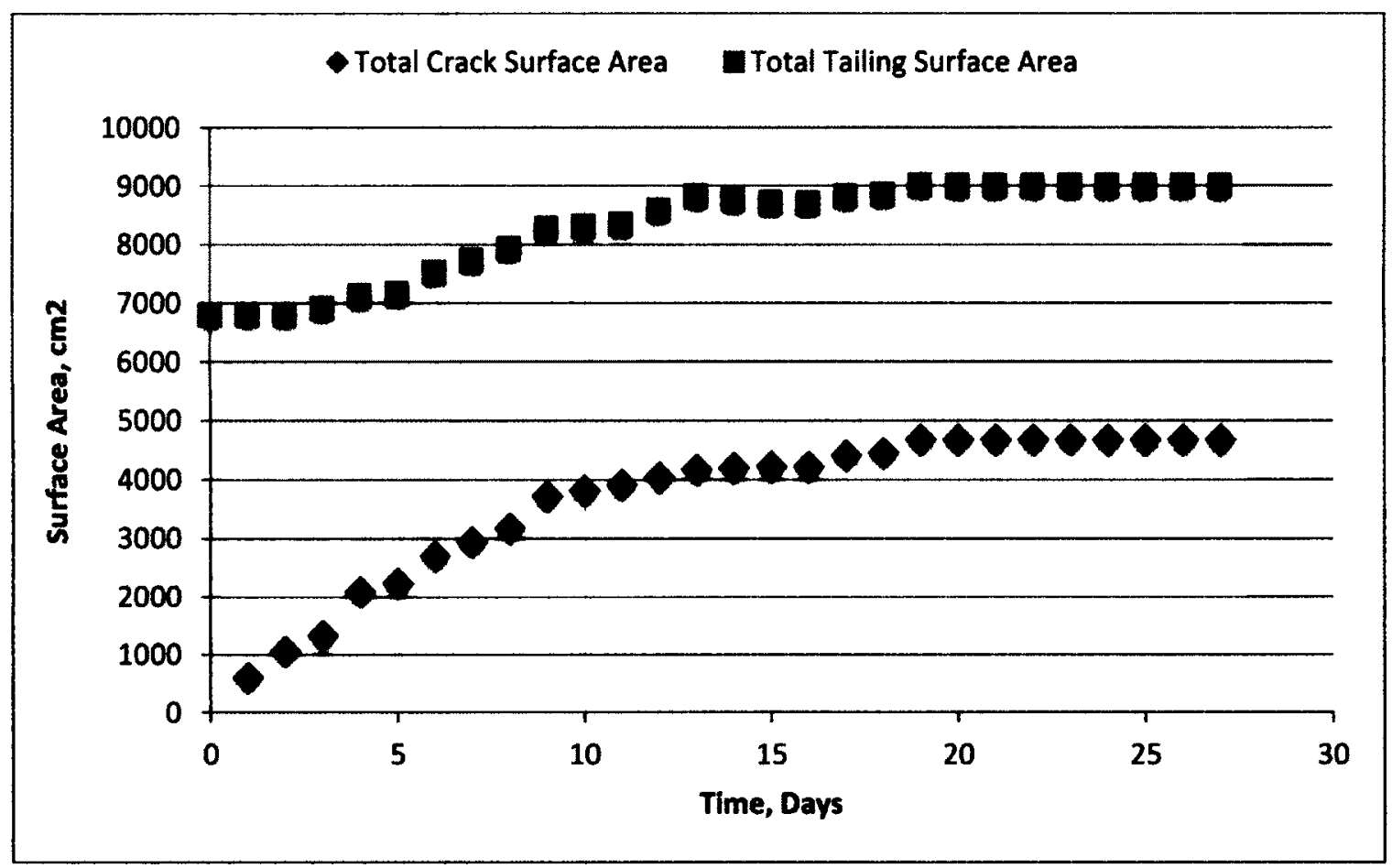

Figure 5-49: Total Crack and Tailing Surface Area - Layer 1 


\subsubsection{Sectional Analysis}

Towards the end of the drying period of layer 1, two sections were extracted for analyses. The samples were taken from two different heights. Separate sampling mechanisms were utilized. For the first sample, a tube of diameter $8 \mathrm{~cm}$ was driven with the use of a hand pump into the higher material which appeared to have a thicker, drier crust (Figure 5-50) and in the second, a tube of equal diameter was hand-driven into the tailings of lower height.

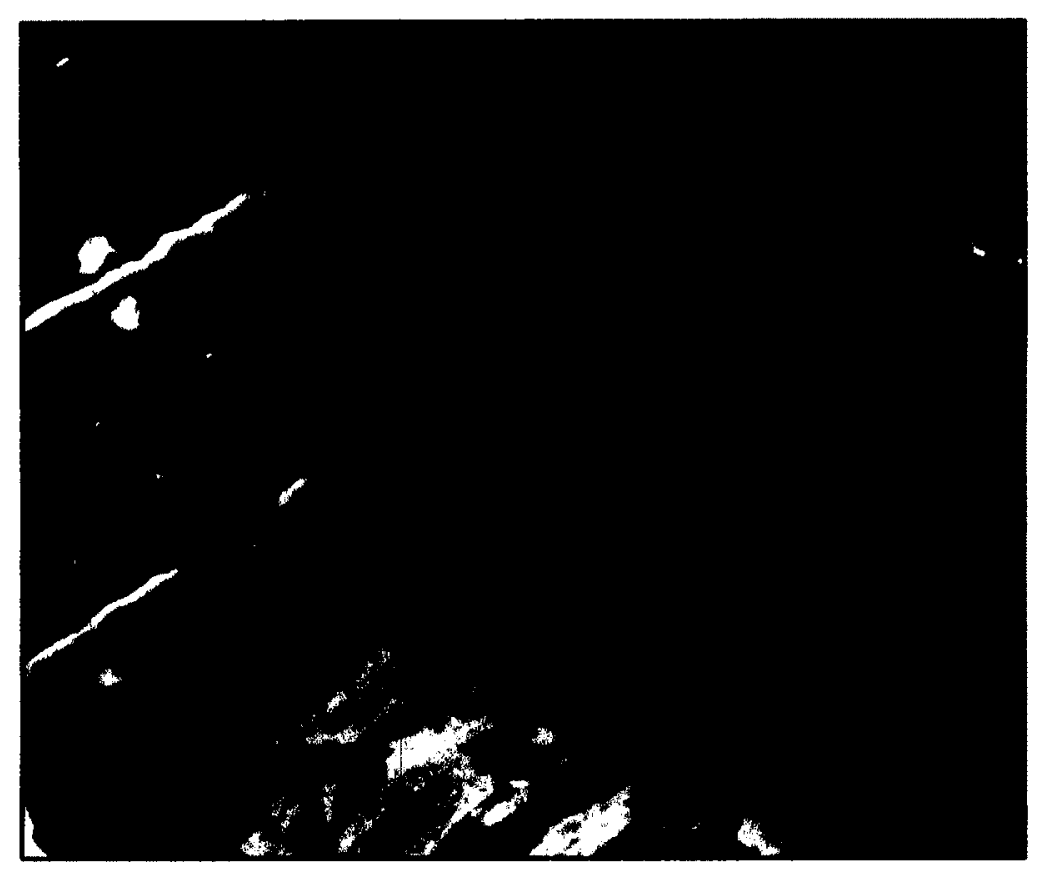

Figure 5-50: Sampling (end of Layer 1)

\section{Sample 1}

At first it was very difficult to penetrate the crust but once penetrated the material below appeared to be very wet. The stiffer material retained by the tube was extracted and a sample of the softer material was collected to perform analyses. The material at the base 
was not able to be reached. In this case, the crust was approximately $7 \mathrm{~cm}$ thick. The solids concentration profile with depth is shown in Figure 5-51.

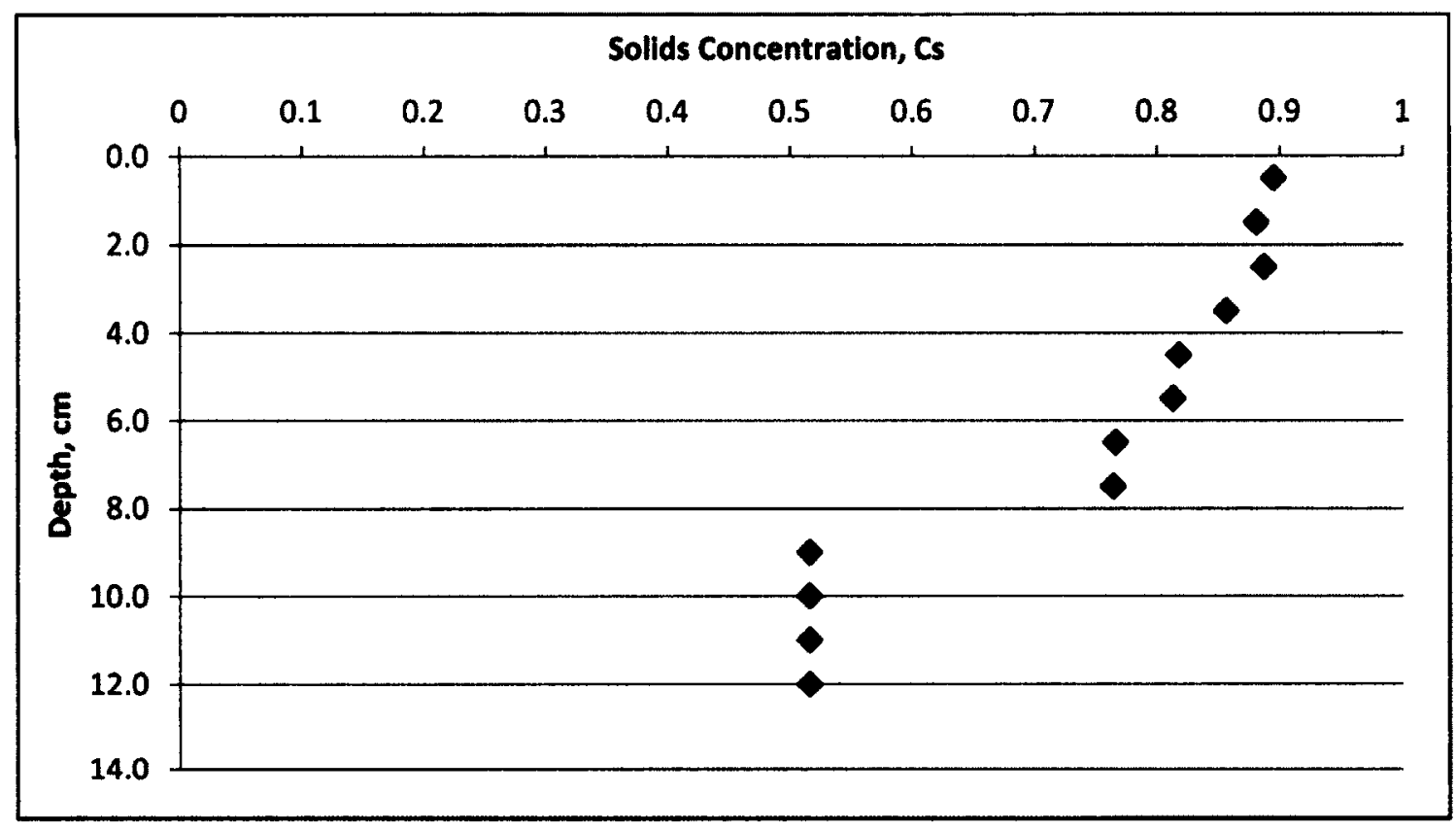

Figure 5-51: Solids Concentration profile (Sample 1)

The solids concentration varied from about 75 to $90 \%$ for the top part of the tailings; however the bottom was still very wet. Although no measurement were made from the base of the box (bottom 1-2 cm), a higher solids content is expected as observed in smaller scale drying tests. The abrupt transition of Cs with depth is a result of the sealing effect of the top crust which grew from a few $\mathrm{mm}$ to $7 \mathrm{~cm}$ in this case.

Total Suction measurements presented in Figure 5-52 show the highest suction at the surface and no particular pattern below just a variation between 0 and $1.2 \mathrm{MPa}$. EC tests will confirm solute transport with the highest osmotic suctions recorded in the top part of the soil profile. 


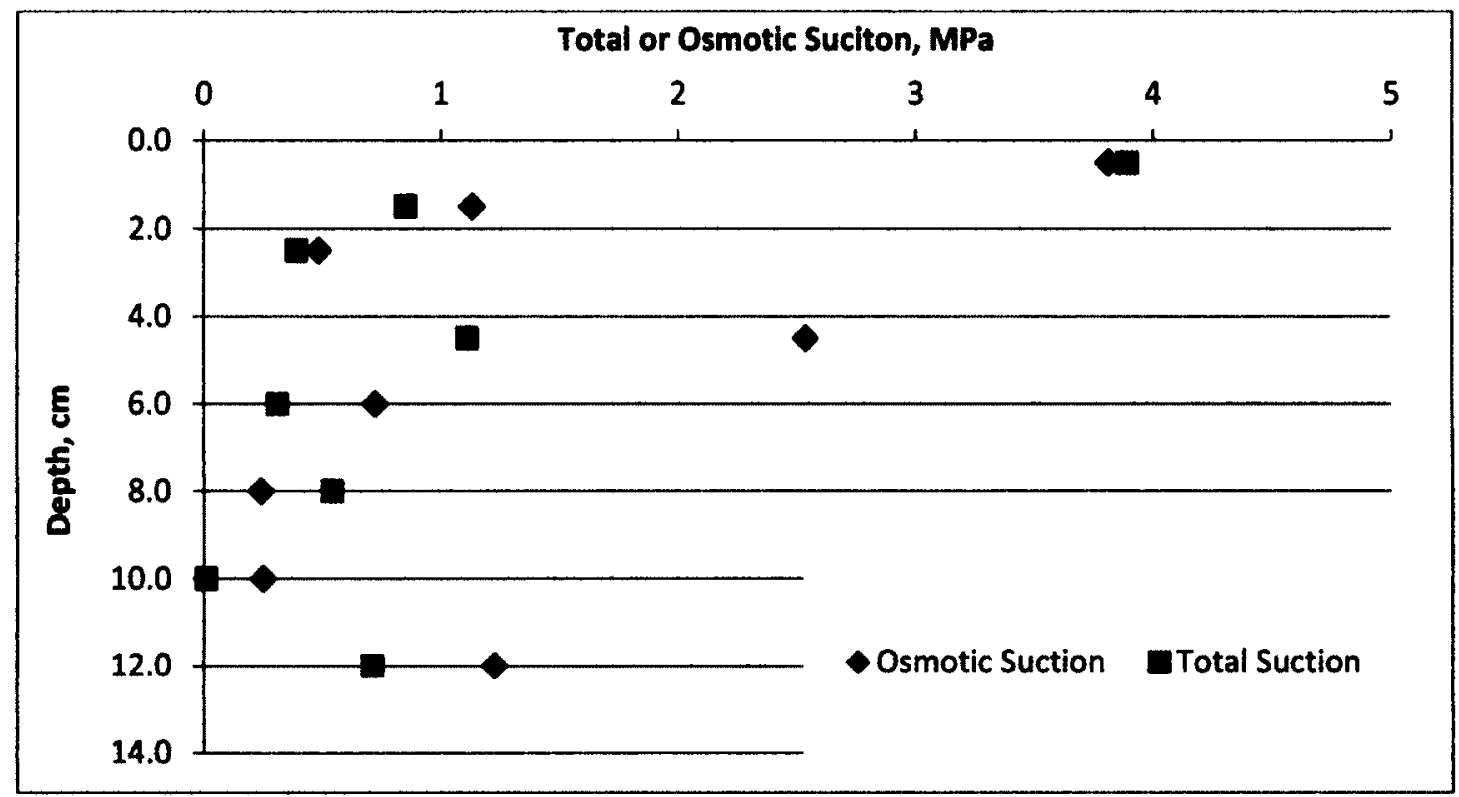

Figure 5-52: Total and Osmotic Suction Profile (Sample 1)

\section{Sample 2}

In this case, the height of the material was about $10.8 \mathrm{~cm}$. Again, the bottom of the tailings was very soft and could not be extracted by the tube (Figure 5-53) while the top appeared to be significantly lower in water content (Figure 5-54) The crust was about 3$4 \mathrm{~cm}$ thick and appeared to be a little drier at the base than sample 1.

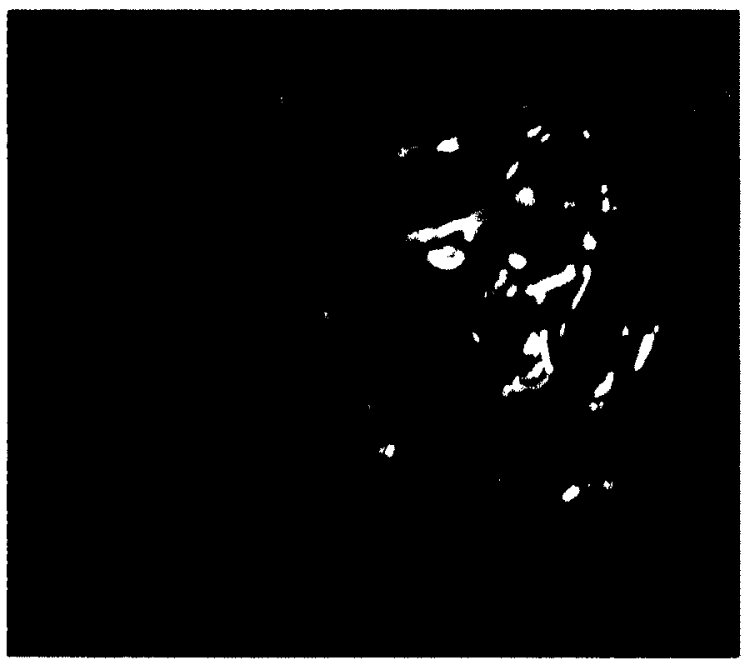

Figure 5-53: Base of tailings - Sample 2 


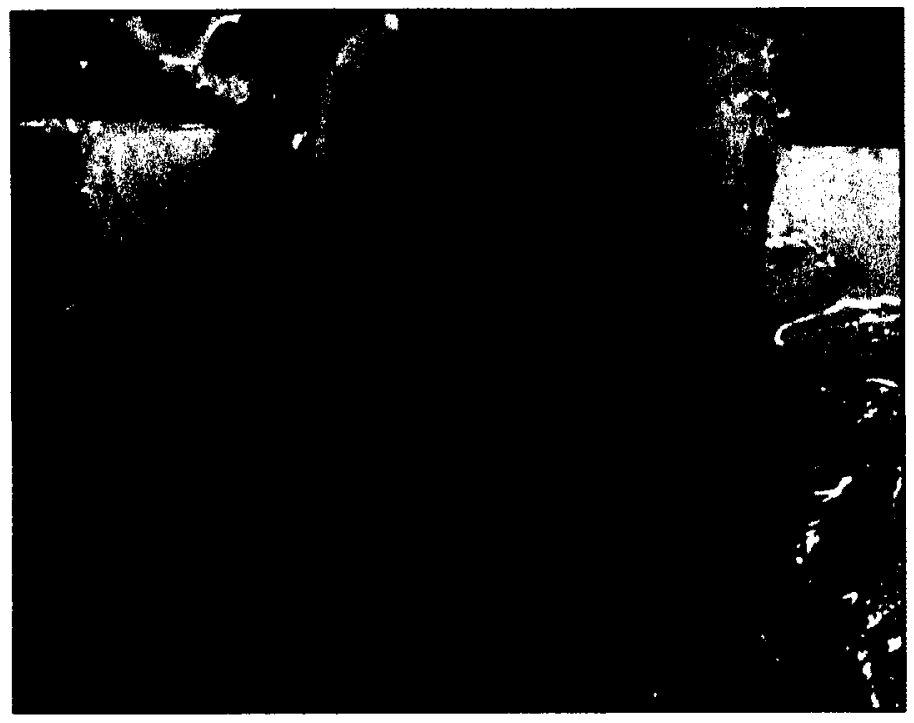

Figure 5-54: Upper Part of Tailings Section - Sample 2

The profile of solids concentration with depth is shown in Figure 5-55. Even though the values are a little lower than Sample 1, the softer material had a higher solids concentration.

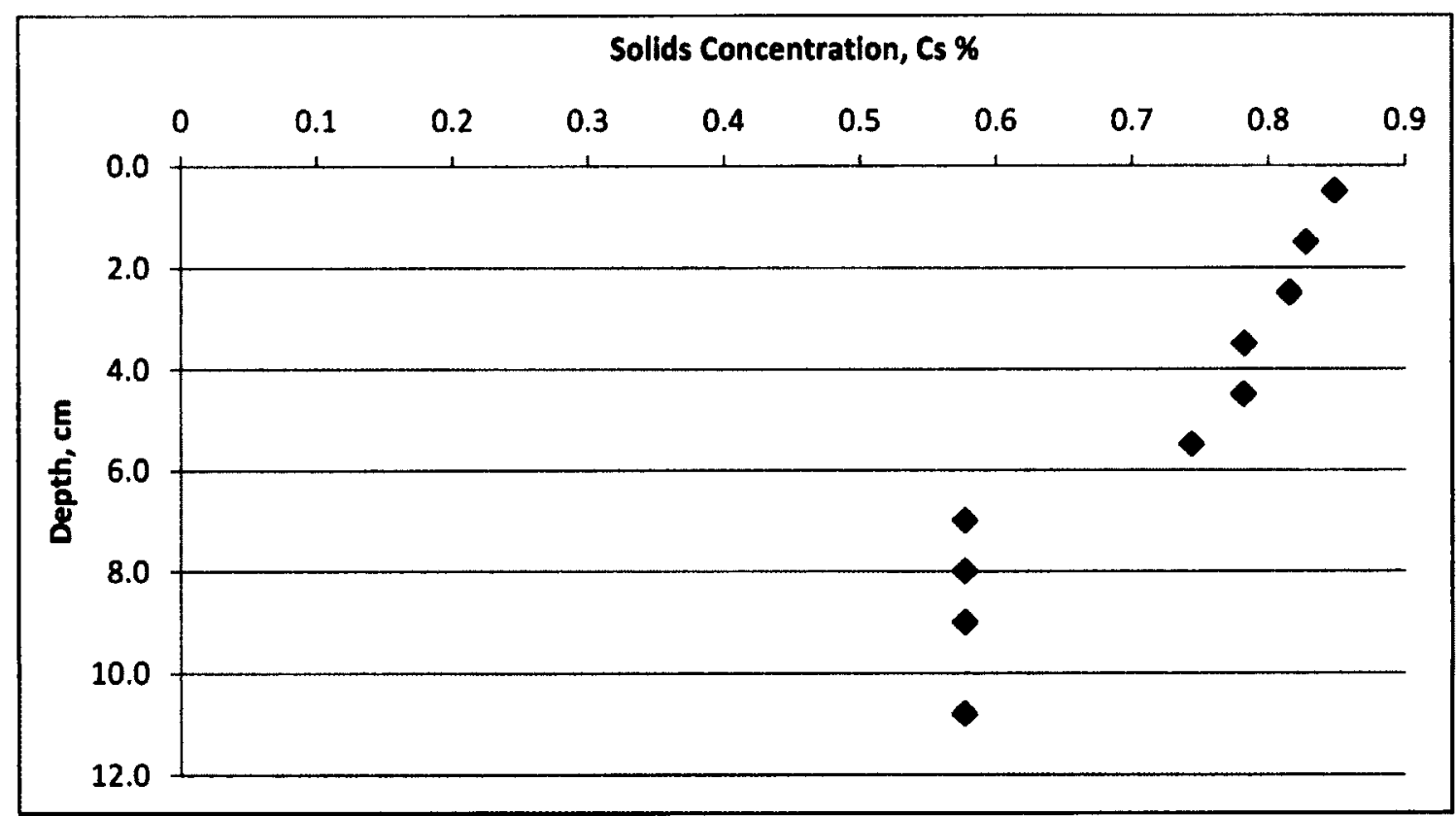

Figure 5-55: Solids Concentration Profile (Sample 2) 
Total and osmotic Suction (Figure 5-56) was much lower at the surface while a more uniform suction is found with depth, indicating the high salt content at the surface of the tailings possibly due to lower water content and solute transport. The latter, evidenced by the higher osmotic suctions at the surface.

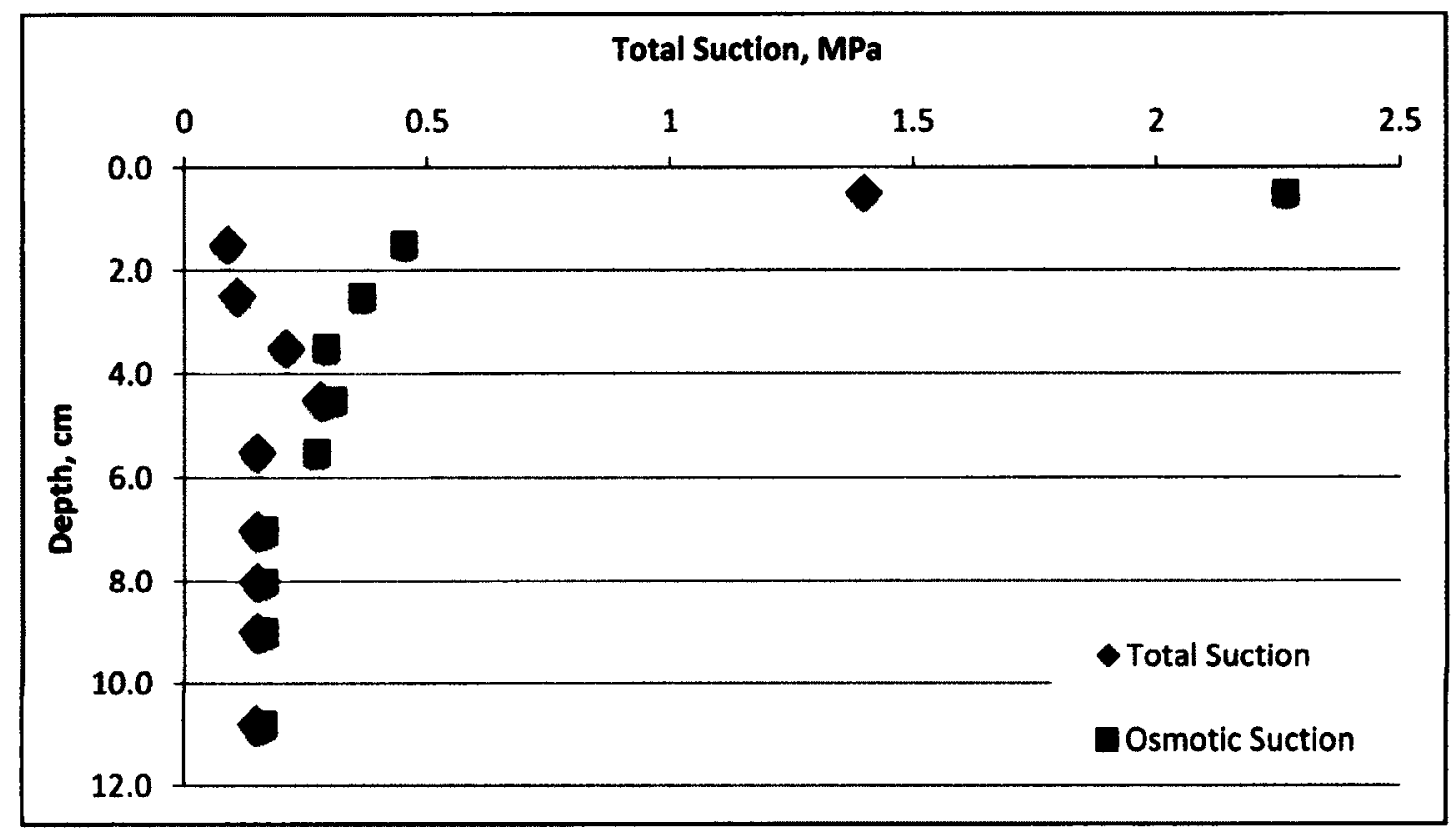

Figure 5-56: Total and Osmotic Suction Profile (Sample 2)

The osmotic suction is reportedly higher than the total suction in the top part of the sample and this is mainly due to the higher EC measured. Upon dilution of the soil sample, dissolved salts present in the pore water and the already precipitated salts (due to the fact that solubility limits had been reached), were both present. Therefore, EC values were very high and account for osmotic suctions higher than total suction. This behaviour was also reported by Dunmola (2012) in his wax column tests performed on soil samples of varied salt concentrations. With increasing salt concentrations, Dunmola (2012) recorded ratios of osmotic suction to total suction of up to 1.5. 


\subsubsection{Layer 2 Deposition}

On day 29, after samples had been extracted from the first layer for analysis, the tensiometers were replaced and instrumentation for the second layer was inserted into the sample ports. The remixed sample was deposited as layer 2 into the box and was allowed to dry (Figure 5-57). The final height of the tailings after deposition was $31.3 \mathrm{~cm}(0.31$ $\mathrm{m})$. The results obtained are presented in the following sections.

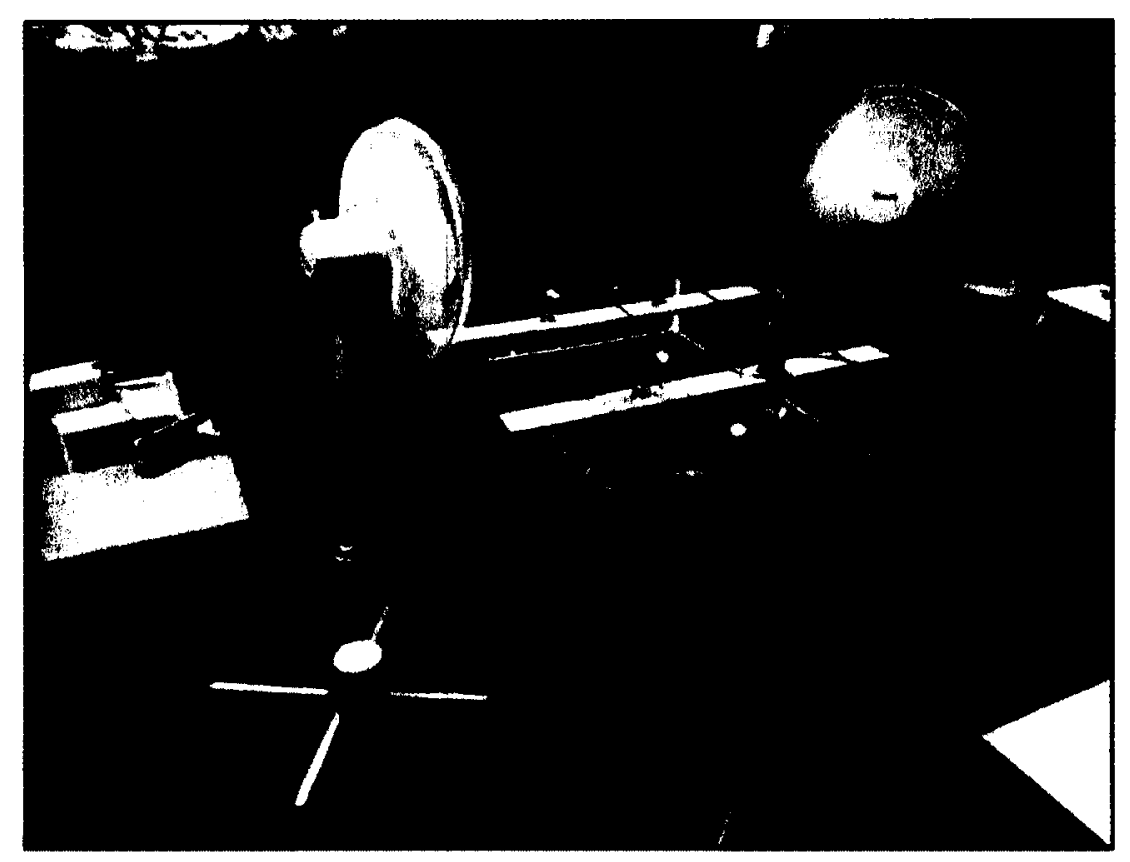

Figure 5-57: Final setup Layer 2

\subsubsection{Mass Loss and Evaporation}

Mass loss due to evaporation after deposition of the second layer had fewer oscillations and evaporation rates range from 1.17 to $4.56 \mathrm{~kg} / \mathrm{d}$, slightly higher than the top $4.27 \mathrm{~kg} / \mathrm{d}$ observed in the previous layer. Figure 5-58 shows that the maximum rates achieved decreased with time. 


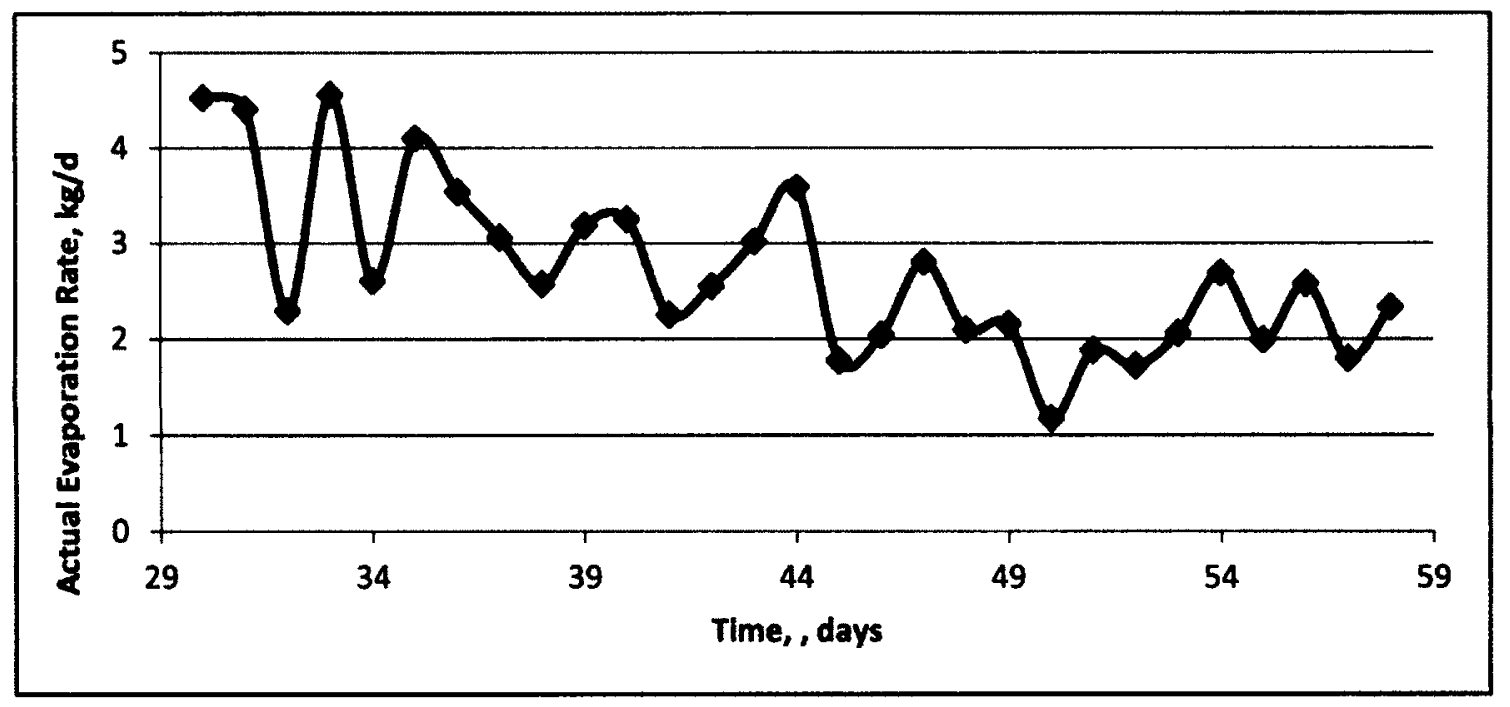

Figure 5-58: Actual Evaporation in $\mathrm{kg} / \mathrm{d}$ - Layer 2

When plotted in $\mathrm{mm} / \mathrm{d}$, the same trend is observed even with the consideration of crack surface area (Figures 5-59 and 5-60). However, the gradients in between peak and low rates are much lower and values fall way below the potential value as is expected with time.

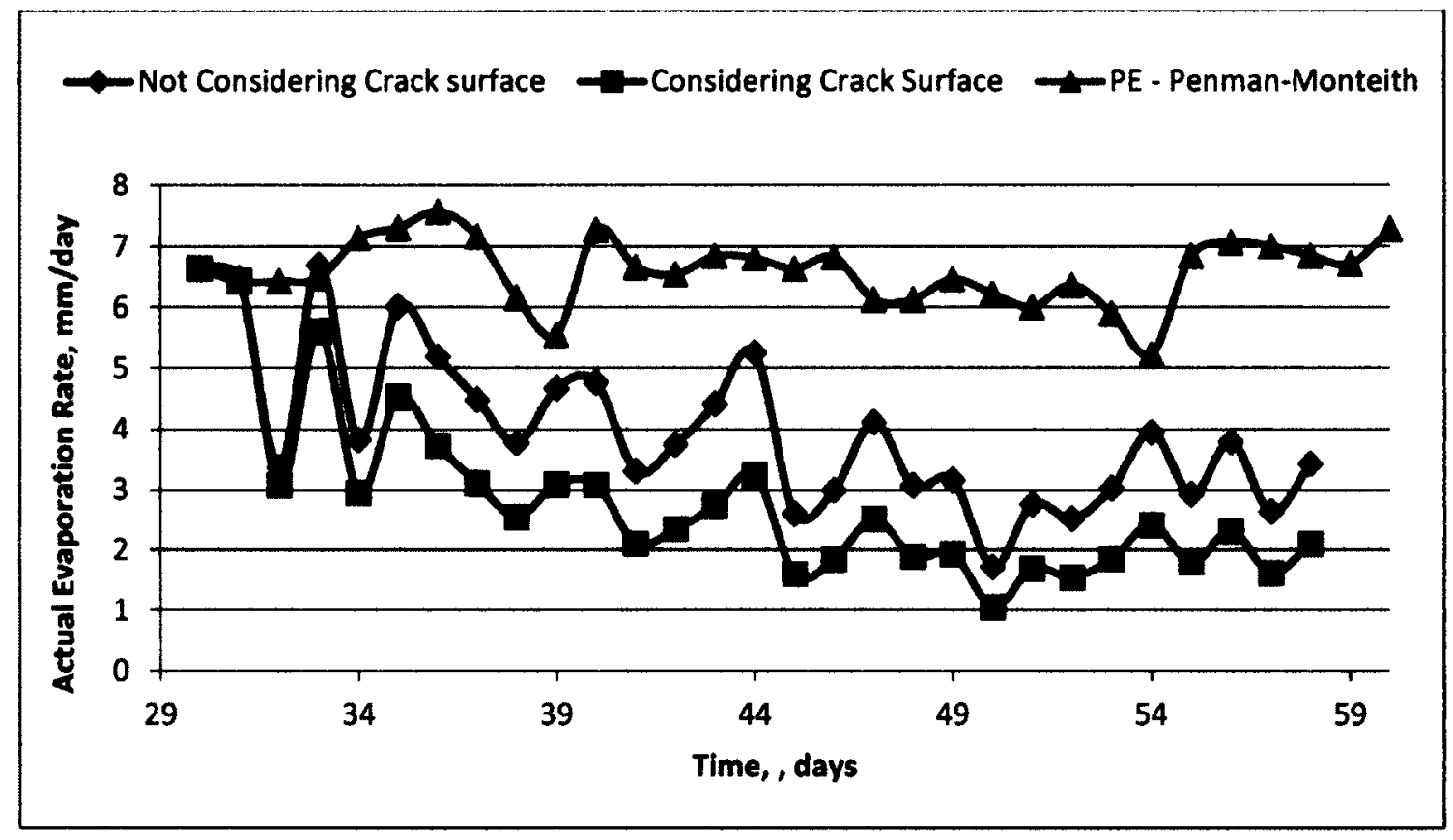

Figure 5-59: Actual Evaporation in $\mathrm{mm} / \mathrm{d}$

174 
Actual evaporations rates with crack consideration range from 1.05 to $6.63 \mathrm{~mm} / \mathrm{d}$. When RE is plotted, the oscillations are still present, even in the graph with crack consideration shown in Figure 5-60.

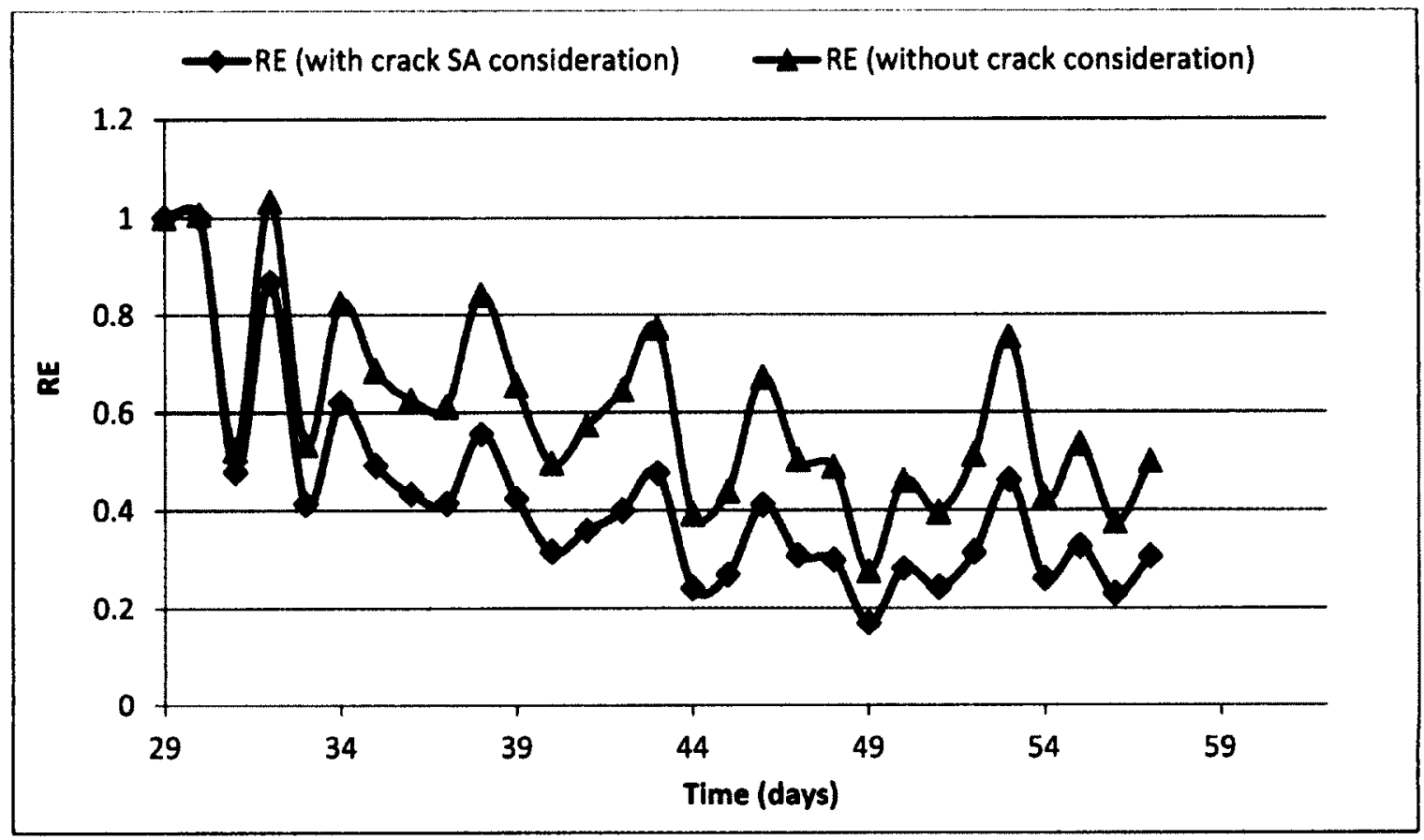

Figure 5-60: Evaporation rate in $\mathrm{kg} / \mathrm{d}$

When the peak values are investigated, it is noted that on these days, there was either expulsion of wet underlying material from the weight of the dry surface layer as shown in Figure 5-61 or an increase in the depth of the cracks which in both cases resulted in the exposure of tailings with very low suction values. Further investigation into the evaporative behaviour is presented in subsequent subsections. 


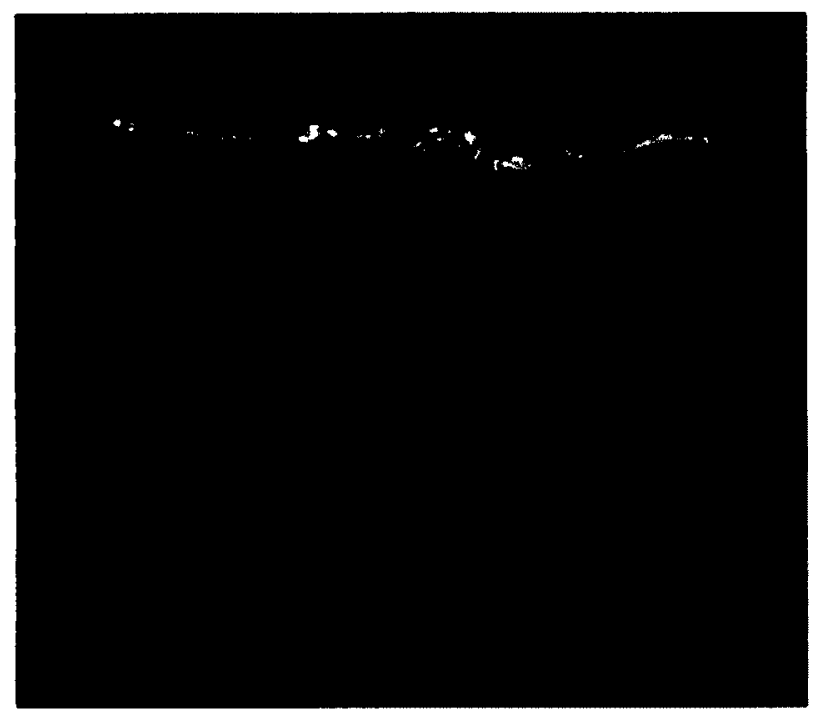

Figure 5-61: Visual of Exposure of underlying material (Day 32)

\subsubsection{Temperature and Humidity}

Temperatures fluctuating from 12 to $21{ }^{\circ} \mathrm{C}$ were measured at the surface, a slightly wider range than the first layer, which had a range of $4{ }^{\circ} \mathrm{C}$. Relative humidity highs reached $56.5 \%$ while lows hit $19 \%$. Some interruptions occurred in data logging using RH/Temp sensors. Relative humidity and Temperature profiles are presented in Appendix M. Temperatures recorded from within the tailings were generally higher, 11 17 compared to $10-15.4$ for the first layer. See Appendix $M$.

\subsubsection{Gravimetric Water Content, $w$}

Using values of average volumetric water content and void ratio, the average gravimetric water content, $w$, for layer 2 was estimated and results show a decrease from 99 to $20 \%$. The test was ended when the void ratio of $\sim 0.6$ was achieved for layer 1 and the overall box gravimetric water content was at $17.3 \%$ from an initial value of $59 \%$. This occurred 
within a period of 33 days, 29 in the case of the previous layer (Figure 5-62). Overall GWC refers to the change in total mass of water to total mass of solids reflective of both layers.

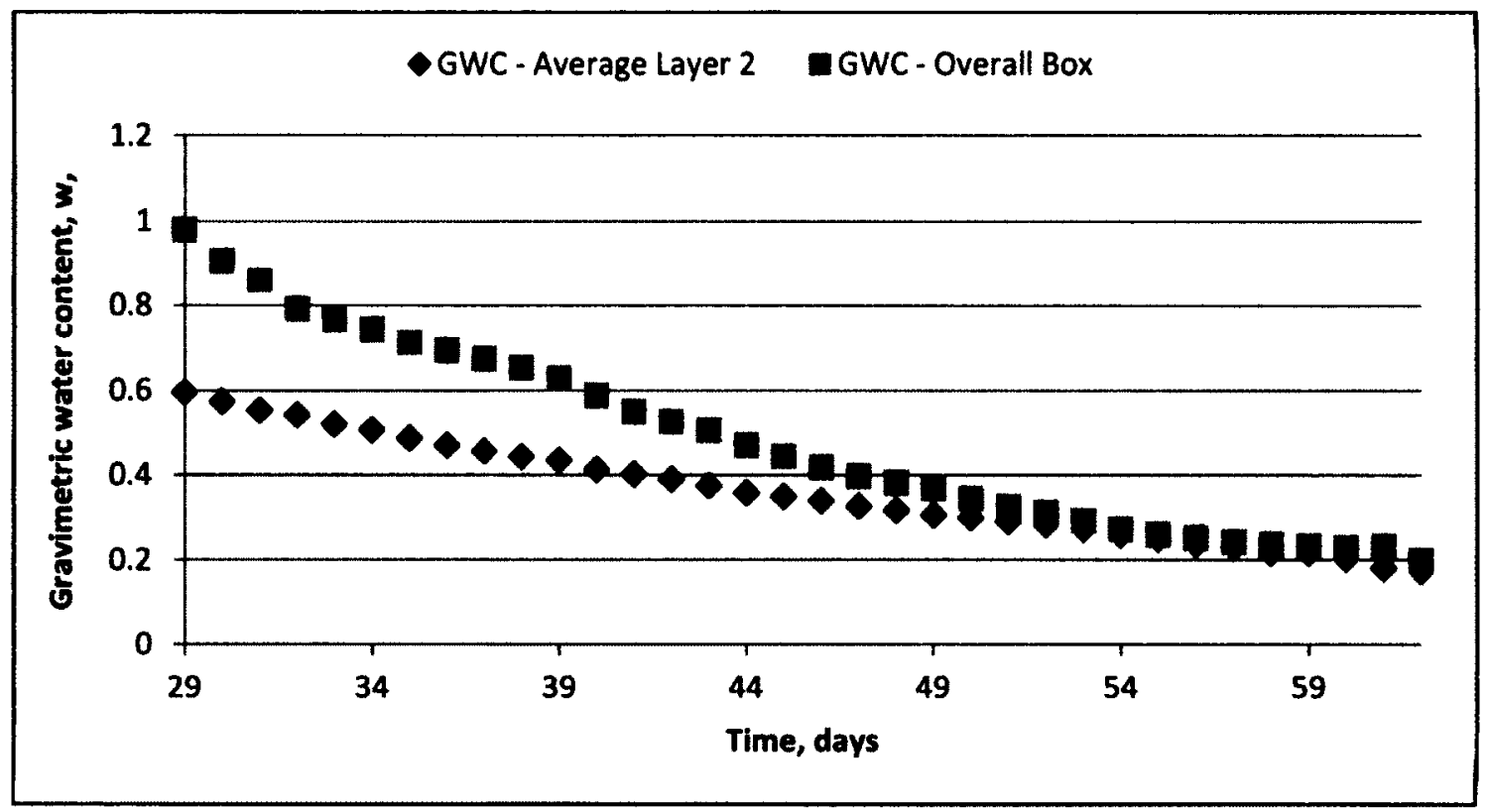

Figure 5-62: Average and Overall GWC - Layer 2

The box overall gravimetric content was used as the indicator to stop the test because water lost through evaporation came from not only the layer directly exposed to the atmosphere but from all layers where water was available. With the infiltration of water to layer 1, manifested in the following section from the increase in volumetric water content, water is also available from this layer.

Gravimetric water content at the surface fell quickly from 100 to $28.8 \%$ within a day to $10 \%$ at the end of the drying period, lower than the 36 and $11 \%$ respectively for Layer 1. Refer to Figure 5-63. 


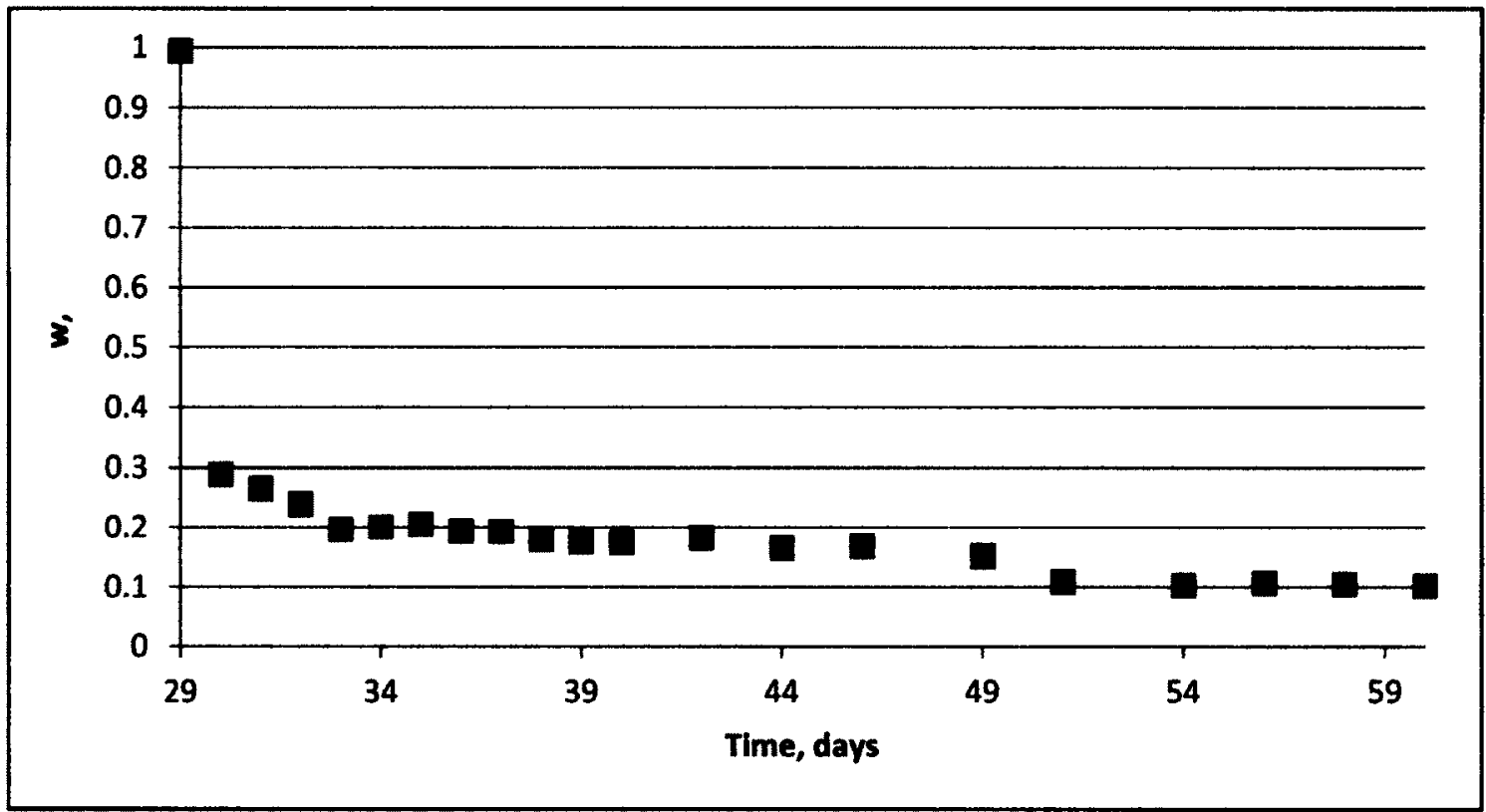

Figure 5-63: Variation in Gravimetric Water Content at the surface - Layer 2

\subsubsection{Volumetric Water Content, $\theta_{w}$ -}

Figure 5-64 shows an increase in the volumetric water content of the underlying material (Sensor 1,2 and 3) on day 29 which corresponds with the deposition of the second layer. This signifies that water from the deposited layer infiltrated the unsaturated material by way of the cracks and fissures and available permeability. It shows a decrease in water available from top soil by. 


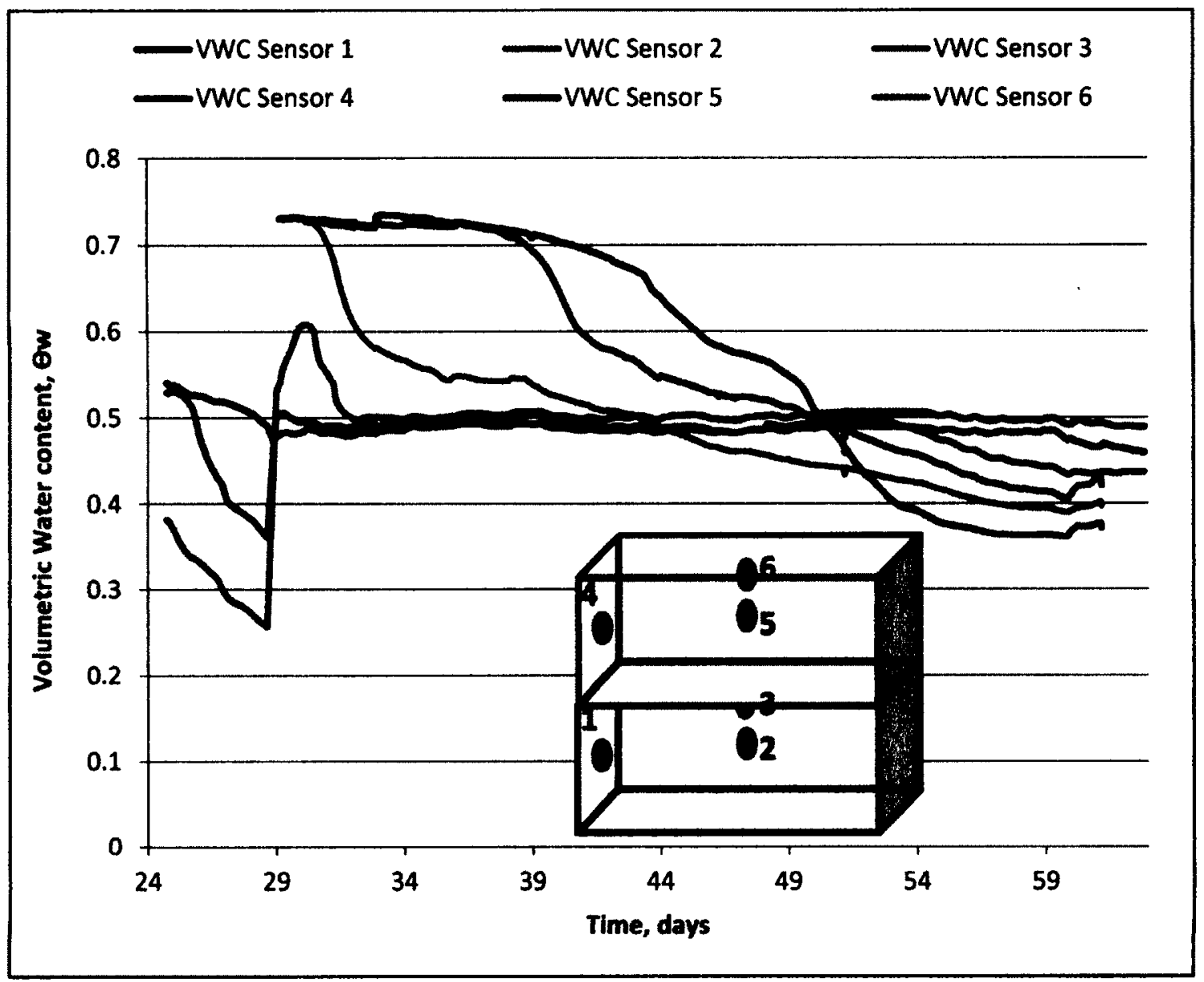

Figure 5-64: Volumetric water content data (After Layer 2 deposition)

The upper portion of the first layer experienced the highest increase in volumetric water content from 25.8 to $60 \%$ and then levelling off to $50 \%$ within two (2) days. This decrease was not captured by an increase in the other sensors, so it may have to do with interlayer flow, something that could be detected if there was a sensor right at the interface. The other two sensors both registered increases, also levelling to $50.5 \%$. The increases in volumetric water content of the underlying layer were due to the infiltration of water from layer 2. This loss of water was very beneficial in the evaporation of the 
tailings and eventual strength development within the soil core in both layers 1 and 2 as is further demonstrated in the results of the sectional analysis.

A more gradual change in volumetric water content was observed at the centre of layer 2 for the first nine (9) days after which there was a decrease to $40 \%$ to the end of the test. At the top $5 \mathrm{~cm}$, within three (3) days there was a sharp decrease from 70 to $60 \%$. Overall gravimetric water content was approaching $17.3 \%$ and volumetric water contents had not decreased as much as in the first layer but material showed significant strength in top and underlying material. However, the decreases observed in volumetric water content for layer 2 were much higher throughout the layer (sensors 4 and 5 compared to 1 and 2 in layer 1; Figure5-40), indicating that infiltration aided in a more uniform dewatering.

Slight increases in the volumetric water content of underlying material around day 45 may indicate the downward movement of water from overlying tailings as surfaces got drier. In addition, towards the end of the test slight increases in the top layer with simultaneous decrease in the underlying material may also signify the upwards movement of water from underlying materials.

Figure 5-65 captures the volumetric water content change in three (3) cracks. It could be seen that the change is very gradual. For example, crack 3 shows only a $7 \%$ change in volumetric water content for a period of 14 days, while crack 2 had a change of only $4 \%$ for a period of eight (8) days. 


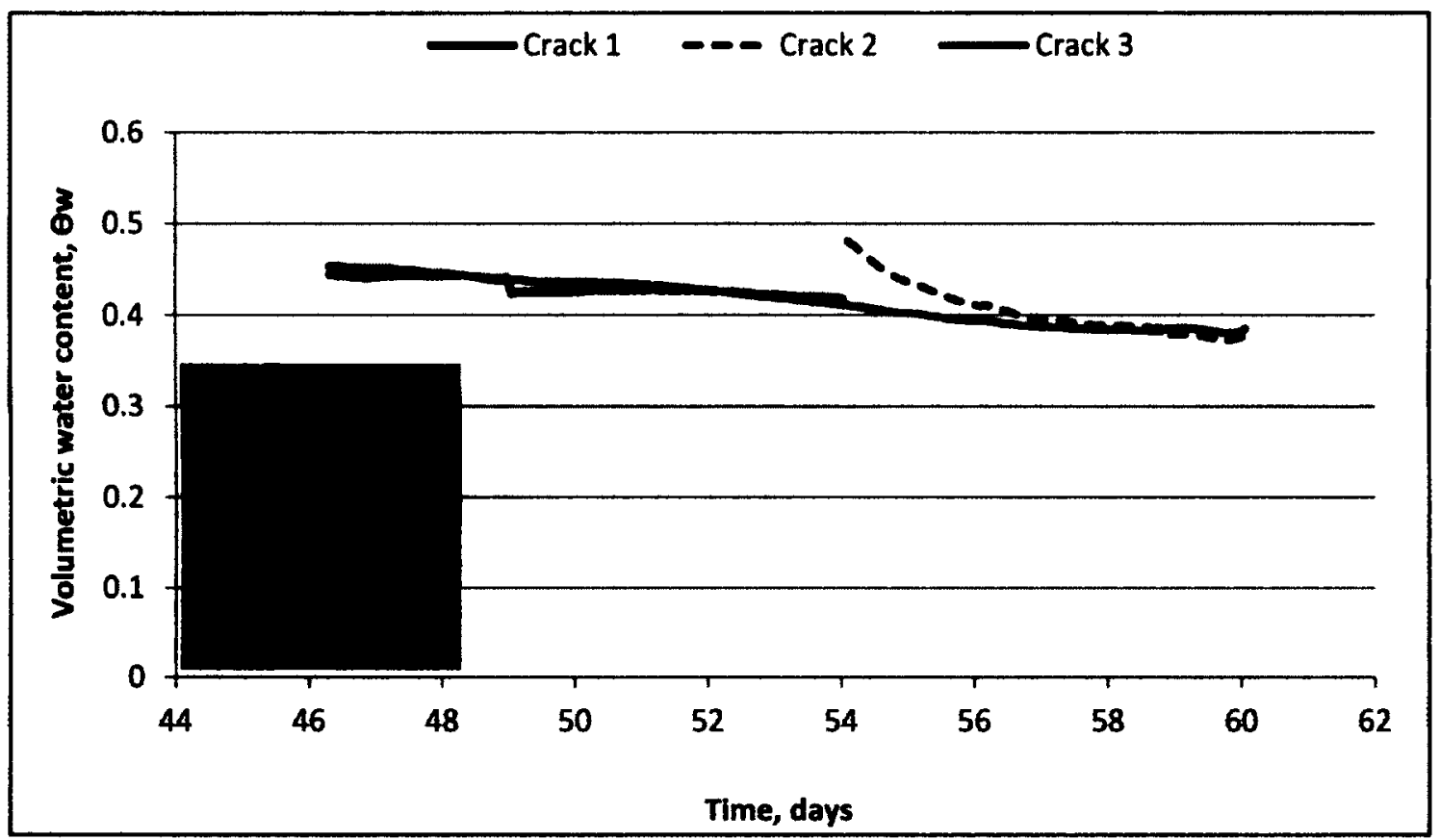

Figure 5-65: Change in Volumetric water within cracks

\subsubsection{Volume change and Settlement}

Assuming that there was no swelling of the bottom layer from infiltration of water, settlement for Layers 1 and 2 was computed based on height change detected by the Senix distance sensors. Figure 5-66 shows settlement and accumulative evaporation. In the first few days (6-8) the curves are close but later the difference increases from 0.5 to 0.6 for most part. After 28 days, it increases to $1.2 \mathrm{~cm}$ as volume change levels off. The trend was much different from Layer 1 where from day four (4) a difference of $1.5 \mathrm{~cm}$ dominated the length of the drying test (See Figure 5-66).

Although water removal (accumulative evaporation) was lower by $0.2 \mathrm{~cm}$ with second layer deposition, settlement was greater by $1.2 \mathrm{~cm}$. This is attributed to the reduction of the available water in the second layer due to infiltration into the drier lower 
layer depicted in the Figure 5-66, where in the first five (5) days, settlement is higher that water removal. Less water available for evaporation and water infiltration led to volume reduction.

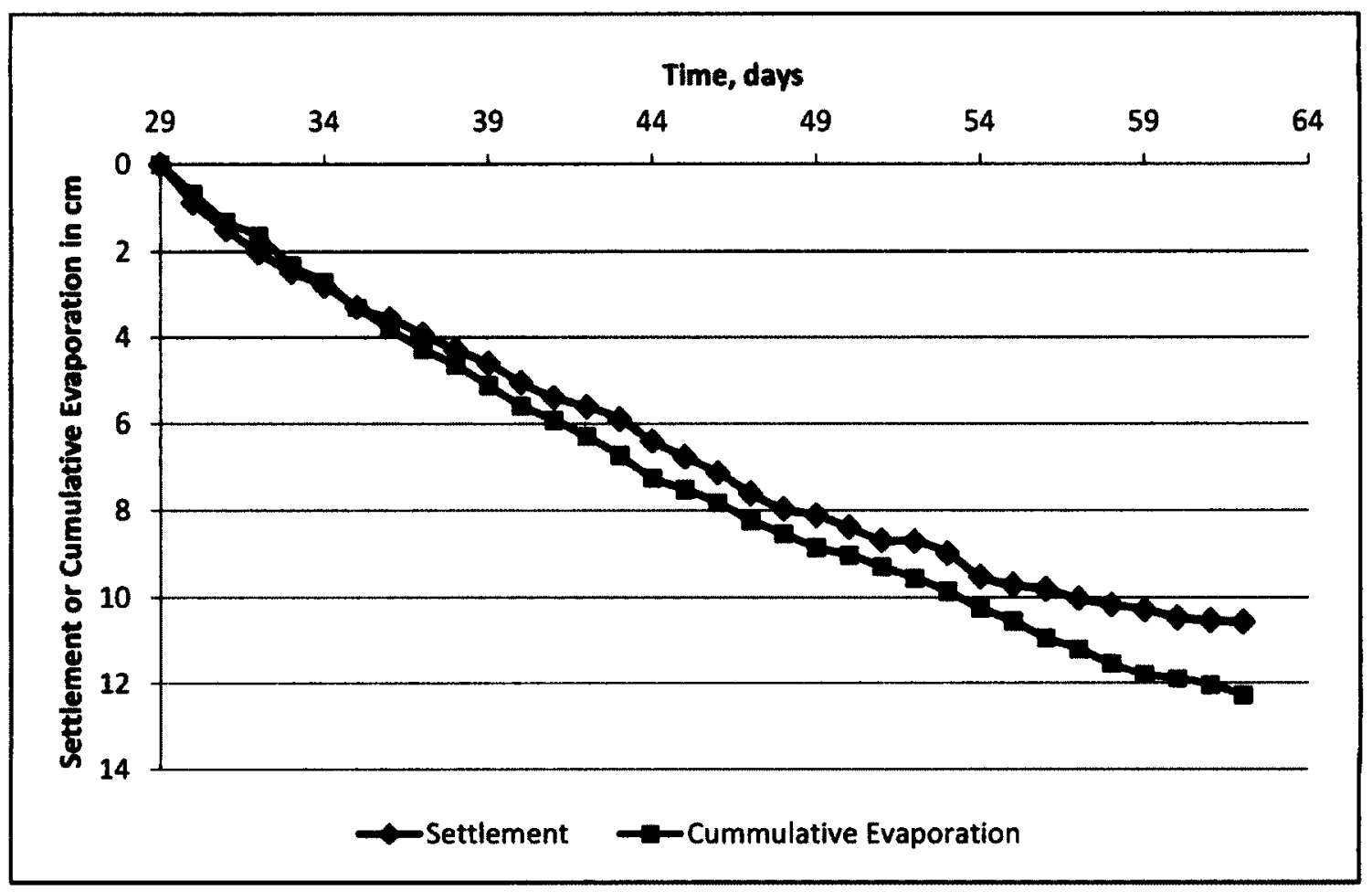

Figure 5-66: Settlement and Cumulative Evaporation with time - Layer 2

From Figure 5-67, the overall initial void ratio of the second layer deposition was 2.36 and it decreased, based on height data, to 0.61 and 0.5 , with and without crack consideration respectively. Crack volume initiated from day two (2), and showed a steady increase till day four (4) where due to expulsion of underlying wet material, crack volume reduced. With layer 1 , crack volume initiated on day three (3) as shown in Figure 5-68. The author is of the belief that due to the infiltration of water into layer 1 , crack development was more rapid in layer 2 and extended quickly throughout the layer causing a greater total volume of cracks in layer 2 . 


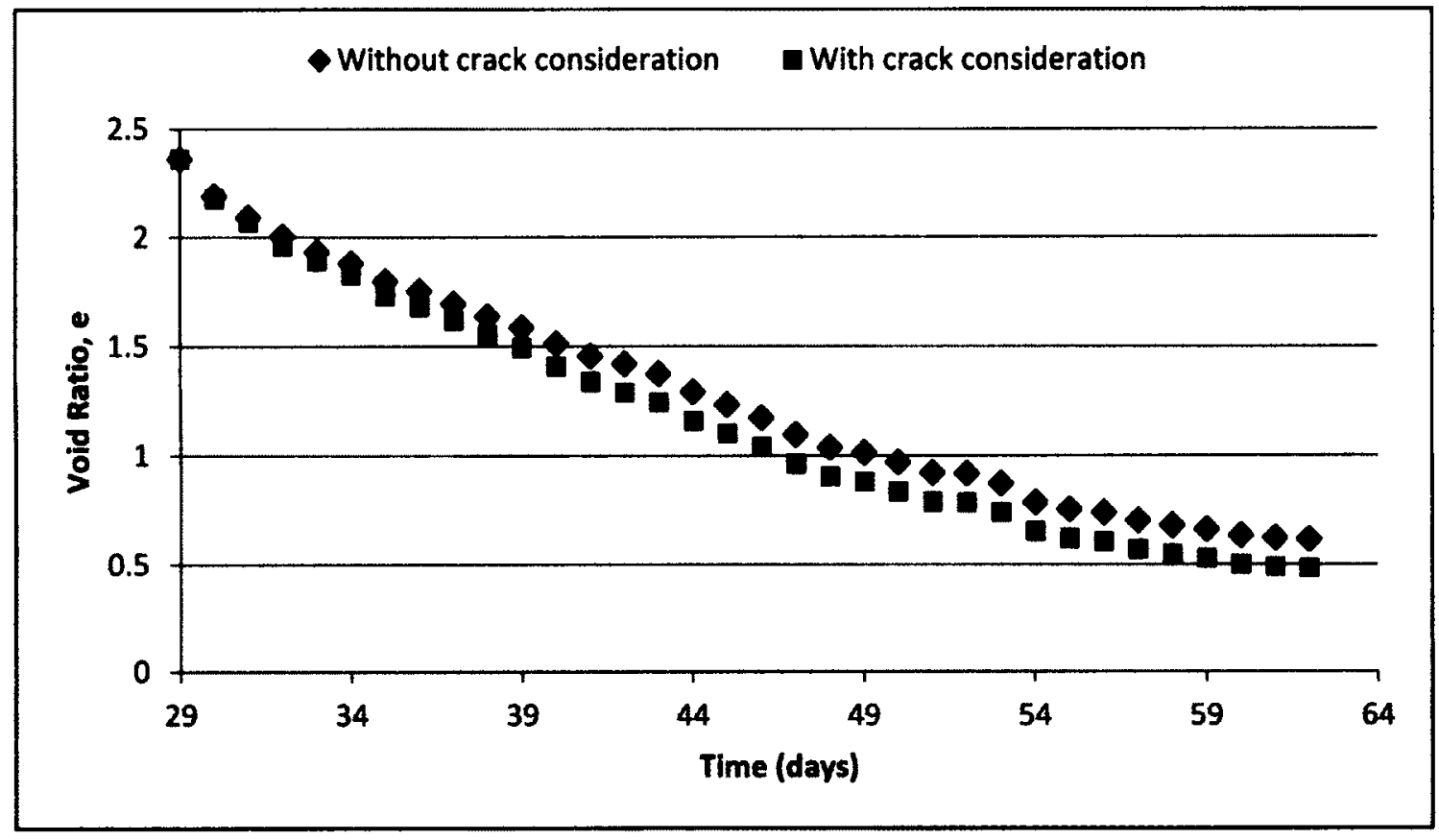

Figure 5-67: Evolution of Void ratio - Layer 2

The final total volume of cracks was higher in layer 2 .

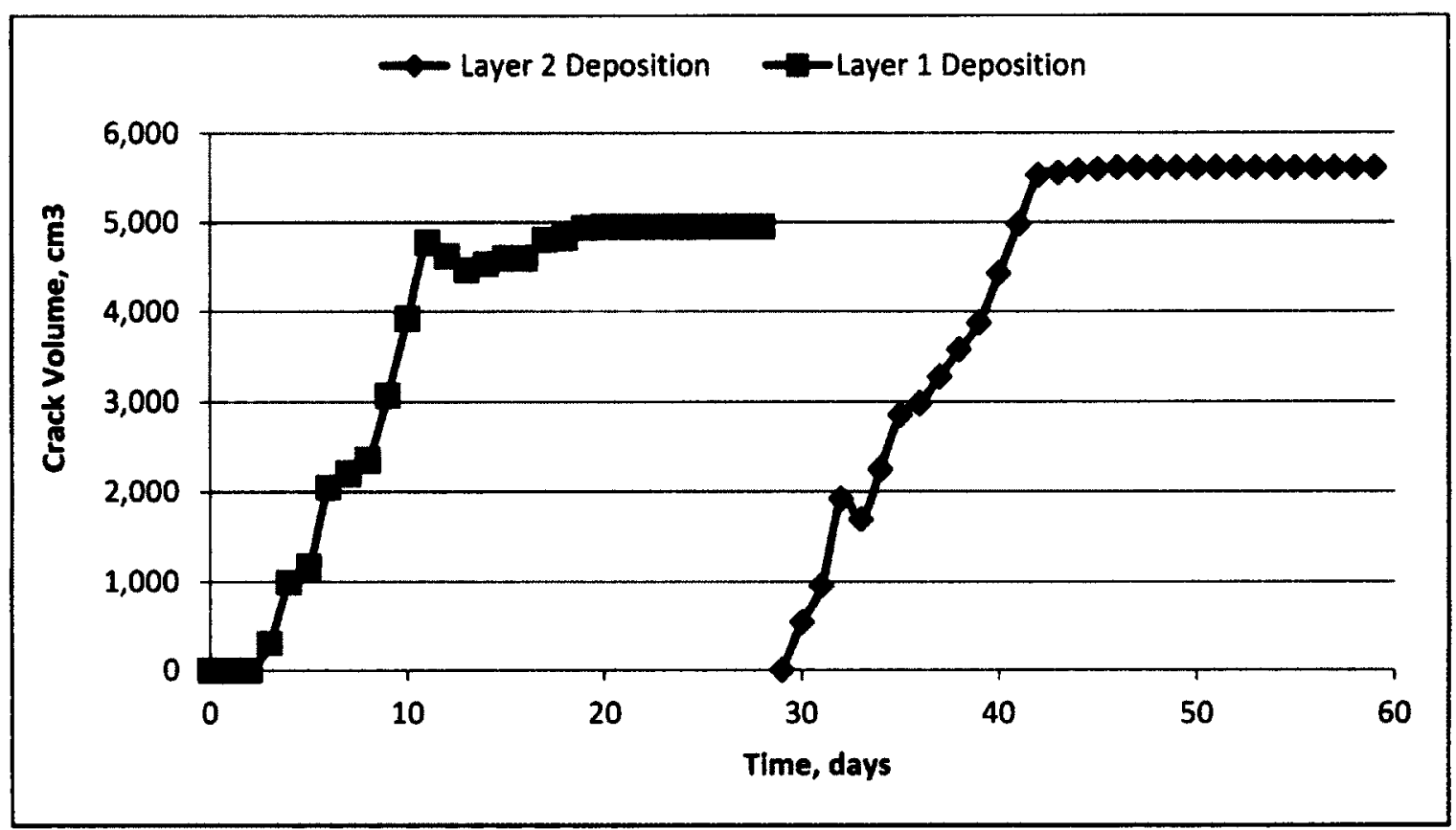

Figure 5-68: Comparison of Crack Volumes - Layers 1 and 2 
The shrinkage curve is presented in Figure 5-69.

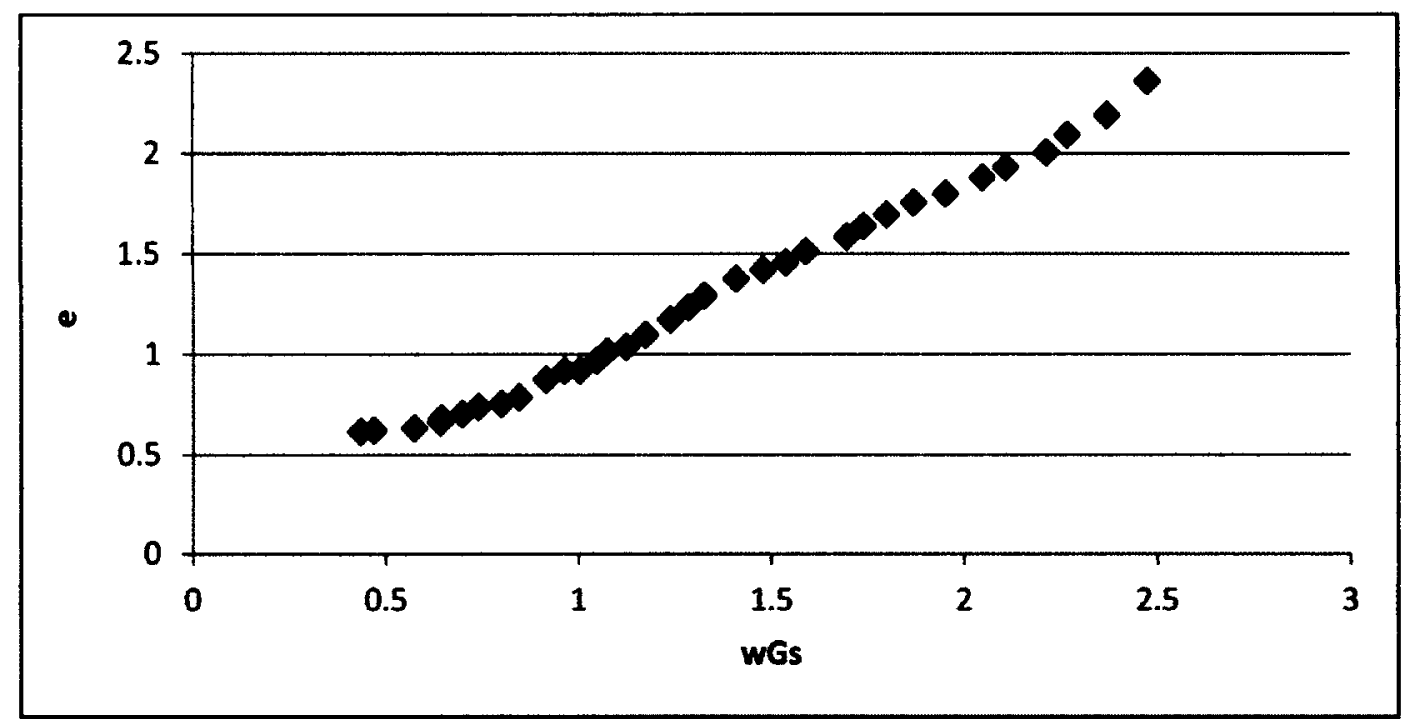

Figure 5-69: Shrinkage Curve showing the variation in the Degree of Saturation (S)

\subsubsection{Suction}

\section{Matric Suction}

Tensiometers 1 to 3 were replaced before deposition of Layer 2 and three (3) additional tensiometers were installed to monitor matric suction. Two (2) were placed at the centre of layer 2 and the other within the top $5 \mathrm{~cm}$ of the tailings surface. Figure 5-70 shows the location of the 6 sensors.

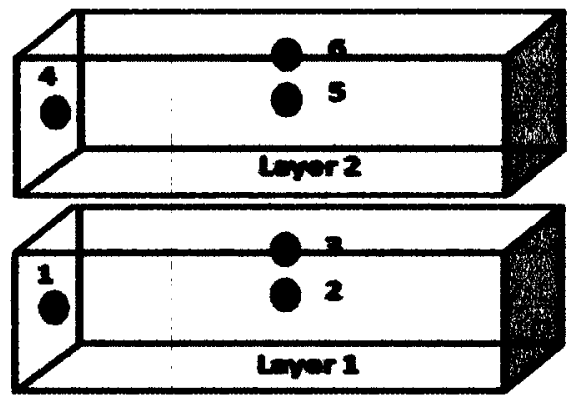

Figure 5-70: Sample Ports in Layers 1 and 2 
Tensiometers 2 and 5 at the midpoint of layers 1 and 2 respectively, did not record significant developments in matric suction. Tensiometer 6 cavitated a few hours after the start of the test. In the bottom layer, Tensiometer 1 at an elevation of about 5 $\mathrm{cm}$, recorded developed matric suctions after 25 days (day 54) of the test to a maximum of $72 \mathrm{kPa}$ (Figure 5-71). These values are concurrent with the drop in volumetric water content at this height from day 54 .

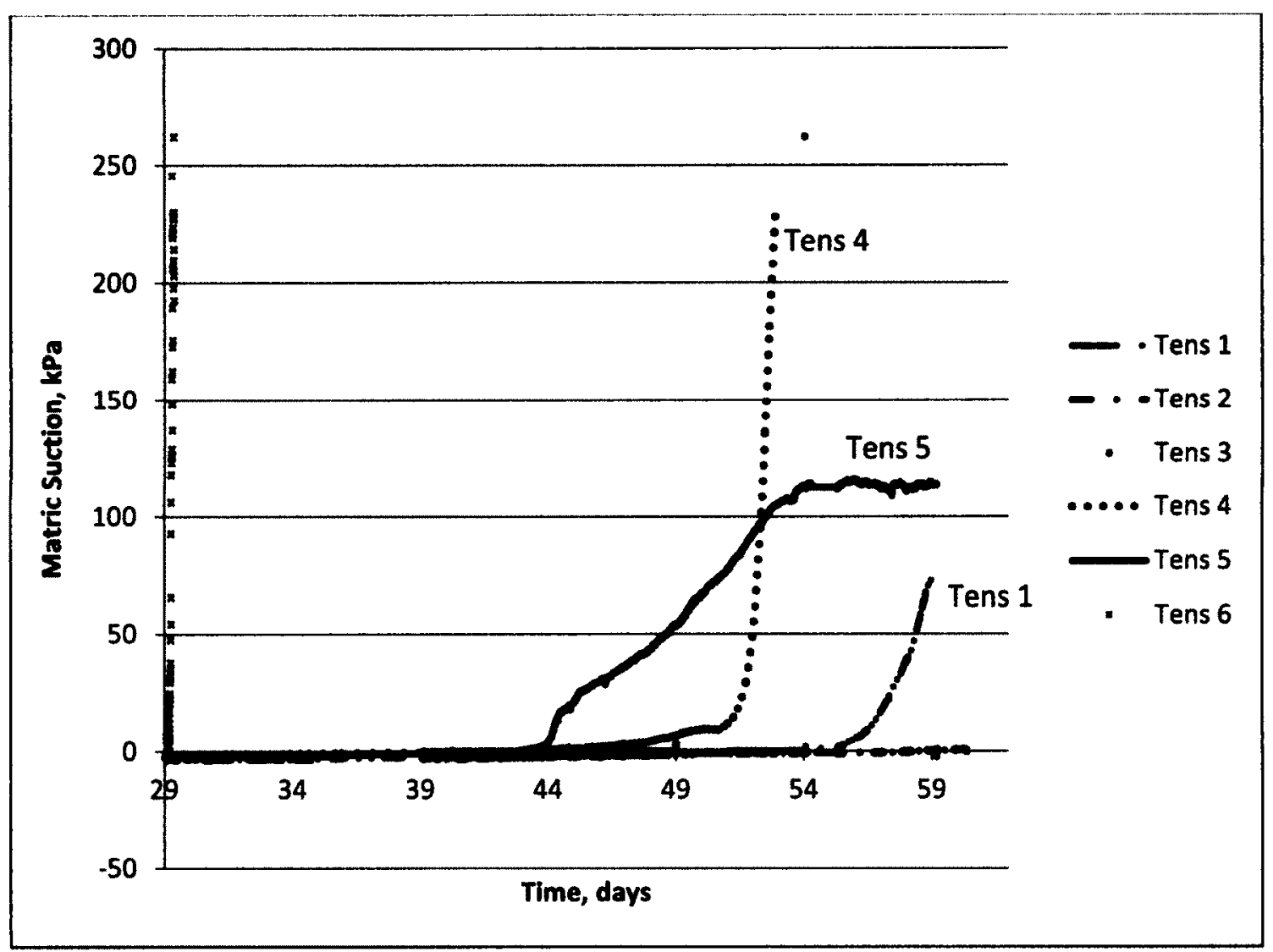

Figure 5-71: Evolution of Matric Suction - New (Layer 2) and Old (Layer 1) Layers

Tensiometers 4 recorded a gradual development in matric suction from day 44 from a volumetric water content of $49 \%$ until cavitation. Tensiometer 5 reveals significant matric suction development from day 49 where the volumetric water content measured was $49.9 \%$ before cavitation on day 52 . 
The break in the graph from day $35-39$ is a result of the lack of data collection due to logger malfunction. To avoid such occurrences, logged results were downloaded daily for layer 3 . Tensiometers 4,5 and 6 were replaced with newly conditioned tensiometers before deposition of layer 3 .

\section{Total Suction}

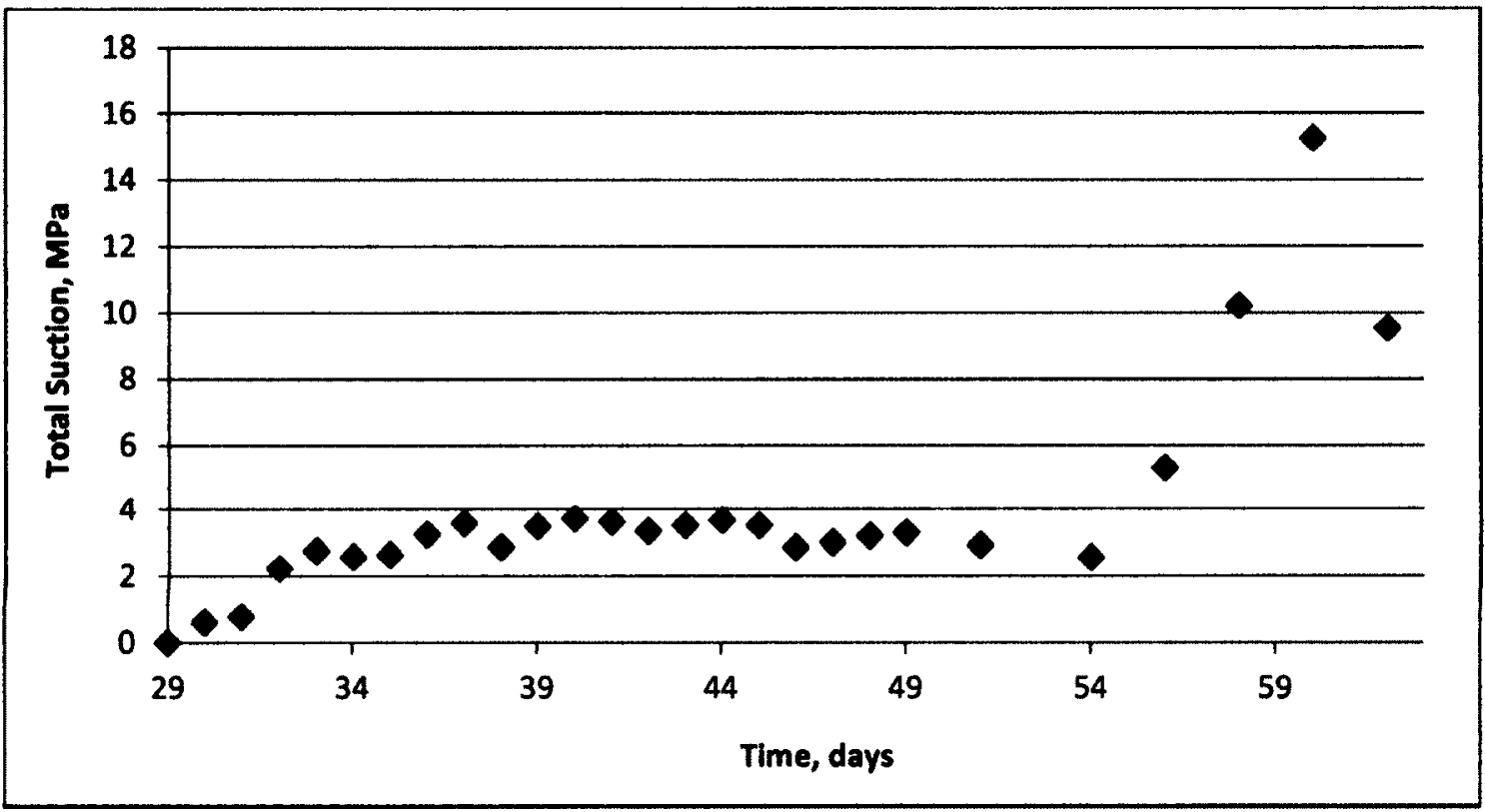

Figure 5-72: Evolution of Total Suction at the surface - Layer 2

Total suction values measured from samples of the top $1 \mathrm{~cm}$ of the tailings surface are shown in Figure 5-72 and ranged from 0 to $10.19 \mathrm{MPa}$. Although a higher value was obtained than in layer 1, the total suction at the surface increased to about $4 \mathrm{MPa}$ and varied a little from this value. In layer 1 , values oscillated around $5 \mathrm{MPa}$.

Electrical conductivity measurements presented in Figure 5-73, indicates an increase in salt concentration with time. The osmotic suction corresponding to measured EC values (Figure 5-73) surpass total suction after 4 days. As has been previously 
discussed, this may be an indication of the commencement of salt precipitation which when dissolved during EC tests give high results. As a result, osmotic suctions are reported as higher than total suction.

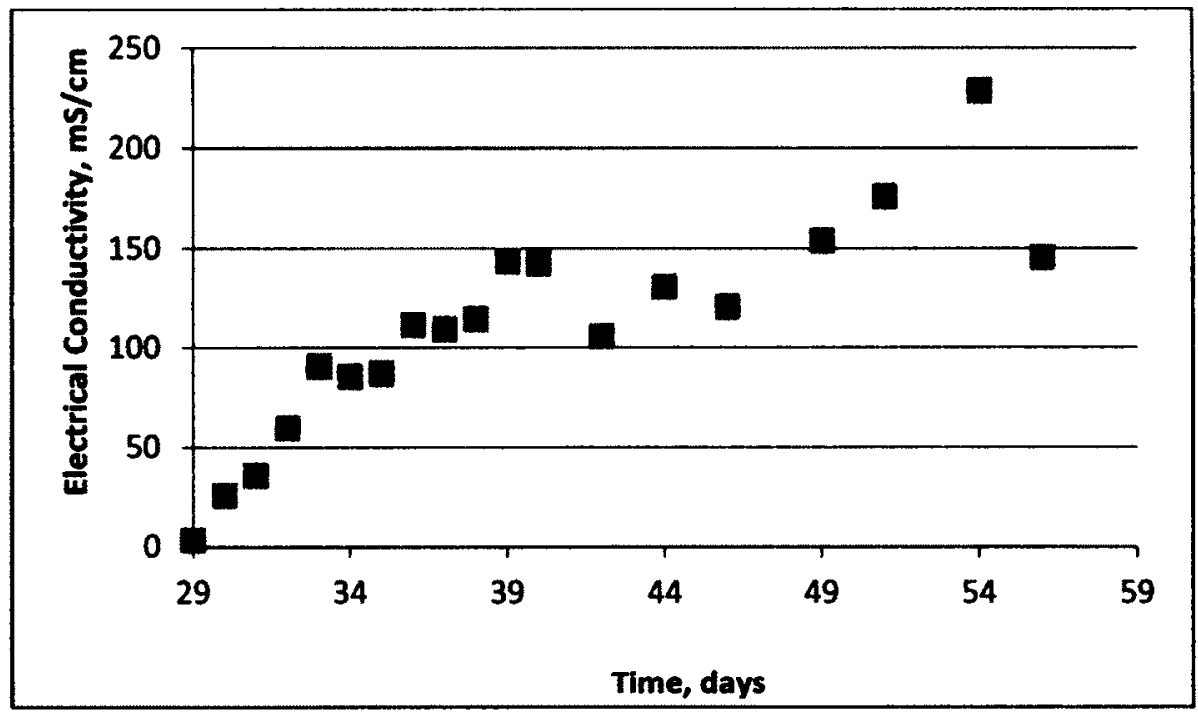

Figure 5-73: Electrical Conductivity measured at the surface

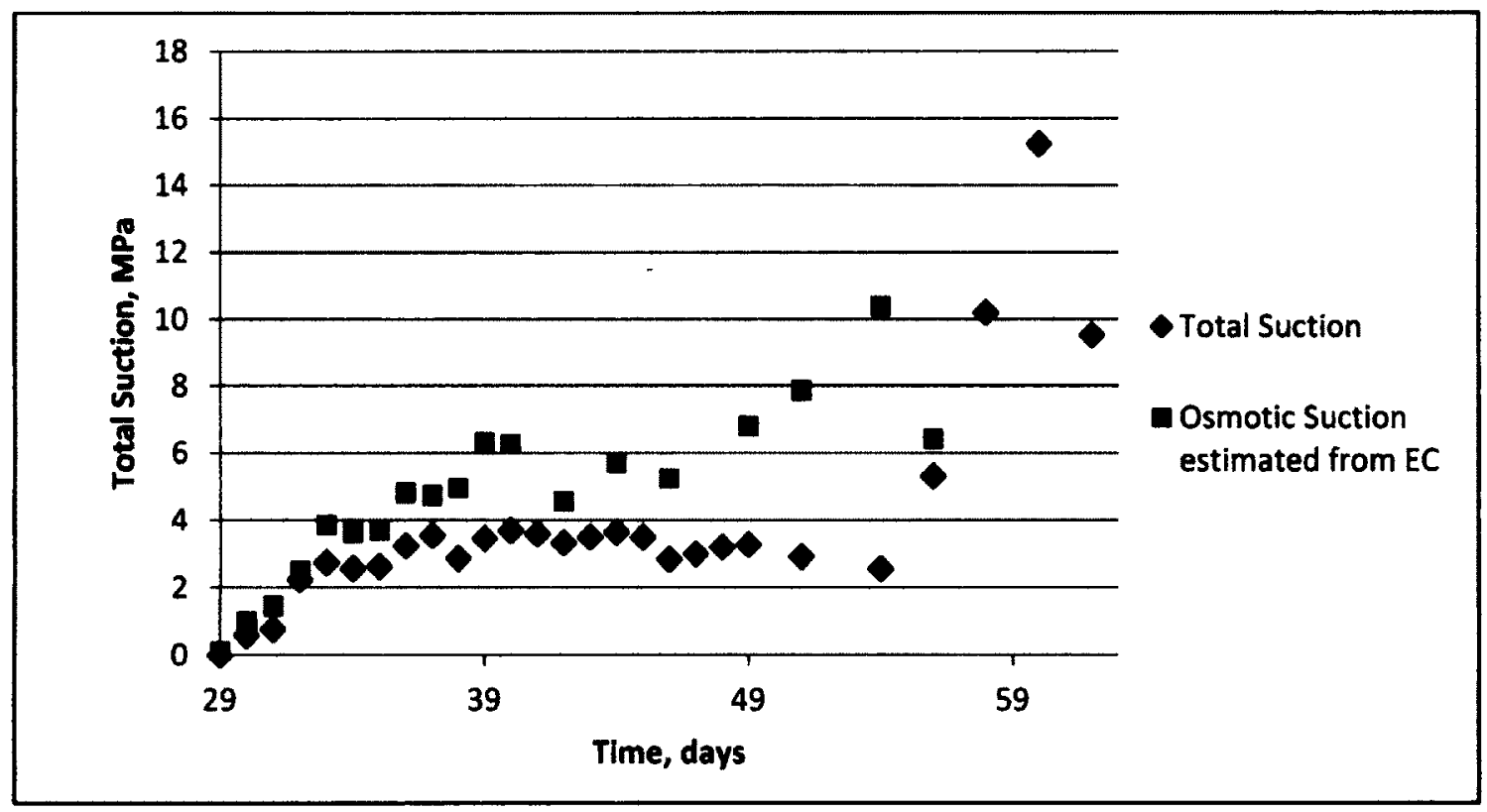

Figure 5-74: Osmotic and Total Suction measurements at Surface - Layer 2 
Within the cracks total suction remained very low. See Table 5-5. However, along the edges of the cracks, high suctions were registered and salt deposits were visible; Figure $5-75$.

Table 5-5: Measured Total Suction - Crack Surface - Layer 2

\begin{tabular}{|r|r|r|r|l|}
\hline & \multicolumn{3}{|l|}{ Total Suction, MPa } & \\
\hline & \multicolumn{1}{|c|}{} & & 0 & $\begin{array}{l}\text { Shutdown } \\
\text { crack }\end{array}$ \\
\hline Time (Days) & N/A & & & \\
\hline 31 & 0.01 & 0.71 & & \\
\hline 32 & 0.01 & 1.48 & & \\
\hline 33 & 0.05 & 1.4 & & \\
\hline 34 & 0.23 & 1.02 & & \\
\hline 35 & 0.14 & 1.66 & & 1.85 \\
\hline 36 & 0.23 & 1.22 & & \\
\hline 39 & 0.07 & 0.5 & 5.36 & \\
\hline 42 & 0.15 & 0.35 & 8.66 & \\
\hline
\end{tabular}

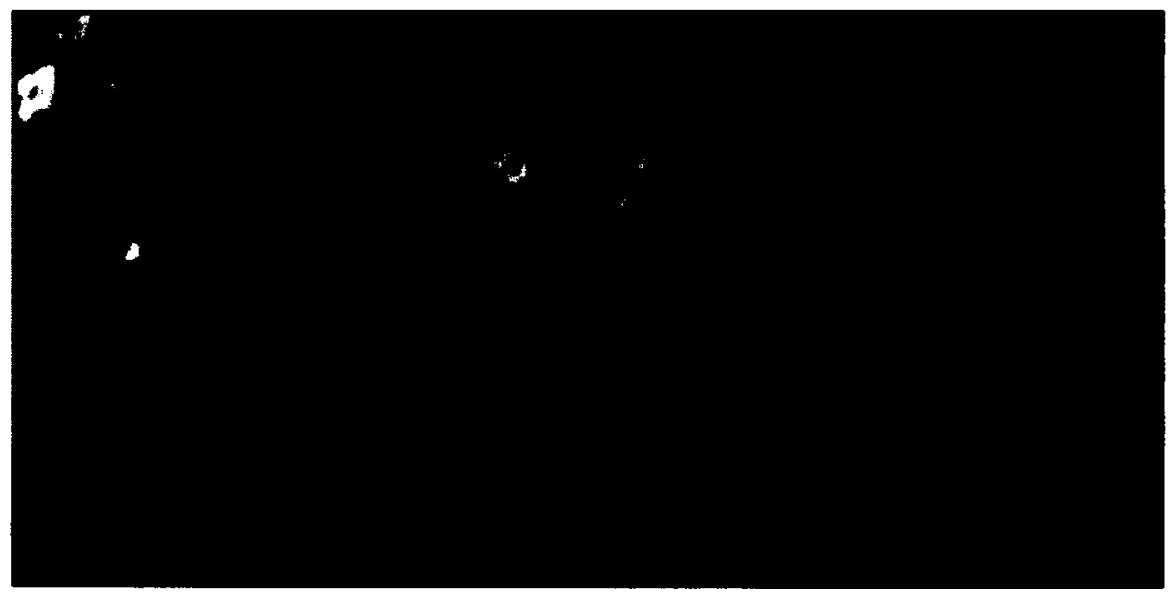

Figure 5-75: View of salt deposits along crack edges

The cracks contributed to a final increase in the surface area of approximately $4300 \mathrm{~cm}^{2}$ leading to a final surface area of $11120 \mathrm{~cm}^{2}$ shown in Figure 5-76. 


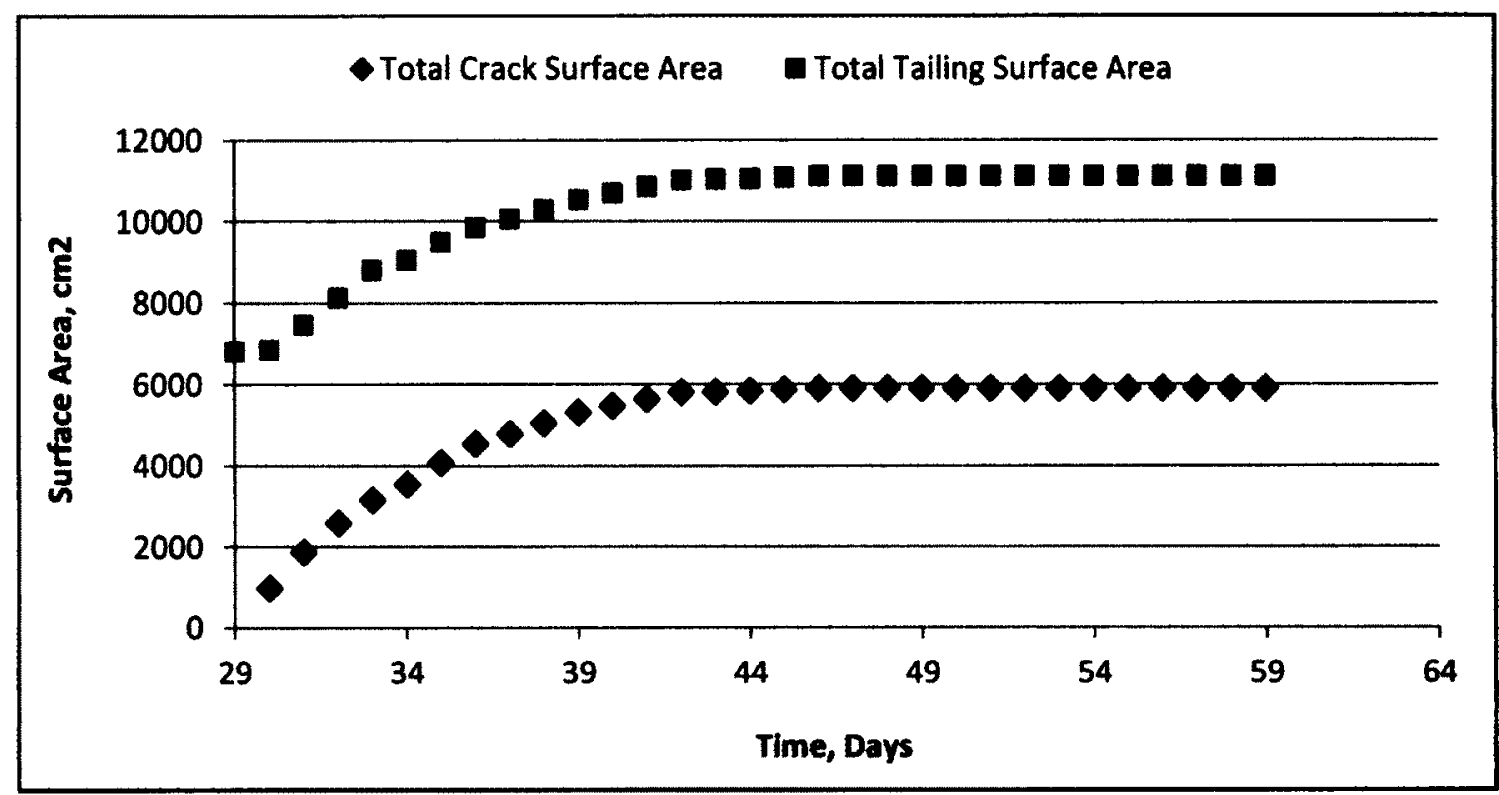

Figure 5-76: Total Crack and Tailing Surface Area - Layer 2

As mentioned previously, there was a sharp increase in surface area within the first few days and this is all due to the early appearance and development of cracks. Figure 5-77 shows the sizes of cracks which appeared by day 2 for both layers.

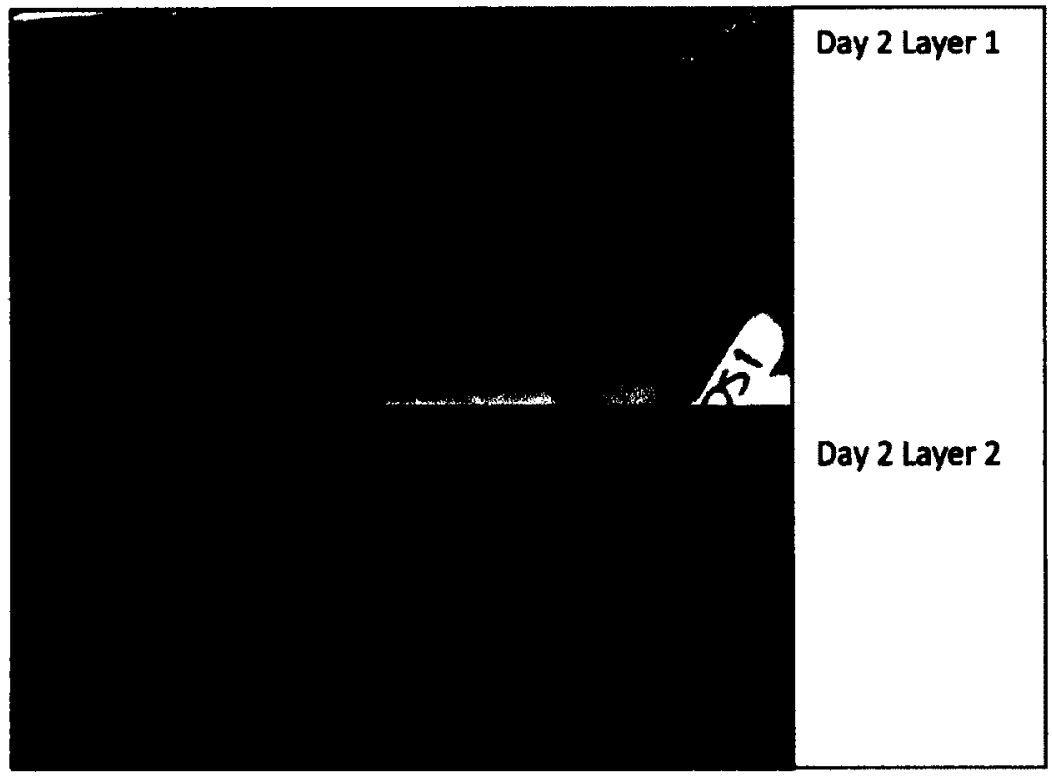

Figure 5-77: Difference in Crack formation in first few days of Layer 1 and Layer 2 deposition 


\subsubsection{Sectional Analyses}

Vane shear tests carried out just below the top surface, in the centre and at the bottom of the tailings gave the following strengths:

Below top crust: $66 \mathrm{kPa}$; residual $-20 \mathrm{kPa} \quad$ Depth: $6 \mathrm{~cm}$

Middle: $16 \mathrm{kPa}$; residual $-12 \mathrm{kPa} \quad$ Depth: $12 \mathrm{~cm}$

Bottom: $13 \mathrm{kPa}$; residual $-8 \mathrm{kPa} \quad$ Depth: $18 \mathrm{~cm}$

This increase in strength is due to suction development in the top part of the tailings due to water loss through evaporation resulting in increasing solids concentration. At the bottom of the tailings solids concentration increased and so did strength due to densification of the tailings and also water loss especially as cracks developed more and extended deeper into the tailing, allowing more evaporation.

Acknowledging the considerable development in strength throughout the tailings sample, two samples were extracted and analysed for solids concentration, total suction and electrical conductivity with depth. A Shelby tube was used to extract both samples.

\section{Sample 1}

The first sample extracted had a total length of $21 \mathrm{~cm}$. It was sectioned into $1 \mathrm{~cm}$ - thick sections as shown in Figure 5-78. 


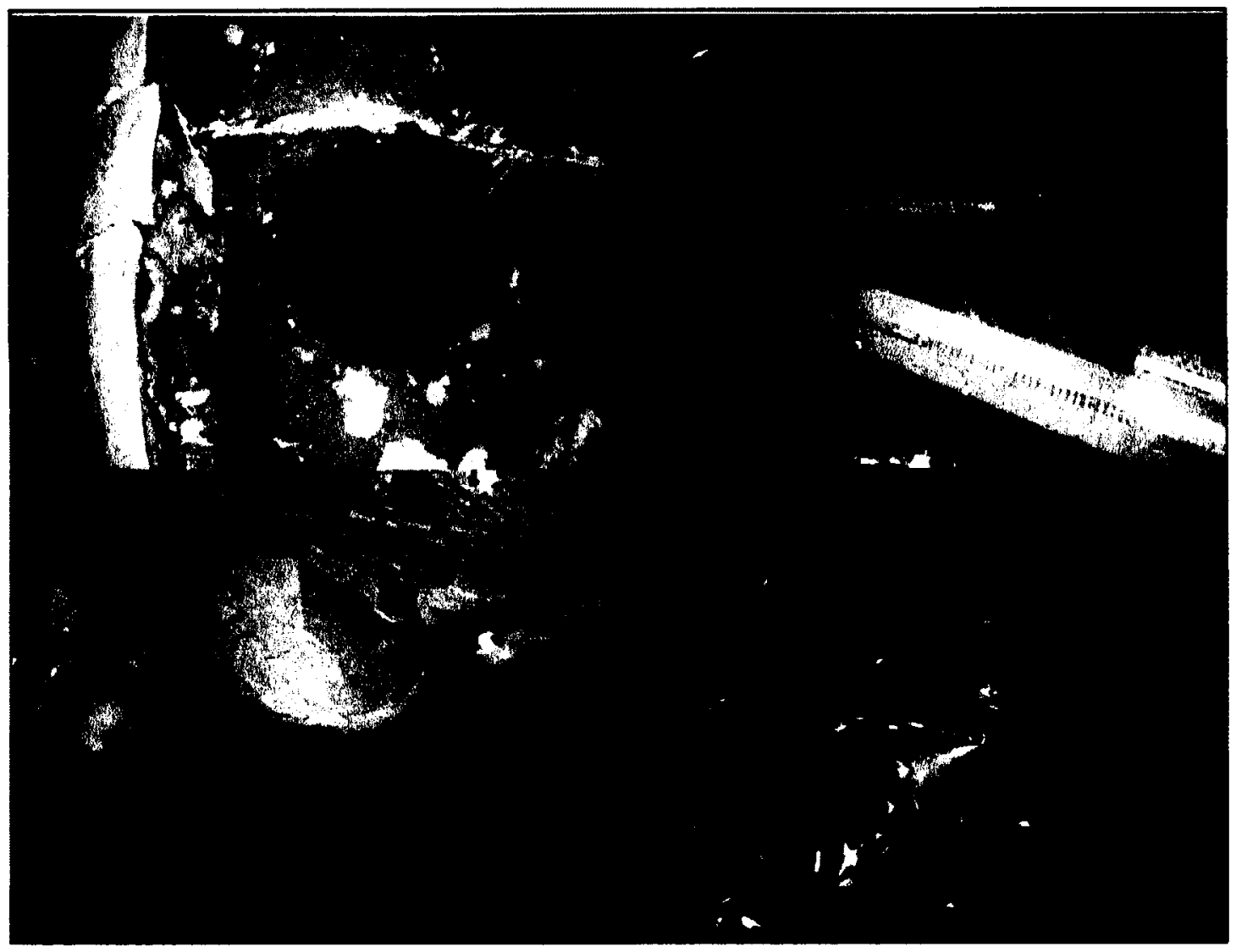

Figure 5-78: Extraction of Sample 1 along depth of Layer 1 and 2

There were $2 \mathrm{~cm}$ of material in the base which were later extracted manually for testing. The profile of solids concentration with depth, shown in Figure 5-79, reveals a more uniformly dry material with a solids concentration varying from $73 \%$ at the base of the sample to $88 \%$ at the top. The softer material before the base had a solids concentration of $69.6 \%$ whereas the base had a solids concentration of $74.8 \%$. Higher solids concentrations were observed compared to layer 1 which had about $4 \mathrm{~cm}$ of wetter material with a solids concentration of $57.8 \%$, only a $7 \%$ increase from the original material deposited. 


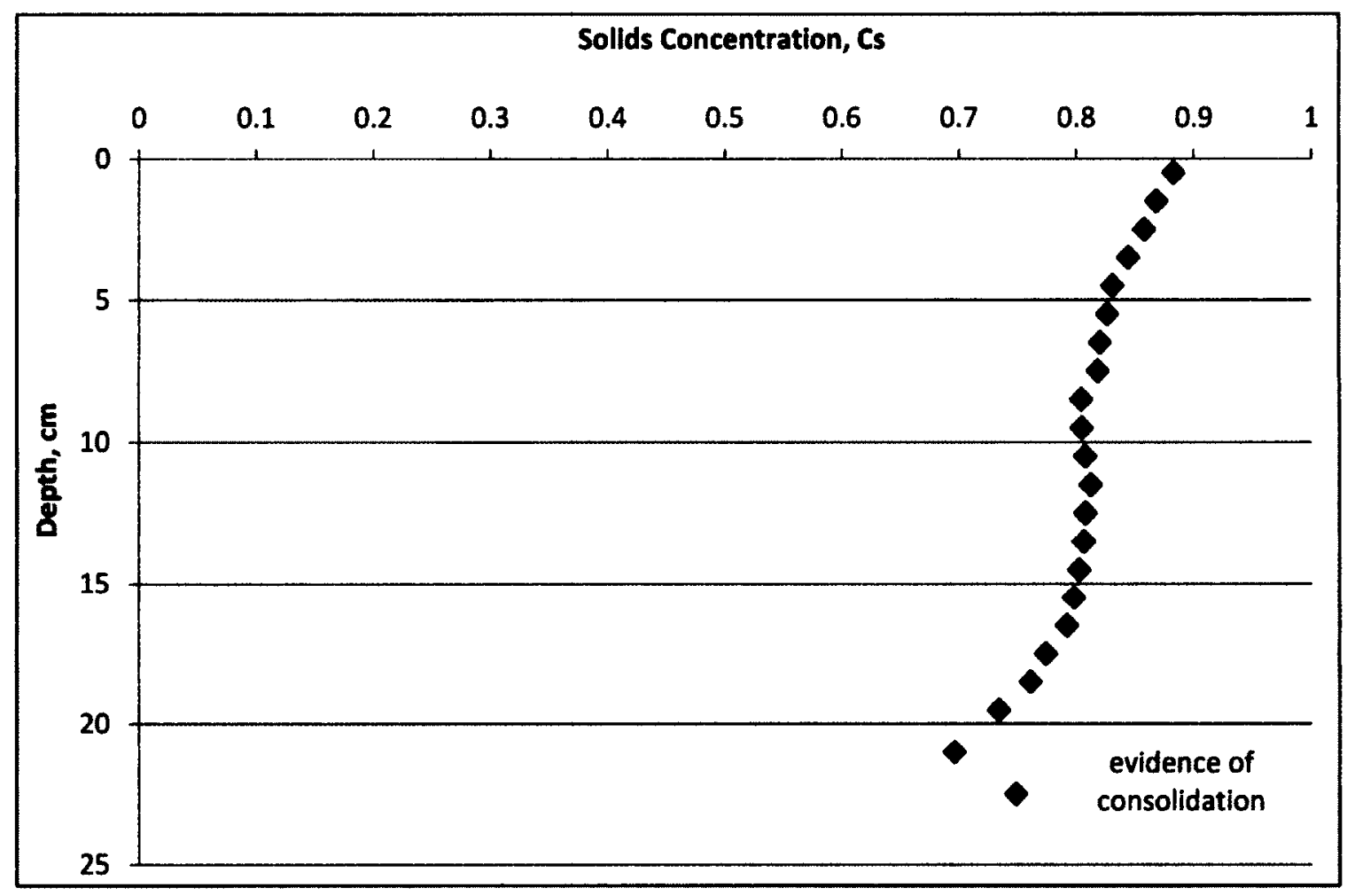

Figure 5-79: Solids Concentration profile (Sample 1 - Layer 2)

The Total suction profile obtained shows very low suction values throughout the sample and very high suction value at the surface. The high suction value at the surface is attributed to the high salt content, the osmotic component of the total suction. The variation in osmotic suction, estimated through EC test results, is also captured in Figure 5-80. At low total suctions, there appears to be higher osmotic suction values than total suction. As previously discussed this is due to the dissolution of salt precipitates during dilution for EC measurement. 


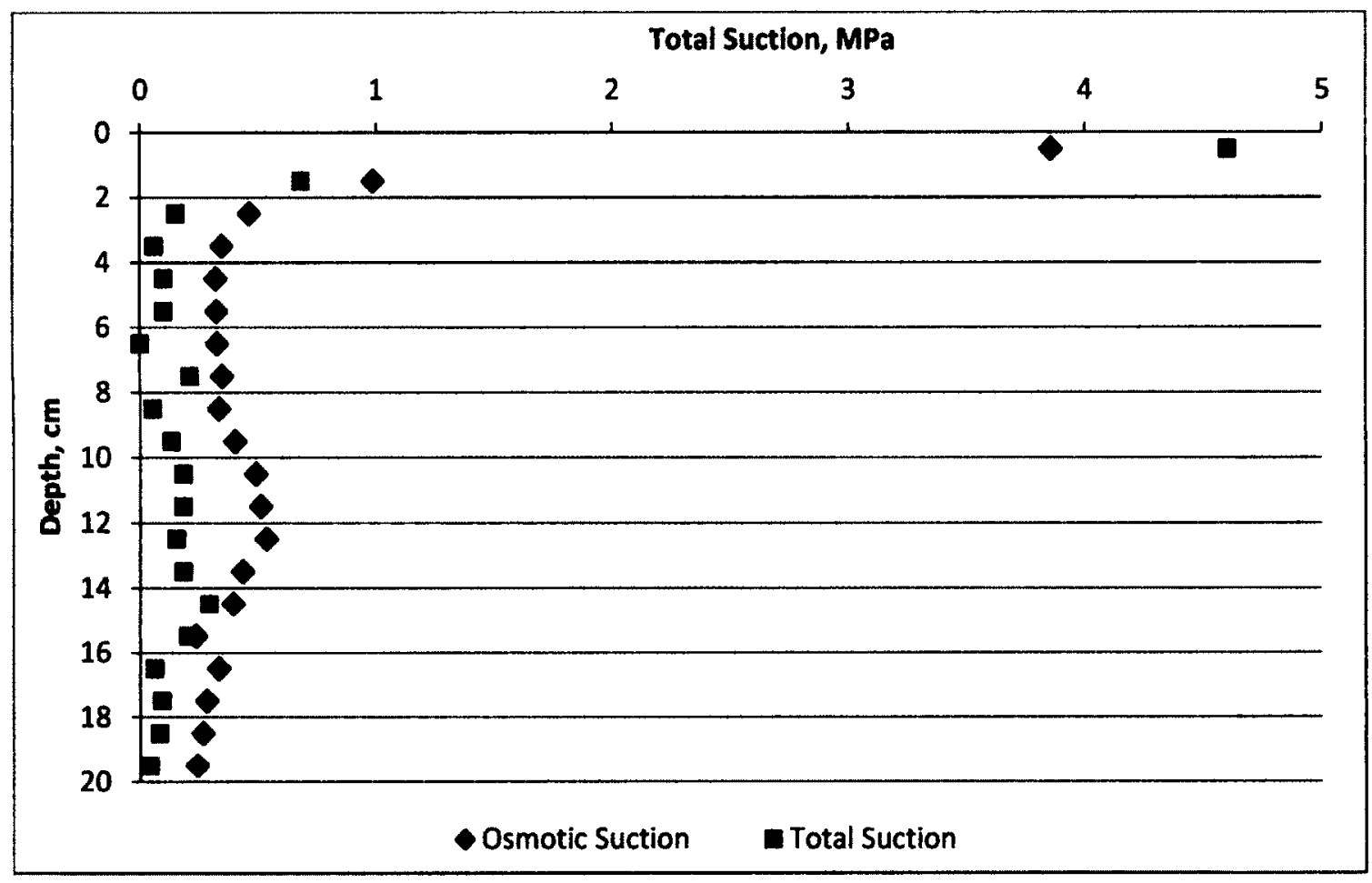

Figure 5-80: Total Osmotic Suction Profile (Sample 1 - Layer 2)

\section{Sample 2}

Sample 2, when extracted, had a total height of 15.4 within the Shelby tube. The base of the sample had approximately $5.4 \mathrm{~cm}$ of material which was scooped out in layers and placed into specially marked beakers. See Figure 5-81.

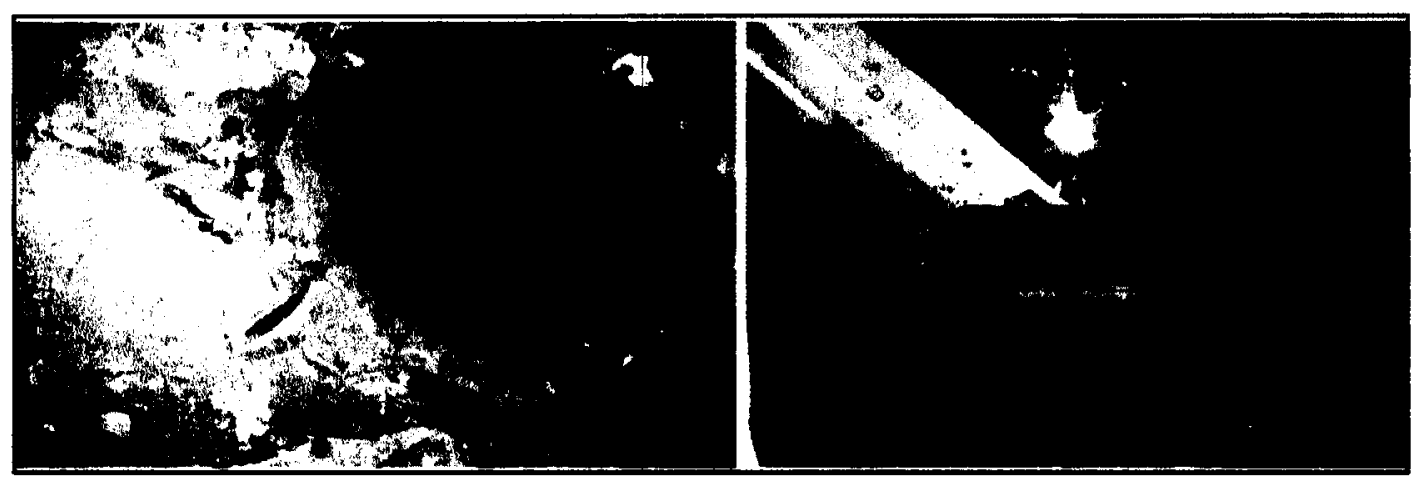

Figure 5-81: Base of tailings - Sample 1 - Layer 2 
Obtaining a second sample from a different location, affords the opportunity to see whether tailings dried similarly within the entire sample. As was illustrated by the $5.4 \mathrm{~cm}$ of softer material at the base, it could be concluded that not all areas dried similarly. However, significant change in solids concentrations were measured at that depth and presented in Figure 5-82. Even the wetter material had a solids concentration of 0.65 and for the top $12.5 \mathrm{~cm}$, the tailings present higher solids concentrations than the previous sample ( $83.8-90.1 \%$ in sample 2 to $80.7-88 \%$ in sample 1$)$.

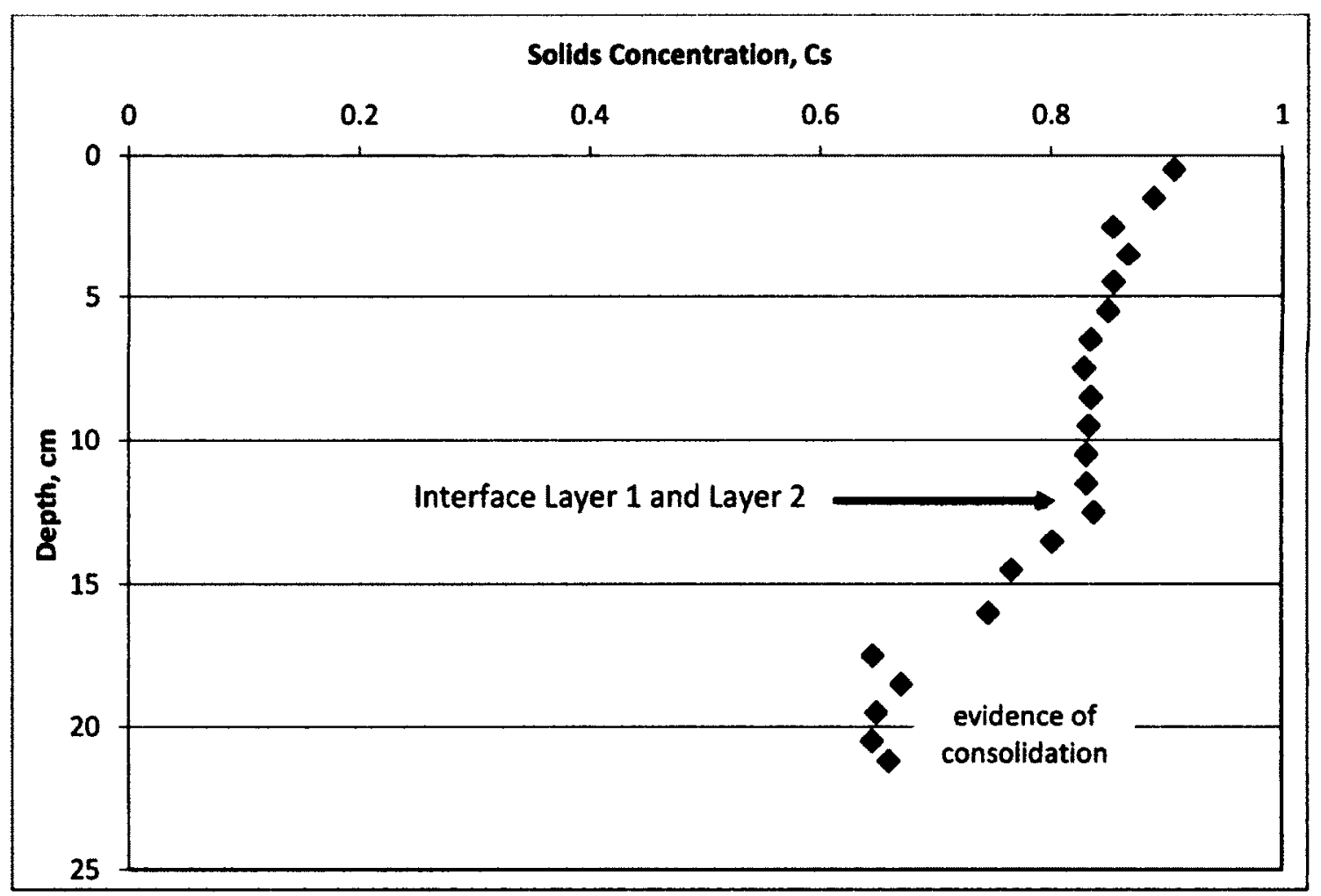

Figure 5-82: Solids Concentration profile (Sample 2 - Layer 2)

Total Suction measurements reveal similar patterns to sample 1 and are presented in Figure 5-83. 


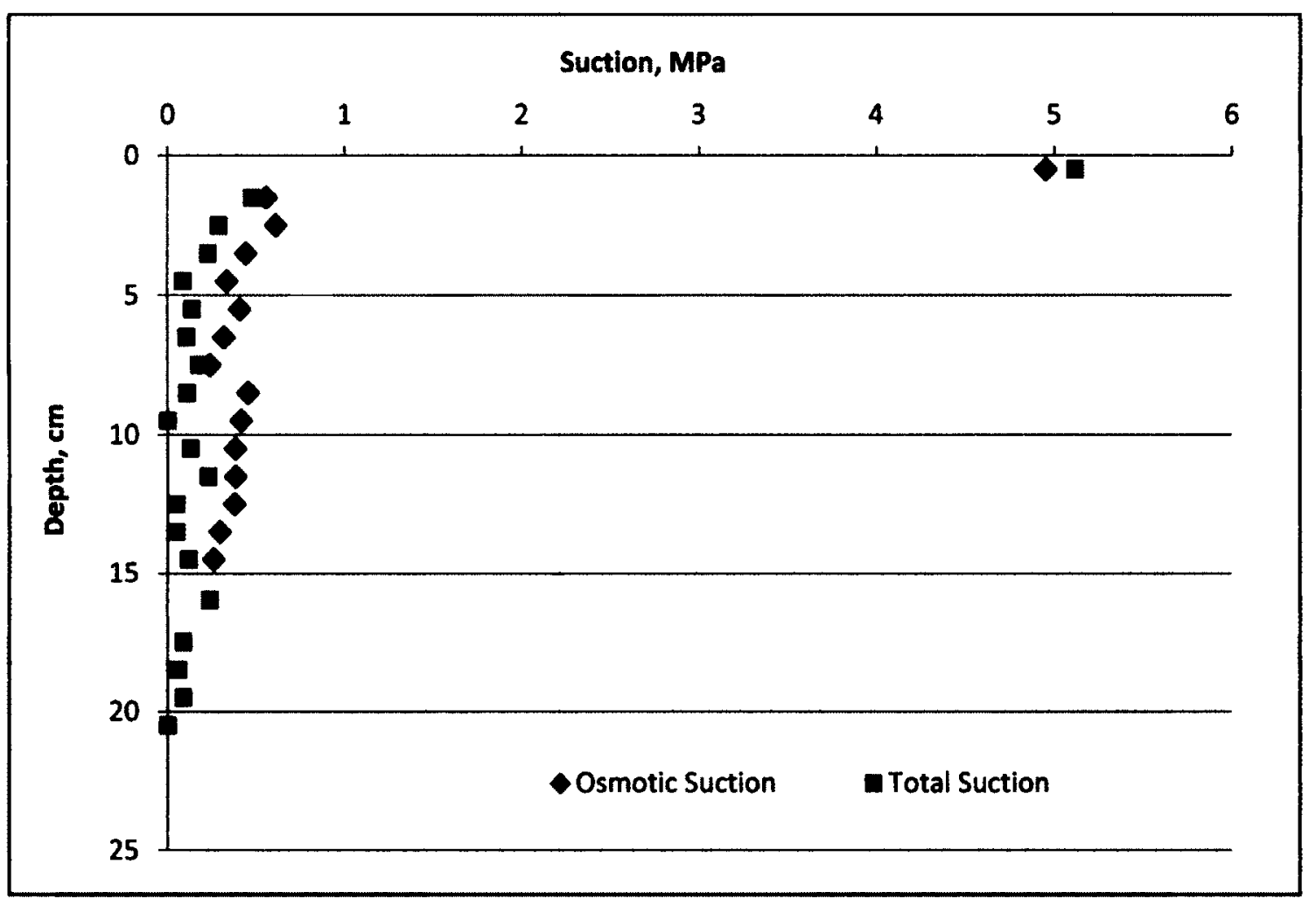

Figure 5-83: Total and Osmotic Suction Profile (Sample 2 - Layer 2)

The data presented above shows how the rapid infiltration of water through cracks and underlying dry material, can aid in the more uniform drying of the tailings. The available water in the freshly deposited layer was reduced as it was distributed along the profile of both layers. Solids concentrations increase and so does the strength of the material. 


\subsubsection{Layer 3 Deposition}

After sample extraction, additional panels were added to the drying box to increase the volume of the box and tensiometers from the second layer were removed and preconditioned. Height sensors were recalibrated and after installation of all instrumentation, Layer 3 was deposited to a total height of $44 \mathrm{~cm}(0.44 \mathrm{~m})$; shown in Figure 5-84.

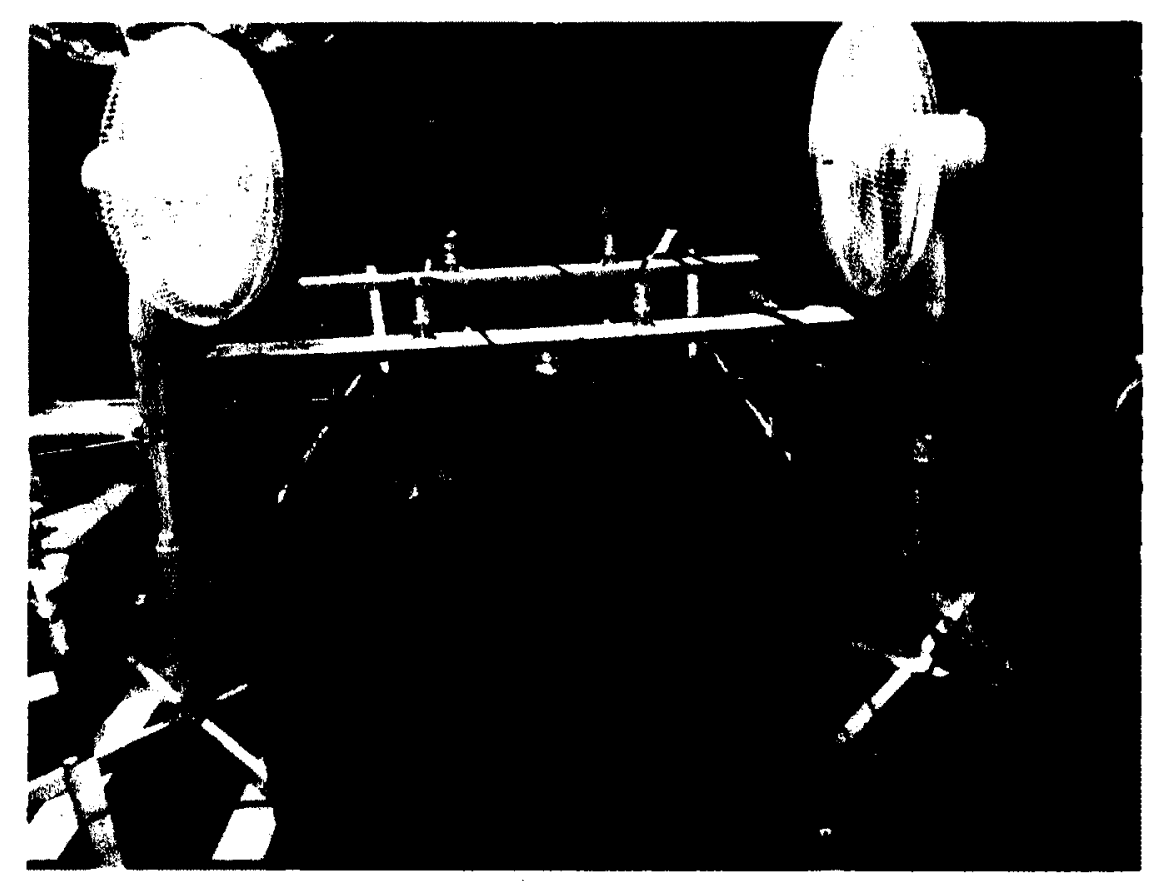

Figure 5-84: Layer 3 Deposition

\subsubsection{Mass Loss and Evaporation}

Water loss from evaporation in $\mathrm{kg} / \mathrm{d}$ oscillated very much after layer 3 deposition. As can be appreciated in Figure $5-85,4.5 \mathrm{~kg} / \mathrm{d}$ was lost for most part of the first 10 days. Eventually the daily rates hit a low of $1.7 \mathrm{~kg} / \mathrm{d}$. 


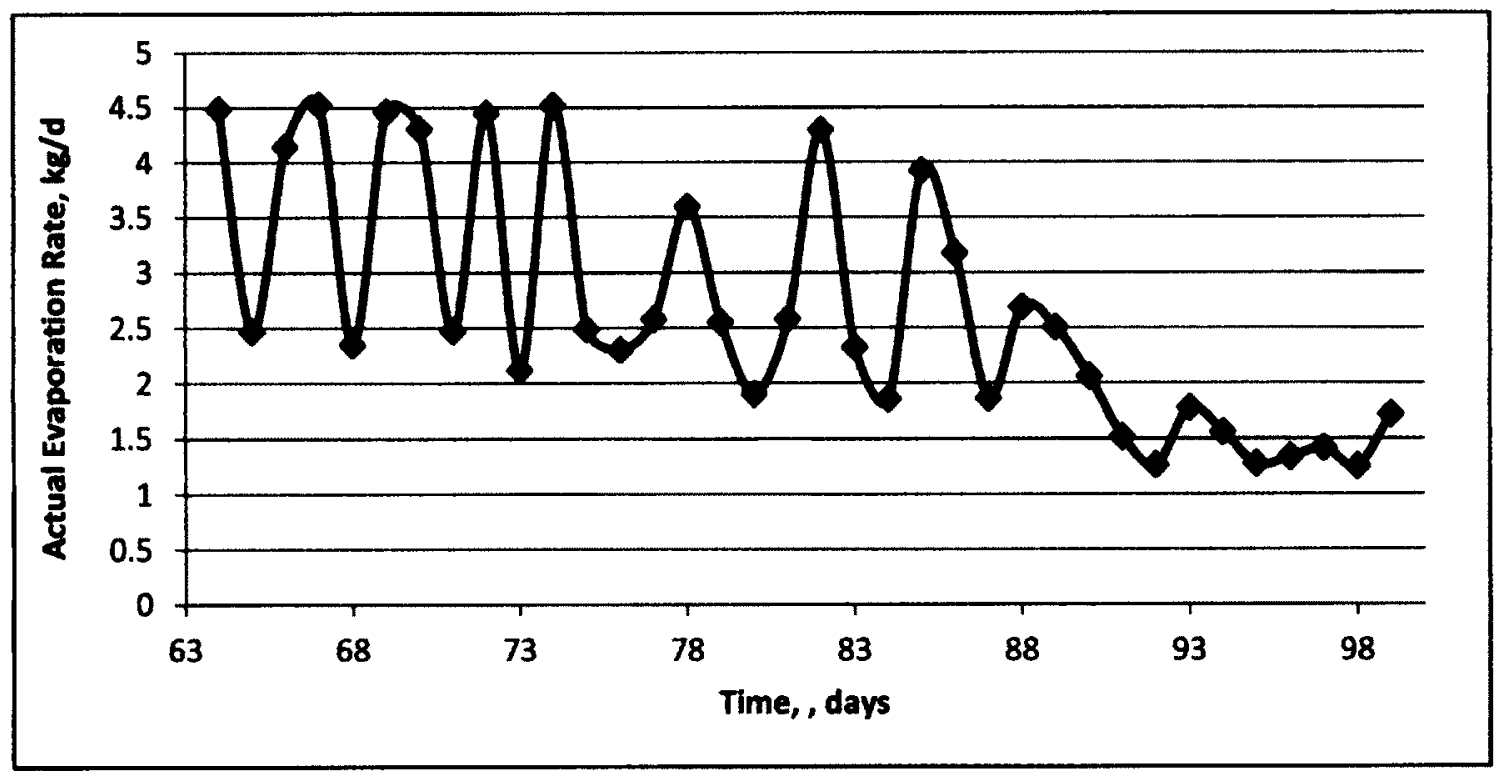

Figure 5-85: Actual Evaporation in $\mathrm{kg} / \mathrm{d}$ - Layer 3

With crack consideration, the actual evaporation rate in $\mathrm{mm} / \mathrm{d}$ decreases steadily with a few peaks observed; as shown in Figure 5-86.

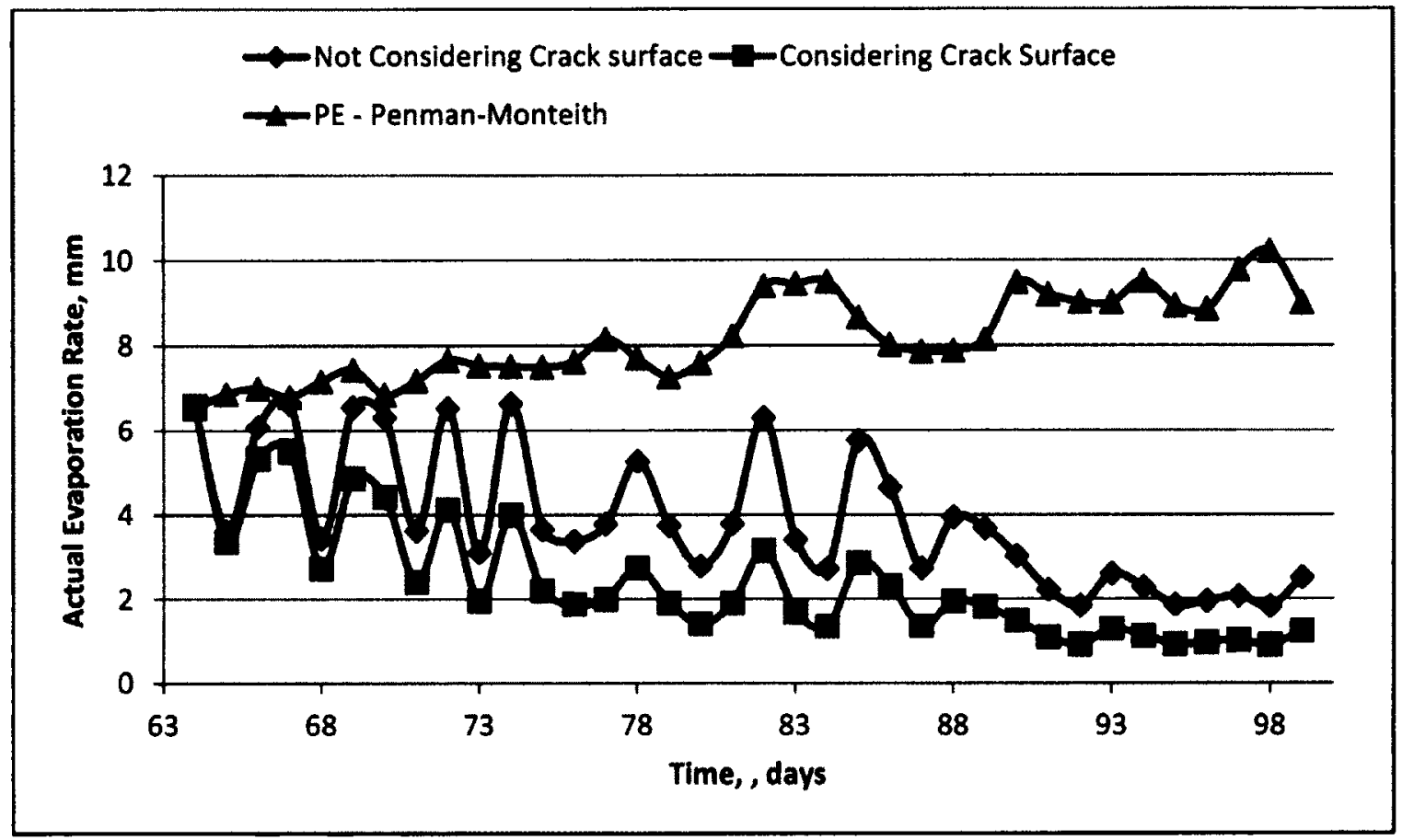

Figure 5-86: Actual Evaporation in $\mathrm{mm} / \mathrm{d}$ - Layer 3 
Although temperatures increased slightly as the winter season drew to an end causing an increase in potential evaporation, AE did not increase as evaporation was already shut down. Crack formation in the third layer was also very quick and cracks were wider and had more depth on day 1 compared to the other two layers; Figure 5-87.

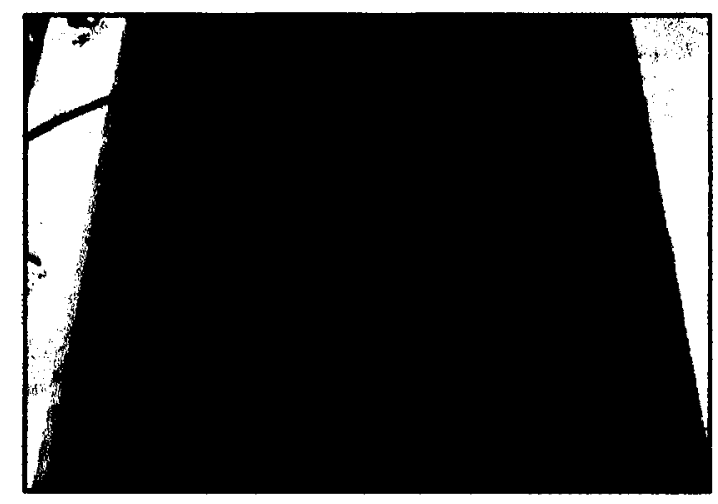

Figure 5-87: Crack formation - Day 1 (63) - Layer 3

The graphs of RE in Figure 5-88, with and without crack consideration, demonstrate the significant effect of crack development in the evaporation rate; a reduction in the points by 0.4 . Once the cracks are considered, a similar curve to Layer 2 is obtained.

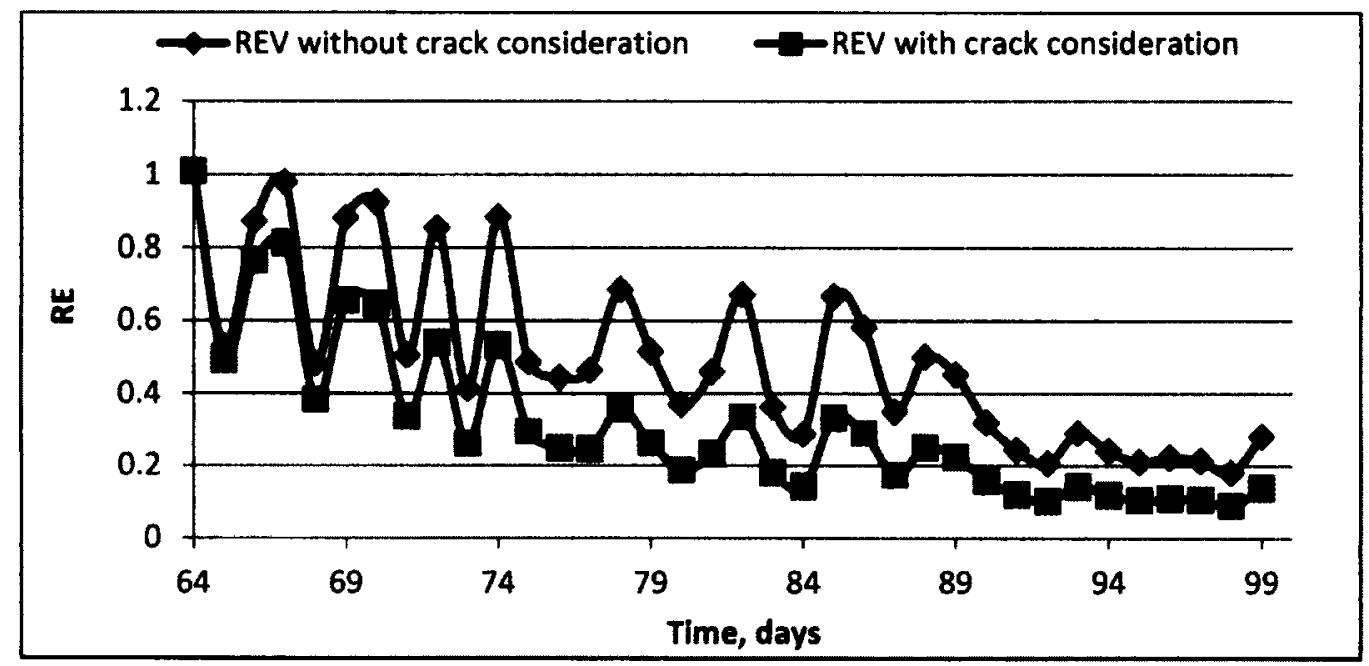

Figure 5-88: Measured RE - Layer 3 
Peaks, as explained before, are associated with the surfacing and exposure of material of lower suctions (Figure 5-89), two details not considered in the RE calculation. RE calculations cancel out the climatic conditions and surface area but do not cover the variation in suction in the cross-sectional area of the tailings.

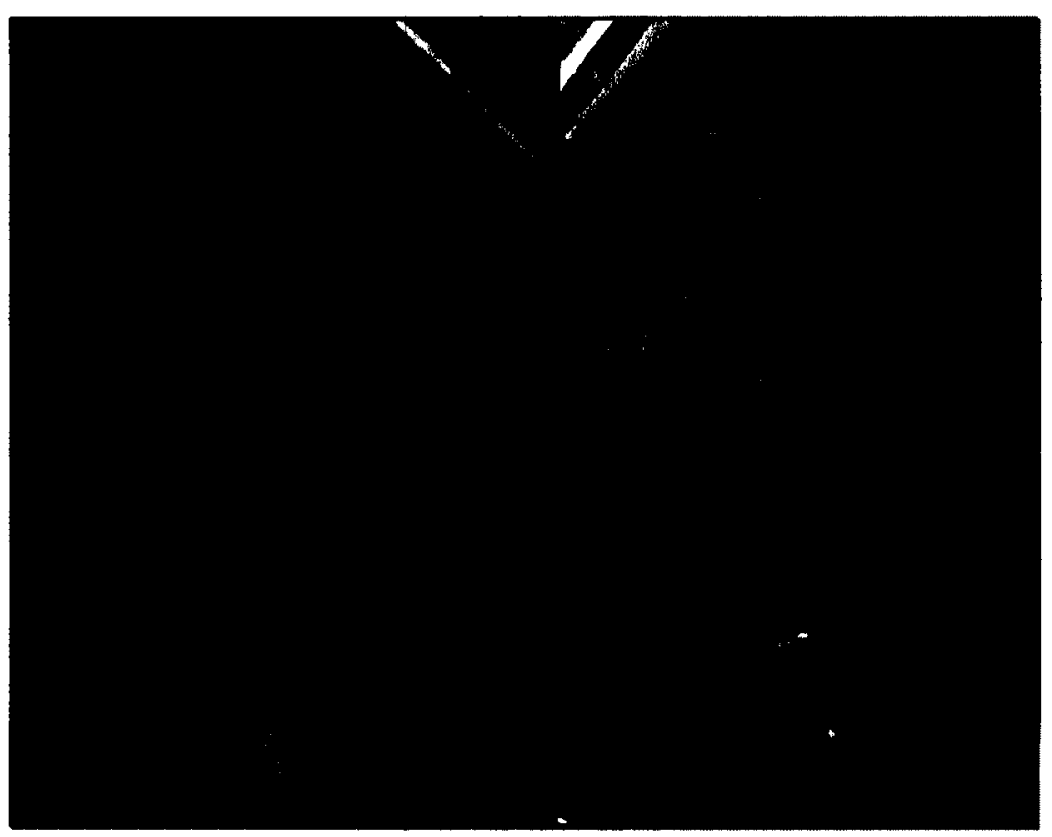

Figure 5-89: Snapshots of the Exposure of underlying material

\subsubsection{Temperature and Humidity}

Temperatures measured within the soil profile presented in Appendix N, show an increase from 15 to $19{ }^{\circ} \mathrm{C}$ within the first 15 days. Subsequently, temperatures decreased. Relative humidity ranged from 14.5 to $46.5 \%$ with very high values at the start of the rest to lower values by day 83 . See Appendix $\mathrm{N}$. 


\subsubsection{Gravimetric Water Content, $w$}

Overall gravimetric water content of the tailings decreased from 45 to $18 \%$ towards the end of the test (Figure 5-90). Layer 3 average GWC decreased from 96 to $20 \%$.

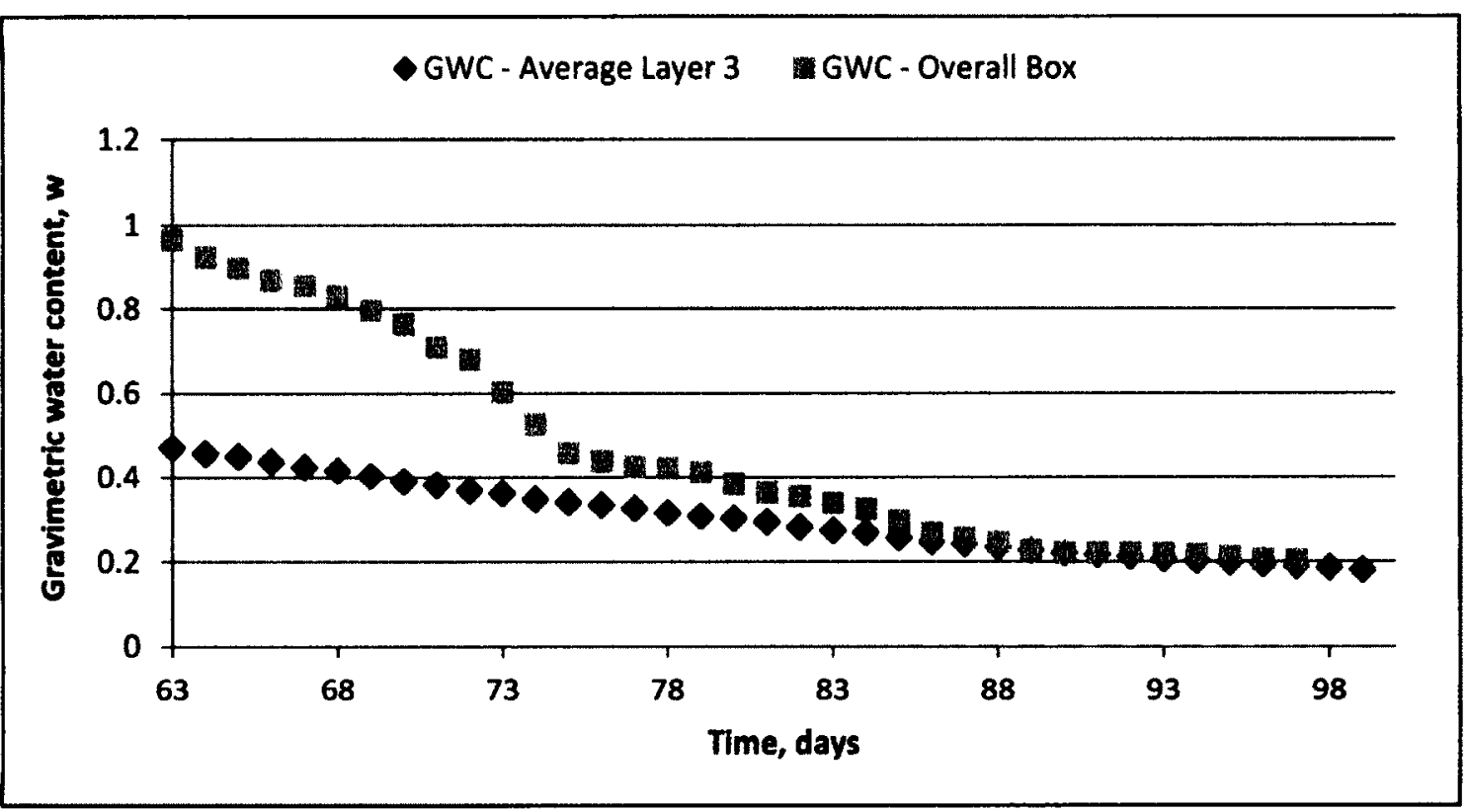

Figure 5-90: Average GWC of Layer 3 and Box overall GWC

From day 63 to day 75 , a very steady decrease is noted to $46 \%$. In previous layers, the GWC attained by this time period were $66 \%$ and $62 \%$ for layers 1 and 2 respectively. This may be attributed to the oscillatory behaviour in the $\mathrm{AE}$ rates during the first few days described in section 5.5.3.1.

At the surface, GWC decreases sharply within one day to $32 \%$ as shown in Figure 5-91. This was a similar trend observed in all three layers. The sharp decrease in GWC signifies a sharp decrease in hydraulic conductivity of the top layer of the soil, making it difficult for water to leave the soil through this channel. Additionally, salt deposited 
within the pores reduces the conductivity and the resulting surface reduces evaporation significantly until water finds alternative paths to exit the soil. Cracks offer the solution with very low suction values and low gravimetric water contents.

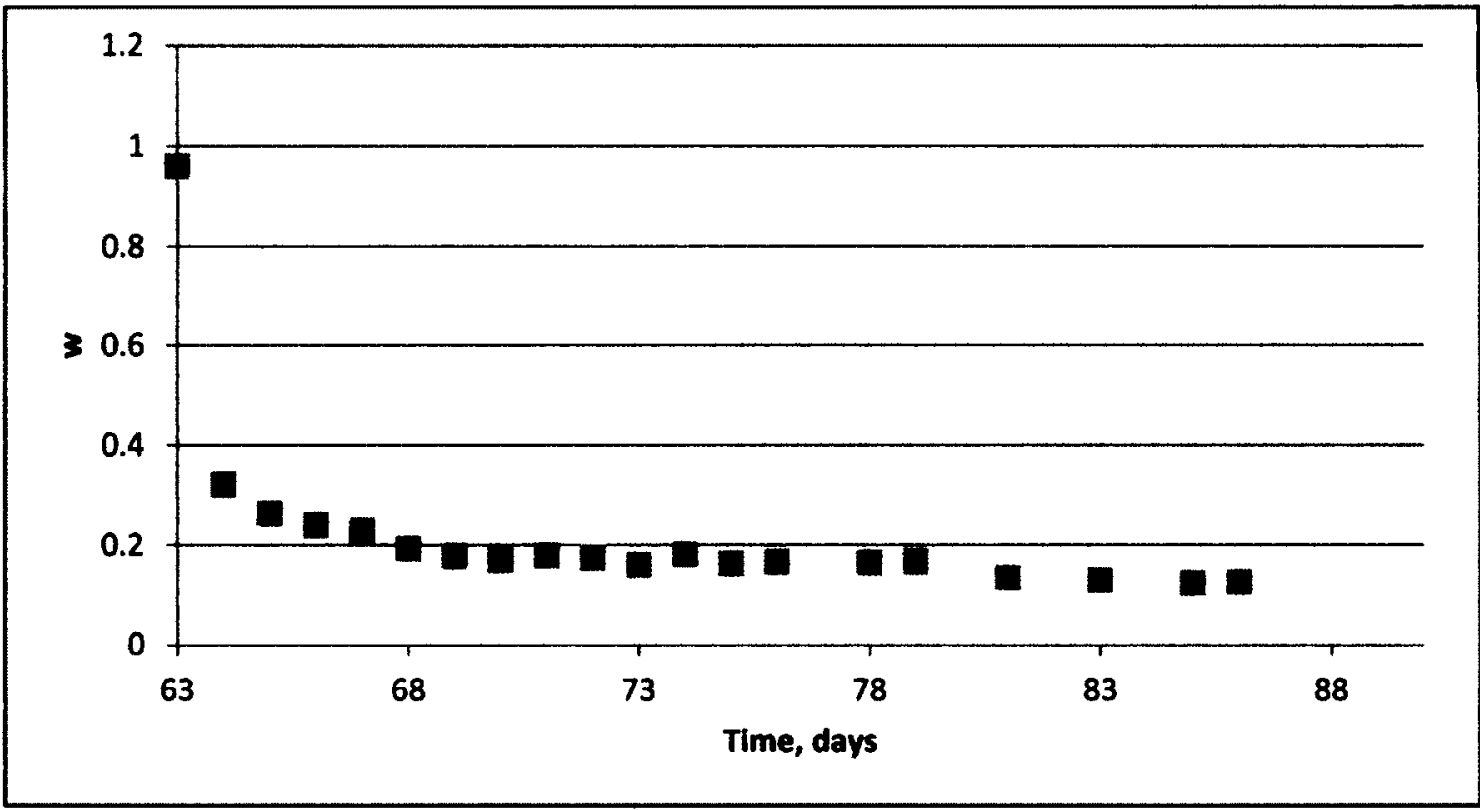

Figure 5-91: Variation in Gravimetric Water Content at the surface - Layer 3

\subsubsection{Volumetric Water Content, $\theta_{\mathrm{w} \text { - }}$}

The infiltration of water to the bottom layers can be seen from the slight increase in volumetric water content detected by sensors 1 to 3 shown in Figure 5-92. In the case of sensors 4 to 6 , sensors may have come into contact with very wet material as the volumetric water contents are similar to that detected by sensors 7 to 9 . This may have been possible from the collapse of surrounding dry material upon the addition of layer 3 through cracks. If not the case, layer 2 increased significantly in water content. The top three (3) sensors, 7, 8 and 9 , due to cracking were almost fully exposed by day 71,82 and 84 respectively. However, similar to the other two layers we can see rapid decreases in 
water content for the sensor at the surface which in this case was about 4 centimetres below the surface and then a decline in the other two as the test proceeded. Layer 3 showed very rapid dewatering within the first 15 days. Observed also, were the cycles of increase and decrease in moisture content of the bottom layer.

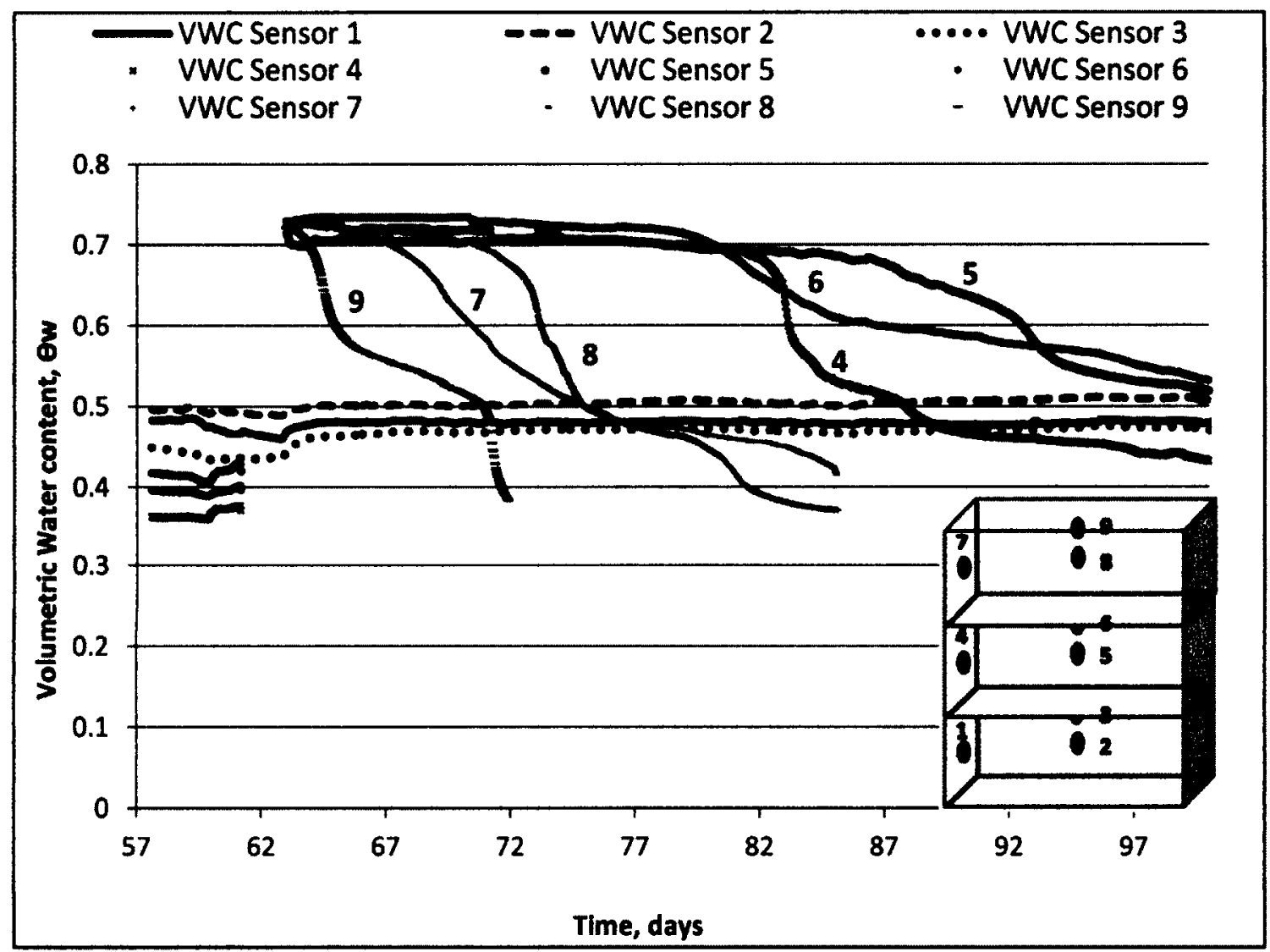

Figure 5-92: Volumetric water content data (After Layer 3 deposition)

For the middle layer, significant dewatering is not noted until day 80 , when all three sensors showed a decline in volumetric water content. Some of this is due to infiltration to the bottom layer which shows an increase in volumetric water content for all three sensors and the rest to evaporation. 


\subsubsection{Volume change and Settlement}

In layer 3, water removal and settlement were equivalent for the first 14 days after which the difference between the two progressively increased. Settlement $(\sim 12 \mathrm{~cm})$ and water removal $(\sim 14.1 \mathrm{~cm})$ were higher than both previous layers. This was due to the removal of water from the new layer through infiltration into drier underlying layer, significant cracking and also higher evaporation rates. Figure 5-93 contains the results for settlement and cumulative water removal through evaporation with time.

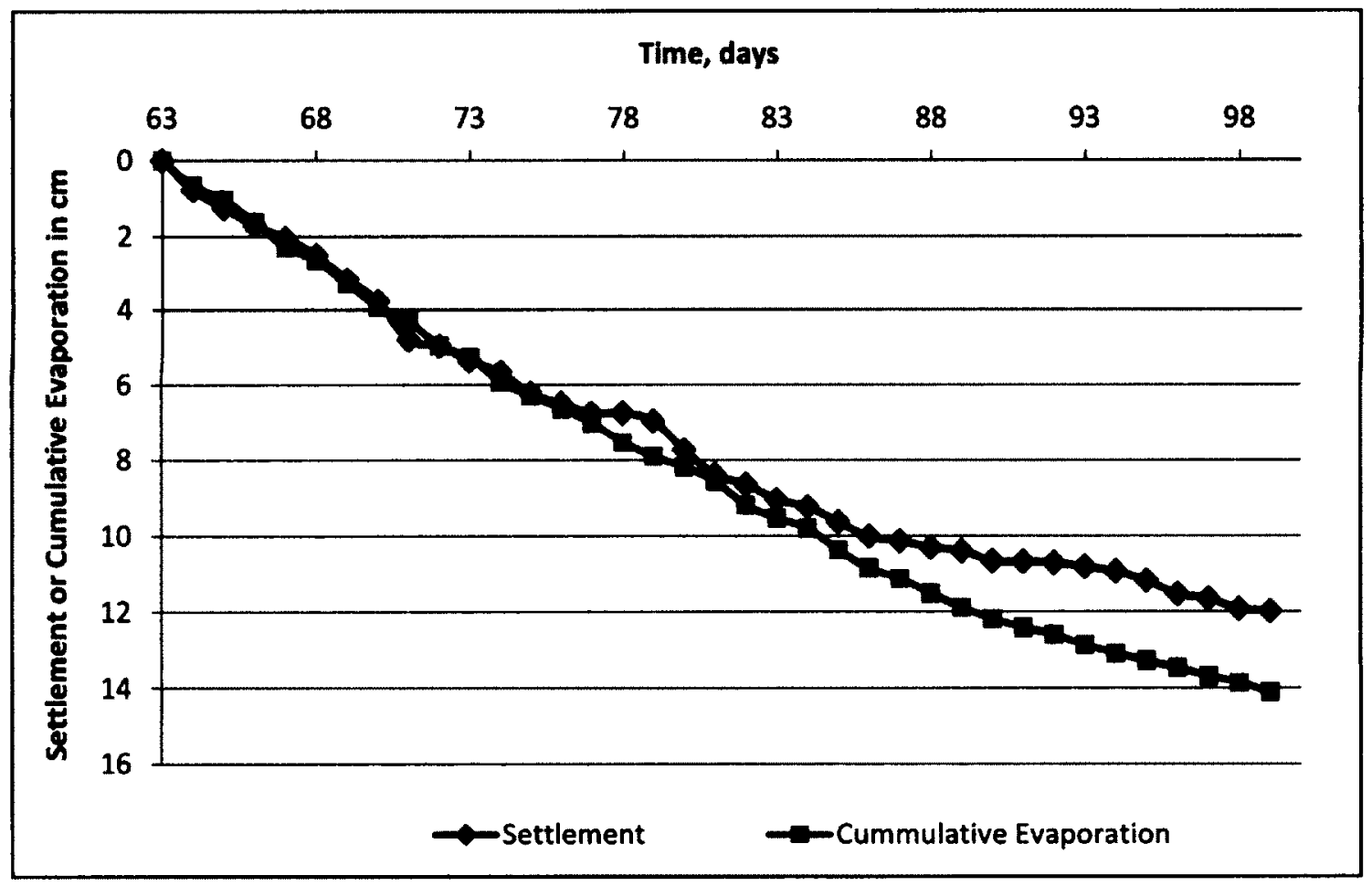

Figure 5-93: Settlement and Cumulative Evaporation with time - Layer 3

Figure 5-94 shows the change in overall void ratio from 2.59 to 0.7 and 0.57 with and without crack consideration respectively. The difference between the two graphs is smaller than that seen in the other layers. Although cracks exposed more surface area (wider sides), they were shallower than the other cracks and when deep, widths were 
smaller; therefore, less volume was recorded. Another contributing factor was the expulsion of material which significantly reduces the volume of cracks.

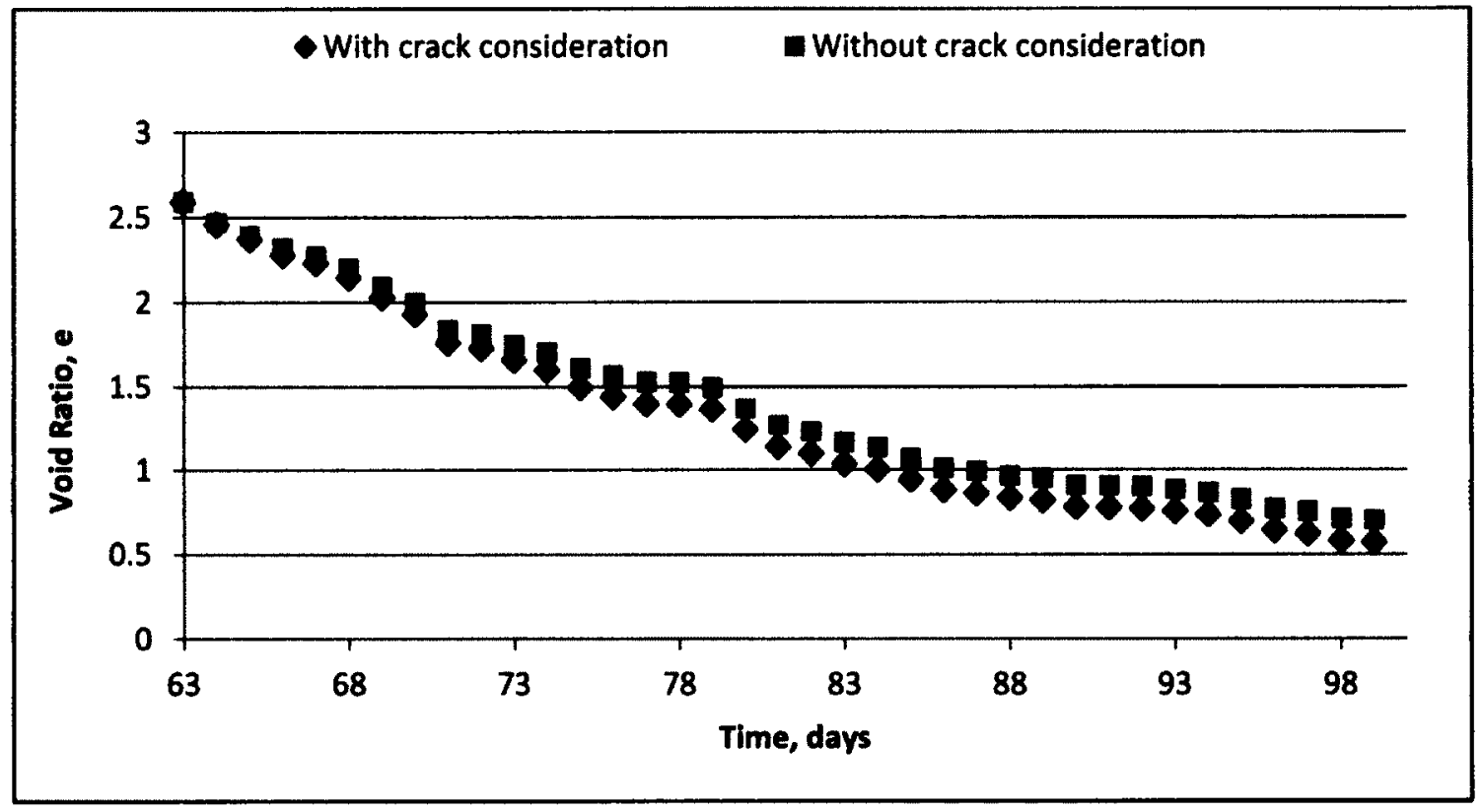

Figure 5-94: Evolution of Void ratio - Layer 3

The shrinkage curve is presented in Figure 5-95.

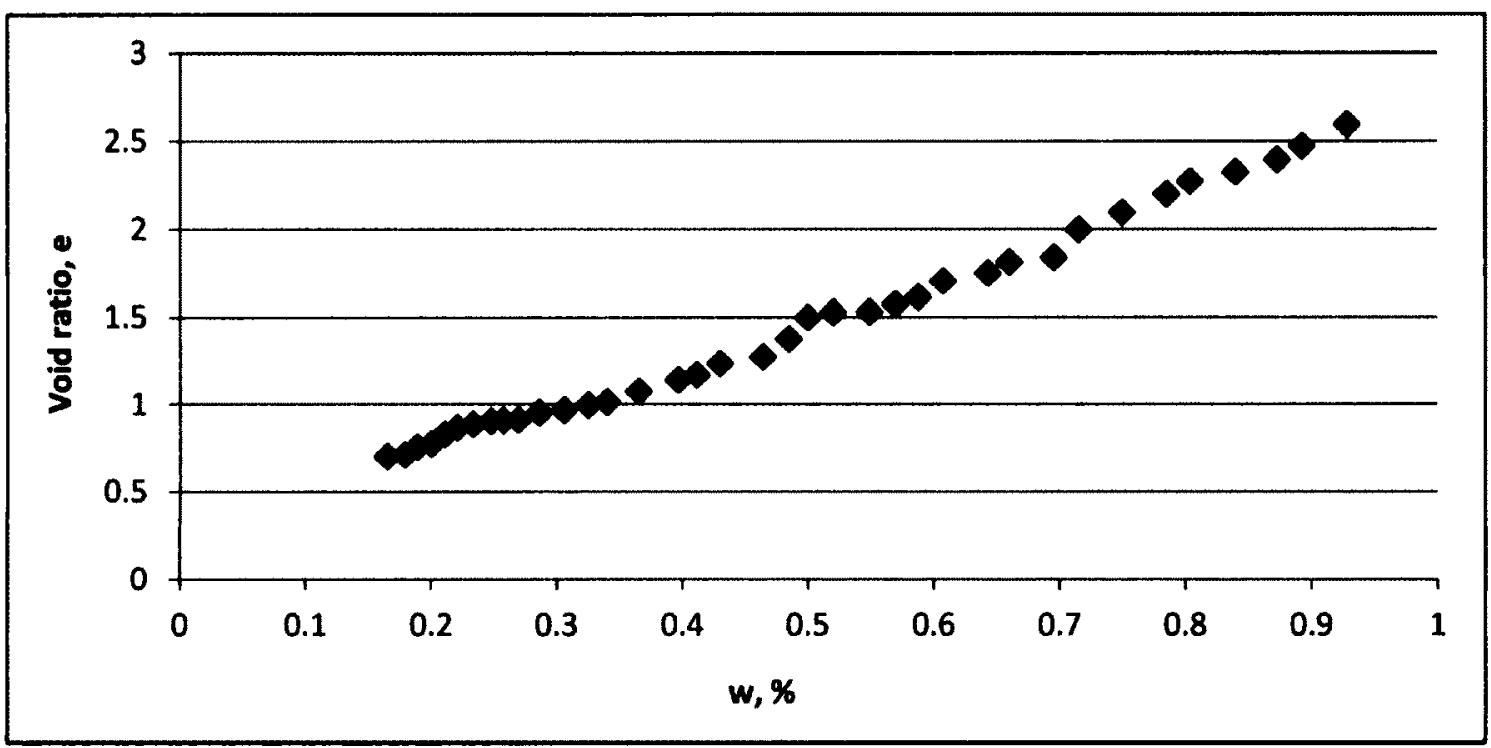

Figure 5-95: Shrinkage Curve - Layer 3 


\subsubsection{Suction}

\section{Matric Suction}

Tensiometers 4 to 6 were replaced before deposition of Layer 3 and three (3) additional tensiometers were installed to monitor matric suction in the newly deposited layer. Two (2) were placed at the centre of layer 3 and the other within the top $3 \mathrm{~cm}$ of the tailings surface. The location of each of the nine (9) sensors is shown in Figure 5-96.

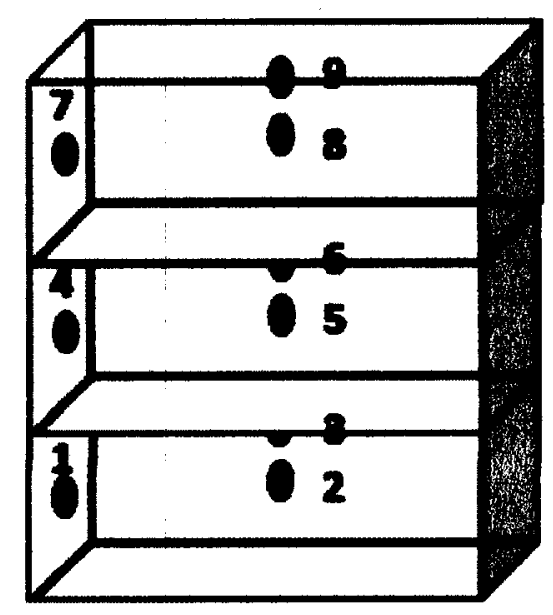

Figure 5-96: Sample Ports in Layers 1, 2 and 3

Figure 5-97 shows matric suction results for layer 3. Tensiometers 3 and 4 are not presented in the results due to cavitation very early into the drying after layer 23 deposition. No significant matric suction was measured by Tensiometers 1 and 2 from the bottom layer. Tensiometer 9 was within the top $3 \mathrm{~cm}$ of the tailings and the rapid dewatering within this top layer was captured by a rapid increase in matric suction to in the first five days of the test until cavitation occurred. Similarly, Tensiometer 7 cavitated within 8 days as it became located within a new crack and matric suction increased as drying occurred within the crack. 


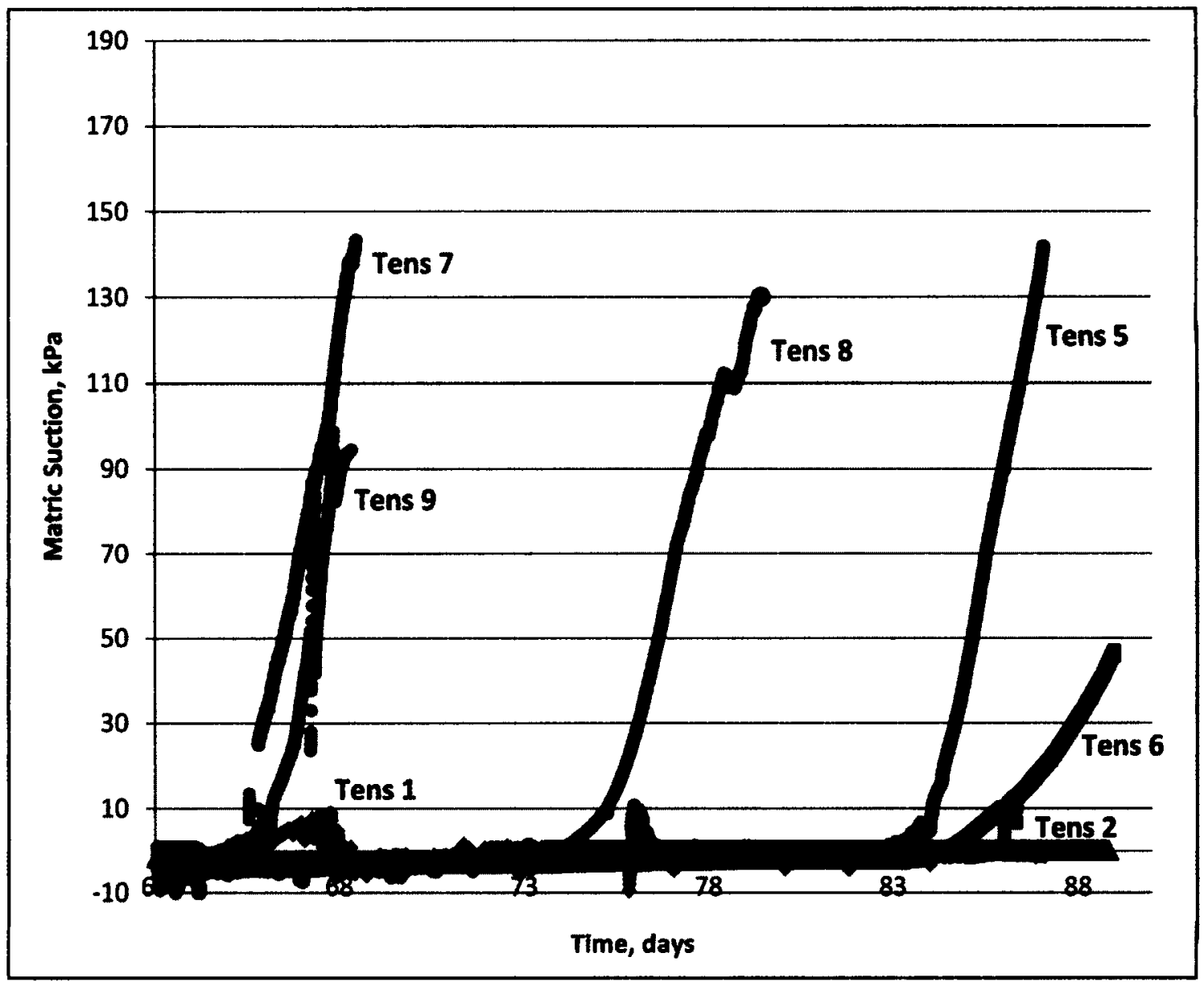

Figure 5-97: Evolution of Matric Suction - New (Layer 3) and Old (Layer 1 and 2) Layers

Tensiometer 8 shows an increase in matric suction from day 73, concurrent with the decrease in volumetric water content. The same trend is observed in the second layer for tensiometers 5 and 6 but in this case from day 79.

\section{Total Suction}

Total suction samples were collected from the surface of the tailings for the first 23 days after which the samples were too dry to be measured in WP4 Potentiameter, Total and 
osmotic suction measured at the surface is presented in Figure 5-98. From these results, rapid suction development in Layer 3 is observed followed by layers 2 and 1 .

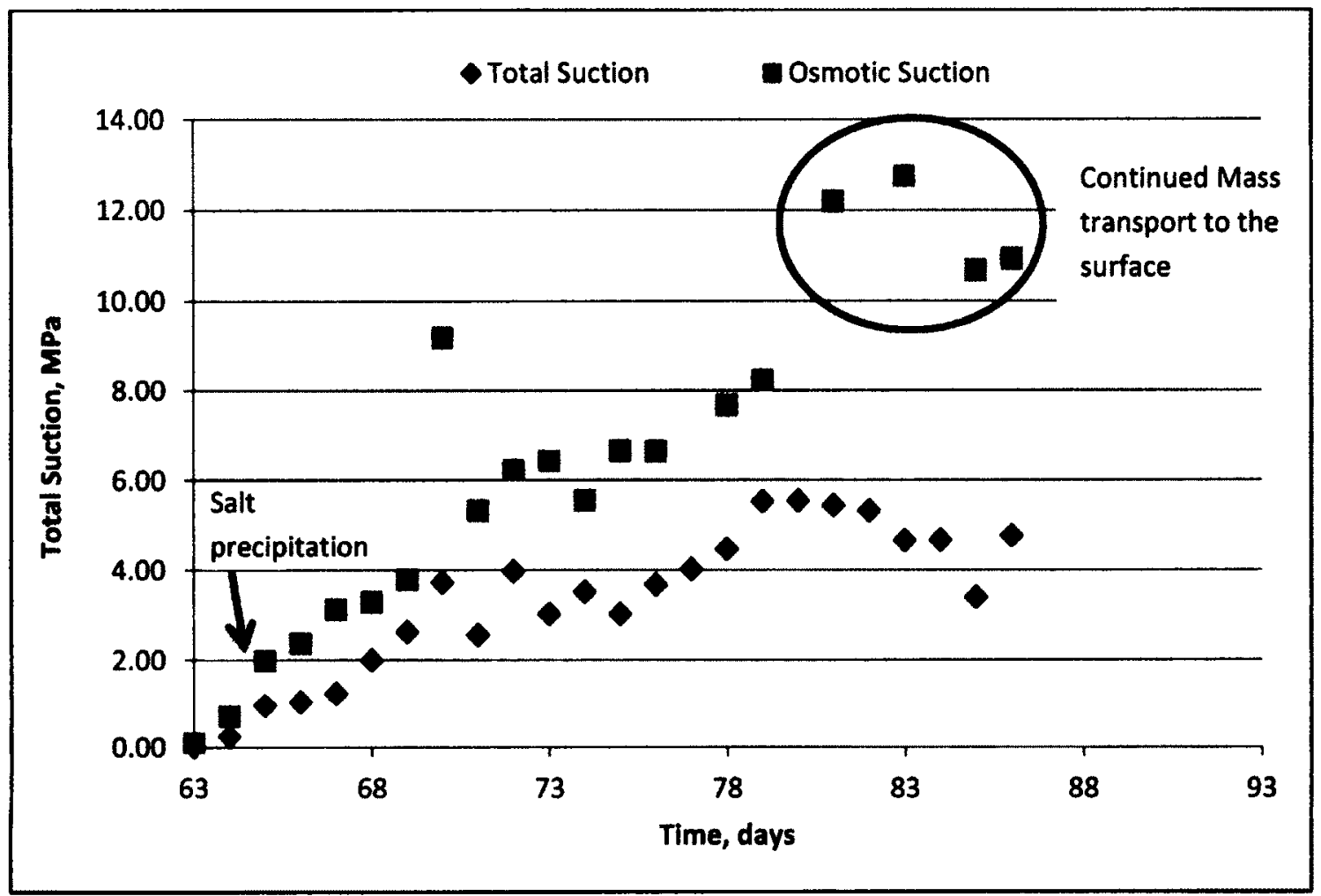

Figure 5-98: Total and Osmotic Suction - Layer 3

Osmotic Suctions are higher than total suction measurements as EC method was used and there was significant salt precipitation at the surface causing an increase in the EC determined upon saturation/dilution of the sample and thus resulting in very high osmotic suctions. The general trend, however, captures the increase in osmotic suction due to the migration of salts to the surface, showing continued mass transport to the surface. Therefore, AE is not 0 at the surface.

Total suctions measured within the cracks are presented in Table 5-6. 
Table 5-6: Measured Total Suction - Crack Surface - Layer 3

\begin{tabular}{|c|c|c|c|c|c|}
\hline \multirow{3}{*}{\begin{tabular}{|l} 
\\
$\begin{array}{l}\text { Time } \\
\text { (Days) }\end{array}$ \\
\end{tabular}} & \multicolumn{3}{|c|}{ Total Suction, Mpa } & & \\
\hline & & & & \multicolumn{2}{|c|}{ shutdown crack } \\
\hline & & & & & \\
\hline 63 & N/A & & & & \\
\hline 64 & 0 & & & & \\
\hline 65 & & 0.39 & & 0.21 & \\
\hline 66 & 0.01 & 1.48 & & & \\
\hline 67 & 0.21 & 0.6 & 3.99 & & \\
\hline 69 & 0.14 & 1.29 & & & \\
\hline 70 & & 1.1 & & & \\
\hline 71 & 0.35 & 0.97 & & 2.02 & 3.31 \\
\hline 72 & 0.29 & 0.55 & & & \\
\hline 73 & 0.18 & 1.8 & 8.57 & 2.18 & \\
\hline 74 & 0.11 & & & & \\
\hline 76 & 0.07 & & 8.66 & & \\
\hline 81 & 0.55 & 1.72 & & & \\
\hline 86 & 0.2 & 0.72 & & & \\
\hline
\end{tabular}

\subsubsection{Sectional Analyses}

As cracks widened in Layer 3, the tailings appeared to be drying very quickly within the cracks from visual inspection. As a result on day 78,13 days from the start of the test, vane tests were carried out at the surface and a few centimetres below the surface. Results showed that the top $3-5 \mathrm{~cm}$ had a peak undrained shear strength of $39 \mathrm{kPa}$ while the residual strength was $10 \mathrm{kPa}$. However, a few centimetres lower, undrained shear strength was at $2 \mathrm{kPa}$, signifying the presence of wetter material. 10 days later, on day 88 , undrained shear strengths were measured at four (4) different heights along the tailings profile. The results are presented in Table 5-7. 
Table 5-7: Undrained shear strength measurements

\begin{tabular}{|l|l|l|}
\hline Depth $(\mathrm{cm})$ & $\begin{array}{l}\text { Peak Undrained strength } \\
(\mathrm{kPa})\end{array}$ & $\begin{array}{l}\text { Residual Undrained strength } \\
(\mathrm{kPa})\end{array}$ \\
\hline 8 & 98 & 22 \\
\hline 12 & 12 & 2 \\
\hline 28 & 48 & 20 \\
\hline 32 & 22 & 12 \\
\hline
\end{tabular}

Cracks had a depth of 13-14 $\mathrm{cm}$ and the top part of the tailings appeared to be very dry. One sample was collected as was done before near a crack and the other away from a crack. A Shelby tube was utilized to extract the samples profile as shown in Figure 5-99.

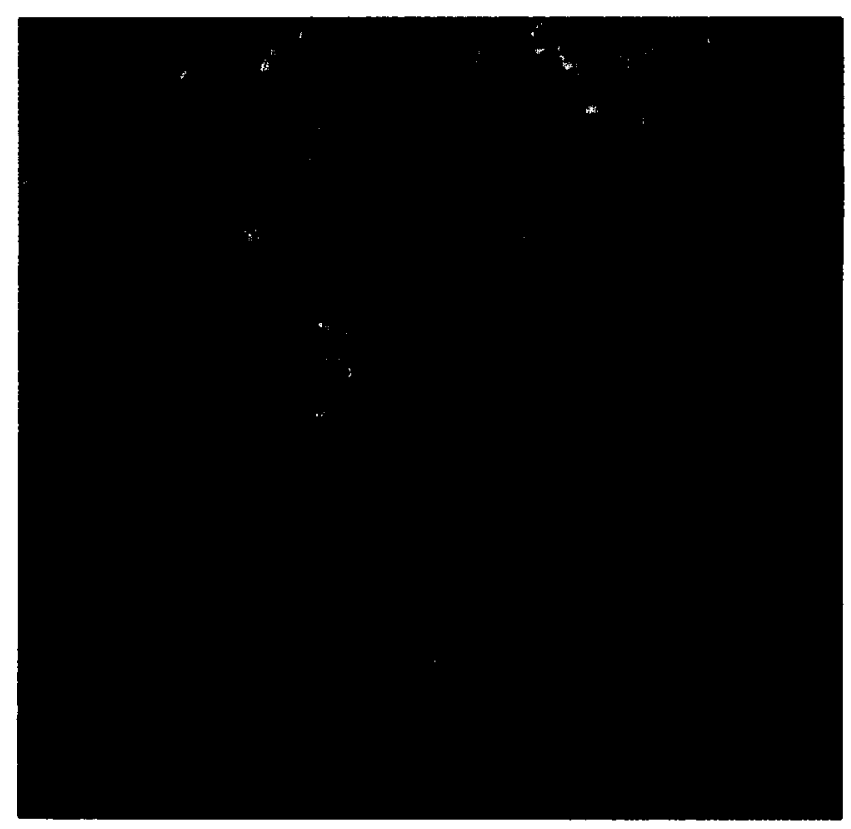

Figure 5-99: Shelby tube Sampling

\section{Sample 1}

The first sample extracted had a total length of $26 \mathrm{~cm}$ of which the top $4 \mathrm{~cm}$ section was very dry material. The top $4 \mathrm{~cm}$ was divided into two (2) parts of $2 \mathrm{~cm}$ and analysed for 
water content. The remaining $22 \mathrm{~cm}$ (Figure 5-100) was divided into $1 \mathrm{~cm}$ sections and analyzed for total suction, EC, water content and solids concentration.

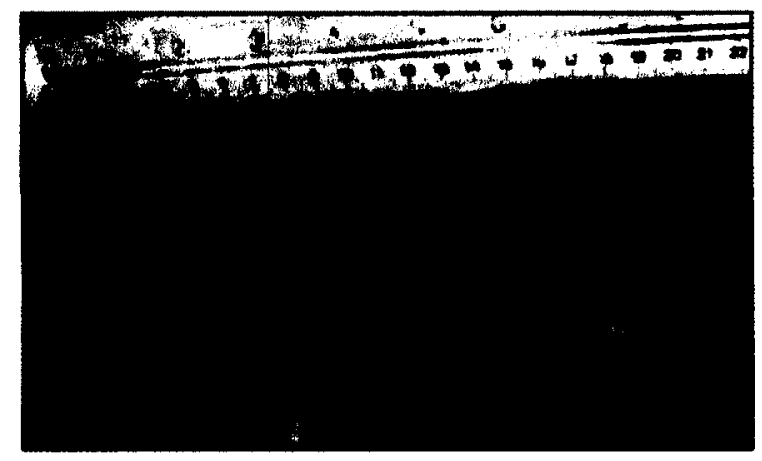

Figure 5-100: Sample 1 - Material extracted using from Shelby Tube - End of Layer 3

At the base of the sample borehole, was $6.5 \mathrm{~cm}$ of material that was not pulled out during extraction (Figure 5-101). This material was carefully dug out by $2 \mathrm{~cm}$ and was placed in separate beakers for solids concentration, EC and water content analyses.

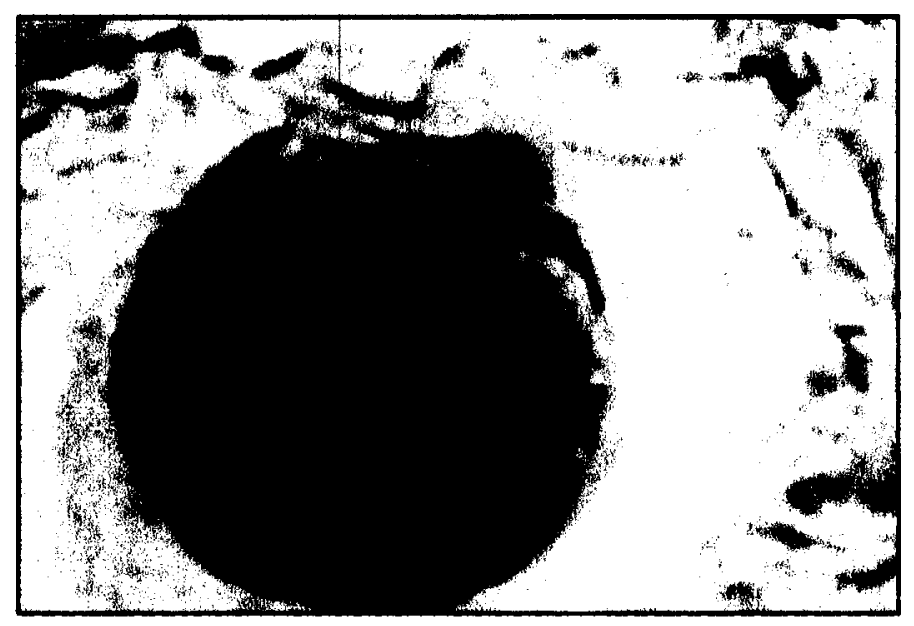

Figure 5-101: Base of sample borehole

The profile of solids concentration is presented in Figure 5-102 below. Along the entire soil profile a solids concentration of more than $75 \%$ was attained. With $97 \%$ solids concentration measured at the top, the solids concentration decreased almost linearly with 
depth until the bottom $6 \mathrm{~cm}$ where some consolidation or densification presented a higher solids concentration in the bottom $2 \mathrm{~cm}$ of $77 \%$.

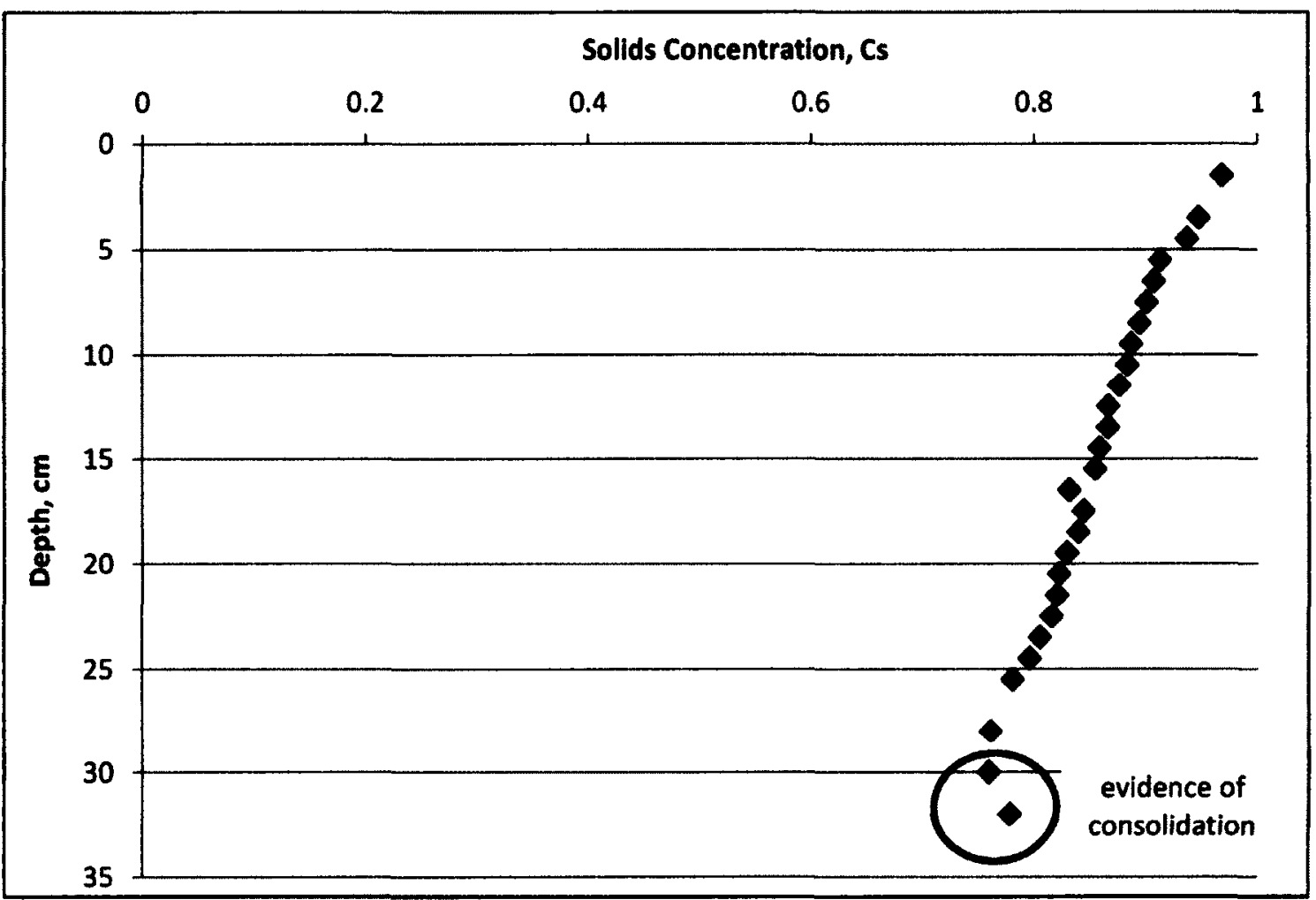

Figure 5-102: Solids Concentration Profile - Sample 1 - Layer 3

Total and osmotic suctions measured throughout the tailings profile are presented in Figure 5-103. The suctions measured are very low for the bottom portion of the tailings and were higher as the top was approached. Total Suction measured for the top 4 $\mathrm{cm}$ of the tailings profile was out of range of the machine as the samples were very dry and were signalled out by the WPs Potentiameter. Likewise, EC was not determined for those samples. 


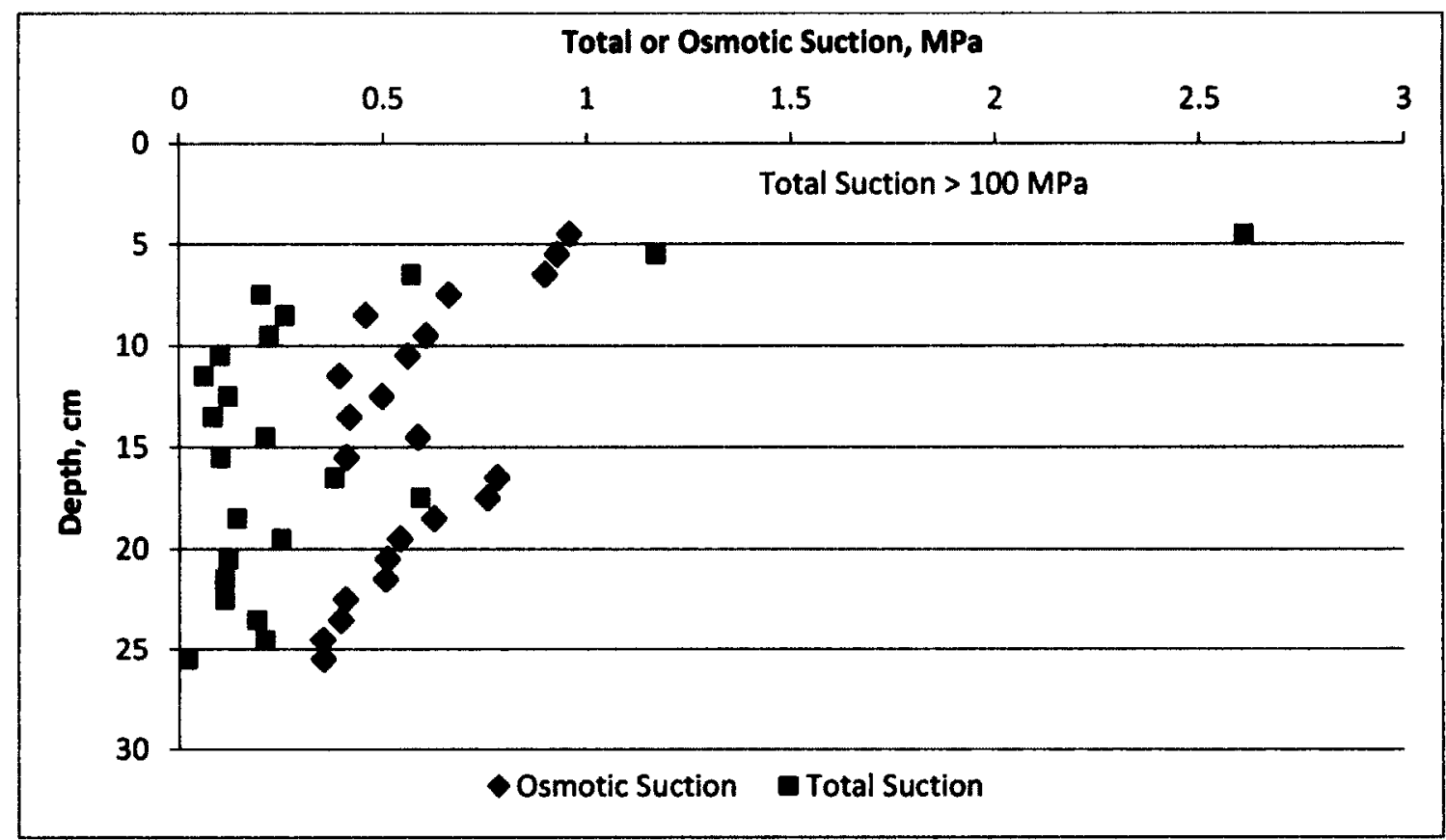

Figure 5-103: Total and Osmotic Suction Profile - Sample 1 - Layer 3

\section{Sample 2}

Sample 2 was very different from sample 1 in that $11 \mathrm{~cm}$ of the full $34 \mathrm{~cm}$ soil profile was extremely dry material and had big void spaces (Figure 5-104b). Salt accumulation was very visible along the cracks (Figure 5-104a).

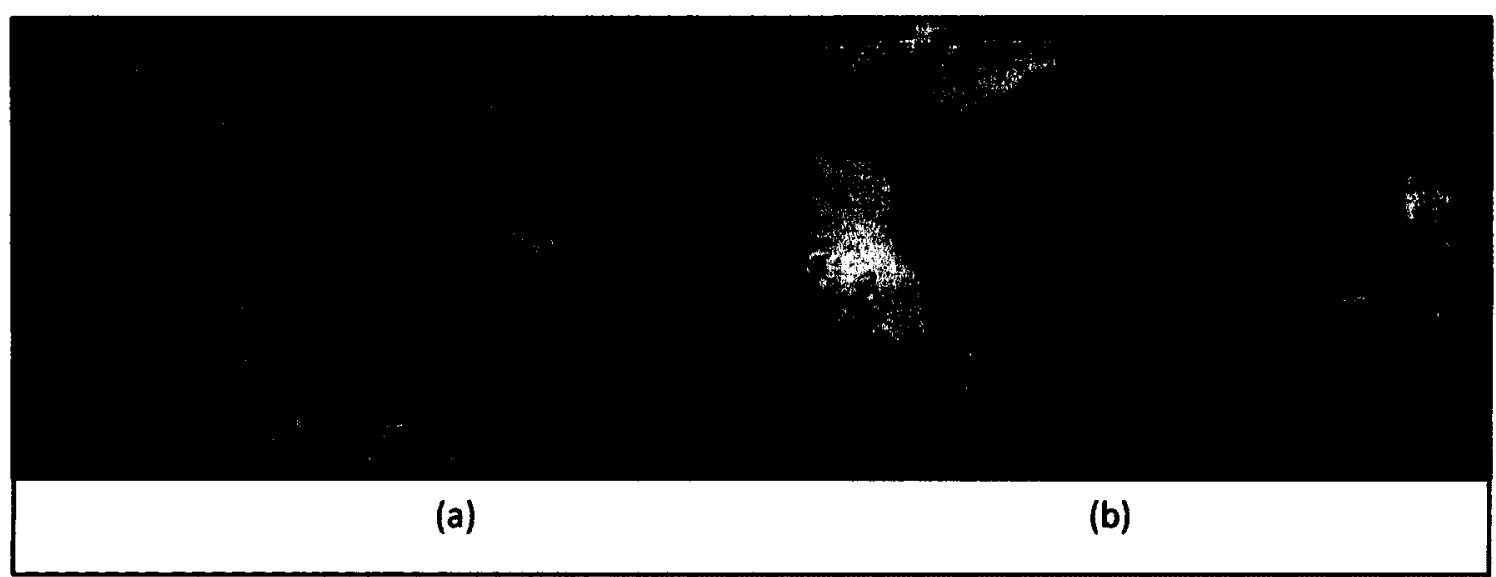

Figure 5-104: Sample 2 (a) Salt accumulation along crack (b) Void spaces top of sample 
Due to the aforementioned, it was very difficult to get the Shelby tube to extract the underlying wet material. Therefore $11 \mathrm{~cm}$ of material was left in the base of the sample hole. An additional $11 \mathrm{~cm}$ was picked up by the tube (Figure 5-105).

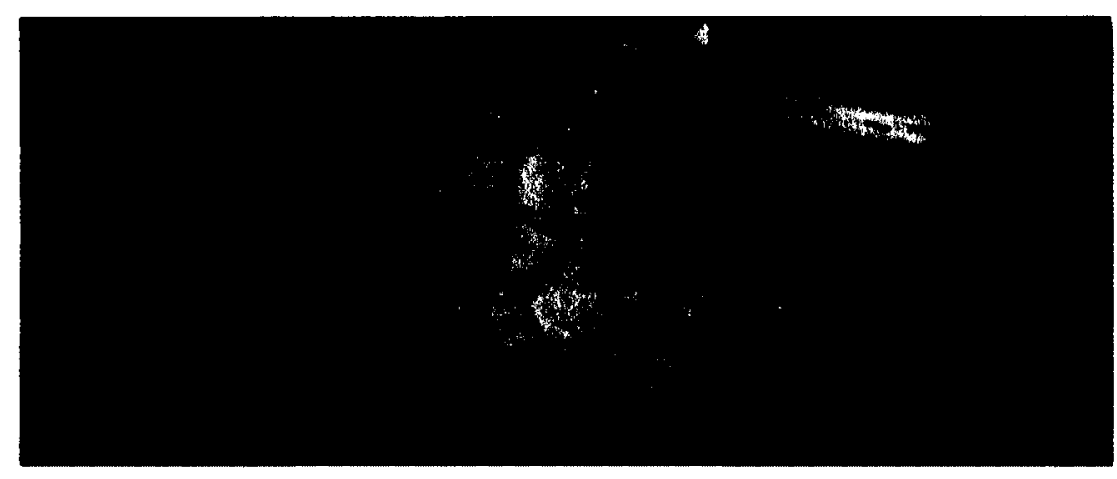

Figure 5-105: Sample 2 - Material extracted using from Shelby Tube - End of Layer 3

Solids concentration with depth ranged from 78 to $82 \%$ in sample 2 with an $82 \%$ achieved at the base of the box. See Figure 5-106. Cracking has proven to aid in further dewatering of the tailings samples. With crack depth at about13-14 cm and with the lower suctions in the regions of the crack, water exits the soil and the material is drier even at depths below the crack surface.

Total and osmotic suction results for sample 2 are presented in Figure 5-107. Suction values were generally low and no marked trend was observed but a slight decrease with depth. However, at the layer interfaces, higher osmotic suctions were measured and this could be due to the salt precipitation from previous desiccation. 


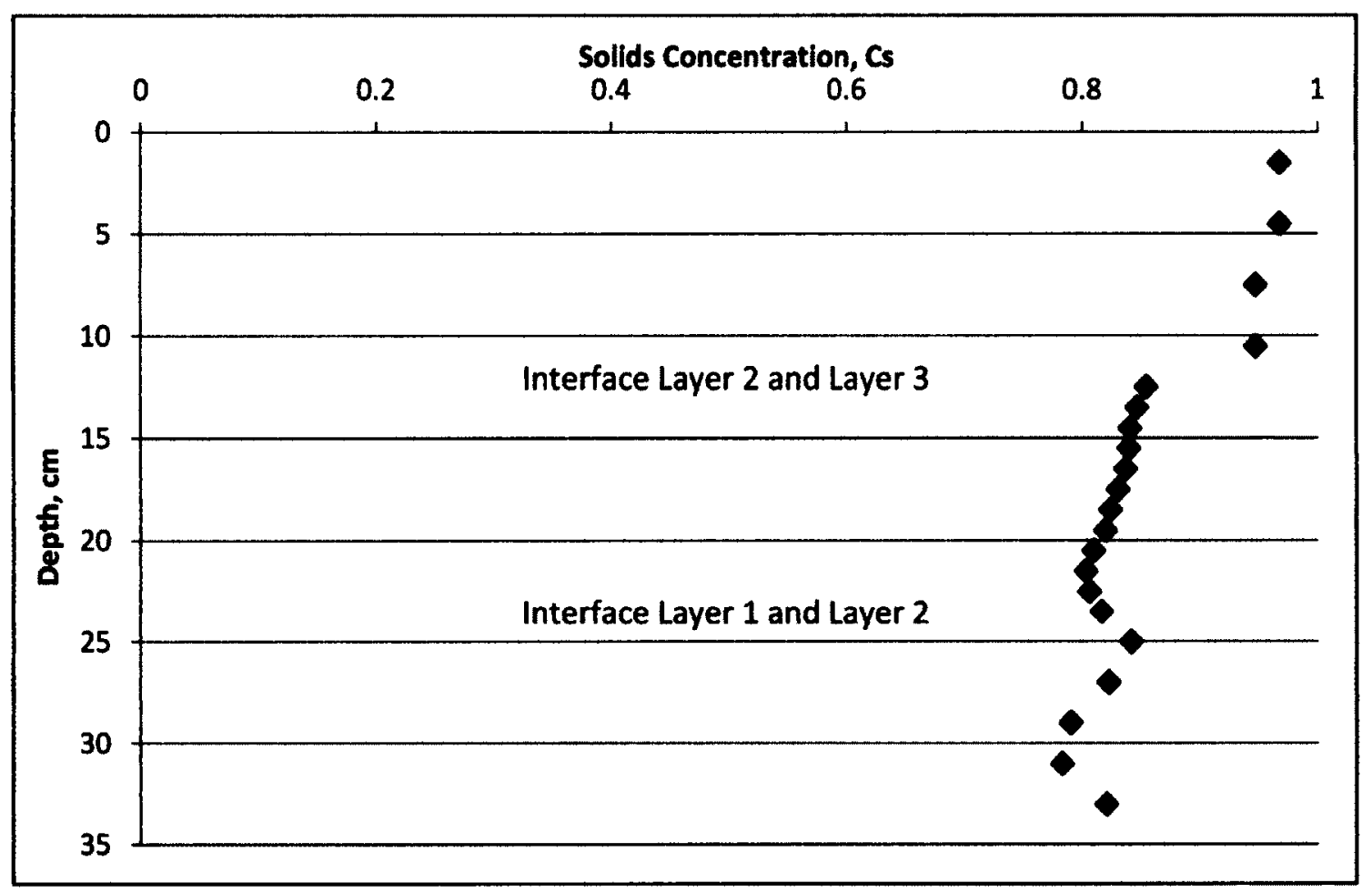

Figure 5-106: Sample 2 - Solids Concentration Profile - End of Layer 3

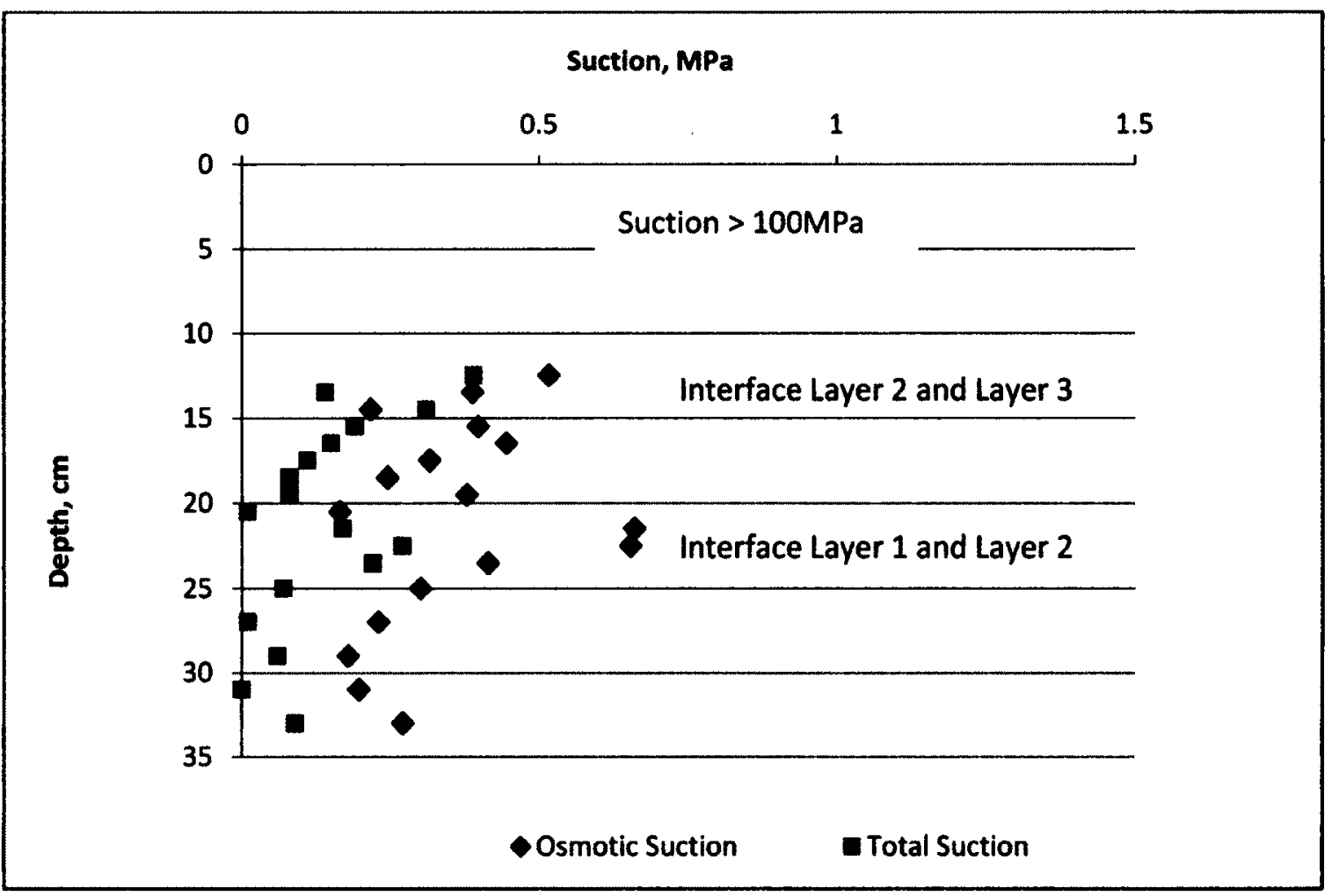

Figure 5-107: Total and Osmotic Suction Profile - Sample 2 - Layer 3 


\subsubsection{Summary of 3 layer tests}

From this suite of tests, it was observed that there were significant differences in the evaporative behaviour of each layer. This was due mainly to the underlying layers, the crack formation and development and the suction at the soil air interface function of the water content and the solute transport which occurred in the soil.

Soil suction at the soil-air interface increased rapidly as the soil surface dewaters and the salts driven upwards are deposited there, verified by EC tests. The reduced availability of water to the surface is due to the lower hydraulic conductivity brought on by the aforementioned factors and so a larger gradient in suction is required to drive water to the surface and so high suctions develop there. This increase in suction should have lowered overall the rate of evaporation. However, this was not the general trend as evaporation rates peaked right back up after a decrease, mainly due to the influence of cracking which was different for each layer.

Solute transport in each layer was very similar, where EC tests carried out showed increasing salt concentration at the surface due to lower water contents and salt movement to the surface. When Osmotic suction was calculated, values reported were higher than total suction especially in the multilayer deposition tests. These results may aid in understanding when salt precipitation begins at the surface.

Gravimetric water content data at the surface of each layer showed a decline in 24 hours from 100 to an average of $32 \%$, dwindling to about $11 \%$ a few days later (See Figure 5-108), a value close to the residual gravimetric water content of $12 \%$. This decline in water content, sealed off the rest of the tailings and only cracking provided an 
alternative for water flow. Additionally, this may have forced downward movement of water especially in the case of the rewetting of layer 1 with the deposition of layer 3 . An increase was noted in the volumetric water content signifying that water from the overlying layers had gotten to this bottom layer.

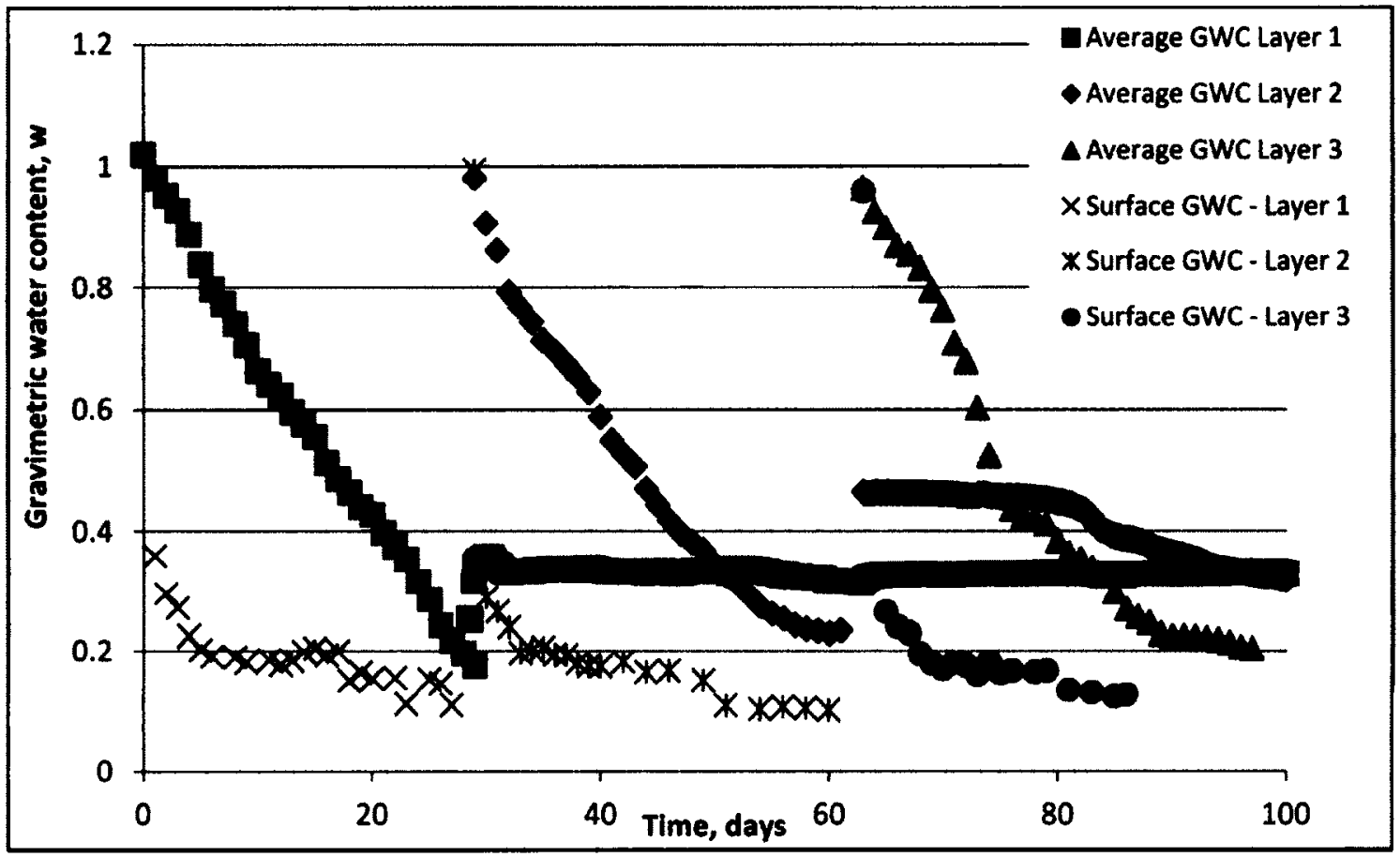

Figure 5-108: Average and Surface Gravimetric Water Content Layers 1-3

To attain overall gravimetric water content equivalent to the shrinkage limit of the tailings, the days for dewatering increased and were $28,33,39$ for layers 1,2 and 3 respectively (Figure 109). This is in part due to the fact that the water is now distributed in the layers (given the increase in gravimetric water content) and has to be driven out but high suction values at the surface do not permit. Once cracking formed, evaporation rates increased and drying continues. Matric suctions measured throughout the layers also show very non-uniform suction development with the most development captured after the deposition of Layer 3 . 


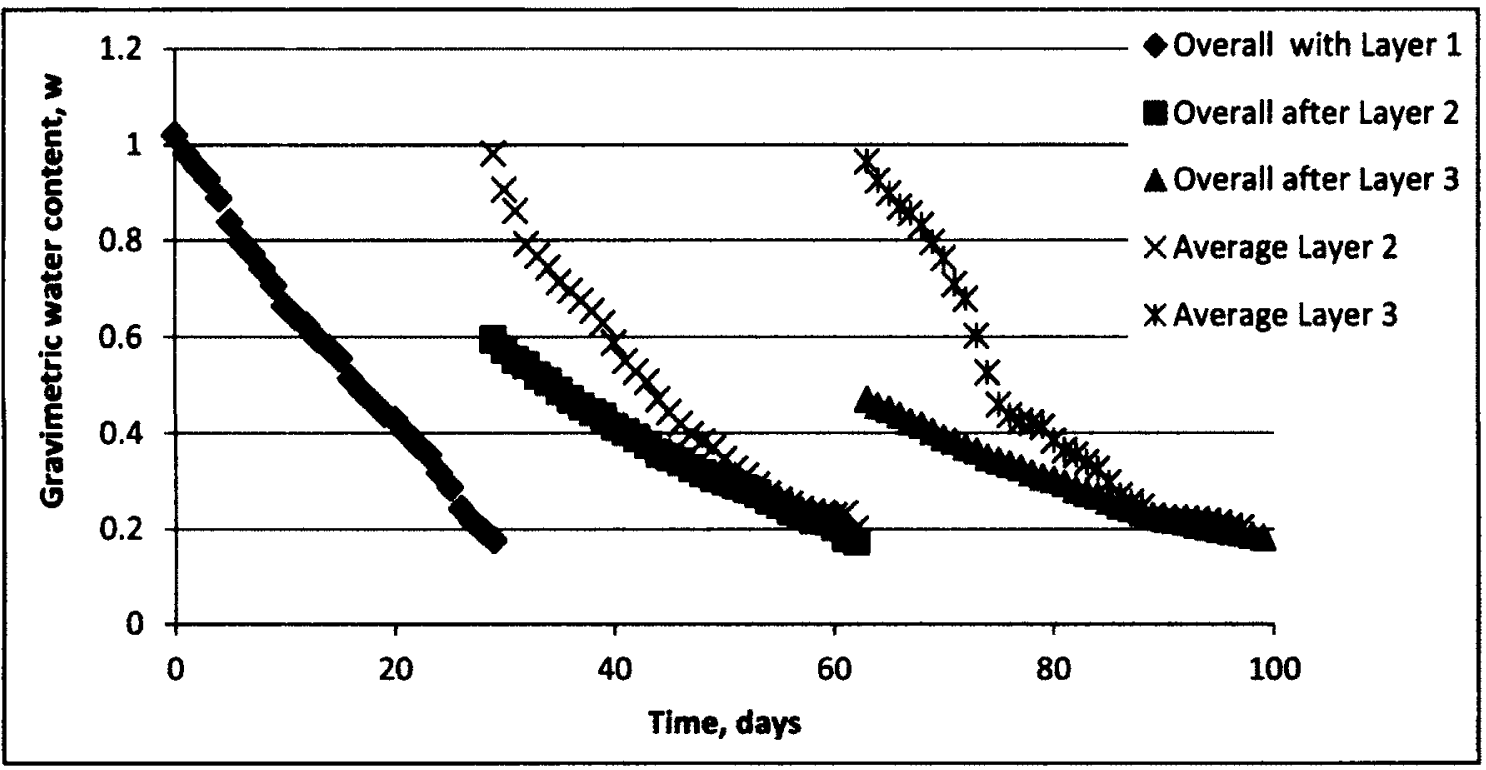

Figure 5-109: Overall and Average Gravimetric Water Content Layers 1-3

Despite the increase in the dewatering times, solids concentration increase with depth was significant (Figures 5-110 and 5-111).

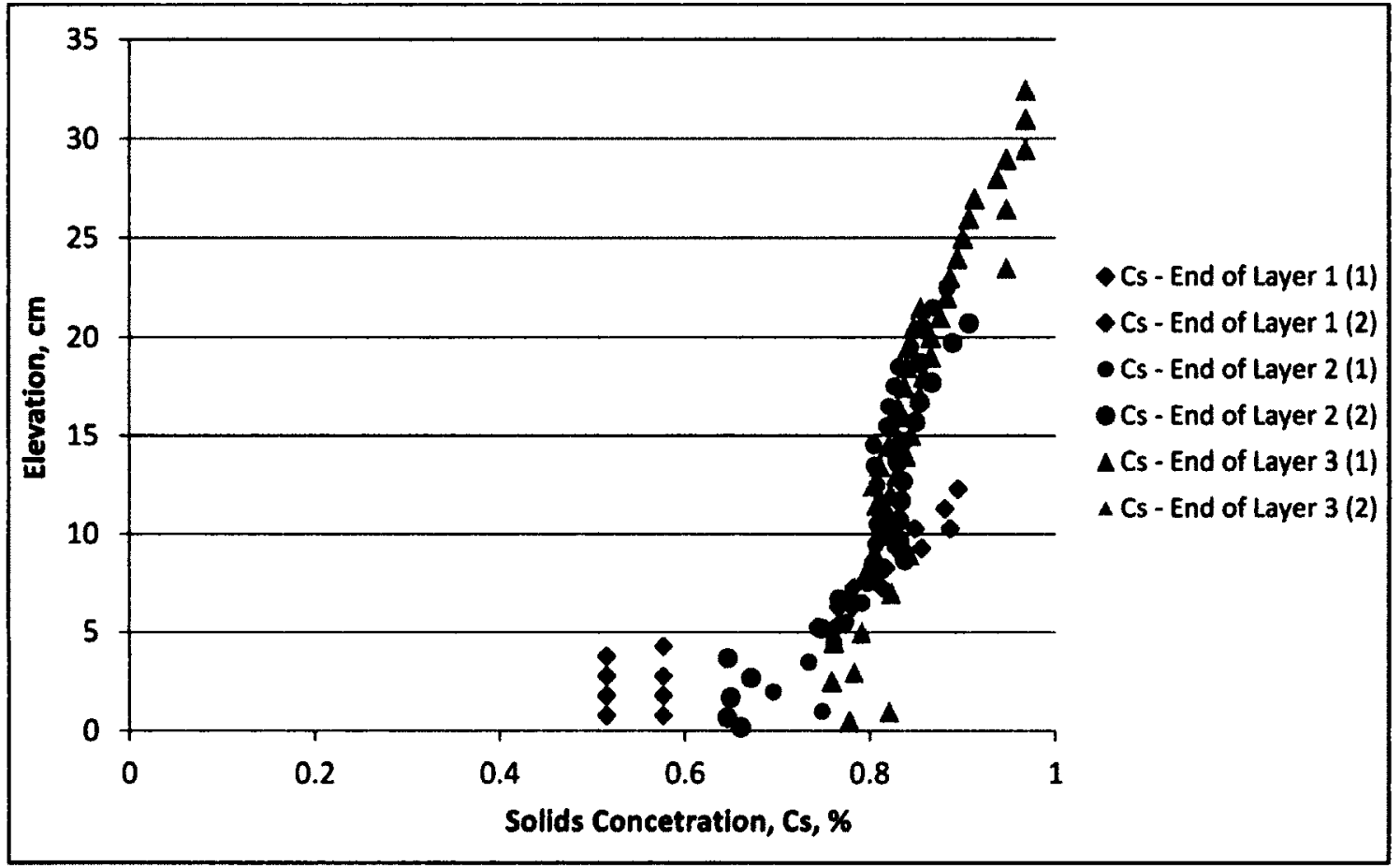

Figure 5-110: Solids Concentration Profiles at the end of Layers 1-3 


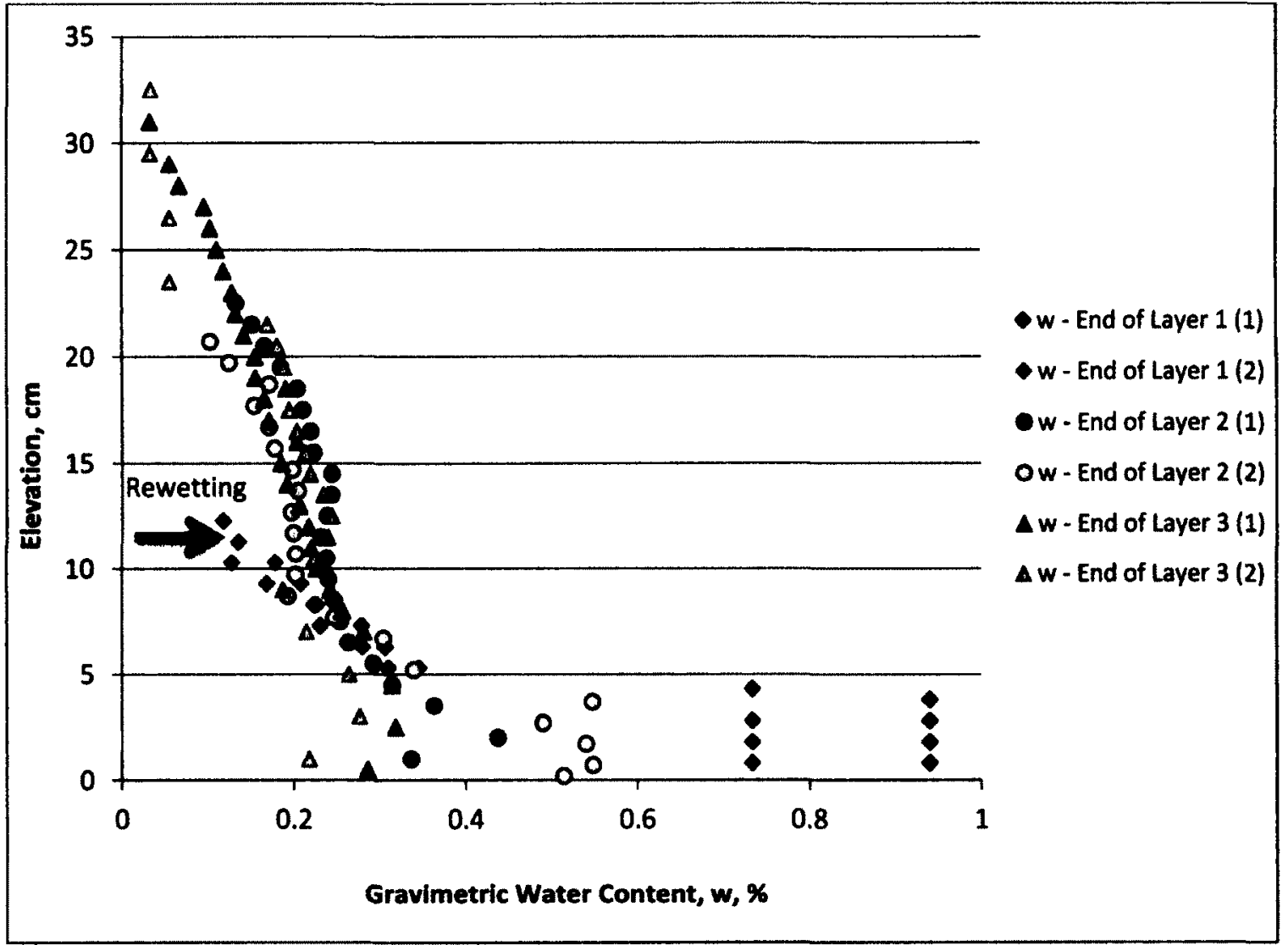

Figure 5-111: Gravimetric Water Content Profiles at the end of Layers 1-3

The volume change of all three layers is captured in Figure 5-112 with the change in void ratio. The final void ratio achieved by the first layer was slightly higher although the gravimetric water content was that of shrinkage limit. This was in part due to the non- uniform drying in some parts of the box. However, with layers 2 and 3, volume change was greater (see also Figure 5-113 of Settlement vs time) as water infiltration aided and evaporation rates were higher. 


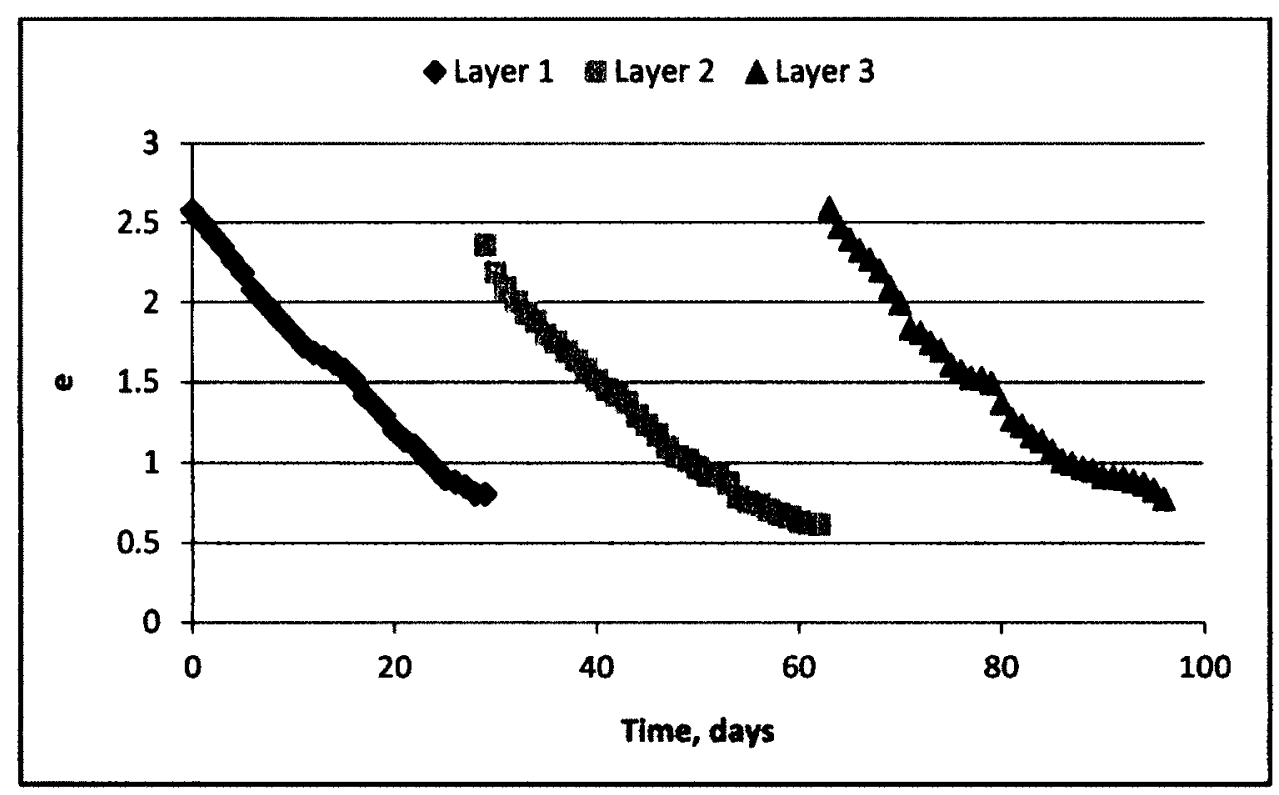

Figure 5-112: Change in Void Ratio in Layers 1-3

From the graph of settlement with time, Figure 5-113, it could also be noted that, for example to get to a settlement of $4 \mathrm{~cm}$, it takes 10,8 and 7 days for Layers 1,2 and 3 respectively. Cumulative evaporation levelled with settlement for the first part of layers 2 and 3, a trend not observed in Layer 1, later increasing as the sample reached shrinkage limit. 


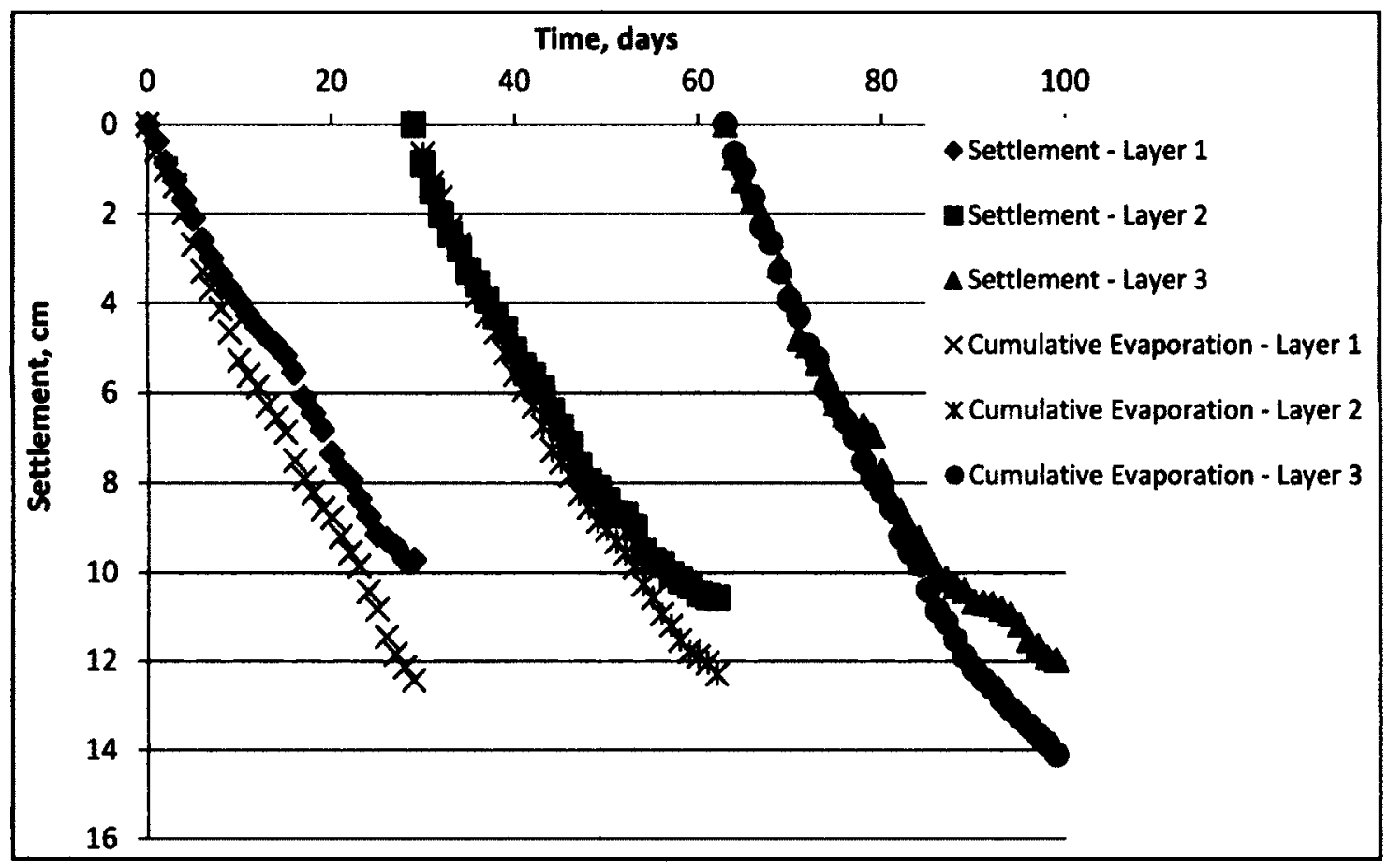

Figure 5-113: Settlement and Cumulative Evaporation in Layers 1-3

Tailings undrained strength increased significantly from an initial value of about $0-1 \mathrm{kPa}$ along the depth of the tailing profile with the distribution of water along the soil profile on deposition of a fresh layer of tailings. Table 5-8 contains shear strength data for all layers.

Table 5-8: Undrained shear strength measurements for soil profile

\begin{tabular}{|l|l|l|l|}
\hline Layer & $\begin{array}{l}\text { Depth } \\
(\mathbf{c m})\end{array}$ & Peak Undrained strength $(\mathbf{k P a})$ & $\begin{array}{l}\text { Residual Undrained strength } \\
(\mathbf{k P a})\end{array}$ \\
\hline \multirow{3}{*}{ Layer 1} & 3 & 24 & 10 \\
\cline { 2 - 4 } & 5 & 18 & 6 \\
\hline \multirow{5}{*}{ Layer 2 } & 6 & 66 & 20 \\
\cline { 2 - 4 } & 12 & 16 & 12 \\
\cline { 2 - 4 } & 18 & 8 & 8 \\
\hline \multirow{5}{*}{ Layer 3 } & 8 & 98 & 22 \\
\cline { 2 - 4 } & 12 & 18 & 9 \\
\cline { 2 - 4 } & 28 & 48 & 20 \\
\cline { 2 - 4 } & 32 & 22 & 12 \\
\hline
\end{tabular}


AE curves considering crack surface area for all three layers presented in Figure 5-114 show similar trend in terms of oscillatory behaviour but with deposition of layers 2 and 3, a more defined decrease is noted with time as water becomes not just available in the overlying layer but the underlying ones as well and removal is not at potential rates. Also observed is the importance of including the surface area of cracks to gain a true idea of actual evaporation rates.

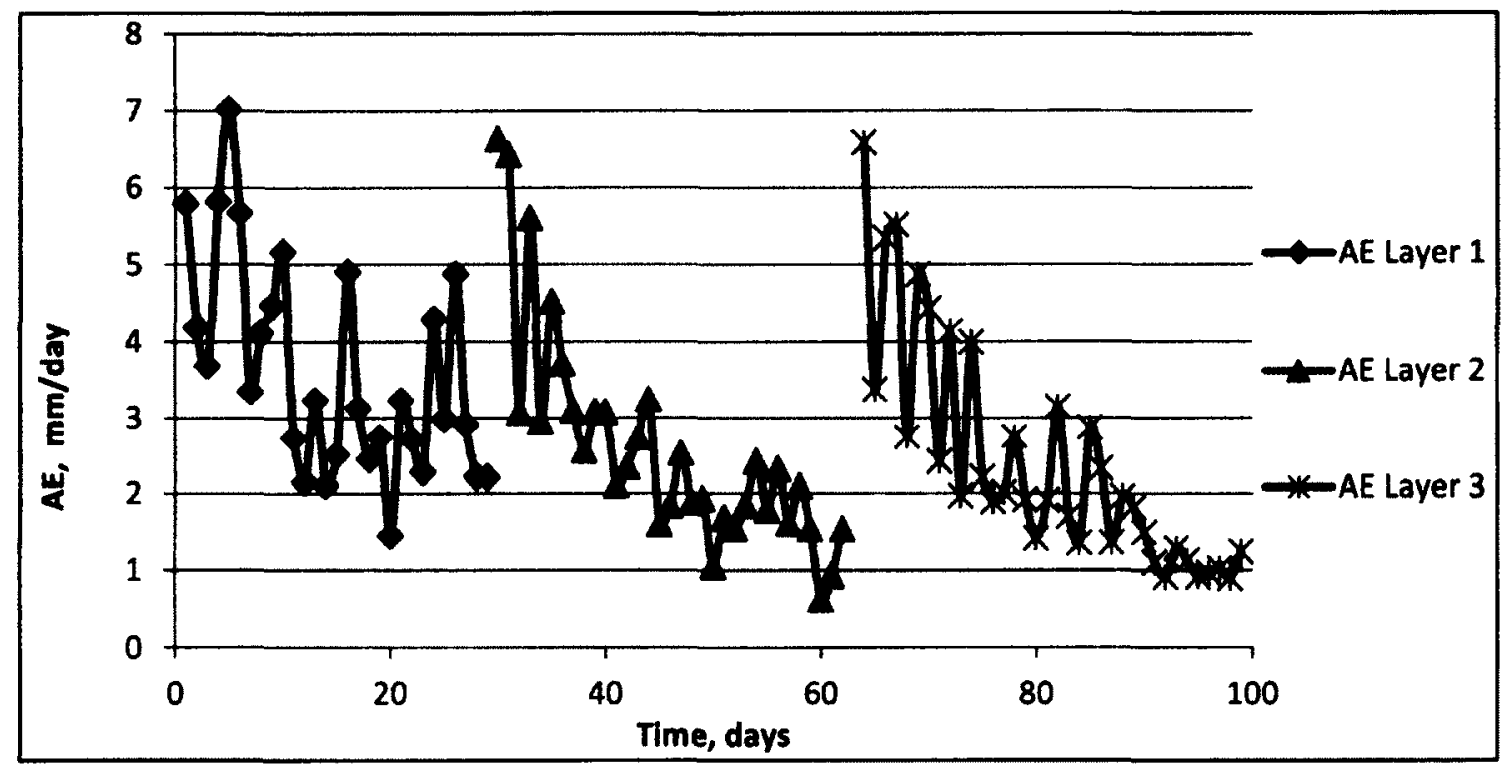

Figure 5-114: AE (with crack SA consideration) in Layers 1-3

Results for predictions of AE for layers 2 and 3 are presented below in Figures 5116 and 5-117. Based on these results and those obtained for previous tests, Dunmola's method gives a reasonable estimation, not over predicted or under predicting the measured data.

In the case of Layer 2, Wilson's method did not fit the data while varying the adjustment factor from -1.3 to -2 . For a factor of -1.3 and -2 it over predicted and under predicted respectively. The increase in osmotic suction is directly translated in a 
decrease in the RE by the equation. Therefore, it can be concluded that this method is sensitive to rapid changes in suction at the surface (crust). This suction is not representative of all the surface area exposed to the overlying air. Finding the right correlation with total suction adjustment and percentage of the surface having that suction, and the appropriate resistance to be applied at each time step is important in obtaining improved results.

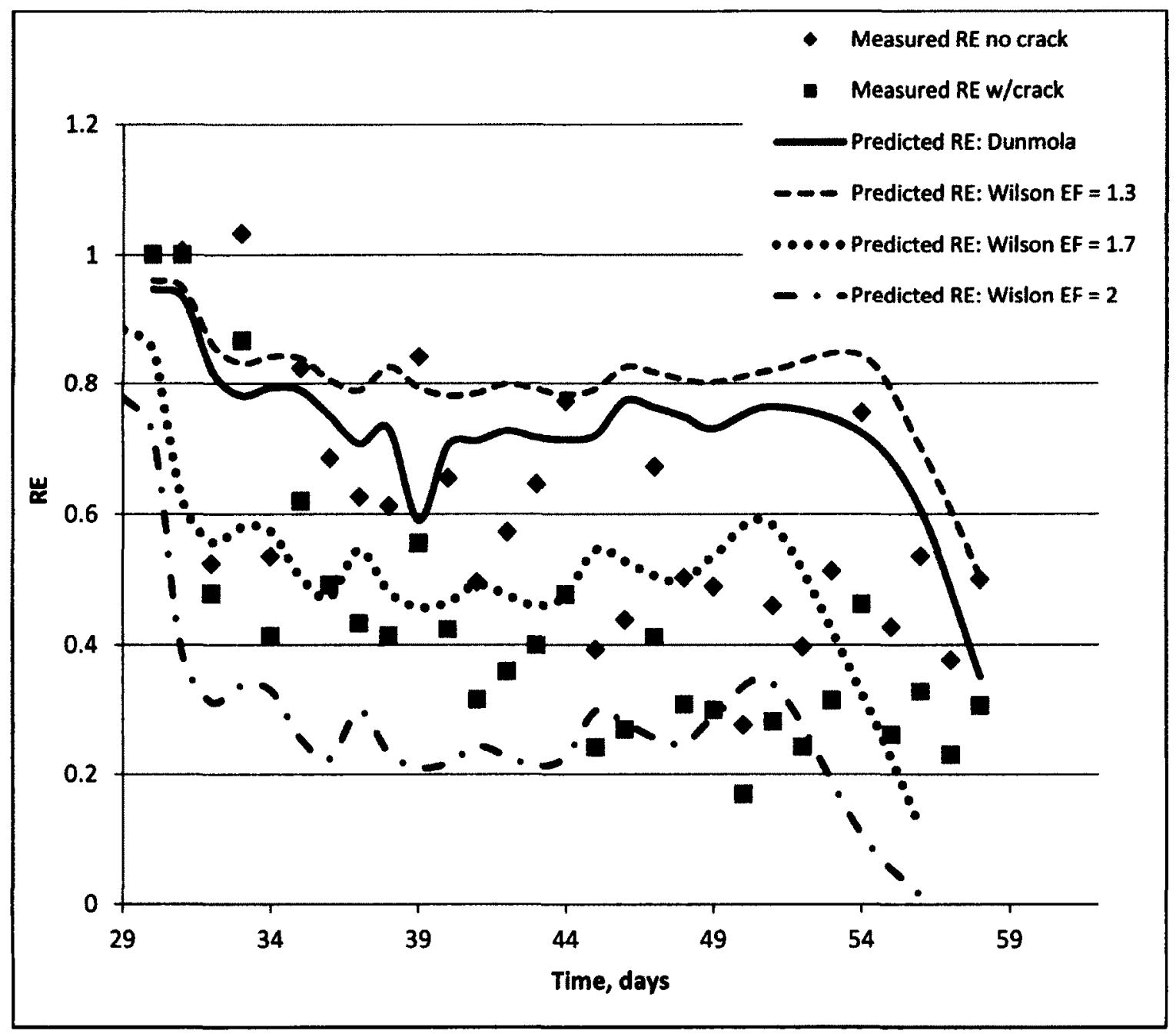

Figure 5-115: Measured and Predicted RE Layer 2 


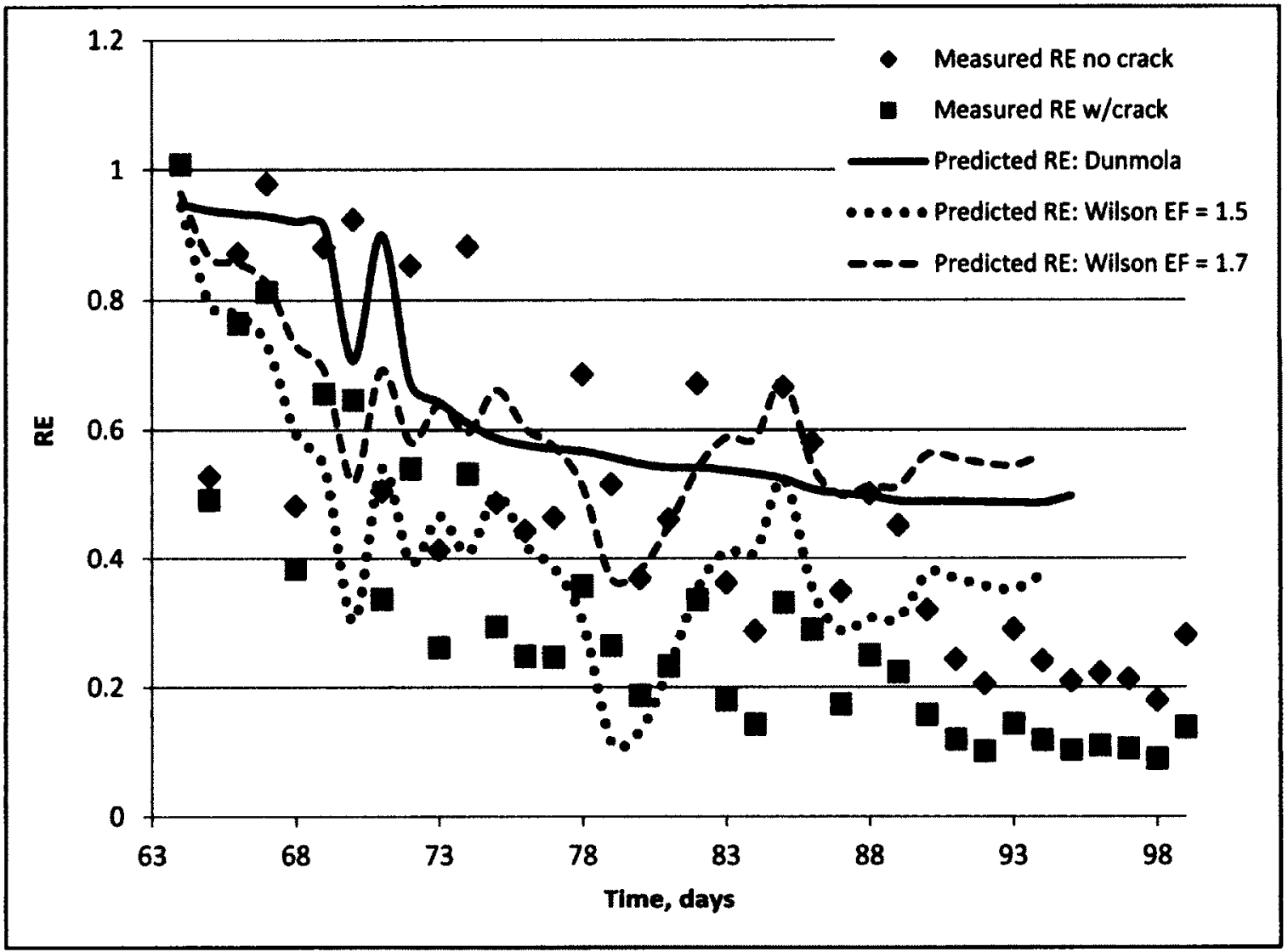

Figure 5-116: Measured and Predicted RE Layer 3

The predictions for layer 3 captured a few oscillations in the measured data for values of the empirical factor of 1.5 and 1.7 .

As per the contribution of cracks on the oscillatory behaviour of the RE, if the change in surface area is plotted with time, one can see the contribution of crack on the increase in AE. The previous was applied to the data obtained in layer three where oscillations were predominant in the first few days of the test. To do this, the change was applied to the previous day (Figure 5-117) or to the day of measurement (Figure 5-118). And this is because the instantaneous measurements were taken at the end of each 24 hour period. 


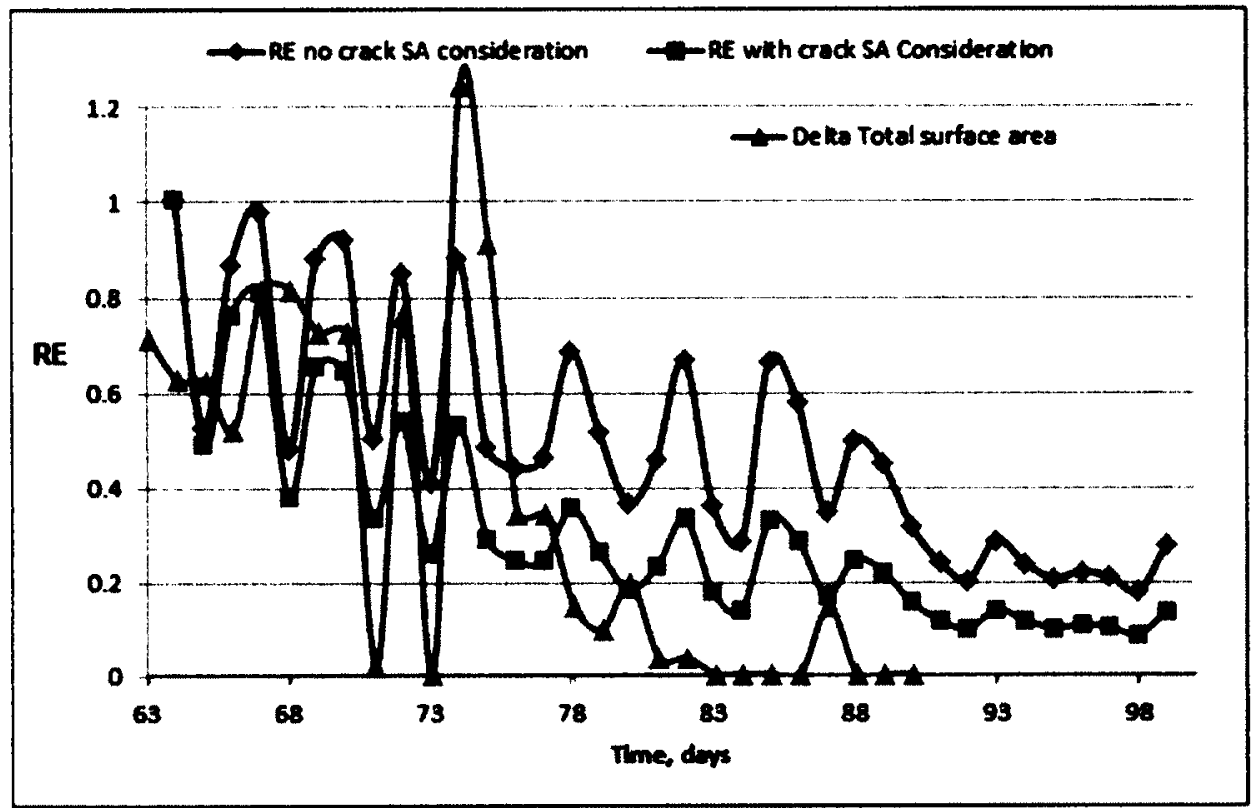

Figure 5-117: Change in Total surface area against RE - Layer 3 - Plot 1

From the both plots, it could be appreciated that an increase in total suction did coincide with an increase in RE and vice versa. However, we do some areas of the graph that do not follow such a pattern but as has been described in the previous sections, the increase in surface area does cause and increase in evaporation and once these surfaces remain at low suctions and high enough water content water will flow out of the tailings with less difficulty. However, should cracks shutdown, that is develop very high suctions or be encrusted by salt precipitates, the rate will decrease in spite of the increase in surface area.

From the results obtained, it can be stated that the evaporation and consolidation is not a 1D problem as was similarly concluded by Fujiyasu et al. (2000b). Crack contrbution ot the overall evaporation rates is not captured in a 1D analysis that assumes vertical transport to the surface and that once this way is obstructed or less permeable, evaporation should shut dow. 


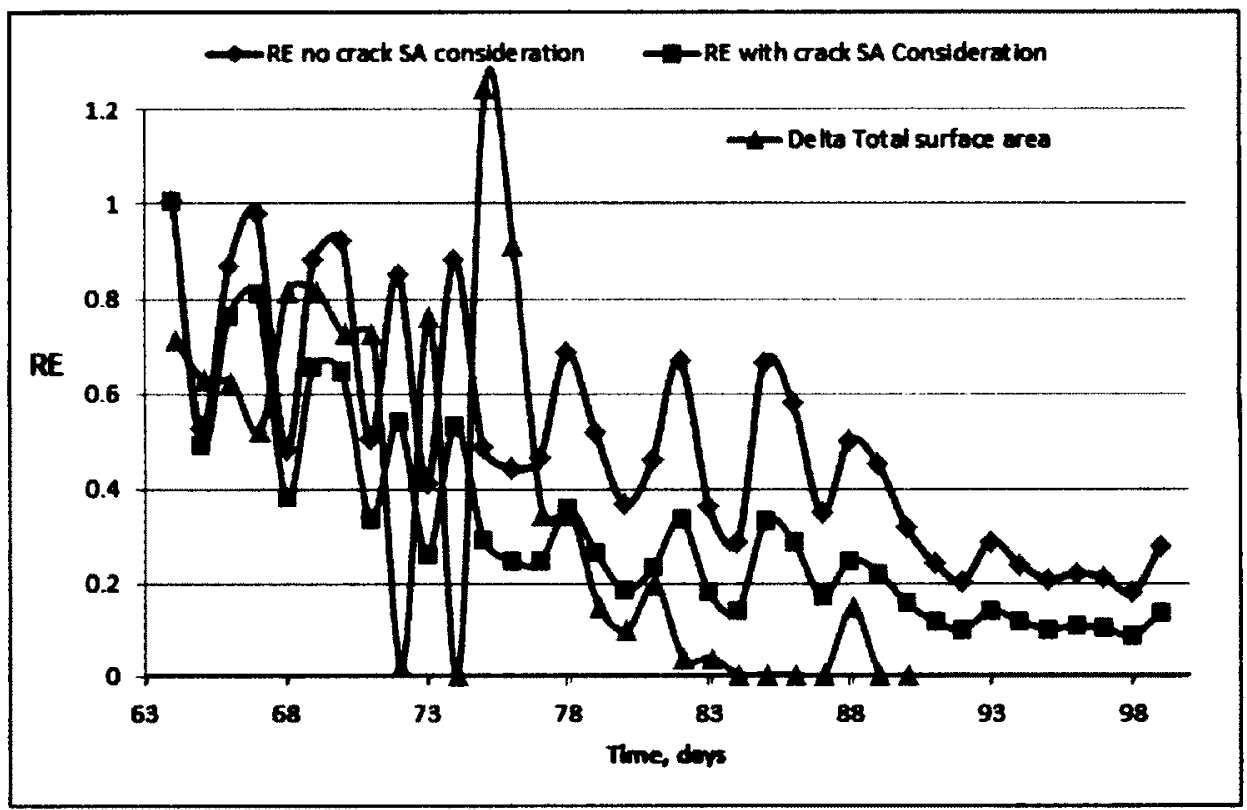

Figure 5-118: Change in Total surface area against RE - Layer 3 - Plot 2

(a) 


\section{Chapter 6 concLusions}

The evaporation of oil sand thickened tailings is in part influenced by the pore water chemistry, the climatic conditions and cracking. This research investigates the evaporative behaviour of oil sand thickened tailings under laboratory conditions.

To achieve this, the tailings were characterized by the determination of baseline and water chemistry analysis and a series of drying tests were conducted which included wax column bench tests and a larger scale dying box tests where multilayer deposition was simulated. Measured temperature, relative humidity and suction values were used to model the results.

During wax column, column and small box drying tests it was found that the top part of the material separated from the bottom wet material as it got drier and underlying material remained very wet (characteristic of non-uniform drying) until the top layer caved in and provided a new opening for water flow.

This is coherent with results found in the larger scale tests where cracking exposed new material of lower suction, an alternative path for water to leave the soil. The percentage of the total surface area represented by these lower suctions and the lower water contents, play a significant role in further dewatering of the tailings.

Crust formation impedes water flow but also allows the surfacing of fresh tailings through cracks. The top crust, formed shortly after deposition with the sharp decrease in 
water content, has very low hydraulic conductivity and is denser than the underlying wet material. As a result, it weighs into the underlying wetter material, causing it to be expelled through the length of the cracks.

This top crust is barely a few millimeters thick when it first forms but later increased in thickness as drying continues. Due to its high salt content, visible from salt crystals on the surface, and its low water content, it has very low conductivity and obstructs water removal from the soil surface

The migration of salts to the surface as water was driven during evaporation results in the precipitation of some of them along the pores at the surface. Apart from decreasing the hydraulic conductivity, the salts increased the salinity at the surface and this pore-water salinity supressed evaporation by development of high osmotic suctions. Results showed that tailings containing lower salt concentrations in the pore-water had higher evaporation rates as lower suction were developed at the surface. Therefore, the control of salinity can aid in evaporation, as the osmotic suction contribution (due to high salt concentration) to total suction on the surface was important.

When evaporation slows down, a downward movement of salts is observed from the decrease in total suction, despite the decrease in gravimetric water content at the surface.

Crack formation in the tailings was a main contributor to the increase in evaporation rates. As the surface dried, the material was mechanically pulled apart and cracks were formed. They adopt three shapes: triangular, trapezoidal or cuboidal. Initially cracks are v-shaped and later take on a trough- like shape increasing the surface 
area. Later on cracks were predominantly cuboidal and deepen with little increase in width occurring.

The increase in surface area due to cracking and the relatively low suctions at the surface gave rise to very high actual evaporation rates but when crack surface area was factored in, they were found to be lower.

However, plots of RE with time still show spontaneous increases. From the study, it can be concluded that these spikes are associated with the exposure of fresh tailings as cracks expand or as surface caves in.

The very low suction in these materials allow for evaporation at these sites at a maximum or near potential rate. Therefore, facilitating cracking in a deposition scheme can prove beneficial to evaporation and further consolidation of tailings

Estimation of RE with consideration of percentage covering with wet material with wet material will aid in quantifying actual RE and shed light on what is actually happening in the field. With the total crust coverage decreasing with time, with the simultaneous formation of cracks, the crust offers less contribution to the overall decrease on potential evaporation.

The desaturation of the underlying later aided in the dewatering and eventual volume decrease/consolidation of the newly deposited layer. The unsaturated material, after rewetting, reached an average maximum volumetric water content of 0.5 (solids concentration of $74 \%$ and gravimetric water content of $34 \%$,), giving an indication of the water storage capacity and the effects of rainfall on the drier tailings. Even at 0.5 volumetric water content the tailings has significant strength. The infiltration of water to 
underlying dry layer was also observed in the latter stages of the test as the upper layers dried. This behaviour translated in an increase of the dewatering times to a specific water content with the increase in number of layers. Although settling increased, dewatering was slower. It is therefore important to fully understand the storage capacity of the drier tailings. Infiltration was also responsible for the higher osmotic suction values at layer interfaces.

The data collected in this thesis will be used to calibrate or train models to assist deposition planning for field implementation of thickened tailings at Total E\&Ps future mining operations. It is evident from this work that cracking is very important to evaporation. Whether it is necessary to model fluxes in 2-D or even 3-D, or rather whether a phenomenological approach, such as the Dunmola or modified Wilson equations, is adequate to define evaporation as a boundary condition in a model, will be the next step in this research. 


\section{Chapter 7 RECOMmendations}

\subsection{Recommendations for future work}

1. From the small drying box tests it was observed that lower suctions and higher evaporation rates were achieved for tailings with lower concentration of salts when compared to one of similar solids concentration but higher salt content. It is recommended that the multilayer deposition tests be repeated for a material of similar solids concentration and different salt content. This will make it possible to determine and establish whether, water storage capacity, crack formation and suction development are dependent on salt concentrations.

2. Having acquired such detailed analysis and a large volume of data, it is recommended that the solute transport be modelled coupled with consolidation and flow models to predict the results. If successful, the model should be extended to field conditions.

3. A complete analysis of pore water to determine which salts are driven to the surface during evaporation would aid in the design of an apt transport model. Therefore, it is recommended that such analyses be carried out.

4. Since the underlying layers aided in dewatering, a study of the effect of a drainage layer under the first layer on dewatering should be conducted. 


\section{REFERENCES}

1) (n.d.). Retrieved May 14, 2012, from http://hyperphysics.phyastr.gsu.edu/hbase/quantum/bragg.html

2) (1954). United States Department of Agriculture Handbook No. 60: Diagnosis and Improvement of Saline and Alkali Soils. Washington, D.C.: U.S. Goverment Printing Office.

3) (2012, January). Retrieved April 20, 2012, from Geotech Wiki: http://geotechwiki.com/wordpress/wp-content/uploads/2012/01/Plasticity-Chart.gif

4) Government of Alberta. (2012).

5) Adams, J. E., \& Hanks, R. J. (1964). Evaporation from soil shrinkage crack. Soil Science Soc. Am. J., 28, pp. 281-284.

6) Aghajani, H. F., Soroush, A., \& Shourijeh, P. T. (2011, December). An improved solution to capillary rise of water in soils. International Journal of Civil Engineering, 9(4), 275-281.

7) Allen, R. G., Pereira, L. S., Smith, M., Raes, D., \& Wright, J. L. (2005). FAO-56 Dual crop coefficient method for estimating evaporation from soil and application extensions. Journal of Irrigation and Drainage Engineering, 2-13.

8) Arasan, S., \& Yetimoglu, T. (2008). Effect of Inorganic salt solutions on the consistency limits of two clays. Turkish J. Eng, Env. Sci.(32), 107-115. 
9) ASTM D4318. (2000). Standard test method for liquid limit, plastic limit and plasticity index of soils. ASTM International.

10) (2003). "Standard test methods for specific gravity of soil solids by water pyconometer (D854-06)". In ASTM International, Annual Book of ASTM Standards Vol. 04.08: Soil and Rock (I). West Conshohocken, PA.

11) Barth, A., \& Wirth, K. (n.d.). Geochemical Instrumentation and Analysis. Retrieved 02 28, 2012, from Carleton College: http://serc.carleton.edu/research_education/geochemsheets/techniques/XRF.html

12) BGC Engineering Inc. (2010). Oil Sands Tailings Technology Review. Oils Sands Research and Information Network, University of Alberta, School of Energy and the Environment, Edmonton, Alberta.

13) Bitelli, M., Ventura, F., Campbell, G. S., Snyder, R. L., Gallegati, F., \& Pisa, P. R. (2008). Coupling of heat, water vapor, and liquid water fluxes to compute evaporation in bare soils. Jouranl of Hydrology, 362, 191-205.

14) Boger, D. (2006). Rheological Concepts. In Paste and Thickened Tailings - A Guide (Second Edition) (pp. 25-37). Australian Centre for Geomechanics.

15) Bowles, J. E. (1979). Physical and geotechnical properties of soils (2 ed.). Michigan: McGraw-Hill.

16) Bowles, J. E. (1992). Engineering properties of soils and their measurement. New York: McGraw-Hill. 
17) Bowles, J. E. (1992). Engineering properties of soils and their measurement. New York: McGraw-Hill.

18) Boxill, L. (2011). Potential for Use of Methylene Blue Index testing to Enhance Geotechnical Characterization of Oil Sands Ores and Tailings. Tailings and Mine Waste 2011. Vancouver, BC.

19) Boxill, L. (2011). Potential for Use of Methylene Blue Index testing to Enhance Geotechnical Characterization of Oil Sands Ores and Tailings. Proceedings Tailings and Mine Waste 2011. Vancouver, BC.

20) Bragg's Law. (n.d.). Retrieved May 14, 2012, from Hyperphysics: http://hyperphysics.phy-astr.gsu.edu/hbase/quantum/bragg.html

21) Brooks, R. H., \& Corey, A. T. (1964). Hydraulic properties of porous medium. Hydrology paper no. 3.

22) Brouwer, C., \& Heibloem, M. (1986). Irrigation Water Management: Irrigation water needs. Rome, Italy: Natural Resources Management and Environment $\begin{array}{llll}\text { Department, } & \text { FAO. } & \text { Retrieved } & \text { from }\end{array}$ http://www.fao.org/docrep/S2022E/S2022E00.htm

23) Camilo, P. J., \& Gurney, R. J. (1986). A resistance parameter for bare-soil evaporation models. Soil Science, 141, 95-105.

24) CANMET. (2008, November 13). Technical Overview - Oil sand processes. Retrieved from http://canmetenergy.nrcan.gc.ca/oil-sands/1219

25) CAPP, C. A. (2012). Crude Oil: Forecast, Markets \& Pipelines. CAPP. 
26) Chen, X. (1992). Evaporation from a salt-encrusted sediment surface:Field and laboratory studies. Aust. J. Soil Res, 30, 429-442.

27) Childs, E., \& Collis-George, N. (1950). The permeability of porous materials. Proceedings of the Royal Society of London. Series A, Mathematical and Physical Sciences. 201, pp. 392-405. The Royal Society. Retrieved from http://www.jstor.org.proxy.library.carleton.ca/stable/98381

28) Clark, K. A. (1939). The hot water method for recovering bitumen from bituminous sand. IN: Report on Sullivan Concentrator. Edmonton, Alberta: Alberta Research Council.

29) Cooper, L. R., Haverland, R. L., Vendricks, D. M., \& Knisel, W. G. (1984). Microtac particle-size analyzer: An alternative particle-size determination method for sediment and soils. Soil Science, 138, 138-146.

30) Darcy, H. (1856). Les fontaines publiques de lu Ville de Dijon. Victor Dalmont, Paris.

31) Das, B. M. (2008). Advanced Soil Mechanics (Third ed.). New York, USA: Taylor \& Francis.

32) Degacon. (2007). WP4 Potentiameter- Operators Manual version 5. Pullman, WA: Decagon Devices, Inc. Retrieved from http://www.decagon.com/assets/Manuals/Inside-Pages-WP4.pdf

33) Devenny, D. W. (2010). A Screening Study of Oil Sand Talings Technologies and Practices. Alberta Innovatives Energy and Environmental Solutions. 
34) Dunmola, A. (2012). Predicting evaporative fluxes in saline soil and surfacedeposited thickened mine tailings. PhD Thesis. Ottawa: Carleton University.

35) Dunmola, A. S., \& Simms, P. H. (2010). Coupled soule mass transport and evaporation in saline soil. In A. Gens (Ed.), Unsaturated Soils (pp. 1369-1374). CRC Press.

36) Dunmola, A. S., \& Simms, P. H. (2010). Solute mass transport and atmospheric drying of high densitygold tailings. Proceedings of the 23th International Conference on Paste and Thickened Tailings, (pp. 279-289). Toronto, Ontario.

37) Edlefsen, N. E., \& Anderson, A. B. (1943). Thermodynamics of soil moisture. Hilgardia, 15(2), 31-298.

38) Energy Resource Conservation Board. (2011, September). EnerFAQs Oil Sands. Retrieved June 2012, from Energy Resources Conservation Board: http://www.ercb.ca/enerfaqs/EnerFAQs12-OilSands.pdf

39) Energy Resources Conservation Board . (2009, February 3). Tailings Performance Criteria and Requirements for Oil Sands Mining Schemes. Retrieved from http://ercb.ca/directives/Directive074.pdf

40) Engels, J. (2006). Xstrata - Kidd Creek Met Site, Timmins, Ontario, Canada. Retrieved February 14, 2013, from http://www.tailings.info/casestudies/kiddmet.htm 
41) Fissheha, B., Bryan , R., \& Simms, P. (2010). Evaporation, unsaturated flow, and salt accumulation in multilayer deposits of "paste" gold tailings. Journal of Geotechnical Geoenvironmental Eng., 135(12), 1703-1712.

42) Fourie, A. B. (2012). Perceived and realised benefiits of paste and thickened tailings for surface deposition. In R. J. Jewell, A. Fourie, \& A. Paterson (Ed.), Paste 2012. Proceedings of the 15th International Seminar on Paste and Thickened Tailings (pp. 53-64). Sun City, South Africa: Australian Centre for Geomechanics.

43) Fredlund, D. G., \& Rahardjo, H. (1993). Soil Mechanics for Unsaturated Soils. New York: John Wiley and Sons, INC.

44) Fredlund, D. G., \& Xing, A. (1994). Equation for the soil-water characteristic curve. Canadian Geotechnical Journal, 31(3), 521-532.

45) Fredlund, D. G., Stone, J., Stianson, J., \& Sedgwick, A. (2011). Determination of water storage and permeability functions for oil sand tailings. Proceedings Tailings and Mine Waste 2011. Vancouver, BC.

46) Fredlund, D. G., Xing, A., \& Huang, S. (1994). Predicting the permeability function for unsaturated soils using the soil-water characteristic curve. Canadian Geotechnical Journal, 31(3), 521-532.

47) Fredlund, D., Fredlund, M. D., \& Rahardjo, H. (2012). Unsaturated soil mechanics in engineering practice. Hoboken, New Jersey: John Wiley \& Sons, Inc. 
48) Fredlund, M. D., Zhang, J. M., Tran, D., \& Fredlund, D. (2011). Coupling heat and moisture flow for the computation of actual evaporation. 2011 PanAm Conference CGS Geotechnical Conference. Toronto, ON.

49) Fujimaki, H., Shimano, T., Inoue, M., \& Nakane, K. (2006). Effect of a Salt Crust on Evaporation from a Bare Saline Soil. VadoseZone Journal, 5, 1246-1256.

50) Fujiyasu, Y., \& Fahey, M. (2000a). Experimental study of evaporation from saline tailings. Journal of Geotechnical and Geoenvironmental Engineering, 1827.

51) Fujiyasu, Y., Fahey, M., \& Newson, T. (2000b). Field investigation of evaporation from freshwater tailingsl engineering. Journal of Geotechnical and Geoenvironmental Engineering, 126(6), 556-567.

52) Gardner, W. R. (1958). Some steady state solutions of the unsaturated moisture flow equation with application to evaporation from a water table. Soil Science, $85(4), 228-232$.

53) Gillies, R., Sun, R., Spelay, R., Goldszal, A., \& Li, C. (2012). Pipeline transport of thickened oil sand tailings. International Oil Sands Tailings Conference. Edmonton, Alberta.

54) Gosselin, P., Hrudey, S. E., Naeth, M. A., Plourde, A., Therrien, R., Van Der Kraak, G., \& Xu, Z. (2010). The Royal Society of Canada Expert Panel: Environmental and Health Impacts of Canada's Oil Sand Industry. Ottawa: The 
Royal Society of Canada (RSC) The Academies of Arts, Humanities and Sciences of Canada.

55) Hatano, R., Nakamoto, H., Sakuma, T., \& Okajima, H. (1988). Evapotranspiration in cracked clay field soil. Soil Sc.. Plant Nutrition, 34(4), 547555.

56) Hillel, D. (1980). Applications of soil physics. New York: Academic Press, INC.

57) Howell, T. A., \& Evett, S. R. (2013, January 10). The Penman-Monteith Method. Retrieved from USDA- Conservation and Production Research Laboratory: http://www.cprl.ars.usda.gov/pdfs/pm\%20colo\%20bar\%202004\%20corrected\%2 09apr04.pdf

58) Hubbert, M. K. (1957). Darcy's law and the field equations of the flow of underground fluids, international association of scientific hydrology. bulletin, 2:1, 23-59. International Association of Scientific Hydrology, 2(1), 23-59.

59) Index Mundi. (n.d.). Retrieved August 07, 2012, from Index Mundi Crude World Crude Oil Consumption by year: http://www.indexmundi.com/energy.aspx

60) Jeeravipoolvarn, S. (2005). Compression Behaviour of Thixotropic Oil Sands Tailings, M.Sc. Thesis, University of Alberta.

61) Jewell, R. (2010, December). The evolution of paste and thickened tailings. Newsletter: Australian Center for Geomechanics, 35, pp. 1-3.

62) Junqueira, F. F., Sanin, M. V., Sedgwick, A., \& Blum, J. (2011). Assessment of water removal from oil sands tailings by evaporation and under-drainage, and the 
impact on tailings consolidation. Proceedind Tailings and MIne Waste 2011. Vancouver, BC.

63) Kaminsky, H. A. (2008). Characterization of an Athabasca Oil Sands Ore and Process Streams. Alberta, Canada: UofA / Infomine.

64) Krahn, J., \& Fredlund, D. G. (1973). On total, matric and osmotic suction. Soil Science, 116(5).

65) Lal, R., \& Shukla, M. K. (2004). Principles of Soil Physics. Basel, Switzerland: Marcel Dekker, Inc.

66) Leong, E. C., \& Rahardjo, H. (1997). Permeability functions for unsaturated soils. Journal of Geotechnical and Geoenvironmental Engineering, 123, 1118-1126.

67) Lideell, P. V., \& Boger, D. V. (1996). Yield stress measurement with the vane. JOurnal od NOn-Newtonian Fluids Mechanics, 63(2-3), 235-261.

68) Lins, Y. (2009). Hydro-mechanical properties of partially saturated sand. Ph.D. Disssertation, Faculty of Civil Engineering, University Bochum, Weibenfels, Germany. .

69) Mahfouf, J. F., \& Noilhan, J. (1991). Comparative study of various formulations of evaporation from bare soil using in situ data. Journal of Applied Meteorology, $30,1354-1365$.

70) Majid, A., \& Sparks, B. D. (1983, July). Determination of residual organic matter in extracted oil sands using a low temperature ashing method. FUEL, 62(7), 772774. 
71) Masala, S., \& Matthews, J. (n.d.). Predicting Development of Undrained Shear Strength in Soft Oil sands tailings r, Calgary, Alberta, Canada Jonathan Matthews Shell Energy Canada, Calgary, Alberta, Canada. Calgarty, Alberta.

72) Masliyah, J., Zhou, Z. J., Xu, Z., Czarnecki, J., \& Hamza, H. (2004, August). Understanding water-based bitumen extraction from Athabasca Oil Sands. The Canadian Journal of Chemical Engineering, 82, 628-654.

73) Melgarejo, M. L., Ridley, A. M., \& Dineen, K. (2002). A comparison of the soil water characteristic curves for reconstituted and undisturbed samples of a colluvium from Rio de Janeiro. Proceedings 3rd Inernational Conference on Unsaturated soils, (pp. 313-316). Recife: Balkema.

74) Mikula, R. J., Munoz, V. A., Kasperski, K. L., Sheeran, D., \& Omotoso, O. E. (1998). Commercial Implementation of a Dry Landscape Oil Sands Tailings Reclamation Option: Consolidated Tailings. 7th UNITAR Conference on Heavy Crude and Tar Sands (p. No. 1998.096). Beijing, China: www.Oildrop.com.

75) Miller, W. P., Radcliffe, D. E., \& Miller, D. M. (1988). An historical perspective on the theory and practice of soil mechanical analysis. J. Agron. Educ., 17(1), 2448.

76) Monteith, J. L. (1981). Evaporation and surface temperature. Quarterly Journal of the Royal Meteorological Society, 107(451), 1-27. 
77) Monteith, J. L., \& Choudury, B. J. (1988). A four layer model for heat budget of homogeneous land surfaces. Quarterly Journal of the Royal Meteorological Society, 114, 373-398.

78) Mualem, Y. (1976). A new model for predicting the hydraulic conductivity of unsaturated porous media. Water Resources Res., 12, 513-522.

79) National Energy Board. (2004). Canada's Oil Sands: Opportunities and Challengies to 2015. An Energy Market Assessment. Calgary, Alberta: National Energy Board.

80) National Energy Board. (2006). Canada's Oil Sands - Opportunities and Challenges to 2015: An Update - Questions and Answers. Retrieved from http://www.neb-one.gc.ca/clfnsi/rnrgynfmtn/nrgyrprt/lsnd/pprtntsndchllngs20152006/qapprtntsndchllngs20152 006-eng.html

81) Newson, T. A., \& Fahey, M. (2003). Measurement of evaporation from saline tailings storages. Engineering Geology, 70, 217-233.

82) Omotoso, D. (2011). Clay Characterization in the Oil Sand Industry. 2nd CONRAD Clay Workshop Presentation. Edmonton.

83) Omotoso, O., Mikula, R. J., \& Stephens, P. W. (2002). Surface area of interstratified phyllosilicates in Athabasca oil sands from Synchrotrom XRD. Advances in X-ray Analysis, 45. 
84) Philip, J., \& de Vries, D. (1957). Moisture movement in porous materials under temperature gradients. Transactions American Geophysical Union, 222-232.

85) Richards, B. G. (1965). Measurement of the free energy of soil moisture by the psychrometric technique using thermistors. Moisture equilibria and moisture changes in soils beneath covered areas. A symposium in print convened by Soil Mechanics Section, CSIRO, in collaboration with the National Building Research Institute and National Institute for Road Research CSIR (pp. 39-46). South Africa: Butterworths, Sydney, N.S.W.

86) Richards, L. A. (1931). Capillary conduction of liquids through porous medium. J. Physics, 1, 318-333.

87) Robinsky, E. (1979). Tailings disposal by the thickened discharge method for improved economy and environmental control. Proceedings of 2nd Int. Tailing Symp., (pp. 75-95). San Francisco.

88) Rutqvist, J., \& Stephansson, O. (2003). The role of hydromechanical coupling in fractured rock. Hydrogeology Journal, 11(1), 7-40.

89) S. E. (2005). 1250 Operating Insructions: Volumetric pressure plate extractor and hysteresis attachments. 12. Santa Barbara, CA: Soilmoisture Equipment Corp.

90) Schumacher, B. A. (2002). Methods for the determination of total organic carbon (TOC) in soils and sediments. Las Vegas: Ecological Risk Assessment Support Center, USEPA. 
91) Scintag, I. (1999). Chapter 7: Basics of X-Ray Diffraction. Retrieved from http://epswww.unm.edu/xrd/xrdbasics.pdf

92) Shimojima, E., Yoshioka, R., \& Tamagawa, I. (1996). Salinization owing to evaporation from bare-soil surfaces and its influences on evaporation. Journal of Hydrology, 178, 109-136.

93) Simms, P., Grabinsky, M., \& Zhan, G. (2007). Modelling evaporation of paste tailings from the Bulyanhulu mine. Canadian Geotechnical Journal, 1417-1432.

94) Skempton, A. W. (1953). The Colloidal Activity of Clay. Proceedings 3rd International Conference Soil Mechanics Foundation Engineering, 1, pp. 57-61.

95) Smits, K. M., Ngo, V. V., Cihan, A., Sakaki, T., \& Ilangasekare, T. H. (2012). An evaluation of models of bare soil evaporation formulated with different land surface boundary conditions and assumptions. Water Resouces Research, 48, W12526.

96) Sun, S. F. (1982). Moisture and heat transport in a soil layer forced by atmospheric conditions. M.Sc. thesis, University of Connecticut.

97) Taylor, D. W. (1948). Fundamentals of Soil Mechanics. New York: Wiley.

98) Terzaghi, K. (1943). Theoretical Soil Mechanics. New York: Wiley.

99) Total E\&P. (2010). Josyln North Mine Project. 
100) UMS. (2009). Manual: T5/T5x Pressure Transducer Tensiometer Version12. 48. $\begin{array}{llll}\text { Munchen. } & \text { Retrieved http://www.ums- }\end{array}$ muc.de/fileadmin/produkt_downloads/Tensiometer/T5_Manual.pdf

101) van de Griend, A. A., \& Owe, M. (1994). Bare soil surface resistance to evaporation by vapour diffusion under semiarid conditions. Water Resources Research, 30(2), 181-188.

102) van Genuchten, M. T. (1980). A closed form equation predicting the hydraulic conductivity of unsaturated soils. Soil Science Society of American Journal, 44, 892-898.

103) Vanapalli, S. K., Fredlund, D. G., \& Pufahl, D. E. (1999). Influence of soil structure and stress history on the soil-water characteristics of a compacted till. Geotechnique, 49(2), 143-159.

104) Vanapalli, S. K., Salinas, L. M., Avila, D., \& Karube, D. (2004). Suction and storage characteristics of unsaturated soils. Proceedings of the Third International Conference on Unsaturaed Soils, UNSAT 2002 (pp. 1045-1069). Recife, Brazil: Taylor and Francis.

105) Venkatramaiah, C. (2006). Geotechnical Engineering (Third ed.). New Delhi, India: New Age International Publishers.

106) Vogel, H., Hoffmann, H., Leopold, A., \& Roth, K. (2005). Studies of crack dynamics in clay soil II. A physically based model forcrack formation. Geoderma, 125, $213-223$. 
107) Wells, P. S. (2011). Long term in-situ behaviour of oil sands fine tailings in Suncor's Pond 1A. Proceeding Tailings and Mine Waste 2011. Vancouver, BC.

108) Wijermars, E. A. (2011). Sedimentation of Oil Sands Tailings. The Netherlands: Delf University of Technology.

109) Williams, M. P., Seddon, K. D., \& Fitton, T. G. (2008). Surface disposal of paste and thickened tailings - a brief hisory and current confronting issues. In R. J. Jewell, P. Slatter, \& A. Paterson (Ed.), Proceedings 11th International Seminar on PAste and Thickened Tailings (Paste 08) (pp. 143-154). Kasane, Botswana: Australian Center for Geomechanics, Perth.

110) Wilson, G. W., Fredlund, D. G., \& Barbour, S. L. (1991). The evaluation of evaporative fluxes from soil surfaces for problems in geotechnical engineering. Proceedings of the 44th Annual Canadian Geotechnical Conference, (pp. 61-69). Calgary, Alberta.

111) Wilson, G. W., Fredlund, D. G., \& Barbour, S. L. (1994). Coupled soilatmosphere modeling for soil evaporation. Canadian Geotechnical Journal, 151161.

112) Wilson, G. W., Fredlund, D. G., \& Barbour, S. L. (1997). The effect of soil suction on evaporative fluxes from soil surfaces. The Canadian Geotechnical Journal, 34(4), 145-155. 
113) Yamanaka, T., Takeda, A., \& Sugita, F. (1997). A modified surface-resistance approach for representing bare-soil evaporation: Wind tunnel experiments under various atmospheric conditions. Water Resources Research, 33(9), 2117-2128.

114) Yao, Y., van Tol, F., van Paassen, L., Everts, B., \& Mulder, A. (2010). Mud farming of fine oil sands tailings. Delft University of Technology.

115) Yeung, P. Y., Johnson, R. L., \& Acharya, S. N. (1993). An improved procedure for determining oil content in wet soil samples. Analysis of soils contaminated with petroleum constituents, (pp. 1-11). Atlanta, GA.

116) Znidarcić, D., Miller, R., Fredlund, M., van Zyl, D., \& Wells , S. (2011). Consolidation Testing of Oil Sand Fine Tailings. Proceedings Tailings and Mine Waste 2011. Vancuver, BC. 


\section{APPENDICES}

Appendix A: Solids Concentration. Gravimetric Water content. Bitumen Content. Density

Table A - 1: Summary of Tailings Composition: Solids concentration and Gravimetric water content

\begin{tabular}{|c|c|c|c|c|}
\hline \multirow{4}{*}{$\begin{array}{c}\text { Date of } \\
\text { Run }\end{array}$} & Drum No & $\begin{array}{c}\text { Average water } \\
\text { content } \\
\text { wrt total sample }\end{array}$ & $\begin{array}{c}\text { Average Solids } \\
\text { Concentration } \\
\text { Cs }\end{array}$ & $\begin{array}{c}\text { Average gravimetric } \\
\text { Water Content } \\
\mathbf{w}\end{array}$ \\
\cline { 2 - 5 } & $(\%)$ & $(\%)$ & $(\%)$ \\
\hline \multirow{5}{*}{ Nov-11 } & 1 & 45.18 & 54.82 & 82.41 \\
\cline { 2 - 5 } & 2 & 45.53 & 54.47 & 83.41 \\
\cline { 2 - 5 } & 3 & 46.51 & 53.49 & 86.95 \\
\cline { 2 - 5 } & 4 & 46.40 & 53.60 & 86.14 \\
\cline { 2 - 5 } & 5 & 45.43 & 54.57 & 83.26 \\
\hline \multirow{4}{*}{ Dec-11 } & 7 & 45.52 & 54.48 & 83.85 \\
\cline { 2 - 5 } & 11 & 45.37 & 54.63 & 83.04 \\
\cline { 2 - 5 } & 12 & 48.53 & 51.47 & 94.37 \\
\cline { 2 - 5 } & 13 & 51.45 & 48.55 & 105.96 \\
\cline { 2 - 5 } & 14 & 50.34 & 49.66 & 101.37 \\
\hline & 15 & 50.18 & 49.82 & 100.71 \\
\hline
\end{tabular}


Table A - 2: Tailings Density

\begin{tabular}{|c|c|c|}
\hline Date of Run & $\begin{array}{c}\text { Drum } \\
\text { No }\end{array}$ & Average Density \\
\cline { 2 - 3 } & & $\left(\mathrm{kg} / \mathrm{m}^{3}\right)$ \\
\hline \multirow{5}{*}{ Nov-11 } & 1 & 1518.52 \\
\cline { 2 - 3 } & 2 & 1528.40 \\
\cline { 2 - 3 } & 3 & 1559.49 \\
\cline { 2 - 3 } & 4 & 1541.98 \\
\hline & 5 & 1595.06 \\
\hline \multirow{5}{*}{ Dec-11 } & 6 & 1595.00 \\
\cline { 2 - 3 } & 7 & 1597.50 \\
\hline & 11 & 1511.25 \\
\cline { 2 - 3 } & 12 & 1554.67 \\
\cline { 2 - 3 } & 13 & 1574.51 \\
\cline { 2 - 3 } & 14 & 1589.39 \\
\hline & 15 & 1517.50 \\
\hline
\end{tabular}

Table A - 3: Tailings Density - Statistical Analysis

\begin{tabular}{|l|c|c|}
\cline { 2 - 3 } \multicolumn{1}{c|}{} & \multicolumn{2}{c|}{ Cs (\%) } \\
\hline Run & Nov-11 & Dec-11 \\
\hline Mean & 1562.2778 & 1549.4644 \\
\hline $\begin{array}{l}\text { Standard } \\
\text { Deviation }\end{array}$ & 33.8354 & 34.3888 \\
\hline SEM & 12.7886 & 15.3791 \\
\hline N & 7 & 5.00 \\
\hline \multirow{2}{*}{} & \multicolumn{2}{|c|}{ ttest } \\
\cline { 2 - 3 } & P & 0.538316627 \\
\hline
\end{tabular}


Table A - 4: Summary of Volatiles study

\begin{tabular}{|c|c|c|c|}
\hline \multirow{3}{*}{$\begin{array}{c}\text { Date of } \\
\text { Run }\end{array}$} & Drum No & $\begin{array}{c}\text { Average Volatiles } \\
\text { Content } \\
\text { wrt total sample }\end{array}$ & $\begin{array}{c}\text { Average volatiles } \\
\text { content per g of Solids }\end{array}$ \\
\cline { 2 - 4 } & $\mathbf{( \% )}$ & $\mathbf{g}$ \\
\hline \multirow{4}{*}{ Nov-11 } & 1 & 2.03 & 0.04 \\
\cline { 2 - 4 } & 2 & 1.86 & 0.03 \\
\cline { 2 - 4 } & 3 & 2.12 & 0.04 \\
\cline { 2 - 4 } & 4 & 2.18 & 0.04 \\
\cline { 2 - 4 } & 5 & 1.83 & 0.03 \\
\cline { 2 - 4 } & 6 & 1.46 & 0.03 \\
\hline \multirow{4}{*}{ Dec-11 } & 7 & 1.54 & 0.03 \\
\cline { 2 - 4 } & 11 & 1.86 & 0.04 \\
\cline { 2 - 4 } & 12 & 1.62 & 0.03 \\
\cline { 2 - 4 } & 13 & 1.54 & 0.03 \\
\cline { 2 - 4 } & 14 & 1.60 & 0.03 \\
\hline
\end{tabular}

Table A- 5: Volatiles Content - Statistical Analysis

\begin{tabular}{|l|c|c|}
\cline { 2 - 3 } \multicolumn{1}{c|}{} & \multicolumn{2}{c|}{ Cs (\%) } \\
\hline Run & Nov-11 & Dec-11 \\
\hline Mean & 1.8611 & 1.7564 \\
\hline $\begin{array}{l}\text { Standard } \\
\text { Deviation }\end{array}$ & 0.2752 & 0.2635 \\
\hline SEM & 0.1040 & 0.1179 \\
\hline $\mathrm{N}$ & 7 & 5.00 \\
\hline \multirow{2}{*}{} & \multicolumn{2}{|c|}{ ttest } \\
\cline { 2 - 3 } & $\mathrm{P}$ & 0.522241277 \\
\hline
\end{tabular}




\section{Appendix B: Atterberg Limits}

Table B - 1: Summary - Atterberg Limits

\begin{tabular}{|c|c|c|c|c|c|}
\hline $\begin{array}{c}\text { Date of } \\
\text { Run }\end{array}$ & \multirow{2}{*}{ Drum No } & Liquid Limit & Plastic Limit & Shrinkage Limit & Plasticity Index \\
\cline { 2 - 6 } & & $(\%)$ & $(\%)$ & $(\%)$ & $(\%)$ \\
\hline \multirow{5}{*}{ Nov-11 } & 1 & 36.60 & 21.44 & 18.84 & 12.86 \\
\cline { 2 - 6 } & 2 & 34.00 & 20.69 & 20.74 & 13.31 \\
\cline { 2 - 6 } & 3 & 34.00 & 19.44 & 17.79 & 14.56 \\
\cline { 2 - 6 } & 4 & 33.70 & 19.44 & 20.74 & 14.26 \\
\cline { 2 - 6 } & 5 & 26.63 & 19.74 & 14.53 & 6.89 \\
\cline { 2 - 6 } & 6 & 26.20 & 18.83 & 19.46 & 7.37 \\
\hline \multirow{4}{*}{ Dec-11 } & 7 & 25.09 & 17.16 & 18.05 & 7.93 \\
\cline { 2 - 6 } & 11 & 25.00 & 19.82 & 17.13 & 5.18 \\
\cline { 2 - 6 } & 12 & 25.50 & 16.23 & 18.57 & 9.27 \\
\cline { 2 - 6 } & 13 & 27.00 & 19.51 & 17.56 & 7.49 \\
\cline { 2 - 6 } & 14 & 26.51 & 17.16 & 17.85 & 9.35 \\
\hline & 15 & 35.00 & 20.00 & 18.01 & 15.00 \\
\hline
\end{tabular}

Table B - 2: Atterberg Limits - Statistical Analysis

\begin{tabular}{|c|c|c|c|c|}
\hline & & & $13 x$ & 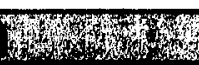 \\
\hline Run & Nov-11 & Dec-11 & Nov-11 & Dec-11 \\
\hline Mean & 30.8886 & 27.8020 & 19.5355 & 18.5439 \\
\hline Standard Deviation & 4.7193 & 4.1010 & 1.3656 & 1.7301 \\
\hline SEM & 1.7837 & 1.8340 & 0.5161 & 0.7737 \\
\hline $\mathbf{N}$ & 7 & 5.00 & 7 & 5.00 \\
\hline ttest & $\mathbf{P}$ & 0.256865335 & $\mathbf{P}$ & 0.32000545 \\
\hline
\end{tabular}

\begin{tabular}{|c|c|c|c|c|}
\hline & \multicolumn{2}{|c|}{ Her } & \multicolumn{2}{|c|}{ PI (x) } \\
\hline Run & Nov-11 & Dec-11 & Nov-11 & Dec-11 \\
\hline Mean & 18.5919 & 17.3210 & 11.0245 & 9.2581 \\
\hline Standard Deviation & 2.1402 & 1.3761 & 3.4523 & 3.6316 \\
\hline SEM & 0.8089 & 0.6154 & 1.3048 & 1.6241 \\
\hline $\mathbf{N}$ & 7.00 & 5.00 & 7 & 5.00 \\
\hline ttest & $\mathbf{P}$ & 0.239782473 & $\mathbf{P}$ & 0.374469084 \\
\hline
\end{tabular}




\section{Appendix C: Specific Gravity. GSD}

Table C - 1: Summary - Specific Gravity

\begin{tabular}{|c|c|c|}
\hline Date of Run & Drum No & Specific Gravity \\
\hline \multirow{4}{*}{ Nov-11 } & 1 & 2.63 \\
\cline { 2 - 3 } & 2 & 2.53 \\
\cline { 2 - 3 } & 3 & 2.56 \\
\cline { 2 - 3 } & 4 & 2.56 \\
\cline { 2 - 3 } & 5 & 2.49 \\
\cline { 2 - 3 } & 6 & 2.51 \\
\cline { 2 - 3 } Dec-11 & 7 & 2.58 \\
\hline \multirow{5}{*}{} & 11 & 2.70 \\
\cline { 2 - 3 } & 12 & 2.48 \\
\cline { 2 - 3 } & 13 & 2.50 \\
\cline { 2 - 3 } & 14 & 2.51 \\
\cline { 2 - 3 } & 15 & 2.56 \\
\hline
\end{tabular}

Table C - 2: Specific Gravity - Statistical Analysis

\begin{tabular}{|l|c|c|}
\cline { 2 - 3 } \multicolumn{1}{c|}{} & \multicolumn{2}{c|}{ Gs } \\
\hline Run & Nov-11 & Dec-11 \\
\hline Mean & 2.5518 & 2.5503 \\
\hline $\begin{array}{l}\text { Standard } \\
\text { Deviation }\end{array}$ & 0.0458 & 0.0898 \\
\hline SEM & 0.0173 & 0.0402 \\
\hline $\mathrm{N}$ & 7 & 5.00 \\
\hline \multirow{2}{*}{} & \multicolumn{2}{|c|}{ ttest } \\
\cline { 2 - 3 } & $\mathrm{P}$ & 0.973929899 \\
\cline { 2 - 3 }
\end{tabular}




\section{GSD November 2011}

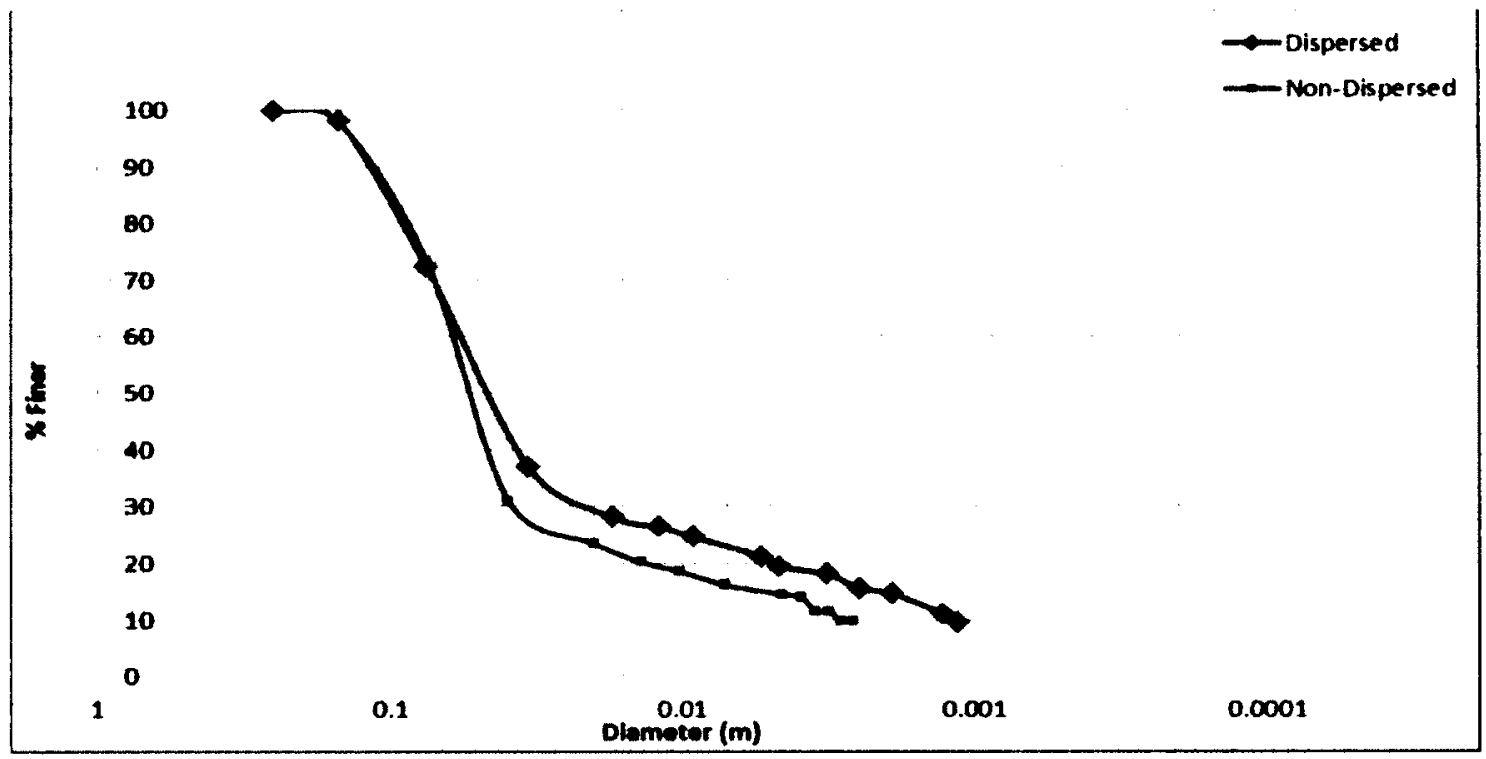

Figure C - 1: GSD Drum 1

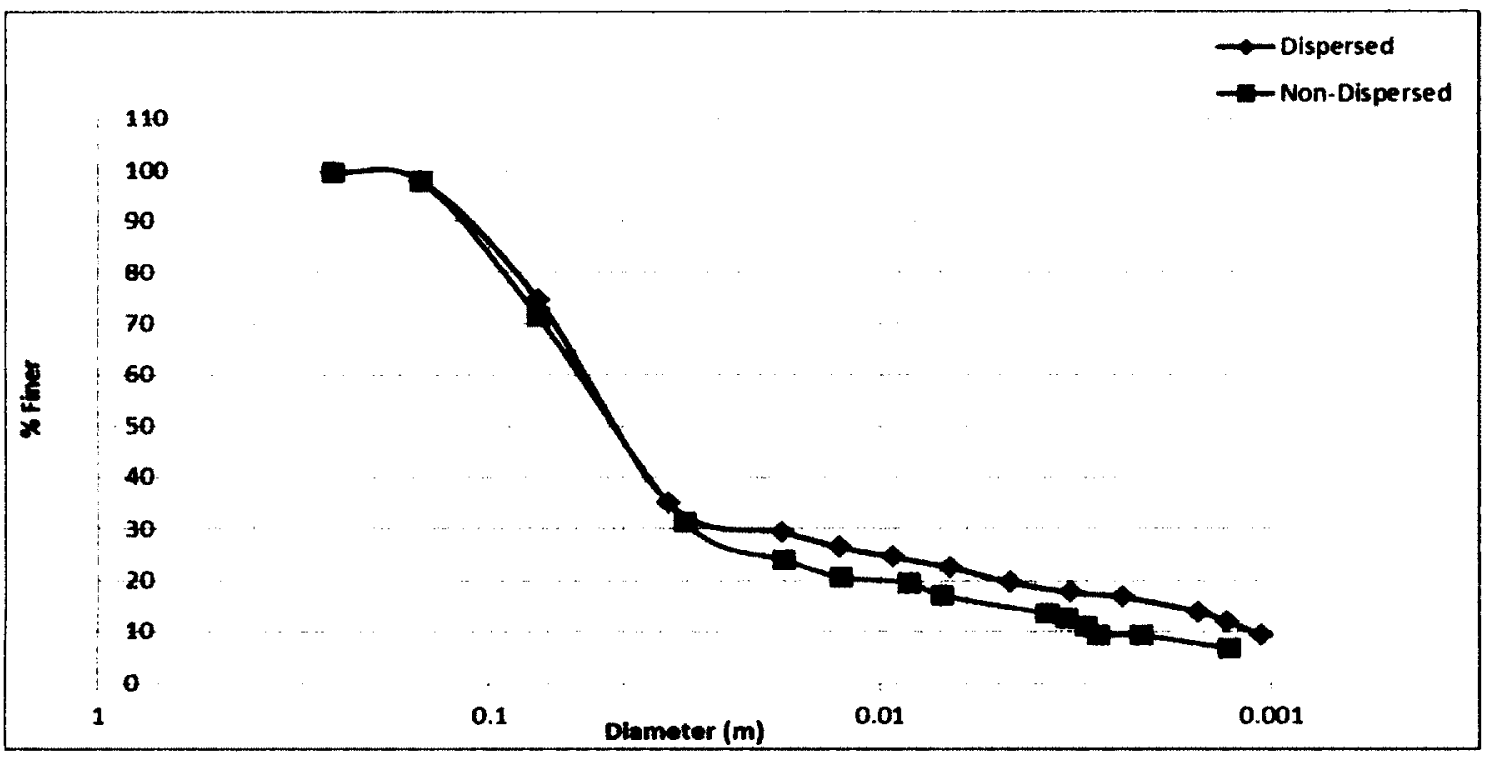

Figure C - 2: GSD Drum 2 


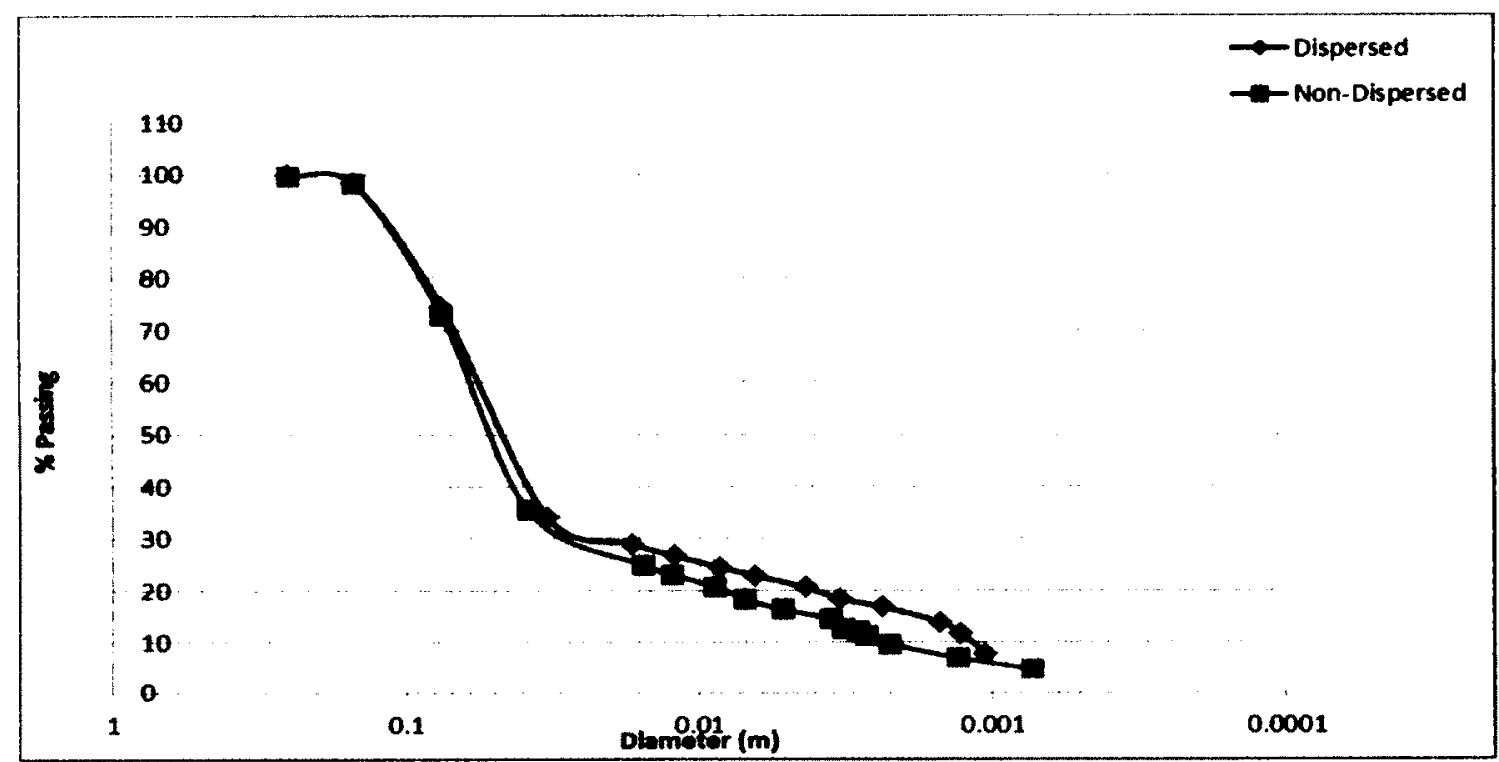

Figure C - 3: GSD Drum 3

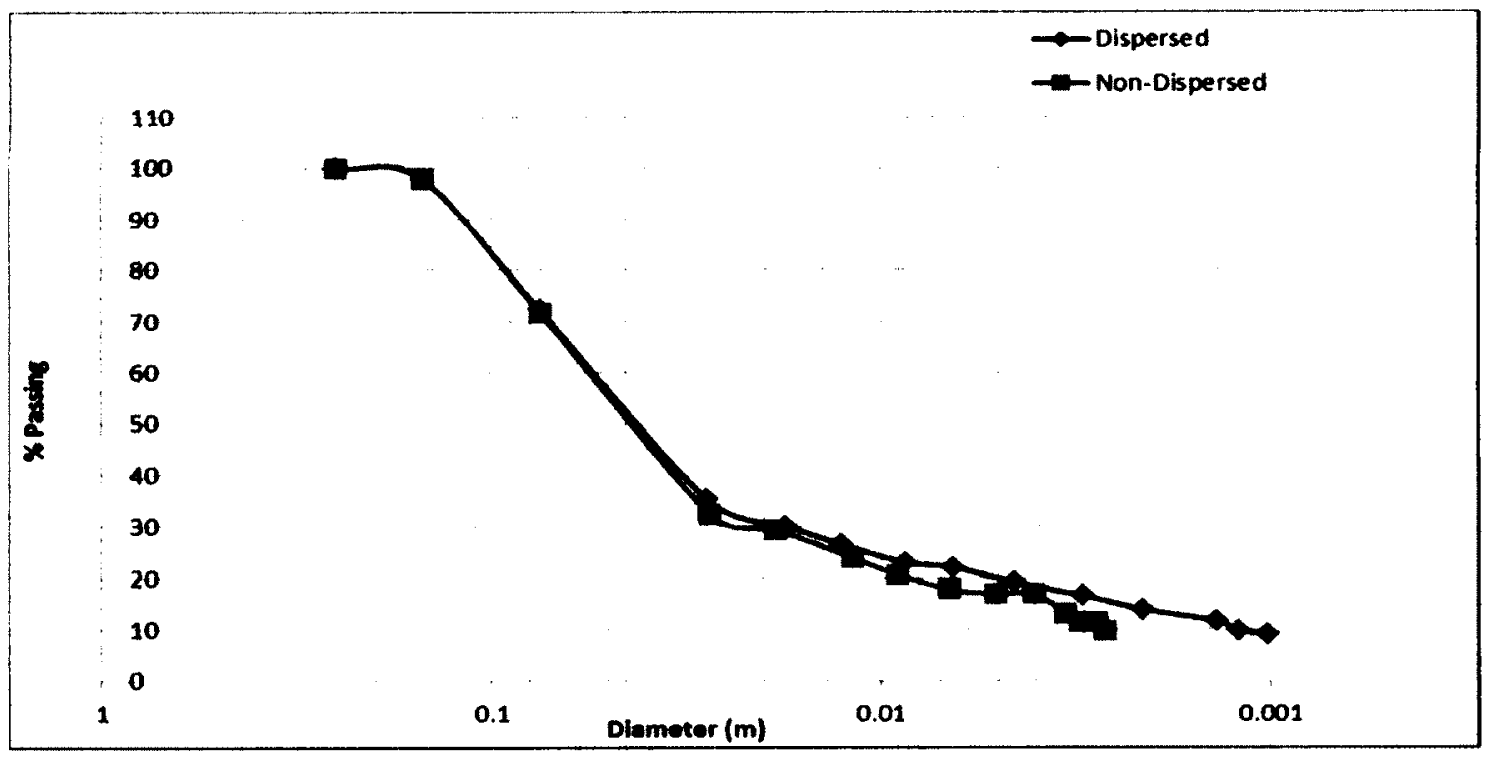

Figure C - 4: GSD Drum 4 


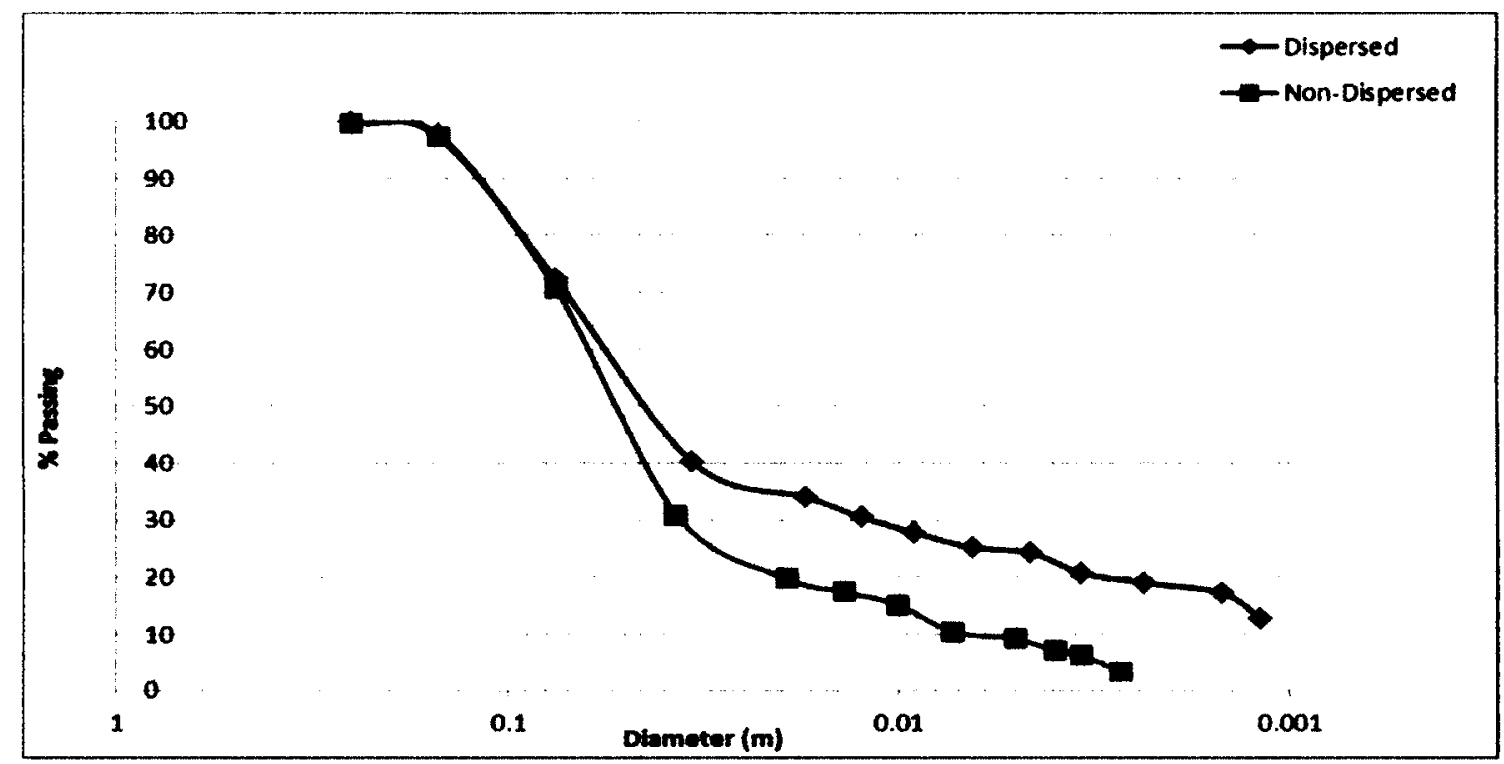

Figure C - 5: GSD Drum 5

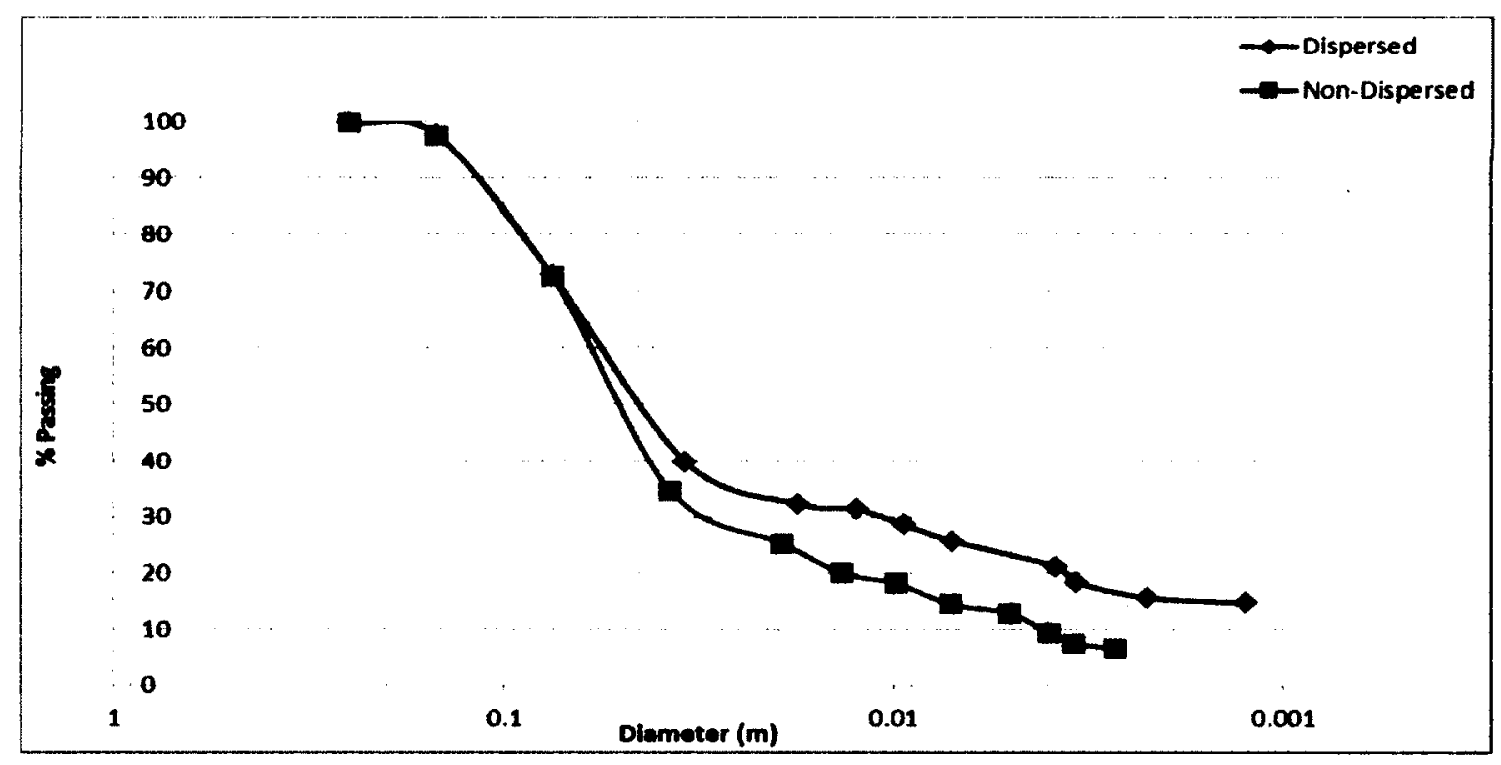

Figure C - 6: GSD Drum 6 


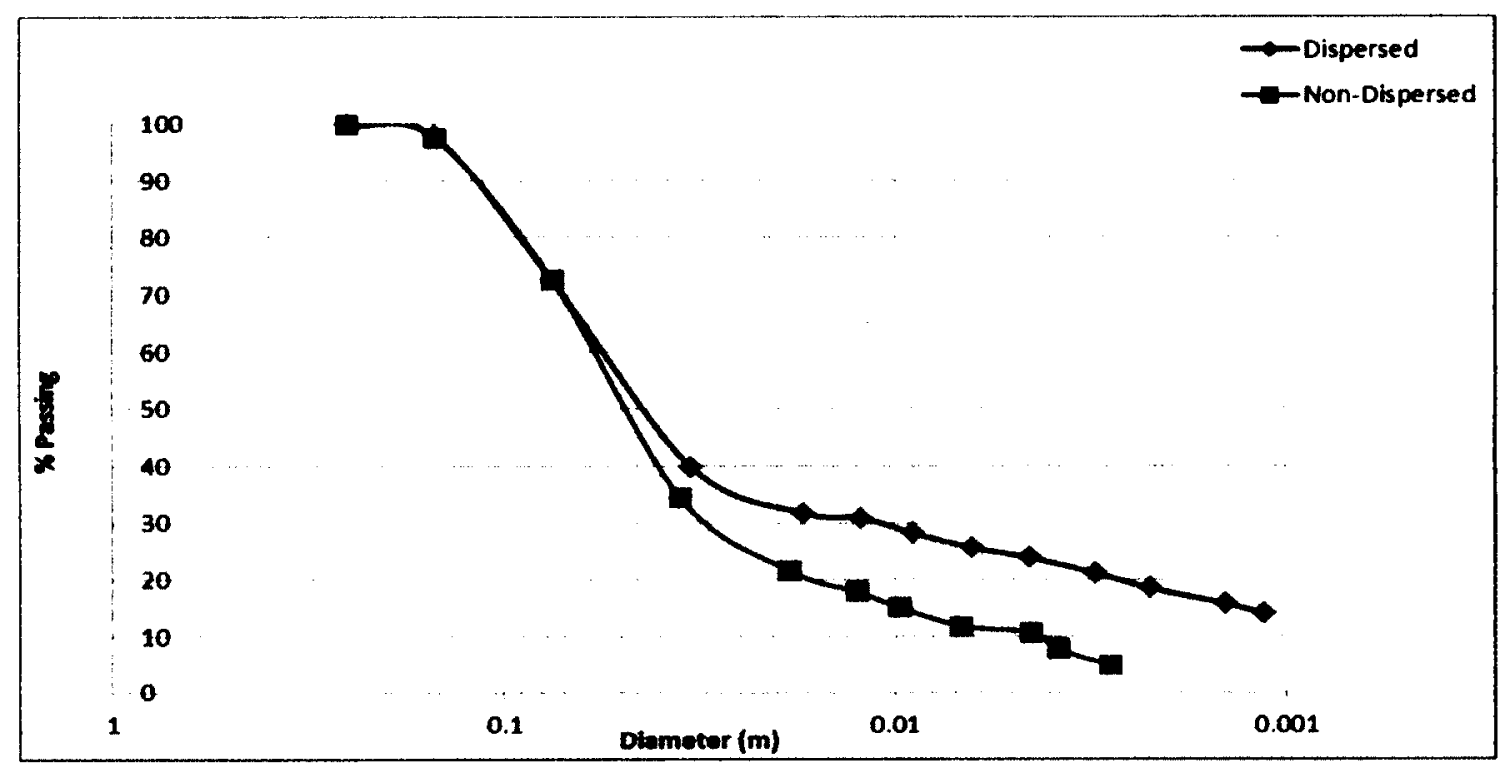

Figure C - 7: GSD Drum 7

\section{GSD December 2011}

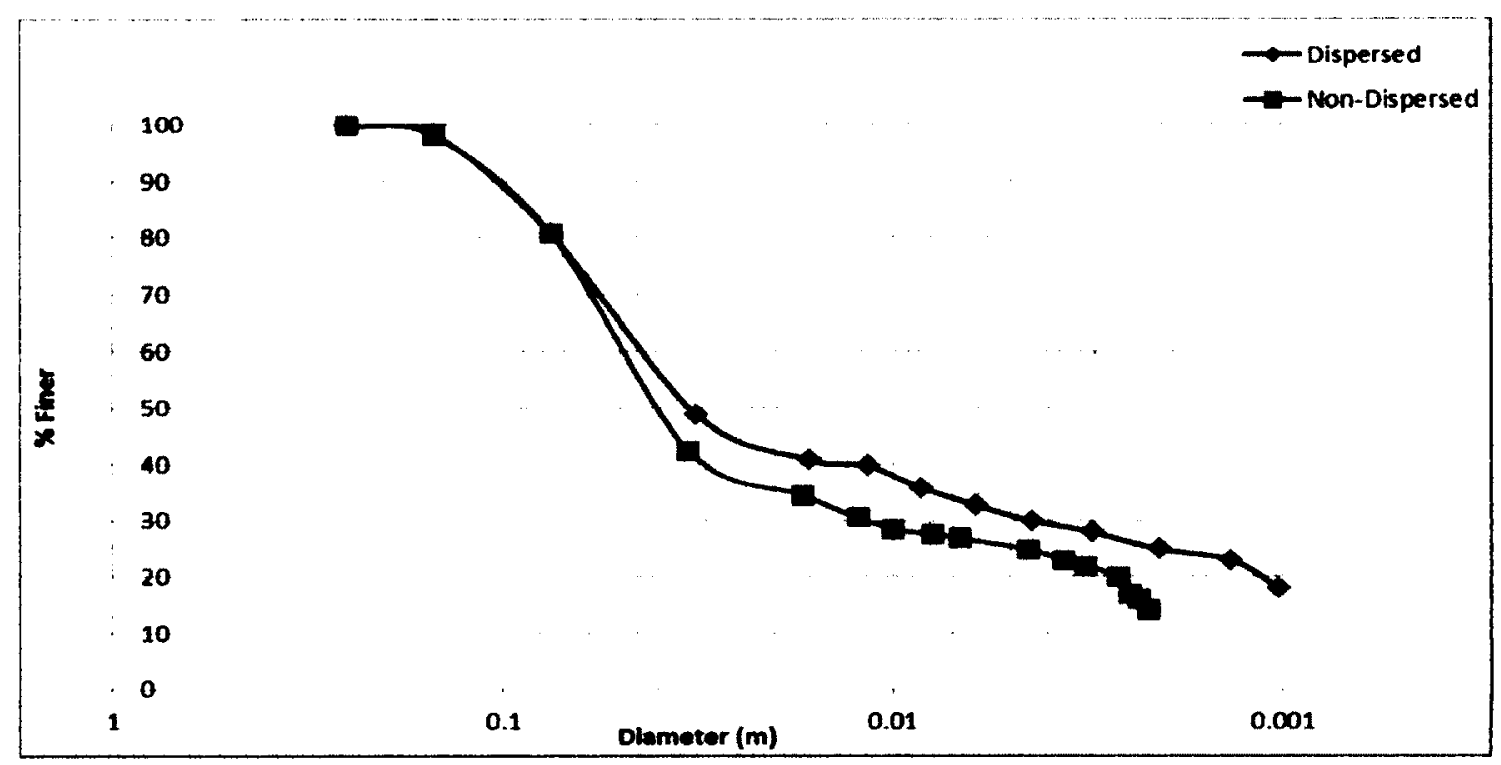

Figure C - 8: GSD Drum 11 


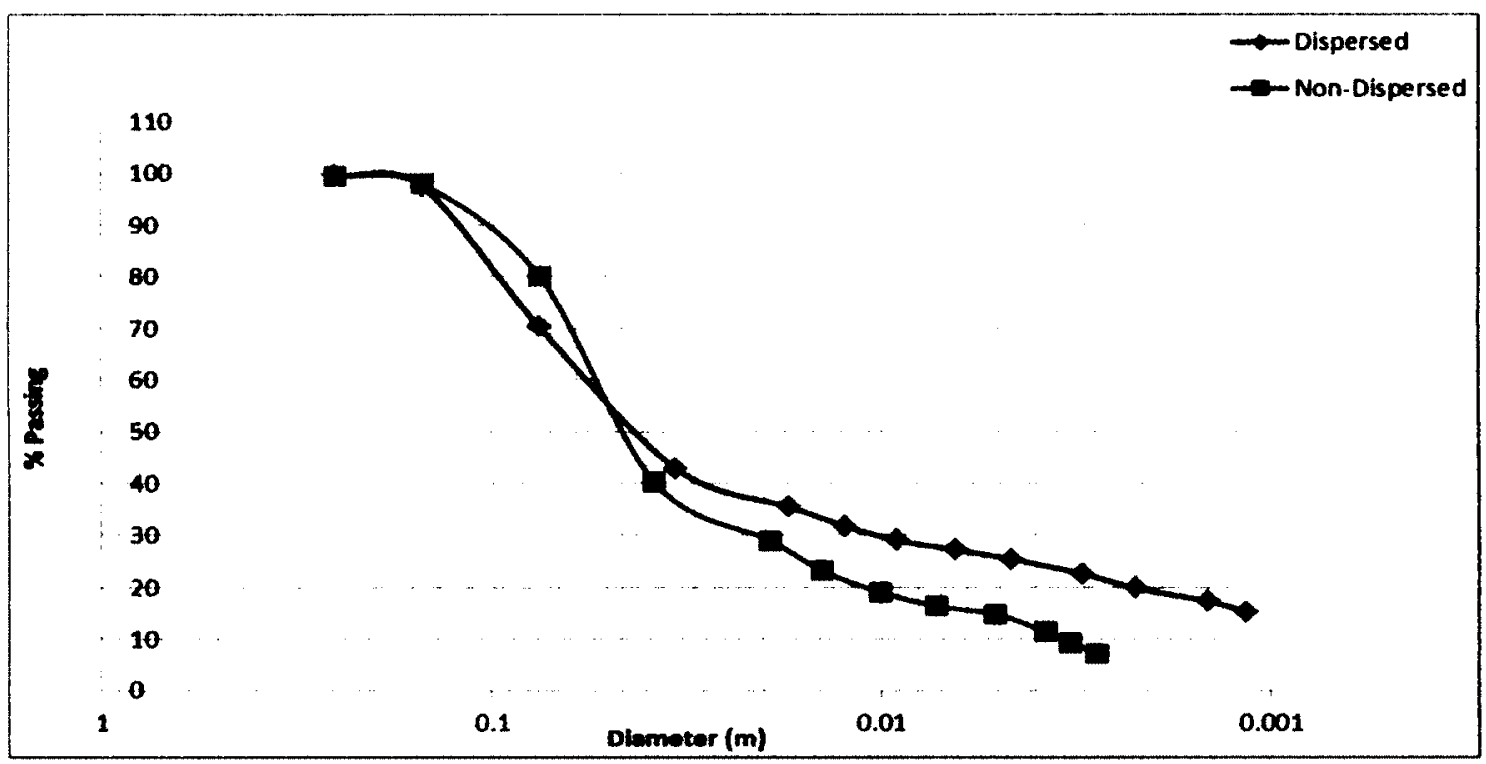

Figure C - 9: GSD Drum 12

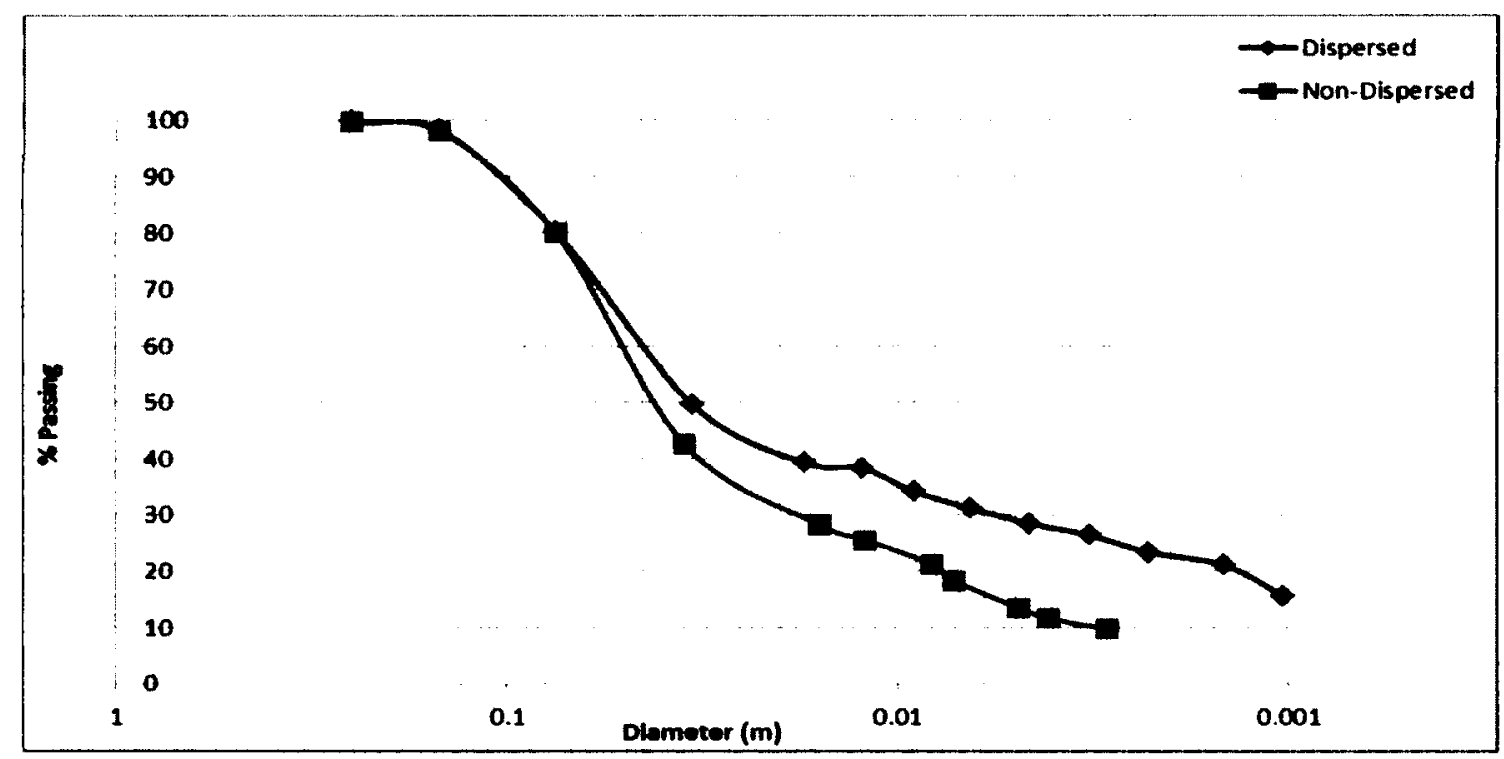

Figure C - 10: GSD Drum 13 


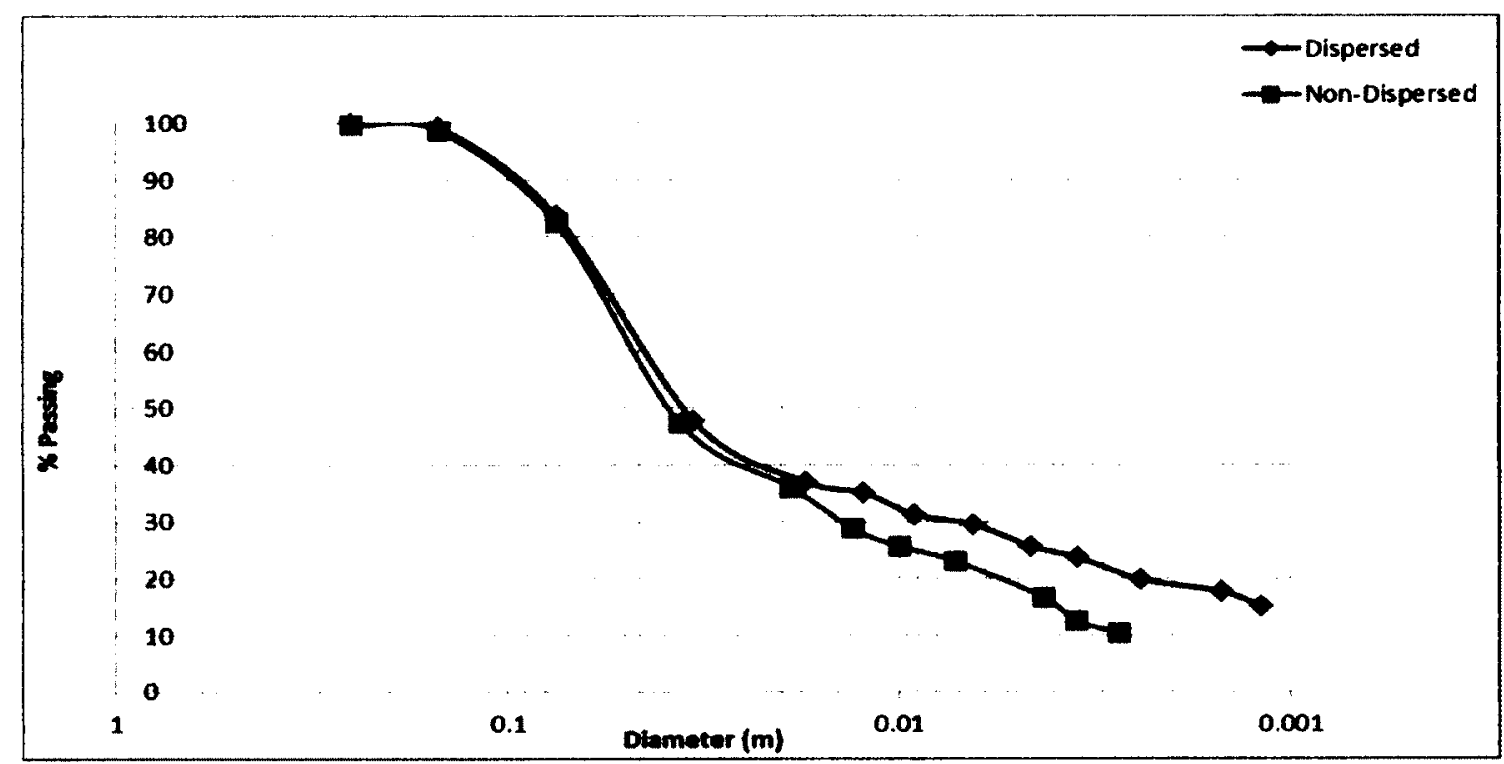

Figure C - 11: GSD Drum 14

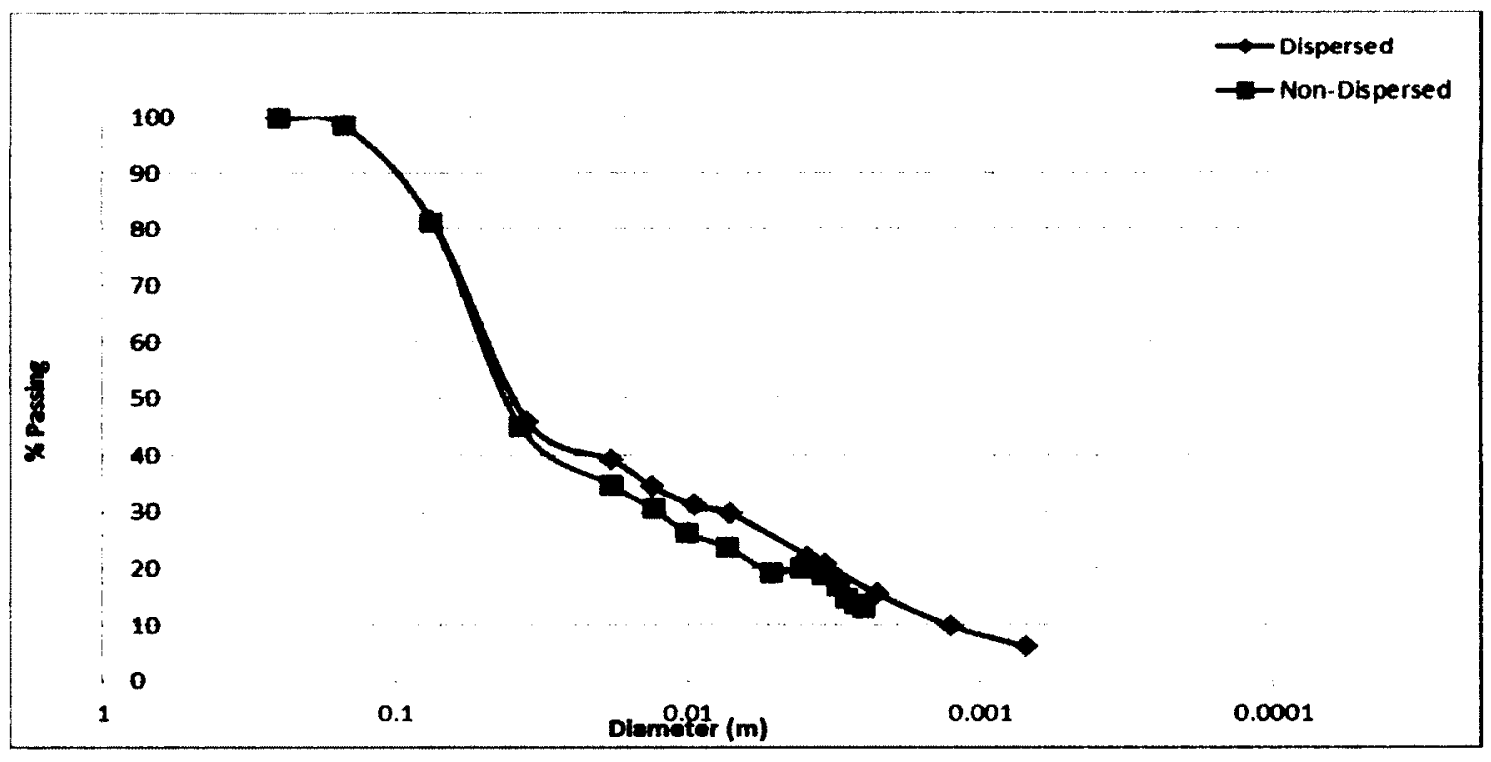

Figure C - 12: GSD Drum 15 
Table C - 3: Summary GSD

\begin{tabular}{|c|c|c|c|c|c|c|c|c|c|c|}
\hline \multirow{2}{*}{$\begin{array}{l}\text { Date } \\
\text { of Run }\end{array}$} & \multirow{2}{*}{$\begin{array}{c}\text { Drum } \\
\text { No }\end{array}$} & D 90 & D 60 & D 50 & D 30 & D 10 & \multirow{2}{*}{$\mathrm{Cu}$} & \multirow{2}{*}{ Cc } & \multirow{2}{*}{$\begin{array}{c}\% \text { passing no. } 200 \\
\text { - dispersed }\end{array}$} & \multirow{2}{*}{$\begin{array}{c}\%<2 \\
\mu \mathrm{m}\end{array}$} \\
\hline & & $\mathrm{mm}$ & $\mathrm{mm}$ & $\mathrm{mm}$ & $\mathrm{mm}$ & $\mathbf{m m}$ & & & & \\
\hline \multirow{7}{*}{ Nov-11 } & 1 & 0.13 & 0.057 & 0.046 & 0.024 & 0.0013 & 43.85 & 7.77 & 72.30 & 15 \\
\hline & 2 & 0.12 & 0.058 & 0.048 & 0.018 & 0.0012 & 48.33 & 4.66 & 74.69 & 15 \\
\hline & 3 & 0.12 & 0.057 & 0.047 & 0.017 & 0.0012 & 47.50 & 4.23 & 74.46 & 16 \\
\hline & 4 & 0.13 & 0.055 & 0.042 & 0.017 & 0.0013 & 42.31 & 4.04 & 72.20 & 14 \\
\hline & 5 & 0.13 & 0.057 & 0.045 & 0.013 & 0.0013 & 43.85 & 2.28 & 72.30 & 18 \\
\hline & 6 & 0.13 & 0.058 & 0.045 & 0.012 & 0.001 & 58.00 & 2.48 & 72.75 & 15 \\
\hline & 7 & 0.13 & 0.057 & 0.045 & 0.014 & 0.001 & 57.00 & 3.44 & 72.57 & 17 \\
\hline \multirow{5}{*}{ Dec-11 } & 11 & 0.12 & 0.045 & 0.035 & 0.0045 & 0.001 & 45.00 & 0.45 & 80.65 & 25 \\
\hline & 12 & 0.13 & 0.058 & 0.043 & 0.01 & 0.001 & 58.00 & 1.72 & 70.35 & 19 \\
\hline & 13 & 0.11 & 0.045 & 0.034 & 0.0055 & 0.001 & 45.00 & 0.67 & 80.30 & 22 \\
\hline & 14 & 0.095 & 0.045 & 0.037 & 0.0068 & 0.001 & 45.00 & 1.03 & 83.71 & 18 \\
\hline & 15 & 0.1 & 0.048 & 0.04 & 0.007 & 0.0013 & 36.92 & 0.79 & 81.65 & 15 \\
\hline
\end{tabular}

Table C - 4: GSD Statistical Analysis

\begin{tabular}{|c|c|c|c|c|c|c|c|c|c|c|c|c|}
\hline \multirow[b]{2}{*}{ Run } & \multicolumn{2}{|c|}{ D 90} & \multicolumn{2}{|c|}{ D 60} & \multicolumn{2}{|c|}{ D 50} & \multicolumn{2}{|c|}{ D 30} & \multicolumn{2}{|c|}{ D 10} & \multicolumn{2}{|c|}{$\%$ passing no. 200} \\
\hline & Nov-11 & Dec-11 & Nov-11 & Dec-11 & Nov-11 & Dec-11 & Nov-11 & Dec-11 & Nov-11 & Dec-11 & Nov-11 & Dec-11 \\
\hline Mean & 0.1271 & 0.1110 & 0.0570 & 0.0482 & 0.0454 & 0.0378 & 0.0164 & 0.0068 & 0.0012 & 0.0011 & 73.0387 & 79.3311 \\
\hline SEM & 0.0018 & 0.0064 & 0.0004 & 0.0025 & 0.0007 & 0.0017 & 0.0015 & 0.0009 & 0.0001 & 0.0001 & 0.6931 & 0.2189 \\
\hline $\mathbf{N}$ & 7 & 5.00 & 7 & 5.00 & 7 & 5.00 & 7 & 5.00 & 7 & 5.00 & 7 & 5.00 \\
\hline
\end{tabular}




\section{Appendix D: XRD}

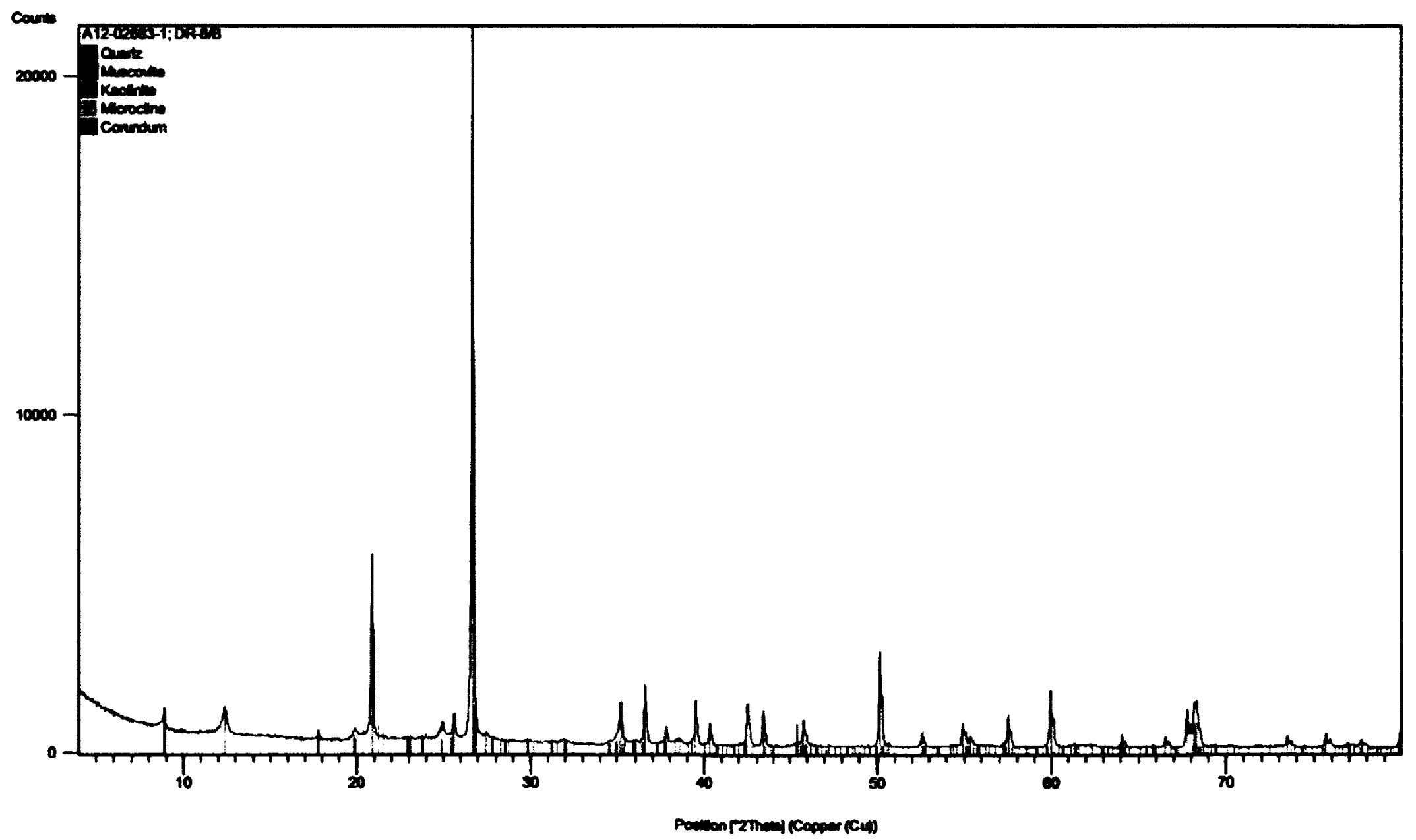

Figure D - 1: Bulk Sample Diffraction Pattern S-1 


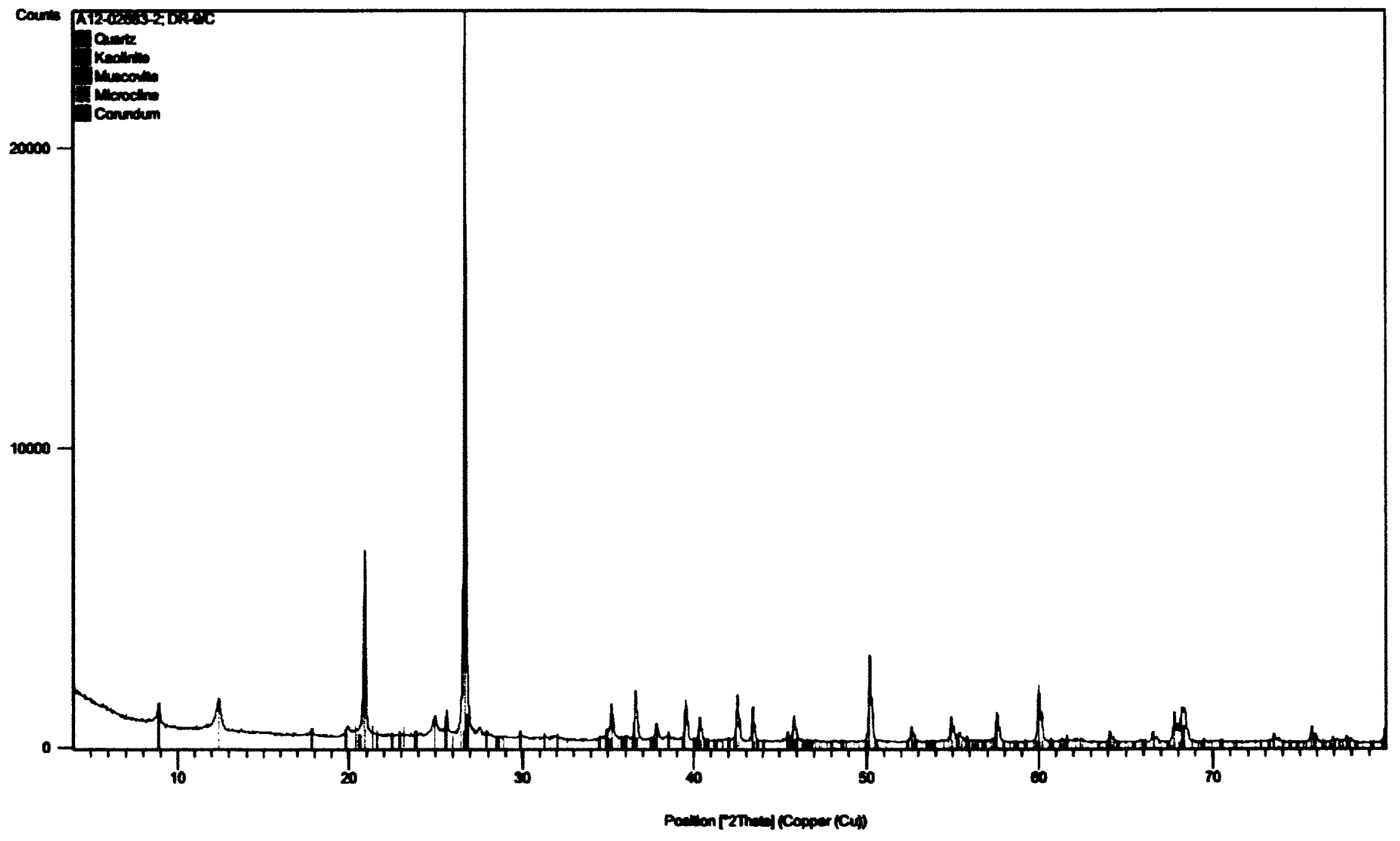

Figure D - 2: Bulk Sample Diffraction Pattern S-2 


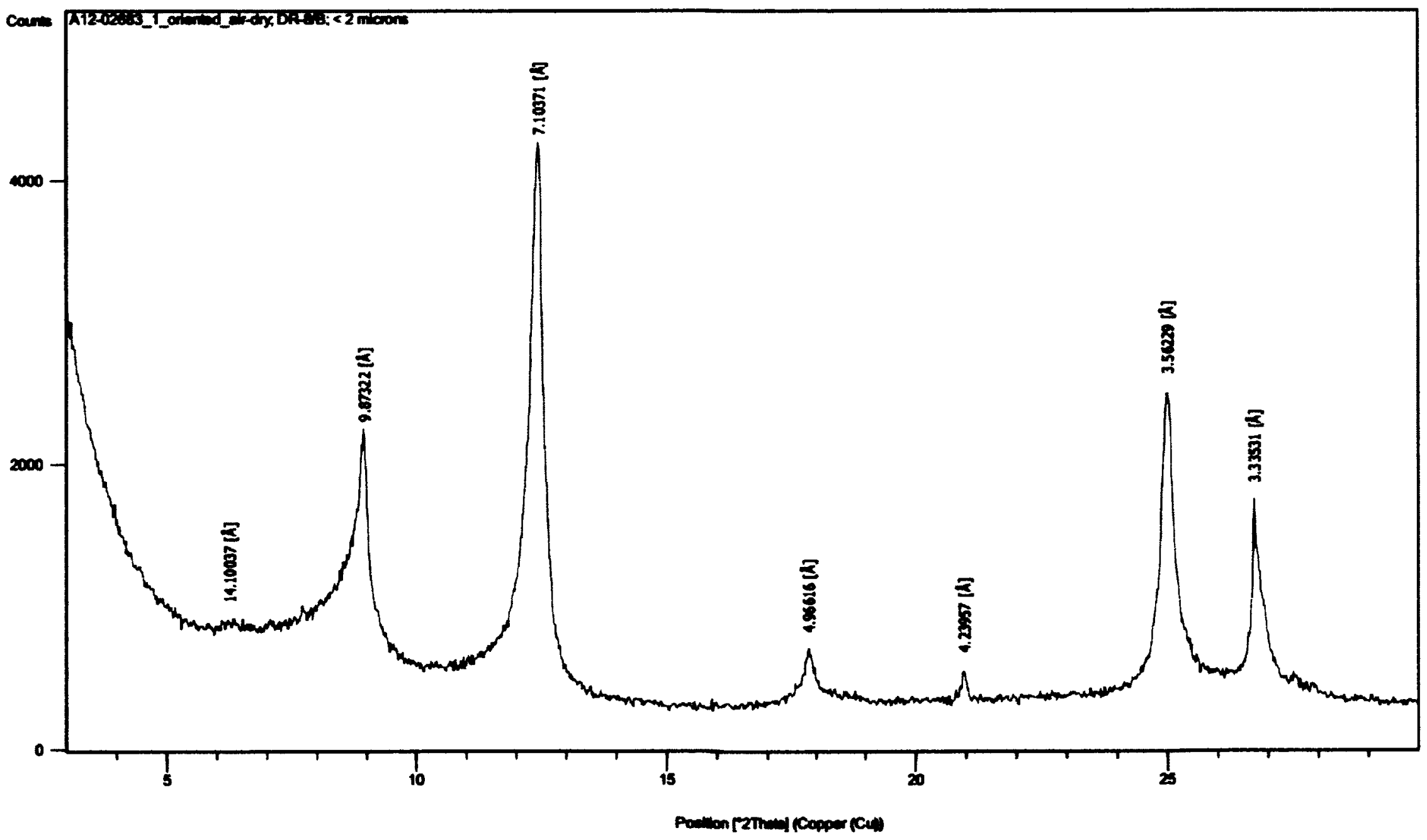

Figure D - 3: XRD - Clay speciation (Air Dry) -S1

261 


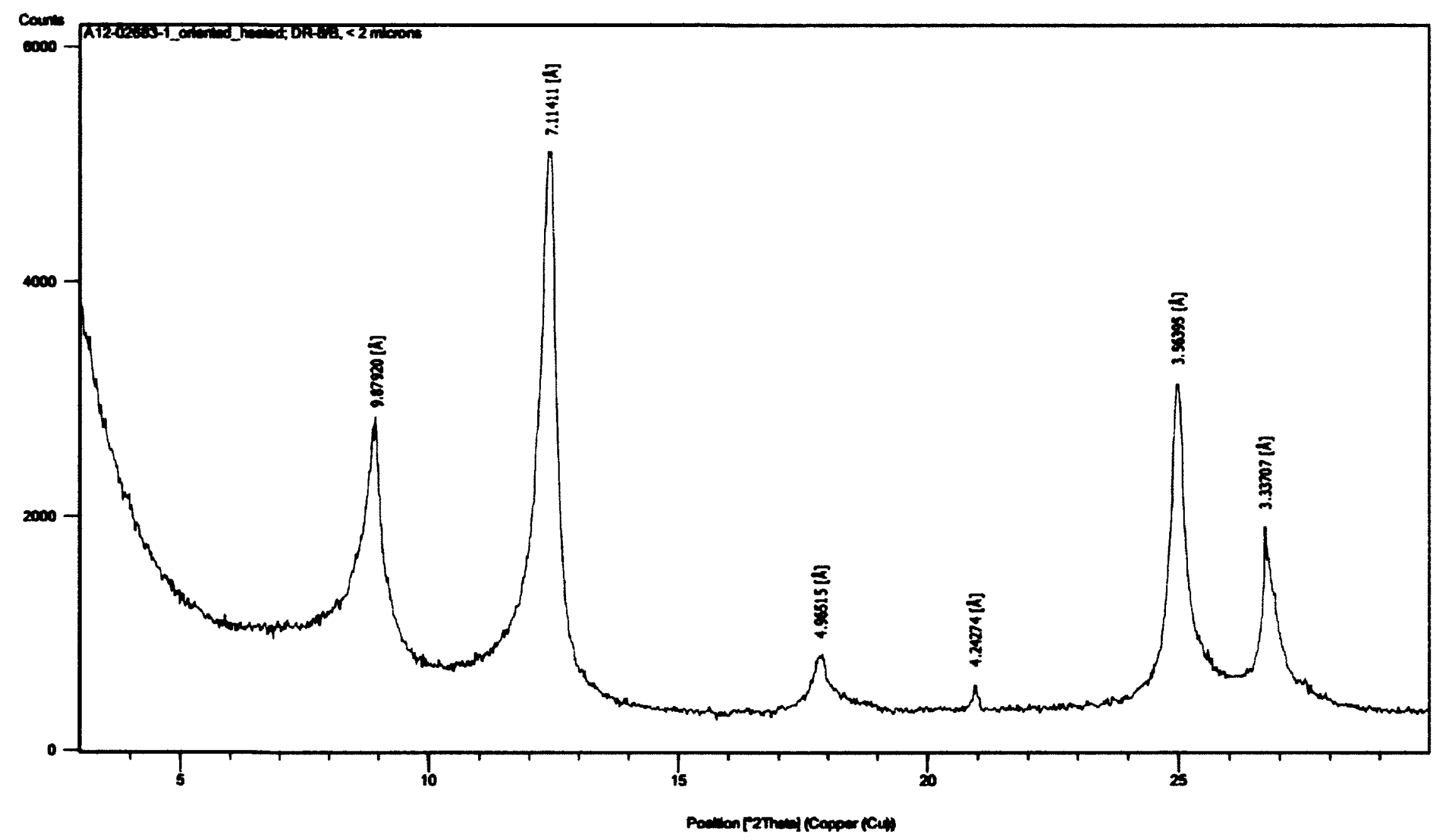

Figure D - 4: XRD - Clay speciation (Heated) -S1 


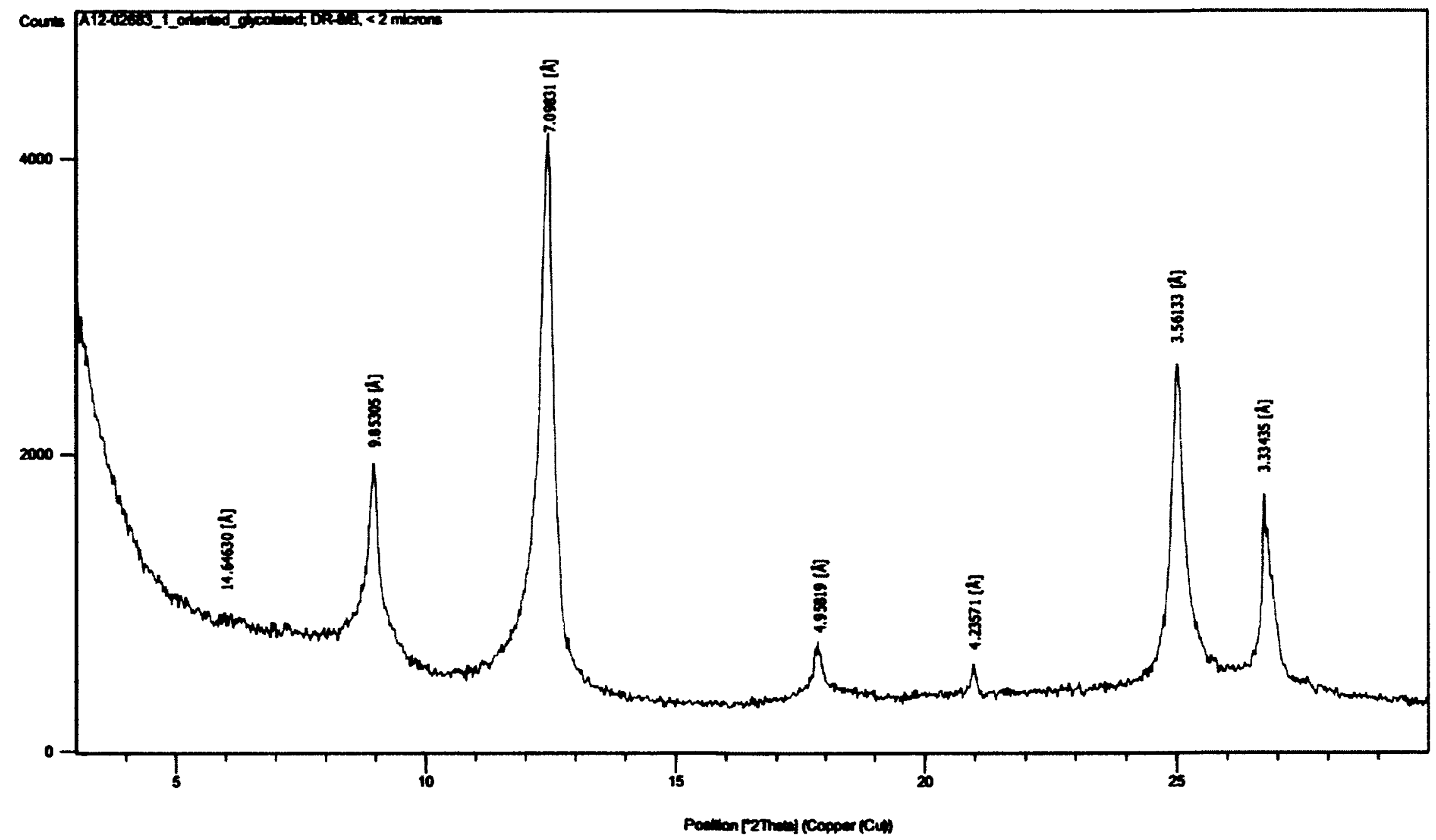

Figure D - 5: XRD - Clay speciation (Glycolated) -S1 


$$
\text { Lيle }
$$




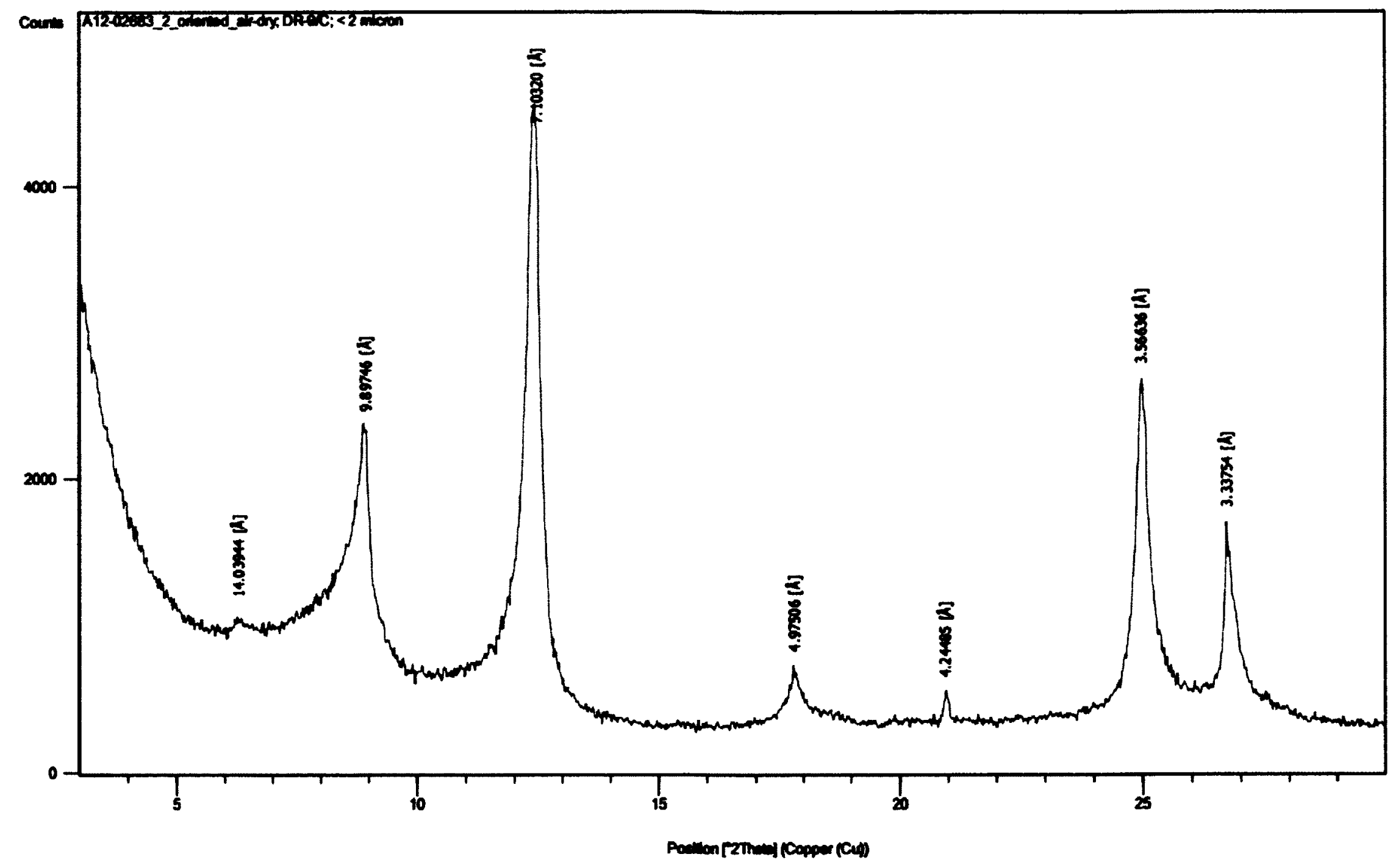

Figure D - 7: XRD - Clay speciation (Air Dry) -S2 


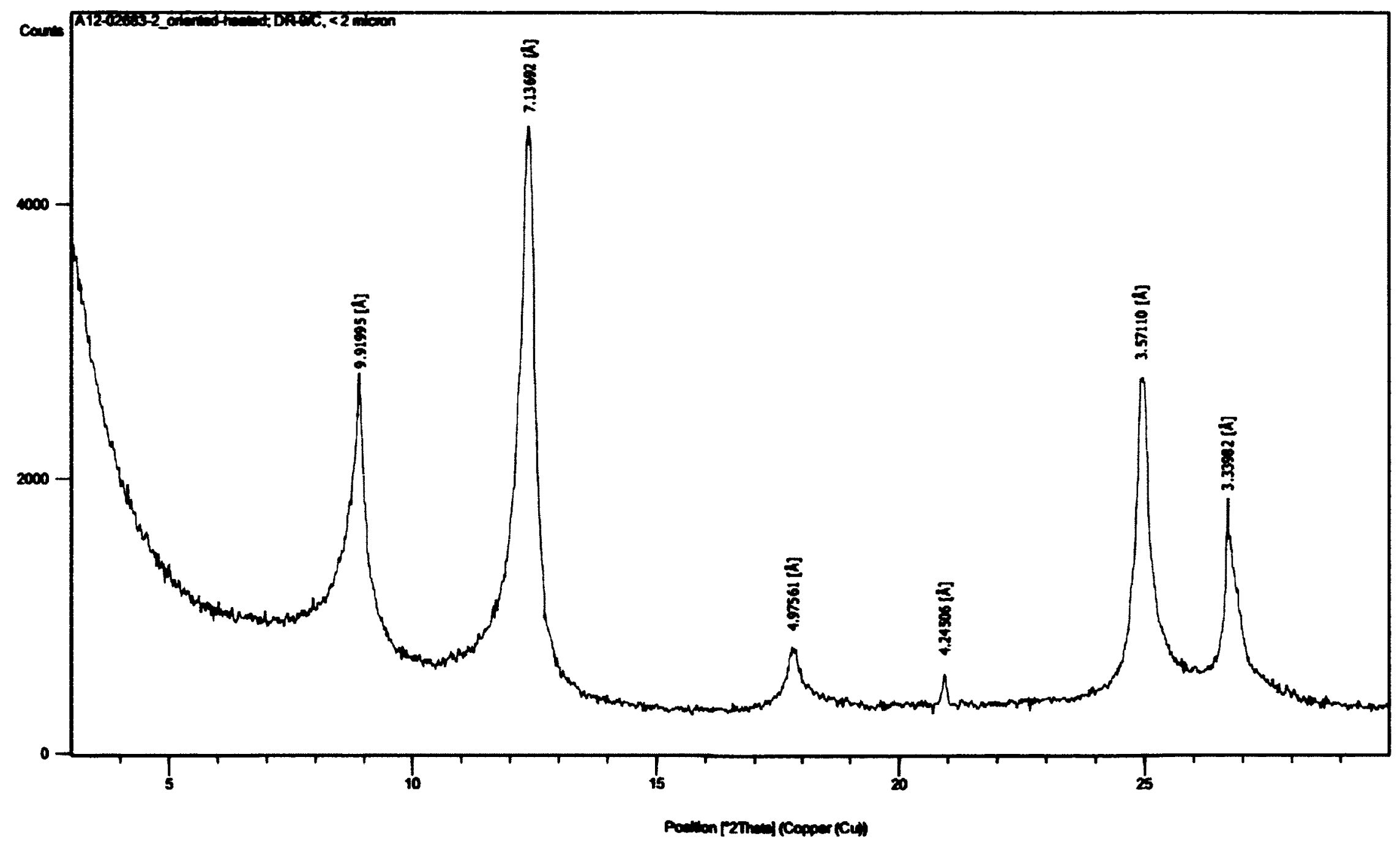

Figure D - 8: XRD - Clay speciation (Heated) $-\mathrm{S2}$ 


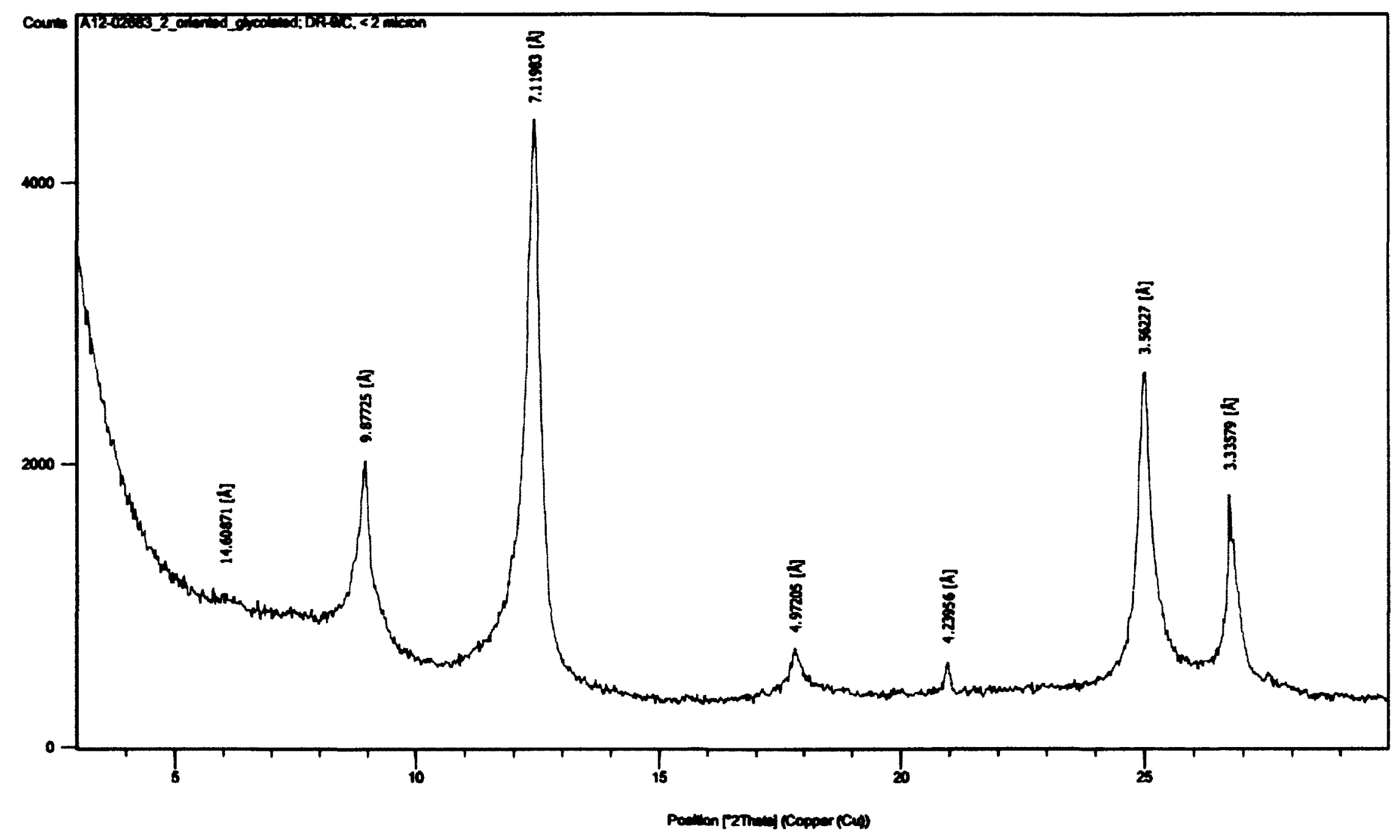

Figure D - 9: XRD - Clay speciation (Glycolated) -S2 


$$
\text { Ululu }
$$




\section{Appendix E: Rheology - Flow Curves}

\section{November 2011 - Cs: $55 \%$}

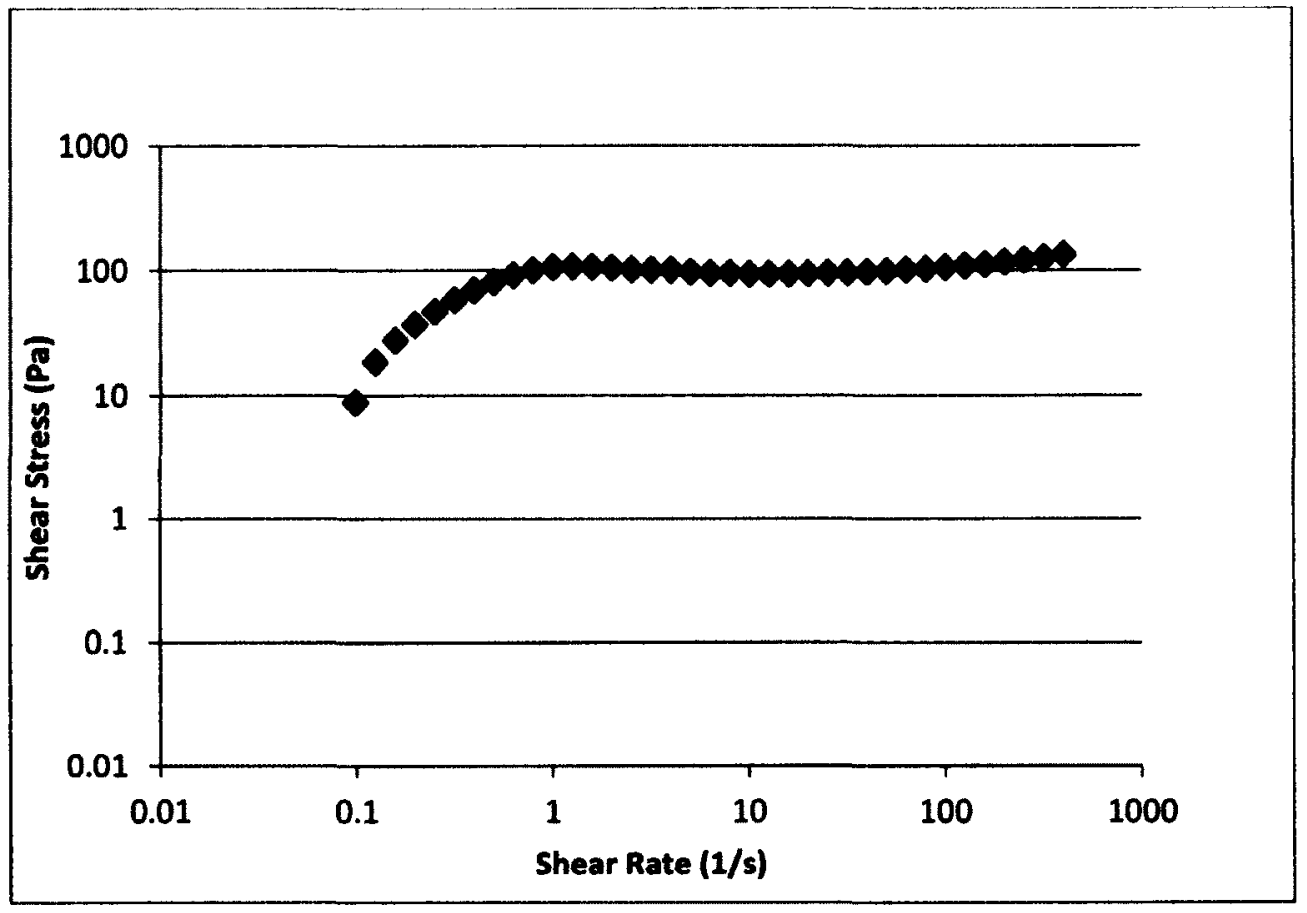

Figure E - 1: Flow Curve Drum 1

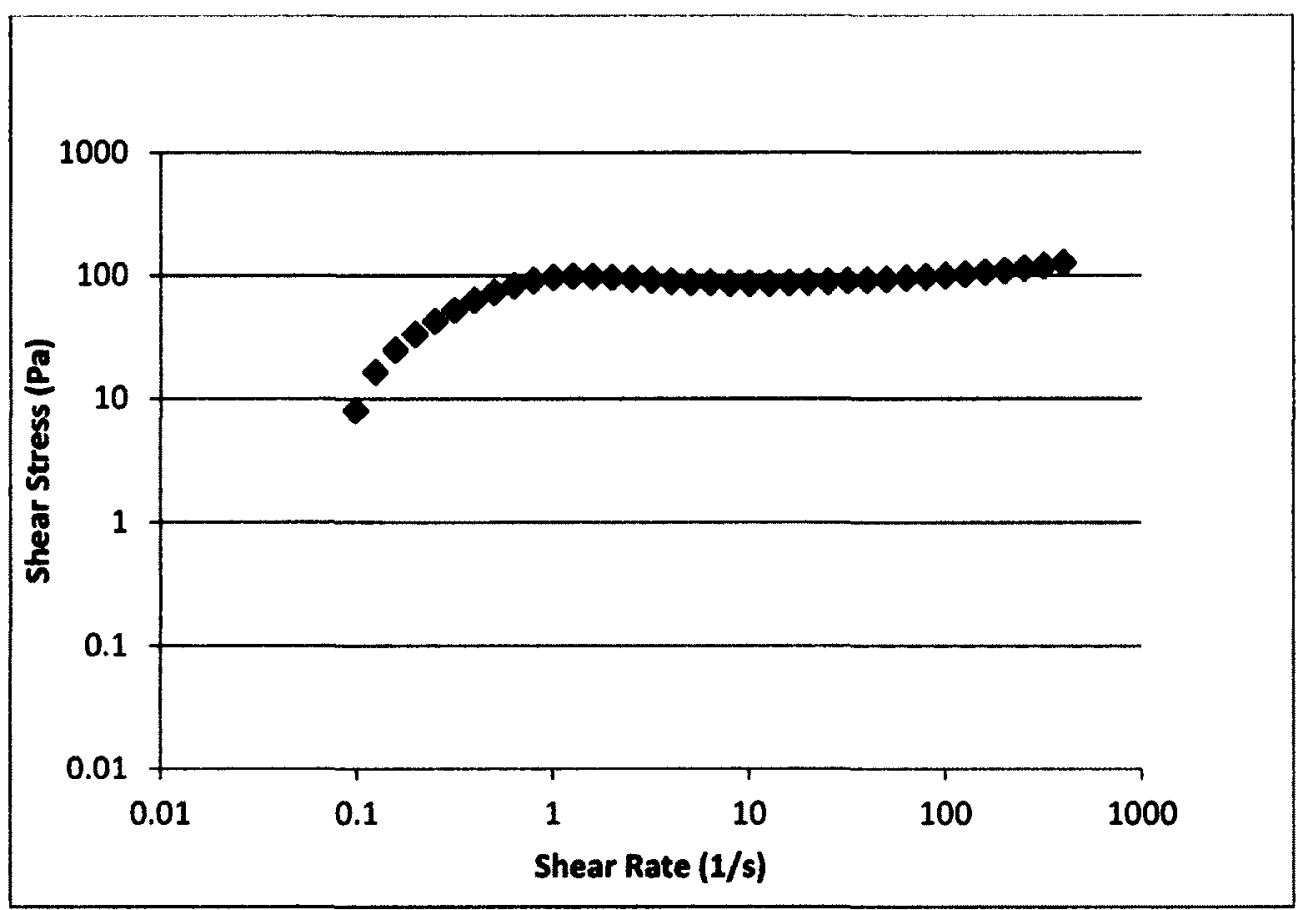

Figure E - 2: Flow Curve Drum 2 


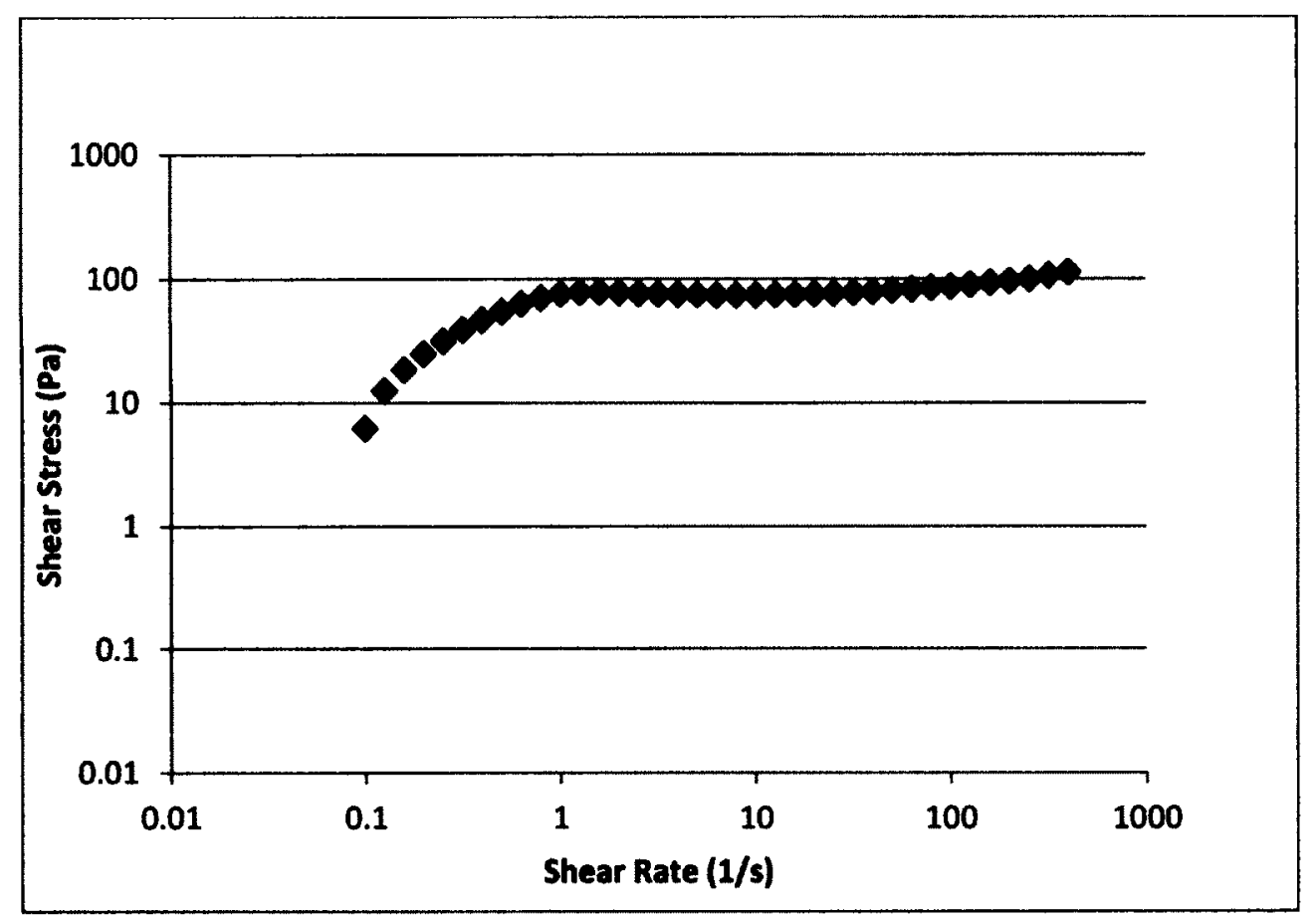

Figure E - 3: Flow Curve Drum 4

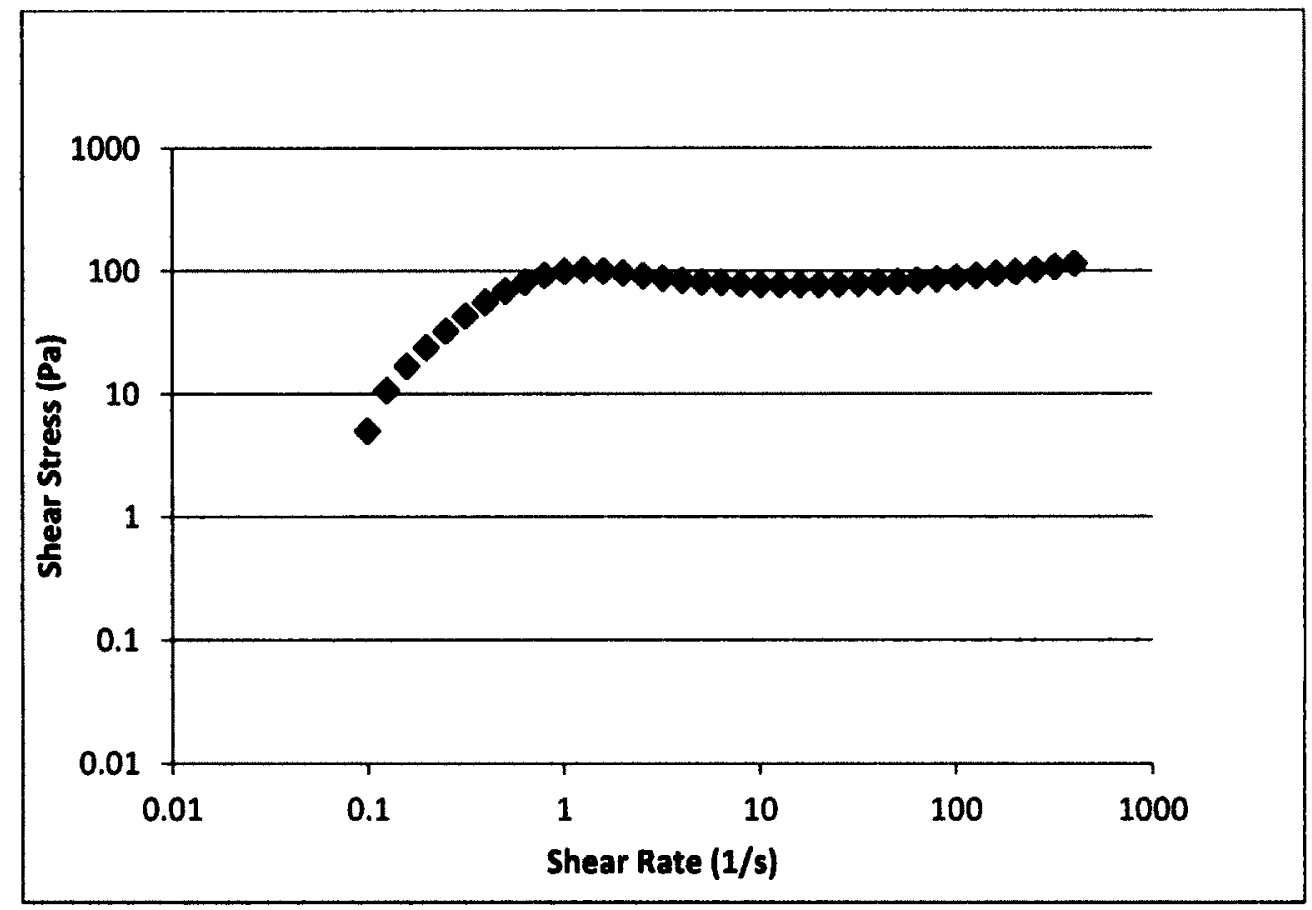

Figure E - 4: Flow Curve Drum 5 


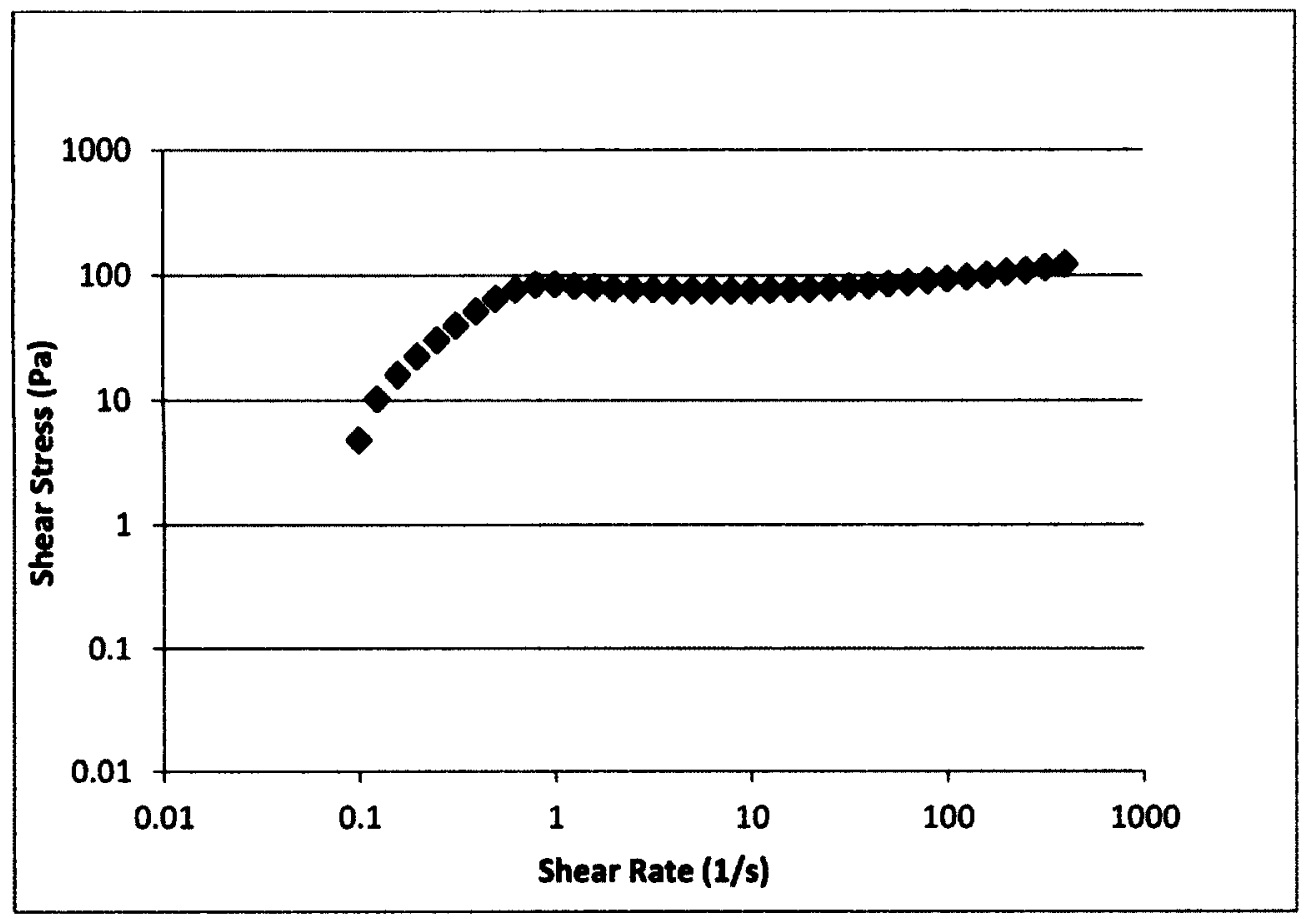

Figure E - 5: Flow Curve Drum 6

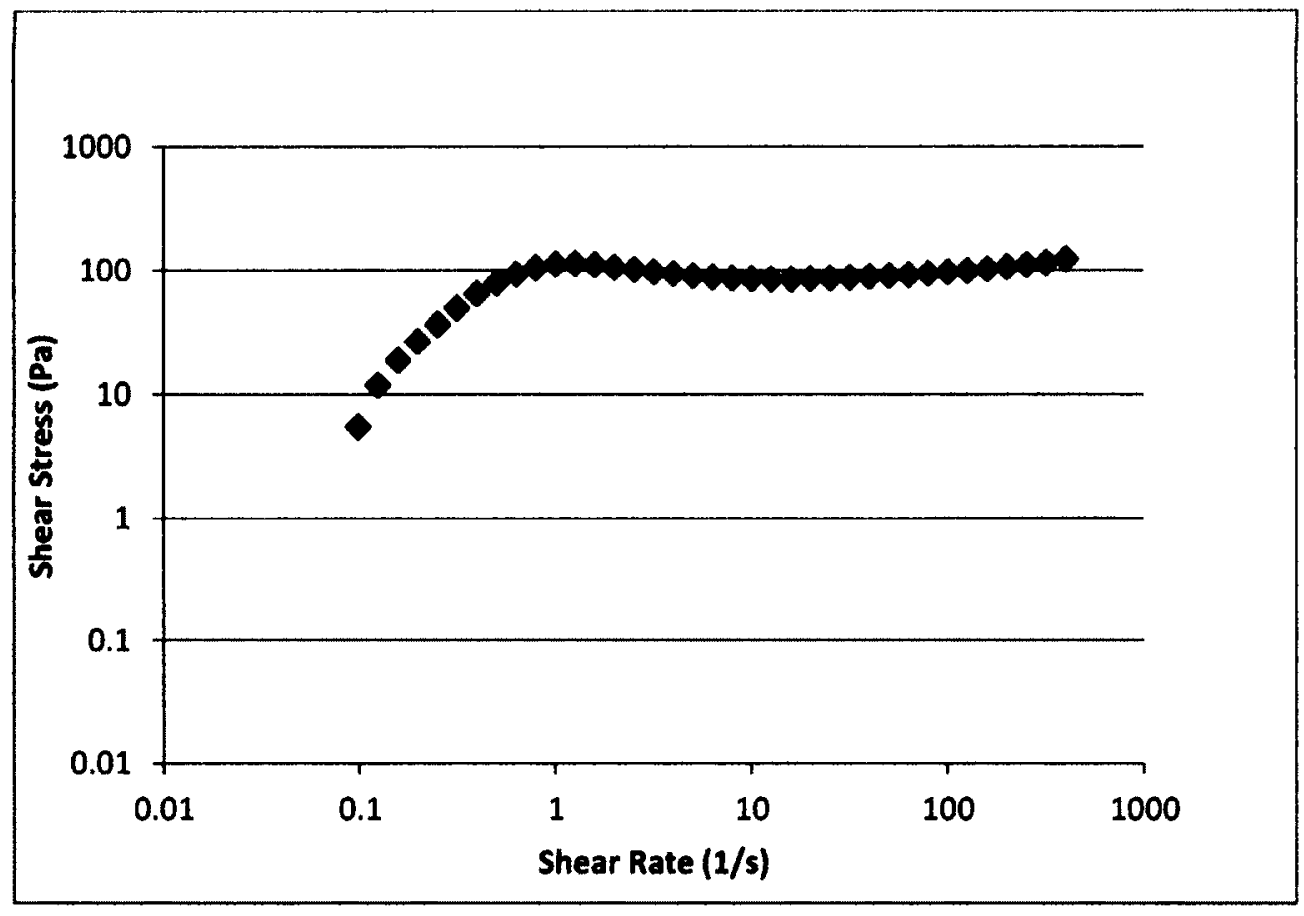

Figure E - 6: Flow Curve Drum 7 
December 2011 - Cs: $50 \%$

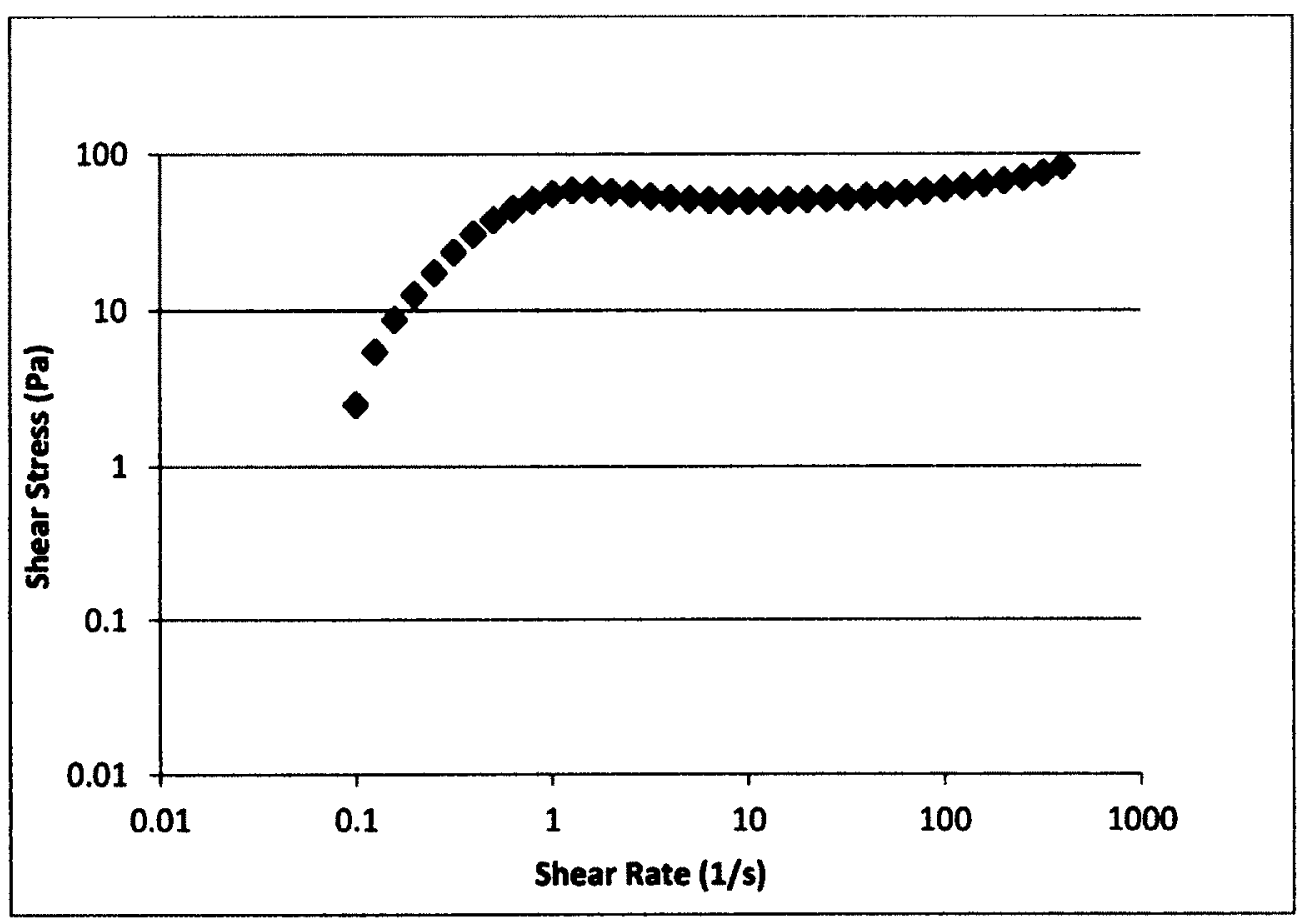

Figure E - 7: Flow Curve Drum 12

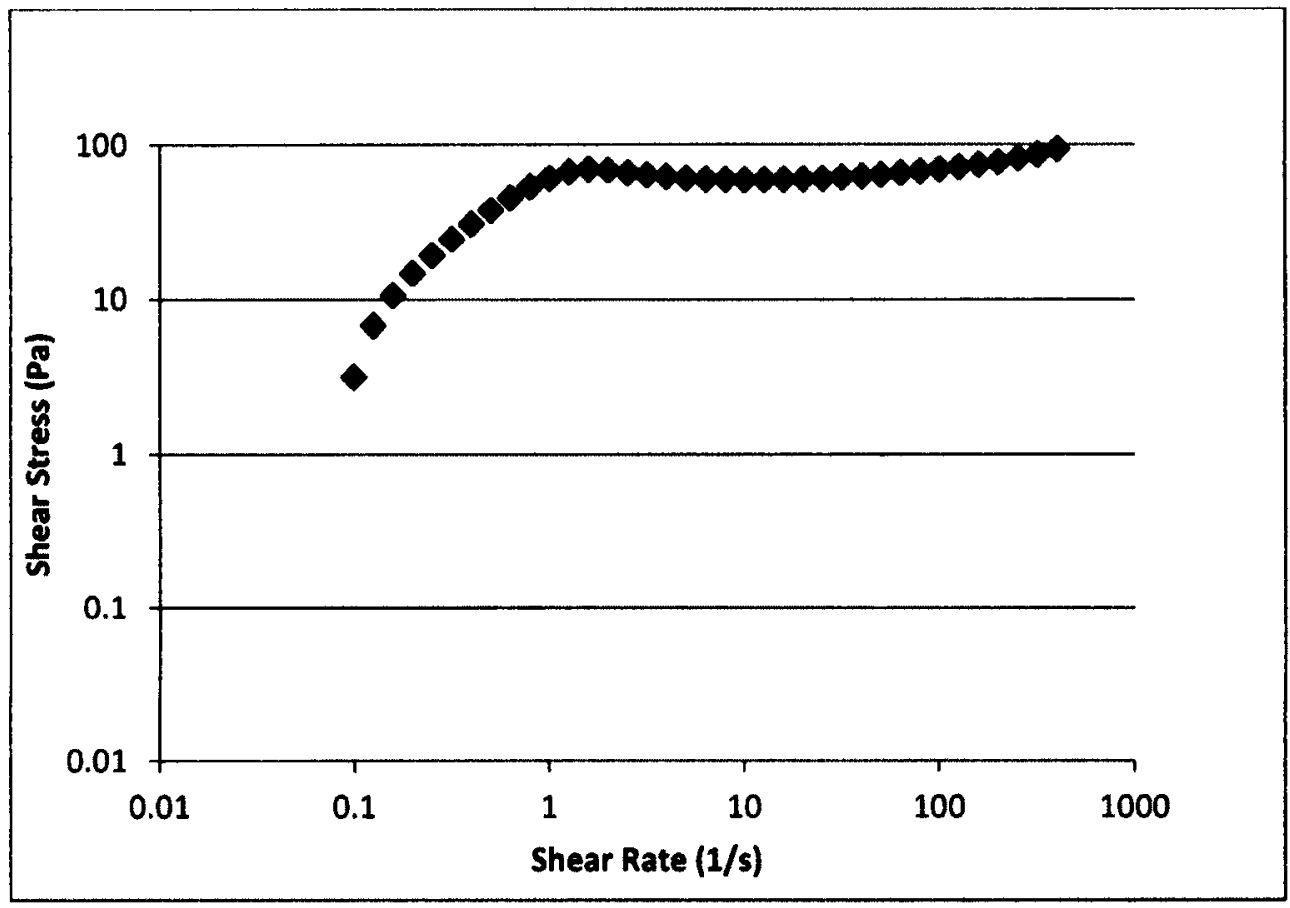

Figure E - 8: Flow Curve Drum 13 


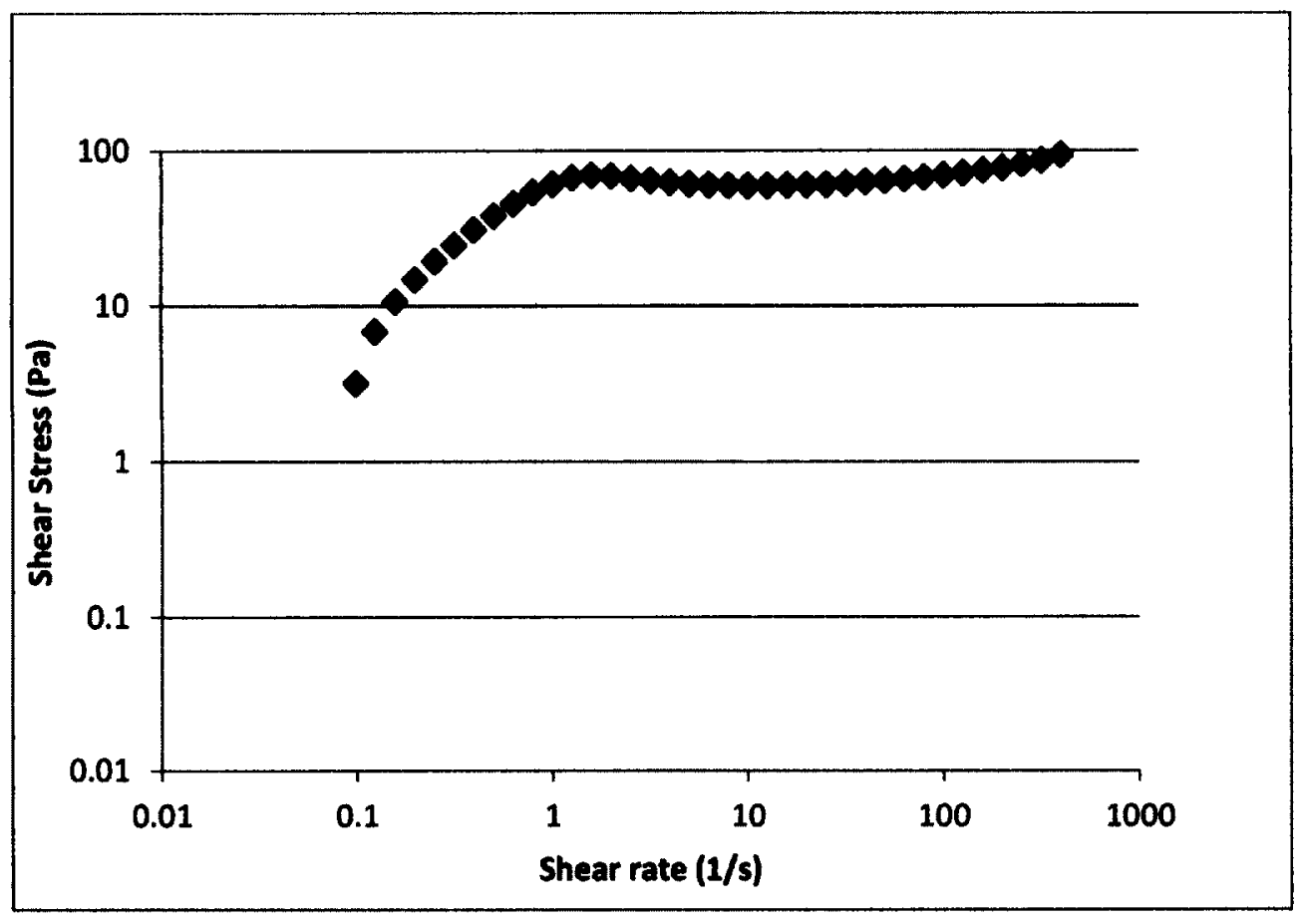

Figure E - 9: Flow Curve Drum 14 


\section{Appendix F: Rheology - Maximum Yield Stress Measurement}

\section{November 2011}

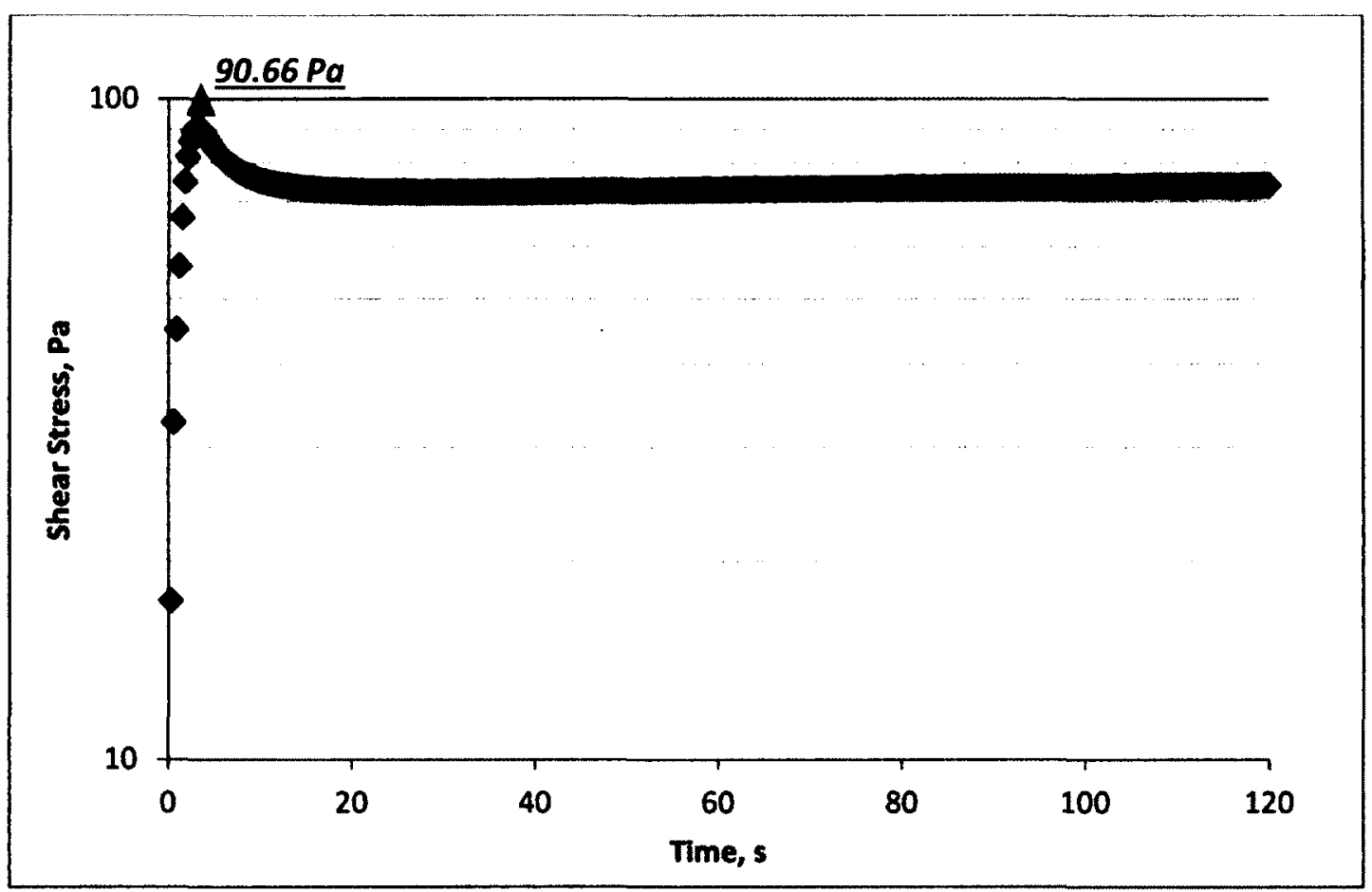

Figure F - 1: Maximum Yield Stress measurement Drum 1

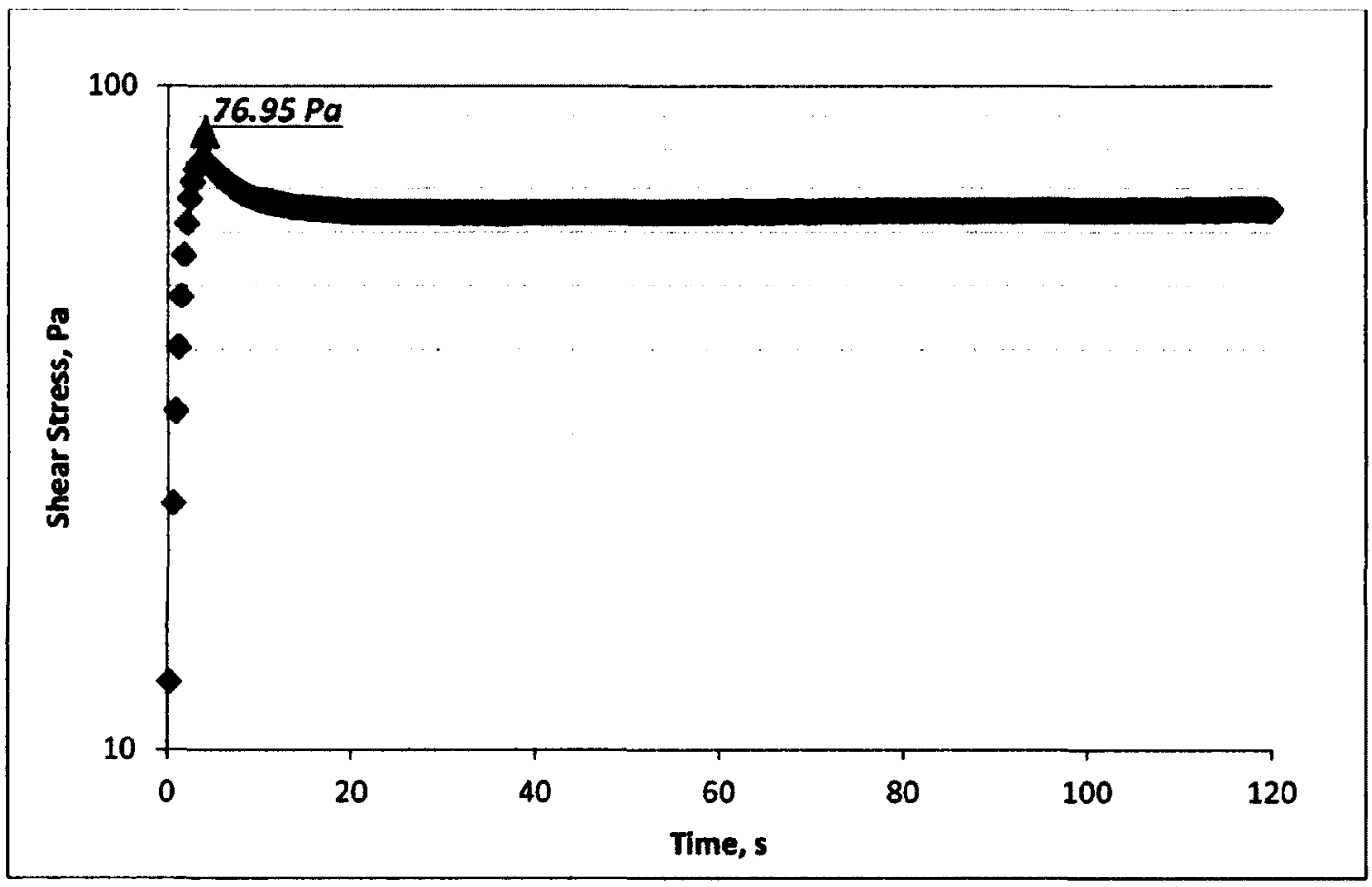

Figure F - 2: Maximum Yield Stress measurement Drum 2 


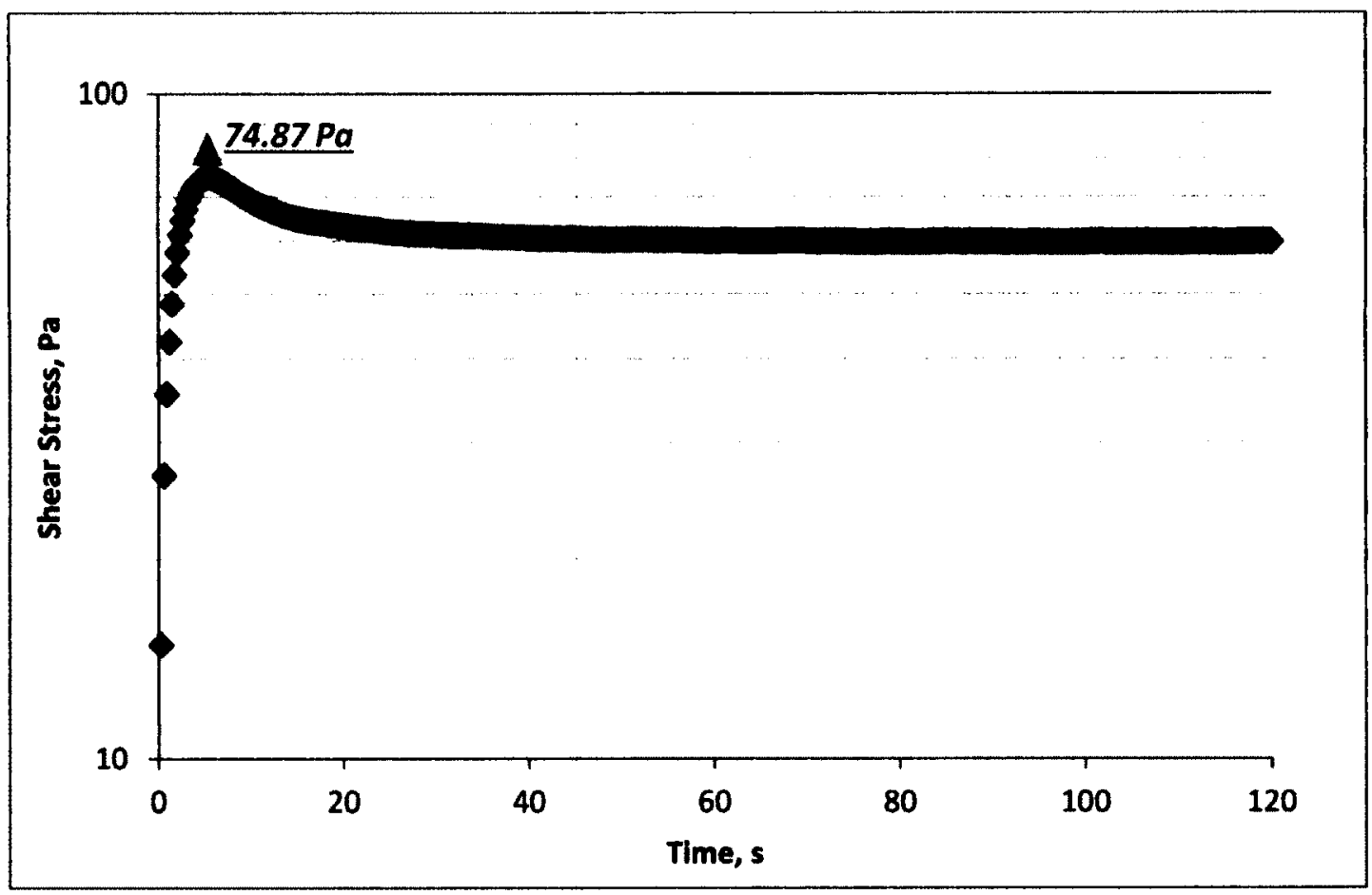

Figure F - 3: Maximum Yield Stress measurement Drum 4

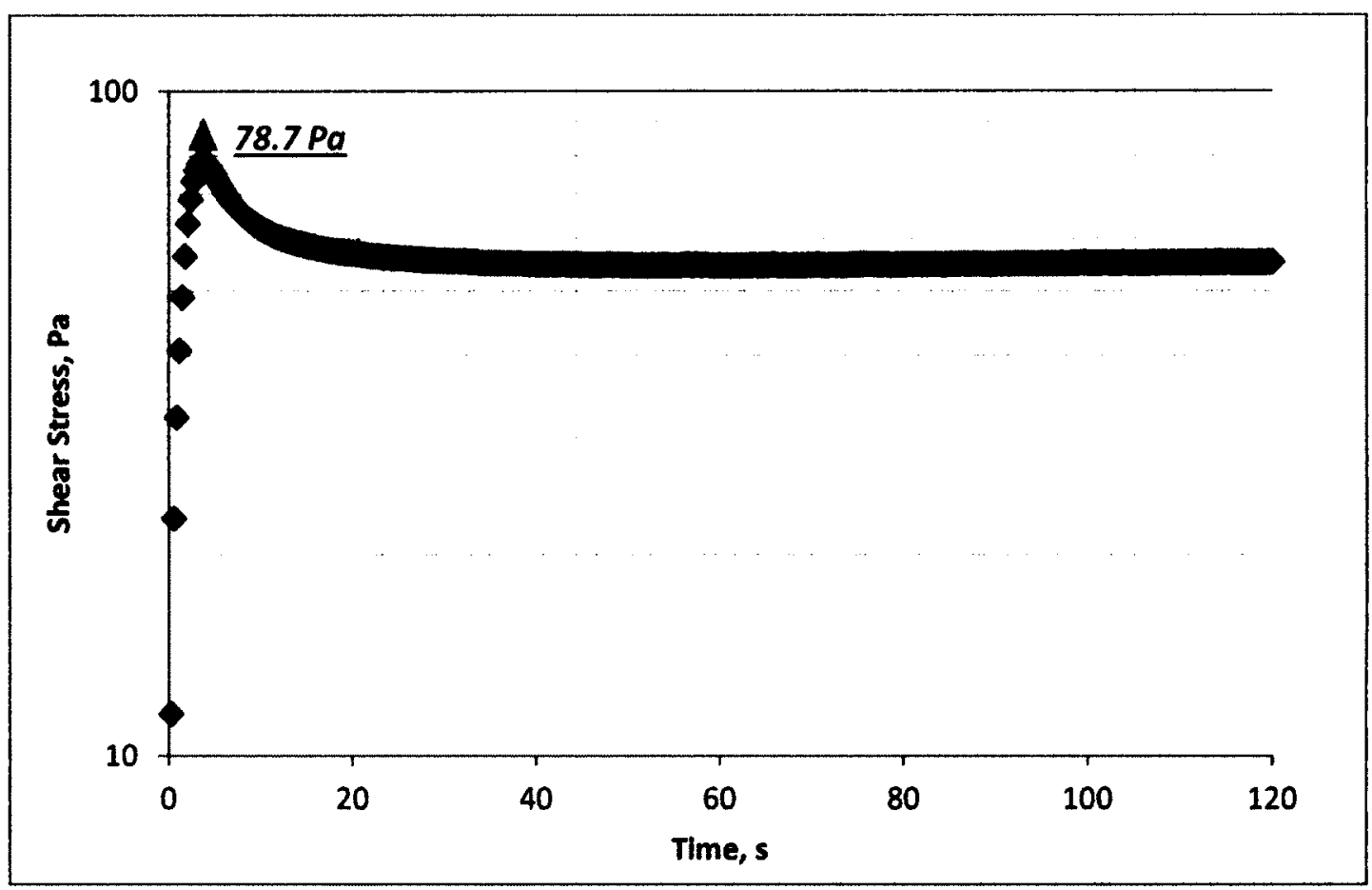

Figure F - 4: Maximum Yield Stress measurement Drum 5 


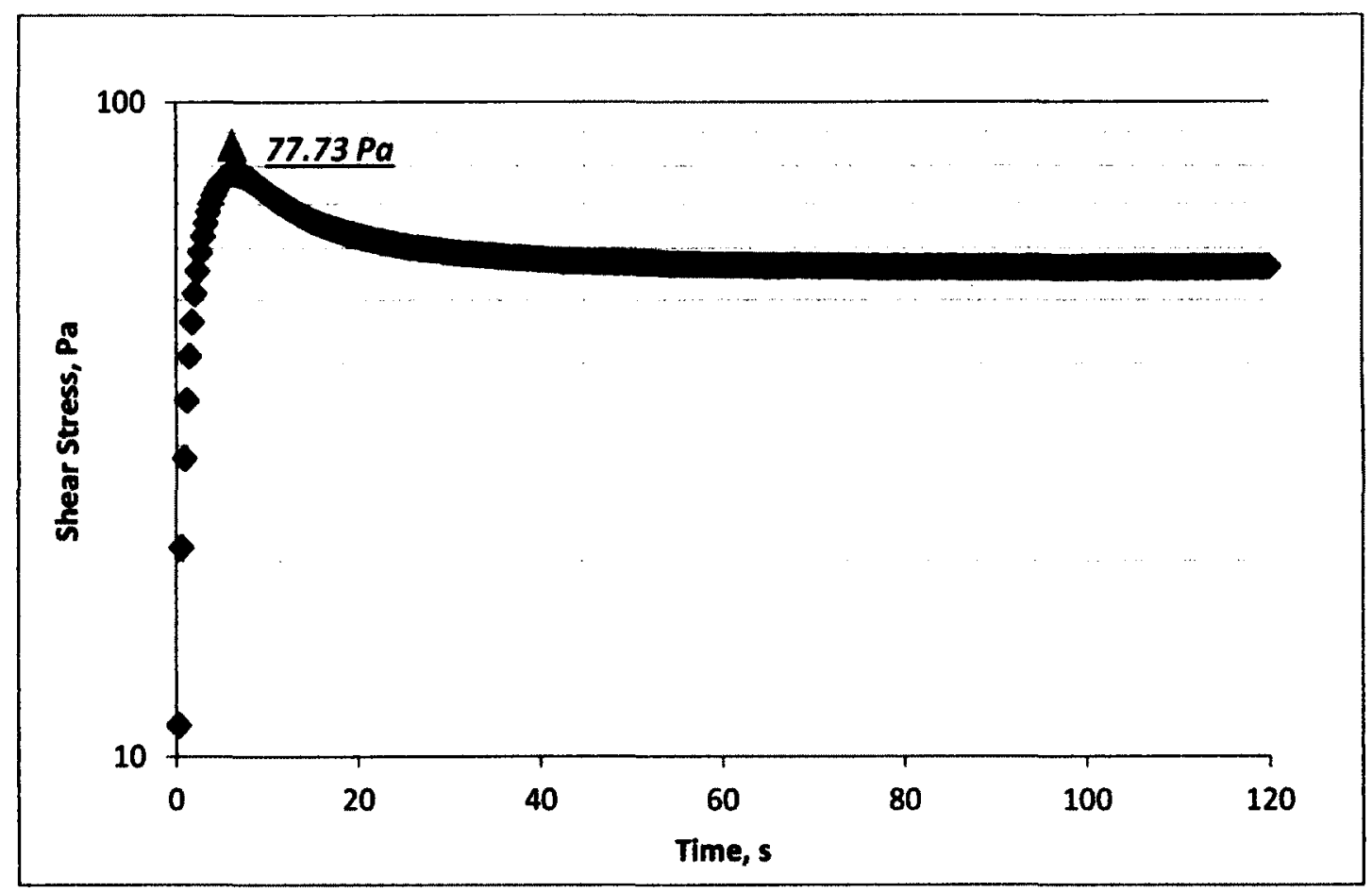

Figure F - 5: Maximum Yield Stress measurement Drum 7

\section{December 2011}

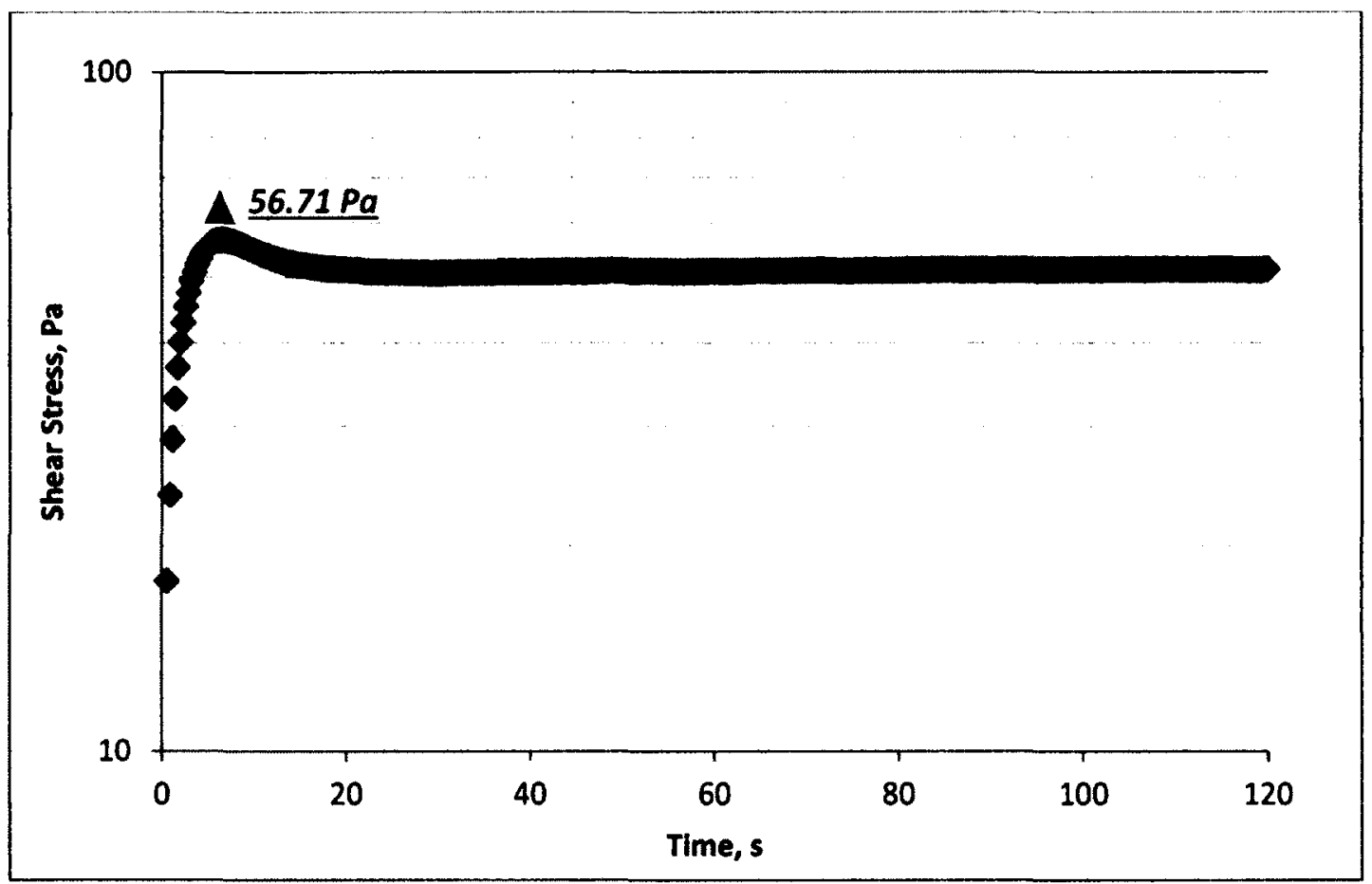

Figure F - 6: Maximum Yield Stress measurement Drum 13 


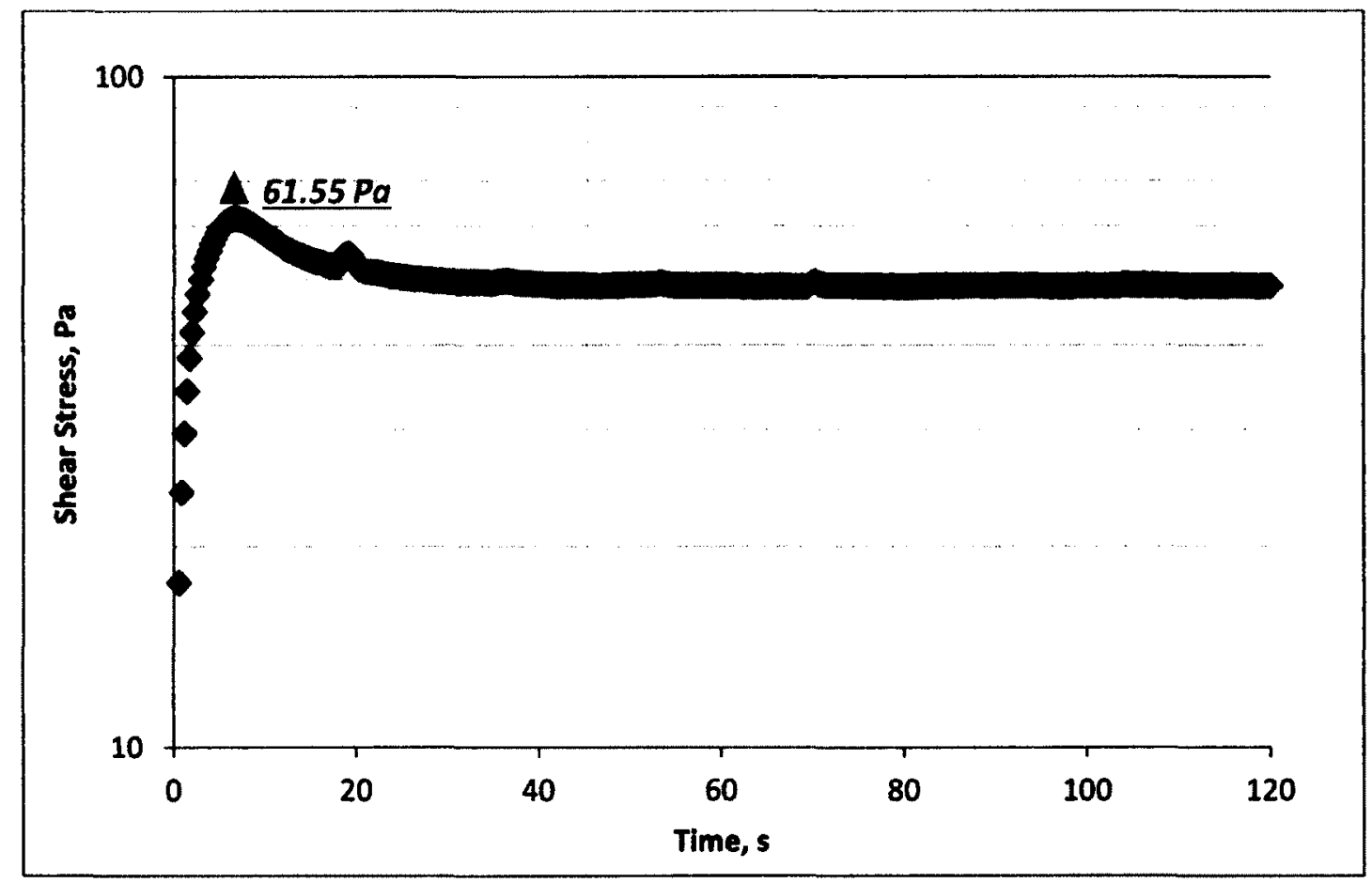

Figure F - 7: Maximum Yield Stress measurement Drum 14 
Appendix G: Rheology - Controlled Mode

\section{November 2011}

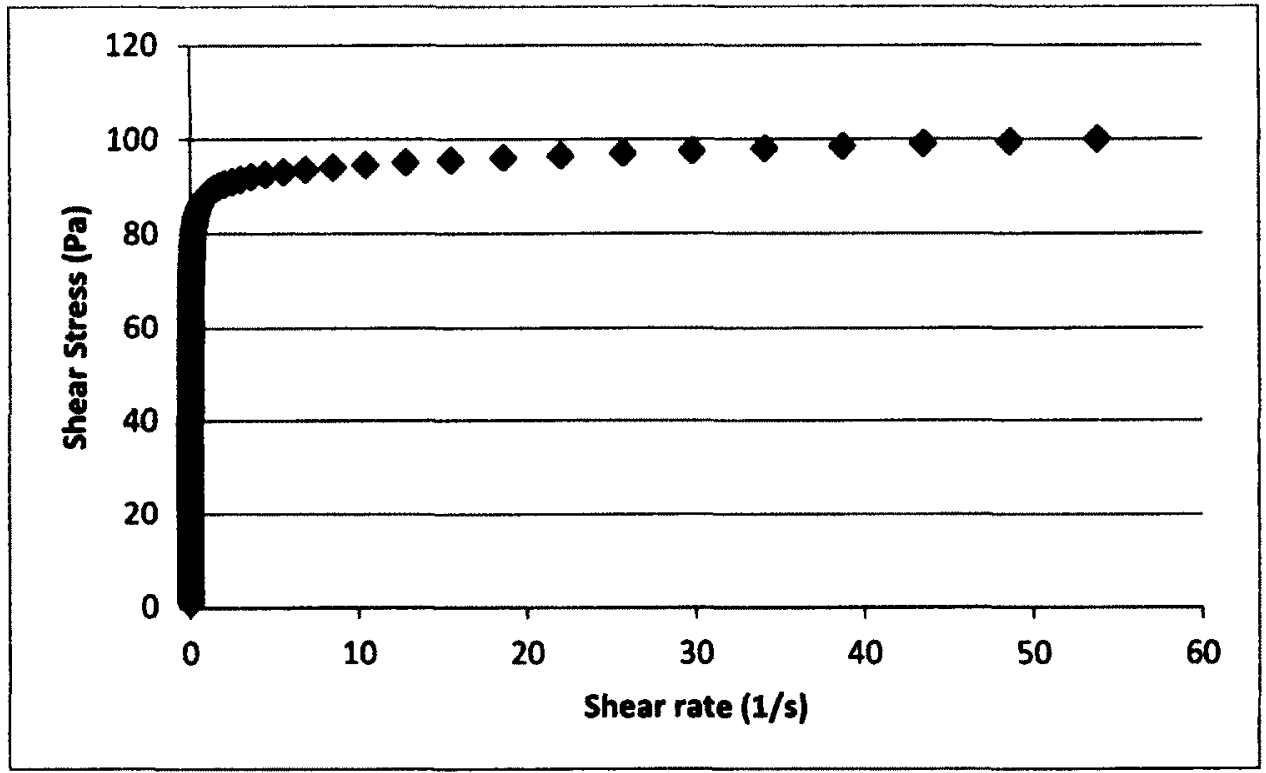

Figure G - 1: Controlled Mode Drum 1

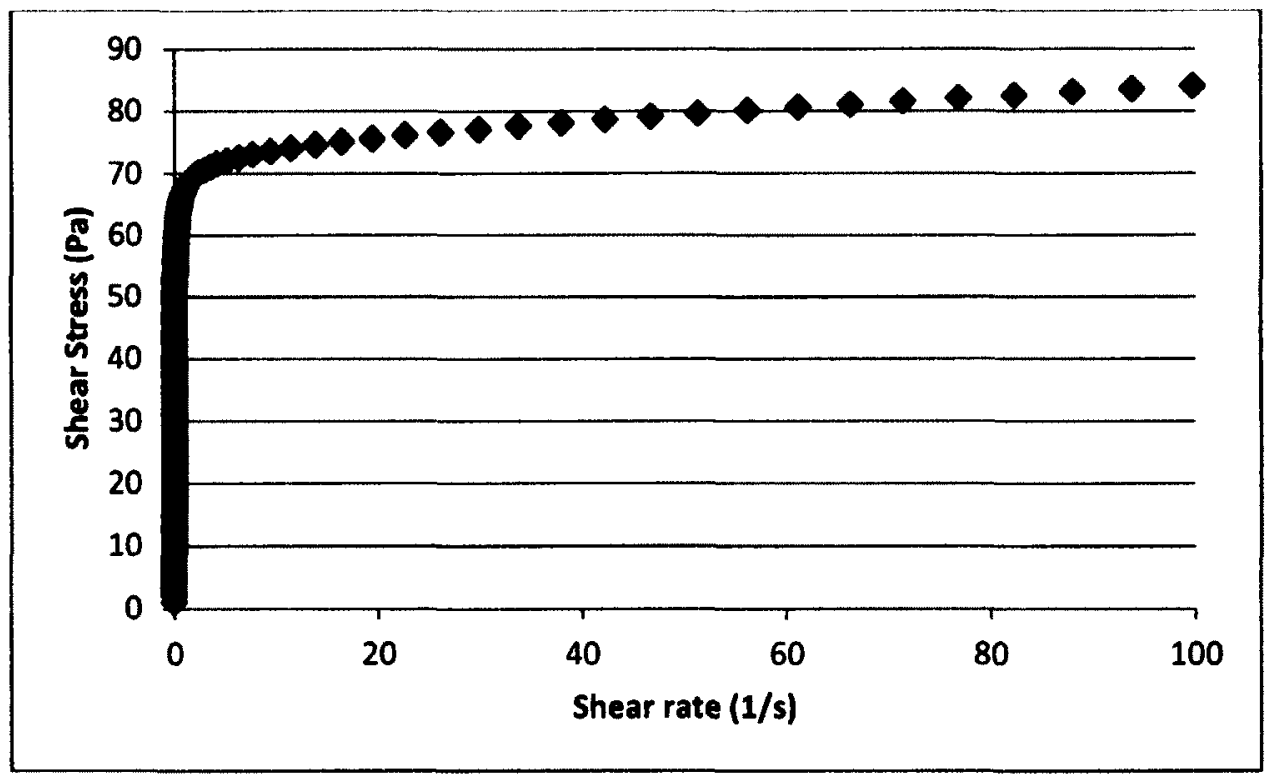

Figure G - 2: Controlled Mode Drum 4 


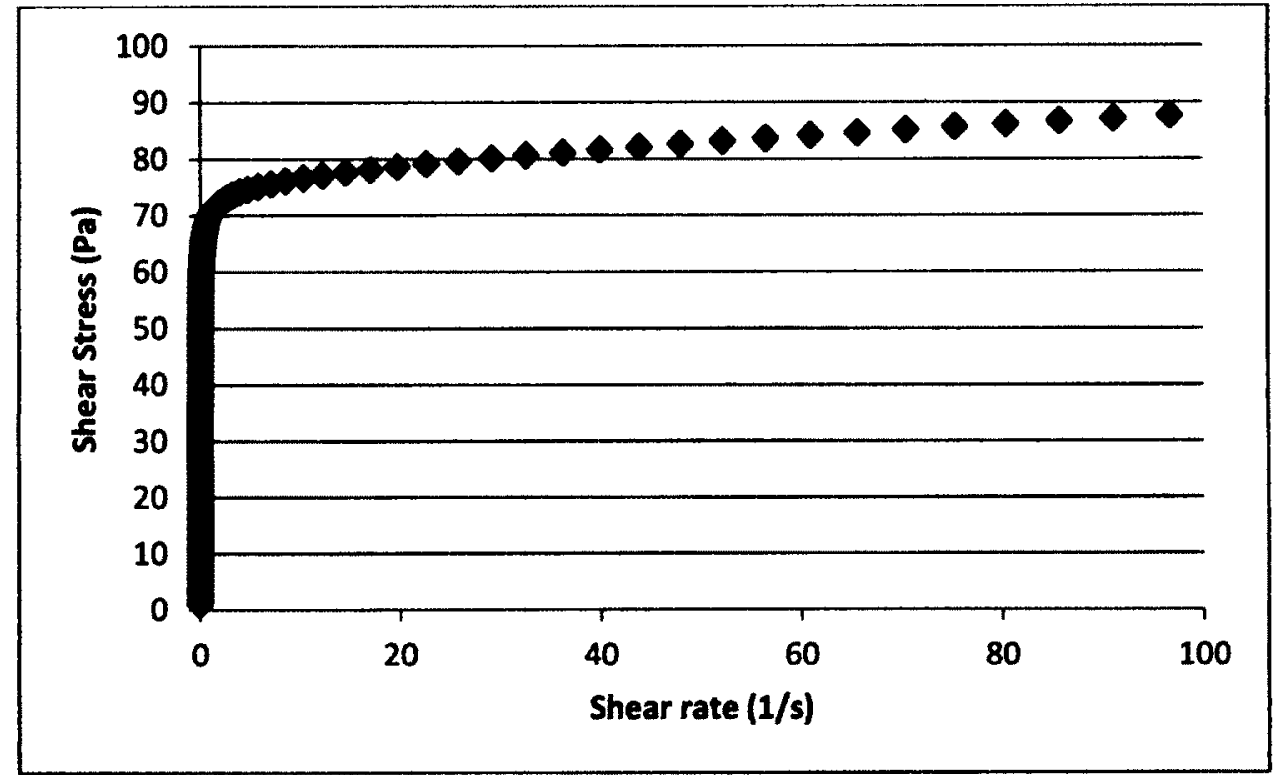

Figure G - 3: Controlled Mode Drum 7

\section{December 2011}

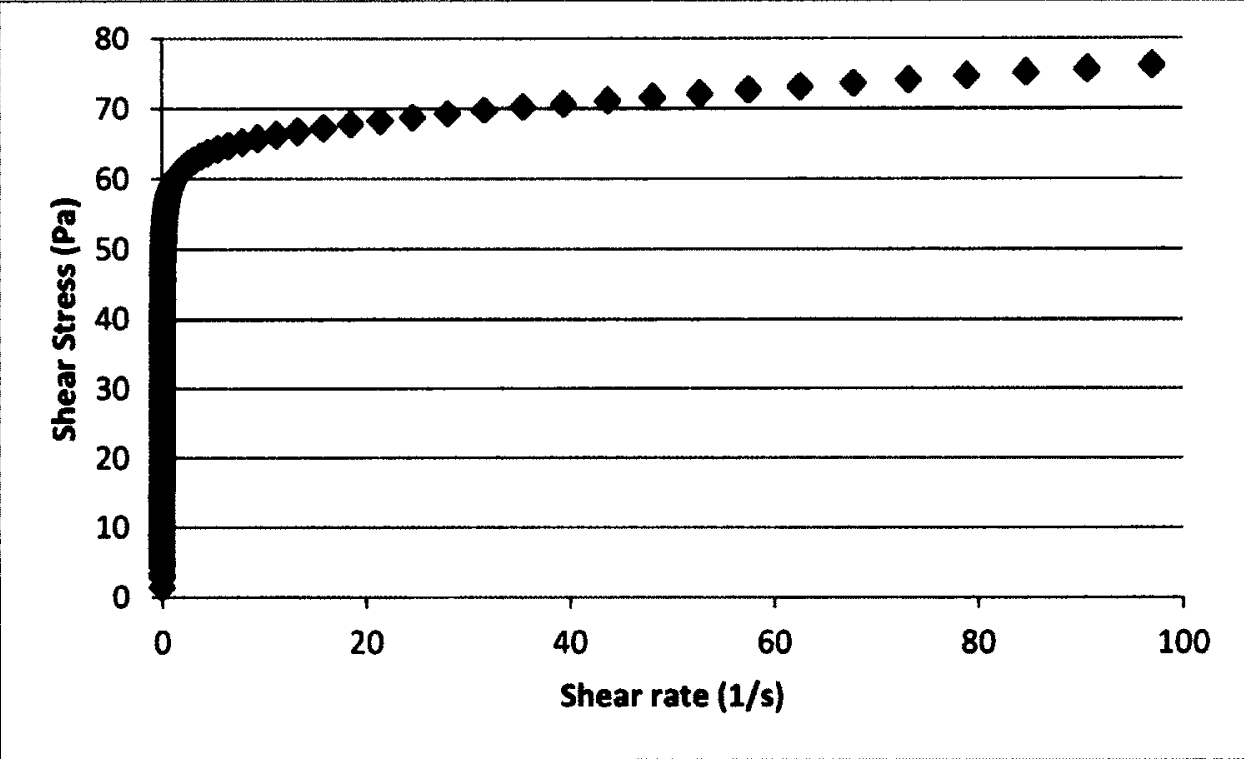

Figure G - 4: Controlled Mode Drum 13 


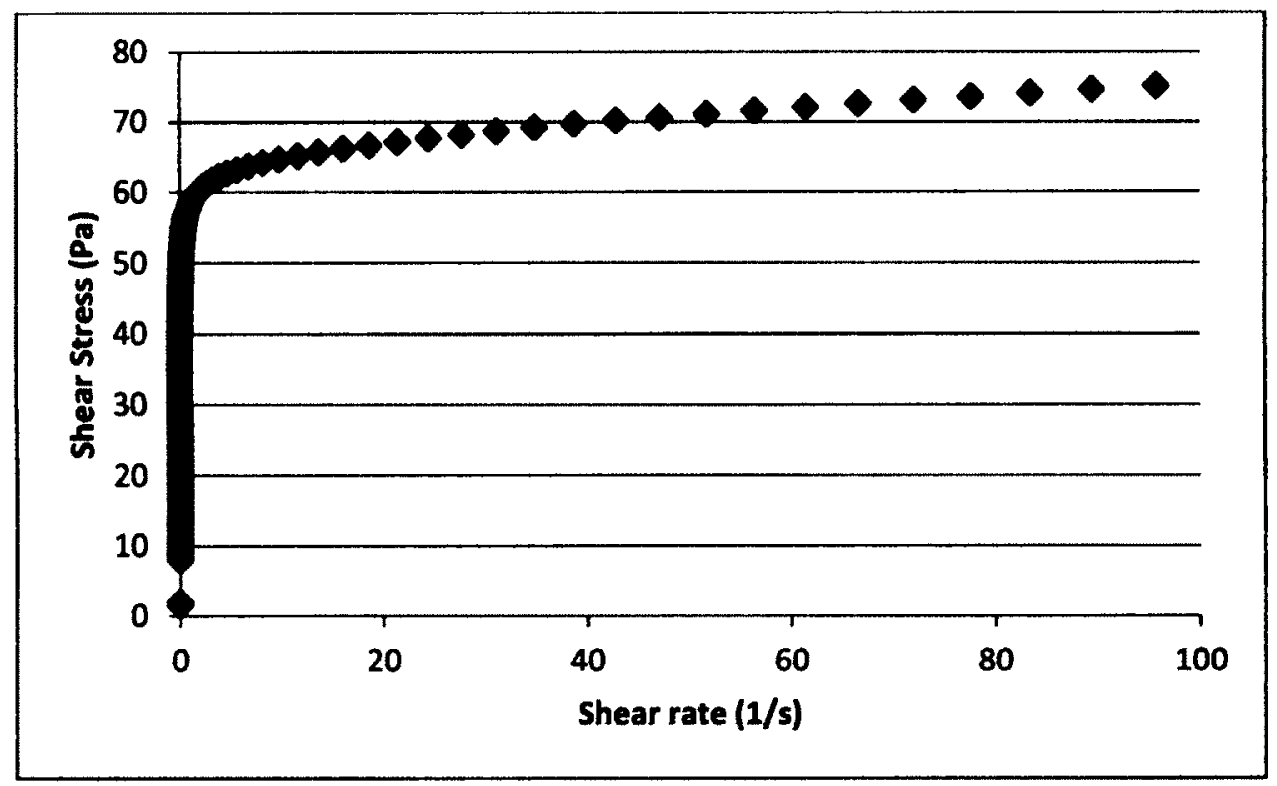

Figure G - 5: Controlled Mode Drum 14

\section{Appendix H: Water Retention Curves}

\section{November 2011}

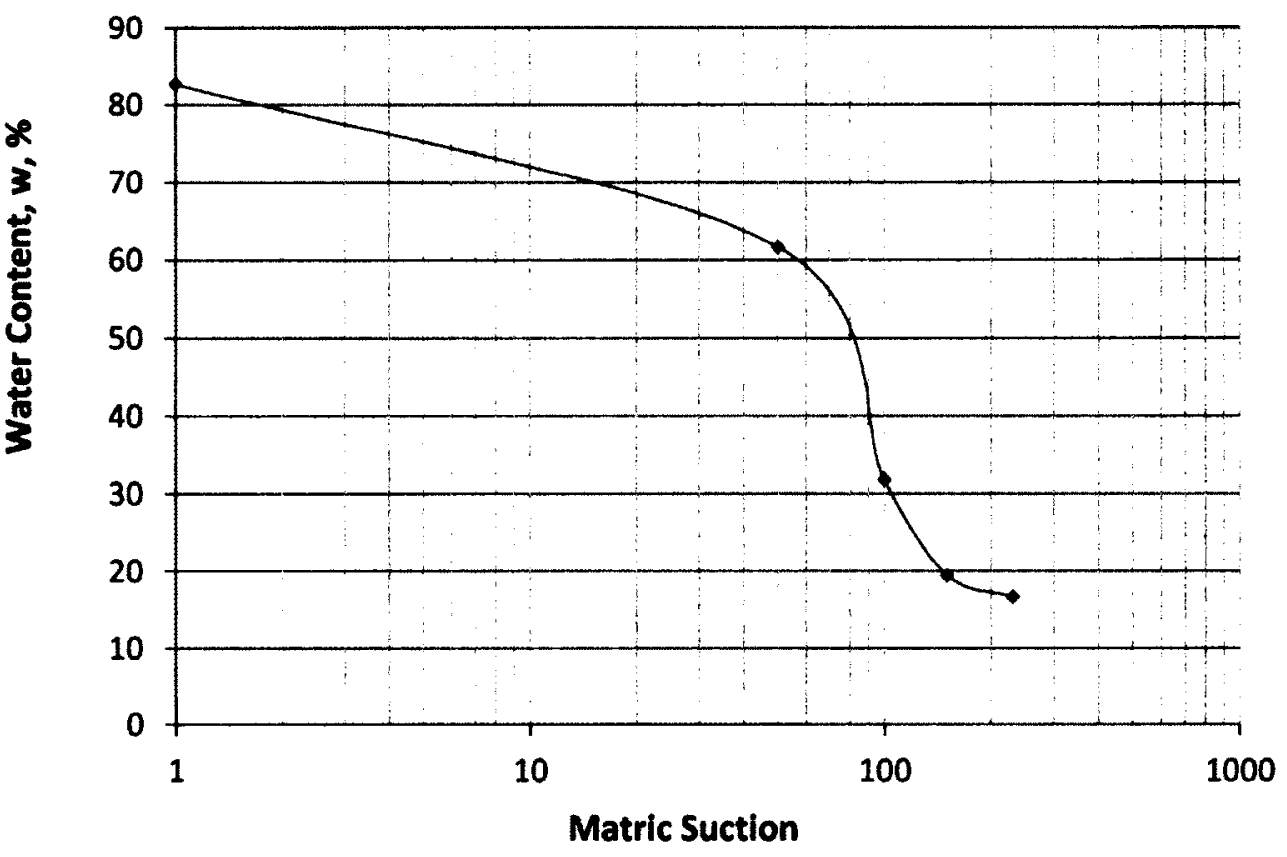

Figure H - 1: SWCC Drum 1 


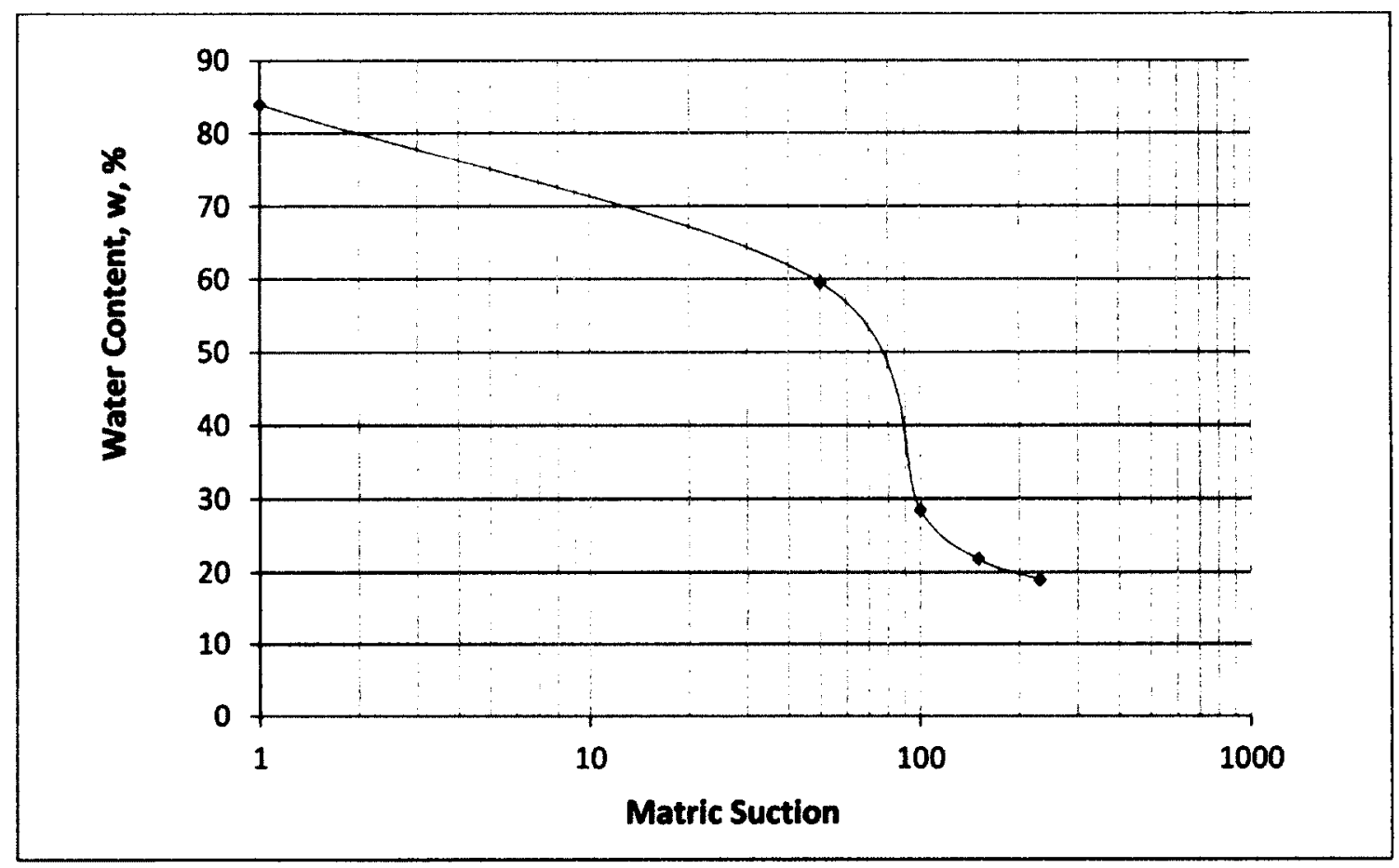

Figure H - 2: SWCC Drum 2

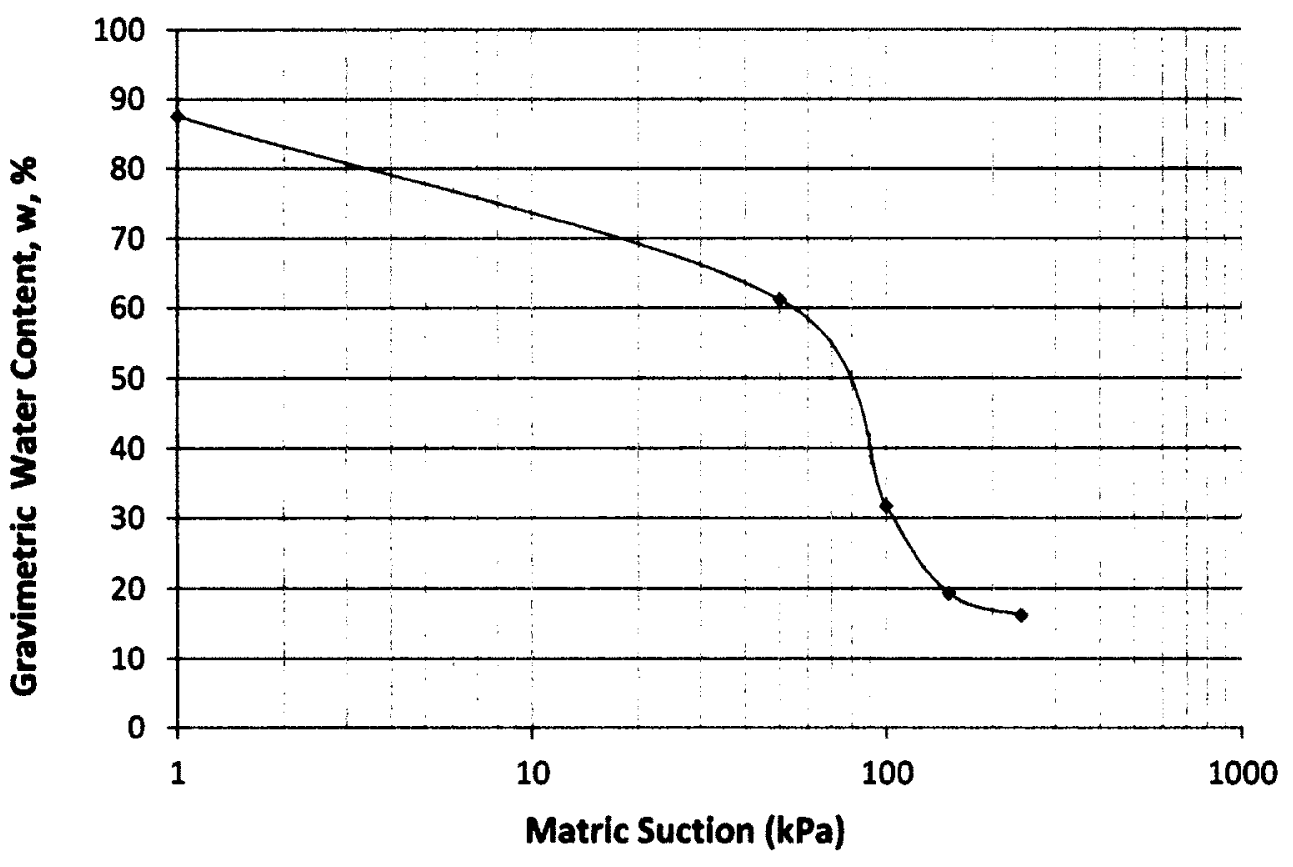

Figure H - 3: SWCC Drum 4 


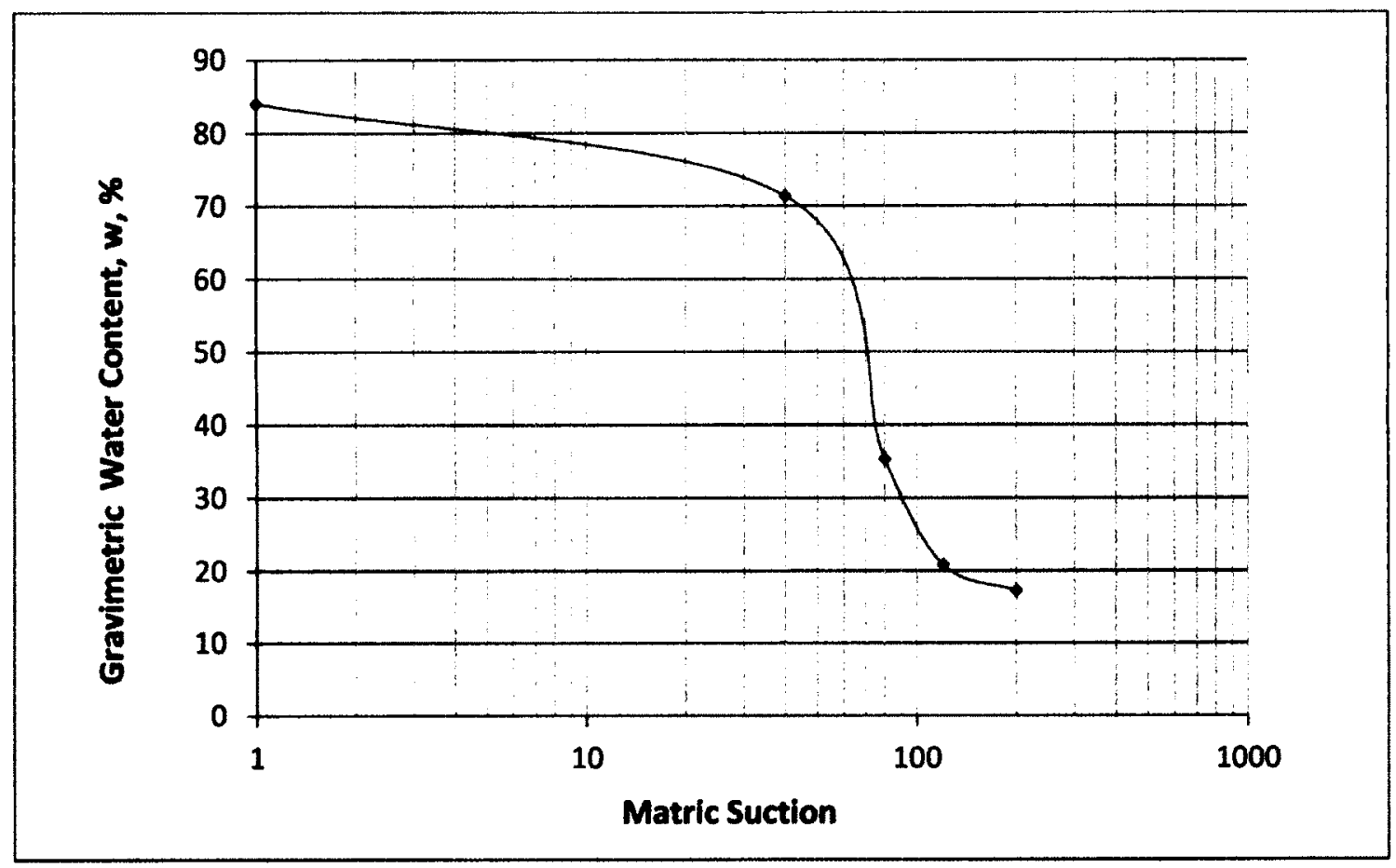

Figure H - 4: SWCC Drum 5

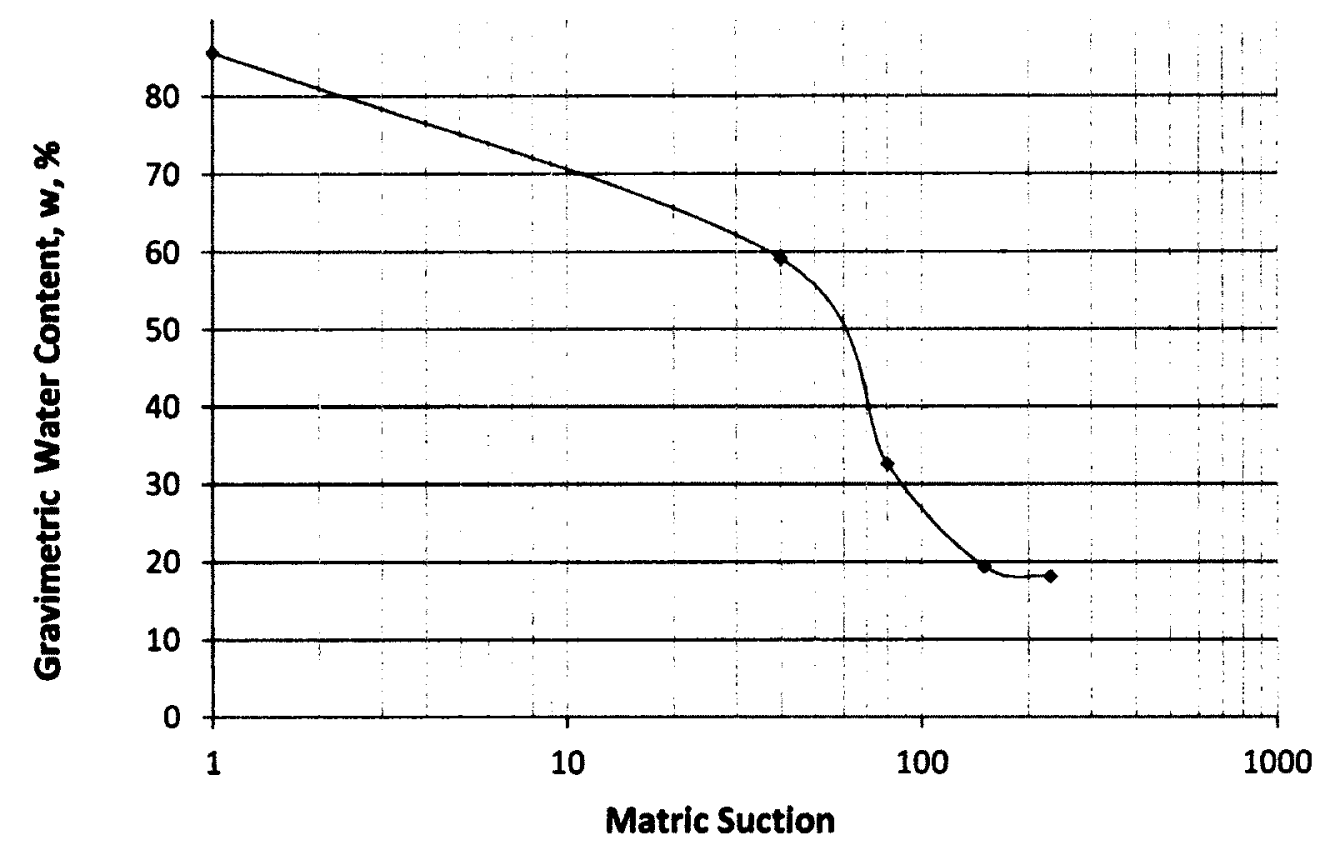

Figure H - 5: SWCC Drum 7 


\section{December 2011}

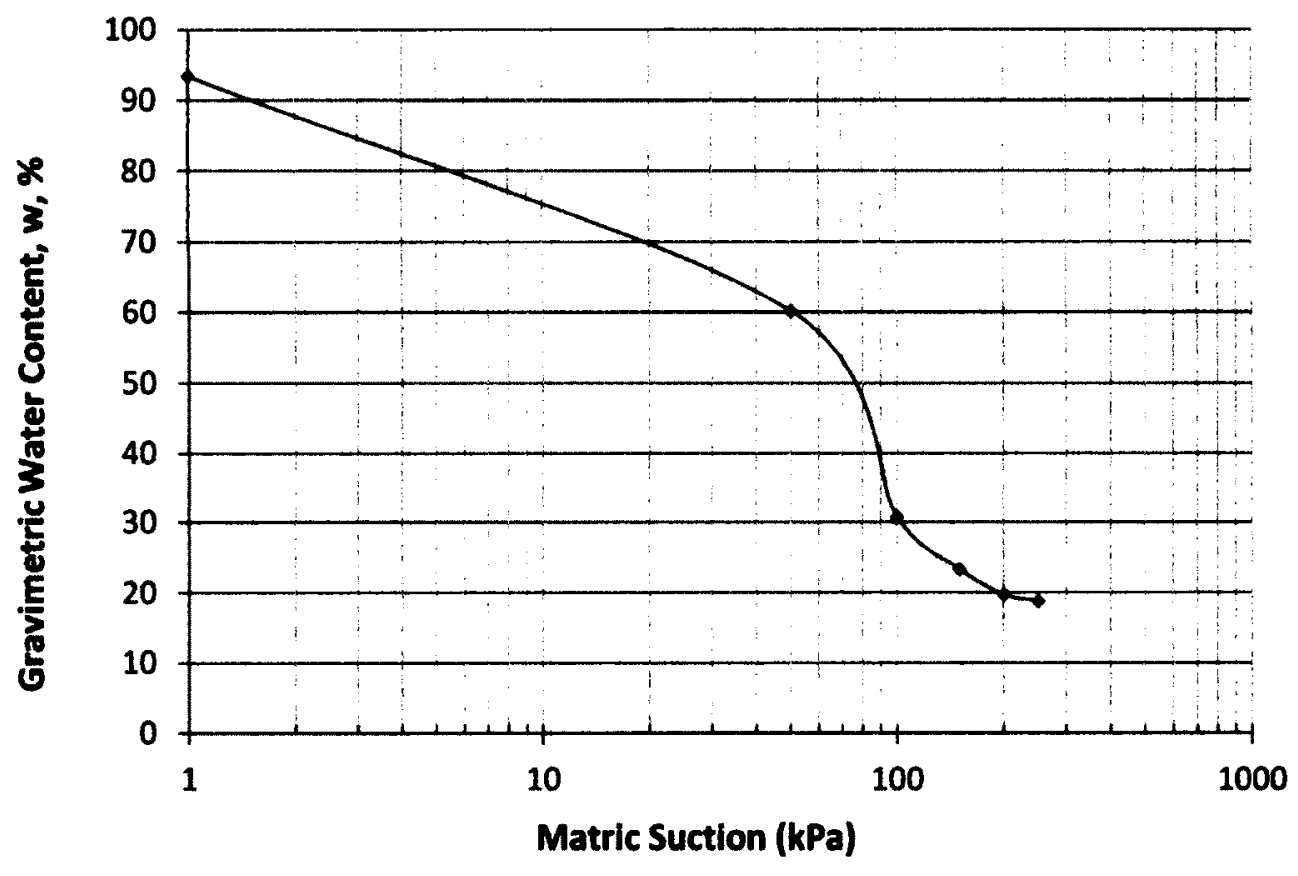

Figure H - 6: SWCC Drum 11

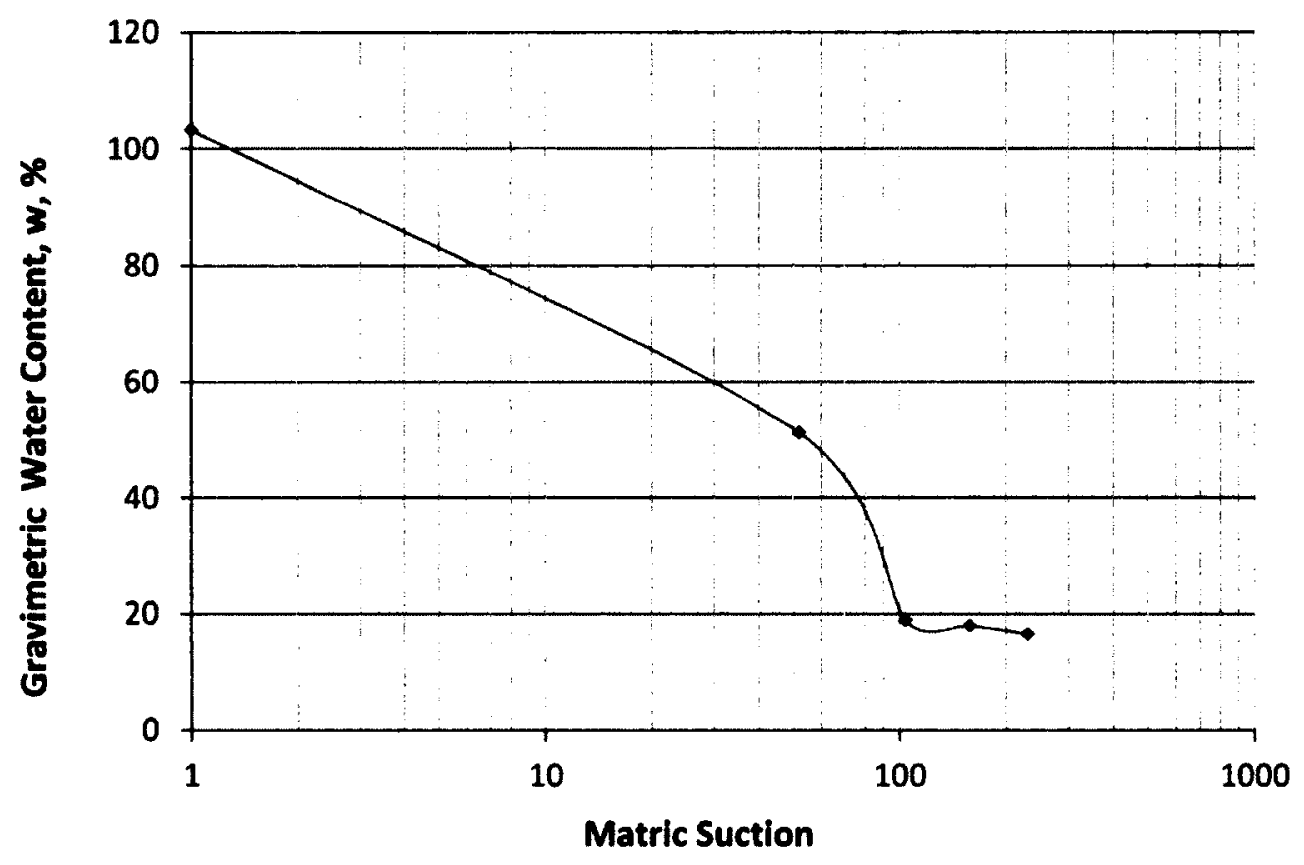

Figure H - 7: SWCC Drum 12 


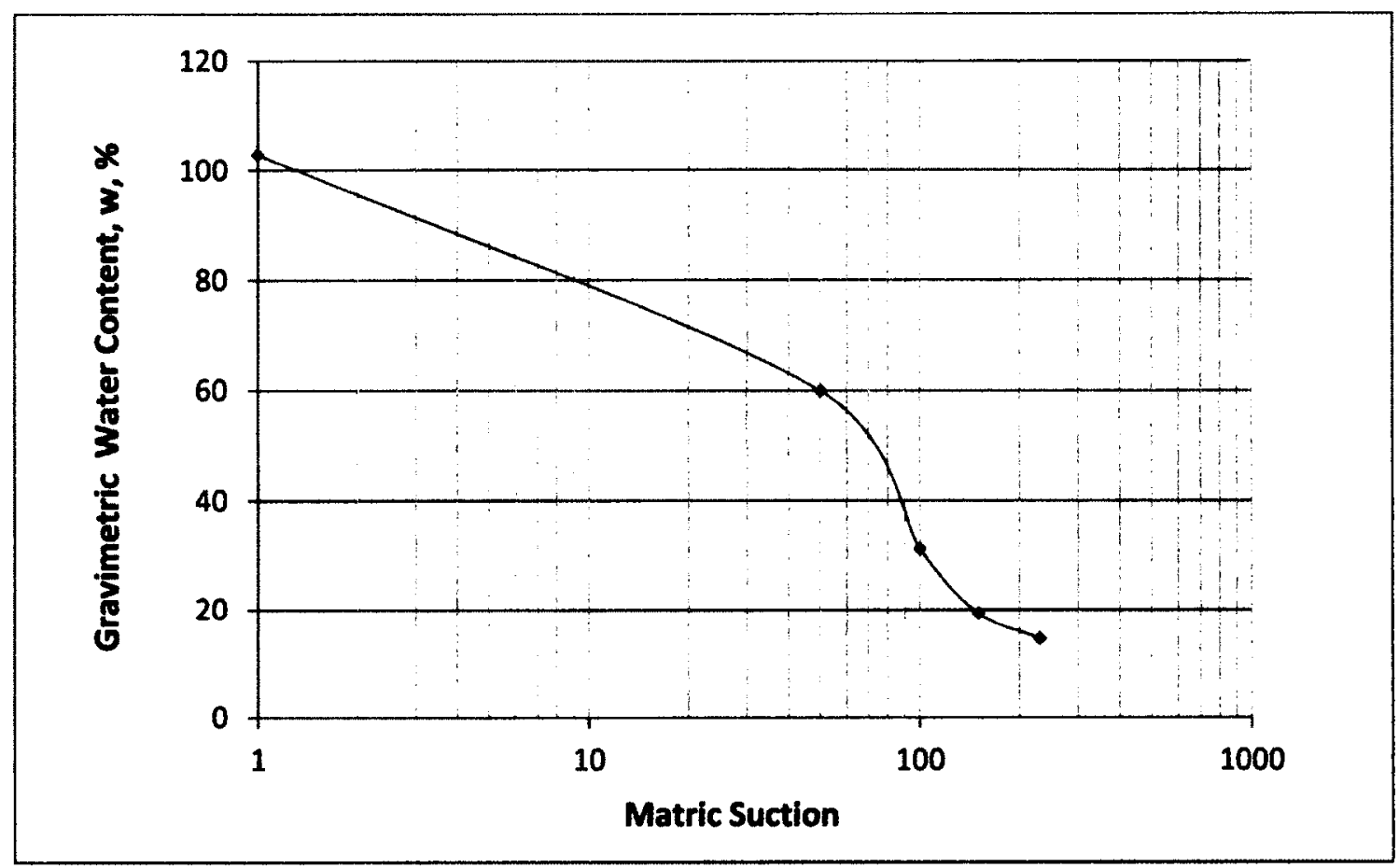

Figure H - 8: SWCC Drum 13

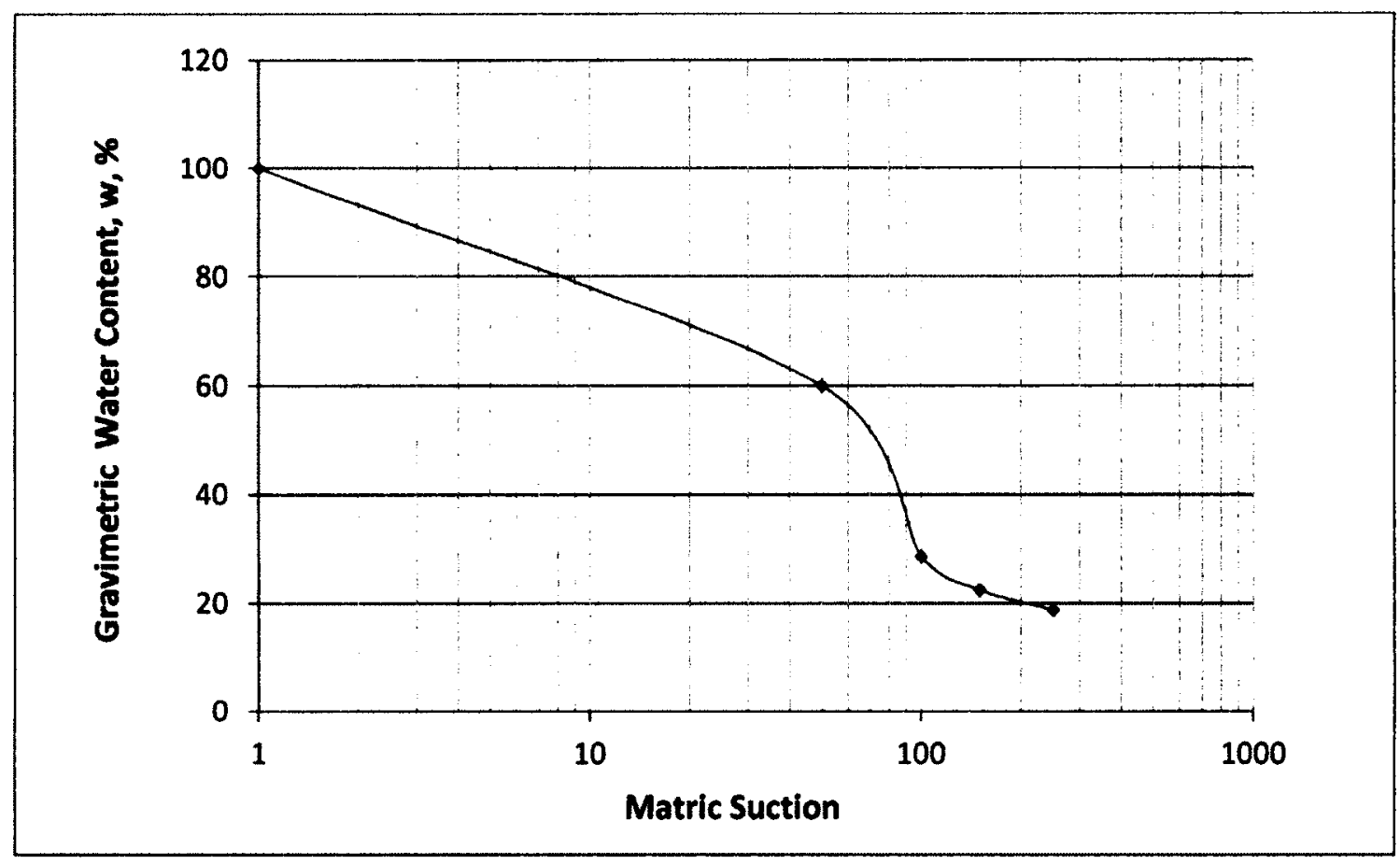

Figure H - 9: SWCC Drum 14 


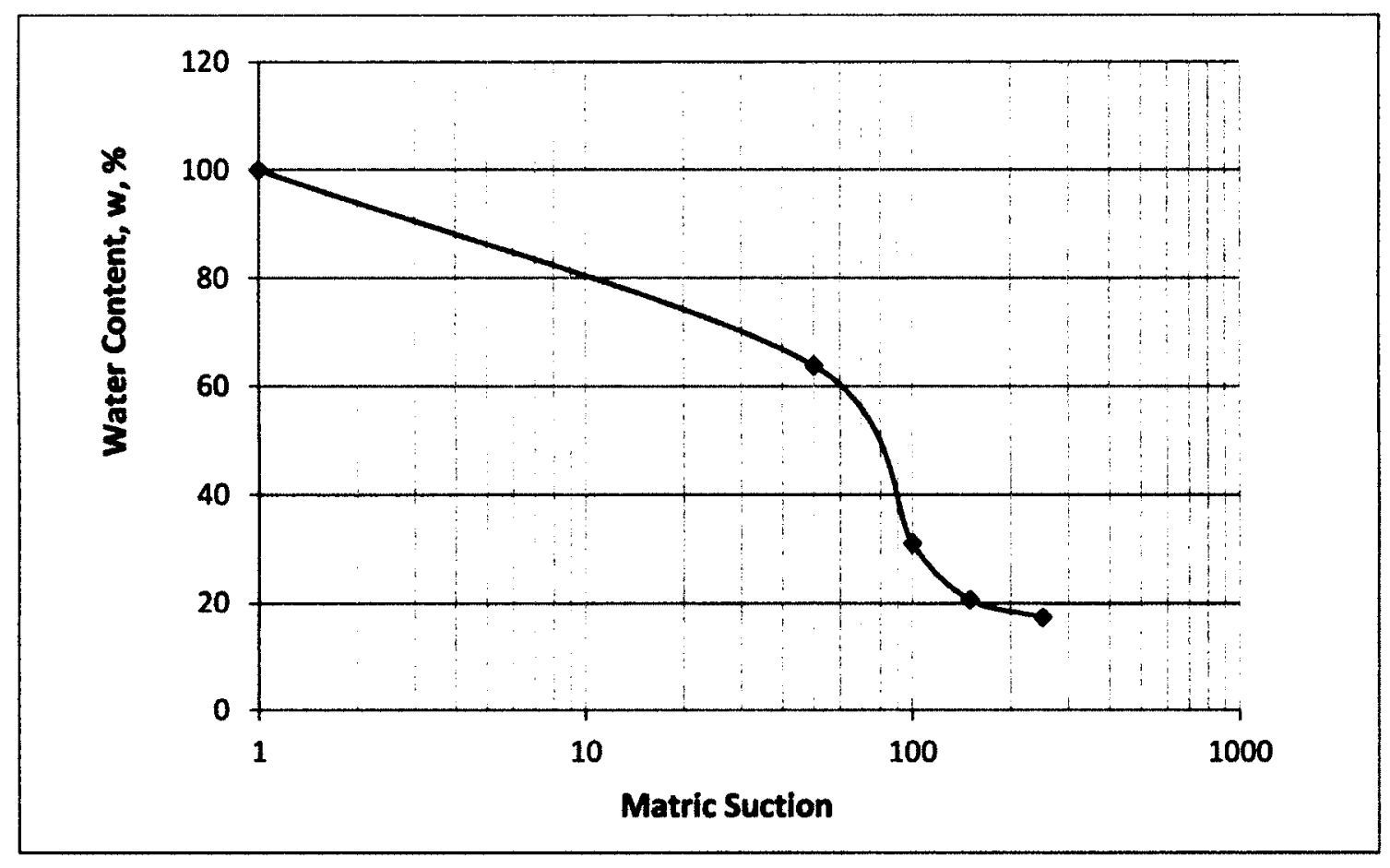

Figure H - 10: SWCC Drum 15 


\section{Appendix I: Drum Sectional Analysis}

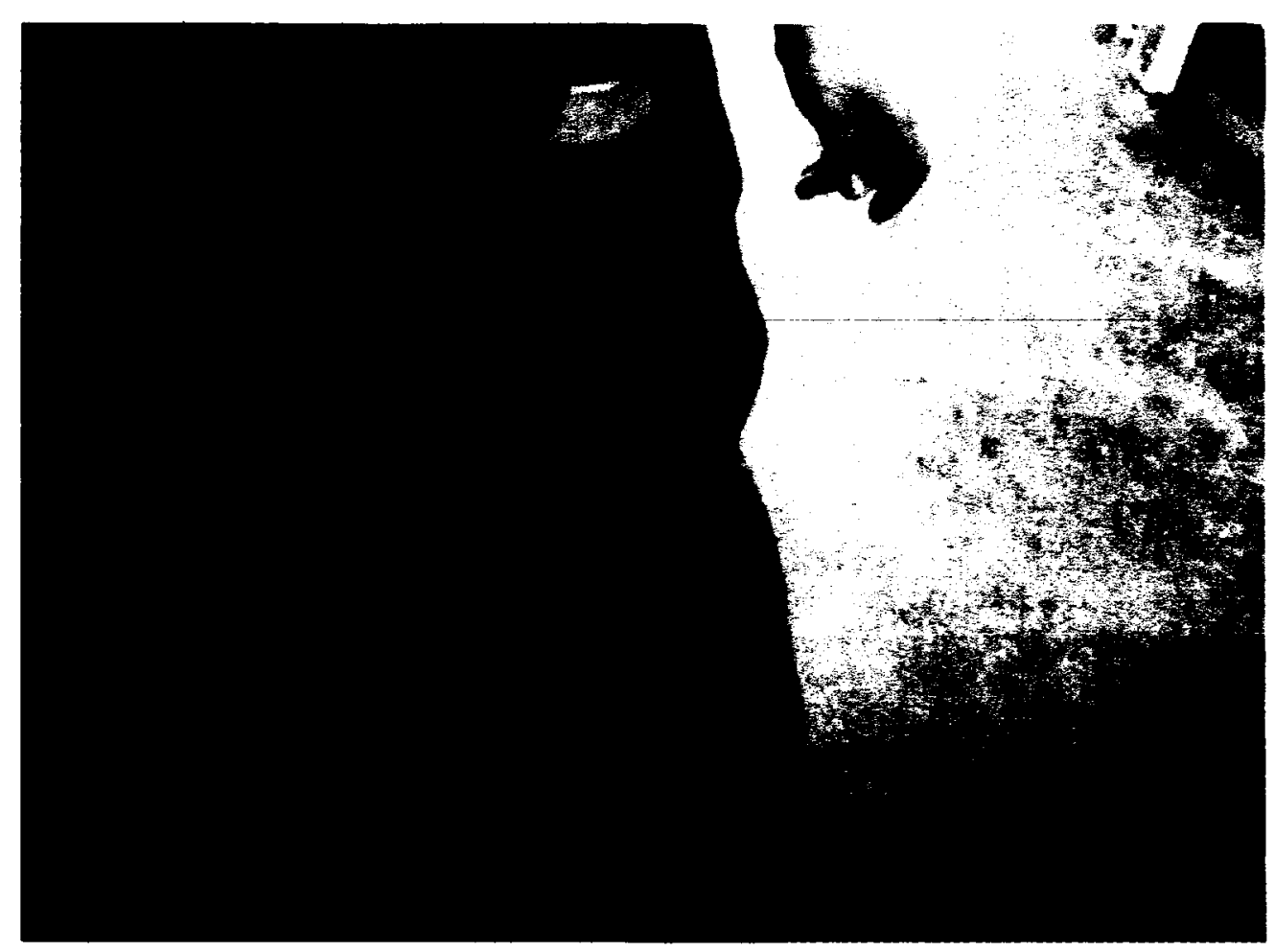

Figure I - 1: Sampling full drums 
Table I - 1: Summary Table for Sectional Analysis of Drums 12 and 4

\begin{tabular}{|c|c|c|c|c|c|c|c|c|c|}
\hline \multirow{2}{*}{$\begin{array}{c}\text { Depth } \\
(\mathrm{cm})\end{array}$} & $\begin{array}{c}\text { Midpoint } \\
(\mathrm{cm})\end{array}$ & \multicolumn{4}{|c|}{ Drum 12 } & \multicolumn{4}{|c|}{ Drum 4 } \\
\hline & $\mathbf{w}$ & Cs & Density & Gs & $w$ & Cs & Density & Gs \\
\hline $0-7$ & 3.5 & 79.3651 & 55.7522 & 1609.224 & 2.0139 & 71.5329 & 58.2979 & 1615 & \\
\hline $7-14$ & 10.5 & 67.8161 & 59.5890 & 1678.651 & 2.1774 & 61.1511 & 62.0536 & 1637.037 & 2.0303 \\
\hline $14-21$ & 17.5 & 60.8696 & 62.1622 & 1698.487 & 2.3281 & & & & \\
\hline $21-28$ & 24.5 & 56.3636 & 63.9535 & 1718.324 & 2.5918 & 59.4828 & 62.7027 & 1641.975 & \\
\hline $28-35$ & 31.5 & & & & & & & & \\
\hline $35-42$ & 38.5 & & & & & 55.3333 & 64.3777 & 1652.941 & 2.0455 \\
\hline $42-49$ & 45.5 & & & & & 50.8929 & 66.2722 & & 2.2432 \\
\hline $49-56$ & 52.5 & & & & & 48.0263 & 67.5556 & 1730 & 2.5446 \\
\hline
\end{tabular}


Table I - 2: Drum 12 Sectional analysis - GSD Non-dispersed.

\begin{tabular}{|c|c|c|c|c|c|c|c|}
\hline \multicolumn{8}{|c|}{ Section } \\
\hline \multicolumn{2}{|c|}{3} & \multicolumn{2}{|c|}{2} & \multicolumn{2}{|c|}{1} & \multicolumn{2}{|c|}{ Bottom } \\
\hline \% Pass & Diam (m) & \% Pass & $\operatorname{Diam}(m)$ & \% Pass & $\operatorname{Diam}(m)$ & $\%$ Pass & $\begin{array}{c}\text { Diam } \\
\text { (m) }\end{array}$ \\
\hline 99.75 & 0.25 & 99.75 & 0.25 & 99.75 & 0.25 & 99.5 & 0.25 \\
\hline 98.25 & 0.15 & 98.5 & 0.15 & 98.25 & 0.15 & 98.5 & 0.15 \\
\hline 84.5 & 0.075 & 81.5 & 0.075 & 82 & 0.075 & 82.25 & 0.075 \\
\hline 30.42 & 0.04395 & 36.7575 & 0.04063 & 32.5325 & 0.03876 & 28.0963 & 0.02874 \\
\hline 17.745 & 0.01562 & 15.6325 & 0.01366 & 17.745 & 0.01280 & 17.745 & 0.01092 \\
\hline 11.4075 & 0.008530 & 10.3513 & 0.007401 & 11.4075 & 0.007008 & 9.295 & 0.006659 \\
\hline 7.499375 & 0.005991 & 7.4994 & 0.005488 & 7.4994 & 0.005137 & 6.1263 & 0.004798 \\
\hline 7.499375 & 0.004865 & 6.4431 & 0.004687 & 7.4994 & 0.004254 & 5.3869 & 0.003947 \\
\hline 6.443125 & 0.003600 & 6.4431 & 0.003333 & 7.4994 & 0.003077 & 5.3869 & 0.003469 \\
\hline & & & & & & 5.3869 & 0.002709 \\
\hline
\end{tabular}


Table I - 3: Drum 4 Sectional analysis - GSD Non-dispersed

\begin{tabular}{|r|r|r|r|r|r|}
\hline \multicolumn{7}{|c|}{ Section } \\
\hline \multicolumn{2}{|c|}{2} & \multicolumn{2}{|c|}{7} & \multicolumn{2}{|c|}{ Bottom } \\
\hline \% Pass & Diam $(\mathbf{m})$ & \% Pass & \multicolumn{1}{|c|}{ Diam $(\mathrm{m})$} & \multicolumn{1}{|c|}{ \% Pass } & \multicolumn{1}{|c|}{ Diam $(\mathbf{m})$} \\
\hline 99.5025 & 0.25 & 96.38554 & 0.25 & 98.44358 & 0.25 \\
\hline 97.0149 & 0.15 & 86.74699 & 0.15 & 96.88716 & 0.15 \\
\hline 65.6716 & 0.075 & 60.24096 & 0.075 & 67.70428 & 0.075 \\
\hline 24.2938 & 0.04874676 & 10.35125 & 0.048495425 & 29.575 & 0.04362564 \\
\hline 3.5913 & 0.00832476 & 1.05625 & 0.009400738 & 6.020625 & 0.00784076 \\
\hline 0.2113 & 0.00579805 & & 0.005894717 & 4.43625 & 0.0055085 \\
\hline & & & & 0.4225 & 0.00448173 \\
\hline
\end{tabular}

Table I - 4: Drum 4 Sectional analysis - GSD dispersed

\begin{tabular}{|c|r|r|r|r|r|r|r|}
\hline \multicolumn{9}{|c|}{} & \multicolumn{2}{|c|}{6} & \multicolumn{2}{c|}{ S } & \multicolumn{2}{c|}{ Bottom } \\
\hline \% Pass & Diam (m) & \% Pass & Diam $(\mathbf{m})$ & \% Pass & \multicolumn{1}{|c|}{ Diam (m) } & \% Pass & Diam (m) \\
\hline 99.7416 & 0.25 & 99.8765 & 0.25 & 99.6845 & 0.25 & 99.5402 & 0.25 \\
\hline 97.41602 & 0.15 & 97.4074 & 0.15 & 97.7918 & 0.15 & 97.9310 & 0.15 \\
\hline 70.54264 & 0.075 & 72.2222 & 0.075 & 70.6625 & 0.075 & 75.4023 & 0.075 \\
\hline 39.55491 & 0.04297 & 42.2634 & 0.04219 & 41.6842 & 0.04389 & 44.5480 & 0.03463 \\
\hline 21.32684 & 0.02302 & 24.7874 & 0.02134 & 26.3034 & 0.02302 & 23.7474 & 0.01884 \\
\hline 18.59263 & 0.01591 & 19.4376 & 0.01577 & 22.0681 & 0.01646 & 20.2806 & 0.01347 \\
\hline 15.31158 & 0.01157 & 16.2277 & 0.01205 & 18.9474 & 0.01213 & 16.8138 & 0.009634 \\
\hline 12.21281 & 0.008567 & 13.1962 & 0.008832 & 16.2724 & 0.008488 & 14.2138 & 0.007007 \\
\hline 10.02544 & 0.006353 & 10.1646 & 0.005587 & 13.8204 & 0.005530 & 11.4403 & 0.004848 \\
\hline 7.473509 & 0.003971 & 7.4897 & 0.003923 & 11.3684 & 0.003952 & 8.6669 & 0.003471 \\
\hline 4.010176 & 0.002442 & 4.9931 & 0.002504 & 7.3560 & 0.002608 & 5.7202 & 0.002109 \\
\hline 3.281053 & 0.001728 & 3.2099 & 0.001724 & 5.1269 & 0.001720 & 3.9868 & 0.001455 \\
\hline 2.369649 & 0.001562 & 3.2099 & 0.001527 & 5.1269 & 0.001523 & 3.9868 & 0.001288 \\
\hline 2.369649 & 0.001146 & 2.3182 & 0.001131 & 5.1269 & 0.001127 & 2.2534 & 0.000958 \\
\hline
\end{tabular}




\section{Appendix J: Water Chemistry}

Table J - 1: Water Chemistry Data

\begin{tabular}{|c|c|c|c|c|c|c|c|c|c|c|c|c|c|c|c|}
\hline \multirow{3}{*}{$\begin{array}{l}\text { Run } \\
\text { No. }\end{array}$} & \multirow{3}{*}{$\begin{array}{c}\text { Drum } \\
\text { No }\end{array}$} & \multirow{3}{*}{ pH } & & & \multirow{3}{*}{$\begin{array}{c}\begin{array}{c}\text { Conducti- } \\
\text { vity }\end{array} \\
\mu S / c m\end{array}$} & & \multicolumn{4}{|c|}{ Anions } & \multicolumn{5}{|c|}{ Cations } \\
\hline & & & TDS & TSS & & $\begin{array}{l}\text { Alkalinity } \\
\text { as CaCO3 }\end{array}$ & $\cos$ & $\mathrm{HCO} 3$ & SO4 & Cl & Fe & $\mathbf{K}$ & $\mathbf{N a}$ & $\mathrm{Ca}$ & $\mathrm{Mg}$ \\
\hline & & & \multicolumn{2}{|c|}{$\mathrm{mg} / \mathrm{L}$} & & \multicolumn{10}{|c|}{$\mathrm{mg} / \mathrm{L}$} \\
\hline \multirow{10}{*}{$\begin{array}{c}\text { Nov- } \\
11\end{array}$} & 1 & 8.33 & 1580 & 306 & 2420 & 766 & 15 & 750 & 9 & 311 & 24 & 13 & 527 & 6 & 8 \\
\hline & 2 & 8.23 & 1570 & 52 & 2400 & 762 & 17 & 742 & 11 & 323 & 24.5 & 15 & 530 & 5 & 6 \\
\hline & 3 & 8.38 & 1580 & 320 & 2430 & 774 & 17 & 760 & 9 & 317 & 16 & 13 & 516 & 5 & 8 \\
\hline & 4 & 8.46 & 1580 & 84 & 2430 & 762 & 20 & 742 & 19 & 325 & 20.5 & 15 & 520 & 5 & 8 \\
\hline & 5 & 8.34 & 1560 & 134 & 2400 & 763 & 15 & 748 & 9 & 315 & 23 & 15 & 514 & 5 & 7 \\
\hline & 6 & 8.23 & 1570 & 43 & 2420 & 770 & & 770 & 9 & 318 & 16.3 & 13 & 549 & 5 & 6 \\
\hline & 7 & 8.33 & 1570 & 10 & 2420 & 820 & 16 & 804 & 8 & 320 & 15.6 & 13 & 527 & 5 & 7 \\
\hline & 8 & 8.33 & 1570 & 775 & 2410 & 775 & 15 & 760 & 26 & 342 & 33.5 & 18 & 527 & 6 & 9 \\
\hline & 9 & 8.39 & 1580 & 373 & 2430 & 768 & 17 & 751 & 11 & 317 & 22.3 & 15 & 530 & 5 & 8 \\
\hline & 10 & 8.41 & 1580 & 62 & 2430 & 772 & 18 & 754 & 10 & 331 & 26 & 16 & 532 & 6 & 8 \\
\hline \multirow{5}{*}{$\begin{array}{c}\text { Dec- } \\
11\end{array}$} & 11 & 8.41 & 1965 & 236 & 3025 & 793.5 & 19 & 774.5 & 72 & 463 & 16.05 & 15 & 689 & 7 & 7.5 \\
\hline & 12 & 8.5 & 1900 & 66 & 2920 & 775 & 22 & 752 & 78 & 445 & 19 & 17 & 637 & 6 & 9 \\
\hline & 13 & 8.28 & 1980 & 193 & 3050 & 810 & & 810 & 68 & 454 & 17.3 & 12 & 650 & 6 & 7 \\
\hline & 14 & 8.29 & 2000 & 106 & 3070 & 810 & & 810 & 80 & 433 & 12.7 & 13 & 652 & 6 & 7 \\
\hline & 15 & 8.4 & 1980 & 310 & 3050 & 810 & 19 & 791 & 74 & 449 & 12.5 & 12 & 673 & 6 & 6 \\
\hline
\end{tabular}




\section{Appendix K: Wax Column Tests - Solute Transport}

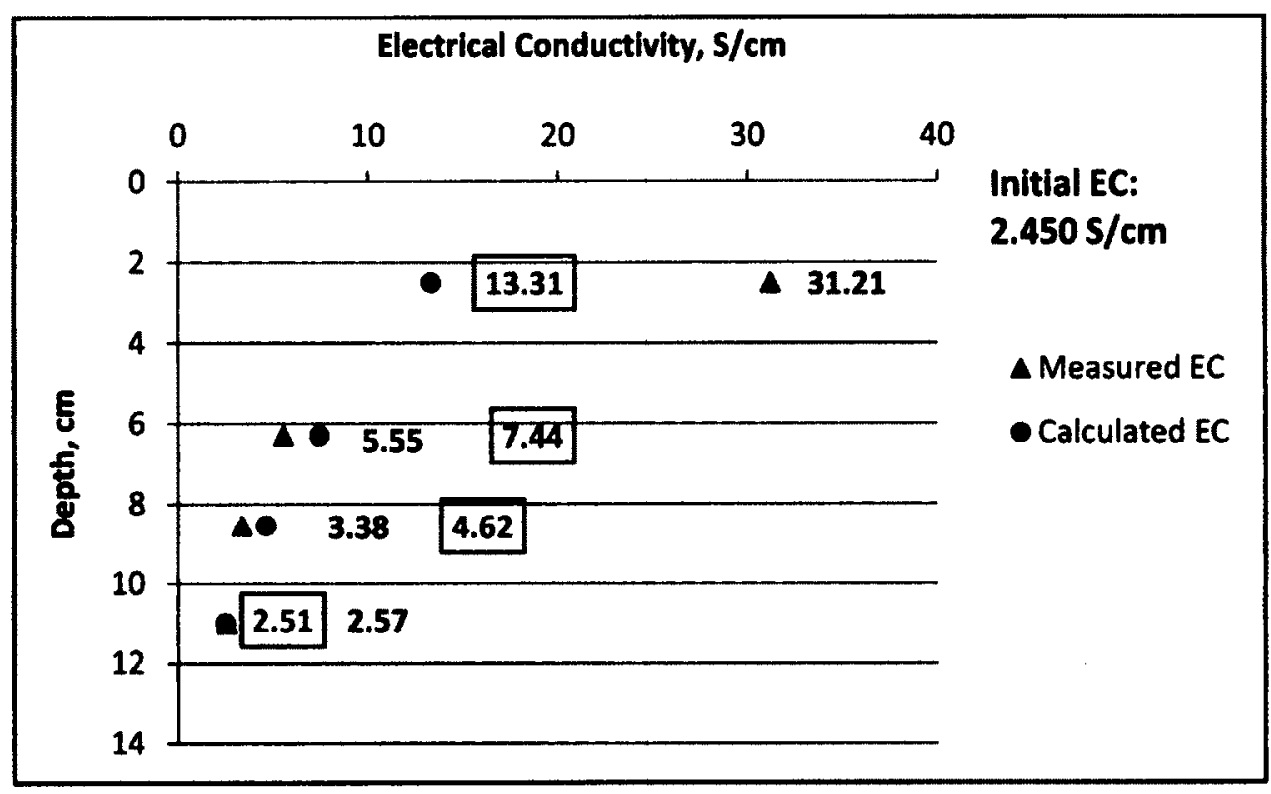

Assuming NO

transport

Figure $\mathrm{K}-1$ : EC profile Column A2

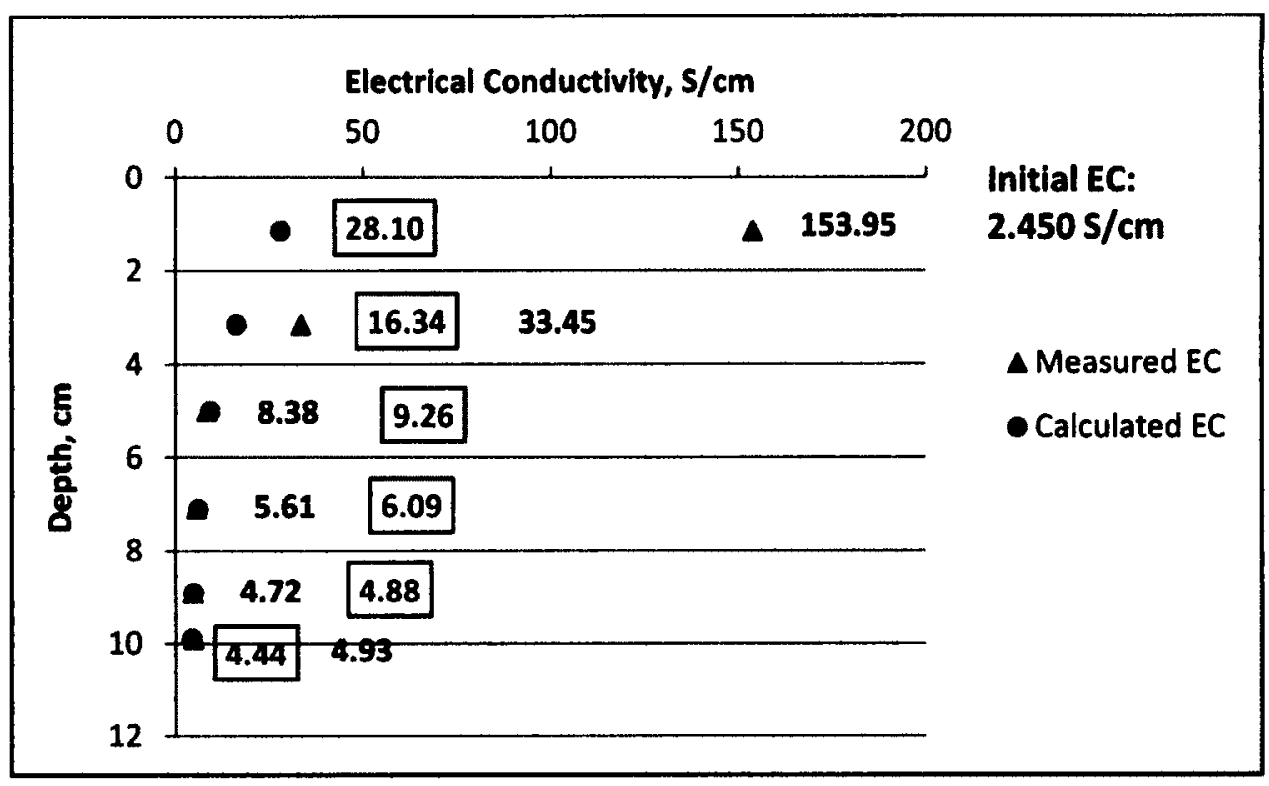

Figure K - 1: EC profile Column A3 


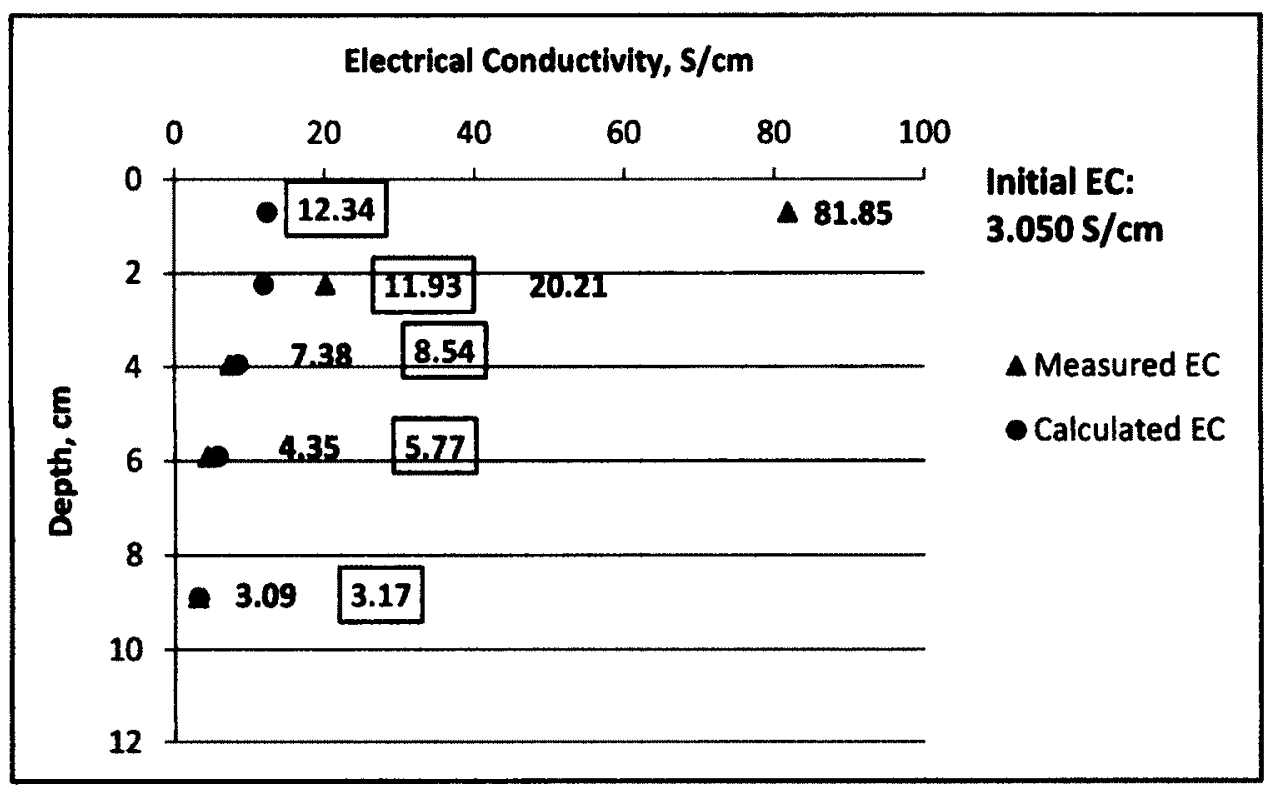

Figure $\mathrm{K}-1$ : EC profile Column B2

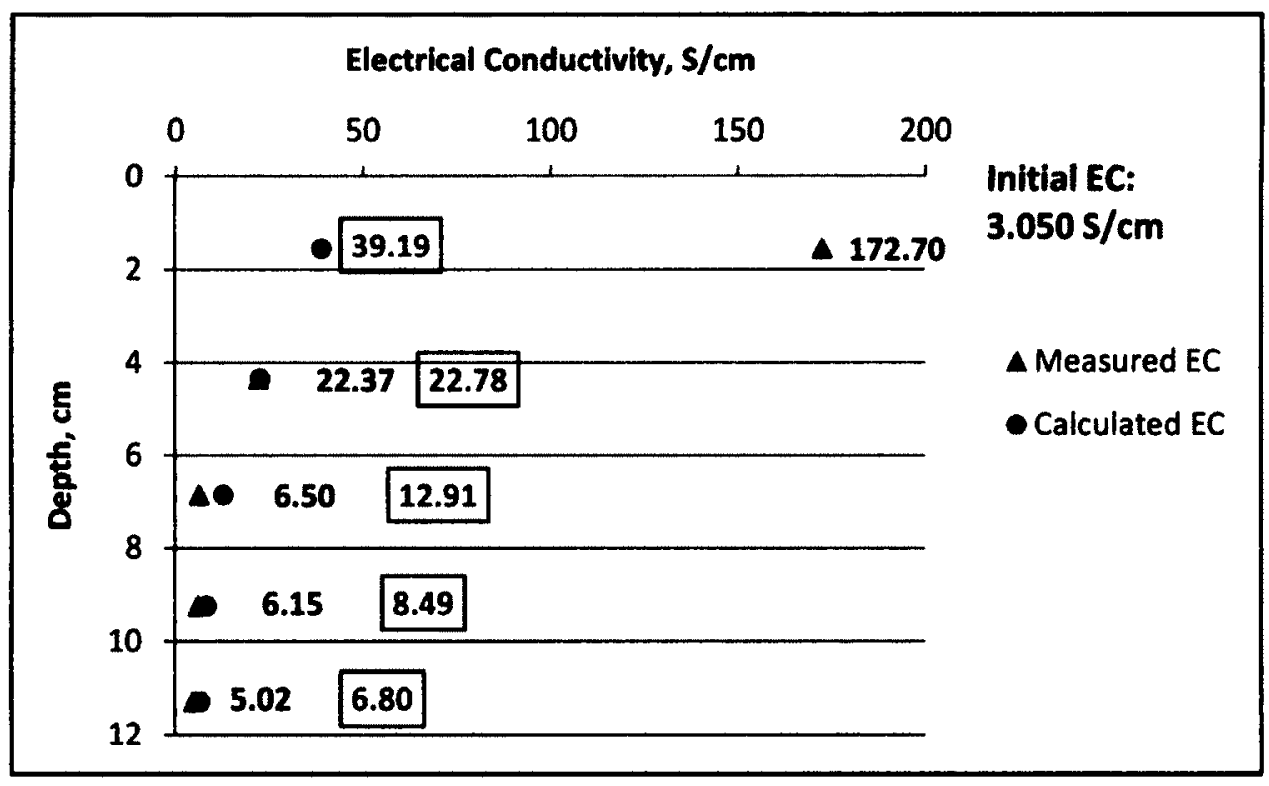

Figure $\mathrm{K}-1$ : EC profile Column B3 


\section{Appendix L: Drying Box 5 cm Tests}

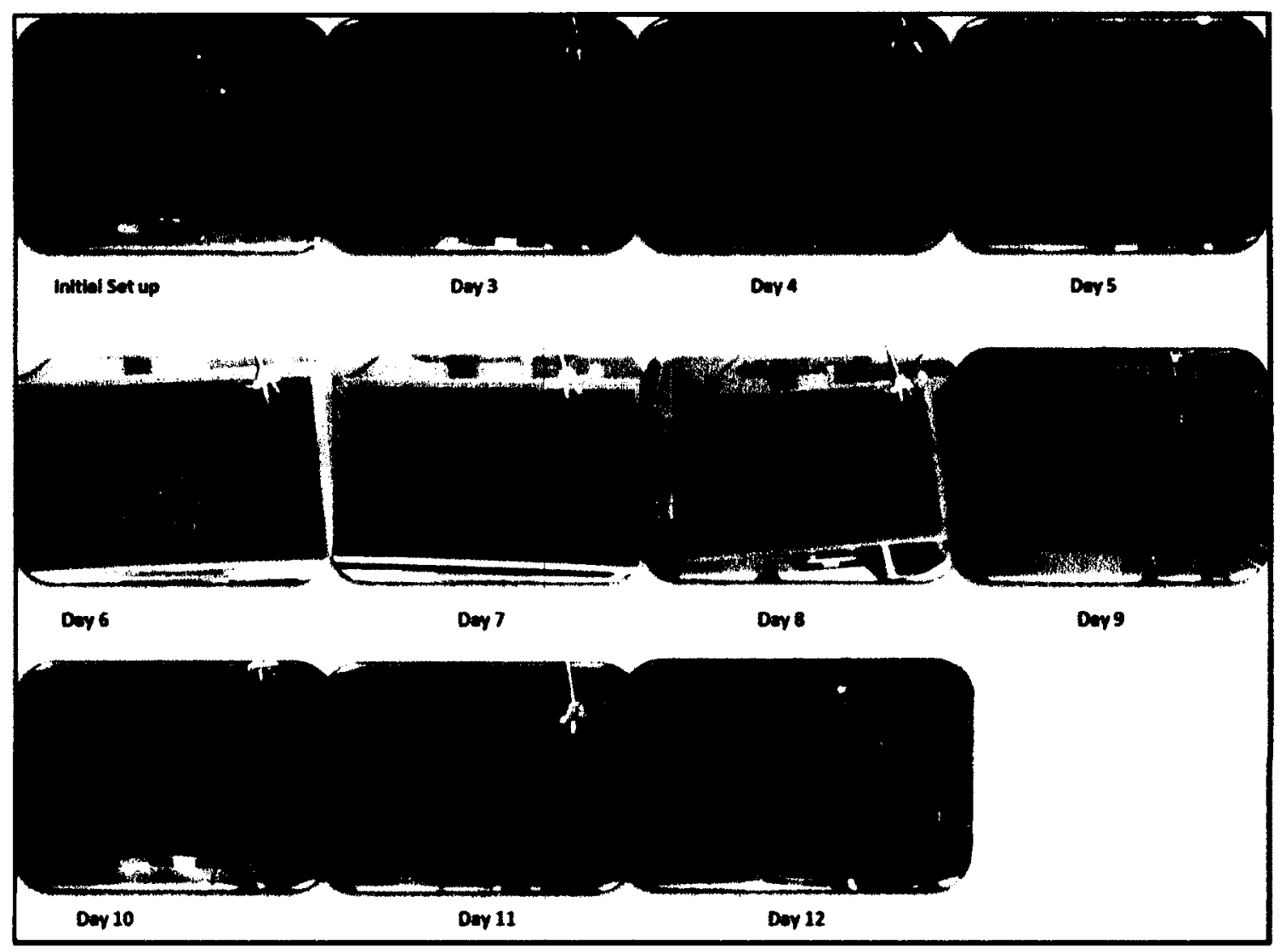

Figure L - 1: Sample Drying Box Test - Sample 1 


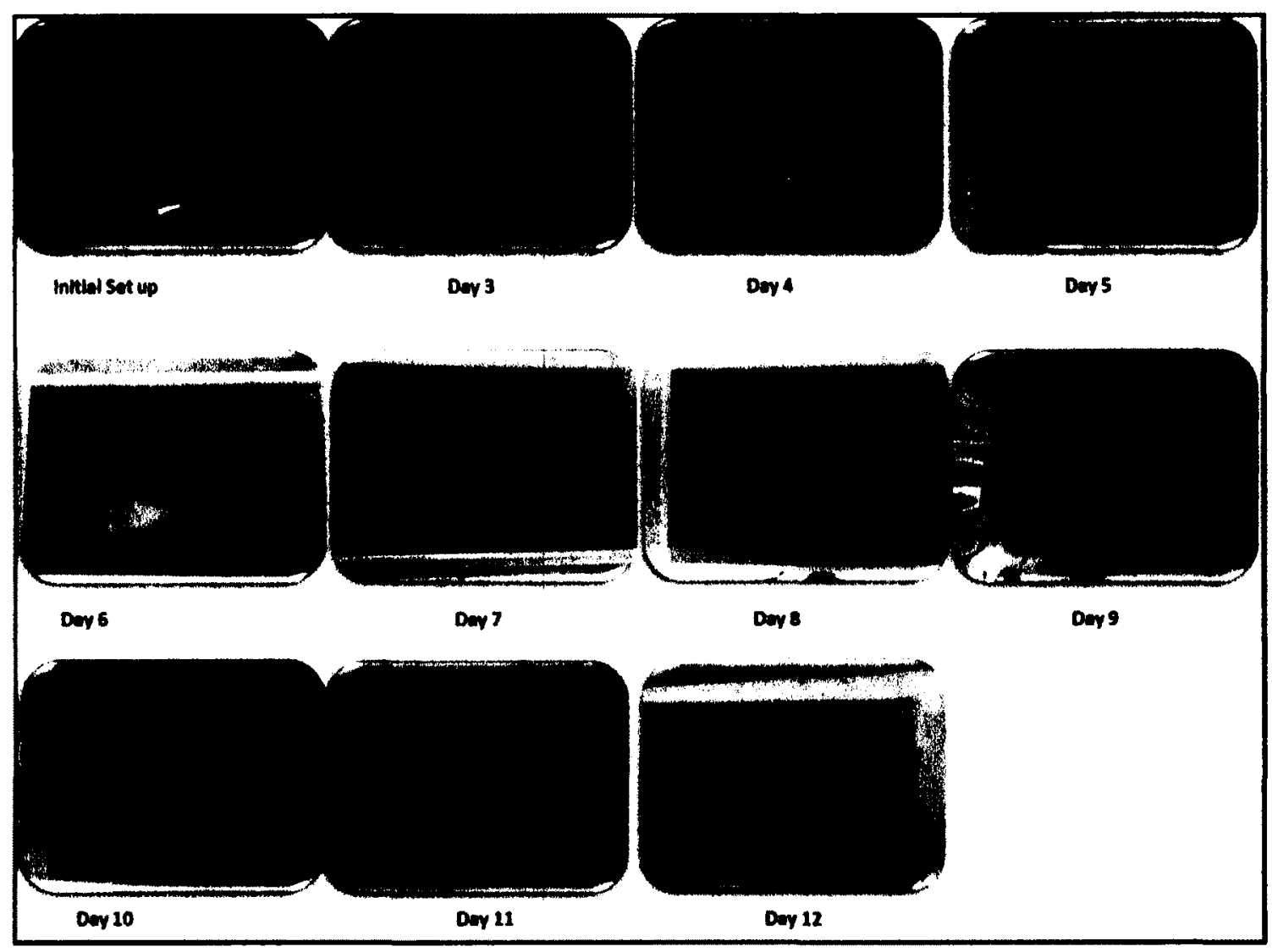

Figure L - 2: Sample Drying Box Test - Sample 2 
Appendix M: Layer 2 - Graphs

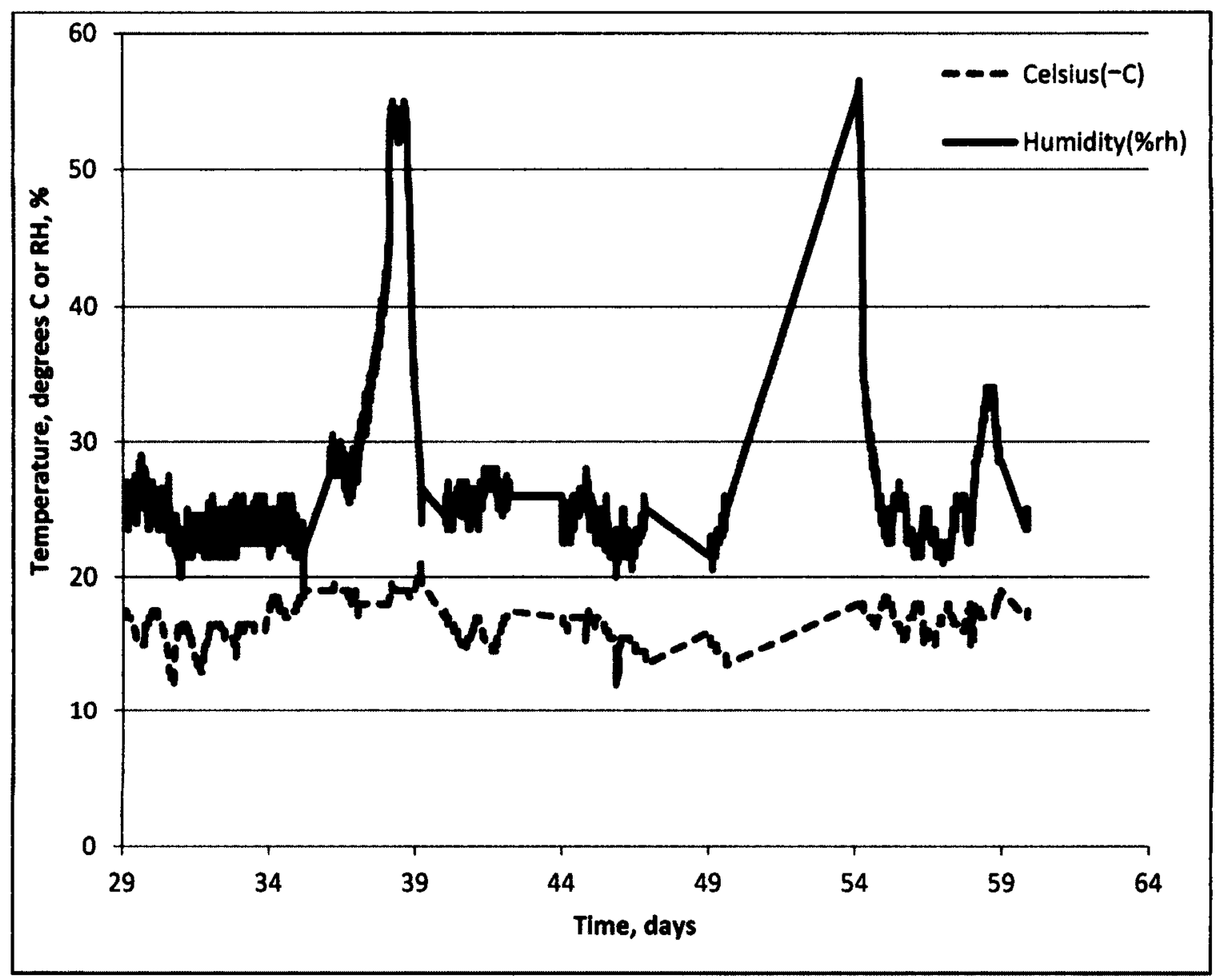

Figure $\mathrm{M}-1$ : RH and Temperature Data at soil surface 


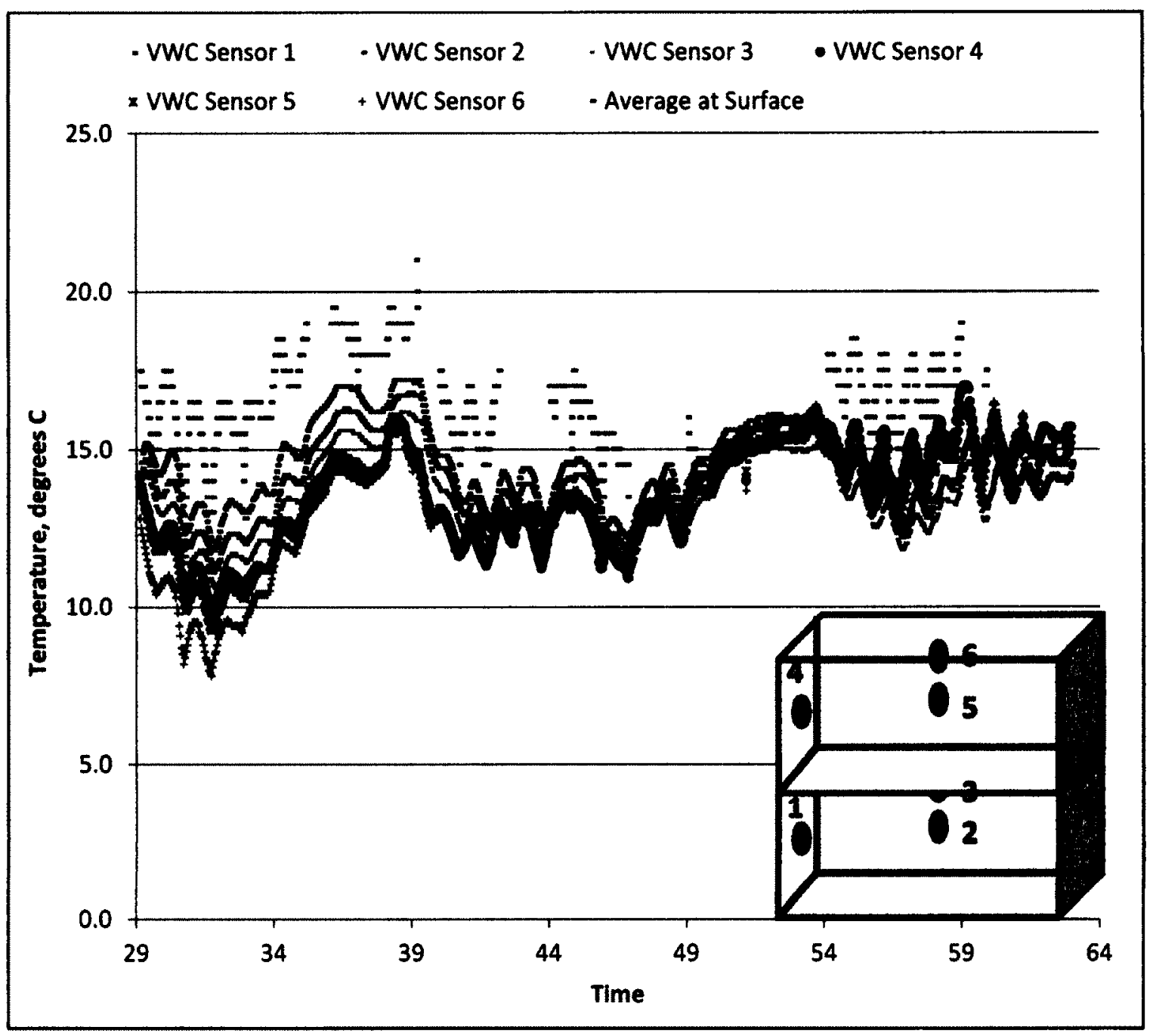

Figure $M-2$ : Temperature profile within the soil and at soil surface 


\section{Appendix N: Layer 3 - Graphs}

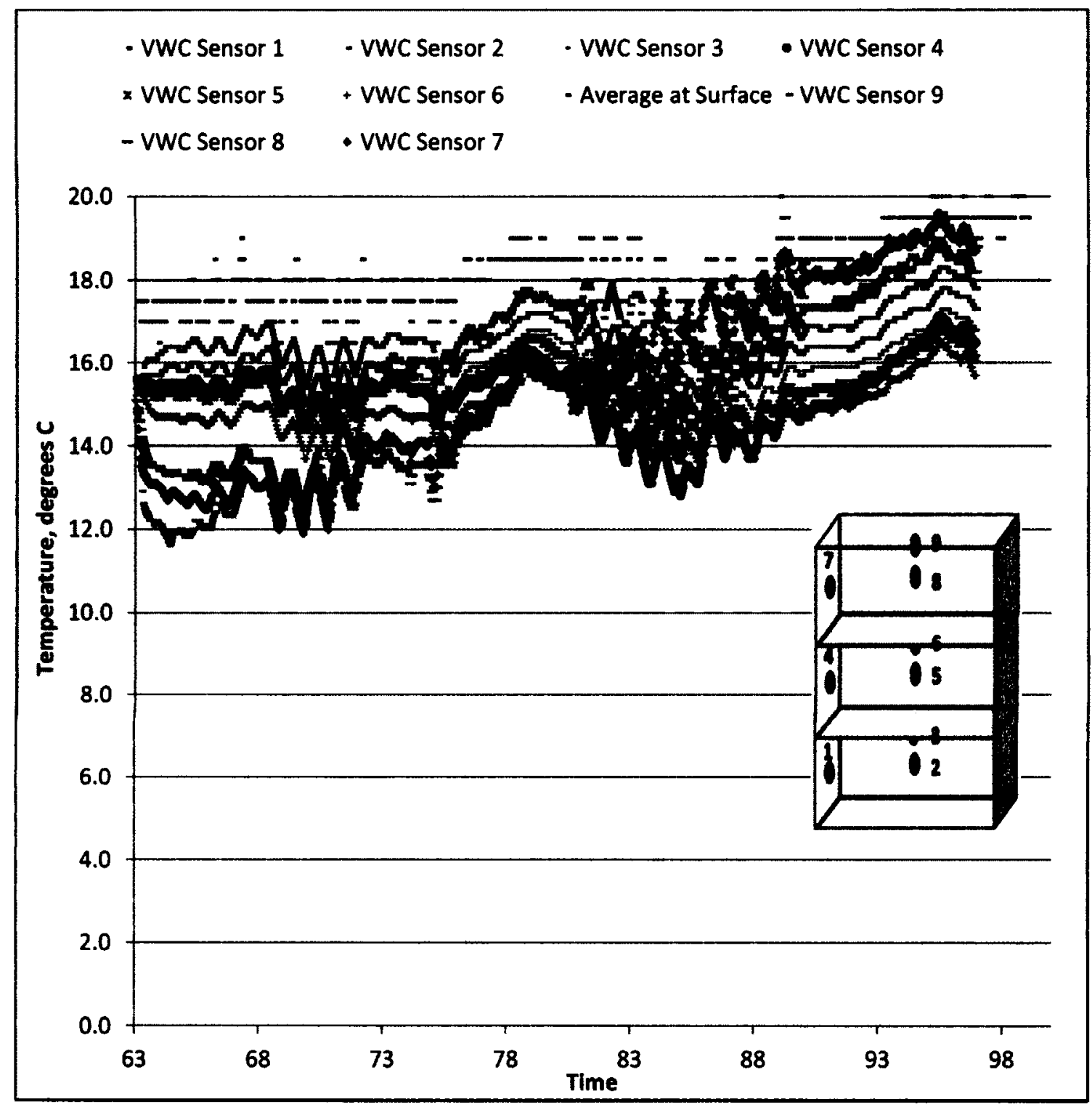

Figure $\mathrm{N}-1$ : Temperature profile within the soil and at soil surface 


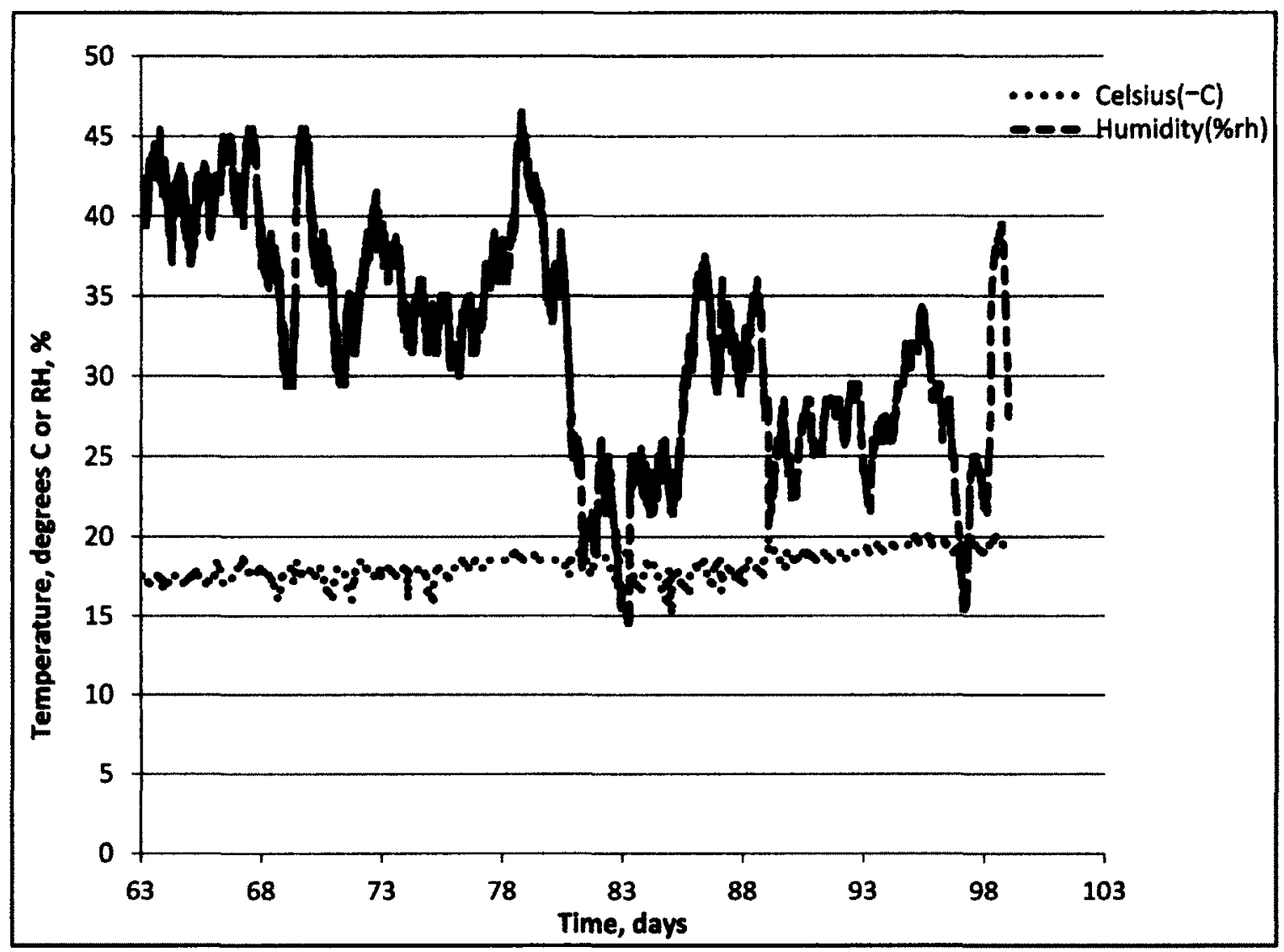

Figure $\mathrm{N}-2$ : $\mathrm{RH}$ and Temperature Data above the soil 